\title{
Wolfgang Lutz
}

Editor

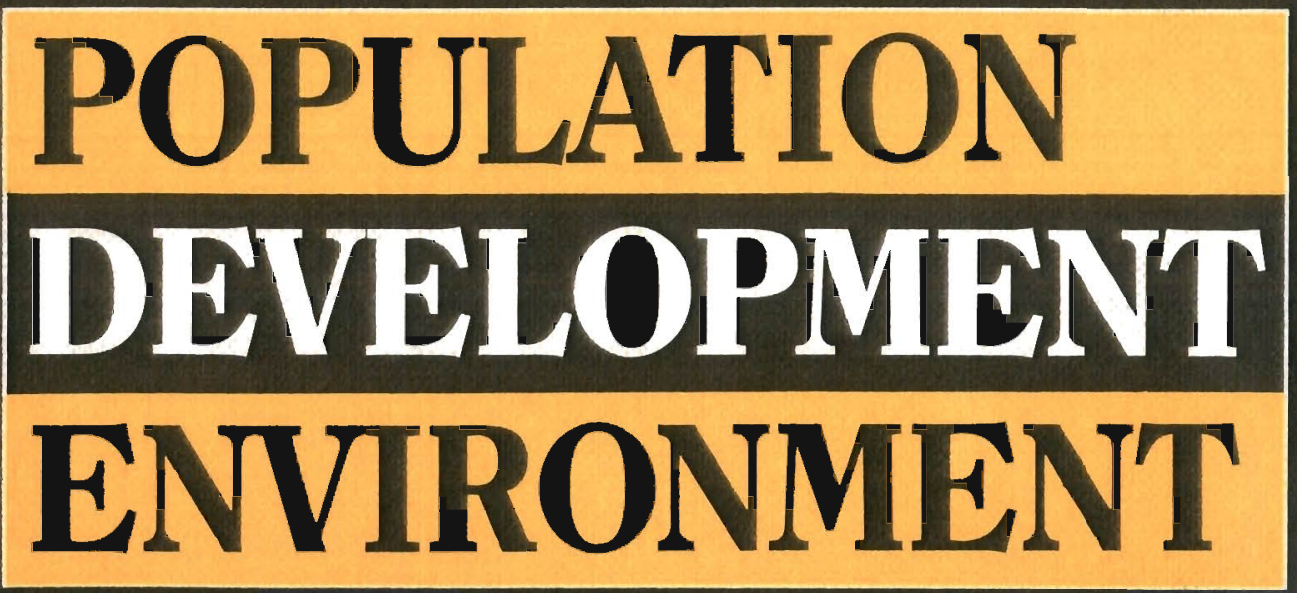

Understanding their

Interactions in Mauritius

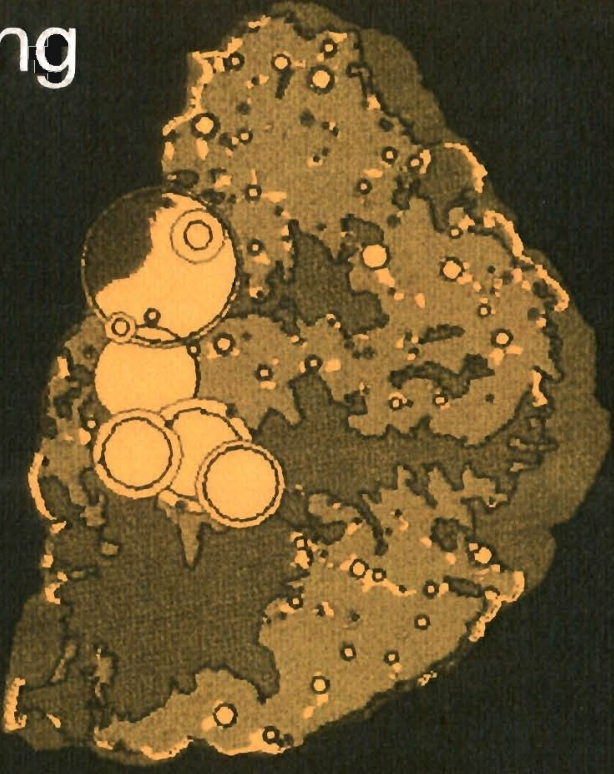

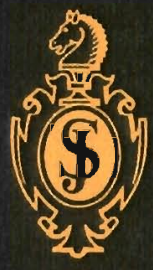

Springer-Verlag

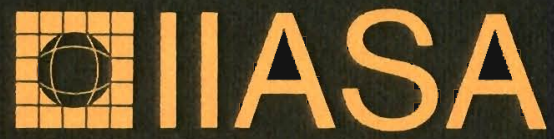

International Institute for Applied Systems Analysis 



\section{Wolfgang Lutz (Editor)}

\section{Population - Development - Environment}

Understanding their Interactions in Mauritius

Associate Editors:

Jawaharlaal Baguant, Christopher Prinz, Ferenc L. Toth, Anne Babette Wils

With 52 Figures

Springer-Verlag

Berlin Heidelberg New York

London Paris Tokyo

Hong Kong Barcelona Budapest 


\author{
Wolfgang Lutz \\ International Institute \\ for Applied Systems Analysis (IIASA) \\ 2361 Laxenburg / Austria
}

The project on which this book is based was conducted with financial support from the United Nations Population Fund (UNFPA).

The designations employed and the presentation of material in this publication do not imply the expression of any opinion whatsoever on the part of the United Nations Population Fund concerning the legal status or authority of any country, territory, city or area or the determination of its frontiers or boundaries. Views expressed are the authors' own and do not necessarily reflect the opinions or policy of the Fund.

\title{
ISBN 3-540-58301-7 Springer-Verlag Berlin Heidelberg New York Tokyo ISBN 0-387-58301-7 Springer-Verlag New York Berlin Heidelberg Tokyo
}

This work is subject to copyright. All rights are reserved, whether the whole or part of the material is concerned, specifically the rights of translation, reprinting, reuse of illustration, recitation, broadcasting, reproduction on microfilms or in other ways, and storage in data banks. Duplication of this publication or parts thereof is only permitted under the provisions of the German Copyright Law of September 9, 1965, in its version of June 24, 1985, and a copyright fee must always be paid. Violations fall under the prosecution act of the German Copyright Law.

(C) 1994 International Institute for Applied Systems Analysis, Laxenburg, Austria, and United Nations Population Fund (UNFPA), New York, USA

Printed in Germany

The use of registered names, trademarks, etc. in this publication does not imply. even in the absence of a specific statement, that such names are exempt from the relevant protective laws and regulations and therefore free for general use.

42/2202-543210-Printed on acid-free paper 


\section{Foreword}

Because the number of options is often limited, small island states tend to find it uncommonly difficult to strike a balance between population, environment, and development. Relatively high population density and small land areas, without much in the way of natural resources, do not provide the best of circumstances for improving the living conditions of the population, especially a fast-growing one. The result is often stunted economic development and environmental stress both on land and offshore.

The developments in the island state of Mauritius over the past 30 years, however, can serve as an inspiration and illustration of how extremely adverse conditions can be overcome. In the early 1960s Mauritius was trying to cope with rapid population growth, extreme poverty, and grim economic prospects. Population density was 324 inhabitants per $\mathrm{km}^{2}$, total fertility was 5.7 , and GNP per capita was less than $\$ 200$.

In 1990 the situation in Mauritius was radically different. Although population density had increased to 527 inhabitants per $\mathrm{km}^{2}$, total fertility had dropped to 2.0, and GNP per capita had increased to $\$ 2,310$. Economic stagnation had been replaced by steady growth and full employment, and environmental problems were being addressed as issues of high priority.

These developments attracted the attention of researchers at the International Institute for Applied Systems Analysis (IIASA). With the assistance of the United Nations Population Fund and the cooperation of the Government of Mauritius, IIASA and the University of Mauritius set out to develop a computer-based model to demonstrate the interaction among population dynamics, socioeconomic development, and environmental factors. A case study on recent and future trends in these three sectors was conducted in Mauritius to provide the database for a computer model.

The result is a welcome and timely contribution to both the difficult enterprise of model building and the demand for careful case studies on the links among the most salient dimensions of today's development debate. It 
is hoped that the Mauritius endeavor provides a useful example for governments in their efforts to design and implement strategies and programs to meet the challenges of population growth and distribution, socioeconomic development, and environmental protection.

Dr. Nafis Sadik

Executive Director

United Nations Population Fund (UNFPA)

March 1994 


\section{Preface}

It gives me great pleasure to write this Preface in the double capacity as former Head of the School of Agriculture, University of Mauritius, and as the current Minister of Economic Planning and Development. As part of the study "Mauritius 2000," which was initiated by the University of Mauritius in the early 1980 s to address national problems through the then novel approach of multidisciplinary research, biotechnology and population studies were given prominent importance. The latter developed into the present collaborative study, Population-Development-Environment: Understanding their Interactions in Mauritius. This project was made possible through the invaluable inputs of the International Institute for Applied Systems Analysis (IIASA).

Human activities and population dynamics are inextricably linked to environmental problems in all countries. The IIASA Mauritius model, which is also called the population-development-environment (PDE) model, is an excellent attempt to integrate the dynamics of key developmental parameters within the constraints imposed by resource allocation and environmental degradation. I am confident that this long-term physical-planning tool will not only be useful to complement the tasks of planners in Mauritius, but will also serve as a methodology for training planners of the developing world at large. This approach allows for identification of required measures for the desired outcomes while pointing out the dangers and opportunities facing the economy. It also provides an opportunity for developing a more detached and long-term view than usually presented in a five-year plan and, more importantly, allows policy makers a chance to view trends without the distortion of the immediate short-run pressure that they face in day-to-day decision making.

Our preoccupation in the concluding years of this century will be to develop a better understanding of the nexus of interrelated issues of environmental sustainability and economic growth. Environmental degradation, 
agricultural exploitation, natural resources depletion, population explosion, and poverty alleviation - to name but a few - fall within this wide ambit.

Fortunately for humankind, ongoing studies are proving to be optimistic. There are many "win-win" opportunities. Policy options exist which could ensure that measures for efficient income growth complement environmental protection measures. For Mauritius, the demographic watershed was reached in the 1970s when the main dip in population growth rates occurred. Today, we are positioning ourselves for other challenges: to upgrade our production technology within the context of sustainable development.

This study, which brings together several critical parameters, should assist Mauritian planners, industrialists, and educators in taking wellconsidered decisions on the future policy options for the country. The Ministry of Economic Planning and Development has provided much of the socioeconomic data on Mauritius and has contributed to the formulation of the population-labor-market-educational model.

On behalf of the government of Mauritius, I would like to express my thanks to the United Nations Population Fund (UNFPA) office in New York for providing the funds to enable this project to be carried out by the University of Mauritius and the International Institute for Applied Systems Analysis. My thanks also go to the local United Nations Development Program (UNDP) office and UNFPA office for providing the local support.

Professor A.S. Kasenally Minister of Economic Planning and Development Mauritius March 1994 


\section{Contents}

Foreword $\quad$ v

Preface vii

Contributors xi

Map of Mauritius xiv

1 Introduction

Wolfgang Lutz 1

Part I: What Do We Want To Understand?

2 Background: People and Development

Nathan Keyfitz 11

3 Simulation Models of Demographic, Economic, and Environmental Interactions

Warren C. Sanderson

Part II: Understanding Through History

4 People on Mauritius: 1638-1991

Wolfgang Lutz and Anne Babette Wils

5 From No-Man's-Land to a Congested Paradise:

An Environmental History of Mauritius

Ferenc L. Toth

6 Water Resources and Water Management

Toolseeram Ramjeawon

7 Sugar Cane and Other Agriculture

Jairaj Ramkissoon 
8 Industrial Development and the Labor Force Esther Hanoomanjee

9 Sustainable Tourism

M. Sen Ramsamy

10 Energy

Jaishree Beedasy and Revin Panray Beeharry

Part III: Understanding Through Modeling

11 Philosophy of the PDE Approach

Wolfgang Lutz

12 The Population Module

Wolfgang Lutz and Christopher Prinz

13 The Economic Module

Anne Babette Wils

14 Land Use and Regional Distribution

Einar Holm

15 Modeling the Water Systems

Ferenc L. Toth

16 Scenarios for Mauritius, 1990-2050

Christopher Prinz and Anne Babette Wils

17 Alternative Histories Since 1962

Christopher Prinz

Part IV: Our Present Understanding:

What Have We Learned?

18 Lessons From Mauritius in the Global Context

Wolfgang Lutz

19 Epilogue: How Useful is the Mauritius Study for Other Parts of the World?

Wolfgang Lutz

References 


\section{Contributors}

Jawaharlall Baguant is head of the school of engineering at the University of Mauritius. He received his Ph.D. in chemical engineering from the University of Tennessee. His main research areas include energy planning, biomass resources, ethanol production, and use of cane tops and leaves.

Jaishree Beedasy is a lecturer in engineering at the University of Mauritius. She received her M.Sc. in information technology from the University of York. Her main research interests include GIS modeling information systems and physical resource management.

Revin Panray Beeharry is a lecturer in engineering at the University of Mauritius. He received his M.Sc. in chemical engineering from the Illinois Institute of Technology. His main research interests include energy systems modeling.

Esther Hanoomanjee is a principal economist for the Ministry of Economic Planning and Development in Mauritius. She received her M.A. in economics from Madras University. Her main research interests include social development planning related to population, the labor market, education, and human resources.

Einar Holm is head of the department of geography at the University of Umeå. He received his Ph.D. in social and economic geography from the University of Umeå. His main research interests include development methods based on time geography, actor-driven simulation, geographical information systems, and models on population and environmental systems.

Nathan Keyfitz is an Institute Scholar at IIASA. He is Andelot Professor of Sociology Emeritus at Harvard University and Lazarus Professor of Social Demography Emeritus at Ohio State University. He received his Ph.D. in 
sociology from the University of Chicago. His main research interests include population change and social policy, mathematical demography, population forecasting, and the relation of population to environment and development.

Wolfgang Lutz is leader of the Population Project at IIASA and adjunct professor at the University of Vienna. He received his Ph.D. in demography from the University of Pennsylvania. His main research interests include interactions between the population variable, socioeconomic development, and the natural environment.

Christopher Prinz is a research scholar in IIASA's Population Project. He received his M.Sc. in social and economic science from the University of Vienna. His main research interests include population and household projections, family demography, and the impact of demographic changes on social and economic development.

Toolseeram Ramjeawon is a lecturer in environmental studies at the University of Mauritius. He received his M.Sc. in the field of water technology from the University in Montpelier. His main research interests are modeling population-development-water interactions on small island states and treatment of industrial wastewaters by high-rate anaerobic treatment processes.

Jairaj Ramkissoon is a senior lecturer in animal science and production at the University of Mauritius. He received his M.Sc. in physics and biochemistry from the University of Reading. His main research interests include agricultural/food and livestock strategic and policy studies and land-use evaluations.

M. Sen Ramsamy is a tourist officer at the Ministry of Tourism in Mauritius. His research interests include the social, economic, and environmental impacts of tourism.

Warren C. Sanderson is a professor of economics at the State University of New York at Stony Brook. He received his Ph.D. in economics from Stanford University. His main research interests include modeling economic, demographic, and environmental interactions in Third World countries and population forecasts after an environmental catastrophe.

Ferenc L. Toth is a research scholar in IIASA's project on Environmentally Compatible Energy Strategies. He received his Ph.D. in economics from the 
Karl Marx University of Economics. His main research interests include population, economy, and environmental interactions.

Anne Babette Wils is a research scholar in IIASA's Population Project. She received her M.Sc. in economics from the University of Vienna. Her main research interests include migration trends and future scenarios in population and development. 


\section{MAURITIUS}

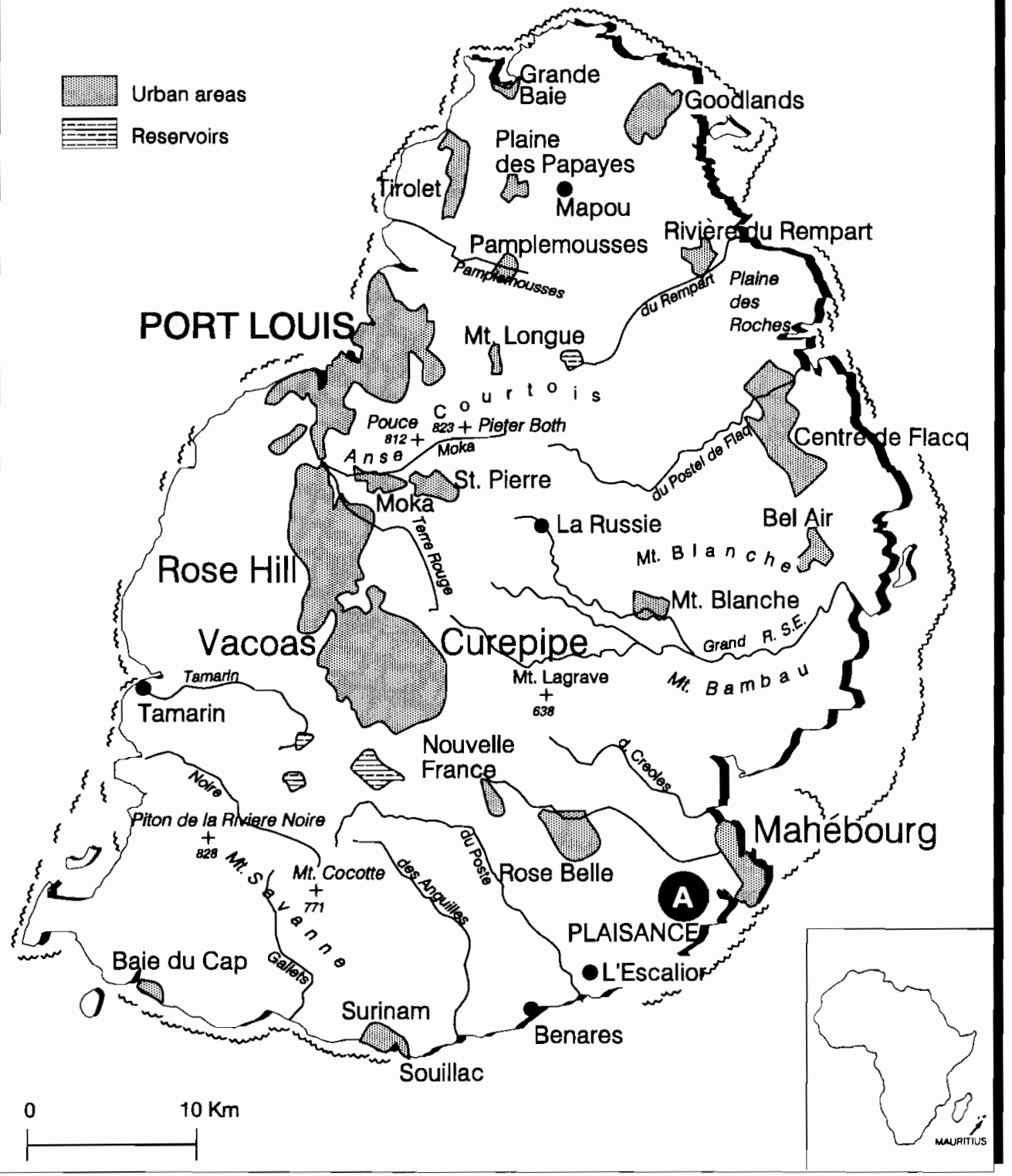




\title{
Chapter 1
}

\section{Introduction}

\author{
Wolfgang Lutz
}

Is the rapid increase in the number of people on our planet the main reason for growing environmental stress, or is it due to consumption patterns together with wrong policies? This has become a very controversial question dividing not only scientists but also political, diplomatic, and even religious circles in different parts of the world. The disruptive force of this question stems from the fact that the Northern Hemisphere can largely be blamed for today's consumption and emission patterns, whereas present (and future) population growth is concentrated in the South.

This controversy was an important underlying issue at the 1992 Earth Summit (United Nations Conference on Environment and Development) in Rio de Janeiro and figures prominently in the planning of the 1994 World Population Conference in Cairo. Shortly before UNCED '92, the Archbishop of Canterbury wrote to the pope in Rome that the Catholic view on contraception needs to be reconsidered because rapid population growth is threatening our global commons. Rome answered that the reasons for the world's environment and development crisis were other than population growth. This political and religious controversy essentially goes back to a purely scientific question, admittedly not a very easy one, requiring interdisciplinary analysis. Nevertheless, it is astonishing to see how little empirical and solid scientific analysis on the issue has been conducted so far. This is the area in which this book hopes to make a contribution. 
When the distinguished British economist J.E. Meade and the equally distinguished sociologist Richard Titmuss visited the small Indian Ocean island of Mauritius in 1960 to assess the development potentials of this sugar island, they found a desperate and crowded place; the population was trapped in extreme poverty and had one of the highest growth rates on Earth and no prospects for economic improvement. Both scientists concluded that population growth was the main problem and a fertility decline the prerequisite for improvement. A few years later Mauritius experienced what was probably the most rapid (strictly voluntary) fertility decline in human history.

Today, 30 years after the Titmuss and Meade visits, Mauritius has a booming economy with no unemployment, its fertility is around replacement level, and life expectancy on the island is almost as high as in Europe. Economically sometimes characterized as a newly industrializing country, the government is now seriously trying to control pollution and preserve the fragile environment of this beautiful and very densely populated island.

What are the factors behind this stunning success? How did fertility decline in the absence of any economic growth? Where did the following economic boom originate? What were the environmental constraints for Mauritius in the past, and what will they be in the future? How can the government design robust policies for sustainable development in Mauritius? To answer some of these questions, a multi-sectoral computer simulation model was developed, the essence of which is described in Part III of this book.

But what can Mauritius, with only 0.00125 percent of the world's land surface and 0.020 percent of its present population, contribute to the global population-environment debate? The authors of this study believe that we can learn a number of very important lessons from Mauritius and that this case study can strengthen our understanding of the highly complex interactions between population, development, and the environment. We believe that only concrete empirical evidence, presented in a broad and unambiguous framework that both the social and the natural scientists can accept, will prepare the grounds for a common understanding across disciplines. To gain such common grounds in the global population-environment debate, it is essential to have well-studied cases to refer to. Especially when the global debate is as confusing and ideological as the present one, an analytical approach developed for a specific case study (such as the model presented in this book) may well help to serve as a guideline for the global discussion. 


\section{Are There Analytical Approaches to Resolve the Population-Environment Debate?}

The number of scientific conferences as well as books and articles, on the population and environment issue has been growing exponentially over the past five years. A glance in the Social Science Citation Index shows very few titles with combinations of the keywords population and environment (or sustainable) before 1988. Since then, there has been an upsurge in such titles and many more are in the process of being published. At the moment there is at least a dozen books on the topic under production. Many of them are conference proceedings with very diverse sets of papers approaching the broad issue from different angles and different levels (global, regional, individual). So far the scientific community seems to be a long way from a general analytical framework to analyze the issue. Even the demographic and environmental variables chosen for analysis (not to mention the assumed mechanisms of causation) tend to vary greatly. The number of comprehensive quantitative models on population and environment is very small so far.

One equation that has gained prominence in the debate and has become a kind of common point of reference is the $I=P A T$ equation described in Ehrlich and Ehrlich (1990). This identity equation describes environmental impact $(I)$ as being composed of three factors: population $(P)$, affluence $(A)$, and technology $(T)$. Since $A$ is defined as per capita consumption $(C / P)$ and $T$ as environmental impact per consumption unit $(I / C)$, the $C$ s and $P$ s cancel and the equation becomes $I=I$. Hence $I=P A T$ gives a decomposition of environmental impact into the three presumably independent and relevant components - population size, affluence, and technology. This decomposition serves the useful purpose of telling people that it is not one factor alone that causes environmental problems but some combination of several factors.

Beyond this the $I=P A T$ equation proves to be problematic as a point of departure for analytical studies. First, the given decomposition into the three factors is just one of many possible decompositions that also may include a larger number of components. Before its application as an analytical tool, it is necessary to justify the choice of components. This depends crucially on what is meant by environmental impact: the factors considered relevant for the depletion of the ozone layer will be very different from those assumed to cause deforestation or decreasing biodiversity. Second, this form of the equation suggests the independence of the factors considered. Yet a 
major discussion on the population-environment issue concerns interactions between the factors; one side stresses that higher population will increase technology, while another side assumes that population growth decreases affluence, and still others stress that increasing affluence reduces population growth.

Is there any analytical tool that can help to resolve the dispute? This question needs to remain open until the scientific discussion evolves further. The analytical tool proposed in this volume is intended as a step toward a more comprehensive formalization of this question. It is an attempt to set some basic parameters for a structured and scholarly discussion on the interactions between population change, economic development, and environmental degradation.

In addition to the difficulty arising from the fact that different scientific disciplines have different paradigms and different languages for approaching the question, there is one very serious problem for any empirical analysis namely, the strong heterogeneity that makes every result highly dependent on the level of aggregation. For instance, the estimated effect of population growth on future $\mathrm{CO}_{2}$ emissions differs greatly depending on whether one calculates it at a global, regional, or even subnational level. It has been shown (e.g., Lutz, forthcoming) that identical assumptions of constant fertility and mortality rates together with constant per capita $\mathrm{CO}_{2}$ emissions may result in 16,10 , or 8 gigatons of global carbon emissions in the year 2050 depending on the aggregation level at which the calculations are being performed (global, South and North separately, poor and rich separately across boundaries). The reason for this huge discrepancy is that those population groups with the highest birth rates also have the lowest per capita emissions.

This example illustrates a heterogeneity effect that seriously distorts all kinds of associations in the population-environment fields which are conducted at a higher level of aggregation. This is a powerful argument in favor of giving priority to the analysis of case studies. Environmental, economic, political, and cultural conditions are globally very diverse and yet crucially important for understanding the mechanisms in which population, development, and environment interact. As a consequence, statements on the population-environment issue that should have universal validity need to be so general that their information content is limited.

Case studies may be both qualitative and quantitative, and these approaches may complement each other. The quantitative model suggested 
in this book provides a methodology for organizing and analyzing complex data so that interrelationships can be more easily understood and intellectually managed - thereby facilitating policy making, planning, training, and awareness-creation on population-development-environment interactions.

For many different reasons, the island of Mauritius was chosen as the case study for the first application of the analytical framework developed here. Among the most important reasons are the environmental isolation of this mid-Indian Ocean island, the extremely high population density, and especially the broad availability and generally very high quality of statistical information on most demographic, economic, and environmental aspects. Another important reason for choosing Mauritius was the presence of a competent local team of scientists at the University of Mauritius that was willing to collaborate closely with IIASA on the project. Seven of the fourteen authors contributing to this volume are Mauritian.

\section{Structure of the Volume}

This volume is structured around the notion of understanding. Understanding is a process which always remains incomplete. But understanding implies also the progression to a clearer and more complete picture of how the system works. Understanding also has the connotation of a holistic perception of the system that does not take specific questions out of context. All three aspects of understanding are meant when the notion is being used in this volume.

The first section of the book, "What Do We Want To Understand?," tries to define the question. It gives a background paper by Nathan Keyfitz that puts the present volume into the broader perspective of global development trends over recent decades and presents concerns about the role of population in future development considering environmental constraints. The chapter also looks at the role of nation-states in development policies and scientific approaches to the global issue at a case study level. Chapter 3 gives a more technical survey of simulation models in the population-developmentenvironment field. Warren Sanderson, who published a systematic and comprehensive survey of economic-demographic simulation models in 1980, was invited to write this chapter expanding the analysis to models that explicitly consider environmental aspects.

There are different ways of understanding and different tools to help advance our understanding. This book takes a dual approach. The sections "Understanding Through History" and "Understanding Through Modeling" 
complement each other. Part II, "Understanding Through History," is an attempt to write an integrated history of the population, the economy, and the environment in Mauritius up to the present. Despite all efforts to have an interdisciplinary approach to the issue, the section is still structured according to specific relevant topics. This was necessary because individual expertise still exists largely by scientific disciplines. The section provides a highly condensed and greatly revised version of the conference proceedings entitled Population, Economy, and Environment in Mauritius (Lutz and Toth, 1991). The authors of this section are mostly Mauritian.

Part III describes our efforts for an "Understanding Through Modeling." It gives the design and many applications of the population-developmentenvironment model which was carried out at IIASA in close contact with the University of Mauritius. This model, which is built for the simultaneous consideration of the various aspects discussed in this section, allows a higher degree of integration than the approach taken in Part II, "Understanding Through History." If Part II is labeled multidisciplinary, Part III may be called interdisciplinary.

Part II consists of a set of seven papers which are devoted to some key issues for understanding the evolution of the Mauritian social, economic, and physical systems. Chapter 4 by Wolfgang Lutz and Anne Babette Wils gives the population history of Mauritius emphasizing its most prominent feature, namely, the extremely rapid fertility decline during the 1960s and early 1970s; but it also describes the social and political structures of the country. Stepping back from this socio-demographic perspective and looking at the life-support system in a broader sense, Chapter 5 by Ferenc Toth gives an environmental history of Mauritius. It stretches from the early colonia] days to the time of independence.

Chapter 6 by Toolseeram Ramjeawon gives a compact survey of Mauritian water resources and water management, issues that are crucial for sustainable development in Mauritius. Chapter 7 by Jairaj Ramkissoon addresses the traditional backbone of the Mauritian economy, sugar cane, and puts it into the perspective of general agricultural development. Special emphasis is given to the question of food supply. Chapter 8 by Esther Hanoomanjee studies non-sugar manufacturing and the recent boom of export-oriented industry. The chapter also outlines the role of governmental development policies and pays special attention to changes in the labor force. Chapter 9 by M. Sen Ramsamy works out the special role of tourism 
in Mauritius, which represents a rather strong and immediate linkage between environmental preservation and economic profit in an international competitive market. Chapter 10 by Jaishree Beedasy and Revin Panray Beeharry studies another important area that relates to economic as well as environmental issues, namely, energy systems in Mauritius.

Part III, "Understanding Through Modeling," consists of five chapters that describe the structure of the PDE Mauritius model and two chapters that present applications of the model to the future and to hypothetical alternative past trends. The design and implementation of the model resulted from the work of an interdisciplinary and international team over more than two years. The authors of the chapters describing the different modules of the model are also primarily responsible for those parts of the model. At this point the absolutely essential contribution of our programmer, Frantisek Gyarfas, is gratefully acknowledged.

Chapter 11 by Lutz gives a short introduction to Part III by describing the basic reasoning behind the modeling approach chosen. Chapter 12 by Lutz and Christopher Prinz summarizes the population module, which considers the composition of the population by age, gender, education, and labor-force participation in the form of a multistate model. Chapter 13 by Wils gives an outline of the economic module that essentially consists of an input-output model with certain additions and modifications. Chapter 14 by Einar Holm outlines the structure and the basic assumptions made in the land-use module. Chapter 15 by Toth gives an account of the water module that considers the lagoon as well as quantity and quality aspects of the stream flow. More detailed descriptions of all modules have been published as IIASA Working Papers and are available to the interested reader.

Chapter 16 is, in a way, the culmination of the whole project. Written by Prinz and Wils, it presents a summary of findings from extensive scenario calculations up to the year 2050. The chapter shows the baseline scenarios chosen for the different sectors of the model and then gives aggregate scenarios first in a raw and unadjusted form and then in an adjusted form that makes all sectors of the model more consistent and plausible. Against this background several special policy options are calculated and discussed. Chapter 17 by Prinz gives alternative scenario calculations along the same line, but uses 1962 instead of 1990 as the starting year. Comparing these calculations to the actual path of development, the chapter describes what would have happened if, e.g., fertility had not declined the way it did. 
Part IV is entitled "Our Present Understanding: What Have We Learned?" In Chapter 18, Lutz attempts to pull together the many different findings at various levels reached by differing methods and approaches. It is structured around five basic questions that figure prominently in the present population-environment debate and to which we believe the Mauritius case study could make a contribution. In the Epilogue, Lutz discusses the transferability of the study's findings to other countries. 


\section{Part I}

What Do We Want To Understand? 



\title{
Chapter 2
}

\section{Background: People and Development}

\author{
Nathan Keyfitz
}

\subsection{Stalled on the Road to Development*}

Future historians will see the present world society as frozen. Not that events to occupy the media are lacking, between petty civil wars and terrorism, but in the most important field of all - development that would remove gross inequality, and at the same time adapt to the constraints of our planet - we find hesitation and uncertainty; after exhilarating progress in the 1960 s we see now a discouraged halt. Nearly three-quarters of the 5.4 billion world population are suspended in an intermediate, transitional, condition - they are far from primitive, but not yet fully modern. These people, living in the national units of the developing countries, have been touched by modernity, in a process that should have continued on to complete development, but that is now stalled.

The stalled condition is a frustrating one, full of imbalances and contradictions for the 4 billion people that it affects. The majority are by now literate, and many are educated well beyond literacy, but the jobs in which

*Section 2.1 is the author's contribution to UNCED in Rio de Janeiro, and appeared as an editorial commentary, "Stalled on the road to development," in the Earth Summit Times, Tuesday, June 2, 1992, p. 6 . 
they can apply their education are too few, and available jobs have little relation to those their education led them to expect. They have graphic access through television and otherwise to the way of life of developed countries, but its luxury is withheld from them; they are invited to watch a feast but excluded from partaking. They have a large measure of death control, including mass inoculation against the most common diseases, but lack the indispensable birth control that has to go with it. Their condition of partial development manifests such abnormalities as corruption, unemployment, civil war with modern deadly equipment, internal inequality of income exceeding even that of the rich countries, all problems more serious for the partially developed than they are for either primitive or modern peoples.

The stalled condition comes as a surprise to national and international planners of development. When the United Nations announced the first Development Decade in 1960 it expected that development would occur with a big push over a decade or two. Progress was made toward this goal in the 1960 s and to some extent in the 1970s, but in the 1980s retrogression set in. We see many signs of this retrogression. Birth control effort slowed, and the United Nations has had to raise its estimate of future population. The net flow of capital from the rich countries to the poor reversed, so that the poor have become net providers of capital to the rich. Inequality both within countries and among them has increased.

Some Third World countries report economic growth of impressive amount but it turns out that as much as half of their apparent increase of income is just bad accounting, the drawing down of capital by selling off natural resources and calling the receipts income. Extracting oil from the ground and burning it in internal-combustion motors is called production in conventional accounting; from the ecological point of view the identical activity is destruction. That the economist can call production what the ecologist calls destruction is a striking but by no means unique example of the importance of interpretation in human affairs.

If higher apparent income leaves deteriorating soil, damaged forests, and polluted atmosphere then it comes at the expense of later generations. Badly needed is a proper set of accounts on the development progress, say up to the standards applied in running even a small business.

But the difficulty goes deeper than merely getting the numbers right. Poor countries are placed in a position where they cannot protect their natural heritage of forest and soil. They are fiercely proud of their political independence, vigorously protect their autonomy in a defined territory, but 
they do not equally protect their patrimony of natural resources; remorseless external markets will not let them. As their population grows the pressure on their soil and their forests increases year by year. Traditional peasants evolved practices that preserve their land for their children; they want stability more than higher current income. Their ancient stabilizing practices are abandoned as development gets under way, but the stability that rich countries can contrive is not yet in reach. In the face of growing populations and specialized production for export they are forced to neglect their environments, even though it is above all poor countries that in the end will suffer from a crippled environment.

As long as it lasts this condition is a danger for those concerned and for the world. Not many years ago it was thought that the answer was for the rich countries to supply massive financial aid. We now know that the problem is not so easily disposed of as appeared in the simpler world of the 1950 s and 1960 s.

A solution more imaginative than just handing over money has to be sought. After all, the money in amounts that would make a difference is simply not there. Germany is suffering from the costs of unification plus aid to ex-socialist countries to its east; the United States has become a major borrower, a competitor of the less developed countries for scarce international capital; after years of brilliant success, Japan is in the midst of a recession in which its stock markets have lost half their value.

This introduction presents some background to a case study concentrated on one country, Mauritius, with just 1 million population out of the world's 5.4 billion. What has made its study instructive is that it is in important respects a success story. Its prospects 30 years ago were dreary; today it is industrializing, educating its population, controlling its births. If the work of observation and analysis here reported has been done well it should provide some pointers to what might be possible elsewhere. That it is small and an island distant from the mainland, with a relatively simple economy, has made study feasible in a short period of time, and with limited resources.

But before embarking on a comparison of the Mauritian condition before and after the development effort of the past 30 years, with analysis of what it was that has made Mauritius different from most of the other developing countries, it will be useful to review the situation of the Third World in general, and the way that it has fared in the short but eventful years following decolonization. 


\subsection{The Initial Path: Shortsighted Populationism and Isolationism}

The sense of nationalism that moved through the colonies of Britain, France, and Holland after World War II was both the cause and the result of their struggle for independence. To mobilize whole populations into an irresistible force that would expel the foreign rulers required the construction of symbols in which the intellectuals took a major part, but the messages had to reach broad layers of city people as well as to a lesser extent of peasants. In some instances - Indonesia was an instance - violence was necessary; in others the separation from the colonial power was accomplished by peaceful negotiation. The more protracted and the more violent the struggle the more deeply the new set of national symbols was imprinted on citizens.

Once they attained independence after World War II the new nations set themselves a sequence of objectives: increased population that was thought to give the state more weight in its region and in the world, development under the aegis of the state, nationalization of foreign-owned enterprises in any industry considered nationally important; official encouragement of import substitution regardless of the interest of consumers. Foreign investment was regarded with suspicion when it was permitted at all. Sacrosanct national territory and absolute sovereignty went along with carelessness on the preservation of the qualities of that territory, so that some of the most nationalistic states were the ones that wreaked the greatest destruction on their forests and soils in pursuit of very short-run economic goals. That was the era of one-party constitutions in the new countries, the era of Mao Zedong in China, Sukarno in Indonesia, Idi Amin in Uganda. Looking back on the history in the light of subsequent experience we find it hard to estimate how far these recklessly wrong policies set back development; the least we can say is that it was a very expensive learning experience.

Perhaps that third of a century of misguided effort was not wholly wasted; it could have been necessary to go through it to find out that merely declaring national sovereignty, making the autonomy of the nation the supreme and absolute morality, overriding democracy and human rights, encouraging irresponsible reproduction, would not bring the results hoped for.

So fast have all of us learned that it is hard now to understand the two features of early postwar nationalism: population seen as a symbol of national power, and the governmentally controlled economy as a self-contained 
instrument for national prosperity. Appropriating what the colonial power had left behind did not deliver much wealth to the average citizen; the countries were admittedly poor in goods, and if they had any wealth it consisted of their own people. On a distorted interpretation of this clearly correct proposition, President Sukarno in Indonesia insistently expounded the need for more people; his attitude and that of self-proclaimed patriots everywhere resembled that of the mercantilists writing at the dawn of modern nationalism in Europe.

The new nationalism of the second half of the 20th century did not trust foreigners or even indigenous private enterprisers with the economy. All of the important elements, the "commanding heights" of the economy would have to be placed under national, and governmental, control. Nehru, influenced by Professor Mahalanobis, a brilliant man in other fields who set out to invent economics, sought the physical control of the investment process that would modernize India; that meant among other things a state-run steel industry to provide materials for the capital goods that would produce the multitude of badly needed goods for consumption. Everything basic and therefore important - electric power, transport, telephone, and other communication - had to be run by the state. The development sequence, starting with these, had to be guided by a national plan written out in advance. Marxist theory, and the Soviet practice of the time, seemed to give sanction to all this, but Western donor countries lacked the courage and vision to describe it for what all now know it to have been. The less developed countries had to learn for themselves.

\subsection{Planning Holds Up Progress}

It took two or three decades of experience with increasing population and government control of investment to destroy the faith in this approach. More people were found to be an increased load on the whole national system; excessive guidance of the economy builds up and then preserves sectors like steel - long after they have ceased to be the leading edge. In respect of consumer goods central planning produces the wrong things, and produces them inefficiently. A housewife going to market can write out a shopping list that is her plan for the morning; securing the welfare of the nation is not as simple as a shopping list. No government can have as clear an understanding of its citizens' needs as the housewife has of her family's. 
Worse than that: in the form that planning came to take in a number of countries the plan documents aroused the expectations of the citizenry without providing realistic means to the fulfillment of those expectations. The divergence between the promise of the plans and their meager results became more and more conspicuous, everywhere from Malaysia to the USSR.

\subsection{Nationalism Turns Positive}

Minimal national planning in the form of a budget for government expenditures on social overhead is indispensable, but nearly every country is now moving to give general planning no more than its due place. Nigeria recently passed a law that allows all investments of more than $\$ 2$ million to be entirely controlled by their foreign owners, who do not have to take in Nigerian partners as before, and who have entire liberty to repatriate profits. Only small shops and service establishments are reserved for Nigerians. Permission to invest is provided by a single agency, rather than being controlled by dozens; that saves time for the investor, reduces cost to the country, narrows the scope for corruption.

China has relaxed the many restrictions that it once had on foreign investment. Among other items, foreign consumer products factories that were formally required to export the bulk of their output are now allowed to target 1.16 billion consumers. Foreign banks and law firms are getting more leeway to operate while foreign property developers are encouraged to build apartments, hotels, office towers, and shopping malls (Wall Street Journal, November 25, 1992, p. 9).

Virtually every one of the developing countries has similarly turned around. Now instead of expelling the old multinationals and fighting off new ones, countries are competing to attract foreign industry, especially branch plants. Sometimes indeed they go too far with tax holidays and other expensive inducements. This competition for the attention of investors arises because developed country corporations with spare cash to place abroad are fewer; LDC policies that would have brought a good deal of investment a decade or two back are now not attractive enough. The turnaround in policy has come late, in an era when heavy demands encounter declining funds in all capital markets. We shall see in a moment that this has deadly consequences for rapidly growing populations. 


\subsection{The Nation is Identified With a Territory But Not With its Share of the Biosphere}

Alongside more emphasis on population control and a market economy one feature of the national spirit has been constant: its identification with the certain geographical area. No government could think of giving away or selling a square meter of the national territory. Trading pieces of land with other countries is repugnant, even where there would be a common advantage to the two parties. Renting out land for foreign military bases is suspect even where the state exchequer badly needs the money, and in addition the base would provide a welcome defense. In short the national soil is sacred, to be handed down intact to all the following generations; it is not subject to negotiation, to truck or trade, for any purpose whatever, economic or political.

An outsider therefore finds it strange that there is no such national identification with what lies on, over, or under the soil. It is regarded as perfectly proper to sell the oil, the copper, and other subsoil wealth; to run down the soil itself by producing more peanuts than the world needs - as in Senegal - and so lower the water table and promote the spread of the desert; to sell the forests in the form of plywood or furniture, or to cut them down to produce beef for a few years as in Brazil's Amazon.

In short, holding intact a defined territory, i.e., a piece of land, has been a constant feature of the spirit of nationalism, that on other dimensions has changed substantially; it has moved from encouraging larger population to having a healthy and prosperous population no longer in rapid increase; from the state conducting all investment to the state standing back and encouraging private capital, domestic and foreign. Can we now hope for a move to identify with the ecological content of the national territory as well as with its geographical boundaries? The purpose would be a durable economy, in which development will make a better life for each succeeding generation, rather than a quick sell-off of natural resources for the passing benefit of the generation now on the scene.

So far we still hear that preserving the forests of the Amazon has to yield to more urgent matters, like investment in factories and paying interest on the debt and so maintaining the nation's credit standing. These are indeed of immediate importance for development. But it is in the nature of 
development that it requires harder work and more saving than would be needed if there was no development, a fact temporarily obscured during the 1980 s by the seemingly unlimited funds that could be borrowed in international markets. Development means that the present generation labors and abstains in order to accumulate capital that will make for the ease of future generations. One hopes that the process will be assisted by the nations that are already developed, but ultimately the crucial element is the effort and saving of the poor country's own citizens.

Herein is the paradox that resides in carelessness on ecological matters. Development is promoted with many sacrifices and the increased income that is going to result will mostly benefit children and grandchildren. And to accomplish this economic goal by sacrificing ecological considerations will not leave the means for a prosperous existence to later generations. Selling off those forests to serve developmental purposes makes little sense if the supposedly wealthy descendants will inherit only a barren wilderness. The labor and the abstention of the present generation will be worthwhile if along with a prospering economy the children and grandchildren of those now alive can have a territory as naturally rich as the one that exists today.

The point has often been made in international meetings that industry is what does the major damage to the environment, that fossil fuel emissions and CFCs from refrigerators do far more damage in total than poor people cutting trees for firewood. True of course; the poor and the rich each do damage in their own way, but since the rich command more powerful instruments they do more damage. Insofar as population increase is mostly of the poor it is not the cause of the trouble. That is certainly true of the past, but what of the future? We hope that the poor will become middle class, if not rich, and when that happens their numbers will greatly affect the environment. Facing the future it cannot be true at one and the same time that the numbers of the poor do not matter and that development to raise the level of the poor must go ahead. The poor do less damage than the rich, but if the poor are the rich of the next generation, then their numbers matter greatly.

Put briefly, the one who argues with evidence from the past that it is the rich who do the damage, and therefore the numbers of poor do not matter, cannot carry the argument into the future without saying also that the poor will remain poor. One who expects that the poor will become rich has to accept that the numbers of the poor are going to make a great deal of difference to the world of the future. 
In accord with this will the world go on to a new phase, in which the national state would be the custodian of its ecosystem as well as of its territory? Everyone surely wants to avoid the contradiction discussed above: that development requires sacrifice of this generation to serve later generations; economic activities that destroy the environment will nullify the gains of development and leave the following generations empty handed. And development will sooner and more innocuously raise the level of the poor if the poor do not rapidly increase.

\subsection{MDCS Versus LDCS}

While errors have certainly been made and are being made by the countries of the Third World, the First World has had a relation to the former colonies not entirely innocent. The colonial period itself was initiated because raw materials were needed for the beginning industry of Western Europe, and securing these distorted the precolonial economies, that before had attained some degree of balance over the course of centuries. Having turned their overseas territories into producers of spices, cotton, jute, coffee, sugar, sisal, kapok, rubber, and other tropical products, those Western overlords departed.

They were in some degree pushed out, but from their side the colonies were no longer necessary. Artificial aniline dyes were the forerunners of a process of substitution that went through silk, rubber, beverages, nylon, and other fibers. The invention of substitutes accelerated with decolonization, that gave the strongest economic incentive to the independence of the most advanced countries, independence of their former colonies. After the Dutch East Indies won their freedom from Holland it was the latter that progressed more rapidly.

Part of the reason for the slow progress, for instance of Indonesia, was the fall in prices of rubber, sisal, edible oils, and virtually every other colonial product except petroleum. What was to be the source of capital for development turned out to be grossly inadequate even to maintain the previous level of living.

What seemed like good fortune was the presence of large amounts of petrodollars in United States and other banks, and these were borrowed by the LDCs at rather low rates of interest. Once the loans were made a wholly unplanned shortage of capital appeared, and interest rates - especially long-term rates - rose accordingly. The borrowing countries had no 
way of repaying the loans when they came due, and they had to roll these over at the new high rates prevailing. As a result the flow of funds that traditionally went from the more developed to the less developed countries (for instance, from Britain to the United States at the turn of the century) is currently from the LDCs to the MDCs.

This aspect of the history is worth repeating for the benefit of those who consider that the predicament of the LDCs was wholly the result of their own errors. One can see a nice balance between those errors, on the one side, and the movement of postwar economics and technology that undercut prices of tropical raw materials and tempted into the trap of excessive borrowing.

\subsection{People as Consumers}

Abstracting from both external relations and internal environment for a moment, one way to think about population is to consider its individual members in their role as producers and consumers. People are both the active element making countries develop and the beneficiaries of development. Let us briefly look at the changes now going forward in the LDCs from a people point of view.

In the present LDCs, as in Europe over 200 years, the motor of development is people's wish to rise financially and socially. The unlimited desire for goods on which economic progress hinges is by no means "natural"; the Dutch found this when they failed to attract labor with wages that would have been high for the time and place. Accordingly they introduced forced labor in the growing of sugar, and each peasant in the designated areas was required to contribute as a tax in kind one-fifth of his land and one-fifth of his time. The British preferred a "free" economy, and finding that their colonial subjects had little use for money, and hence saw no point in working to earn it, they made laws that gave their subjects a use for money: to pay a specially instituted poll tax.

But that phase is now over. With the exception of a few isolated and backward parts of countries that have not yet been touched by the urge to social mobility and desire for consumer goods the whole world is now sufficiently advanced that the desire for goods is no longer a problem. In fact economics has spoken of a "demonstration effect," the desire for goods stimulated by the media and then by exhibition of their local use in the 
possession of friends and neighbors. That desire, for example as expressed in a "cargo cult" in the South Pacific, was in some instances so strong that it distracted from the realization that one had to work and sacrifice in order to satisfy it.

Such discussion has largely disappeared from economics and social science generally; progress is no longer held up either by inadequate or by excessive desire for goods. The spread of education and the development movement of the postwar period has achieved this if it did nothing more.

\subsection{Motivations to Produce and Consume Reconciled by the Market}

Once both too little and too much desire for goods are overcome, the problem comes to center on the skilled labor force and the purposeful enterprise that will produce the goods. We have to reckon with the fact that what people would like to do in their capacity of producers does not necessarily accord with what they want to obtain in their capacity of consumers. For the community as a whole, if not for individuals, there has to be an exact correspondence, in fact an identity, between these: the community can only consume what it produces - or what it can obtain by trading its production and services. If people want to work at a desk job in a major city, preferably the national capital, and they want to consume rice, automobiles, television sets, that are not produced by people who sit at desks, then something will have to give. In no conceivable economic system can everybody have just what he or she wants, either what they want to work at as producers or what they want to possess as consumers. The economic problem is to find the minimum departure from what they want that will satisfy the unavoidable constraints.

The congruence between what people want to produce and what they want to consume is readily attained in free exchange. A group of people are making some commodity, say pottery, and the highest price at which they can manage to sell the product determines the wages they will have. If the product is not saleable they will have to find something else to produce, or else so improve the product so that it can be sold. The discipline of the market minimizes the incongruence between what people collectively want to produce and what they want to consume. 


\subsection{Model Dependence is Inevitable}

The growth of population is central to the work reported in this volume. That growth has been rapid over the postwar period, and to it can be attributed many of the difficulties and inefficiencies of the developing countries.

To think about population one sets up a model, and different models produce very different outcomes. As for any other important subject, a variety of models are current, all competing for attention. One can see what difference the model makes by considering two or three very simple ones.

Suppose that production depends only on people, and in particular on their skills and effort. It is people who initially create the inert factors of production - land and capital in classical economics - and hence people and their training are the fundamental factor of production - the sole factor in some extreme formulations. It requires no argument to show that with this model overpopulation simply cannot occur.

Contrast that with a model in which people do not enter abstractly as producers, but require slots, that we call jobs, into which they can fit, and these jobs are created by enterprise and capital. With this model the person cannot be a producer at all without the capital and enterprise that will offer him or her a job. That part of the population in excess of the jobs offered will be a drag on welfare; the model easily recognizes overpopulation once populations have become large.

The above applies to land as well as to capital where the person cannot produce without a suitable plot to till, and when it is so applied we have the economics of Malthus, whose name has become identified with overpopulation.

Not directly related to any of the above three models is one in which production is considered within the environment, the setting in the biosphere that provides the materials we need to keep alive. A simple way of taking this into account makes the drain on the environment proportional to the number of people. On this static view twice as many people will cut twice as many trees for firewood, consume twice as many fish, burn twice as much fossil fuel, all assuming that other factors remain constant.

The four models sketched in rough form above are by no means exhaustive, and to show the richness of the subject we proceed to sketch one more. If it is not entirely novel or surprising, at least it is not in the literature in the form presented. 


\subsection{Population Growth: A Politically Disturbing Element}

Here we consider a causal path starting with the fact that lower death rates and especially lower infant mortality with little change in birth rates leads to much larger cohorts than before, and after a very few years the new cohorts come to working age. Because they are more numerous, at the same time as productivity in the countryside where most of them are born has increased rapidly, there is inadequate land for them to follow the ancestral occupations. How far population growth alone drives people off the land and into cities is debated, with evidence for and against, but there is little doubt that combined with shortage of rural opportunities it adds to the cityward migration. Beyond that, formal education, stimulated by the desire for upward mobility, and eagerly demanded by a population that is ambitious for personal advance, has expanded enormously, and even if the land was available they would not be willing to engage in the traditional way of life of their ancestors. All this leads to a flight to the cities, and one sees everywhere unprecedented expansion of the cities of the poor countries. No longer are cities places where manufacturing draws workers from the countryside to new jobs that its enterprise capital creates, as in 19th-century Europe; they are places where population for which the countryside has no use takes refuge, hoping something will turn up.

The one thing that looks superficially like a solution is to expand government services and establish state enterprises. The pressure to do that becomes enormous, under the impulse of electoral politics where there is democratically elected government, and under the threat of social disorder where there is one-party government. The effect is the same; overstaffed government offices turning over paper, and state factories inefficiently making obsolete products.

Throughout Asia, Africa, and Latin America, it was the rapid growth of population that helped to initiate the process above traced. The new large cohorts of young people wanted jobs; they were far better educated than their peasant parents, and so they were less subservient and less easily put off with excuses for delay; large proportions had migrated to the capital and other cities, where they were a visible threat to governments; if communism has gone out of style as an ideology of protest fundamentalist religion remains and is equally capable of resorting to violence in a cause that it deems just. The rapid increase of population, and especially the increase of young, 
educated, and ambitious young people, is a powerful source of pressure on governments. Offering jobs to as many of its members as possible contributes to civil order, at least in the short run, but it also contributes to debt, internal and external.

It did not take many years of living through such pressure for governments to reverse their view of birth control. Far from seeing each additional birth as a source of strength to the state, they came to see a birth as 20 years later a young adult with a high school diploma looking for a job. Trying to make one for him would distort the development process. The turnaround in attitudes of developing country officials seems to have occurred especially during the 1970s, and was observed by the world between the Bucharest Conference of 1974 and the Mexico City Conference of 1984.

And yet a theoretical case has been presented for paying less attention to population in development planning; that the slowing of progress due to population growth is not as serious as previously thought and could even be favorable. That case rests on a reversal of the argument above. Starting from the fact that increased population destabilizes the preexisting situation, stressing the same pressure on institutions described above, it takes it that this pressure will be exerted in an entirely constructive direction: it will force the abandonment of a directed economy, whose visible inefficiency cannot cope with the larger population. There have indeed been some cases where this occurred, whose description we owe to Ester Boserup (1981, 1990), but its generalization to a general principle has little support; there are equally cases where population density has led to the opposite.

One does not need to go as far as Karl Wittfogel (1957), whose Oriental Despotism created a stir a few years back, but we should remind ourselves of the learned case he built up, found convincing by many in the 1940s and $1950 \mathrm{~s}$, that was exactly the opposite of the populationist argument. In his historical-anthropological analysis large irrigation works were necessary to provide food to dense populations, and once such a piece of construction was in place population would increase further on the foodstuffs grown with the water that it stored. This dependence of large populations on the dams and storage reservoirs permitted - indeed required - absolute rulers. With dense populations dependent on the dams, freedom would have been too dangerous. People realized the danger to themselves if the dam was not protected, and they submitted to subservience because that made their livelihood more secure. Many such "hydraulic civilizations" were listed by Wittfogel (1957), from ancient Babylon to Stalin's USSR. 


\subsection{Technology's Two Faces}

Poor people spend the larger part of their incomes on food. For Adam Smith capital meant the pile of wheat that would pay the workers while they built roads and factories. In modern times, however, such homegrown capital is subordinate to capital as the means by which modern technology is carried, and hence in considerable part only available by import from abroad. For the developing country capital is not mere local production and abstention from consumption, as it was for Smith, but the assembly of funds with which equipment can be purchased abroad. Technology, on the one side, substitutes plentiful materials for scarce ones, and so increases the population that can live on given natural resources. But advancing technology makes capital more indispensable if labor is to support itself. As automated factories reduce prices of many goods it becomes harder for unequipped labor to be competitive. The two faces of technology need to be kept in mind - its capacity to substitute common materials for scarce ones, and its being available to the LDC only by purchase from abroad. The first increases the population that can survive and prosper in a given territory, and the second limits the number of people who can have productive jobs by virtue of limits of capital. Both need to be kept in mind.

When technology is primitive people can make the instruments of production for themselves. Starting only from local trees, a village carpenter makes handlooms, and these are then operated by village girls, the whole process from yarn to cloth, even to clothing, being self-contained. There are villages in Indonesia where this still goes on. Insofar as production takes this artisanal form, using only homemade physical capital for clothing, furniture, houses, tools, any number of people can be accommodated with jobs, and we are back to the limits set by food and fibers. But such local autonomy is more and more undercut by machine-produced goods. The value of its tradeable output is reduced, and if its population has gone beyond what can be supported by cereals from its own fields, it has less and less chance of buying its subsistence from abroad. True that there is a worldwide surplus of food, but that is no comfort to those whose production of tradeables does not suffice to give them access to the markets where foodstuffs are traded.

If the people of tropical Africa have no means to pay for foreign food, and can hardly hope for charitable contributions to keep them going for very long, they might be able to survive in a different way. Could they not provide a labor force that would draw capital and enterprise from abroad? As unskilled labor becomes a smaller and smaller input to currently efficient 
production they would have to educate themselves as a prerequisite to this. In principle this is possible, but educated populations are increasing in many places, and the LDCs are running out of strategies for attracting the capital that would employ the numbers now entering the labor force.

\subsection{Present Shortage of Capital in the World}

All this is rather thoroughly understood in the developing countries. If that indispensable capital is to come from abroad it has to be paid for, and in the circumstances of most of the LDCs the means of payment do not increase with population. More people in Indonesia do not result in more oil to export - indeed the additional population uses oil and so diminishes exports. Borrowing has been extensively tried, but the developing countries as a whole have now reached the limits of borrowing. More people do not increase creditworthiness in the judgment of foreign banks and governments. There are still gifts - foreign aid - but the volume of these will never be great, and in real terms it has been declining.

Once the central importance of foreign-made capital goods for development is recognized, along with the obvious limits on securing enough of them on credit, as gifts, or in exchange for natural resources, then we have to think of additional population as contributing to development only in the measure that it can produce exportable goods or services with little or no capital. One service that countries can provide is tourism, in a sense the sale of its scenery, and it is important to push this further, but again this requires construction of hotels and other facilities (i.e., capital), and even with capital the number of people who can usefully be employed in hotels and museums is not great in relation to burgeoning populations.

When Stalin faced exactly this problem of backwardness in respect of productive equipment in the 1930s he calculated that he needed capital from abroad more than he needed people, so he collected and exported wheat in disregard of the low world price, and allowed his own peasants to starve. The policy had its own brutal logic and a gruesome kind of effectiveness. Contemporary governments are fortunately too humane to adopt it.

To summarize all this in two sentences. The power of technology to get around the limits of resources is great, and if this was all that was to be said there would be no limit to the population that could be sustained. 
But technology also makes large volumes of labor unnecessary in production, and so deprives growing populations of access to the technology that would support them. The outcome is what we see - productivity never greater, including in the production of foodstuffs, hunger widespread.

\subsection{Let the Facts Decide?}

Those concerned with empirical social science would like to be able to say that facts are adequate to decide among models. Facts do provide some evidence. Writers who claim to show that population does not matter much for development justify their departure from the emphasis that classical economics placed on land by showing how prices of natural, which is to say unprocessed, goods have tended to fall in the recent past just as manufactured goods have done. (This can be expressed in terms of the labor time required for production or extraction.) Not only foodstuffs but copper, tin, iron ore, all out of the ground and nonrenewable, are available in abundance at prices that in relation to the general price level, which is to say their real prices, have never been lower.

Such renewable resources as rice, rubber, palm oil, and sisal have likewise shown real price declines. Greatly increased agricultural productivity has deferred any genera! shortage of foodstuffs, and real prices have not risen as the more static classic economics said they would. Price declines in the face of increasing population are enough to show that the goods in question are becoming more abundant, not scarcer. Oil is the only important exception, and even it has not risen in price nearly as much as threatened.

The argument is valid, but partial. It takes no account of the threatened exhaustion of fisheries, forests, and soils, or the possibility of global warming with the increased use of fossil fuels that pour carbon dioxide, methane, and other greenhouse gases into the atmosphere. Every one of these resources, from the fisheries harvest to the amount of emissions that the atmosphere can absorb with only tolerable warming, can be harvested up to a certain amount without damage. Each is like a piece of financial capital that furnishes an income to the rentier who owns it, and lasts forever if drawing is less than or equal to the annual interest, but is quickly exhausted once the owner starts to borrow on his capital. It is in these environmental elements - and not in copper, tin, or iron ore - that the strongest case for population control 
now consists. Paradoxically, it is the so-called renewable resources that will be exhausted long before the nonrenewable, and that due to two elements: increase of population and of income per head.

This is not the place to pursue the matter further. Evidence of the harm done by population growth is offered from many points of view not only by the classical economists, but also by Gunnar Myrdal (1968), W. Arthur Lewis (1955), Coale and Hoover (1958), Herman Daly (1986), Gideon Rosenbluth (1976), the World Bank Report of 1984, various NAS reports, Barney's Global 2000: Report to the President (1980), the Meadows's Limits to Growth $(1972,1992 \mathrm{a})$, as well as other recent writings by biologists Paul Ehrlich (1970), E.O. Wilson (1988), Garret Hardin (1993), and many others who point to the spread of deserts, extinction of species, ecological tenuousness. Shortage of the capital that would permit useful employment for a fast-growing population was the chief reason why population was seen as a problem in the 1960s; while that still applies, the absorptive limits of the environment - including renewable resources of all kinds - seem today more immediate and pressing.

\subsection{Perhaps No General Relation Exists: The General Question May Be Meaningless}

Is it possible that to seek a general relation between population and development is to look for something that is not there? We know that there are countries that would have higher incomes per head with fewer people; we also know that there are countries that would have a higher income per head with more people. In the face of this any claimed universal relation could be said to be sophistry.

Thus an extreme anti-natalist might argue that marginal income is bound to be less than average income, so removing everyone down to the last person would raise the average. This conclusion cannot be right, for it proves too much: it proves, as Marx said in his criticism of Malthus, that the world was already overpopulated when it contained just two persons.

The preceding Malthusian (or classical) and opposed neoclassical models are not infrequently put forth as though they could prescribe a population policy for a particular country. Since both can be argued with equal generality it is clear that we cannot trust either, and we cannot in fact trust any statement put forth with the degree of generality that these claim. 


\subsection{If Overall Growth is not Sustainable}

Up to the 1960s those who speculated that the growth path of the nations could be blocked by limits of the environment were far enough from the mainstream of social science that they could be disregarded. In the 19th century the worst that was contemplated was some country running out of some essential material - as Jevons's fear that England would exhaust its coal resources, and so no longer be financially able to import vital supplies of grain (Jevons, 1909).

A series of books that appeared around 1970 have deprived us of our innocence. Meadows et al. (1972), Paul Ehrlich (1968), Barry Commoner (1971), and others launched the ecological movement that has much affected the intellectual and even the political world. Since its appearance the neutrality of the biosphere toward our activities, its capacity to accept whatever we put into it, to adapt to any changes we make and whatever we do to it, can never again be taken for granted. Whatever we think of the science in the writings of those who aroused us - and judgments on this are varied - we have to concede that they brought about a change in human consciousness.

Whether the change in thinking is justified by a change in the physical condition of the biosphere that became apparent around 1970 will be debated. Perhaps the new thinking was merely due to a number of gifted writers seizing on an anti-development anti-natalist theme and giving it popular currency. Perhaps it was due to incipient deterioration of the environment that was becoming sufficiently visible that people would buy books on the subject.

Perhaps it was opposition to economic progress that paradoxically seems to be aroused by progress itself in the minds of some of those who most benefit from it. Daniel Bell (1990) speaks of the spread of rationality, that for 200 years has given a direction to history, enabled us to know what was "progressive" and what was "reactionary," and produced the radical change in living conditions from which we benefit. Now, he says, "Technology, as an engine of progress, has become demonized by the fears of those who emphasize its spillover effects."

Whatever its cause, we are now aroused to the possibility that the biosphere in which all economies are unavoidably seated - there is no other place for them - is limited in the amount of progress that it can stand. Progress is now called development but the entity has not changed; it was not an invention of the United Nations about 1950, but was an invention of the 18th century (Bury, 1982). Prior to that the dominant view was that 
history was forever proceeding downhill, from an original paradise to classical times, that were still high civilization, to an 18th century that could do no better than repeat the classics.

In two centuries the size of population participating in progress, where progress is measured by consumption, has enormously increased. Not only has the planetary population risen to the point where today it numbers fully five times as many as in 1798 when Malthus (1967) wrote his first Essay in 1798 , but the fraction of that larger population that aspires to participate in progress has gone up far faster. From a few lavishly consuming aristocrats and merchants to the billion or more who drive the half billion motor cars registered in the world by 1990 , and on to the remainder of the five billion on the planet who aspire to the same luxury, is an awesome progression. The consumers present and prospective have multiplied since Malthus's day not in the ratio of 5 to 1 as the population did, but in a ratio that could be 1000 to 1.

To the ecological movement among the beneficiaries of progress only so much development of the kind we have had up to now is possible, and further development is going to depend on research that will change its form. Thus Gro Harlem Brundtland (1989) referring to the Commission [1987] she chaired,

The Commission found no absolute limits to growth. Limits are indeed imposed by the impact of present technologies and social organization on the biosphere, but we have the ingenuity to change. And change we must.

If that requires waiting until new technologies can be invented it will not be accepted in countries that are below Scandinavian levels of opulence. The notion that the form of technology will have to change is not vividly present in the minds of those less well-off. "Let us get on with today's style of development and then we too can comfortably contemplate its evils," is what they seem to say. For them the insistence on anything that draws attention away from development is seen as an only partially relevant diversion. They do not deny that the obstacle exists; it is indeed there, but it has been brought about by the countries that have been developing for a century or two, and it is up to them to worry about it.

What all this comes down to is that if only so much development is tolerable, then the entire character of the development movement of the present half century is altered. It becomes a zero-sum game, in which all the advantages go to the first arrivals. If the latecomers push the game further, 
by industrializing at whatever cost to the ecosphere, they will be punishing those already rich for their greed.

The novel feature of the conflict here engendered is that it is not between contemporaries. The present inhabitants of the First World will not suffer much from the threatened global change. It is the Third World versus the descendants of the present First World. We who live now are the only possible advocates of our grandchildren not yet born, and we are half-hearted advocates. If our personal and immediate level of living was threatened we would be trying harder than we are to resolve the conflict.

\subsection{A Concrete Approach in Terms of What Would Happen If ...}

To formulate a population policy one must ask what any increment to the population will be doing. Supposing that the existing population will take care of itself as it has been doing up to now, we would ask about the economic opportunities for the 26 million gross now being added each year in India or the 4.5 million in Indonesia. We know that in the best of circumstances much of the increment will be on the land, either as landless laborers or further dividing postage-stamp-sized holdings. In Indonesia some will be transmigrants transported out of crowded Java in the hope of making better use of the land resources of the republic, but the number of these will be small compared with the natural increase. A high proportion of the village children who have gone to secondary school will migrate to the cities. The amount of capital needed to put an educated member of the labor force to suitable work is much greater than that required to employ a maker of spice cigarettes, a gardener, or a landless laborer in the sawah.

To repeat once again the message of this chapter. Every attempted general relation is unacceptable in logic and is contradicted by data. Many of the early arguments for population control rested on decreasing marginal returns to population; it was not noticed by those putting them forward that this implies that the first person on the planet would be better off if no second person appeared. On the other side, if human capital is all that is needed for production then population need not stop growing even when we are standing elbow to elbow on the land surface of the planet. Such absurdities are implicit in the common generalizations whenever they are stated without recognition of the range of densities over which they apply. 
But a bound or limit that would apply under all circumstances does not exist. That is why it is so easy for either side to confute its opponents with empirical counterexamples.

Useful policy advice is only to be obtained for concrete cases, individual countries or parts of countries, in which the particular environment - biological, political, economic, social - enables one to make explicit judgments on how the welfare of the community will be affected if the proposed increment to population is born or not born. If it is too difficult to make such judgments we had better forget policy and let Nature take its course. We have today vivid examples to show how disastrous the natural course can be. 


\title{
Chapter 3
}

\section{Simulation Models of Demographic, Economic, and Environmental Interactions}

\author{
Warren C. Sanderson
}

Economic development and sound environmental management are complementary. Development can contribute to improved environmental management, and a healthy environment is essential for sustaining development. [World Bank, 1992b]

The idea that the two pursuits - economic development that looks after the welfare of people, their needs and wants, and environmental conservation that attends to the welfare of the world - can go along merrily hand in hand as equals is false. The first priority has to be the welfare of surrounding ecosystems, for without their healthy functioning no economic system can last. [Rowe, 1990]

At this stage, there are major uncertainties about greenhouse theory, about the effects of a possible warming, and about the economic and political impacts of hasty, ill-considered policies. Does it make sense to waste $\$ 100$ billion a year on what is still a phantom threat when there are so many pressing - and real - problems in need of resources? [Singer, 1992] 


\subsection{Introduction}

This volume aims to deepen our understanding of the interrelations between population, development, and the environment through history and through modeling. This chapter provides an introduction to what we currently know about the modeling of those interactions.

\subsubsection{The challenges}

It now appears that one of the most important challenges facing people in the 21 st century will be sustainable development. It is a challenge because it is not clear that the progressive alleviation of poverty in the Third World, even at the current less than desirable rates, and the continuation of economic growth in the First and Second Worlds over the next century is feasible, given the Earth's environmental and ecological constraints. It is an important challenge because the human, environmental, and economic costs of a crash would be stupendous.

The challenge facing people interested in sustainable development is how to make progress in an area full of contradictory analyses. This book and the simulation model of sustainable development in Mauritius, which is its centerpiece, are responses to this challenge. The purpose of this chapter is to put that response into perspective.

\subsubsection{Simulation models}

Simulation models come in many forms and serve many purposes. Perhaps the best-known simulation models today are the simulators used by pilots to learn how to fly their aircraft in a variety of unusual circumstances. Nowadays some of these simulators are so good that the experience of "flying" them is very close to the real thing. On the other hand, simulation models used for predicting the weather one or two days into the future are not nearly that precise. Still these imperfect models turn out to be very useful in practice; millions of people check their results every day. Thus, simulation models are not something far outside our everyday experience. We rely on their results whenever we fly in a commercial jet aircraft or listen to a weather forecast. In this chapter, we rely on their results to teach us about sustainable development.

What simulation models have in common is that they are all simplified representations of complex systems. To the extent that the representation 
is a useful one, we can learn about the behavior of the complex system by experiencing or studying the behavior of a less complicated model. Typically, simulation models are not "solved" just once, but are run many times to get a "feel" for how they function in a variety of circumstances. People turn to simulation models because for one reason or another it is infeasible to test the system directly. It is not possible to teach pilots about the consequences of engine explosions through direct experience nor is it desirable to teach policy makers about the consequences of their actions by making them experience real environmental catastrophes. Crashes are much cheaper in a flight simulator or in a model of sustainable development than they are in reality.

\subsubsection{Outline}

Models of sustainable development are complex. To explain them better we have constructed a simple model of a place that we call Wonderland. In Section 3.2, we explore the Wonderland model in detail and use it as an example for discussing the basic concepts of sustainable development modeling. We show how it is possible to get Wonderland to experience dreadful environmental crashes and how to get it to experience sustainable prosperity. Armed with models of crashes and prosperity, we address the debate between economists and ecologists on environmental issues. In Wonderland, the nature of their disagreement becomes quite clear.

Once we have been through Wonderland, other models of sustainable development will seem less curious. In Section 3.3, we discuss the World3 model, a sustainable development model for the world, made famous in The Limits to Growth (Meadows et al., 1972) and Beyond the Limits (Meadows et al., 1992b). World3 is best known for its suggestion that the world is not on a sustainable course, and that without a significant change in orientation, we will almost surely crash.

The first, and to our knowledge only, model of an observed environmental collapse was produced by Anthony Picardi in 1974 in a study of the Sahel. His model provides a convincing and detailed account of what caused the crash and what the future of the Sahel would be like under a broad range of policies. We devote Section 3.4 to considering the sustainability of development in the Sahel through the prism of the Picardi model. It turns out to have a great deal to teach us.

One of the oldest continuing modeling traditions belongs to the United States Agency for International Development (USAID), through its funding 
of three RAPID projects over the last two decades. RAPID stands for Resources for the Awareness of Population Impacts on Development, and the models produced under these projects are designed for presentation rather than study. Recently, RAPID III models have developed more elaborate environmental structures. In Section 3.5, we discuss the most recent RAPID model for Costa Rica and show what it teaches us about the interactions between population growth and the environment.

The Mauritius model is presented in broad terms in Section 3.6. We describe its structure and show how it provides a badly needed new perspective. We briefly discuss other related models in Section 3.7 and conclude with some thoughts on the development of sustainable models.

\subsection{Simulation Modeling of Development Paths: In Theory}

\subsubsection{Introduction}

Simulations of development paths are, generally, produced within a framework composed of three basic components: a set of equations, called the model, that specifies how variables are related to one another; a set of numbers, called parameters, that gives specific form to the model's equations; and a development scenario that specifies the model's initial conditions and the time profiles of all its exogenous variables (exogenous variables influence the other variables in the model, but are not themselves influenced by any of them). The World Commission on Environment and Development (1987), also known as the Brundtland Commission, defined sustainable development as "development that meets the needs of the present without compromising the ability of future generations to meet their own needs" (Brundtland, 1987, p. 43). If the resulting simulations are to address questions of sustainable development, a fourth component must be added, one that we call sustainability considerations.

For those without a technical background, these models often seem like black boxes. Certain things go in, certain things come out; but what happens inside is shrouded in mystery. In this section, we open one particular black box and allow the readers to look inside. The box contains a model that incorporates economic, demographic, and environmental interactions. It has eight equations, thirteen parameters, four initial conditions, and one time path of an exogenous variable (see Table 3.1). Because of its small size, it is 
Table 3.1. Notation in the Wonderland model.

\begin{tabular}{|c|c|}
\hline Variable & Explanation \\
\hline$I_{t}$ & Per capita output in year $t$ \\
\hline$N K_{t}$ & Stock of natural capital in year $t$ \\
\hline$N I_{t}$ & Net per capita output in year $t$ \\
\hline$B R_{t}$ & Crude birth rate in year $t$ \\
\hline$D R_{t}$ & Crude death rate in year $t$ \\
\hline$N_{t}$ & Population in year $t$ \\
\hline$P F_{t}$ & Pollution flow in year $t$ \\
\hline$T_{t}$ & Pollution per unit of output (the rate of pollution) in year \\
\hline$P C_{t}$ & Per capita pollution control expenditures in year $t$ \\
\hline
\end{tabular}

possible to go through an entire simulation exercise with everything in plain view.

\subsubsection{The Wonderland model of sustainable development}

To make the basic concepts more concrete, let us consider the simple model of economic, demographic, and environmental interactions presented in equations (3.1) through (3.8). Equations (3.1) and (3.2) deal with the economy; equations (3.3) through (3.5), with the population; equations (3.6) and (3.7) with the environment; and equation (3.8), with environmental policy. The subscript $t$ in the equations refers to the year in which the variables are measured, and all Greek letters refer to parameters of the model (see Table 3.2). These parameters are discussed more fully in Section 3.2.3.

Equation (3.1) says that per capita output in year $t+1\left(I_{t+1}\right)$ depends on the level of per capita output in year $t\left(I_{t}\right)$, the level of the stock of natural capital in year $t\left(N K_{t}\right)$, and three parameters $(\gamma, \eta$, and $\lambda)$. Natural capital may be thought of as the set of things provided to us by the environment, like air and water, which allows us to live healthy and productive lives. When natural capital is undiminished by pollution, the stock is given a value of 1 . As more pollution occurs, the level of the stock of natural capital diminishes, until, in the extreme, it reaches 0. Equation (3.1) incorporates the assumption that the lower the stock of natural capital, the lower the rate of per capita output growth. When $N K_{t}$ is equal to 1.0, the rate of economic growth is $\gamma$; when $N K_{t}$ is equal to 0.0 , the rate of economic shrinkage is equal to $\eta$.

Equation (3.2) defines net per capita output as the difference between the level of per capita output in equation (3.1) and per capita expenditure 
Table 3.2. The Wonderland model equations.

Economy

$$
\begin{aligned}
& I_{t+1}=I_{t}\left[1+\gamma-(\gamma+\eta)\left(1-N K_{t}\right)^{\lambda}\right] \\
& N I_{t}=I_{t}-P C_{t}
\end{aligned}
$$

Population

$$
\begin{aligned}
& B R_{t}=40\left[1.375-\left(\frac{e^{\beta N I_{t}}}{1+e^{\beta N I_{t}}}\right)\right] \\
& D R_{t}=10\left[2.5-\left(\frac{e^{\alpha N I_{t}}}{1+e^{\alpha I_{t}}}\right)\right]\left[1+2\left(1-N K_{t}\right)^{\theta}\right] \\
& N_{t+1}=N_{t}\left[1+\left(\frac{B R_{t}-D R_{t}}{1,000}\right)\right]
\end{aligned}
$$

Environment

$$
\begin{aligned}
& P F_{t}=N_{t} I_{t} T_{t}-\kappa\left(\frac{e^{\epsilon P C_{t} N_{t}}}{1+e^{\epsilon P C_{t} N_{t}}}\right) \\
& N K_{t+1}=\frac{e^{\ln \left(\frac{N K_{t}}{1-N K_{t}}\right)+6\left(N K_{t}\right)^{\rho}-\omega P F_{t}}}{1+e} \frac{\ln \left(\frac{N K_{t}}{1-N K_{t}}\right)+6\left(N K_{t}\right)^{\rho}-\omega P F_{t}}{1+x^{2}}
\end{aligned}
$$

Environmental policy

$$
P C_{t}=\phi\left(1-N K_{t}\right)^{\mu} I_{t}
$$

on pollution control. The latter is determined by pollution control policy, as expressed in equation (3.8). Net per capita output is used in Wonderland as the measure of economic well-being.

Equations (3.3), (3.4), and (3.5) make up the demographic portion of the model. Equation (3.3) determines the crude birth rate (the ratio of births to the population multiplied by 1,000 ) and equation (3.4) the crude death rate (the ratio of deaths to the population multiplied by 1,000 ). The model assumes that both crude rates decrease with increases in net per capita output. In addition, equation (3.4) stipulates that decreases in the stock of natural capital cause the crude death rate to rise. Equation (3.5) is an accounting identity that computes the population in year $t+1$ based on the population in year $t$ and the intervening numbers of births and deaths (the model assumes that there is no net migration). 
Table 3.3. Parameters in the Wonderland model.

\begin{tabular}{llll}
\hline Economy & & Environment & \\
$\gamma=0.04$ & $\eta=0.04$ & $\kappa=1.00$ & $\epsilon=0.02$ \\
$\lambda=2.00$ & & $\delta=1.00$ & \\
& & $\rho=0.20$ & $\omega=0.10$ \\
Population & & Environmental policy \\
$\beta=0.08$ & $\alpha=0.09$ & $\phi=0.50$ & $\mu=2.00$ \\
$\theta=15.00$ & & & \\
\hline
\end{tabular}

The environmental portion of the model appears in equations (3.6) and (3.7). Equation (3.6) determines the annual flow of pollutants as a function of the population size, per capita output, the technologies of production and pollution abatement, and on the amount of money that is spent on pollution control. Equation (3.7) shows how the pollution flow and nature's ability to cleanse itself interact to produce changes in the stock of natural capital.

The final equation represents environmental policy. Here the amount of money per person spent on pollution control is determined depending on per capita output and the stock of natural capital. Per capita spending on pollution control is assumed to increase with per capita output and to increase as the stock of natural capital decreases.

\subsubsection{The parameters}

The 13 Greek letters in the model are parameters. They must be given specific values before the model can be run. If the parameters cannot be precisely estimated, the modeler has a difficult decision to make - either to leave out some potentially important segment of the model or to include parameter values that are just educated guesses. The parameters for Wonderland appear in Table 3.3. For the moment, let us assume that they have all been precisely estimated.

\subsubsection{Initial conditions and exogenous variables}

Before, we can produce any simulated futures, we have two more steps to complete. First, we must specify the current state of affairs, and, second, we must stipulate future time paths of the exogenous variable $(T)$, the amount of pollution per unit of output. The initial conditions for our model refer to the year 1990 and appear in Table 3.4. 
Table 3.4. Initial conditions in the Wonderland model.

\begin{tabular}{ll}
\hline$I_{1990}=1$ & $N_{1990}=1$ \\
$N K_{1990}=0.98$ & $T_{1990}=1$ \\
\hline
\end{tabular}

The Wonderland model has only one exogenous variable, the amount of pollution per unit of output. It appears in equation (3.6) where it is denoted by $T$ for "technology" because it combines the effects of the technology of production and the technology of pollution control. For the moment, we will assume that pollution per unit of output will decrease at an annual rate of 1 percent per annum:

$$
T_{t+1}=0.99\left(T_{t}\right) \text {. }
$$

\subsubsection{The sustainability of development}

Below in Section 3.2.7, we encounter our first simulated future, but first we must ascertain whether the development path is sustainable or not. In Wonderland, we implement the Brundtland Commission's definition with two criteria. We call a development path unsustainable if it entails one of the following: the current generation having a higher level of net per capita output at the expense of future generations who must have lower levels or the current generation having a lower death rate at the expense of future generations who must suffer higher rates. Any particular sustainability criteria that are used to evaluate simulated futures are, like the models to which they refer, partly a matter of judgment.

In practice, models are solved over a finite, and in ecological terms, brief period. Thus, a development path that is sustainable over the simulation period may not be sustainable over a longer one. It follows that the simulation period must be short enough for the model to be useful, yet long enough for the question of sustainability to be meaningful. We call the period over which sustainability is defined the "sustainability horizon." In Wonderland, the sustainability horizon is 111 years, from 1990 through 2100 .

\subsubsection{Positive and negative feedback loops}

Before we see how Wonderland evolves, it is important to take a moment to consider the factors in the model that influence its development path. Of chief importance, in most dynamic models, is the existence and nature of 
feedback loops. Feedback loops exist when, for example, variable $A$ influences variable $B$ which influences variable $C$ which influences variable $A$, perhaps sometime in the future. A negative feedback loop occurs when increases (decreases) in variable $A$ result in changes in other variables that, in turn, put downward (upward) pressure on it. A positive feedback loop occurs when increases (decreases) in variable $A$ result in changes in other variables that, in turn, put upward (downward) pressure on it. Negative feedback loops dampen changes in variables; positive feed back loops reinforce them.

Wonderland has both positive and negative feedback loops. When the emission of pollutants in Wonderland goes up, the stock of natural capital goes down. When the stock of natural capital goes down, expenditures on pollution control go up, thus causing the emissions of pollutants to be reduced. This is a negative feedback loop because forces in the model tend to dampen changes in emissions. On the other hand, the ability of nature to eliminate pollution depends on the level of the stock of natural capital. As the stock of natural capital goes down, the same amount of pollution has a bigger negative effect on it because of those diminished recuperative powers. Thus, a lower stock of natural capital sets in motion forces that cause the stock of natural capital to fall even further. This is a positive feedback loop because forces in the model reinforce changes in the stock of natural capital. The future of Wonderland depends on whether the negative or the positive feedback loops dominate.

\subsubsection{One side of the looking glass: The environmentalists' nightmare}

The model, parameter values, initial conditions, and the future path of the exogenous variable imply development paths for all the endogenous variables in the model. Figure 3.1 shows the rise and then dramatic collapse of both net and gross per capita output in Wonderland. Net per capita output reaches a peak of 19.4 in 2066, and falls 59 percent in the ensuing 10 years. Twenty years after its peak, net per capita output is barely one-quarter of what it was. Clearly, this development path violates the Brundtland Commission's definition of sustainability. People in Wonderland before 2066 were compromising the ability of the next generation to meet its needs. Their high standard of living was borrowed at the expense of the future.

Figure 3.2 shows what happens to the crude birth and death rates, and the size of the population. Over time, both the crude birth rate and the crude death rate fall as net per capita output rises. The rate of population 


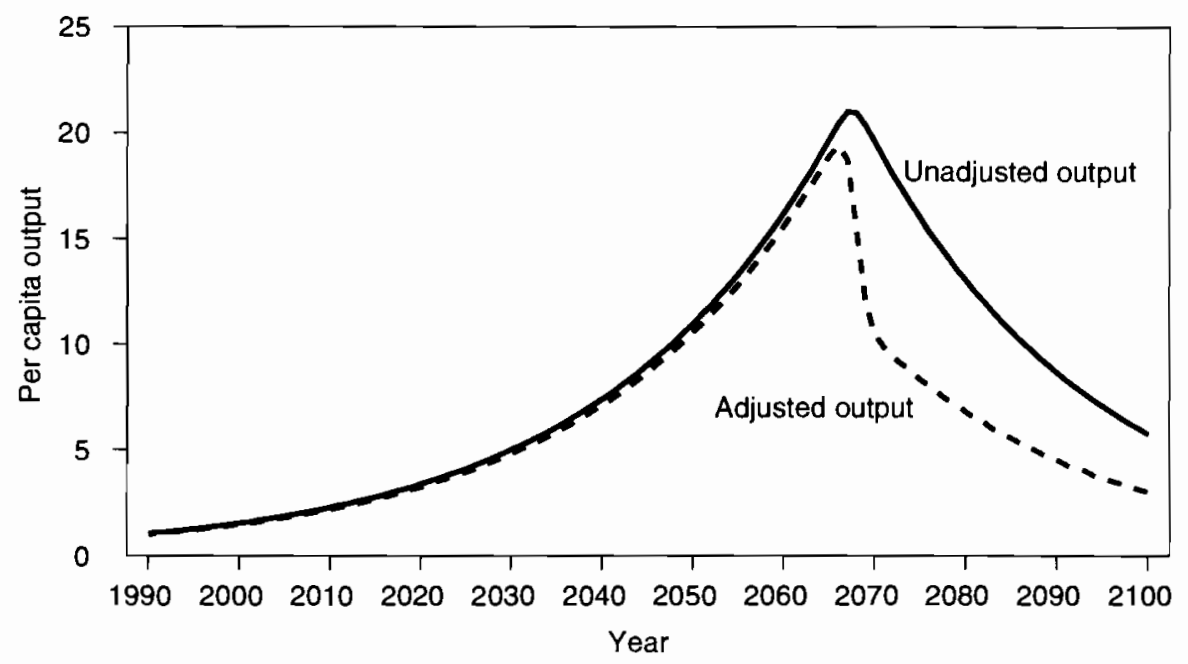

Figure 3.1. Per capita output adjusted and unadjusted for pollution control costs in the environmentalists' nightmare scenario.

growth declines over time from 2.4 percent per year in 1990 to 0.55 percent in 2066. After the crisis, death rates skyrocket from 16.5 in 2066 to 54.8 in 2076 and continue climbing slowly thereafter. This high death rate overwhelms the crude birth rate, which itself rises some, and the population begins to shrink. Thus, this development path also violates the death rate criterion for sustainability. The people before 2066 jeopardized the health of future generations. Their low death rates were purchased at the expense of the health of their children and grandchildren.

The cause of the collapse is easy to trace. The combination of economic growth, population growth, improvements in pollution control technology, and policies toward pollution control expenditures result in an ever rising level of pollution. This could be accommodated in the environment, in essence, because the pollution flows were not large relative to nature's ability to handle them. Thus, for a long time, the stock of natural capital is not degraded, even as the pollution flow increases, but after a while nature's ability to redress pollution diminishes. In its weakened state, even a constant level of pollution would cause the stock of natural capital to fall, but the level of pollution does not remain constant. Continued economic and population growth leads to an increase in the level of pollution and this helps turn the decrease in the stock of natural capital into a precipitous collapse. 


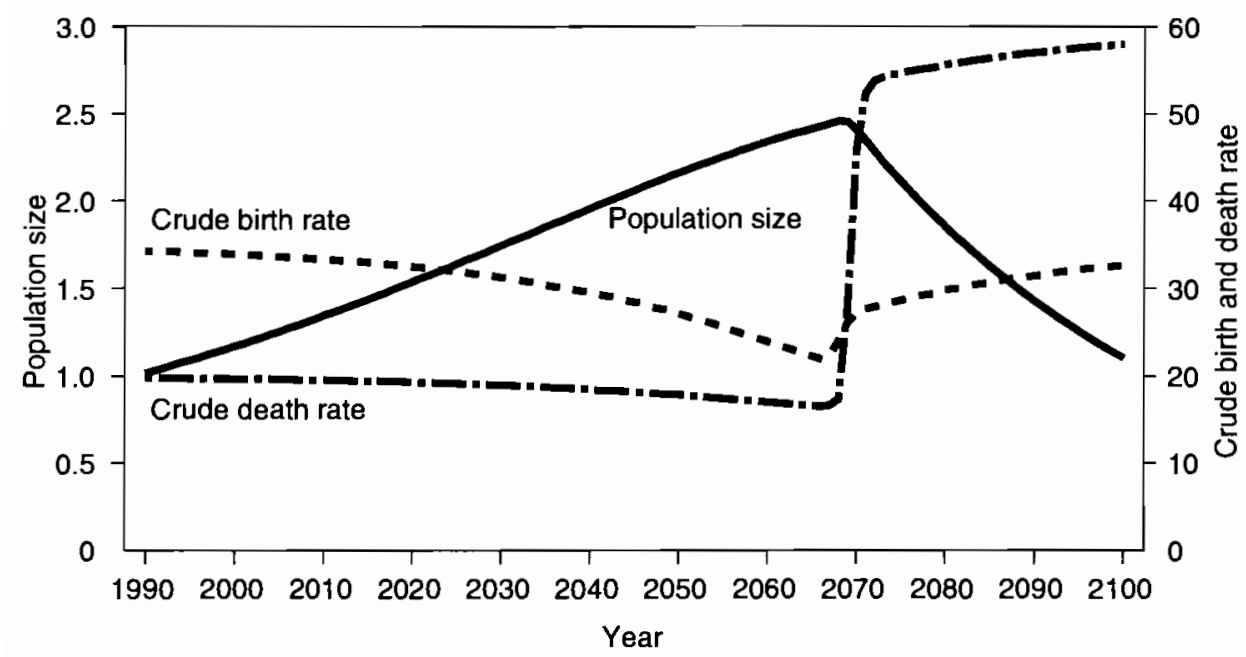

Figure 3.2. Population size, crude death rate, and crude birth rate in the environmentalists' nightmare scenario.

The rate of pollution declines steadily throughout the simulation period. In other words, people are producing less and less pollution per unit output as time goes on. The collapse has nothing to do with a change in the rate of pollution reduction. Even with increasing expenditures on pollution control, a declining rate of pollution, and a falling rate of population growth, the collapse still occurs. What makes this simulated future so nightmarish is that the calamity occurs so quickly and with so little warning.

Imagine two people in Wonderland dressed in T-shirts and shorts arguing loudly in front of a crowd of people. The time is 2050 . His T-shirt reads "ECOLOGIST"; hers reads "ECONOMIST."

"Look," he said, "we've been polluting the country for 60 years now. Sooner or later it is just going to be too much for the environment to handle. We need to cut back on our pollution now!"

"We've been growing very nicely for 60 years now," she replied. "Poverty has been substantially reduced, birth rates are going down, death rates are going down, and the population growth rate is falling. We're doing just fine, no thanks to you. If we listened to you years ago, we would have cut back and had more poverty now."

"Nonsense," he said, "the environment is not like an economic system, it is subject to all sorts of discontinuities. Things can look like they're OK for 
a long time while environmental stresses build up and then, all of a sudden, there's a discontinuous change."

"Yeah," she said, "show me a discontinuous change over the last 60 years."

The crowd doesn't know what to conclude from these mutually contradictory arguments. We now understand that business went on as usual and that 17 years later a dreadful crash occurred, destroying the economy and causing a horrible rise in death rates. But in 2050, without the Wonderland model, they couldn't have known that. ECOLOGIST would have been awarded the Nobel Prize in biology for his work on discontinuities in polluted ecological systems, except that, after the crash, money was short and the prizes were discontinued.

Look, the two are wandering over toward that mirror and the crowd is following. Let's follow too.

\subsubsection{On the other side of the looking glass: The economists' dream}

On this side of the looking glass, Wonderland looks very familiar. The eight equations, the thirteen parameters, and the four initial conditions are all identical. The only thing that is different is the time path of the exogenous variable $T$ (pollution per unit of output). Where we came from, pollution per unit of output fell by 1 percent per year; on this side of the looking glass it falls by 4 percent per year. Figures 3.3 and 3.4 indicate the future of Wonderland on this side of the looking glass.

Figure 3.3 shows that per capita output and per capita output after adjustment for pollution control costs grow steadily. Now there is sustainable prosperity in Wonderland not an environmental catastrophe. Figure 3.4 shows that, over time, the birth rate converges to the death rate and that, by the end of the 21st century, population growth stops. There is never a time when the crude death rate rises precipitously. We call this simulated future, the economists' dream. Clearly, the economists' dream future is sustainable according to the definition that we gave above. Each generation leaves to the future the means to live longer and more prosperous lives.

Population growth and economic growth do cause an increase in the flow of pollution, but the increase is not large enough to degrade the stock of natural capital. Indeed, the pollution flow itself reaches a peak in 2083 and falls continuously thereafter. Thus, by the end of 21 st century, population 


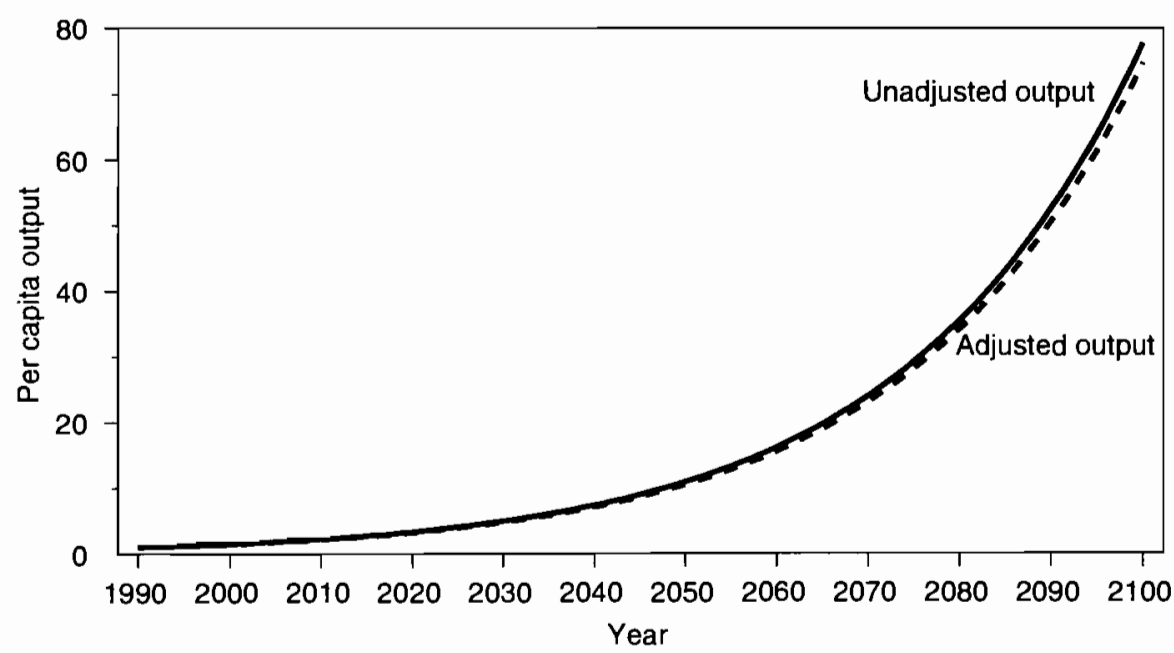

Figure 3.3. Per capita output adjusted and unadjusted for pollution control costs in the economists' dream scenario.

is stable, the economy is growing, pollution flows are falling, and the level of the stock of natural capital is consistently high.

There's that pair arguing again; it's still 2050 and the same crowd is still trying to make sense out of their arguments.

"Look," he said, "we've been polluting the country for 60 years now. Sooner or later it is just going to be too much for the environment to handle. We need to cut back on our pollution now!"

"We've been growing very nicely for 60 years now," she replied. "Poverty has been substantially reduced, birth rates are going down, death rates are going down, and the population growth rate is falling. We're doing just fine, no thanks to you. If we listened to you years ago, we would have cut back and had more poverty now."

"Nonsense," he said, "the environment is not like an economic system, it is subject to all sorts of discontinuities. Things can look like they're OK for a long time while environmental stresses build up and then, all of a sudden, there's a discontinuous change."

"Yeah," she said, "show me a discontinuous change over the last 60 years." 


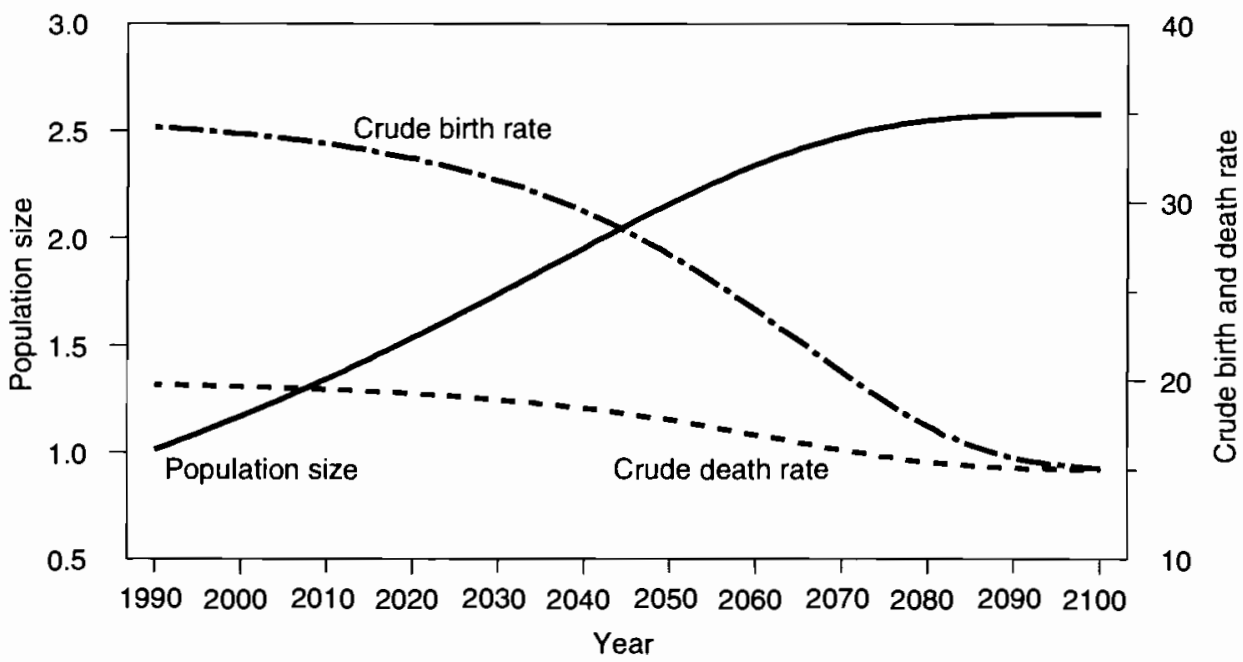

Figure 3.4. Population size, crude birth rate, and crude death rate in the economists' dream scenario.

The crowd, listening to this argument, is thoroughly confused. We now know that nothing changed, that growth continued and that Wonderland became a prosperous developed country, but in 2050, without the Wonderland model, they couldn't have known that. Seventeen year later, ECONOMIST is given the Nobel Prize in economics for her work on continuities in polluted economic systems.

We could ask which view is the correct one, the view from this side of the looking glass or the other one, but there would be no answer to that question. In a sense, both are correct. With a simulation model, we can only make conditional statements. Given the model, the parameters, the initial conditions, and the time path of the exogenous variables, the model can produce a path of development. With different time paths of the exogenous variables, perhaps only slightly different from the original ones, the model's outcomes could change quite radically, as we have seen.

How, then, can we improve our understanding of the interrelationships between economic, demographic, and environmental variables? To make progress, we must create models of particular regions or countries where the important relationships are specified with care and where potential policies are included explicitly. This is exactly what the Mauritius model does. 
Before, we get to Mauritius, though, we have to go through three other models, three other lands. Each has a lesson to teach.

ECOLOGIST and ECONOMIST are walking toward a little bridge. The sign next to it says "World." Let's see what's on the other side.

\subsection{The World3 Model}

Advocates of a world view that is different from the one presented here would enhance future discussions if they would express their theory as a formal model, so that persons in various fields could personally scrutinize its assumptions and independently determine its implications... Those who agree with the basic ideas expressed in World3 can go on to test, improve, and disaggregate the model and to use it where appropriate as a basis for policy in local, regional, or national systems. [Meadows et al., 1974, p. 563]

\subsubsection{Introduction}

The World 3 model is an economic, demographic, and environmental model of the world taken as a whole. It is the outcome of a rapid evolutionary process that took place between 1970 and 1972, culminating in the publication of the best-selling book, The Limits to Growth (see Meadows et al., 1982, pp. 2223 for more details on the origins of World3). By the early 1980s, this book had already sold over three million copies and World 3 easily became the most famous model of sustainable development ever produced. Today, it comfortably maintains this distinction.

Along with its popularity came a substantial amount of notoriety. Meadows et al. (1982, p. 23) called World3 "one of the most criticized models of all time." Criticisms bring with them the opportunity for improvement, and, with so many suggestions and so many interested parties, it seems natural that World3 should have evolved into something better - that by now there would be World4, World5, and World 6 models. Nevertheless, this evolution has not occurred. Understanding why World3 has turned out to be an evolutionary dead-end, even for its creators (the World3 model in Meadows et al., $1992 \mathrm{~b}$, is almost identical to the one used in Meadows et al., 1972), provides important background for understanding the role of the Mauritius model, which traces its roots to an entirely different stock. 


\subsubsection{The structure of the World3 model}

World 3 is a medium-sized model consisting of 149 equations and tables. The population segment of the model includes 48 equations; the economic segment, 81 equations; and the natural resources and pollution segment, 18 equations. The detailed structure of the World3 model appears in Meadows et al. (1974, pp. 567-586).

\section{Population}

The World 3 model keeps track of the population in four broad age groups, $0-14,15-44,45-64$, and 65 and above. Population growth is determined by the difference between the crude birth rate and the crude death rate as in the Wonderland model, but the determinants of those rates are much more elaborate than in the earlier model. Let us consider the crude death rate, for example. An increase in industrial output, holding population size and age structure fixed, brings with it an increase in pollution that increases the crude death rate. An increase in industrial output also entails more crowding, which also causes an increase in death rates. Thus, an increase in industrial output has an unambiguously negative effect on the crude death rate. An increase in service output per capita causes an increase in pollution and an increase in medical services per capita; therefore, it has an ambiguous effect on death rates. Similarly, an increase in agricultural production increases pollution and increases food availability per capita, making its effect on death rates also ambiguous.

Education is not included in the World3 model. There can be no doubt that this is a serious omission, especially since of the effects of education on mortality, fertility, as well as on labor productivity, are substantial.

\section{Economy}

The economy comprises three sectors: industry, services, and agriculture.

Industry and services. Industrial output and service output depend on the amounts of capital in those two sectors multiplied by sector-specific outputcapital ratios. Only in extreme conditions of rapid population decline does the size of the labor force constrain output. In usual times, the model assumes that there is chronic unemployment and that neither the size of the labor force nor its training and education have any bearing on output. 
To understand how the model functions, imagine that we begin this year with the industrial and service capital stocks we inherited from the past. Industrial and service output levels are determined simply by multiplying those stocks by the respective output-capital ratios. Most service output is consumed and vanishes from the model. Some service output goes into health services that influence the crude death rate and family-planning services that influence the crude birth rate. Services do not use natural resources or cause pollution, and essentially play a very minor role in the model.

Industrial output is far more central to the model than are services. The first claimant on industrial capital is the amount needed to obtain natural resources. What industrial capital remains is then used to produce industrial output. The amount of industrial output is the amount of industrial capital not used to obtain natural resources, multiplied by the industrial outputcapital ratio. A fixed fraction of industrial output is consumed and vanishes from the model. Other fractions allocate the remainder to investments in agriculture, services, and industry.

Each year agricultural, service, and industrial capital stocks are assumed to be diminished by depreciation and augmented by investments. The new capital stocks at the beginning of the next period are determined by adding net investments to the stocks at the beginning of this period. From this point, we return to the beginning of our discussion, determine the output of services from the new service capital stock, and compute the output of industry, after subtracting the capital required for obtaining natural resources from the new industrial capital stock.

Industrial output is central to another area of the model as well. Industrial output requires nonrenewable resources. The use of these nonrenewable resources causes persistent pollution (all pollution except air pollution), which decreases the fertility of agricultural land and increases the crude death rate. In addition, industrial output has a direct negative impact on agricultural yields because of air pollution. Persistent pollution and air pollution have no direct effect on industrial output or service output.

Agriculture. The agricultural sector is the most complex in the model. Food is produced on arable land according to a particular yield (in World3, all arable land is assumed to be used for crop production). The amount of arable land and the agricultural yield in any period is predetermined by past circumstances. Next period's amount of arable land and yield will be 
influenced by investment decisions made in this period and by the lagged effects of previous decisions.

The fraction of total available capital that gets invested in agriculture depends on the relationship between the amount of food produced per capita and the amount of food desired per capita. The amount of food desired increases with the amount of industrial output and population size. The amount of food produced depends on the product of the amount of land and the yield. In general, as the ratio of food produced to food desired goes down, an ever larger share of available capital is devoted to agriculture. This follows from an assumption that agricultural production is given priority in the model. The industrial sector is the residual claimant on capital.

Increases in agricultural production set into play a substantial set of countervailing forces that ultimately reduce it. The amount of land erosion that takes place in the model depends positively both on the amount of arable land and on the yield. Thus, investments that increase the amount of arable land and the yield produce additional erosion. Erosion permanently removes land from the model. Persistent pollution increases with both the amount of arable land and the amount of investment per hectare. Persistent pollution lowers yields, causing more investment to be used to produce the same amount of food, which in turn produces additional persistent pollution that lowers yields even more. This is a powerful positive feedback loop and we return to it when we look at the results of the model.

\section{Natural Capital and Pollution}

Despite its importance to the goals of the model, the treatment of nonrenewable resources and pollution in World3 is cursory at best. The model begins with a fixed stock of a single nonrenewable resource. Industrial output uses some of this output, and so every year the remaining stock of the nonrenewable resource falls, causing extraction costs to increase. In the model this is represented by making the fraction of capital that has to be devoted to obtaining resources increase as the stock of the resource decreases.[1] Since, capital needed to obtain resources has priority over everything else in the model, the share of capital that can be devoted to the other sectors of the economy must decline. In addition, rising population and per capita industrial production require still greater investments in agriculture, taking even more from the industrial sector. Since there is no ongoing technological change in the nonrenewable resource sector, nor any substitution between resources, this process causes output to collapse. 
There are two types of pollution in the model, persistent pollution and air pollution. Persistent pollution is generated from the use of nonrenewable resources by the industrial and agricultural sectors. Air pollution is produced only by industrial output. Persistent pollution appears in the environment some years after it was generated. Nature removes some amount of persistent pollution each year, but, like in Wonderland, nature's ability to renew itself is assumed to diminish as the amount of persistent pollution grows. This forms an important positive feedback loop that also leads to collapse. Pollution has two effects in the model. It reduces the agriculture yield per hectare, and it reduces life expectancy.

\subsubsection{The results of the World3 model}

The most widely remembered results of the World 3 model are the mass of graphs showing global collapse. These graphs were coupled with statements like: "even the most optimistic estimates of the benefits of technology in the model did not prevent the ultimate decline of population and industry or in fact did not in any case postpone the collapse beyond the year 2100." The Limits to Growth left readers with three basic conclusions, but it is the first that most people remember.

If the present growth trends in world population, industrialization, pollution, food production, and resource depletion continue unchanged, the limits to growth on this planet will be reached sometime within the next one hundred years. The most probable result will be a rather sudden and uncontrollable decline in both population and industrial capacity. [Meadows et al., 1972, p. 29][2]

It has now been more than 20 years since those words have been written and, according to Beyond the Limits (Meadows et al., 1992b), we have continued on the wrong course. Without change, collapse is now even closer, within the next 80 years. Imagine a couple who had a child in 1992 in a developed country. Given projected life expectancies, that child probably would be alive at the time of the horrible economic, demographic, and environmental crash. If World 3 is an appropriate representation of reality, and we continue to grow as we have been doing, then, clearly, our current standard of living will have been purchased at our children's expense.

Economics got the title "the dismal science" because Malthusian models predicted that population growth would wipe out all productivity gains and keep people at a subsistence standard of living. World3 goes one step beyond 
Malthus, bringing us face to face with the nightmare of impending "sudden and uncontrollable decline."

\subsubsection{Comments on World3}

World 3 is one of the most criticized models ever produced. This body of work is suddenly relevant again with the publication in 1992 of Beyond the Limits, which uses World3 in virtually unchanged form. Perhaps those critiques should be republished as well. Summarizing them would take far too long here. Instead, we concentrate on understanding the unproductivity of the World3 approach.

It could be argued that World 3 has been fruitful as a tool for persuasion, rather than as a base for further sustainable development modeling. Certainly, there is an element of truth to this statement. World3 was definitely designed to be an effective vehicle for communicating a vision of the future to people, but, as the quotation from Dynamics of Growth in a Finite World at the beginning of this section indicates, the creators of World 3 also had a vision of how the scientific dialogue would unfold. Critics of World3 would present alternative simulations; the authors of World3, or perhaps others, would respond and then, round after round, ever better world and local models would result. But this vision never materialized.

We have already encountered the key to understanding the barrenness of World3 in Wonderland. In Wonderland, it was not always so easy to know on which side of the looking glass we stood. A slight change of a number here or there and the model could easily go from collapse to prosperity and back again. It turns out that World3, just like Wonderland, is extremely sensitive to its parameters and particularly its assumptions about the nature of technical change. Gently nudge a parameter here or tweak one over there and collapses give way to continued growth. Thus World 3 contains many visions, some gruesome and some gentle, depending on figures no one can know with assurance.

By 1973 , the community of modelers had already learned the basic story line (see Cole et al., 1973, for example). World3 and models like it could be made to produce continued growth or collapse depending on assumptions about unknown and, possibly, unknowable parameters. Without substantial improvement in our knowledge of the underlying relationships needed to build a global model of sustainable development, further development of World 3 was, in 1973, and still remains a fruitless exercise. This is why modelers never built on the World3 foundation. 
The collapse of World 3 in 1973 was disruptive to the process of environmental modeling. It did teach us, though, that what was needed was not another model with uncertain parameters and stylized equations, but, instead, models of particular places or regions where the equations could be specified with more confidence and made more robust to uncertain parameters.

There's that couple arguing again. The crowd's gone. Let's walk over and listen.

ECOLOGIST: "I admit that you are right about the flaws in the model, but it still shows how a system can collapse. Systems can collapse and the sooner people learn that the better; then perhaps they would do something about it."

ECONOMIST: "Systems don't just collapse, particularly the entire Earth. If there are problems they would show up in some place first. If the price of some raw material rises, people will conserve on its use and substitute some cheaper material. If farm land becomes degraded, it won't become degraded everywhere in the world all at once. The first signs of a problem will gives us time to work up a solution. Anyway, show me a concrete example of a collapse."

He points to a little bridge and they go off. The sign by the bridge says "The Sahel." Let's follow them.

\subsection{The SOCIOMAD Model}

"This study is the first time the tragedy-of-the-commons syndrome has been treated in an explicit interacting ecological-social-economic framework" ( $\mathrm{Pi}$ cardi, 1974, p. 16).

\subsubsection{Introduction}

In 1974, Anthony Picardi, then a graduate student in the Department of Civil Engineering at the Massachusetts Institute of Technology (MIT), wrote a dissertation that included, to our knowledge, the first simulation model of sustainable development applied on a less than global scale. It was devoted to a study of the portion of the Sahel found in the Tahoua region of Niger and was funded by the United States Agency for International Development for the United Nations, as part of a larger project. Unfortunately, Picardi's thesis was never published.[3] Picardi remembers the response it received: 
USAID didn't want our study published. They gave us money to print only a half dozen copies. They forbid [sic] MIT to publish it with Institute funds and refused to send it to the USAID field offices in Africa.

There were several reasons given, some obviously false. My personal opinion is that they wanted a study that recommended a quick fix. Preferably something high-tech that US businesses could supply. Cattle breeding technology or the use of satellites, maybe.

The message of SAHEL is that there is no quick, technical fix. The problems in the Sahel are all interconnected in a complex socio-politicalecological system. The only solutions are long-term... That wasn't what USAID or the UN wanted to hear. [As quoted in Barney et al., 1991, p. 193]

Although it was never published, Picardi's thesis deserves recognition as one of the best simulation studies of sustainable development ever written, and certainly as a fundamental piece of work in the area. One of the most compelling (and chilling) aspects of Picardi's work is its focus on a real economic and environmental crash. During the drought of the early 1970s, thousands of people died, further thousands were turned into environmental refugees, and the loss of grazing animals - the main form of productive capital in the area - to dehydration and starvation was substantial.

The study area lies in the western portion of Niger on the border with Mali. This region, which is about the size of Kentucky in the USA, was chosen because of the availability of data and because there was a single dominant form of economic activity, livestock raising. The dominant lifestyle there is nomadic.

The nomads of the Sahel live a precarious existence. They raise animals for food, milk, transport, and sale. Rain is often scare and usually very unevenly distributed. Herds are moved from place to place depending on the rainfall and vegetation growth. Most of the area is a gigantic common grazing field without clearly defined property rights. During periods of good rainfall, populations of people and animals build up, the animals overgraze the land, the land deteriorates and this produces a situation ripe for the next collapse.

\subsubsection{The SOCIOMAD model of the Sahel}

Picardi's thesis contains three successively more complex models called, from the simplest to the most inclusive, SAHEL2, ECNOMAD3, and SOCIOMAD. SAHEL2, the underlying ecological model, deals with the 
relationship between the quality of rangeland, the size of herds, and the length of periods of migration into the Sahel from areas outside the region, among other things. Rainfall, the quality of rangeland, and government policies constrain what the nomads can do. What they will do, in terms of variables such as their number of children ever born, the animal slaughter rate, and amount of capital held in nonanimal form, depends not only on what nature and the government will allow them to do, but on their preferences as well. ECNOMAD3 adds these preferences to the SAHEL2 model. The result is a framework in which the behavior of the nomads is responsive to their environment and to government policies. As in most economic models, preferences in ECNOMAD3 are assumed to be fixed. SOCIOMAD goes one step further and explicitly specifies the process by which preferences change with experience and because of various government programs.

\section{The Economic Segment}

In the Sahel, the main resources are water and rangeland. Rainfall is exogenous in the model, and the quality of the rangeland in any period depends on the amount of rainfall, on the forage utilization intensity during that period, and on the quality of the rangeland in the previous period. The forage utilization intensity depends on the number of animals grazed on the land, the amount of land available for grazing, and the duration of migratory periods, among other things. Once the sustainable level of forage utilization is exceeded, the soil begins to deteriorate. The sustainable level of forage utilization of degraded soils is even less, so a constant high level of forage utilization causes an accelerating decline in soil quality, ending either in desertification of the land or in massive livestock die off. This is the dominant positive feedback loop in the model. Land regeneration is included in the model, but it happens at a much slower rate than does degeneration.

There are two populations in the model, the population of livestock and the population of people. The population of animals is given quite a sophisticated treatment. There are birth rates and death rates that depend on the amount of forage available. Besides the factors mentioned above, the amount of forage depends on the extent that water is available from wells. Improvements in veterinary services reduce the livestock death rate, but, of course, the more crucial determinant of that rate is the size of the human population.

In the model, humans use the livestock for four different purposes: for meat, for milk, for sale (so that other goods can be purchased), and for what 
Picardi calls "social infrastructure." This last category includes the use of animals for gifts, dowries, establishing social ties, transport, and drought and disease insurance.

The allocation of the herd for these four purposes is computed using the prices of animals, millet, and milk and a set of desired allocations, which can change slowly over time with experience and government policy. The nomads also determine the length of migratory periods in the Sahel and the herd slaughter rate. If the herd grows too large and degrades the rangeland, less forage will grow and both the human and animal populations will suffer.

\section{The Demographic Sector}

In the SOCIOMAD model, people are born, die, and migrate. The age structure of the population does not explicitly appear, but approximate agestructure effects are included in some demographic equations. For example, the crude birth rate is assumed to depend on the fraction of women in the reproductive ages (an age-structure variable), per capita wealth, and a lagged value of life expectancy. The fraction of women in the reproductive age in a given period is approximated using that period's value of life expectancy.

\section{Natural Capital and Pollution}

Pollution, per se, does not exist in the SOCIOMAD model, and there are no nonrenewable resources. Natural capital is represented by the quality of the rangeland. Like in Wonderland and World3, nature in the SOCIOMAD model has the power to undo some or all the damage done by human or animal sources, and this power is assumed to wane as the damage increases.

\section{Policy Variables}

SOCIOMAD is rich in its array of policy variables. This is one strength of the model. Among the policy variables are: well-digging to increase the amount of land over which the nomads can graze, veterinary interventions to reduce livestock death rates, food relief for people in bad times, changes in the prices of animals due to government policies, supplemental livestockfeeding programs, taxes based on herd size, and a set of range-management policies. 


\subsubsection{Results of the SOCIOMAD model}

Picardi's discussions of the effects of past and potential future policy interventions are extensive and rich in detail. In the space available, we can provide only a brief glimpse of them. Picardi used the SAHEL2 model to run historical experiments with a starting date of 1920 . One question addressed was whether the severity of the crash of the early 1970s was due to the severity of the drought. The answer is that it was not. The severity of the drought of the 1970s was not unprecedented.[4] The simulations slowed that the drought determined the timing of the crash, but not whether there would be one. If the crash did not occur in the early 1970s, it would have occurred later when the next drought came. The root cause of the severity of the crash was not the severity of the drouglit, but the cumulative effects of excess grazing brought about by a prior period of unusually good rainfall and other factors.

A simulation was also used to assess the impacts of three historically significant interventions: well-digging, improved veterinary care, and improved public-health conditions. The outcome of this experiment is striking. The interventions worsened the effects of the drought and increased the loss of human life. In the period after the drought, population size is higher in the Sahel in the no intervention scenario than in the case observed because, in the former, the population approached the carrying capacity of the land at a slower rate of growth, leading to less overshooting, less land deterioration, and a higher long-run soil quality.

In a forward-looking analysis, Picardi goes one step further and uses the SOCIOMAD model to ask what would happen if the three interventions listed above, after having occurred, were slowly reversed, so that by 2020 the Sahel returned to the conditions observed in the 1920s. The answer is that, in this "complete neglect" scenario, human and animal populations were higher in 2020 than in the case where the interventions were maintained. Those particular interventions appear to be counterproductive in the long run.

Picardi considers other polices, including raising the real price of cattle, increasing the preference for nonanimal wealth holding, increasing taxes on animals, and limiting the amount of time nomads spend in the Sahel. The results of all of these are dismaying - land degradation, starvation, and outmigration. The reason is that the land remains a common property, whose services are free to the nomads. Picardi finds that the only policies that have a possibility of succeeding are those that regulate the numbers of animals maintained on the land according to the condition of the soil. He argues 
that this sort of regulation would not likely be obtained voluntarily from the nomads and probably would require the imposition of some kind of outside authority.

To simulate what this outside authority might do, an experiment was created in which the herd size is varied year by year so that the size of the herd to be carried over the dry season plus expected additions to the herd would not exceed the prior season's sustained carrying capacity. This scenario was much more optimistic for land quality, but the annual required slaughter rates varied enormously, sometimes leading to massive herd reductions followed by human starvation and waves of out-migration. These fluctuations could be eliminated through a supplemental feeding program, where herd sizes were related to the long-run state of land quality, but other simulations show that these programs could, sometimes, be more costly than the value of all the stock slaughtered.

A combination of policies that include direct stock control, supplementary feeding, veterinary interventions to reduce stock death rates, and education that increases material aspirations would have the effect of increasing incomes and decreasing desertification over the long run.

When health, nutrition, and family-planning interventions are added as a package to this optimistic simulation, matters get worse. The range still improves in quality, but incomes per capita are not nearly as high because of the increased population size. The increased population size is due, in part, to an assessment that family planning can play only a limited role in reducing fertility among the nomadic people of the Sahel. In the simulations, the introduction of a family-planning program only reduces the prior fertility level by 10 percent, a very modest amount.

\subsubsection{Comments}

The sorts of economic and demographic crashes feared by ecologists do occur and the history of the Sahel region provides us with dramatic case studies. Picardi's choice of the Sahel as the setting for his sustainable development simulation models was inspired. The results show the power of systems dynamics methodology - as it was in the early 1970s - for understanding the interrelationships between economic, demographic, and environmental concerns. In retrospect, it is a great shame that Picardi's thesis was never published and that it has not served as a point of departure for other models.

The Sahel is the vision of the early Malthus manifested on Earth, but with an additional dismal twist. In the Sahel, when there is a period of good 
rains or when there is progress in keeping livestock or humans alive, the population begins to grow and this growth builds up a certain momentum. In this situation, a drought could trigger a collapse that does not return the system to some stable equilibrium point. The overshooting that happens, when the drought comes and people try desperately to maintain their herds and themselves, can cause damage to the environment that can only be repaired over a long period. Thus the collapse of a rapidly growing population does not return the system to the same equilibrium that is reached when a more slowly growing population crashes, as we saw from Picardi's historical simulations. The collapse of a more rapidly growing population leads to a worse situation. Interventions to help the nomads after the 1930s left them worse off after the drought of the early 1970s than they would have been without those interventions.

The extra dismal element that Malthus did not foresee was that there is a relationship between economic and demographic growth paths and the local equilibrium that the system can attain. If population and economic growth rates slow down gradually as the system's limits are approached, there may not be a crash. If those growth rates do not decline, as in SOCIOMAD, World3, and Wonderland, there is the possibility of a crash, bringing with it more damage and a lower local equilibrium.

In arguing in favor of lowering population growth rates, many people cite the role of slower population growth in postponing crises. Picardi's work emphasizes another advantage. If a crisis does occur, less damage is likely to result if the system as a whole has less momentum.

In the Sahel, the environmental crisis was caused by the existence of a crucial common property resource, grazing land. In theory, there are several ways of dealing with such situations. One is to privatize the common property, but this is impossible in the Sahel. Although it is possible to sell parts of the land, this would not be a solution to the nomads' economic problems. Rains are very spotty. Any given fixed parcel of land may or may not get rainfall. The advantage of nomadism is that people and herds can move to those random places where rainfall has occurred. Government management of the common property is another approach. This requires a government that has a strong preference for the future over the present, is relatively free of corruption, understands the long-run relationship between a set of characteristics of soil condition and the appropriate aggregate number of animals that should be allowed to graze, has the monetary resources to fund a supplementary livestock-feeding program, and has the means to 
enforce its decisions. Such a set of characteristics is difficult to find in any of the region's governments.

The difficulty of finding an easy solution to the problems of the Sahel is one of the chief conclusions of the Picardi models. Perhaps the next generation of models needs to broaden the system boundaries. Could the problems be addressed more appropriately in a model that also included the greener areas farther to the south?[5] Then, policies might be able to be designed that allow for continuous migration out of a small Sahelian population.

For sustainable development modeling, common property problems are especially crucial because they can produce strong positive feedback loops that can cause crashes. In Mauritius, the main common property problems relate to water use. When we get there, we will see that they have been treated in great detail.

Directly in front of us now, stands that couple again, arguing as usual, and looking somewhat bedraggled for having spent so long in this dry and dusty part of the world.

ECONOMIST: "Don't you owe me some money?"

ECOLOGIST: "What are you talking about?"

"Don't you remember the bet we made about the prices of nonrenewable resources? You said that nonrenewable resources were finite and therefore, as we ran out of them, they would cost more and we bet on it."

"Yes, I remember," he said glumly, writing her a check for $\$ 10,000$. "But that doesn't mean that economic and ecological structures can't collapse. Look around you. Here is a terrible crash. People are suffering and dying and you keep saying that economies can't crash. Why don't you open your eyes to reality?"

"Of course, the economy collapsed," she said. "What did you expect? It's a one-sector economy based on a common resource that is unpriced and uncontrolled. There is no possibility of substituting land for anything else, and no technological progress in the number of these shrubs the land can produce. I answered a question about this sort of situation in a prelim I took in grad school."

"You knew all about crashes?" he asked with astonishment. "You knew all about crashes from graduate school and you've argued with me all this time that crashes can't happen. I can't believe it!" he added looking at the heavens. "What's going on here?" 
"It's not so difficult," she said. "In a complex economy, where prices play their role in allocating resources, where substitution is possible, and technological progress accumulates from small changes in a wide variety of processes, negative feedback loops dominate and, in the aggregate, the behavior of the system is smooth and reasonably predictable. This is how I won the bet with you. The Sahel is a case of a single-sector economy based on a common resource with no prices and few substitution possibilities."

"All right," he said, "where markets function well we do not have to be so worried about collapse, but look around you; the market doesn't always function well and can't always be made to function well. What do we do in these cases? Say that the Sahel does not fit our textbook models and walk away."

"Give me another example of a case of a complex economy where an unpriced common resource plays a crucial role," she asked.

"That's easy," he replied, "the place is the Earth, and the unpriced common resource is the air." there?"

"Speaking of air," she said, "isn't it awfully hot here? What's over

It's a small bridge and a sign that reads "Costa Rica." Immediately they begin walking in that direction. Let's follow them.

\subsection{POMA: Interactive Model of Population and Environment in Costa Rica, 1990}

\subsubsection{Introduction}

The POMA (Poblacion y Medio Ambiente) model is devoted to the consideration of the relationship between population and the environment with special emphasis on Costa Rica's central valley (see Arcia et al., 1991). It is the result of a collaboration between the Asociación Demográfica Costarricense and the RAPID III project, funded by the United States Agency for International Development. Three RAPID projects funded by USAID have been producing models of the effects of population growth on development since the early 1970s. Thus, in contrast with World 3 and SOCIOMAD, the RAPID models have been developing over a period of two decades. To our knowledge, there does not exist any other continuous program of model development in the population area with a longer history. 
Since the beginning of the RAPID program, the objective of the models has been presentational. The models were designed to demonstrate negative effects of population growth to policy makers, to motivate them to spend more resources on programs to reduce fertility. Because of this objective, RAPID models tend to be highly simplified in comparison with more scientifically oriented ones. The POMA model is no exception. Although it contains economic, demographic, and environmental variables, it is not a model of sustainable development, because it does not permit intergenerational welfare or income comparisons.

\subsubsection{The POMA model}

\section{The Economic Segment}

Real income per capita is assumed to grow at a fixed percentage rate per year over the projection period, which is from 1985 to 2025 for both Costa Rica as a whole and the central valley and is from 1975 to 2025 for the metropolitan area of San José. The fixed percentage rate of growth is assumed not to vary over time or over region or to be influenced by the rate of population growth or by the effects of any sort of pollution. Thus, the model cannot answer questions about the effects of population growth or environmental degradation on per capita income growth. This is extremely unfortunate in the Costa Rican case, because there is evidence that these feedbacks are significant (see Repetto, 1992).

\section{The Demographic Segment}

The POMA model has at its core a standard (cohort components) population projection module. Populations are projected for Costa Rica as a whole, the central valley of Costa Rica, and the San José metropolitan area (San José lies within the central valley). The projections take as inputs the time paths of two sorts of variables, life expectancies at birth by sex and total fertility rates.[6] Life expectancy improvements are assumed to be exogenous, and therefore unaffected by pollution or income changes. Two paths of total fertility rate have been chosen. One maintains the total fertility rate at the 1980-1985 level, and the other allows the total fertility rate to fall slowly to 2.21 in the $2020-2025$ period.

The authors of the POMA model did not have any life expectancy or total fertility rate data except for the country as a whole, so, in lieu of a more convincing idea, they assumed that the levels and time paths of life 
expectancies and total fertility rates would be the same in all three regions. In addition, the POMA model assumes that there is no net migration between San José and any other part of the country, and between the central valley and any other part of the country. All these assumptions are highly questionable and their correspondence to the reality that they are supposed to represent is dubious.

Under the low fertility assumption Costa Rica's population would grow by 97 percent in the 40 -year period from 1985 to 2025 , or at an average annual rate of 1.7 percent. Under the high fertility assumption, the population would grow by 152 percent in the 40 -year period, or at an average annual rate of 2.3 percent. If pollution per person were constant, going from the high scenario to the low one would reduce the increase in pollution from 152 percent to 92 percent. Of course, if Costa Rica wanted to reduce pollution rather than accept a large increase, other steps in addition to reducing fertility would be required.

\section{The Natural Capital and Pollution Segment}

Most of the POMA model is designed to look at the effects of population growth on various forms of environmental degradation. These are: airquality reductions due to automotive emissions, increases in the production of solid wastes, deforestation, and the encroachment of urban areas on the use of land for agriculture and forests.

Air quality is considered in terms of amounts of sulfur dioxide, carbon monoxide, nitrogen oxides, suspended particulates, and hydrocarbons contributed by vehicles to the air of San José. From the population projection, we know the future population of San José at five-year intervals from 1985 through 2025. Three time paths are given for the ratio of people to vehicles. In the first, it remains constant at 7.1. In the second, it falls to 5.0 in 2025, and, in the third, it falls more rapidly to 4.2 in 2025 . Roughly speaking, we can think of each path referring to a different rate of per capita income growth, in San José. The faster the rate of economic growth, the faster the ratio of people to vehicles is expected to fall.

For each fertility path, there are three paths of the ratio of people to vehicles, making for six possible combinations. For any given combination, the number of vehicles in each year in San José can be easily computed. Since each vehicle is assumed to produce a fixed amount of each of the five pollutants, the amount of each pollutant contributed by the vehicles also may be easily calculated. The implicit assumption is that vehicles will not 
become less polluting over time and that less polluting fuels will not be formulated or, at least, that if there are less polluting vehicles and fuels they will not be used in Costa Rica. All possible policies with regard to vehicular emissions are ignored.

Analogously, three exogenous time paths of the amount of solid waste per person-day are given. One remains constant at 0.677 kilograms per person-day. The second rises from 0.677 kilograms per person-day in 1990 to 0.900 in 2025 ; and the third, from 0.677 to 1.200 . When we multiply the amount of solid waste per person-day by the number of person-days from the population projection, we obtain the amount of solid waste. Given the time path of solid waste per person-day, the more people, the more waste. All possible policies with respect to recycling and other ways of dealing with solid waste production are ignored.

Deforestation is studied in two ways: directly, using a three-step process; and indirectly, under the rubric of land use. The first step in the direct procedure is to determine per capita demand for processed wood. An ordinary least squares (OLS) regression was run on data from 1970 to 1989 with the per capita consumption of wood as the dependent variable and population size and the price of wood as the independent variables. Per capita income and government foreign-trade polices were assumed to have no effect on the demand for wood. Based on this equation, an assumption about what the future price of wood might be, and other adjustments, two time profiles of wood consumption per capita were produced: one for the higher fertility scenario and one for the lower fertility scenario. Multiplying wood consumption per capita by the number of people produces the total amount of wood consumed.

The second step is to translate cubic meters of wood consumed to hectares of forest cut down. Two possibilities are considered: a more efficient one, where fewer hectares of forest are harvested per cubic meter of wood produced; and a less efficient one, where more hectares are used. Multiplying the number of hectares harvested per cubic meter of wood produced by the number of cubic meters demanded, the authors obtain the number of hectares that must be cut down to meet that demand.

In the third step, the amount of commercial forest remaining is computed. Since it is assumed that there is no replanting of commercial forests, the number of hectares of commercial forest at time $t+1$ is just the number of hectares at time $t$ minus the number of hectares harvested. If the inefficient technology is used, the commercial forests of Costa Rica are wiped 
out by 2003 in the high fertility case and by 2004 , in the low fertility case. Given the more efficient technology, the entire commercial forests of Costa Rica are wiped out by the year 2013 , no matter which fertility assumption is used. Apparently, better governmental policies toward commercial forestry are urgently needed.

Land use in the central valley is determined using a set of four equations. In the first, the amount of urban land used in a given year is assumed to depend on the population of the central valley in that year and on past values of income per capita and municipal infrastructure costs. In the second, municipal infrastructure costs in a given year depend on the current population and the past amount of urban land used. In the third, agricultural land is assumed to decrease as urban land grows, and, in the last equation, forestland is assumed to decrease as agricultural land shrinks.

This analysis predicts a substantial decline in the remaining forestland in the central valley by the year 2025. If these computations are consistent with the ones on deforestation, we must assume that the remaining forests are not commercial ones.

\subsubsection{Comments}

As expected, increases in population size always cause increases in pollution. This conclusion is built into the model.

An important problem with RAPID models, like this one, is that they tend to avoid consideration of all possible governmental policy responses to a growing population. This is, of course, their nature. The models are designed to spread awareness of problems associated with population growth, and to suggest that slowing fertility is the only solution to them. A presentation of alternative policies would be contrary to the mission of the RAPID project.

There's a RAPID presentation of the POMA model just ending over there. ECOLOGIST and ECONOMIST get up and start discussing what they have just seen.

"Wasn't that fun," he said. "I hope that really gets their attention. I like the color graphics on the screen."

"Fun," she said. "That wasn't fun; that was dreadful. How could they treat population policy as the only policy in the entire world that can be used against pollution? Even their own figures show how ridiculous that is. There is no population policy that can save their commercial forests. Saving their commercial forests will require other sorts of policies. Probably each of the effects they showed could be completely eliminated by using up-to-date 
technology already in use in a dozen countries. Why do you support such biased work?"

"Because," he replied, "it gets people's attention. Then maybe they'll do something about pollution and about population growth."

"Look," she said, "we've agreed that in some parts of the economic system markets work..."

"Yes," he interrupted, "that little bit of wisdom cost me $\$ 10,000$. And we've also agreed that crashes can happen and have really happened."

"Yes," she said, "but mainly in cases with important unpriced and uncontrolled common property resources. But then shouldn't you also agree to stop supporting this one-sided form of modeling where only one set of policies is explored. Wouldn't it be better if we got people's attention by giving them the whole story and telling them about population options, environmental options, and technological options instead of pretending that one or another set didn't exist?"

"Of course, for scientific work it's better to have models that include all the options," he said, "but I've never seen a model that did that."

"What's over there," she asked as she pointed to her right.

"It looks like another bridge," he said. "The sign says 'Mauritius'. Do you want to try it?"

They're walking toward the bridge. Let's follow them.

\subsection{The Mauritius Model}

\subsubsection{Introduction}

While the past two decades produced a lively and rapidly growing literature on the interrelationships between economic, demographic, and environmental variables, [7] the development of simulation models that included these three factors almost came to a complete halt, after the burst of activity in the early 1970s. In the early 1990s, some people at IIASA grew uncomfortable with this state of affairs. They believed that researchers could learn a great deal about the relationship between the environment and development, in general, by studying it in specific settings. It is that belief that motivated the creation of the Mauritius model.

From the beginning, the Mauritius modeling project had three goals: to help Mauritian decision makers formulate sustainable development policies; to address specific questions in the literature and to show how they could be 
answered in the context of Mauritius; and to provide a first step in the process of reinvigorating the subject of sustainable development modeling. The Mauritius model does not, by itself, provide answers to general questions, but it does provide answers to particular questions.

In order meet its objectives the Mauritius modeling team avoided the nebulous relationships found in World3; put substantial emphasis on common property problems, as suggested by the SOCIOMAD model of the Sahel (in the Mauritius case, this common property resource is water); and included specific economic, demographic, and environmental policies, in contrast to the POMA model. A strength of the Mauritius model is the detail with which those policy alternatives are articulated.

\subsubsection{The Mauritius model in brief}

The Mauritius model is described in detail in Part III of this book, so here we only present highlights of its structure. The model has four modules: population, economy, land use, and water resources. The population module produces projections of the population of Mauritius by age, sex, student status, and educational attainment. The Mauritius model is the only one considered here to incorporate education explicitly. Education is allowed to increase the productivity of labor, but costs money to produce. This treatment of education is of crucial importance to the model. If people were not allowed to become more productive with education, the effect of population growth on per capita income growth and pollution would essentially be predetermined. The population module is linked to the land-use module through the demand for urban land and to the water module through the water needs of the population and the consequent water pollution.

The economic module is based on a 15-sector input-output framework with fixed relative prices. It is linked to the demographic sector through labor supply and labor productivity. It is connected to the land-use module through the demand for land for agricultural purposes. Because agricultural activities compete for land with urban development, population growth can reduce economic growth through the reduction of land available for farming. The economic module and the water module are interconnected; economic activities cause various sorts of water pollution, and water pollution causes a diminution of the amount of water available for irrigation and a resulting decline in crop yields. 
Like the economic module, the land-use module is connected to all the others. Land can be used for sugar-cane growing, other agriculture, recreation, urban commercial purposes, and urban residential purposes. Land quality cannot degrade in the model, and there is no provision for erosion.

The water module is the model's key component for shedding light on questions of sustainable development. People use water, and their wastes cause water pollution. Economic activity also uses water and causes pollution. When water gets too polluted, labor productivity falls, as the everyday activities of people get disrupted, and agricultural output decreases because of limitations on irrigation. On the other hand, though water is treated as an unpriced common property resource, it is not uncontrolled. The government can spend money on building reservoirs and on water treatment facilities of various sorts.

An unusual and very desirable feature of the Mauritius model is the great detail with which policy options in the water module are treated. For example, the module contains a list of possible reservoir sites being considered by the Mauritius water authorities, their costs, and their capacities. The user can specify which particular reservoirs get built in each period. Still, good reservoir sites are limited and water purification systems can only eliminate a. certain amount of pollution from the water. We will not spoil the enjoyment of reading this book by giving away its ending here. The reader will have to wait to see how water provides limits to Mauritian growth.

The Mauritius model is extraordinarily open. There are over $1,000 \mathrm{pa}$ rameters that can be set by the user. The disadvantage of this is that the use of the model can be daunting at first. On the other hand, experienced users have at their disposal a flexible tool for the study of both the Mauritius economy and the nature of sustainable development from which much more can be learned than can be presented in this volume.

\subsection{Other Models}

Space and time have severely limited the number of models that could be reviewed here. The first model we sought for this review was the ECCO (Enhancement of Carrying Capacity Options) model.[8] The ECCO framework is a recent modeling approach explicitly devoted to the study of sustainable development. What made it particularly attractive to us was the existence of a Mauritian application (MECCO). 
In ECCO models, the equations are written in terms of energy use and so are very different from those of the IIASA Mauritius model. With some 700 equations, the MECCO model is a large one and the task of comparing it with the IIASA model would have been both challenging and interesting. Because the equations of the ECCO and MECCO models have never been published, a comparative study of the two approaches must be left on the agenda for future work.

This chapter neglects a whole set of models oriented toward energy use and the consequent atmospheric pollution.[9] One of these, the EdmondsReilly model (Edmonds and Reilly, 1983, 1985), is evolving into a model that seems like it could be used for the study of sustainable development (Edmonds et al., 1991), but the new "second generation" model was not yet running when this chapter was written. Reviewing these models would have led us much too far from our main themes.

Other interesting models have been left out as well (see Barney et al., 1991). There were severe limits to the length of this chapter and overshooting them would have led to a painfully personal crash.

\subsection{Toward the Development of Sustainable Models}

If the discussion among biologists, demographers, ecologists, economists, and others is to become more productive in the future, it has to move beyond the current cycle of scare-and-soothe studies. On the one hand, we are told that our economy will crash and our children and grandchildren will be devastated by famine and disease, and, on the other hand, we are told that everything will be fine forever. To break this cycle, requires that we become more committed to science and less to causes. It requires that we do not first decide what is most important and then try to convince others by presenting only the pieces of information that fit our preconceptions. It requires a dedication to the quantification of the results of different polices and, above all, it requires that biologists, demographers, ecologists, and economists listen to one another, and take one a nother seriously.

The Mauritius model project is an attempt to break out of this cycle by treating a variety of concerns in an evenhanded manner. More than anything else, this is its greatest strength.

But are modeling schools that focus on science sustainable? Science can be messy. One kind of effect can dominate in some countries, but not in 
others. Will agencies fund projects that show that sometimes their favorite interventions are very useful and that sometimes they have a marginal impact? If not, the public will be left wandering in a land filled with alternating visions of havoc and prosperity, until perhaps one of them came true. There must be a better way to find out on which side of the looking glass our path lies.

ECONOMIST: "What do you think of Mauritius so far?"

ECOLOGIST: "It seems pleasant enough. But then again, we haven't gotten very far. There seems to be concern about pollution and environment here. I like that."

"And a variety of options for improving the environment are considered. I like that," she said. Just as she finished, she glanced down and saw a group of strange looking birds walking in front of her. She picked one up. "Look," she said, "they don't have any wings; none of them have any wings."

"That's impossible," he said, picking up another one of them.

"What is it?" she asked.

"I don't know," he replied as he looked through its feathers. "It's got small vestigial wings hidden under its feathers. It obviously can't fly. I've never seen anything like it in my life. They certainly seem to like this forest," he continued. "They're all over the place."

They were standing in a forest of large trees. She looked around and said, "What kind of trees are these, anyway?"

He looked at the trees and then at a branch that had fallen to the ground. The wood was jet black. "These look like..." He caught himself before he finished his sentence. "And we're on Mauritius, right?"

"Yes," she said.

"Then," pointing at one of the birds, he went on, "these must be ... oh, for heaven's sake, I think I know exactly what these are. These birds are dodo birds, and those trees are ebony trees."

"But dodo birds are extinct," she said.

"And there are no more ebony trees on Mauritius," he said continuing her thought. "They were unpriced and uncontrolled common property resources caught in positive feedback loops," he said and they both laughed.

"Do you think there are any positive feedback loops on Mauritius today," she asked.

"Of course," he answered.

"How about betting on that," she said, "double or nothing."

"You're on," he replied. "Let's go see." 


\section{Notes}

[1] If natural resources really grew scarcer over time, we would expect to see a longrun upward trend in their prices. Unfortunately for the World3 modelers, this is diametrically opposed to the historical record, which shows generally falling prices during the last century. See Simon (1981) for a discussion of this issue.

[2] The page numbers for The Limits to Growth refer to the Signet (New York) paperback edition.

[3] We obtained a copy of his thesis by writing to Dr. Anthony C. Picardi, 58 Washburn Avenue, Wellesley, Massachusetts, 02181, USA. We obtained this address from Barney et al., 1991.

[4] The drought in the early 1970s was not exceptionally severe by historical standards. Picardi presents evidence suggesting that a similar period of drought occurred twice before in the 20 th century, roughly at 30 -year intervals.

[5] An excellent choice of settings for future work in this area would be the Sudan. In northern Sudan, the pressures of increasing human and animal populations have been causing increased desertification. As a consequence, nomadic people have been pushed southward causing intertribal warfare. A model of the Sudan, then, could weigh the costs of such environmentally caused conflicts against the costs of policies which could avoid them.

[6] The total fertility rate is the average number of live births a woman would have over her lifetime, given the observed fertility behavior of a given period.

[7] There are nearly 400 references in the bibliography of the World Development Report 1992: Development and the Environment (World Bank, 1992b). The vast majority of these were written in the past two decades. Even this bibliography is hardly complete. For example, no work done by Julian Simon or his collaborators appears there.

[8] See Gilbert and Braat (1991) for a general description of the model and for some case studies. The ECCO framework was first described in an unpublished paper by Slesser in 1984 (see Slesser, 1991) and subsequently elaborated in Slesser and King (1988).

[9] A good starting point for studying these models is The Energy Journal Special Issue on Global Warming 12(1), 1991. It contains applications of some currently active models and references to many others. 



\section{Part II}

Understanding Through History 
. 


\section{Chapter 4}

\section{People on Mauritius: 1638-1991}

Wolfgang Lutz and Anne Babette Wils

\subsection{Introduction}

This chapter approaches a better understanding of population-developmentenvironment interactions by providing a short multidisciplinary history of Mauritius which focuses on the primary agents of change over the last century - the human population (a more detailed account of population change in Mauritius is given in Lutz and Wils, 1991). Chapters 5 through 10 describe the environmental and economic spheres that form the context of human life on Mauritius influencing the population and being influenced by the population.

Mauritius - situated in the Indian Ocean about $800 \mathrm{~km}$ east of Madagascar and with a land surface of about $1,860 \mathrm{~km}^{2}$ - has been known to civilization much longer than it has been settled. Arab merchants had it marked on their maps 1,000 years ago and called it Dina Mozare, but they did not live on it. The population history of the island of Mauritius started in 1638 when the Dutch East India Company sent a group of settlers to the previously uninhabited island. A major interest of the Dutch was in cutting and selling the valuable ebony trees. The island also served as a haven for merchant ships to Asia. The large populations of turtles became a welcome supplement to the sailors' diet, while the famous flightless dodo birds were 
quickly exterminated. It is estimated that by the end of the 17th century, about 200 Dutch colonists and 500-1,000 slaves lived on Mauritius. But in 1710 the Dutch abandoned Mauritius in favor of their new stronghold, the Cape of Africa.

In 1721 a small French party landed on Mauritius, which was then called Ile de France. Soon the French East India Company brought more settlers to Mauritius. It is reported that during the influential governorship of Mahe de Labourdonnais (1735-1746), the population of the island increased from under 1,000 to over 3,000 . During this time sugar cultivation was introduced, and increasing numbers of slaves were brought from Madagascar and West Africa to work on the sugar estates. By 1817 the population of the island had increased to almost 100,000 , consisting of more than 80 percent slaves, 11 percent free colored inhabitants, and 8 percent Europeans or descendants of Europeans.

In 1810 Mauritius was conquered by the British. Initially, this made little difference to life on the island and its people because the French were guaranteed the rights to keep their properties, to use their language, to follow their laws, and to practice their religion. The biggest change came with the abolition of slavery between 1834 and 1839. Large numbers of indentured laborers were brought in from India to replace the freed slaves. Between 1851 and 1861 more than 100,000 Indians arrived in Mauritius. Since that time the majority of the Mauritian population has been of Indian origin.

In 1968 political power was passed to the Mauritians themselves after long, but nonviolent negotiations with the UK. In terms of population trends, this had little immediate impact. In the late 1940s and early $1950 \mathrm{~s}$, mortality had already declined considerably due to the eradication of malaria and other health improvements. Simultaneously, fertility rates increased, thus resulting in a steep increase of population growth rates to levels of more than 3 percent per year. This demographic discontinuity which dominates the picture of any kind of visual or quantitative description of Mauritian population trends resulted in a large number of young Mauritians born in the 1950s. This phenomenon, together with a second remarkable discontinuity of past trends, namely, a steep decline of fertility during the late 1960s and 1970s, resulted in an unusually large cohort of young people - the youth cohort - that will characterize the Mauritian age structure for decades to come. 


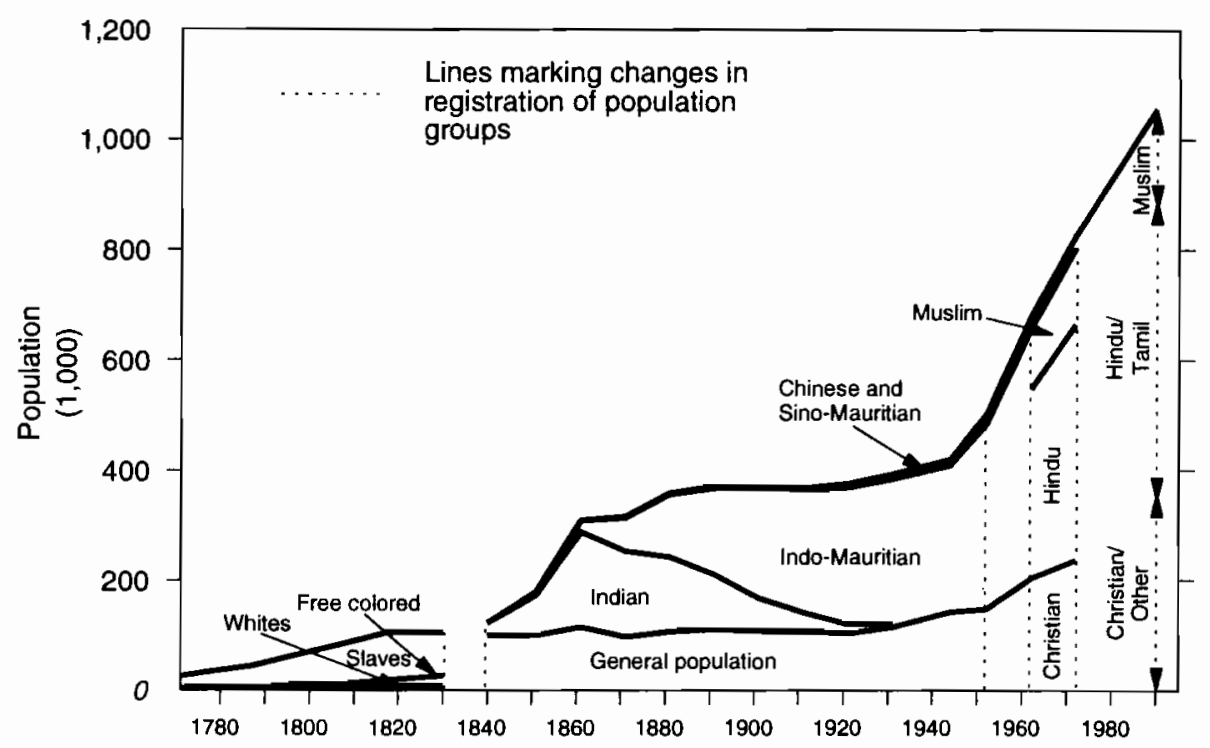

Figure 4.1. Population on the island of Mauritius by group, 1767-1990. Discontinuities are due to changes in classification from census to census; this figure is an approximation of the population composition. Source: CSO, 1956.

\subsection{The History of Population Growth}

Official censuses of the population living on the island of Mauritius are available from 1767 onward. Generally the censuses were taken in 10-year intervals, with irregularities during the middle of the last century and since World War II. The censuses also give an ethnic breakdown of the population which is very informative for understanding the population history of Mauritius. The abolition of slavery after 1834 brought about a reclassification of the categories. After that year the category "General Population" included the descendants of Europeans and the freed slave population; whereas for the Indians, the Indo-Mauritians (Indians born in Mauritius), and the Chinese, separate categories were kept in the census. A breakdown of the total population from 1767-1990 is given in Figure 4.1 and Table 4.1.

During the 18th century the largest part of the population was slave from Africa. White Europeans and their descendants made up a small portion of the population. A third group, the free coloreds, was about as large as the 
Table 4.1. Total population on the island of Mauritius enumerated in the censuses from $1767-1990$.

\begin{tabular}{rrrrrr}
\hline 1767 & 18,777 & 1846 & 158,462 & 1921 & 376,485 \\
1777 & 29,761 & 1851 & 180,823 & 1931 & 393,238 \\
1787 & 40,439 & 1861 & 310,050 & 1944 & 419,185 \\
1797 & 59,020 & 1871 & 316,042 & 1952 & 501,415 \\
1807 & 77,768 & 1881 & 359,874 & 1962 & 681,619 \\
1817 & 97,847 & 1891 & 370,588 & 1973 & 826,199 \\
1830 & 96,945 & 1901 & 371,023 & 1983 & 966,863 \\
1840 & 124,335 & 1911 & 368,791 & 1990 & $1,022,456$ \\
\hline
\end{tabular}

European population. The island's capital was established in Port Louis. Other residential areas at that time were Moka, Pamplemousses, Flacq, and Port Bourbon, now called Mahebourg (see map on frontispiece). Population growth from 1767 (the first year we have data) to 1834 (the year slavery was abolished) was steady and high. The average annual increase was 8 percent. The data indicate that very little of this growth was natural; almost all of it was due to the import of new slaves and immigration of Europeans and others from 1767 to 1834 . The sex ratio in the slave population, the majority, was about 1.6 men to each woman, and the crude birth rate in that population was accordingly low - estimated at around 25 per 1,000. The sex ratio among the white and free colored population was more even. In the colored population, it was even 0.8 men to each woman because women who married out of their race were subsequently categorized as colored. In this free population the birth rate is estimated to have been around 40 per 1,000. Together, this amounted to a total crude birth rate slightly under 30 . In 1875 , the first year for which we have data on mortality levels, the death rate was also just under 30 , resulting in natural growth close to nil.

In 1834, after slavery was abolished, the freed slaves chose to live in the townships, in Port Louis, or in the mountains and coastal regions of the south. To replace the slaves, active recruitment of indentured laborers from India began. The white plantation owners, who were expanding their sugar production, instigated the wave of indentured labor, often misleading the Indians about the conditions they would live and work under. Initially, the laborers were mostly males and promised a free return passage, but after 1853 , the landowners decided it was more profitable to bring over men and women and to scrap the return passage from the contract, meaning that all laborers who arrived after this date were in fact emigrating from India for good. The Indian laborers were not treated much better than the slaves, 
the sanitary conditions were terrible (Parahoo, 1986), and death rates were extremely high.

The rate of immigration was enormous, and the population of Mauritius tripled during this time from around 100,000 in 1834 to 310,000 by the census of 1861 . The strongest intercensal immigration decade was 18511861 , with a total of over 100,000 immigrants. As women began to arrive from India soon after the men, the sex ratio normalized, and the native IndoMauritian population was born. By the end of the century immigration had virtually ceased.

During the period of Indian immigration and the birth of the IndoMauritian population, other ethnic groups in the population - previously the white, free colored, and slave populations, classified as "General Population" after the census of 1846 - barely grew. There were 101,000 classified as general population in the 1846 census; 100 years later, there were 143,000 . The general population includes those of mixed origin, for example, white and Indian origin. The almost zero growth rate of the general population may indicate that intermarriage was not common: descendants of mixed marriages were classified as general, and if there had been intermarriage, the group of mixed descendants would have increased.

Figure 4.2, which shows the crude birth and death rates in Mauritius between 1875 and 1991, depicts the low population growth in the half century after immigration ended. Crude birth and death rates in the 19 th century up to the early 20 th century were roughly at the same level but showed enormous annual variations that are typical for premodern conditions. This resulted in very little if no natural growth. From 1875 to about 1893 , the crude birth rate was slightly higher than the death rate. Death rates were unstable, ranging between 30 and 35 . The peaks were caused by various epidemics - cholera, smallpox, the Bubonic plague in 1899 - and particularly strong hurricanes. Prior to 1862 malaria, a major killer in subsequent years, was not endemic to Mauritius. Malaria was worse in the coastal areas, and many people moved to the higher, central plateau of the island where the towns of Curepipe, Vacoas, and Quatre Bornes are now located. Many Indians acquired the land in the low areas during this period.

In 1919 there was a mortality peak of more than 60 per 1,000, caused by an outbreak of the Spanish flu which killed thousands of Mauritians (Titmuss and Abel-Smith, 1968, p. 49). In the early 1920s, mortality rates declined more consistently for the first time. During this period the water supply was chlorinated and there were campaigns against malaria and hookworm 


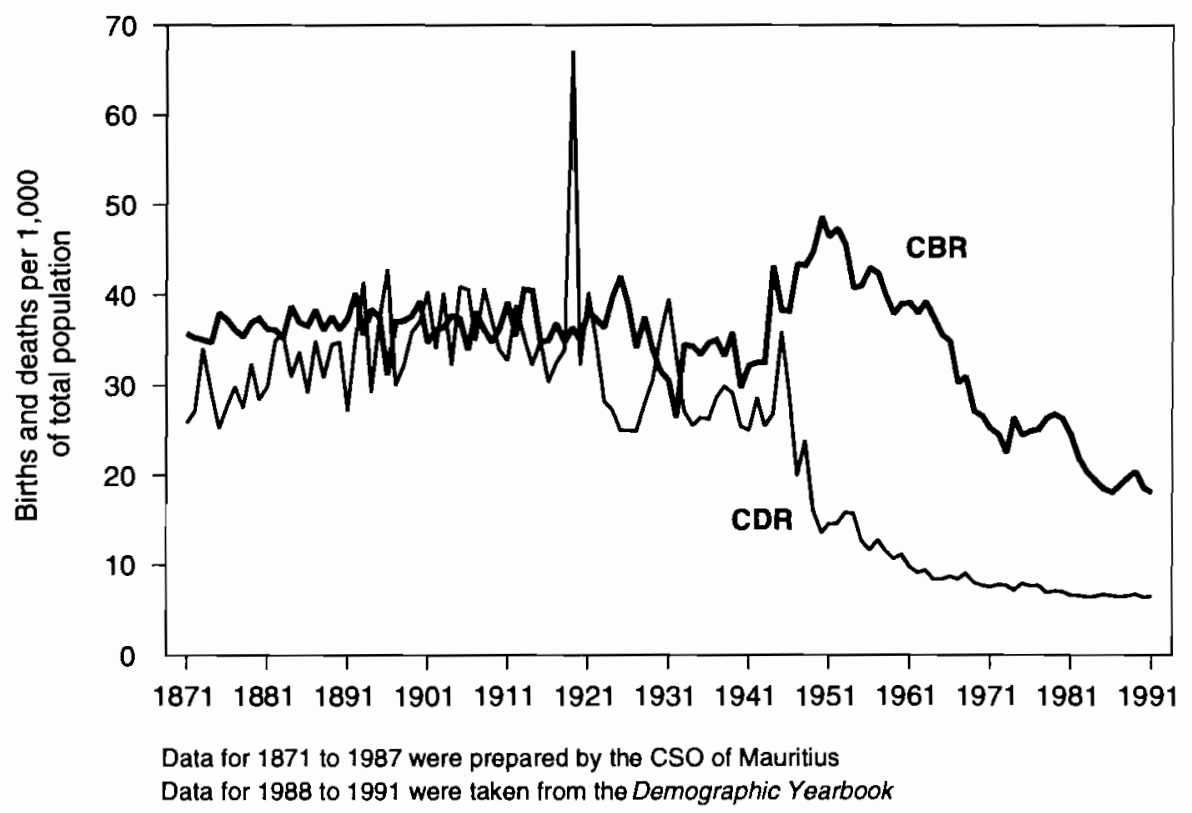

Figure 4.2. Crude birth and death rates in Mauritius, 1875-1990. Source: Mitchell, 1982.

apparently resulting in the permanent decrease of the crude death rate (see Figure 4.2). There continued to be mortality peaks from epidemics, but they became less frequent. During this time, the birth rate was usually above the death rate, resulting in some natural growth after many decades of stagnation. However, this growth was still small.

The big blow to mortality came in 1948-1949 mostly as a result of the eradication of malaria. Death rates dropped to a little over half of their previous (average) level in a few years. Simultaneously, birth rates increased to their highest level ever. In 1950 the crude birth rate (49.7) was 3.6 times greater than the crude death rate (13.9). The enormous gap between birth and death rates resulted in a burst of Mauritian population growth.

The growth rate was around 3 percent from the early 1950s to the mid1960s. Although birth rates had been declining from their peak in 1950-1954, death rates also continued to fall quickly after the eradication of malaria in 
1948-1949. In the 1960s and 1970s, the death rate stabilized while the birth rates plummeted. Together this brought the current growth rate down to just over 1 percent annually. The current observed growth is only due to the young age structure of the population; the net reproduction rate has remained around 1.0 since 1984, indicating that one generation will just replace itself and the population size will stop growing in the long run if this fertility level stays constant.

The increase of the crude birth rate in Mauritius right after World War II is an example of a fertility increase in response to, among other things, better health of mothers which is often observed at the beginning of the demographic transition. The precipitous decline in the birth rate that started in the 1950s is attributable to delayed marriage followed by the marital fertility transition. The fertility decline was more rapid in Mauritius than in any other country with accessible data.

The total fertility rate (TFR) - an indicator free of effects from the age structure - hovered around five children per woman in the first half of the century. By 1952 the TFR had increased to a high level of 6.74, and 10 years later in 1962 was still high at 5.86. Over the following 10 years it then fell precipitously to 3.42 in 1972 , a phenomenon that will be discussed in more detail below. In the mid-1980s the Mauritian TFR was even below 2.0, a Western European level. Since then it has slightly increased to around 2.4 in 1992.

During the past three decades total population grew very rapidly from 681,619 in 1962 to 826,199 in 1972 and 966,863 in 1983 . Figures from the most recent census in 1990 show that after 1983 the population grew by another 100,000 people to $1,056,660$.

Figure 4.3 shows the population density of the island in 1990 . The height of the peaks in the map show the level of population density - high peaks mean high density. The highest density is in Port Louis, and continues along the urban corridor - Quatre Bornes, Vacoas, and Curepipe. There are a few other small urban centers, but otherwise there is a fairly even low density in rural areas. The lowest densities (not easily discernible on the map) are in the mountainous south. In 1990, a little over 40 percent of the population lived in areas classified as urban, and this proportion had been stable since 1970 (Keyfitz and Flieger, 1990). 


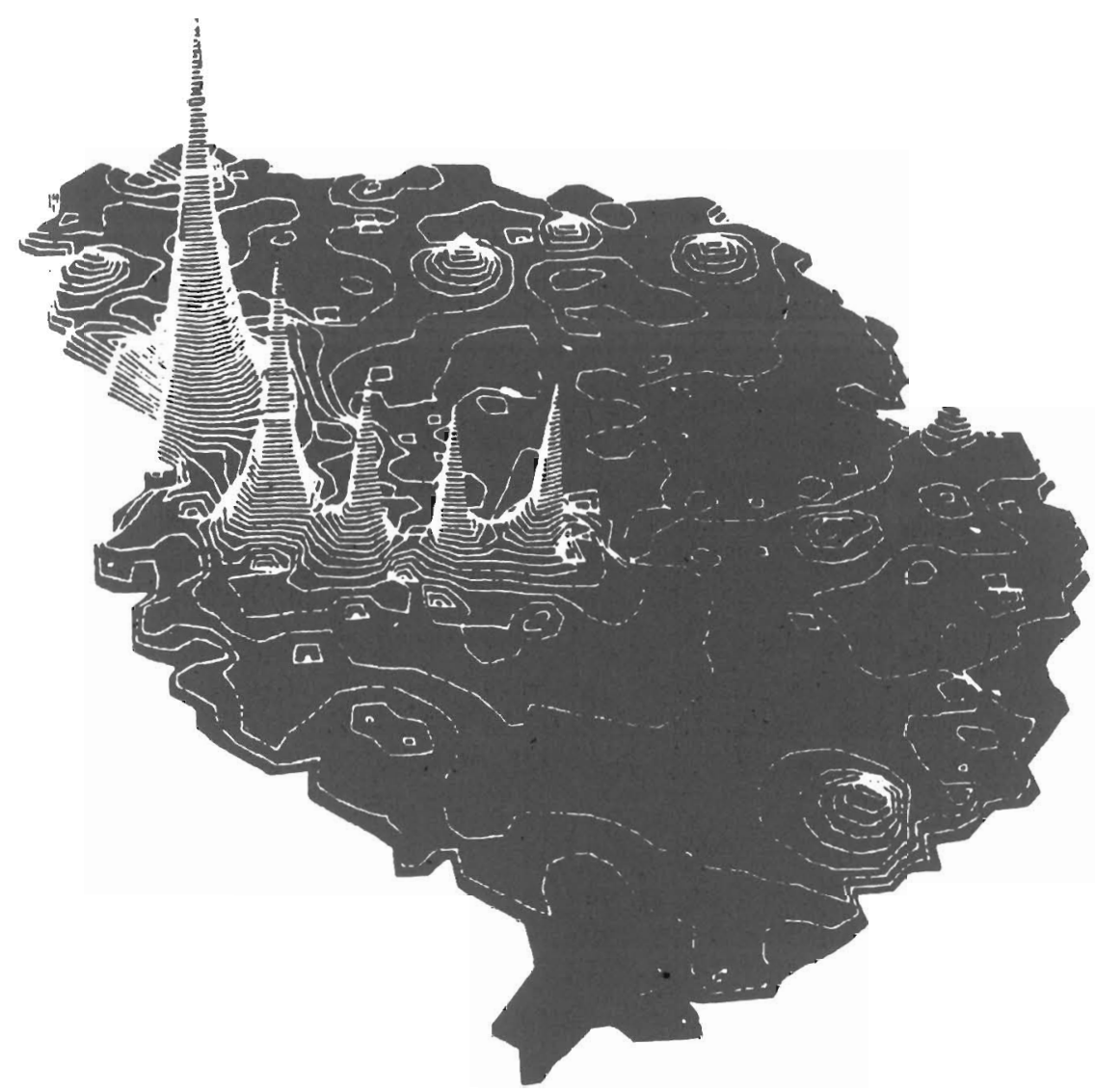

Figure 4.3. Population distribution on the island of Mauritius in 1990.

\subsection{Family Planning and the World's Most Rapid Fertility Decline}

The population history of Mauritius is unique in many respects and has seen many spectacular changes such as the massive Indian immigration and the very rapid mortality decline right after World War II. The most remarkable event, however, was the extremely rapid fertility decline between 1963 and 1972. Here Mauritius probably holds a world record, at least for national populations.

Table 4.2 shows that fertility declined simultaneously among all ethnic groups of Mauritius. We see that among the Chinese population, fertility 
Table 4.2. Total fertility rate by ethno-religious groups in Mauritius, 1962 1972.

\begin{tabular}{llllll}
\hline Year & Total & Hindu & Muslim & General & Chinese \\
\hline 1962 & 5.860 & 6.555 & 6.019 & 4.760 & 5.501 \\
1963 & 6.232 & 7.122 & 6.630 & 4.758 & 5.492 \\
1964 & 5.890 & 6.543 & 6.012 & 4.894 & 5.139 \\
1965 & 5.478 & 5.870 & 5.790 & 4.803 & 4.312 \\
1966 & 5.370 & 5.992 & 5.270 & 4.573 & 3.856 \\
1967 & 4.658 & 5.109 & 4.483 & 4.083 & 3.431 \\
1968 & 4.564 & 5.079 & 4.334 & 3.966 & 3.048 \\
1969 & 4.004 & 4.362 & 3.750 & 3.670 & 2.724 \\
1970 & 3.702 & 4.093 & 3.541 & 3.244 & 2.449 \\
1971 & 3.460 & 3.726 & 3.212 & 3.270 & 2.196 \\
1972 & 3.280 & 3.508 & 2.972 & 3.191 & 2.082 \\
\hline
\end{tabular}

Source: Xenos, 1977.

fell first and most rapidly: from 5.5 in 1962 to 2.1 only 10 years later. The general population (including those of European descent) had by far the lowest fertility of all groups in 1962 , with a TFR of 4.8 , but declined only to 3.2 in 1972, whereas the Muslim population at that time had a fertility rate of only 3.0. The Hindu majority of the population always had the highest fertility of all groups; in 1963 their TFR was even above 7.1. Over the following nine years fertility declined to only 3.5 .

This very rapid pace of the fertility decline occurred in the absence of any economic growth. Per capita income was very low and even declined between the early 1960s and 1970. On the other hand, social development and especially education was well advanced. In the early 1960 s most young men and women already had some primary education. Hence one reason for the great success of the family-planning efforts that will be described below was the fact that a rather high educational status, especially of women, had prepared the population for very quick changes in reproductive behavior.

The discussion concerning population and family planning in Mauritius began almost immediately after the beginning of rapid population growth when malaria was eradicated in 1948. In the first years of population growth the solution to overcrowding in Mauritius was sought in emigration; suggestions to limit births were vehemently opposed, particularly by the Catholic church and vocal Muslims. During the 1960s this religious objection gradually disappeared, and two national family-planning programs were founded. 
By the mid-1980s the majority of the women in union in childbearing ages were using contraception and almost all of them had done so at some point.

Without doubt the efficiently conducted family-planning programs played a key role in the spectacular decline of fertility in Mauritius. For this reason we take a closer look at the conditions that led to the successful implementation of family planning despite the influential religious opposition when the programs first began.

Until 1949, concern about overpopulation was not great, if it existed at all. A report by the Labor Commissioner was presented to the government suggesting emigration to Borneo and Madagascar when the numbers of people become too great. Soon thereafter, in 1950, the first suggestion was made in Parliament that present birth rates needed to be curbed by population control. Reaction was hostile from all sides. Members of all three large religious communities objected vehemently, stating that family planning was contrary to their faith. Extensive, vehement opposition to that proposal followed in the Mauritian newspapers.

Despite this objection it was clear that continued population growth presented a problem, and the government elected a committee to investigate. In 1953, this committee, consisting of at least one Protestant, one Muslim, one Hindu, one Chinese descendant, and five Catholics, recommended that the government should initiate a social-services system including familyplanning support. Although the report was never discussed in Parliament, it was presented in the press. This time, reactions were mixed rather than completely negative. The Catholics conceded that married couples were not obliged to produce as many children as possible, but stressed that abstention was the only acceptable means of avoiding pregnancy.

This change of attitude culminated in the foundation of their own familyplanning organization, the Action Familiale (AF), in 1962, five years after the independent Mauritius Family Planning Association (MFPA) had been founded. What caused this change of attitude, especially within the very influential Catholic church which reluctantly not only accepted abstention but, during the early 1960s, also explicitly supported family planning by allowing the natural rhythm method?

The Catholic church's willingness to think about family planning using the rhythm method was critically influenced by a French Jesuit, Professor Lestapis. His view was that the Catholic doctrine was not against the free decision of couples to have a limited number of children, but rather against 
the artificial methods of interference in the process of procreation. With this argument Lestapis obviously convinced church authorities and Catholic politicians. Vicar General Margeot, today Cardinal of Mauritius, also played an important role in the establishment of the active Catholic family-planning organization (Action Familiale, 1988).

Two scientific reports on the Mauritian situation and the grim prospects for this poverty-stricken island also contributed significantly to the public discussion on population control between 1960 and 1968. Both reports delivered in 1961-1962, Social Policies and Population Growth in Mauritius (Titmuss and Abel-Smith, 1968) and the somewhat broader and even more influential Economic and Social Structure of Mauritius (Meade et al., 1968), concluded that rapid population growth was the most outstanding long-term problem of this small, already crowded island. There is little doubt that these scientific studies were important components in forming the national consensus on family planning.

In 1964 the Catholic church withdrew its objections to the use of public funds to subsidize family planning that included methods other than those propagated by the church. Shortly before, Action Familiale had started to receive financial support from the Mauritian government, and this support continues today. In the meantime, the MFPA has been obtaining funds from the International Planned Parenthood Federation since 1963. The use of family-planning methods began to increase quickly. The Action Familiale remained a private organization, although it obtained almost all of its funding from the Mauritian government. The MFPA was mostly assimilated into the government health service in 1972 following UN recommendation, and became the Family Planning Division (FP) of the Ministry of Health (1987) while parts of MFPA remained independent.

Statistics show that the diffusion of contraceptive use began quickly. Two years after the beginning of government support, the annual number of new users had reached a high level which would be maintained over the next 20 years. Apparently, Mauritian women quickly abandoned their traditional reluctance to discuss sexual matters.

By 1972 , the MFPA was running 92 centers. The density of these centers relative to the number of women in childbearing age was great: in 1972 there was one center for just over every 1,000 women aged $15-49$. In other words, if a large country like India had the same density in 1975, it would have had 70,000 clinics set up in the country. Comparatively, in the Philippines in 
1972 , there were 1,800 clinics registered at the end of the year, or one clinic for every 2,800 women aged 15-49, only one-third the Mauritian density.

Reflecting the density of the two family-planning organizations relative to population, a survey in 1975 - only ten years after family planning was intensified in Mauritius - found that almost all married women under age 50 had knowledge of family-planning methods, and most knew of more than one method. The pill was the most familiar method. The survey also showed that almost half of the women in union under age 50 were current users of contraception. There were twice as many users of supplied methods (predominately the pill) as of natural methods.

In 1985 a second survey was undertaken by the government because the very low fertility rate indicated that more women were using contraceptives than were officially registered. The results showed that almost 75 percent of the married women 15-49 were using some form of contraception. The most common method was still the pill, although the percentage of women using the pill had not increased since 1975. Condoms and spermicide were in use more often in 1985 than in 1975 , and sterilization, not available in 1975 , was the contraceptive method used by 5 percent of the women. Natural methods were also more widely used; almost all of this increase was due to more couples practicing withdrawal. Since withdrawal was not propagated by any of the family-planning organizations, the increase is remarkable. One can observe a small increase in the total percentage using the three rhythm methods instructed by the Action Familiale, and a considerable shift within the methods.

The survey did not ask about abortion, which is illegal in Mauritius. The 1983 Census Report on health, morbidity, and mortality reports that in $1975,2,479$ women were released from hospitals after abortions, and in 1983, 2,815 women had been admitted because of complications from abortions. Compared to the 20,000 or so annual births, this is a high number. One can theorize that some women who have had abortions would not want to admit this, and they may say they are using withdrawal to avoid pregnancy.

Today the rate of contraceptive use in Mauritius is comparable to that in Europe and North America. In the 30 years between 1950 and 1980, Mauritius moved from complete absence of and opposition to family planning to, 15 years later, the beginning of an intense effort to spread family planning to, again 15 years later, 75 percent contraceptive use among women in union aged $15-45$, which is about what is needed for replacement fertility. 
But contraception is only part of the story. Parallel to the increase in contraceptive use, marriage patterns in Mauritius changed significantly to delayed marriage. This shift began in the $1950 \mathrm{~s}$, and already depressed the birth rate slightly. It gained momentum in the 1960s and by the early 1970 s a new marriage pattern at later age was established. Xenos (1977) calculates that between 1962 and 1972 half of the birth rate decrease was due to delayed marriage. This fundamental change in reproductive behavior in Mauritius is also mirrored in the age patterns of fertility. Age-specific fertility rates for Mauritius are available on an annual basis from 1962 onward. This makes it possible to closely follow the changes in the age pattern during the rapid fertility decline described above.

Figure 4.4 gives the age profiles of fertility for 1962, 1972, and 1987. From this figure we can clearly see that the fertility decline was relatively stronger at the ages above 35 than in the prime childbearing ages. The curve for 1962 is slightly convex after its peak, that for 1972 is almost a straight line, and the one for 1987 is even concave. This is a typical change over the course of fertility transition from the convex curve of "natural" fertility to the concave curve of controlled fertility.

\subsection{The Youth Cohort in Mauritius}

Figure 4.5 gives a three-dimensional representation of the changing age structure of the male population on the island of Mauritius since the 1851 census. The right-hand axis gives the year of observation. Censuses were usually taken in the first two years of a decade. For irregular intervals data were interpolated. The left-hand side gives the age distribution of the population in five-year age groups starting with the age indicated in the label. The height of the "mountain" gives the number of men in the specific year of the specific age group. The figure shows two pronounced peaks. The first is in 1861 in the age range $25-39$. This peak represents the Indian indentured laborers who arrived in large numbers after 1851 . Historical statistics show that during the 1850 s and 1860 s about 138,000 men and 50,000 women were brought to Mauritius. Since these were mostly young adults, the age structure of Mauritius became very peculiar. The graph also shows that the Indian immigrants must have had extremely high mortality because they do not show up in large numbers in later censuses at higher ages, and statistics show that only less than one-third of the immigrants left Mauritius again. 


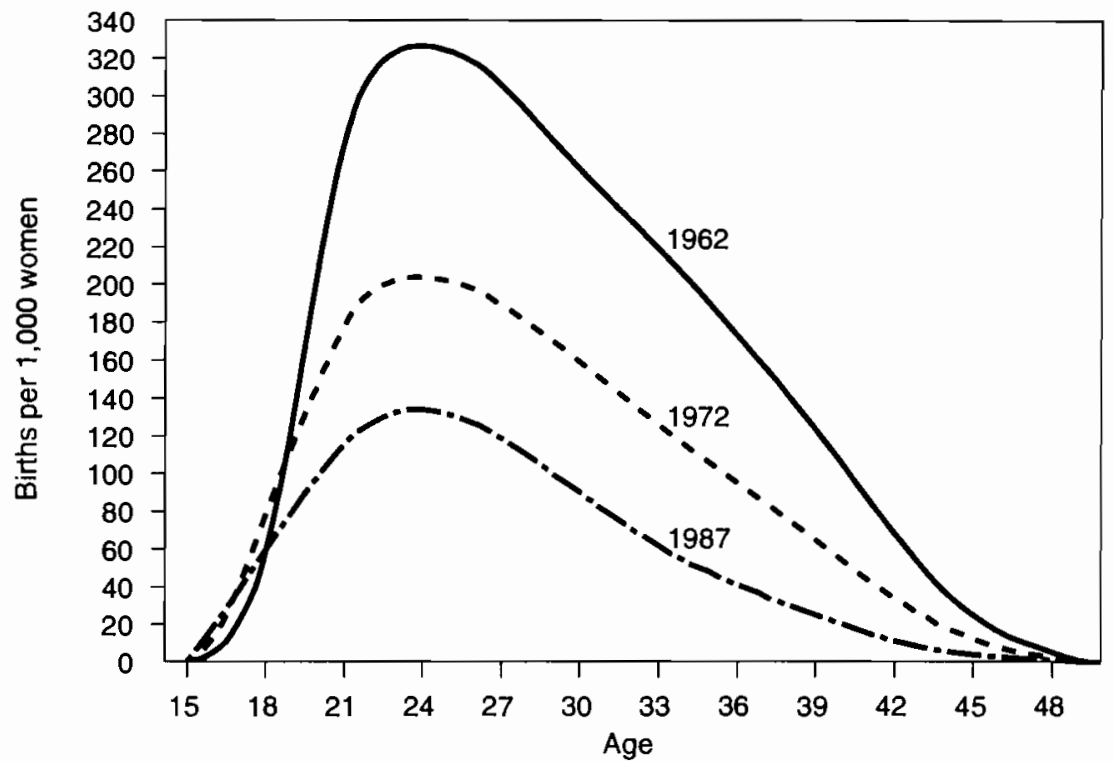

Figure 4.4. Age-specific fertility rates in Mauritius for 1962, 1972, and 1987.

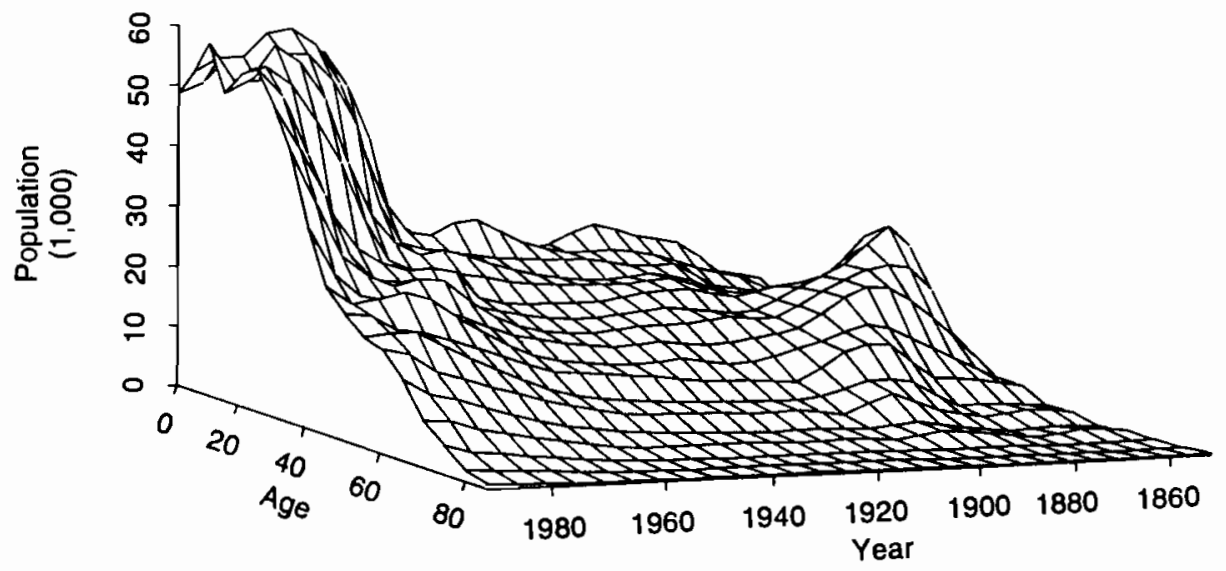

Figure 4.5. Three-dimensional plot of the male population on Mauritius in five-year age groups, 1851-1990. 
The most dominating feature of Figure 4.5 is the very rapid increase in young age groups after 1945. The high fertility of this period together with the rapid decline in child mortality resulted in this strong discontinuity in the evolution of Mauritian age structures. A detailed account of the effects of the mortality and fertility components in the growth of this youth cohort is given in Lutz and Wils (1991). The cohort born in the period between 1960 and 1965 was the largest ever born in Mauritian history and stands out even more due to the subsequent fertility decline. Because of the low mortality in Mauritius this large youth cohort will have a different fate than the youth cohort of Indian immigrants and will be influential for many decades. In the census of 1983 more than half of this cohort was registered as unemployed. These young men and women have profited most from the economic boom and full employment over the last decade. The fate of this now well-educated youth cohort is likely to be crucial for the stability and further development of the island.

\subsection{Health and Mortality}

As mentioned above, there has been a great improvement in the health of the population since the beginning of the century. Implementation of certain hygienic measures, health education, and better standards of living have led to a continued decrease in mortality rates. Malaria, which kills but also causes considerable morbidity, was practically eradicated in 1948-1949, and this greatly improved the health as well as the life expectancy of the population. During this century, another major cause for the increase in life expectancy has been the declining infant mortality rate from levels of almost 200 per 1,000 live births to 34 in 1981 and further to only 19 in 1991. This is among the lowest infant mortality rates in developing countries, although it is still higher than in most industrialized nations.

In the course of this mortality transition, deaths from infectious diseases such as malaria and smallpox and infant mortality were overtaken by the deaths from so-called non-communicable diseases (NCDs) such as cancer, cardiovascular diseases, and diabetes mellitus which is a specific problem in Mauritius. Although this change in the cause of death structure is associated with increasing life expectancy because NCDs are typical old-age diseases, the associated longer periods of disease and disability pose a problem to the country in terms of medical, financial, and social support for the rapidly increasing number of elderly. Figure 4.6 shows the development of mortality 


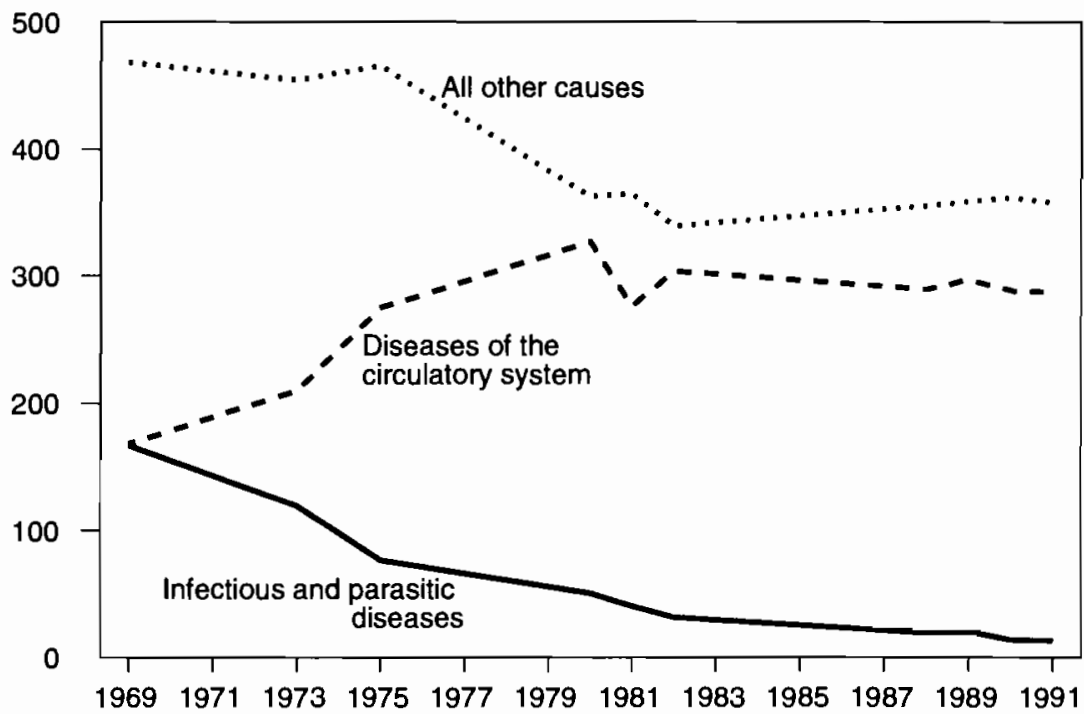

Figure 4.6. Deaths per 100,000 population for selected major causes of death in Mauritius from 1969 to 1991. The marked dip between 1981 and 1982 is ascribed to the extension of compulsory medical certification of cause of death to all districts in 1982. Source: Data adapted from WHO, 1993; and CSO, 1988b.

by cause of death from 1969 to 1991 . The decrease of deaths from infectious diseases is clearly visible, as well as the increase in cardiovascular diseases.

This mortality transition resulted in a doubling of life expectancy at birth since the 1940s. Between 1942 and 1946 life expectancy was only 33 and 34 years for men and women, respectively. When malaria was eradicated, life expectancy jumped by more than 10 years to 50 and 52 for men and women, respectively, in 1952-1953. Since then, it has been increasing steadily but much more slowly for men than for women. In 1989 the period life expectancy at birth was 73 years for women and 65 years for men. The reason for this increasing gender difference is that infectious diseases tend to hit men and women equally whereas NCDs, especially cardiovascular disease, kill men earlier than women.

To learn about the prevalence of the newly arising NCDs, a health survey was held in Mauritius in 1987 to find the prevalence of illnesses and related risk factors. The results were astonishing: of the population aged 25 years 
Table 4.3. Prevalence of diabetes mellitus in Mauritius by ethnic group, 1987 , in percent.

\begin{tabular}{lrrrr}
\hline & Hindu & Muslim & Creole & Chinese \\
\hline Males & & & & \\
$25-34$ & 4.3 & 3.6 & 0.4 & 2.4 \\
$35-44$ & 12.9 & 4.1 & 7.9 & 14.0 \\
$45-54$ & 24.5 & 28.1 & 13.0 & 20.8 \\
$55-64$ & 23.7 & 34.5 & 11.2 & 24.4 \\
$65+$ & 27.7 & 15.4 & 27.1 & 35.5 \\
$25+$ & 14.0 & 12.7 & 7.7 & 13.5 \\
Females & & & & \\
$25-34$ & 3.4 & 2.2 & 2.8 & 2.3 \\
$35-44$ & 7.6 & 8.3 & 12.0 & 7.4 \\
$45-54$ & 15.2 & 15.9 & 21.2 & 9.1 \\
$55-64$ & 25.6 & 37.0 & 23.9 & 20.7 \\
$65+$ & 25.4 & 47.8 & 33.3 & 36.7 \\
$25+$ & 10.9 & 13.8 & 13.0 & 9.5 \\
\hline
\end{tabular}

Source: King and Dowd, 1991.

and over, 12.7 percent had diabetes mellitus, and a further 17.5 percent had impaired glucose tolerance. Approximately one in three people with this condition will develop diabetes within the next five years, and they all have increased risk of cardiovascular diseases. This makes diabetes one of the most serious health problems on Mauritius. The survey showed that prevalence of diabetes in the four main ethnic groups of Mauritius differs considerably (Table 4.3). Among the male Hindu population with the highest prevalence, 14 percent of the adults over 25 had diabetes, compared with only 7.7 percent among the Creole population. Risk factors for diabetes include physical inactivity, obesity, and prevalence in the family.

Another serious problem is prevalence of diseases and risk factors related to the circulatory system. The survey found that 16 percent of the men over 25 and 13.8 percent of the women had hypertension. Even more prevalent is high cholesterol level in the blood. At least 50 percent of the adults have an elevated cholesterol level, and one-fifth of these have received intensive treatment for their condition. Another risk factor is obesity. In Mauritius, 39 percent of the women and 13 percent of the men are found to be overweight by international standards. Reflecting the high prevalence of risk factors, heart diseases were found to be more prevalent in Mauritius than in other industrialized countries. 
Mauritius is one of the few countries in the African region which provides good public-health services to its population, which are free to all. Most of the hospital beds are public, and more than half of the doctors and dentists are in public service.

Health services in Mauritius were developed relatively early. In 1967 there were 3,112 hospital beds in Mauritius, about 4.5 beds for every 1,000 persons. By 1988 the situation had actually worsened. There were 3,071 hospital beds, or about 3 per 1,000 persons, but perhaps this has been compensated by better quality or more ambulatory treatment. The Mauritius health-care system comprises many small medical centers. In 1967 there were 94 such small centers on the island. By 1988 the number had decreased to 67 . These centers, in existence before the family-planning activities began in Mauritius, also distribute contraceptive materials and information. Their existence and relatively dense distribution no doubt aided the success of the family-planning exercise.

In 1969 there was one doctor for every 5,000 people; in 1975 there was one for 3,000 ; in 1983, one for 1,500; and in 1991, fewer than 1,000 people had to share one doctor. This increase in medical personnel over the past 20 years is also reflected in the number of dentists and nurses.

Parallel to the official medical circuit, there are many alternative medical practices. Particularly, traditional spiritual healers remain to this day the preferred method or at least the method of last resort, with considerable medical success, according to many Mauritians.

The costs of official care, especially for the government, have increased enormously over the past decade. We mentioned above that the treatment of chronic diseases like heart diseases and diabetes is very costly. Health expenditures doubled from 1980 to 1986 and almost doubled again by 1991. A large part of this increase probably arises from improved treatment. But there is also a large increase in the elderly population in Mauritius, who typically requires more treatment, and this group will continue to grow considerably in the next decades. Thus, Mauritius can expect that health expenditures will rise greatly in the future.

\subsection{Education, Social Welfare, and Politics}

\subsubsection{Education}

As early as 1878 a Royal Commission inquiry into the conditions of the Indian laborers recommended compulsory education for all. Not much of this 
Table 4.4. Education of the employed population 12 years and older in Mauritius, 1990.

\begin{tabular}{lrc}
\hline Education & Number & Percent employed \\
\hline No education & 32,980 & 8.33 \\
Primary & 181,125 & 45.73 \\
Secondary & 171,807 & 43.37 \\
Tertiary & 9,255 & 2.34 \\
\hline
\end{tabular}

Source: CSO, 1990a.

recommendation was realized. When Gandhi visited the island in the beginning of the century, he "admonished Indians for not ensuring that their children were given the educational opportunities necessary for their economic and political future. After his visit, many Hindu and Moslem schools were opened" (Mannick, 1989, p. 14).

When the voting laws were changed in 1947 to give suffrage to all who could read or write simple sentences in any language, plus those who had served as soldiers in World War II, about two-fifths of the adult population was eligible to vote. In 1962, 40 percent of the women aged 35-44 had primary or secondary education. Among the 15-19 and 20-24 age groups in 1962, about four-fifths of the women had some schooling (Xenos, 1977). These statistics indicate that education for large parts of the population developed early in Mauritius compared with other less developed countries.

In the 1960 s and 1970 s school enrollment continued to increase. Figure 4.7 shows the secondary school attendance for boys and girls from 1960 to 1989. The school system in Mauritius is competitive. There are good public and private secondary schools, but they are few and require an entrance examination. The other secondary schools are not as good. As education is important for the Mauritians, many parents send their children for extra tutoring, and sometimes children have a longer working week than parents!

Table 4.4 shows the educational distribution of the employed population 12 years old and over. In 1990, the largest group in the labor force comprised persons with primary education, followed closely by those with secondary education. The educational attainments of the labor force as a whole are much less advanced than the school enrollment rates because, like many population changes, a long time period is required for the educational structures from the past to outgrow the labor force. The young labor force members, beneficiaries of the recent high school enrollment, are, on average, much better educated that the older members. Virtually none of the young 


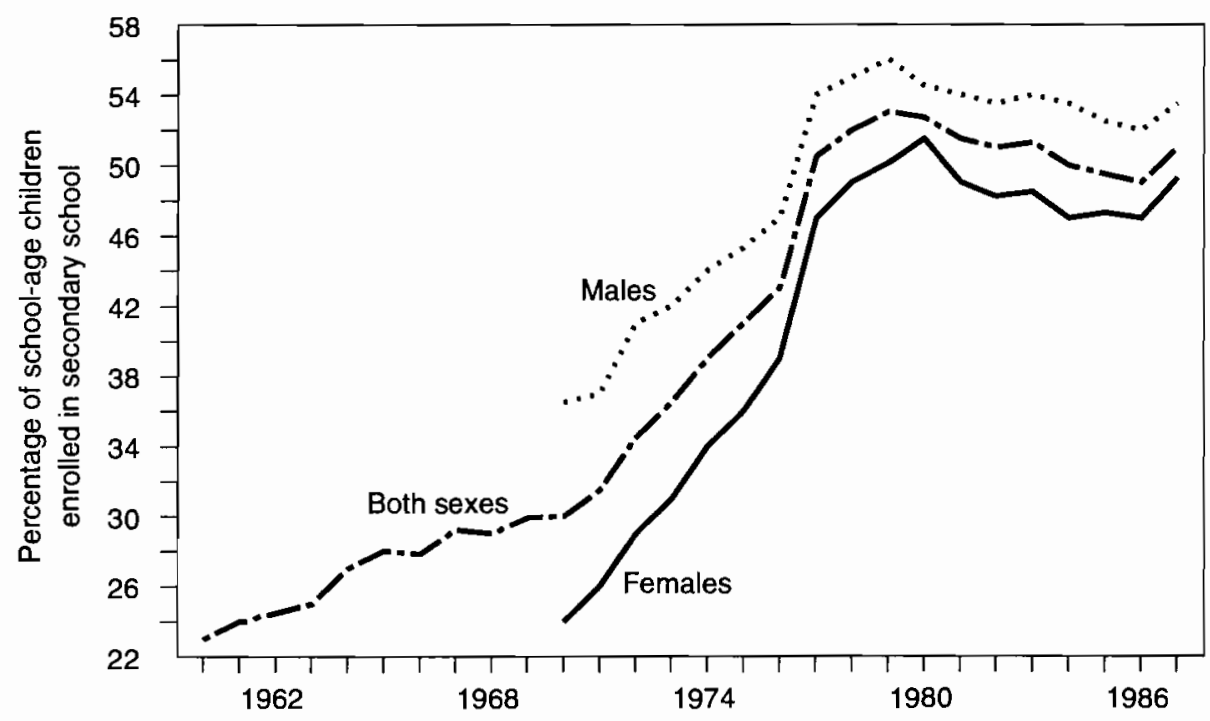

Figure 4.7. Secondary school enrollment for boys and girls in Mauritius, 1960-1987. Source: Lutz et al., 1990.

members have "no schooling"; almost all of the 8.33 percent of the labor force with no schooling is in the oldest working age groups.

\subsubsection{Social welfare}

In contrast to most other African countries, Mauritius has had a basic pension scheme for all since 1959, and a number of other supplementary schemes.

In 1959 the old age pension plan included all women over 60 , all men over 65 , and all blind persons over 40 . The allowance was not much -22 rupees monthly - and was meant as a supplementary income. The minimum weekly full-time wage for men in the sugar fields was 15.48 rupees and for women 12.48 rupees. The average rent for a house in the rural areas was 8-15 rupees monthly (of course, one elderly person would not need to rent a whole house). The cost of a healthy diet for a child, calculated by the Bon Secours Convents, was 1.68 rupees daily or about 50 rupees monthly. But a healthy diet for a child is more costly than for an elderly person. At that time, 22 rupees was probably a below-subsistence income, but it was substantial enough to enable the elderly to be independent to a certain extent. 
In addition to the basic pension, there were other employment-related schemes: 10,000 clerical and higher civil servants in 1959 - out of under 200,000 active population - were covered by a comfortable pension scheme providing them with up to two-thirds of their final salary. An additional 11,000 nonwhite-collar government employees were covered by a less generous pension scheme. Another source of pensions was the Sugar Industry Pension Fund, which had 8,377 contributing members in 1959 consisting of staff, artisans, and monthly paid laborers. Other organizations appear to have been either much smaller or less formal. The three big funds provided 15 to 20 percent of the employed with a comfortable pension scheme.

In 1976 the government introduced a far-reaching social program. The scheme provided "for a combination of earnings-related, inflation-proof contributory pensions" (Mannick, 1989, p. 127). The scheme comprises three parts: universal basic benefits for pensioners, widowers, children under 10 , inmates in institutions, and invalids (beneficiaries do not need to be contributors); contributory benefits for everyone who contributes; and industrial injury benefits.

\subsubsection{Politics}

The development of education, health facilities, and social and economic policies shows that Mauritius has had responsible governments who have cared for the population of the island. On several vital issues, including the family-planning policies of the $1960 \mathrm{~s}$, the economic policies of the $1980 \mathrm{~s}$, and recent environmental policies, the Mauritian political system has proved to be capable of setting priorities with a long time horizon and finding political consensus beyond day-to-day quarrels.

The island was ruled by the British until 1967, when it became independent. Complete independence was preceded by decades of political activity in the population of the island and shared political responsibility with the British. The transition to independence was negotiated and nonviolent; the people of Mauritius voted for it in an election in 1967. Since then, although not without periods of trouble, and even some riots, each government has been elected democratically, all political parties have been allowed (from far-right to Trotskyites), and there have been continual shifts of power from one political party to another, as in any other mature democracy.

Mauritius has a strong socialist or labor tradition. The winning parties in elections have been of the social left - the Labor Party, the Mouvement 
Militant Mauricien (MMM), the Mouvement Socialiste Mauricien (MSM). A constant conservative player on the political field is the Parti Mauricien Social Democrate (PMSD). However, in all governments, except one brief interlude in 1982-1983, the socialist or labor parties have formed coalition governments with the PMSD. Thus, in spite of the usual political squabbles, the country seems to have been ruled by consensus rather than by opposition.

The government of Mauritius has been troubled by intermittent attempts to suppress riots and strikes with repressive methods such as calling a state of emergency, enacting strict laws on political activity, and arresting political leaders. In fact, in some years - e.g., in 1971-1972 a state of emergency was called; in 1979 strikes occurred; in 1985 the government tried to curtail press freedom - the country appeared to be heading for a coup and a dictatorship, but it never happened. Why not?

In short, to an external observer, there seem to be three pillars to the democracy of Mauritius. The most important is the empowerment of the people themselves. The people of Mauritius can read; they are informed. In times of trouble, they have reacted with solidarity, have gone on strike (paralyzing the economy), have rallied, and have vocalized their discontent. These activities were organized; the people were informed and knew about the issue at hand. This homeostatic element in the political system of Mauritius cannot be underestimated.

A second important element is the tradition of ruling by consensus which was explicitly started by Sir Ramgoolam, the first prime minister after independence. In 1967 his alliance of parties grouped together to form the Independence Party and gained 39 seats in Parliament with 55 percent of the vote, while the PMSD received 23 seats with 44 percent of the vote. Rather than proceeding on his own, Sir Ramgoolam invited the PMSD, the party which represented the interests of those with money on Mauritius like the sugar barons, to join him in a coalition. This stroke of genius kept much-needed capital and entrepreneurial skills in the country, and later also turned out to be important for forging the connection with the EEC.

The third important element is that the group of Mauritians who have traditionally owned most of the wealth in the country, the Franco-Mauritian sugar landowners, has long been separated from the group with political power. When the British took over the island in 1810, the Franco-Mauritians stayed, and were allowed to keep their land, language, and traditions. They are accustomed to owning the wealth but not the government, and they know how to make this situation work for them. Thus, now that political power 
lies with the Indo-Mauritian majority of the population, no life-threatening change has occurred for them.

\subsection{Conclusion}

This chapter has given a brief overview of the population development in Mauritius from the time of the first settlements in the 17 th century. Throughout its history, different peoples have come to Mauritius - French settlers, Malagasy slaves, Indian workers and traders, Chinese businessmen - and have formed a unique collage of cultures. In the 18th and 19th centuries, life was hard on the island. Social and health conditions were bad, and frequent epidemics of malaria, cholera, and other diseases kept mortality rates high. The situation started improving in the early 20 th century. Death rates decreased, especially after the eradication of malaria. This resulted in a population explosion. In a remarkable effort over only two decades, the Mauritians curtailed their fertility to replacement levels and thus averted further excessive population growth on their already very densely populated island. The country has enjoyed high education levels from the $1930 \mathrm{~s}$ onward, and very high levels since the 1960s and 1970s. The political system of Mauritius is an example of a functioning democracy in the developing world that is capable of effective long-term planning. 



\section{Chapter 5}

\section{From No-Man's-Land to a Congested Paradise: An Environmental History of Mauritius}

Ferenc L. Toth

\subsection{Introduction}

The fascinating social, political, and economic history of Mauritius has been told by many (e.g., Barnwell and Toussaint, 1949; Bissoondoyal, 1963; Mannick, 1979; Addison and Hazareesingh, 1984). This chapter takes a different perspective. It attempts to describe and explain sudden changes and long-term evolutionary processes that, over the centuries, shaped natural resources and various ecological systems of the island resulting in what contemporary inhabitants and visitors experience. The environmental history of Mauritius is by no means less fascinating than its social history. Human intervention, in many cases inadvertently, profoundly transferred the landscape, fauna, and flora over the centuries. The balance between direct, local causes behind these interventions and remote and often indirect driving forces has changed over time, but this chapter shows the overall dominance of the latter group. Even in the position of full political sovereignty, the 
remote economic, political, and increasingly environmental processes and forces tend to shape local structures. This is the main reason behind our confidence that the island's environmental history has useful lessons for the future of Mauritius and perhaps many other small islands.

Over the past three hundred years, the most dominant and persistent long-term trend in the history of global environment was the expansion of agricultural land, mostly at the expense of prime forests. Land conversion proceeded at an increasing speed in Eastern Europe, the Americas, South and East Asia, and Australia as European settlers gradually moved to these regions. Richards $(1986$, p. 56$)$ gives a concise summary of driving forces:

[T] he driving impetus behind this spread of agricultural land is not due directly to pressures of population growth.... Most land clearance and plowing has been undertaken... responding to market forces.... Cash sale and profits were the motor propelling this trend....

These opportunities opened up as one after another peripheral regions of the globe became increasingly involved in the world economy centered on Western Europe (Wallerstein, 1974, 1980). The environmental history of Mauritius is a unique blend of general patterns and special, local variations of processes of frontier development. Shifts in the relative importance of the island's linkages to regional centers and to the European core of the world economy triggered profoundly different motivations for and processes of economic development in Mauritius over the centuries. The implications for managing the island's natural resources clearly reflect these changes as many of them left long-term, if not permanent, marks on the environment.

\subsection{Extreme Forms of Exploitive Development: Early Days and the Dutch}

The preamble to the emergence of the modern world economy, the great seaborne extension of the European core, was marked by the Age of Discovery. Ships sailed across the oceans in search for new trading partners and for new trading routes to old ones. Large continents and small islands were discovered in these travels. In the region of our interest, the Indian Ocean, results were fascinating. Sailing around the Cape of Good Hope in Africa and then northeast through the Mozambique Channel opened the sea link to India. The next step was the establishment of trade linkages to Southeast Asia. Throughout the 16th century, the majority of the trading ships used 
this so-called inner route and only a few of them passed east of Madagascar to have a stopover at the Mascarene Islands.

Human intervention and destruction of the native fauna and flora on Mauritius began more than a century before the establishment of even a temporary human settlement on the island. The Portuguese ship commanded by Domingos Fernandez (considered to be the European explorer of Mauritius) left pigs, goats, and cattle from Madagascar on the island as early as 1510 . These alien species were soon followed by monkeys and rats. All these animals apparently found their niche among the local species of the island because ships stopping over on the island over the next few decades were able to replenish their food supplies not only with exotic but also with domestic animals.

Nonetheless, the aliens took a heavy toll on natives. Except for two small birds, predators were missing from the fauna. This made possible the evolution of flightless birds and large but defenseless reptiles. The rich and versatile bird population was the worst affected by the newcomers. Monkeys destroyed nests and killed the young of endemic birds, rats robbed their nests, while pigs mainly affected ground-nesting birds. Other species suffered, too. Rats practically eliminated snakes and large lizards. But almost all endemic species were affected, at least indirectly, by the intervention and impacts of aliens on their habitats. Monkeys destroyed flowers, small branches, and fruit trees in the canopy; pigs and grazing animals trampled and uprooted seedlings on the ground.

During this period of more than a century between the European discovery of Mauritius and the first Dutch settlement on the island, it was an open-access common property resource. Whoever cast anchor on the island could freely take as much as was needed. But the limited number of users and their limited capacity to take things with them prevented the depletion of the island's resources.

By the early 17 th century, improvements in vessels and navigation permitted sailing across the Indian Ocean between the southern tip of Africa and South and Southeast Asia. As a result, the number of ships using the Mascarene Islands, mainly Mauritius as a stopover to stock up on freshwater, food, and wood for ship repair, increased. The strategic importance of Mauritius was increasing, and it was merely a question of time before some nation would claim exclusive rights over the island.

Given the Dutch supremacy in the early 17th century in Southeast Asia and on the trading routes leading there, it was the Dutch who first claimed 
it. They already had a well-established settlement at their final destination in Batavia, on the island of Java, since 1619. The primary interest of the Dutch East India Company was trade and an uninhabited island had nothing to offer toward this end. A major motivation for the Dutch to take Mauritius was strategic: to prevent the French and English from using Mauritius as their stopover base. So the primary source of attraction for the Dutch to settle in Mauritius was its location. The typical motivations for establishing and expanding frontiers were access to arable land and cash crop production, but Mauritius had to wait 200 years - for its third owner - until these goals were established and developed.

In the emerging network of colonies controlled from the sea, securing a safe port to provide supplies and refuge for ship repair was extremely important.[1] All other resources and services provided by the island of Mauritius emerged only as by-products of this preventive use. The Dutch kept Mauritius even after they established another settlement at the Cape of Good Hope. Although they returned to the island after a few years of temporary abandonment, with the well-established settlement at the Cape, the strategic importance of Mauritius for them became much smaller by then.

The above order of priorities was also reflected by the Dutch attitude toward the island's resource base and their resource management practices. The first Dutch period in Mauritius (1638-1653) represented an extreme form of exploitive development: maximize output with the lowest possible amount of investments regardless of the short- and long-term consequences. Investments were limited to building a few roads for transporting timber to the port and to constructing shelters for the small number of inhabitants. In the history of Mauritius, this period was the heaviest and most destructive human intervention in the natural environment per unit of time. In just two decades, the Dutch cleared huge tracts of the ebony forests, exterminated the dodo, and continued the introduction of alien plant and animal species. Even the single forest conservation measure of this period had purely economic reasons. The market for ebony in Europe became saturated and falling prices did not justify the relatively high transport costs. As a pure market-control measure, ebony felling was restricted to 400 trees per year.

The small investment made by the Dutch from the proceeds of the island's resources was completely destroyed when they abandoned the island in 1653. Mauritius was left much poorer than it had been two decades earlier not only ecologically but also economically. Had the ebony forests been left uncut, the income from selling the timber later could have been an enormous 
investment potential for the local economy to take off. Instead, the proceeds became just a small fraction of the tremendous wealth accumulated by the Dutch empire in those decades.

The second Dutch period (1664-1710) did not bring better management or development of the island's abundant resources. The number of people on the island never exceeded 400 throughout the Dutch period. This was simply below the critical mass necessary to establish a developing community, let alone start the various accumulation processes (capital, land, labor). Neither the Dutch East Indian Company nor its governors and employees stationed in Mauritius had the slightest short-term interest in doing anything in this direction. Apparently, the natural resources of the island were so abundant relative to the number of people on the island that they provided sufficient supply despite very poor management. Failure to build up sufficient reserves, however, left early settlers at the mercy of external sources when their crops were destroyed by natural calamities.

The tremendous intensity of destruction, so typical of the first Dutch period, decreased somewhat in the second phase. Woodcutting continued, but the motivation changed: there was an increasing need for agricultural land. Thus the typical pattern of land conversion, which can be observed in many regions of the world over the centuries, can be identified in the early history of Mauritius. The first step of the sequences is forest degradation followed by total land clearing. "Frequently, forest cutting and consequent degrading has been a prelude to clearance and conversion of land to sedentary agriculture" (Richards, 1986, p. 59). In Mauritius, selective cutting of the ebony tree deprived the forest of its most voluminous tree, disrupted the spatial and temporal balance of forest succession, and opened large gaps for unprecedented competition in regrowth. Fast-growing and, in many cases, alien species, usually not the economically most valuable, were able to increase their share significantly. The result is that even in regions where there would have been sufficient time for the forest to regrow, the species composition, and thus the economic value, was much lower than those of the original forests. Thus they could easily be cleared for agriculture in the second Dutch period or later.

The seven-decade Dutch period in Mauritius shows a reverse populationdevelopment relationship compared to the typical pattern of recent decades in many parts of the developing world. In the developing world, high population density and fast population growth absorb resources that would be required to initiate and accelerate economic development (see, for example, 
Keyfitz, 1991). In 17th-century Mauritius, in addition to the lack of motivation, the small size of the population prevented economic development despite external trade and economic linkages. This is not an unusual situation on small, island-based economies. Even in the late 20th century, with all the blessings of modern transport and communication technologies, development processes are suppressed by low population densities and by the small size of local markets. The result is emigration of mainly the young and able, thus closing the loop in a downward spiral. These processes are neatly documented by Brookfield (1981) for the outer islands of Fiji.

The problem of low population density was further aggravated by the unbalanced sex ratio. The settler community was predominantly made up of males, for whom the island was a temporary station. For these settlers, there was simply no reason to worry about the future of the state of the resources. There was a complete lack of concern to leave something useful for their descendants. On the contrary, they wanted to maximize what they could take with them.

In summary, the political and strategic interests (not to be used by others) and the resources extracted from the island (timber, food, freshwater) justified the not very high transaction costs of ensuring exclusivity for the Dutch. The Dutch era was also the transition period: Mauritius was not a common property resource anymore, but the owner, the Dutch East India Company, did not consider it a high-value property either. When its value relative to their other assets and to their management capacity became too low, the company simply gave it up, probably based on the principle of "easy come, easy go."

\subsection{Establishing an Agricultural Frontier: French and Early British Colonial Times}

The French were latecomers among the West European trading nations in the Indian Ocean. In their effort to secure strategic naval ports, they had to take whatever was left by others. In the region of our interest, they established two bases: one on Madagascar and another on the small island of Bourbon (today known as Réunion). Neither was appropriate, however. The hostility of and regular attacks by the local population on Madagascar and the lack of a good port on Bourbon made the French East India Company eager to capture Mauritius when it became evident that the Dutch had abandoned the island. 
The role intended for Mauritius in the early French period was similar to that under the earlier Dutch rule. With a prospering coffee-based agricultural settlement on Bourbon, Mauritius was supposed to become a commercial port and strategic naval base. A necessary condition for this role, however, was a considerable improvement in the level of food self-sufficiency. High-yield, cyclone-resistant food crops were needed, and manioc and cassava were successfully introduced. Maize and vegetables were also grown for human consumption and for animal feed. As a result of these efforts, the 3,000 or so population on the island in 1739 became food self-sufficient in just a few years.

This period of agricultural expansion marked the first attempt in biological pest control in Mauritius. Grasshoppers caused major damage to agricultural crops therefore myna birds were brought from India to control them. Mynas virtually wiped out the grasshopper population, but also caused a lot of damage to the exotic and native fauna and flora.

Sugar-cane growing was spreading slowly during this period, nonetheless the first sugar factory was built in the early 1740s. Some considered sugar the main industry in the future of the island despite the fact that signs were not very promising. Even two decades later, the quality of locally produced sugar was so poor that it was used as cement in the construction industry and sugar for human consumption had to be imported.

Shifting the naval base and main port from Port Bourbon on the southeast coast of the island to Port Louis in the northwest had several implications. Large construction projects required huge quantities of wood. The first river diversion was constructed to deliver water from Grand River North West in order to secure the freshwater supply for Port Louis.

The program to increase food production was so successful that by 1756 , the outbreak of the Seven Years' War between France and Great Britain, Mauritius was able to provide significant food supplies to the French Navy on the Indian Ocean. This period also marked the origins of "export-oriented" industrial production: Mauritius provided arms and gun-powder for the French troops. But this period also showed the limitations and vulnerability of a small economy on a small island. Stocks and reserves were soon depleted leaving the islanders totally dependent on fluctuating current production. When crops were destroyed by a cyclone in 1760 , the situation became hopeless. After the breakdown of trade links to India, where Britain took over all French trading posts, clothes and other imported manufactured goods became scarce. The island with its 19,000 desperate inhabitants 
was transferred from the bankrupt French East India Company and became property of the French crown in 1766.

The first 15 years of French crown rule was a period of improvements and prosperity. The balance of agricultural production shifted again toward commercial products, especially spices, that provided higher profits. Less attention was devoted to food self-sufficiency, and, once again, an increasing fraction of food supplies was imported from Madagascar. Sugar cane kept its relative share, but it was produced to satisfy domestic needs only, as the European demand was largely satisfied from Caribbean sources. The bulk of the production from the sugar mills was used to produce spirits for local consumption.

Increasing population and expanding agriculture apparently led to massive deforestation. As early as 1761 a law was passed to stop cutting down the forests. As it was not observed, it had to be reinforced a few years later. Interestingly, the reasons behind these laws did not include the prime consequence, namely, erosion of the fertile top soil, but rather the secondary impacts: damage to the harbor of Port Louis due to siltation and drying up of the land surface in the absence of trees that prevents plant development. Obviously, the first victims of demand for wood for construction and fuel were the forests near the larger settlements. As a sharp contrast to the reports by early travelers who described the animals and the vegetation cover of the island so glowingly 200 years earlier, Bernadin de Saint-Pierre's vision of the environs of Port Louis in the late $1770 \mathrm{~s}$ is rather unattractive: the city "was surrounded by rocky hills without trees or bushes, ... the mountainsides were covered with burnt grass for six months of every year" (Mannick, 1979, p. 28).

The slowly but steadily increasing economic power of Mauritius was clearly demonstrated by the role it played in the next war between the French and the British between 1778 and 1783. The island was able to support huge fleets of the French Navy with food, arms, and ammunition.

The increasing appreciation of the value and environmental services of forests was demonstrated in the next cycle of agricultural expansion. In the 1780 s a large number of new farmers settled on the island. They were allowed to clear land for agriculture in the southern region, but new forests were planted in other parts of the island where soils and terrain were deemed less suitable for agriculture. This was also the time of the first large-scale environmental redevelopment program in Mauritius. The reforestation program initiated in 1781 resulted in more than 100,000 trees planted along the 
coast where ebony forests were cut by the Dutch and early French settlers. Yet again, the program involved new tree species (ravanala and casuarina) brought to the island from East India, thus the newly planted forests further increased the share of alien vegetation.

The 1780s was not only a period of economic expansion and prosperity, but also one of fraud (use of public funds for personal benefits), power abuses (speculations with real estate), macroeconomic mismanagement (uncontrolled printing of paper money leading to inflation), and scandals. As on many occasions before and after in the history of natural resources, scandals also involved the forests. Ignoring the reinforced 1761 law against forest cutting, a friend of the then governor, for example, cleared huge tracts of government-owned forests and sold the wood back to the government.

The historical changes in Europe, and especially in France, and the repeated wars between France and Great Britain made little impact on Mauritius. Even the transfer of political power over the island from the French to the British in 1810 was relatively smooth. The ownership of private property, including those of agricultural land and plantations was left untouched. Inhabitants were allowed to preserve their languages, laws, customs, and religions. Even outlawed conditions survived several decades of British rule, the most prominent example being slavery and slave trade. As early as 1794 the French government passed a law to abolish slavery and ordered slaves to be freed without compensation to their owners. Nothing happened in Mauritius except that the two officers who came to enforce the law were expelled. Slave trading had been abolished in all British colonies years before Mauritius came under British rule. Yet, some 25,000 slaves were brought to Mauritius between 1810 and 1835 , almost half of them just in the last eight years.

The early 19th century was still characterized by patterns of exploitive development in Mauritius. Most plantation owners and farmers strove for quick profits in order to accumulate some wealth to establish their new life back in Europe. Successful landowners returned to Europe with their accumulated capital rather than investing it in Mauritius. This attitude resulted in a series of negative impacts on the natural resource base, social morale, and general economic conditions. In an attempt to reduce costs and increase profits, no fertilizers were applied to the plantations. Instead, the response to declining yields from depleted soil fertility was to open up new lands for agriculture. Land clearing took the most destructive form of land conversion. Trees, bushes, and other vegetation were simply burned down, 
the area was cultivated for a few years, and then abandoned. The sugar-cane area declined (total area around 4,000 hectares in 1810) at the expense of coffee and tea plantations and fruit and vegetable cultivations.

Despite the general patterns of exploitive development, there were several attempts in these decades to improve local conditions. At least part of the government revenue raised in Mauritius was invested locally. New roads were built and the old ones upgraded, and bridges were constructed as part of the effort to improve access to the newly opened agricultural areas inland. The coastal defense system was fortified and institutions to provide primary education were established. But the vigor and success of these efforts largely depended on the talent, vision, and determination of individual governors.

As the island became more densely populated, it ceased to be as healthy a place as it used to be. Less than two centuries before, the Dutch brought sick people to Mauritius to recover because it had a pleasant climate and was free of diseases. The smallpox epidemic of 1792 apparently failed to create sufficient concerns about public health. By the early 19th century the large population of mixed origin, the increasing number of visiting ships, and poor hygienic conditions led to a series of disease outbreaks: smallpox in 1811, rabies two years later, and cholera in 1819. The last disease killed almost one-fifth of the population.

In the early 18 th century, the primary importance of Mauritius for its owner was still its strategic location. The island's involvement in the world economy had begun, but it was in the early phase of the process. Political control over Mauritius was exercised from Europe, but many important economic linkages were restricted to the South Asian and East African regions. Slave labor required to extend agricultural production was imported from Madagascar. The island was more or less self-reliant in agricultural products, but imported most manufactures. The rate of population increase was low, mainly driven by the labor need of the slowly increasing European settlers. The white to slave ratio of one to six was roughly maintained throughout the whole period.

\subsection{Closing the Agricultural Frontier: 1830s to World War II}

Similar to the Dutch motivations to conquer Mauritius, the original objective of the British to take the island was to wipe out the nuisance of corsairs attacking and robbing their merchant ships from Mauritius as their base. They 
simply wanted to secure their rule in and trade routes to India. Yet, a series of developments in the 1820s and 1830s led to the increasing involvement of Mauritius in the British Colonial Empire and thus in the world economy. Without them, the island could have become a forgotten land by the second half of the century when the proliferation of steam vessels and opening of the Suez Canal robbed Mauritius of its original strategic and geographic importance on a major trading route of the expanding world economy.

Some of these developments were rooted in the internal biophysical and socioeconomic conditions of Mauritius, but a variety of significant ones originated from outside. Probably the most important factor was the increasing importance of sugar in the European diet. Sold as a luxury good first and as medicine later, it gradually became a commodity in the 18th century. Between 1700 and 1800, sugar consumption in England increased 15-fold. Per capita consumption in Paris was estimated at five kilograms, but this seems to be high in view of another estimate of one kilogram per capita for France as a whole. Braudel's (1979) warning is fully justified: although sugar was increasingly popular, it still counted as a luxury good. In many French peasant households, a cone of sugar was hanging above the table. Instructions for use: lift your cup for a second so that the melting sugar can sweeten its content.

By 1750 the world economy emerged from the relative recession that began around 1620. The first target for new geographical expansion was the Caribbean region. Here one of the most profitable activities was sugarcane growing based on slave labor. No wonder the French government paid special premium for slave-trading ships transporting slaves to the French West Indies (French Antilles) in order to promote sugar production (Hopkins, 1973). In the 18th century, sugar was the most important import commodity from overseas to France. It was also the biggest import item to England. Sugar-cane growing and sugar production conquered Southeast Brazil and the Caribbean: Martinique, Guadeloupe, Curaçao, Jamaica, and San Domingo. While on most of these islands, sugar was the prime reason behind land conversion and it remained the main crop for centuries, in other regions it was only a transient factor in the long-term environmental transformation process. In the subtropical coastal provinces of Southeast Brazil, for example, aboriginal swidden cultivation was intensified in the first phase of European expansion that left a greater effect on the forests of the region than sugar later (Dean, 1983). Gold and diamond mining pushed land conversion one step further when demand for local food production (manioc, 
corn, rice, and ranching) significantly increased (Williams, 1990). Plantation sugar as an export crop was the main driving force behind the deforestation of the region only between 1750 and 1830 (Richards, 1986). By 1830 , coffee became the main export commodity.

In Mauritius, following a devastating cyclone in 1818 , a thorough reconsideration of agricultural policy was initiated by the governor. The conclusion was that sugar cane proved to be the most resistant crop to cyclones, and once again the hundred-year-old vision of sugar cane as the main agricultural crop of Mauritius had been revived. Sugar cane in fact became the dominant crop, followed by beans, manioc, and barley which were grown for local consumption. The area of sugar plantations doubled in less than a decade, reaching 20,000 hectares by 1830 .

At about the same time, a technological innovation further energized the sugar industry. The first modern sugar factory was built. In addition to reducing labor requirement, it provided higher rates of juice extraction. The result was a dramatic improvement in the profitability of sugar production. Higher extraction ratios also made less fertile soils profitable to cultivate.

Probably the most significant impulse for the expansion of sugar industry was a change in British economic policy. Mauritius enjoyed a special status among the British colonies. It was allowed to trade freely with all countries of the world, but its sugar export to Britain was subject to a special duty which made it less competitive compared to sugar from the West Indies. After fierce negotiations with the British government, the discriminative duty was abolished in 1825 but the free-trading right was retained. These events generated profound changes in the social structure, economic conditions, and natural-resource use over the next decades.

Owners of sugar plantations in the West Indies, where slavery was in fact abolished, feared that Mauritius could gain a competitive edge by producing sugar cheaper with its still existing slaves. The primary concern behind these protests was in fact not Mauritius. Plantation owners in the West Indies wanted protection against competition with slavery-based production in Brazil and Cuba (Williams, 1964). External political pressure to abolish slavery in Mauritius mounted, and in 1835 slaves were finally freed in a complex compensation and transition arrangement. Slave owners were handsomely compensated for their losses in property. Slaves were ordered to continue working on the plantation as wage laborers for some period of time in order to prevent economic disruptions due to a sudden drop in labor 
supply. These arrangements provided sufficient capital for plantation owners to experiment with different sugar-cane varieties and cultivation methods. As a result, both yields and quality of the sugar were improving.

The abolishment of slavery not only brought major transformation to the social structure in Mauritius. It also induced major changes in the number and demographic composition of the population over the next few decades (see Chapter 4). Already in the first few years after slavery was outlawed, some 24,000 indentured laborers arrived from India to replace slaves on the sugar plantations. In just a decade their number doubled and by 1870 over 70 percent of the island's 316,000 population was Indian or an Indian descendant.[2] It took more than a century for the population to slowly increase from virtually zero to 100,000 . As a response to a political institutional change and a series of external economic changes, the population tripled in less than 30 years. It took almost another century to add the next 100,000 people to the island's population.[3]

The vacuum of increasing market opportunities and the feared labor shortage in a period of rapid expansion of the agricultural frontier pulled huge crowds to Mauritius. (This lies in contrast to land conversion due to increasing population pressures in many regions of the developing world a century later.) A continuous flow of indentured laborers was necessary to keep labor prices low. Securing cheap and reliable labor was the top priority of old plantation owners and new European settlers. The historical significance and root causes of these processes can be compared to what happened in Eastern Europe in the early phase of the European agricultural expansion in the 16 th and 17 th centuries. Responding to the rapidly increasing grain market in Western Europe, cultivation areas in the East were extended and required labor. "Only a harshly repressive system could hold peasants in a labor-scarce economy" (Richards, 1990, p. 168) leading to a revived manorial system (zweite Leibeigenschaft) east of the Elba. The Mauritian equivalent was the requirement to save the return fare to India, an efficient way to keep laborers on the plantations for an extended period of time.

The order and causal relationships of population growth and land conversion were opposite in most regions that had indigenous populations prior to the frontier expansion. Newly established market relationships relaxed the constraints on local land use and the need for self-sufficiency in food production which kept local population numbers at the endogenously sustainable level for centuries. Once it was possible to obtain food from outside 
in exchange for cash crops, the population started to grow even in the absence of any change in lifestyles, sanitary conditions, or modern medicine (Roth, 1983).

The population boom in Mauritius gave rise to severe problems because with new people came new diseases. A series of cholera outbreaks in the 1850 s and a major malaria epidemic in 1865 killed almost 100,000 people. In these days, Mauritius was obviously one of the most unhealthy colonies of the British Empire. Sanitary conditions were below any standard, and health precautions virtually nonexistent. Domestic wastes were dumped in nearby streams and rivers, making the outbreak and spread of waterborne diseases easy. These practices existed for many decades and did not cause major problems, but, with the dramatically increasing population density, waste loads soon exceeded the absorptive capacities of the freshwater systems. The British governor of the time found all streams and rivers on the island severely polluted. Yet, the first clean drinking-water supply was put into use only in 1895 .

The change in the mode of production from slave labor to free indentured laborers was yet another component of productivity and profitability improvements in sugar production. Although working and living conditions of the two groups did not significantly differ, their incentives and attitudes were quite different. Indians were considered to be good and reliable workers, and this soon resulted in higher yields and better-quality crops.

Expanding market opportunities induced an extension of sugar-cane lands and required even more labor. As yields and profitability of sugar production were improving, the attitude of plantation owners began to change. Instead of running away with their profits, they invested their money locally. After a long period of exploitive development and permanent land degradation, investments were made to improve land productivity. The first canals were built to support small-scale irrigation schemes. Soil fertilization also began in this period using guano imported from the nearby Seychelles and the distant Peru. As labor was no longer cheap, better machines were used on the plantations. After 1850 a railway network was built to transport processed sugar to Port Louis.

By 1853 , in less than two decades, the sugar-cane area grew to over 50,000 hectares (almost one-third of the island's total area) and remained at that level for a few decades. Annual sugar production was around 115,000 tons. Starting in this period sugar determined the fate of the island, especially after 1869 when opening of the Suez Canal stripped its income from 
trade, ship repair, and other services related to long-distance trade between Europe and South Asia.

Given the general climatic conditions in Mauritius, sugar proved to be by far the most profitable crop. Yet, its overwhelming dominance made the island totally vulnerable to local weather variabilities and global economic fluctuations. When yields were high and prices were favorable, Mauritius prospered. When cyclones destroyed the crop or world market prices for sugar were depressed, it often needed external assistance to survive. The vulnerability of this practically single-crop economy is illustrated by mentioning just a few events in the history of Mauritius: the worst cyclone in history destroyed sugar-cane plantations and damaged sugar factories in 1892; the first decade of the 20th century brought depressed sugar prices and economic downturn. Starting with the First World War, the next 15 years were a period of economic boom until sugar prices fell again in 1927 and many mills had to be closed. The Great Depression of the world economy and another big cyclone in 1931 resulted again in hard times with no economic revival until 1937.

We recall that common driving forces for both processes, population growth and expansion of the agricultural frontier, originated with the outside. External market opportunities for sugar were grabbed up by local entrepreneurs, and a large number of people were brought to the island to make these opportunities feasible. The two decades in the history of Mauritius between 1835 and 1855 is a clear example of how geographically remote causes and forces of the world economy were shaping local structures, created and intensified or suppressed local social, demographic, economic, and ecological processes. The magnitude of local impacts is especially astounding if we consider that the role of Mauritius in world trade, in both value and tonnage terms, was practically negligible.

Sugar is a forest killer in two respects. First, huge tract of forests had to be cleared to increase plantation area. Second, sugar processing is an energyintensive process. Efficiency was low and the process required enormous quantities of wood. Before the arrival of steam-powered vacuum-pans in the modern mills of the late 19th century, crystallization of cane juice was very wasteful of fuel. In the sugar-cane growing regions of the Philippines, for example, wood had become so scarce around 1850 that planters had to use the pulp of pressed sugar cane as fuel (Roth, 1983).

By 1882 less than 3 percent of the original $1,800 \mathrm{~km}^{2}$ of virgin forests survived, almost entirely in the least accessible high-altitude regions. In 
a new wave of environmental rehabilitation efforts, the government began to buy back land, planted trees, and introduced a series of reafforestation laws. These ecosystem redevelopment efforts were partly oriented toward protection of water resources as new forests stands were mainly planted along streams and rivers.

External linkages of Mauritius in the late 19th century were rather atypical compared with other parts of the British colonial system. In South and Southeast Asia a nested hierarchy of economic relations and political administration emerged in which regional centers and their subcenters directed resource extraction and agricultural frontier expansion in their subregions and hinterlands (Richards, 1990, p. 165). In contrast, Mauritius was directly governed from London and major economic policies affecting the island (abolishment of slavery, foreign trade rights, export duties) were also drafted in the European core. Although trade linkages with England were apparently important and significant (witness the debate about special tariffs on sugar exports and the concern of Caribbean sugar producers about the competitiveness of Mauritian sugar due to slave labor), they were complemented by a series of export-import relationships with other regions in the Indian Ocean. For example, a significant portion of sugar exports went to India in exchange for rice imports to feed the Mauritian population of Indian origin. Madagascar was also an important absorber of Mauritian sugar and rum exports until 1895 when it was conquered by the French and trade links broke down.

Wallerstein's (1976) analysis about the three zones of African production is valid to some extent for Mauritius in a special form. In Wallerstein's scheme, the first zone produces for the world market directly (sugar production in Mauritius); the second zone produces food for workers in the first zone (rice imports from India). The third zone provides labor for the first and, to some extent, for the second zones (import of indentured laborers from India to Mauritius). The form of social organization of production in the first zone involves either white settlers/farmers and/or companies/concessions. Labor in the first zone consists mainly of indentured laborers. This form keeps labor costs worldwide at a low level. The slow increase of the economic power of indentured laborers and their descendants results in their "peasantization": an increasing number of them are able to purchase and work on their own land. 
In Mauritius this process, however, was combined with a series of other forces at work. They included fluctuations in prices and market opportunities, technological changes in growing and milling sugar cane. The net outcome in Mauritius involved major shifts in the number and average size of sugar-cane plantations and sugar factories. A delayed and long-lasting effect of the primary social and technological changes was a concentration of landed properties in the hands of those who adapted fastest to changing conditions and grabbed emerging new opportunities. The number of plantation owners decreased from 4,000 in 1846 to 1,600 by 1871 , although the plantation area increased five-fold in about the same period. Beginning in the $1880 \mathrm{~s}$, the tendency reversed as large estates were subdivided and sold to Indians who accumulated sufficient capital to start their own small-scale plantations.

Given the technologies and land-management practices of the time, there was hardly any increasing return-to-scale in sugar-cane growing. Yet, land use on small-scale plantations was probably more intensive than on large estates. In the absence of any reserve capital and appropriate credit schemes, however, investments in increasing soil fertility were more or less a direct function of fluctuating income. The concentration trend was more apparent in the sugar-milling sector. Largely due to the economic slump of the 1880 s, four out of five sugar mills closed down, but the surviving ones were modernized. The result was higher sugar extraction rates from the cane and improving profitability of sugar production and milling.

Land-management practices generally improved in the early 20 th century. Unused parts of the cane were increasingly returned to the fields as fertilizers. As sugar-cane plantations were extended to drier areas, expansion of the irrigation network became necessary to reduce losses from droughts and to increase yields in these areas. This involved large-scale hydrological projects, at least under Mauritian conditions. The La Ferme Reservoir constructed in 1914 for irrigation with 11.8 million $\mathrm{m}^{3}$ useful capacity is still the second largest reservoir on the island.

In another attempt to control agriculture, the mongoose from India was introduced in the early 1900 s to reduce rats in the sugar-cane fields. The effort brought mixed results in terms of its original objective, but, yet again, the side effects were clearly unfavorable. The mongoose completed the elimination of native ground-nesting birds that began centuries ago by pigs. 


\subsection{High Population Density: World War II to Independence}

Following the economically prosperous years of the Second World War, a new period started in the environmental history of Mauritius. It was dominated by changing population-environment relations largely due to high rates of population growth. As a result of sustained high birth rates and a sudden fall in mortality following the eradication of malaria, the average annual rate of natural population increase between 1948 and 1958 was about 3 percent (see Chapter 4). Total population increased by 36 percent in this decade, adding 158,000 people to the population (see Brookfield, 1957, for a thorough analysis of the demographic situation of the early 1950s). The growth rates themselves were not alarming, since many other countries at that time and many more in subsequent decades experienced this kind of population explosion, but none of these other countries started from the already high population-density level in Mauritius (269 persons for each $\mathrm{km}^{2}$ in 1952) in relation to land and other natural resources.

The prospects and disastrous consequences of continued fast population growth alerted the British Colonial administrators and the local government. A series of committees were set up and reports commissioned to evaluate the situation and propose action. They all pointed to the poor natural resource endowments of the island as a severe constraint in its future development, but their major focus was on the combination of potential economic, social, and political disasters as a result of overpopulation. None of them addressed environmental issues directly. This is not surprising because environmental quality does not really matter when there are other threats such as a disintegrating economy, a complete breakdown of social services, and potential social unrest.[4]

One would expect that the combination of a rapidly increasing population from an already high density level and finite land and natural resources could have made Mauritius a showcase of Malthusian collapse in the 1950s. On the contrary, analysts of the situation (see, for example, Brookfield, 1957; Meade, 1967) deny the relevance of the Malthusian scheme in the case of Mauritius. A superficial observer could easily draw false conclusions related to population-environment interactions from some of the developments in Mauritius in the period of fast population growth. Real national income per capita declined by more than 10 percent between 1953 and 1958; 
Table 5.1. Sugar production, area, and employment in 1950 and 1959.

\begin{tabular}{lllllc}
\hline & $\begin{array}{l}\text { Production } \\
(1,000 \text { tons })\end{array}$ & $\begin{array}{l}\text { Area } \\
(1,000 \text { ha) }\end{array}$ & $\begin{array}{l}\text { Average } \\
\text { employment } \\
(1,000 \text { persons })\end{array}$ & $\begin{array}{l}\text { Output/area } \\
\text { (tons/ha) }\end{array}$ & $\begin{array}{l}\text { Output/ } \\
\text { employment } \\
\text { (tons/person) }\end{array}$ \\
\hline 1950 & 457 & 63.6 & 55.5 & 7.19 & 9.86 \\
1959 & 580 & 79.2 & 57.4 & 7.32 & 10.10 \\
\hline
\end{tabular}

Source: Meade et al., 1968, p. 15, and author's calculations.

sugar output per head of total population decreased at the same rate despite an increase of sugar-cane land area. The standard conclusion would be that increasing population pressure would force less fertile areas into production and this, combined with diminishing returns on earlier cultivated areas, would lead to lower output per head and a declining standard of living.

A closer look, however, reveals a completely different situation. Production, land area, and employment data for two "normal" years are summarized in Table 5.1 (normal here refers to years, if at all this is possible in Mauritius, in which neither cyclones nor droughts had any major effect on yields). Land area and sugar production had increased significantly between 1950 and 1959 (by 24 percent and 27 percent, respectively), whereas the number of people employed in the sugar sector grew by a meager 3 percent. In addition, output per area and output per employee also increased, making the question of diminishing returns irrelevant.

In the light of the small increase in the number of people earning their living in the sugar industry, the argument for population pressure to expand agricultural land seems to be false, too. Once again, the reason is purely economic and originates outside of Mauritius. After several decades of market and price uncertainties, the Commonwealth Sugar Agreement provided fix quotas and guaranteed prices for the bulk of the Mauritian sugar exports. Negotiated prices regularly exceeded the world market prices and the arrangement, though well-intended, distorted an already extreme economic structure. Meade et al. (1968) provide an explanation of economic disincentives, marketing problems, and institutional rigidities that prevented agricultural diversification, except for an increase in tea production.

Despite increasing land under cultivation, employment opportunities in agriculture remained relatively stable. One consequence of this situation could also lead to false conclusions. The number of persons applying for medical assistance because of sickness other than chronic diseases increased 
over six times between 1953 and 1959 (Titmuss and Abel-Smith, 1968, p. 11). With a view to the fast rate of population growth, one would assume that this was a result of increasing congestion, declining living standards, and deteriorating public hygiene. In fact, the reason is economic rather than environmental. The majority of the applicants for medical treatment simply failed to find employment and used the medical system to get financial assistance. In the 1950s public-health conditions were improving: malaria had already been wiped out, and tuberculosis was getting under control resulting in sharply declining mortality rates.

As a result of a fast increase in sugar-cane area in the 1950s, virtually no other land was left that could be reclaimed for further agricultural expansion. The only way to increase output was more intensive land use. An important part of this effort was a major soil survey and land classification project completed by 1962 . The survey suggested most suitable crops for various soil types in different regions, together with cultivation practices including irrigation and fertilizer use. Soil conservation was an important part of the project as it identified areas where cultivation should be abandoned because of high rates of soil erosion.

Some of the new areas brought under sugar-cane cultivation in the 1950s were located in the relatively drier regions of the island. Droughts had always been a problem in Mauritius. An obvious solution to both problems was to improve the utilization of water resources. No reservoirs had been built between 1929, when La Nicolière was constructed, and the early 1950s. In 1953-1954, three reservoirs were completed (Piton du Milieu, Mare Longue, and Tamarind Falls) two of which were built for a combined purpose of irrigation and hydroelectricity generation with a total useful capacity of 7.7 million $\mathrm{m}^{3}$. They both supported current production and encouraged agricultural expansion in the dry areas.

These efforts of the Mauritian government were reconfirmed by the Meade report: "Much capital has already been invested in schemes to provide water for agriculture and further schemes are under investigation, and we can think of no safer or more profitable form of investment" (Meade et al., 1968). It is highly unlikely that it was the direct result of this report, but the largest reservoir in Mauritius was completed in 1961 (Mare aux Vacoas, 22 million $\mathrm{m}^{3}$ useful capacity), and another smaller one was constructed in 1962 (Eau Bleue, 6 million $\mathrm{m}^{3}$ useful capacity). 
Another convenient method to increase sugar output, especially when prices were high and guaranteed, was increasing the input of chemical pesticides and fertilizers. Despite abundant labor and high rates of unemployment, the application of herbicides began in the early 1950s and has gained in increasing popularity ever since. The use of chemical fertilizers shows a similar pattern making Mauritius one of the heaviest users per unit of area in the world (for details, see Chapter 7).

\subsection{Summary and Conclusions}

The preceding analysis shows that during the 400-year history of Mauritius, various forms of natural resource exploitation and environmental transformation were to a large extent the results of fluctuating opportunities in international trade (fluctuations of the sugar price, availability of food for imports), changes in economic policies of the colonial power and other important trading partners (reduction of sugar-export tax to Britain in the 1830s, setting up a tariff and quota system after World War II), various forms of technological change (diffusion of more efficient sugar-milling technologies, construction of railways, improving agrotechniques), institutional changes (abolition of slavery), and political changes (shift of colonial power from France to Britain, changes in policies of consecutive governors and other local political authorities). The combination of these factors conditioned the aspirations and behaviors of various economic and social actors in Mauritius over the centuries. It is possible to tell the story of the dodo without considering the external factors, but it is impossible to understand it. It is hoped that this chapter has been able to provide some of the missing explanations.

\section{Notes}

[1] It is worth noting that the first, modern stock exchange in Amsterdam was largely based on shares of trading companies (Kostolany, 1987). Besides the standard prompt deals, the Amsterdam Stock Exchange handled options and forward deals, compensation courses, and report and deport deals. Because of dangers and uncertainties involved in the long sailing trips across the Indian Ocean and on the Atlantic, real and, in many cases, manufactured news about the fate of the ships provided on excellent base for speculations on the stock exchange. 
[2] In addition to the strong "pull" factor in Mauritius, severe "push" forces were at work in India as well, such as a series of famines in the early 18 th century.

[3] The prospect for a boom of the sugar industry was already in the air in the 1830s. When Charles Darwin visited Mauritius in 1836 he was impressed with the landscape and the mixed population of various races. He noted in his diary: "the country on this side of the island appears pretty well cultivated, the whole being divided into fields \& studded with farmhouses. I am, however, assured that of the whole land not more than half is yet in a productive state; if such is the case \& considering the present great export of sugar, at some future period this island when thickly peopled, will be of great value" (Darwin, 1934).

[4] Meier (1959) suggested that fast population growth could lead to martial law or even to establishing concentration camps as a way of handling the large number of unemployed people. 


\section{Chapter 6}

\section{Water Resources and Water Management}

Toolseeram Ramjeawon

\subsection{Introduction}

Water is an extremely complex resource. It is closely involved in a number of basic natural constraints to societal development (soil productivity, industrial production, energy resources, health promotion, etc.), and is active in generating side effects of human intervention in natural systems by its mobility and erosive and chemical properties.

Mauritius has a specialized environment: it is open to wave action from all sides; it has small catchment areas so that a high proportion of eroded material is lost into the sea; and the limited water-retaining capacity makes it sensitive to drought conditions. River basins are large in number but small in size, with limited regulation capacity. The turnover time of groundwater systems tends to be short - a few years at most. Seawater intrusion is a problem in coastal areas, especially where overexploitation occurs due to increasing populations, industrial production, and agricultural developments.

Environmentally, even more than economically, Mauritius is exposed to external forces. This vulnerability is directly correlated to its small size. The following discussion synthesizes the most important aspects of the watermanagement situation on the island, and analyzes the complexity of water in relation to sustainable development. 


\subsection{Geology and Climatology}

Except for the beaches and the coral reefs, Mauritius is entirely of volcanic origin, with altitudes varying from sea level to a central plateau with a maximum height of $600 \mathrm{~m}$. The landscape of Mauritius owes its origin to the superposition of volcanic activity at different periods and the differential rates of erosion. Four major periods can be distinguished:

- Emerging period of the island (between 10 and 6.7 million years).

- The old series: during this period of activity (6.2 to 5 million years) the island acquired its circular shield shape. The basaltic masses make up the island's skeleton and cover nearly 20 percent of its area as high mountain masses and a few hills scattered on the center of the island.

- The intermediate series: after a relatively calm period (1.5 million years) during which heavy erosion took place, depressions were filled by volcanic flows between 3.5 and 1.7 million years. This was followed by a calm period of about 1.2 million years.

- The late volcanic series: during this period (700,000-25,000 years) flows sprang from volcanoes situated in the core of the original volcano and spilled through gaps toward the sea.

Only the late volcanic series gave rise to good aquifers in view of their thickness and permeabilities. Groundwater is abstracted from the doleritic basalts of the younger volcanic series which overlie the hard compacted impermeable rocks of the older volcanics. The younger series are characterized by medium to high permeability, due mostly to fissures and cavities.

The coastline is some $200 \mathrm{~km}$ long and is surrounded by fringing coral reefs which enclose a lagoon area of $243 \mathrm{~km}^{2}$. Living coral reef formations resist destruction from sea action by continuously growing, due to a preference for light and sediment-free waters. Growth rate is of the order of $2 \mathrm{~mm}$ per year. The island has no continental shelf proper; the water reaches a depth of 3,000 meters within $20 \mathrm{~km}$ of its coastline. The volcanic nature of the island's origin, the existence of coral reefs, and the access to the lagoons of about 50 rivers and rivulets determine the diversity of the coastal habitats.

Climatic conditions prevailing in Mauritius determine not only the water resources of the island but also land use and irrigation needs. Mauritius enjoys a moderate tropical climate. Two seasons are observed:

- Summer from November to April. This is the warmer and rainier season, during which tropical cyclones may occur. February and March are the wettest months. 
Table 6.1. Water balance for Mauritius, values in $\mathrm{mm}$ (percent values in parentheses).

\begin{tabular}{lrr}
\hline Precipitation & $2,100(100)$ \\
Actual evapotranspiration & $1,330(63)$ \\
Infiltration & 211 & $(10)$ \\
Surface runoff & 559 & $(27)$ \\
\hline
\end{tabular}

Source: Rogbeer, 1984.

- Winter from May to October. This is the cooler and drier season. October is the driest month, with severe droughts usually occurring during November and December, before the start of the rainy season.

The mean monthly temperature varies from $22^{\circ} \mathrm{C}$ to $28^{\circ} \mathrm{C}$ on the coastal plains and from $17^{\circ} \mathrm{C}$ to $22^{\circ} \mathrm{C}$ on the central plateau. Rainfall is the most significant climatic feature for development in Mauritius. The rainfall generated by the east-southeastern trade winds rises from a mean of $1,300 \mathrm{~mm}$ per year on the windward eastern coast to almost $4,000 \mathrm{~mm}$ per year on the central plateau. The potential evapotranspiration drops from $2,000 \mathrm{~mm}$ per year on the coastal plains to $1,400 \mathrm{~mm}$ per year on the central plateau. The global balance is positive, since the yearly rainfall is equivalent to a $2,100-\mathrm{mm}$ water layer over the whole island, whereas the mean potential evapotranspiration reaches $1,700 \mathrm{~mm}$ per year. The actual evapotranspiration is approximately $1,330 \mathrm{~mm}$ (Table 6.1 ). Figure 6.1 gives the isohyets for the period 1951-1980, and shows that there is a regional distribution with the north and west that is much drier than the east, south, and center. In addition there is a seasonal variation; 40 to 50 percent of the rain falls in the months of January, February, and March, and 10 to 20 percent falls in the months of June, July, and August. The maximum 24-hour rainfall recorded was $700 \mathrm{~mm}$ and the maximum intensity was $84 \mathrm{~mm}$ per hour. Abnormal rainfall is caused by tropical cyclones passing over the island between December and April.

\subsection{Water Resources}

\subsubsection{Surface water resources}

Due to diurnal, weekly, monthly, seasonal, and annual variations in the amount of precipitation received in Mauritius, the amount of freshwater found in the natural waterways varies greatly. The high grounds act as 


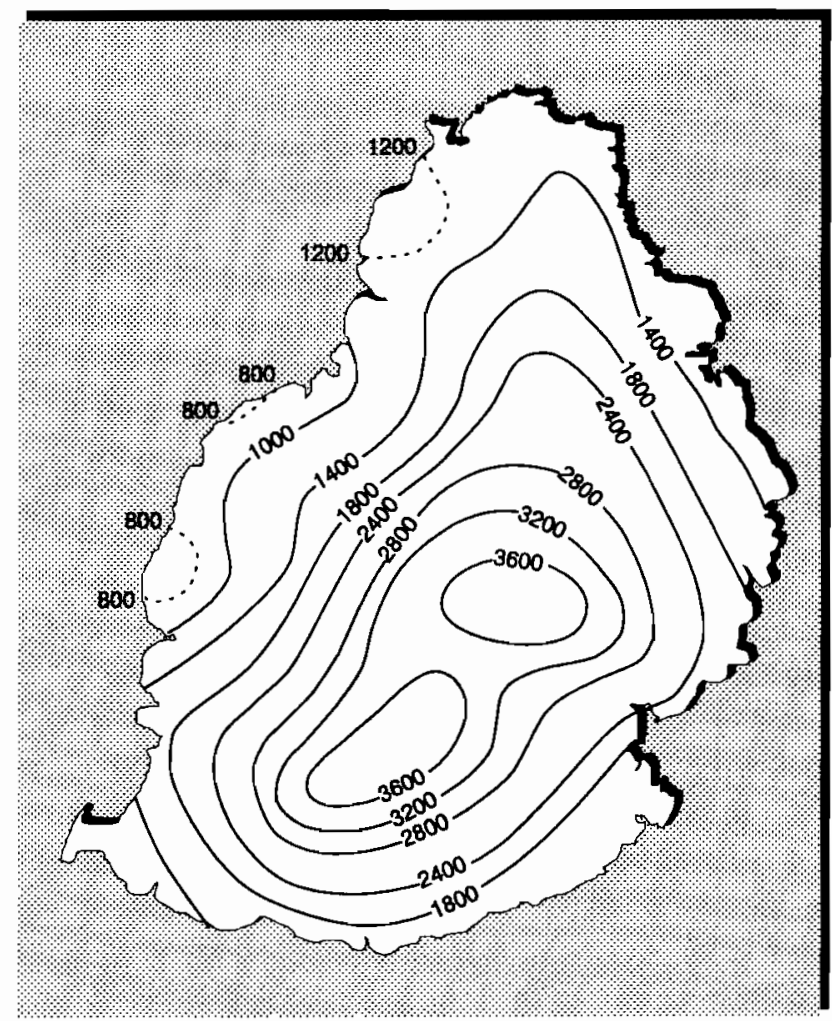

Figure 6.1. Normal annual rainfall in mm, 1951-1980. Source: Padya, 1989.

a water tower from which the water runs radially to the sea. Forty-seven catchment areas exist which vary from 3.8 to $164 \mathrm{~km}^{2}$ in size. All rivers except two are perennial. Many of the rivers are in the relatively unpopulated southern regions, but the highly touristic northern area has very little drainage. The average annual yield of surface flows of the 25 main basins excluding the subbasins - as per observed flows from 1977 to 1986 is 1,625 million $\mathrm{m}^{3}$ and is mostly made up of flood flows during the rainy season.

One of Mauritius's most serious hydrological problems is that, although most rivers are perennial, flash flood flows are very high and low flows are relatively low. The flow that is equaled or exceeded 95 percent of the time under present regulating conditions has been worked out for each watershed by the Central Water Authority, and the aggregated data show a flow of 
Table 6.2. Aquifer potentials and exploitations.

\begin{tabular}{|c|c|c|c|c|}
\hline Aquifer & $\begin{array}{l}\text { Superficial area } \\
\left(\mathrm{km}^{2}\right)\end{array}$ & $\begin{array}{l}\text { Potential yield } \\
\left(\mathrm{m}^{3} / \text { day }\right)\end{array}$ & $\begin{array}{l}\text { Yield exploited } \\
\left(\mathrm{m}^{3} / \text { day }\right)\end{array}$ & $\begin{array}{l}\text { Exploitation } \\
(\%)\end{array}$ \\
\hline Curepipe & 204 & 130,000 & 67,000 & 51 \\
\hline North & 220 & 50,000 & 25,000 & 50 \\
\hline East & 350 & 110,000 & 19,000 & 17 \\
\hline South & 185 & 55,000 & 8,000 & 14 \\
\hline Total & 959 & $\begin{array}{l}345,000 \\
(125 \text { million } \\
\left.\mathrm{m}^{3} / \text { year }\right)\end{array}$ & 119,000 & 34.5 \\
\hline
\end{tabular}

Source: CWA, 1991.

about 125 million $\mathrm{m}^{3}$ per year. This can be considered the current minimum flow under present regulating conditions (see Toth, 1992; and Chapter 15).

\subsubsection{Groundwater resources}

The aquifers of Mauritius contribute substantially to domestic, industrial, and agricultural production. Over the whole island, the late lava flows have given rise to four main aquifers: those of Curepipe, the northern plains, the eastern plains, and the southern aquifers. These aquifers are very sensitive to precipitation, the hydraulic gradient is high, and the transmissivities are very heterogeneous in both space and time. Most of the recharge flows downslope inside the younger volcanics from the high altitudes where recharge is maximum to the shore, and groundwater is directly discharged into the sea. The potential yields ascribed to each aquifer, together with the total yield that is currently exploited, are shown in Table 6.2.

More in-depth studies need to be carried out to determine the true potential of these aquifers. The water table is between 5 and $20 \mathrm{~m}$ deep, and the water quality is generally very good. Groundwater is pumped directly into the mains, and chlorine is added as a precaution.

\subsubsection{Freshwater availability}

Table 6.3 summarizes the results of a 1986 survey by the World Resources Institute. The survey found that water availability in 51 out of 100 selected countries was either low or very low (UNEP, 1991). The yearly per capita availability ranges from about $120,000 \mathrm{~m}^{3}$ in water-rich Canada to only about $70 \mathrm{~m}^{3}$ in water-poor Malta. 
Table 6.3. Per capita freshwater availability in selected countries.

\begin{tabular}{lll}
\hline Category & Per capita availability & Prop. of countries \\
\hline Very low & $1,000 \mathrm{~m}^{3} /$ year or less & $14 \%$ \\
Low & $1,000-5,000 \mathrm{~m}^{3} /$ year & $37 \%$ \\
Medium & $5,000-10,000 \mathrm{~m}^{3} /$ year & $14 \%$ \\
High & $10,000 \mathrm{~m}^{3} /$ year and more & $35 \%$ \\
\hline
\end{tabular}

Source: UNEP, 1991.

Assuming that 250 million $\mathrm{m}^{3}$ of the 1,625 million $\mathrm{m}^{3}$ of the water resources are surface flows that can be neither diverted to neighboring basins nor used in the same basin, the annual total freshwater resources of the country can be taken as

$$
1,625+125-250
$$

i.e., 1,500 million $\mathrm{m}^{3}$. The per capita freshwater availability is therefore about $1,500 \mathrm{~m}^{3}$ per year, meaning that Mauritius belongs to the group of water-poor countries close to the situation where water resources may create a serious barrier to social and economic development. The average water resources may be rich enough to meet demands, but their random distribution in time and space results in periodic deficiencies. Water management is mostly oriented to increasing the reliability of supply by means of storage reservoirs and interregional transfer of water resource.

\subsubsection{The marine environment}

Mauritius, like many other small island, developing countries, is among the main beneficiaries of the new Law of the Sea, and has acquired an Exclusive Economic Zone (EEZ) of 1.7 million $\mathrm{km}^{2}$. The exclusive access and rights to the exploitation of the living and nonliving resources of the EEZ provides Mauritius with an opportunity for diversifying its economy and for developing new sources of foreign exchange, thus enlarging its base for sustainable development. When all else has failed, the sea and its resources will still be there. Possible developments of the marine resources include oil, commercial fisheries, mariculture, renewable energy resources, marine mineral resources, offshore sand mining, and waste disposal through sea outfalls.

The coastal resources of the island have important economic and social benefits. Coral reefs and lagoons are the country's natural physical asset providing a vital sea defense barrier and enhancing the island's beauty. They have also inspired the intensive capital investment in the tourism industry. 
Table 6.4. Uses of exploited groundwater.

\begin{tabular}{llc}
\hline Use & No. of groundwater stations & Estimated production $\left(\mathrm{m}^{3} /\right.$ day $)$ \\
\hline Domestic & 50 & 136,000 \\
Irrigation & 27 & 10,000 \\
Industrial & 38 & 6,000 \\
\hline
\end{tabular}

Source: CWA, 1991.

Coral reefs, mangrove communities, and seagrass beds are fragile ecosystems and particularly vulnerable to "external" interference. They are areas of high biological productivity and are extremely important in food chains and as support structures for marine life.

\subsection{Freshwater Uses}

The water uses in Mauritius can be categorized into the following:

- Agriculture, particularly irrigation for sugar cane.

- Potable water supply for urban and rural areas.

- Industrial uses.

- Hydroelectric power generation.

The first three types are classified as "off-stream" uses since the water is used and then evaporates, or is discharged as wastewater. In the case of irrigation, a fraction of it returns to the ground. The last type is an "in-stream" use, since the water is subsequently used for other purposes.

There are 10 main impounding reservoirs with a total storage capacity of about 70 million $\mathrm{m}^{3}$ and about 300 abstraction points from surface streams. About 135 wells and boreholes are exploited, the bulk of which goes to domestic water supply (see Table 6.4).

The greatest use of water in Mauritius is for agriculture, primarily for sugar-cane cultivation. The existing 16,000 hectares of agricultural land under sprinkler, drip, and surface irrigation consumes about 303 million $\mathrm{m}^{3}$ of surface water resources (see Table 6.5). The irrigated zones are the north, west, and the coastal zones of the east and south. Irrigation rights have been granted to riparian owners since the 18 th century, and correspond to a very substantial volume with legal entitlements ranging from 1 liter per second to 1,240 liters per second. Only 34 of the more important ones are gauged on a regular basis, the rest being gauged occasionally and sometimes not at 
Table 6.5. Existing irrigation of 16,000 hectares.

\begin{tabular}{lcc}
\hline Type of irrigation system & Area covered (ha) & Consumption (million $\mathrm{m}^{3}$ ) \\
\hline Sprinkler & 9,500 & 133 \\
Drip & 300 & 3 \\
Surface & 6,200 & 167 \\
Total & 16,000 & 303 \\
\hline
\end{tabular}

Table 6.6. Water mobilized for potable water production, 1989 , in $\mathrm{m}^{3}$ per day.

\begin{tabular}{lccc}
\hline Source & Nos. & Dry season & Wet season \\
\hline Reservoirs & 3 & 105,500 & 133,500 \\
Surface abstraction & 13 & 53,100 & 96,300 \\
Pumping stations & 49 & 136,100 & 168,100 \\
Total & & 294,700 & 397,900 \\
\hline
\end{tabular}

Source: CWA, 1991.

all. These water rights are not reflected in the hydrological statistics of the Central Water Authority, the sole water authority in Mauritius.

The population census of 1990 revealed that 96.7 percent of the population had access to a piped water supply, with 57.1 percent enjoying an in-house connection. Some 145 million $\mathrm{m}^{3}$ of water was mobilized by the Central Water Authority from various sources for potable water production in 1989 (see Table 6.6).

The share of groundwater production in the total water production has increased from 21 percent in 1974 to 42 percent in 1989. Losses in the network are currently high (around 55 percent), and an average of 183,000 $\mathrm{m}^{3}$ per day of potable water is sold daily to consumers. The present average domestic water consumption is from 180 to 220 liters per day, and is expected to reach 250 liters per day in the year 2000 . In the industrial sector, the water demand may be illustrated as:

Personal use: 40 liters per day.

Personal use and industrial process: 200 liters per day.

Personal use and dyeing and washing: 3,000 liters per day.

Most of the industrial water consumption is used by a small number of very large users such as the dyeing industries, and the remainder is spread among a multitude of small businesses with low demand. 
Table 6.7. Future exploitations of aquifers.

\begin{tabular}{|c|c|c|c|c|c|c|}
\hline \multirow[b]{2}{*}{ Aquifer } & \multirow{2}{*}{$\begin{array}{l}\text { Potential yield } \\
\left(\mathrm{m}^{3} / \text { day }\right)\end{array}$} & \multicolumn{5}{|c|}{ Future exploitation $\left(\mathrm{m}^{3} /\right.$ day $)$} \\
\hline & & 2000 & 2010 & 2020 & 2030 & 2040 \\
\hline Curepipe & 130,000 & 87,000 & 100,000 & 111,000 & 124,000 & 119,000 \\
\hline North & 50,000 & 38,000 & 47,000 & 47,000 & 50,000 & 50,000 \\
\hline East & 110,000 & 62,000 & 96,000 & 102,000 & 103,000 & 111,000 \\
\hline South & 55,000 & 33,000 & 51,000 & 49,000 & 47,000 & 54,000 \\
\hline
\end{tabular}

Source: CWA, 1991.

The per capita water usage is higher in the tourist sector than in the domestic situation. The consumption per bed varies from 200 liters per day in ordinary hotels to 1,000 liters per day in five-star hotels.

The theoretical water demand at present is of the order of $283,000 \mathrm{~m}^{3}$ per day, while water sales are of the order of $183,000 \mathrm{~m}^{3}$ per day, meaning a water-supply satisfaction of around 63 percent.

Hydroelectrical power production reaches a ceiling of about $110 \mathrm{GWh}$, i.e., about 25 percent of the total energy production. The amount of water used in the seven hydro power stations is estimated at about 300 million $\mathrm{m}^{3}$, representing over 40 percent of total water usage (Rogbeer, 1984). However, it should again be stressed that this is nonconsumptive use, as this water is subsequently used for irrigation and domestic purposes. Considering a 10 percent growth rate for the demand, hydroelectricity will become marginal in the long term.

A forecast of the potable water requirements has been made by the Central Water Authority for the years of 1990, 2000, 2010, and 2040, based on the assumptions that the present tendencies in employment distribution will remain the same, while the percentage of people employed will make up 24 percent of the total population with a saturation level of 400,000 tourists annually. The forecast has been confined largely to fitting trends to the data on present demands, and experience in developed countries shows that the results are often not satisfactory. The total amount of water required for domestic and industrial uses by the year 2040 is estimated at 290 million $\mathrm{m}^{3}$. A steep upward trend in water resources development, coupled with the necessary pace of development island-wide, will put an increasing strain on day-to-day water resources management. Table 6.7 compares the potential yields already referred to with the forecast outputs from each aquifer between 2000 and 2040. 
Growth in the agricultural sector has been almost absent during the last decade, emphasizing the need for increasing the yield of sugar cane per hectare, especially in the small planters' sector. Improvements can only be achieved by providing irrigation in areas requiring it, matched with better agronomic practices. It is estimated that future additional irrigation of 50,000 hectares will be required in the long term which, assuming surface irrigation will be utilized, will need about 700 million $\mathrm{m}^{3}$.

\subsection{Water Pollution}

Questions of water supply and demand cannot be disentangled from issues of water quality. The nature and level of water pollution depend strongly on socioeconomic development. Industrialized countries have experienced several major stages of freshwater pollution (see Figure 6.2). Countries at different stages of socioeconomic development experience similar sets of problems at different times. A sequence of events similar to those in industrialized countries will occur in industrializing Mauritius, though the problems are likely to succeed and even overlap one another more quickly than they did in the industrialized countries. The main sources of water pollution in Mauritius are discussed below.

\subsubsection{Domestic}

Figures for sanitation facilities show that nearly two-thirds of the population (62 percent) has a flush toilet, with 17.8 percent connected to sewerage systems and 44.2 percent connected to septic tanks or absorption pit. Some 37.4 percent of the population relies on pit latrines, the vast majority of which are simple, nonimproved types. Municipal sewage collected by conventional systems, together with some industrial effluents, is discharged through sea outfalls after only preliminary treatment. The total dry weather flow from these outfalls is estimated to be around 3,000 liters per second, depositing a biological oxygen demand (BOD) load of around 6,000 tons per year in the coastal waters (UNEP, 1982). Clearly, the development of sanitation systems has not kept pace with the economic development of the country. Analysis of health statistics show that deaths from infections and parasitic diseases account for only approximately 3 percent of all deaths. Although this demonstrates that excreta-related diseases are not a great problem in Mauritius, rapid urbanization and industrialization will intensify such contamination if the capacity of existing sewage-treatment facilities is not enhanced. 


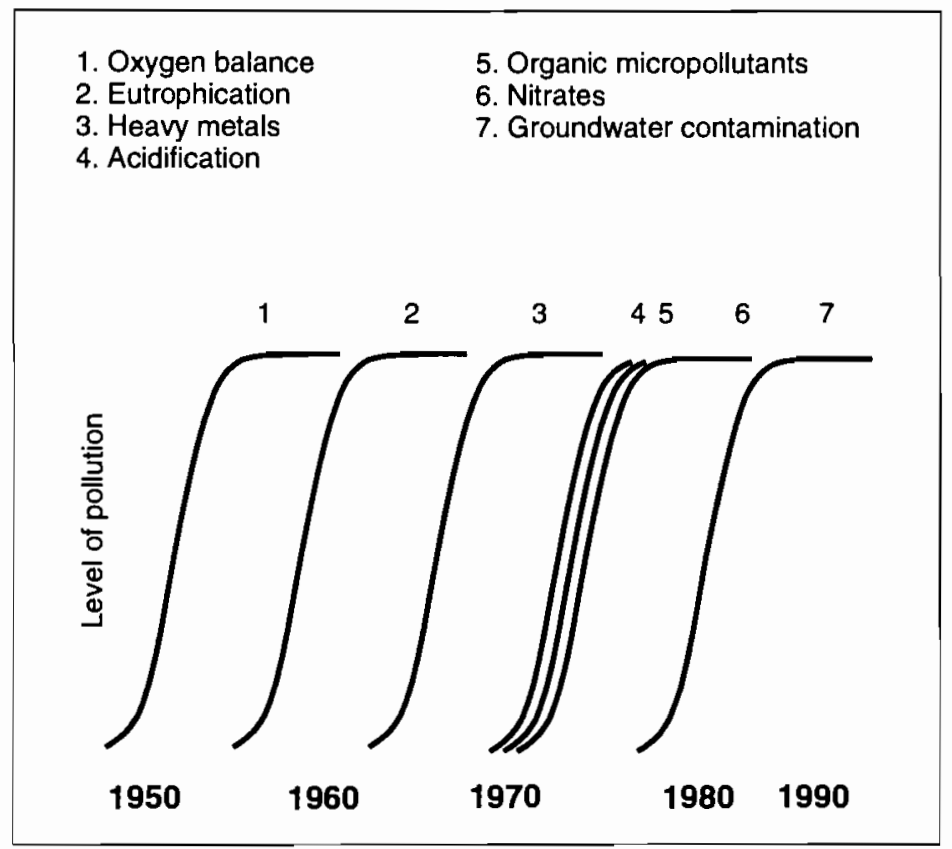

Figure 6.2. Onset of major water pollution problems in Europe. Source: UNEP, 1991.

\subsubsection{Industrial}

There were some 615 manufacturing industries in 1989, with a predominance of food-processing and textile industries. During the boom in development of EPZ industries, several of the new factories were encouraged to locate in rural areas in order to alleviate unemployment problems. This was effected with little or no regard to wastewater problems. The absence of legislation regulating the discharge of effluents into the environment was a further incentive to those industries which responded to the call by the government to develop employment opportunities in rural areas (in addition to financial, energy, and other incentives). This has resulted in a rather haphazard disposal of effluents into the environment, through water courses and soakaways. Particular attention has been focused on dyehouse effluents because of the aesthetic problems that resulted with their colored, hot, and foamy effluents. Of the 48 dyeing industries operating in 1990, 36 discharged their effluents to the public sewer, 8 to the ground through soakaways, and the 
remaining 4 to water courses. The sewer network is limited to urban areas and only 14 percent of all industries in Mauritius are connected to it. These industries are receiving a cheap and easy disposal option, since their effluents are not treated and are being discharged together with municipal sewage through sea outfalls. Strong public pressure and the need to protect water resources have forced the Central Water Authority to adopt discharge standards to all water sinks (surface, ground, and lagoon waters).

These standards are viewed as very strict and difficult to meet at reasonable cost. Industries not connected to the sewer network feel that they are being penalized for answering the call in the mid-1980s to locate quickly in rural areas in order to decrease unemployment. Treatment facilities installed for dyehouse effluents are limited in effectiveness, and the authorities cannot realistically enforce the standards as the economy is, at present, too dependent on this sector. The result is a waste of resources for all those concerned. The 19 sugar mills in operation, mostly in the rural areas, represent an important source of organic pollution. These industries are close to rivers for obvious water requirements and produce organic wastes on a seasonal basis. Treatment has, up to now, been limited to preliminary processes only. The sugar industry is much more well established in Mauritius, and, because it does not produce colored effluents, the pollution problems of this industry have not been pursued to the same extent as textile factories.

\subsubsection{Agrochemical}

Agriculture is intensive over half the island's area, and constitutes an important non-point source of pollution. Some 93 percent of the cultivated area is under sugar cane, 2 percent under tea, 0.5 percent under tobacco, and the rest supports miscellaneous vegetables, fruits, and horticultural production. The use of agrochemicals is therefore largely conditioned by sugar-cane agriculture. About 25 percent of the sugar-cane land is administered by the agricultural diversification program.

From 120 to $150 \mathrm{~kg}$ of nitrogen is applied per hectare of sugar-cane fields. Interlining with maize would bring another 40 to $62 \mathrm{~kg}$ of $\mathrm{N}$; potatoes, some $80 \mathrm{~kg}$; groundnut, $20 \mathrm{~kg}$; and beans, around $29 \mathrm{~kg}$ of $\mathrm{N}$ per hectare for each crop cycle. The intensive use of fertilizers is explained by the scarcity of prime agricultural land. It is estimated that only about 20 percent of the nitrogen applied is recovered at harvest, while 30 percent is immobilized in soil organic matter. According to Deville and $\mathrm{Ng}$ (1984), there is very little direct leaching (less than 5 percent of the fertilizer applied) during the 
year of application. However, the soil organic nitrogen may be gradually released over time, and may create problems in the future. Nitrate levels in groundwater need a more in-depth investigation in order to determine a general trend.

Sugar-cane fields annually receive between 3.0 and $7.0 \mathrm{~kg}$ of active ingredients per hectare of pesticides - almost exclusively herbicides. When intercropped, the sugar-cane lands additionally obtain some 2.0 to $5.0 \mathrm{~kg}$ of active ingredients per ton of herbicides. It is to be noted that the second application of herbicides in Mauritius occurs at the same time as the summer rains. Up to $6.0 \mathrm{~kg}$ of active ingredient per hectare may be used per crop cycle for leafy vegetables on non-sugar-cane land. Given that multicropping and mixed-cropping are intensive on non-sugar land, and that the method of spraying allows over 90 percent of the pesticides applied to spill on the ground, the resulting chemical contamination of soil and groundwater can be regarded as a chemical time bomb that will eventually explode. It is obvious in Mauritius that the main environmental impact of agrochemical usage is regulated by sugar-cane agriculture and usage of sugar-cane lands. It is necessary for the sugar industry to investigate the marginal costs of every extra ton of food or sugar it produces.

\subsubsection{Lagoon}

The lagoon around Mauritius is the ultimate sink for all the land-based sources of pollution. It is bound by coral reefs and is more or less a semienclosed system. At least 50 percent of the lagoon water is estimated to be renewed daily by water exchange with the ocean through passes and deep channels cut across the reefs.

Much concern has been expressed over the quality of the reefs and the coastal waters along the shores of Mauritius. Three main reasons are given for this degradation:

1. Effect of pollutant discharges into the lagoons directly or through water courses.

2. Effect of cyclone damage.

3. Effect of coral blasting with dynamite for fishing.

The last source has now virtually stopped due to strict legislation and enforcement, whereas the second source is a natural phenomenon which cannot be altered. The list of land-based activities that can greatly reduce the productivity or even destroy coral reefs, mangrove communities, and seagrass 
beds is very long, but can generally be summarized under two main headings: silt and pollution. The healthiest reefs are always found in the clearest waters. Typical causes of siltation are land reclamation, soil erosion, and dredging. It is estimated that between 500,000 and 600,000 metric tons of coral sand are removed from the coastal and marine environment annually.

The types of pollution that have damaging effects include agricultural runoff (containing residues of pesticides and fertilizers), industrial pollution (especially through sea outfall discharges), sewage pollution (through sea outfalls and coastal tourism development), and solid waste disposal near the coast. These forms of pollution affect mainly the nutrient balance, either destroying the processes through which nutrients are created and recycled or "fertilizing" the water, causing entrophication problems. Coral mining, commercial shell and coral collection, spear fishing, and anchor damage must also be added to the list of factors destroying the coral reefs.

\subsection{Water-Resources Development and Management}

Water resources management will never be easy in Mauritius given the uncertainties and extremes of annual and seasonal distribution of rainfall. Compounding the present problems will be the rate at which demands are likely to increase over the next 50 years and the speed at which additional water resources will be mobilized. Based on historical observations and an analysis of current trends, the main objectives of water-resources management in a water-poor country like Mauritius may be summarized as follows:

1. To increase the reliability of water resources by constructing storage systems and by protecting water resources against pollution.

2. To increase the efficiency of water use through a good distribution network, reuse and recycling, efficient irrigation systems, and economic incentives.

3. To satisfy the needs of the population, tourism, agriculture, and industry according to socially justified priorities.

It is increasingly evident that the present level of production cannot be sustained in severely dry periods. Existing surface resources are unable to relieve pressures in groundwater during droughts, due to lack of reservoir storage. Groundwater extraction is currently less than the recharge, 
but, when discharge into the sea (diffuse along the coasts) is added, a great deficit appears that is compensated by a marked reduction in groundwater storage during non-rainy periods. Over the 20-year period from 1990 to 2010 , output from surface resources for domestic, industrial, and commercial uses is projected to increase from 187,000 to $342,000 \mathrm{~m}^{3}$ per day ( 83 percent increase) and groundwater from 125,000 to $294,000 \mathrm{~m}^{3}$ per day (135 percent). The long-term future use of water resources implies a full utilization of aquifer potentials island-wide. Future water-resource development may be close to the safe or sustainable yield. The different types of water-resources development systems needed in the future are as follows:

1. Surface water: streamflows in Mauritius are highly variable, due to the small catchment sizes and steep channels. Unless seasonal balancing storage is available, water use has to be sanctioned, monitored, and controlled under dry period flow conditions (i.e., those less than the mean but higher than the minimum) to prevent waste of water at sea. There will be a need to increase the yield of sugar cane per hectare to a significant level, especially in the small planters' sector, and this can only be done by providing irrigation for areas requiring it. To meet water demands in the dry areas that arise as a result of irrigation, flood water has to be stored in reservoirs and regulated flows given to the command areas according to irrigation demands. One important aspect of future dam construction is the need to prevent in-stream storages from rapidly silting up. A novel reservoir construction technique ("reservoirs in the sea") has been used in Hong Kong to dam sea inlets, pump out the salt water, and replace it with freshwater (Chan and Chan, 1981). The two reservoirs constructed so far (capacity of 450 million $\mathrm{m}^{3}$ ) have been an innovative solution to Hong Kong's water supply problems.

2. Rainwater harvesting: this is not suitable as a primary source of water for public-water supplies for economic reasons. However, it is a good primary or supplementary source at the household or local level.

3. Groundwater: given the need to substantially increase groundwater development in the future, the knowledge of hydrogeology of the island needs to be increased in order to determine the true potential of aquifers.

4. Wastewater reuse: examples already exist for the use of wastewater on a small scale in Mauritius. For instance, tourist accommodations make use of treated wastewater from package treatment plants to irrigate gardens and lawns. However, the opportunity for wastewater reuse is much 
higher in an agricultural country like Mauritius. For health and aesthetic reasons, reuse of treated sewage effluent could be primarily used for such non-potable applications as irrigated agriculture and industrial cooling. The main actual limitation of this option is the lack of a central reticulated sewerage system from which the wastewater can be used, as well as the lack of a conventional treatment plant. Treated urban stormwater runoff is used to supplement potable water supplies in Singapore (Bingham, 1985), but this demands extensive treatment of the water to ensure that it satisfies drinking water standards. This can find applications in urbanized areas of Mauritius, but whether it is an appropriate technology for use in Mauritius remains to be proved. In Israel, 65 percent of the flow of water is reused, increasing the available quantity of water in agriculture by 20 percent. The feasibility of wastewater reuse in Mauritius will depend on the cost relative to alternative supplies and on public acceptance. Costs presented by Ertuna (1988) show a variation between about $\$ 0.30$ and $\$ 0.80$ for four countries in the Middle East, and it is likely that the costs for small island applications will be higher. The unit cost of water production for Mauritius in 1985 was $\$ 0.29$ per $\mathrm{m}^{3}$ (Worldwater/WHO, 1987).

Other nonconventional methods of producing freshwater such as desalination, importation, weather modification, and seawater intrusion barriers exist, but do not appear to be economically feasible options in Mauritius. They can only be considered if the conventional water sources are fully committed and more expensive to develop.

The piped systems in Mauritius very often suffer from problems caused by inadequate maintenance and repairs as well as the age of the materials used. It is necessary to strike a balance between high investment costs to mobilize water resources and the costs involved in reducing water losses. Efficient use of water in irrigation schemes should be encouraged, such as the use of drip (or trickle) irrigation methods rather than traditional flood irrigation in furrows. Proper irrigation scheduling, based on knowledge of the water requirements of different crops, is also required. Non-potable sources of water such as brackish water and treated wastewater should be considered for agriculture if the freshwater resources of the island are under stress.

Water-quality management in Mauritius is faced with numerous obstacles. It has been a neglected subject for various reasons, including lack of political will, resource and labor constraints, institutional inertia, and public apathy. Decision makers need to be convinced that investments in enhancing 
water quality will directly contribute to social and economic benefits, similar to investments in other sectors. Water and land use are closely related, and a coordinated plan of the land-use resources in each watershed is necessary. The policy adopted in the past, by which land-use-planning decisions were first made and the corrective measures to face the impacts of these decisions on the water resources were only taken afterward, must be abandoned.

The next important step is the determination of water-quality objectives and criteria. These should consider the country's economic and climatic requirements, along with the work force, expertise, and institutions which are necessary for their implementation. A comparison of the statistics for sanitation facilities in 1983 and 1990 shows that the proportion of the population connected to a sewer network has remained steady (18.4 percent). The failure of some of the preliminary treatment plants and the lack of operational skills in others would suggest that reliance should only be placed on a few conventional treatment plants.

One approach to the problem of disposal of effluents may be to have long sea outfalls, where the large degree of dilution available may allow only preliminary treatment. This will also eliminate the need for extensive land facilities or sludge-handling problems. The outfalls need to be wellsituated and of adequate length. But this option, of course, precludes the use of treated effluents for non-potable uses such as irrigation. The sewer network cannot realistically be expected to cover the whole island including rural areas. A thorough investigation of the efficiency of septic tanks and soakaways needs to be carried out, with particular regard to the impact on groundwater. If there are no adverse impacts, their use should not be discouraged as they are likely to be the preferred option for many people, as the increase in the figures for type of sanitation facility reveal.

The treatment of industrial wastes, particularly from dye houses, will always pose technological problems. It would, then, be advisable to rely on a few common treatment plants so that problems and resources are shared. The importance of anaerobic digestion for environmental protection and recovery of renewable resources is now recognized. Anaerobic treatment, using modern high rate anaerobic processes, is feasible for a wide range of wastes, including very low strength effluents such as domestic sewage. Regarding the technological simplicity of high rate systems like the Upflow Anaerobic Sludge Blanket (UASB) process, the implementation of these systems can make developing countries like Mauritius almost self-sufficient with respect to the protection of the environment. 
The potential value of the living and nonliving resources of the marine environment should not be underestimated; but it would similarly be foolish to underestimate the enormous constraints that confront the country in the exploitation of the potentials. The skills, information, technology, and financial resources required to translate potentials into tangible benefits are still lacking.

In July 1971, the Central Water Authority was created by an act of Parliament. Its task is to control, develop, and conserve the country's water resources; it is the sole water authority in the island. Nowadays, there is a need for an agency for water-resources assessment, monitoring, licensing, and control of water resources. This should be undertaken by a government department or ministry that is not a user agency to ensure that there is no conflict of interest in allocating available water resources. A sole water authority may favor the use of water resources in its own sector at the expense of other sectors such as agriculture. It may also lack the incentive to make the most efficient use of water measures such as leak detection, and waste prevention may be given low priority.

\subsection{Conclusion}

The availability of water is a key factor in the socioeconomic development of the island and its use is subject to severe competition. The complexity of the water resource system and the immutability of the water cycle will result in expanding environmental problems for Mauritius as it rapidly develops in the 21st century. Problems of aggravating water scarcity and deteriorating water quality will increase, unless the sectoral approaches of the past are complemented by new approaches. The water demand in the long run will be met only through an integrated approach, including legislative, economic, and technical measures aimed at the rational use of water resources. On the other hand, the country must learn to live on the terms of the water cycle on the island. It is essential that the new paradigm distinguishes between what the Mauritian society can change - i.e., its own behavior - and what it cannot change - i.e., the laws of nature. Awareness of such distinctions is necessary in seeking the new strategies that will carry Mauritius into the next century. 


\section{Chapter 7}

\section{Sugar Cane and Other Agriculture}

Jairaj Ramkissoon

\subsection{Introduction}

Mauritius has long been characterized as a sugar island. "Sugar is King in Mauritius," said J.E. Meade in 1966 in his presidential address to the Royal Economic Society (Meade, 1967, p. 244). This was before recent industrialization. But still today sugar-cane fields completely dominate the landscape of Mauritius and the attachment of the population to sugar cane is more than just economic. This chapter describes the interaction between man and nature as it has evolved around sugar production and other agricultural production on Mauritius.

\subsection{History}

The island of Mauritius, as humans first encountered it, was completely covered with lush tropical forests and was the habitat of many small species of birds and reptiles, many unique to the island.

The Dutch made two attempts at settlement in the 17th century, mainly for strategic reasons. They introduced sugar cane from Batavia (Indonesia) in 1639 , as well as deer, rabbits, and cattle. They also introduced several other crops including rice, wheat, maize, sweet potato, coconut, pineapple, 


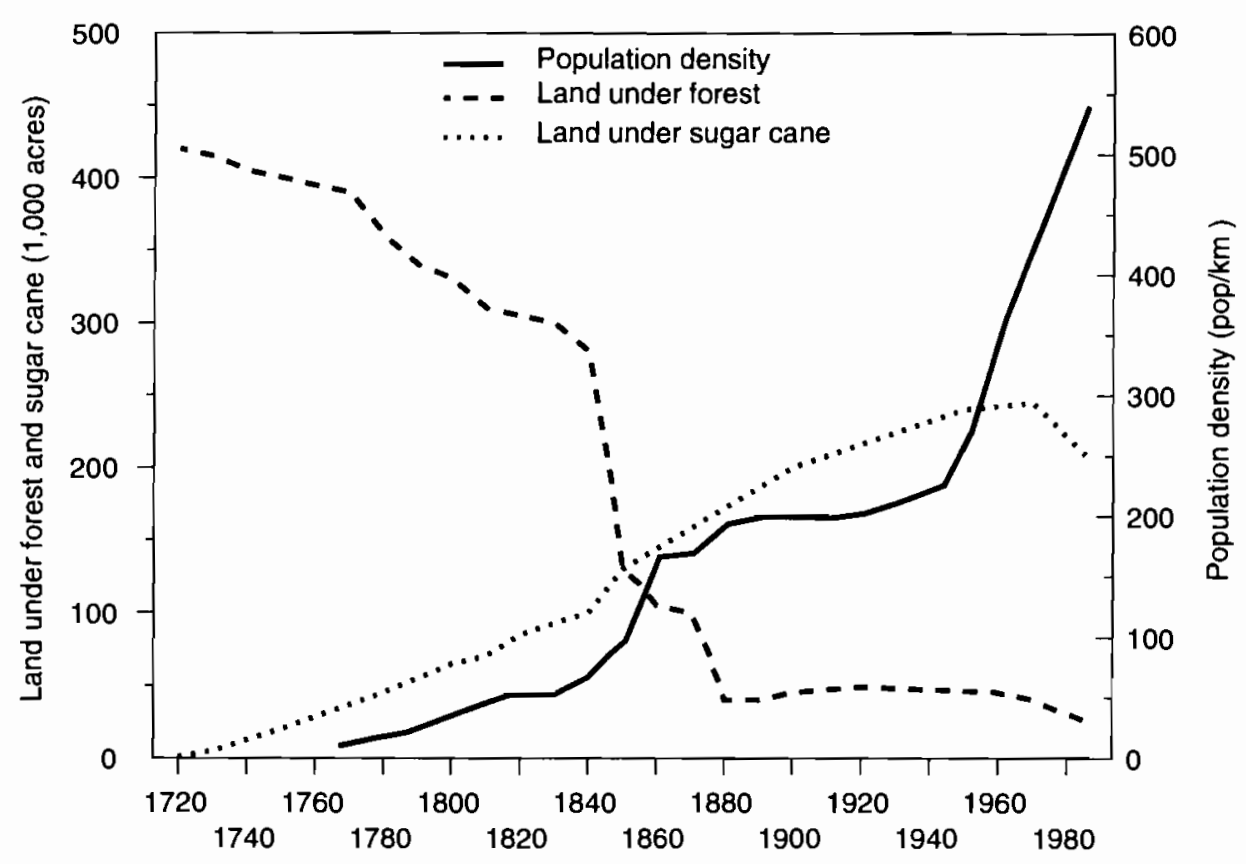

Figure 7.1. Land under forest and sugar cane. Source: Paturau, 1988.

tobacco, indigo, and citrus. Their main interest, however, was the exploitation of ebony trees and ambergris, together with the use of sugar cane for arrack, with simple means of cropping food through hunting and fishing.[1] Sugar, as such, was first produced in 1694 , but its production was not emphasized by the Dutch settlement. The Dutch eventually abandoned the island in 1710 following problems of cyclones, droughts, food shortages, attacks from runaway slaves (which they had brought in), decimation of the cattle herd by epizootics, and after having made the dodo extinct. When the Dutch departed, they left behind a considerably altered island: mostly devoid of ebony trees, with a myriad of new flora and fauna, and a small human population of ex-slaves. By this time, between 10 and 15 percent of the original forest cover had been removed (Figure 7.1).

The French settlement which started in 1715 gave a boost to the development of agriculture. Mahé de Labourdonais, governor from 1735, gave large land concessions to settlers who at first came mostly from neighboring Bourbon (Réunion Island) to produce food for the ships of the French East 
India Company (De Sornay, 1950). The population settled mostly along the warm coastal areas, and by 1742 about 16 percent of the island had been cleared for cultivation. Maize was an important crop, and cassava from Brazil was introduced in 1740 to constitute the main staple diet of the slaves. Magon, governor from 1755 to 1759, further fostered sugar cane and animal husbandry by removing all previous restrictions on deforestation in 1755.

Many crops were introduced with varying success. The crops were not resistant to the periodic cyclones and droughts. Wheat production varied from 500 metric tons in 1773 to 330 metric tons in 1787 (De Sornay, 1950). Coffee was planted on an industrial scale in 1765 , but was virtually wiped out in 1776 , although it recovered by the early 19th century. Poivre, the island intendant, first introduced spices, mainly cloves and nutmeg (and other food crops), in the early 1770 s. His intention was the establishment of a nursery to supply seeds to other French colonies. This attempt eventually proved successful and spice seeds were sent, for example, to Cayenne in the West Indies and Zanzibar (Ly-Tio-Fane, 1958).

The sugar component was still of marginal significance, being fraught with marketing problems. The French crown, which took possession of the island from 1767 , made re-allotments of lands with conditions relating to slave and animal labor inputs per unit area of land offered. The primary objective of French policy was expansion of food production. The strategic importance of the island, especially in the context of the war between France and England for India, led to all efforts and resources being diverted to service the war, particularly by way of food production (Coombes, 1963). Internal food security considerations also became prominent as a result of famine which occurred in 1793 and 1794 (Paturau, 1988).

When the British conquered the island in 1810 (Treaty of Reims 1814), 18 percent of the island was involved in agricultural production, mainly along the coastal areas, but sugar cane covered only 14 percent of the agricultural lands (Coombes, 1963).

The period of peace that followed British takeover was conducive to the development of the island, particularly the sugar industry. The instrumental factor was the opening of the British market to sugar. The British were interested in producing cash crops in Mauritius rather than food, which could easily be supplied from other colonies, mainly India and Australia (De Sornay, 1950). Several factors led to the choice of sugar cane, not the least being the cyclones of 1818,1819 , and 1824 which removed all interest in 
coffee and other tree crop plantations. The next few decades were times of great change in Mauritius.

Slavery was abolished in 1833 . The ex-slaves, after leaving the plantations, collected mainly along the coastal areas. There they started with subsistence agriculture and fishing (Walter, 1910), without much effect on forest and environment. Meanwhile, due to massive Indian immigration, agricultural activities increased. Sugar plantations were mainly in the northern and eastern plains. The introduction of the natural fertilizer guano from Peru in 1843 further enhanced sugar-cane yields and acreage, as is apparent in the increase of sugar-cane production in the years 1843-1947 (see Figure 7.1).

Sugar-cane production became better regulated and organized through the creation of the Chamber of Agriculture in 1853. This institution, whose purpose was "to defend the interests of the planter community," became extremely valuable to subsequent agricultural development, particularly for the sugar industry. By the mid-19th century, 259 sugar factories were in operation, while 50,000 hectares (almost one-third of the island) had been put under sugar cane.

To support the initial expansion of the sugar plantations, forestland was cleared. Also, private forests, mostly in the central plateau leased out to timber merchants and fuel makers, were being indiscriminately cut down. Another factor led to further diminution of forests as well as major socioeconomic changes: the outbreak of malaria in 1868 along the coastal areas of the island. This led to a mass movement of the population to the heretofore forested central areas, which subsequently became deforested. By now, almost all of the indigenous forests had disappeared: the area under primary forests, 121,000 hectares ( 65 percent of the total island area) in 1835 , was reduced to only 6,800 hectares ( 4 percent of the island) in 1872 (see Figure 7.1).

The spread of malaria seriously curtailed labor availability to the sugar industry, but there also were a series of other setbacks: the sugar crisis of London in 1847; reduced production as a result of pest and disease proliferation, e.g., the borer pest in 1850 and sugar-cane diseases (1866 to 1875) (Rouillard, 1990); sugar-price slumps in the 1870s; and increasing competition of "bounty-fed" beet sugars (Mauritius Chamber of Agriculture, 1953).

As a result, the sugar industry went through a restructuring process aimed at improving technical efficiency through centralization and the formation of sugar companies, along with factory modernization. Many small factories were closed. The coastal lands, deserted by the large estate owners, 
were sold at relatively low prices mostly to the Indian population (Walter, 1910). This was the beginning of the redistribution of wealth and the rise of prosperity of a segment of the Indo-Mauritian population.

Another significant development took place in the 1880s. The government, after several enactments in 1874 and 1875 to check uncontrolled land clearances, commissioned an investigation on forestry and the environmental state of the island. The ensuing report submitted in 1881 by Thomson, Deputy Conservator of Forests for India, concluded that "the whole of the central ridge of the table land...the great watershed in which all the larger rivers take their rise, requires to be permanently retained under forests" (Thomson, 1881). His recommendation, which was repeated later (Gleadow, 1904), started the reacquisition by the government of private forests and the initiation of a reforestation program.

The year 1881 thus marked an end to ruthless land use and deforestation, as the colonial government immediately launched a vast land acquisition program. All previous legislation was repealed and new regulations contained stricter provisions for the conservation, restoration, and management of woods and forests. A number of boards and a fund were set up to administer the acquisition and enforce the legislation. From 1881 to 1930 the government purchased some 21,000 hectares of forestlands in the central plateau region (Ministry of Economic Planning and Development, 1986).

The sugar industry was subjected to a Royal Commission Inquiry in 1909. Its important recommendations included the evaluation of irrigation possibilities and the creation of cooperative credit societies to help improve the poor cane productivity of the small planters. The cooperative movement was launched in 1913 to provide loans to the small planter community. The irrigation expert, Harriet, in turn recommended the creation of reservoirs. La Ferme was one of them, and began providing water to the sugar estates in June 1916.

The period of prosperity and development that culminated during the First World War (1914-1918) crashed again in the 1930s during the world recession. Mauritius was hit hard by the slump in sugar prices. In reaction, the UK, which had already reestablished the system of Imperial Preferences for sugar in 1919, undertook to import the bulk of all colonial and dominion sugar in 1937. It maintained this venture during World War II in order to guarantee its own supply.

The onset of World War II called for exceptional measures, particularly regarding food supply in terms of production of selected foodcrops such as 
maize, cassava, sweet potatoes, and rice. The government imposed on the sugar estates and large planters (those having more than 20 arpents of land) the conversion of 22.5 percent of the acreage, later increased to 27.5 percent, to the exclusive cultivation of foodcrops. Thus, by 1943, foodcrop acreage rose to 14,350 hectares, although the production targets could never be reached. The program had to be scrapped in 1945 and all the lands reverted to sugar cane, despite the continuing food crisis (Ministry of Economic Planning and Development, 1986).

The Food Production Board was created in 1947 and took control of some crown lands. The Board offered subsidies and price guarantees for selected crops, and imposed the exclusive use of newly cleared lands for foodcrops for at least a year. The foodcrop area again rose to around 10,370 hectares during the period 1947-1950, with significant increases in food production. However, the success was short-lived as a result of the removal of the subsidies and price guarantees by 1950 . The Board published a "Memorandum on Food Policy" in 1950, defining "normal time" and "emergency" policy guidelines. Later, that policy became a more generalized statement in terms of land-use optimization, the maintenance of the sugar industry, and diversification into tea and food production.

The postwar period also witnessed another dramatic development of the sugar sector, arising from a combination of favorable bioclimatic and marketing conditions, and generating a period of socioeconomic stability on the island. Malaria was virtually eradicated and cyclones were rare in the period from 1946 to 1960 . A high-yielding sugar-cane variety (the M134/32) released in 1937, together with enormous increases in the use of fertilizers, doubled sugar production within a short period (Rouillard, 1990). Infrastructure and irrigation were also developed.

The Mauritius Sugar Industry Research Institute (MSIRI) was created in 1953 and took over all sugar-related research. The sugar industry extended the use of land-clearing machinery and lorry transportation. The security of the sugar sector was further enhanced by the setting up of the Cyclone and Drought Insurance Scheme in 1946. The Commonwealth Sugar Agreement (CSA) was signed in 1953 and maintained the marketing guarantees of the first agreement signed in 1937.

Sugar-cane acreage expanded by 63 percent during the period from 1945 to 1966 , from 53,800 hectares to 87,600 hectares (the highest ever attained) in 1966. These two postwar decades were a real discontinuity with the past. After these changes had taken place, the sugar industry stabilized. Yields 
were about 60 metric tons per hectare, fertilizer use was about $120 \mathrm{~kg}$ per hectare, and some 70,000 to 90,000 hectares were under cultivation. The Commonwealth Sugar Agreement remained in effect until 1974.

The agricultural sector, the main industry of the island since British rule, has been experiencing a gradual erosion of its socioeconomic importance over the short span of the last decade. Its share in GDP has depreciated from 22 percent in 1976 to 15 percent during 1984-1987, and further to an estimated low of 12.7 percent for the period between 1988 and 1990. The contribution of the export duty levied on sugar to total government revenue has substantially decreased recently, from 9.8 percent in 1987 to 4.4 percent in 1989 .

A decline is also noted in the share of agriculture in total export earnings, from 88 percent in the mid-1970s to about 40 percent in the late 1980s. Also, agriculture was surpassed by the Export Processing Zone (EPZ, see Chapter 8 for details) sector even in terms of net foreign exchange earnings in 1991. A similar phenomenon is noted with respect to agricultural employment which appears to have leveled off over the past few years to some 75,000 . In fact, a different problem has surfaced recently. The increasing competition from the nonagricultural sector is causing a seasonal lack of labor which has turned out to be a serious constraint to agricultural development.

\subsection{The Sugar Sector}

\subsubsection{Ownership}

The sugar sector consists of miller-planters and associated large estates (about 30 in all), along with other small sugar planters constituting independent holdings (approximately 35,000). There are 19 sugar mills, of which 3 are foreign-owned and 1 has been government property since 1973. The miller-planters accounted for 52.6 percent of the total cultivated area under sugar cane and 60.3 percent of the total sugar production in 1990 (Mauritius Chamber of Agriculture, 1991). More than half of the small planters have holdings of less than half a hectare. The number of small holdings has been on the increase over time, particularly as a result of fragmentation arising from inheritance or tax and labor laws (World Bank, 1986). This has been a cause for concern in view of the lower productivity of such small holdings: small planters' yields average out to 6.7 metric tons of sugar per hectare compared with 9.6 metric tons for each hectare for the large estates (1990 data) although considerable regional and holding size differences exist. 
Table 7.1. Marketing commitments for Mauritian sugar.

\begin{tabular}{lc}
\hline Destination & Tonnage (metric tons raw value) \\
\hline Local sales & 40,000 \\
EEC quota & 507,000 \\
US quota & 15,000 \\
Special sugars (world) & 100,000 \\
Carry over strategic stocks & 25,000 \\
Total & 687,000 \\
\hline
\end{tabular}

Source: Mauritius Chamber of Agriculture, 1991.

\subsubsection{Sugar marketing}

The Commonwealth Sugar Agreement was replaced at the end of 1974 by the Sugar Protocol of the Lomé Convention, which retained the CSA features (Boullé, 1989). The Sugar Protocol still prevails today and connects Mauritius to the EEC market. The EEC agrees to import specified quotas of sugar, for an indefinite period at a guaranteed price that is negotiated annually and indexed to the price paid for beet sugar produced within the EEC. A Monetary Compensation Scheme is also included, depending on the extent of depreciation of the British pound against the ECU. The Protocol was signed at a time when world prices were climbing to unparalleled heights, and the EEC was in a deficit in sugar production. The initially offered guaranteed price was well below the world price, but the subsequent stability offered by the Protocol has proved to be a major factor in development.

Most of the residual sugar exports have been absorbed under ad hoc arrangements with the USA at preferential prices well above the free-market level. Mauritius thus had a quota of 27,000 metric tons under the US Sugar Act until its expiry in 1975. In 1977 duty-free access was secured to the US market under the Generalized Scheme of Preferences. The US market is currently defined for the period 1991-1995 by the Farm Act, which guarantees Mauritian sugar exports at an annual minimum quota of 14,000 metric tons.

Present annual commitments stand at around 690,000 metric tons ( Table 7.1), compared with an average yearly production during the period from 1981 to 1990 of 630,000 metric tons. The implementation of marketing arrangements is entrusted to the Mauritius Sugar Syndicate, which organizes delivery to external and internal outlets, as well as works out the payments accruing to all the sugar producers after deduction of all statutory and administrative charges. 


\subsubsection{Fiscal policy and profitability}

A tax on sugar was introduced in 1961 at a uniform rate of 5 percent of the gross value of exports, and increased to 6 percent in the early 1970s. The initial rationale was purely fiscal. Later, the tax served as a disincentive for sugar and an incentive for diversification toward other crops. In 1975 the small planters (producing less than 20 metric tons of sugar) were exempted, while a progressive rate was introduced. Thus, the tax policy also acquired a redistributive function. A surcharge of 75 percent on the basic tax was levied in 1979 to mop up windfall gains, while the industry was also liable to corporate tax (after payment of dividends). In this period, sugar taxes were a major source of government revenue. Simultaneously, the enhanced production and high sugar prices in the mid-1970s led to increased profits which were partly invested in non-sugar sectors such as the new Export Processing Zone and tourism, to a large extent spurring the economic growth of this period. Investments within the sugar sector also increased.

Profitability, however, was greatly reduced by the early 1980s during the world recession, and further aggravated by cyclones and droughts. The financial burden of labor laws also became critical. Large estates were required to maintain a regular work force all year round. The main consequences were the fragmentation of estates with 100 to 500 arpents and decreasing capital investments.

\subsubsection{Other problems and measures}

The sugar sector went through a major reform period starting from the early 1980s. The government provided some relief by decreasing the surcharge to 50 percent in 1982. Following the recommendations of the Commission of Inquiry on the Sugar Industry, a Sugar Authority was established in July 1984 and a Sugar Action Plan published in February 1985. Support from the World Bank, in terms of a Sugar Industry Project, became available in September 1985. The sugar export duty was further relaxed by broadening the exemption and applying progressive rates, and standardized accounting formats were established. Two mills were allowed to close in 1985, and support services for the small planters were to be provided by the creation of Farmers' Service Centers. Following the Sugar Industry Efficiency Study (1988) and the positive measures in the Sugar Industry Efficiency Act of 1989, declining profit margins have been offset to some extent. 
Table 7.2. Selected indicators of the sugar sector.

\begin{tabular}{lrrr}
\hline Indicator & $1976-1979$ & $1980-1985$ & $1986-1990$ \\
\hline Production sugar (1,000 metric tons) & 688 & 643 & 645 \\
Sugar export/total export (\%) & 71 & 62 & 34 \\
Yield (tons cane/ha) & 79 & 73 & 75 \\
Yield (tons sugar/ha) & 8.43 & 7.56 & 8.40 \\
Employment (1,000) & 54 & 48 & 44 \\
Share of sugar in total employment (\%) & 27 & 24 & 17 \\
Share of sugar in GDP (\%) & 17 & 12.8 & 12.7 \\
Sugar export earnings p.a. (mill. Rs) & 1,411 & 2,387 & 4,476 \\
Share of sugar in total export earnings (\%) & 69 & 54 & 35.1 \\
\hline
\end{tabular}

Source: Compiled from CSO, 1985-1990; and CSO, 1976-1988.

These developments, coupled with the world economic recovery, have improved the investment and profit position. However, profitability appears to be on the decline again: Rs 13 million only for 1991 as estimated for the corporate sector (Mauritius Chamber of Agriculture, 1990), although physical productivity in Mauritius is rated high in relation to other sugar-producing countries (World Bank, 1986). An expansion of the irrigation infrastructure and mechanization is being envisaged in order to further improve productivity and profitability.

About 16,000 hectares (19 percent of the sugar-cane acreage) are currently irrigated mainly in the rainfall deficit areas of the north and west, where the annual average sugar production shortfalls arising from droughts are estimated at 26,000 metric tons and 15,300 metric tons for the north and west, respectively (Mauritius Chamber of Agriculture, 1991).

The labor shortage and increasing wages have become a major problem in the past decade, affecting in particular the small planters who rely heavily on seasonal labor for harvest. In reaction, the corporate sector has increased mechanization efforts. Land preparation is totally mechanized, and loading up to 70 percent while harvesting has reached 5 percent. Some fertilizer and herbicide applications are also being mechanized.

The small planters, further constrained by poor soil quality and fragmentation, are being incited to group into larger land area management units with advisory support from the Farmers' Service Centers, which are expected to increase in number. Facilities will also be provided by the Sugar Planters' Mechanical Pool Corporation in the implementation of a national land-clearing project.[2] 
Table 7.2 gives selected indicators of the sugar industry in the economic and social development of Mauritius.

\subsection{Other Agriculture}

\subsubsection{Food for local consumption}

lmprovements in food self-sufficiency have been tried repeatedly, for example, in the 1970s as part of the then reigning strategy of import substitution and food security. At the same time, subsidies on imported rice and flour have been maintained. Some measure of success has been achieved with foodcrops, particularly potatoes, but the profitability of most of these diversification programs is still difficult to assess.

The producers are again segmented into the large sugar estates that focus on the utilization of sugar-cane interline and rotation lands for the production of potatoes, maize, and groundnuts mainly and small planters who produce a variety of foodcrops and vegetables on small plots (less than a hectare).

A major effort was started in the 1980s to review agricultural pricing issues. A scheme of guaranteed prices was initiated for selected crops (potatoes, maize, onions, and garlic) by the Agricultural Marketing Board (AMB), which maintains a monopoly over the imports of these (and some other) food items and has recourse to imports only when local production faces shortfalls.

Similar incentives have been given to the livestock, milk, and meat sectors, but production, except for poultry, has always lagged behind set targets. The same impediments continue to prevail and hamper diversification efforts: cyclones and droughts; lack of irrigation facilities; rocky soil; marketing constraints for most food items outside the control of the AMB, which are subject to extreme volatility in prices; problems of land and labor scarcity; and, not least, the seemingly traditional and customarily accepted dependence on external supplies for foodstuffs which have been dramatically increasing over the years.

Table 7.3, which indicates the structure of food production and imports for the period 1988-1990, gives the continuing high dependence of Mauritius on food imports, which amounted to Rs 2.65 billion in cost, insurance, and freight (CIF) in 1990, i.e., 11 percent of total imports and 47 percent of total agricultural and food export earnings. Table 7.4 gives a summary picture of land allocations to various agricultural activities since the mid-1940s. 
Table 7.3. Food production, imports, and consumption in Mauritius, 19881990, selected commodities (in metric tons).

\begin{tabular}{|c|c|c|c|}
\hline Commodity & Production & Imports & $\begin{array}{l}\text { Domestic } \\
\text { utilization } \\
\text { as food }\end{array}$ \\
\hline \multicolumn{4}{|l|}{ Cereals } \\
\hline Wheat flour & 32,915 & 32,869 & 62,305 \\
\hline Paddy/milled rice & & 81,207 & 70,117 \\
\hline Maize & 2,817 & 25,485 & 1,073 \\
\hline Cereals preparation & - & 3,926 & 3,743 \\
\hline \multicolumn{4}{|l|}{ Starchy foods } \\
\hline Potatoes & 17,771 & 4,814 & 20,078 \\
\hline Sweet potatoes & 365 & - & 330 \\
\hline Cassava (manioc) & 238 & - & 233 \\
\hline \multicolumn{4}{|l|}{ Sugars } \\
\hline Cane/Sugar & 608,942 & 3 & 36,098 \\
\hline \multicolumn{4}{|l|}{ Pulses, nuts, and seeds } \\
\hline Pulses & 117 & 11,043 & 10,950 \\
\hline Groundnuts (in shell or not) & 1,643 & 312 & 1,847 \\
\hline \multicolumn{4}{|l|}{ Vegetables } \\
\hline Tomatoes & 9,303 & - & 8,954 \\
\hline Other (fresh) & 25,365 & 140 & 24,463 \\
\hline Onions & 2,983 & 3,626 & 6,147 \\
\hline Vegetables prepared or preserved & 517 & 716 & 1,174 \\
\hline \multicolumn{4}{|l|}{ Fruits } \\
\hline Bananas & 6,232 & - & 5,924 \\
\hline Citrus & - & 2,087 & 2,027 \\
\hline Apples & - & 1,959 & 1,939 \\
\hline Pineapples & 1,398 & - & 1,303 \\
\hline \multicolumn{4}{|l|}{ Miscellaneous } \\
\hline Ginger & 408 & 5 & 378 \\
\hline Pepper, chilies, etc. & 505 & 134 & 485 \\
\hline Garlic & 165 & 570 & 731 \\
\hline \multicolumn{4}{|l|}{ Meat } \\
\hline Beef & 1,820 & 5,467 & 6,732 \\
\hline Goat meat, mutton & 220 & 3,203 & 3,382 \\
\hline Pork & 752 & 61 & 808 \\
\hline Poultry & 10,833 & 1,724 & 12,547 \\
\hline Game & 425 & & 415 \\
\hline Meat preparations & 608 & 931 & 1,234 \\
\hline \multicolumn{4}{|l|}{ Eggs } \\
\hline Hen & 5,142 & 18 & 4,622 \\
\hline \multicolumn{4}{|l|}{ Milk } \\
\hline Fresh milk and cream & 12,333 & 200 & 12,462 \\
\hline \multirow{2}{*}{\multicolumn{2}{|c|}{ Fish }} & 13,684 & 13,386 \\
\hline Fresh or frozen & 14,494 & 6018 & \\
\hline Other & 9,020 & 4,412 & 6,151 \\
\hline Oils and fats & 20,111 & 18,955 & 22,697 \\
\hline & (Refined) & (Crude) & \\
\hline
\end{tabular}

Source: CSO, 1989, 1990. 
Table 7.4. Land allocations and agricultural production of selected crops, 1947-1987, area in hectares and production in metric tons.

\begin{tabular}{|c|c|c|c|c|c|c|}
\hline \multirow[b]{2}{*}{ Crops } & \multicolumn{2}{|l|}{1947} & \multicolumn{2}{|l|}{1967} & \multicolumn{2}{|l|}{1987} \\
\hline & Area & Prod. & Area & Prod. & Area & Prod. \\
\hline Sugar & 62,974 & 348,000 & 86,657 & 638,322 & 82,752 & 619,134 \\
\hline Tea & 848 & 235.4 & 3,189 & 2,175 & 3,661 & 7,148 \\
\hline Tobacco & 270 & 344 & 540 & 579 & 633 & 912 \\
\hline Aloe fiber & $1,055-1,266$ & 940 & 1,384 & 1,603 & - & - \\
\hline Potatoes & 308 & 2,000 & 559 & 8,932 & 788 & 15,535 \\
\hline Tomatoes & - & - & - & - & 647 & 6,825 \\
\hline Maize & 1,646 & 1,900 & 335 & 554 & 1,088 & 3,865 \\
\hline Onions & - & - & - & - & 202 & 2,145 \\
\hline Bananas & - & - & - & - & 371 & 7,920 \\
\hline Pineapples & - & - & - & - & 63 & 1,015 \\
\hline
\end{tabular}

Sources: Mauritius Chamber of Agriculture, Annual Reports; CSO Yearbook of Statistics, $1947,1957,1967$.

\subsubsection{Non-sugar agricultural export}

The tea industry is second to sugar in the agricultural economy. Tea exports started in the 1950s, and an ambitious program was launched in the early 1970s funded by the International Development Association to plant 2,357 hectares of state-owned lands. This land was to be leased to 3,730 small holders who were to be trained by a parastatal organization, the Tea Development Authority (TDA). Implementation problems were numerous, and many tea factories incurred financial losses. There was some relief in 1984 when world prices rose, but the economic viability of tea subsequently became suspect because of quality constraints and the absence of marketing arrangements similar to the sugar sector.

More recently, a more market-biased strategy has been unfolding in favor of an export-oriented agroindustrial sector for high-value crops. A package of incentives is being offered under the Development Incentives Act of 1990 , placing Agricultural Development Certificate (ADC) holders on par with Export Enterprise Certificate holders. For example, tremendous interest has been generated in intensive deer farming. Eight feedlots with a capacity of 8,500 heads exist currently and export outlets for venison and live deer have been planned.

There is also interest in aquaculture. The corporate sector of the sugar industry has been producing freshwater prawns since 1974. The annual output of the 11 commercial prawn farms was 45 metric tons on 33 hectares of 
Table 7.5. Exports of agricultural and food products (quantities), 19861990 .

\begin{tabular}{lrrrrr}
\hline & \multicolumn{1}{c}{1986} & 1987 & 1988 & \multicolumn{1}{c}{1989} & \multicolumn{1}{c}{1990} \\
\hline Palm cabbage (units) & 9,550 & 10,371 & 8,632 & 8,595 & 9,625 \\
Fruits \& vegetables (metric tons) & 555 & 577 & 754 & 512 & 566 \\
Flowers (million blooms) & 4.3 & 4.7 & 7 & 8 & 7.7 \\
Canned fish (tons) & 3,999 & 3,776 & 4,676 & 5,060 & 4,059 \\
Sugar (metric tons) & 624,949 & 656,317 & 652,452 & 636,223 & 578,037 \\
Tea (metric tons) & 6,364 & 6,595 & 5,436 & 5,676 & 5,474 \\
Molasses (metric tons) & 140,791 & 153,068 & 153,828 & 140,817 & 137,543 \\
\hline
\end{tabular}

Source: Mauritius Chamber of Agriculture, Annual Reports, 1987-1991.

pond area in 1990 (Mauritius Chamber of Agriculture, 1991). The productivity of the farms may be tripled, but the main constraints are the high risk and capital investments. Anthurium flower export started in the 1960s and grew appreciably in the past decade with the widening of the export market and the formation of a producers' association.

The liberalization of the export policy in 1984 gave a boost to exports of vegetables and fruits to the EEC market. The creation of an export unit at the AMB and offers of air-freight rebates have been additional factors in promoting export-oriented agriculture. Table 7.5 shows recent trends in the magnitude of agricultural exports.

\subsection{Conclusion}

Mauritian agriculture continues to play a significant role in society and the economy. Returns from the sugar industry formed the base for manufacturing and tourism development in the 1970s and the development of water resources in terms of irrigation infrastructure. Sugar earnings have compensated for agriculture's limited role in food production by supporting food imports. Duties and income tax derived from sugar by the government have been used as a major redistribution instrument to reduce income inequality. In fact, the Gini coefficient has declined from 0.5 in the period 1961-1965 to 0.37 in $1986-1967$. However, numerous problems have been afflicting both the demand and supply sides.

Demand for sugar, essentially exogenously determined, has been tackled by various international marketing arrangements. However, the effectiveness of these arrangements has become questionable for several reasons: the reform of the Common Agricultural Policy (CAP) within the EEC tending 
toward decreased agricultural support; the uncertainties of the GATT outcome favoring trade liberalization; and the formation of other trade blocks such as the North American Free Trade Association. The world sugar market has been in chronic surplus since 1981, and the EEC is in a sugar surplus position now, contributing about 25 percent to the residual world market for sugar. The US market has been dwindling over the past decade: it represented 16.6 percent of total sugar exports in $1979-1980$ but only 4.4 percent in 1990-1991. Sugar prices on the world market have been stumbling while the EEC-offered prices have remained frozen since the mid-1980s, with the prospect of prices becoming even more depressed in real terms in coming years. The increase in sugar earnings in terms of Mauritian rupees in the past decade, in fact, has derived essentially from the adoption of a flexible exchange rate system since 1983 , the net effect of which has been a continually depreciating rupee against the most important international currencies. Boom prospects appear elusive, particularly considering the increased utilization of sugar substitutes since 1974. Tea prices also have been low since 1984. However, the internal demand for food has been increasing and the pattern of food consumption has been changing toward more expensive items, as a result of economic growth.

The supply side has also been experiencing several constraints. Labor shortage and low productivity have become acute. The land resource base is still greatly limited by the rocky terrain. Agriculture land is being lost to nonagricultural use at an annual rate of 300 hectares (Mauritius Chamber of Agriculture, 1991). There has been a reduction of 16,000 hectares of agricultural lands - a decrease of 15 percent between 1965 and 1986 (Ministry of Housing, Lands, and the Environment, 1990). The profitability of agricultural enterprises is eroding. Agricultural diversification has had limited success except for poultry and potato production, and to some extent fresh vegetable production. This effort, furthermore, has been essentially restricted within the boundary of the sugar system, necessarily subservient to sugar production, although it constitutes an efficient use of the sugarindustry resources.

There are also more specific social implications in terms of agricultural and food policy. Who is going to produce the food that could and should be produced? And who in the population is actually going to adapt consumption patterns to the production potential of the agricultural sector and the natural-resource endowments of the country? Could the "cash-crop/cheapfood" policy be indefinitely sustained with the likely substantial expansion 
in food imports and a heavier burden of food subsidies? And could nutritional/health interactions be forceful enough toward a gradual shift in dietary patterns? Little success has been achieved so far in these areas. The classic producer-consumer conflict can only partially explain the lack of achievement. In fact, it derives more from the socioeconomic complexity of the Mauritian society, which makes the whole issue a sensitive one with significant political overtones.

Environmental considerations are also receiving increasing interest. Sustainable agriculture has become an issue. Concern has been expressed about nitrate and pesticide effects (Ministry of Environment and Quality of Life, 1991). Preliminary studies undertaken by the Central Water Authority in the late 1980s indicate that nitrate levels in groundwater were approaching recommended tolerance limits (50 mg per liter) in some areas during certain periods of the year. MSIRI investigations, however, show that nitrate leaching is not significant in the year of application. The method of spraying pesticides results in over 90 percent of the pesticides falling on the ground in some places, and application rates are suspected to be high, particularly in sugar-cane fields with crop interlining or in rotation with foodcrops. Residual tests on some foodcrops do not appear to be alarming at this point. Residual effects of triazine herbicides (commonly used in Mauritius) have been detected in Western Europe and the USA, but to date no studies on this pesticide have been undertaken in Mauritius.

However, efforts are continuing on several fronts to address these issues. Political diplomacy and foreign policy, which are increasingly viewed as instruments of support to economic development, are extensively geared to the preservation of the Sugar Protocol and other marketing contracts. The only strategy appears to be long-term arrangements, which so far have been powerful instruments of socioeconomic stability and the best example of North-South cooperation. The so-called "EEC dividends" in favor of African, Caribbean, and Pacific (ACP) countries should be viewed in the context of the long history of sugar marketing - itself deriving from a colonial legacy of sugar plantation economies - where there have been many instances of "colonial dividends," as well as in favor of the colonial powers.

On the domestic front, consumer subsidies particularly on rice and flour are still maintained, while food prices of other foodstuffs are either fixed or controlled and import tariffs removed from almost all food items. Furthermore, provisions for rice and flour are secured by the government. 
Additionally, there is stricter control on agricultural land use, although reallocation of land resources have to be faced in the long term not only within the agricultural sector, but also between it and the rest of the economy. The current exercise of the National Physical Development Plan is extremely important in the creation of agricultural and land-resource policies favorable to sustainable development. Various studies designed to look at environmental impacts are under way. The government, with the support of the World Bank, has also presented an Indicative Investment Program (containing a comprehensive list of agricultural development projects including environmental activities and R\&D) to the International Aid Donors meeting in 1990. Recently, the government has even started to incorporate nutritional considerations in its policy-making process.

The potential to improve land and labor productivity in agriculture does seem considerable, but massive capital and technological inputs, plus a package of socioeconomic measures and incentives to offset the relatively disadvantaged position of agriculture in comparison to the EPZ and the services sectors are needed. Past experience of dealing with crises ought to help. Nevertheless, there may still be prospective situations that should be looked into more carefully, such as the presumed effects of world climate change and more effective development and/or application of emerging technologies, in addition to more effective exploitation of existing low-technology possibilities.

Clearly, the issues are complex. The interconnectedness of the agricultural system with the rest of the economy and the environmental implications increase the complexity. A systematic and integrated approach to planning, not only with a short-term view but perhaps more so within a long-term perspective horizon, is needed.

\section{Notes}

[1] Ambergris is a waxy substance found floating in or around the shores of tropical waters, believed to originate in the intestines of the sperm whale, and used in perfumery. Arrack is a spirit manufactured from sugar-cane juice.

[2] This project aims at removing heavy volcanic rocks, which can be found practically everywhere, from the sugar fields. 



\title{
Chapter 8
}

\section{Industrial Development and the Labor Force}

\author{
Esther Hanoomanjee
}

\subsection{Introduction}

In 1990 Mauritius had a per capita GNP of $\$ 2,250$ which is about equal to that of Bulgaria, Algeria, Malaysia, and Argentina. The average growth rate in total GNP was 5.2 percent between 1965 and 1980 and 6.0 percent over the last decade. Growth rates in manufacturing were more than 10 percent (World Bank, 1992b). This very rapid growth was mostly due to the development of the Export Processing Zone (EPZ) in the 1980s. This chapter traces the industrial development of the Mauritius economy since the colonial period. The chapter then focuses on the conditions under which EPZ grew, giving special emphasis to the role of labor and in particular female labor.

\subsection{The Role of Non-sugar Manufacturing Before 1968}

8.2.1 Non-sugar production: A historical perspective

Industries were started in Mauritius in the Dutch period. The introduction of sugar in the late 16th century led to the emergence of several supportive 
manufacturing activities. These included shipbuilding, iron foundries, distilleries for rum and alcohol, salt pans, and limekilns. The earliest records on the Mauritius economy - the Administrative Report 1879 of the Colony of Mauritius - indicates that, apart from sugar, other manufactured produce for export, including vanilla, aloe fiber, coconut oil, and rum, was negligible (Ministry of Industry and Industrial Technology, 1990).

There was little development over the next century, and in 1961 it was observed that, "For the most part, manufacturing in Mauritius was at a rather primitive stage of development, carried out on a small scale and often struggling to keep alive against many difficulties and obstacles" (Meade et al., 1968). In sharp contrast, the production of sugar from sugar cane was highly organized and undertaken in an efficient manner with up-to-date equipment and technology. Thus, there was a dichotomy between the production of the main export - sugar - and manufacturing in the rest of the economy.

The industries serving the sugar sector, such as timber, engineering, and aloes, were better organized than the rest of the manufacturing sector. Thus, of the several engineering workshops which had developed for the maintenance of the equipment used by the sugar industry, two or three of them could produce some of the smaller tools required by the sugar and the other industries. However, the small size of the total market for such equipment did not render the production of this equipment viable on a commercial basis. This was also true of the by-products of the sugar industry - namely, molasses and bagasse. Some 50 percent of the molasses was exported, about 10 percent used in the local distilleries for the production of rum, and the rest used as fertilizers. The possibility of setting up a distillery for the production of alcohol for export was proposed in 1969, but was not retained because of the lack of initiative of local entrepreneurs.

By 1948, several small establishments were producing a variety of items for domestic consumption. A summary of industrial production is given in Table 8.1.

\subsubsection{Employment in non-sugar manufactures}

In 1948 , there were some 370 persons licensed to manufacture oil, lime, salt, gold, and silverware, etc. Employment in the non-sugar manufacturing sector continued to grow slowly over the century. By 1951, the number of persons employed in non-sugar manufacturing industries was 11,000, 
Table 8.1. Summary of industrial production, 1948.

\begin{tabular}{ll}
\hline Article & Quantity produced or manufactured \\
\hline Sugar & 392,000 metric tons \\
Aloe fiber (raw) & 852 metric tons \\
Rum & $1,000,000$ liters \\
Alcohol for exports & $5,233,000$ liters \\
Tobacco (leaf) & 378 metric tons \\
Cigarettes & 450 metric tons \\
Tea & 280 metric tons \\
Wines & $2,897,782$ liters \\
Sacks (aloe fiber) & 854,000 units \\
Cloth (aloe fiber, width $\left.20^{\prime \prime}-46 "\right)$ & 101,000 yards \\
Yarn & 56 metric tons \\
Lime & 12,000 metric tons \\
Salt & 40,000 metric tons \\
Soap & 314 metric tons \\
Hides and skin, cattle & 200 metric tons \\
Timber (building and furniture) & $8,500 \mathrm{~m}^{3}$ \\
\hline
\end{tabular}

Table 8.2. Employment of skilled and unskilled workers in industries, 1958.

\begin{tabular}{lrrr}
\hline Sector & Skilled & Unskilled & Total \\
\hline Non-sugar industries & 5,793 & 10,264 & 16,057 \\
Engineering and motor workshop & 864 & 668 & 1,532 \\
Docks & 150 & 960 & 1,110 \\
Building trade & 1,399 & 814 & 2,213 \\
Lime industries & 187 & 369 & 556 \\
Other manufacturing & 3,193 & 7,453 & 10,646 \\
Public services & 2,998 & 8,702 & 11,700 \\
Government & 2,799 & 7,604 & 10,403 \\
Municipal & 199 & 1,098 & 1,297 \\
Sugar industries & 4,239 & 51,207 & 55,446 \\
Total & 13,030 & 70,173 & 83,203 \\
\hline
\end{tabular}

Source: Meade et al., 1968.

accounting for about 15 percent of total employment. By 1958, the number had increased to 16,000 . Skilled workers made up 30 percent of the total number employed in the non-sugar manufacturing sector in 1951 and 1958 (see Table 8.2). 
Table 8.3. Economically active population, 1962, 1972, 1983, and 1990, by sex.

\begin{tabular}{lllrl}
\hline Year & Total & Male & Female & \% female \\
\hline 1962 & 192,360 & 159,920 & 32,440 & 16.9 \\
1972 & 254,730 & 204,130 & 50,600 & 19.9 \\
1983 & 355,960 & 263,090 & 92,870 & 26.1 \\
1990 & 415,500 & 289,180 & 126,320 & 30.4 \\
\hline
\end{tabular}

Source: CSO, 1987.

\subsection{Employment, Labor Force, and Education}

\subsubsection{Trends in labor supply}

Labor supply is determined by the size of the total population. As discussed in Chapter 4, the dramatic growth in the population after 1948 gave rise to a similar increase in the labor supply, and to corresponding increases in the economically active population (or the labor force). The labor supply includes all those who are working and are looking for jobs. As shown in Table 8.3, the labor force increased by 60 percent between 1972 and 1990 . This increase has been largely due to the massive inflow of female workers to the labor market ( 150 percent increase of female workers in the labor market between 1972 and 1990). The net result has been a change in the share of females in the labor market from 20 percent in 1972 to 30 percent in 1990. Similar changes are evident in the labor-force participation rate, which is the ratio of the economically active population to the working-age population. While for men the participation rate has ranged between 86 percent and 81 percent between 1962 and 1990, the rate has increased for women (see Table 8.4). It rose from 17 percent in 1962 to 28 percent in 1983. According to the 1990 Housing and Population census, the female participation rate was 35 percent, but it has been speculated that the figure could actually have been between 40 percent and 44 percent.

\subsubsection{Educational levels}

Development is as much dependent on the quality of the labor force as on its quantity. Although it is difficult to make direct comparisons between the level of education between one period and another, because data have not always been collected according to the same format, the gradual improvement in the educational level of the labor force is evident. In 1990, the share of the tertiary qualified to the total labor force was 2.3 percent, as compared with 
Table 8.4. Labor-force participation rates, 1962, 1972, 1983, 1990, in percent.

\begin{tabular}{lll}
\hline Year & Males & Females \\
\hline 1962 & 85.7 & 17.4 \\
1972 & 83.0 & 20.4 \\
1983 & 82.5 & 28.0 \\
1990 & 81.0 & 35.0 \\
\hline
\end{tabular}

Source: CSO, 1987.

2.2 percent in 1983 . There was a similar increase in the percentage share of secondary-level qualified workers in the labor force: 44 percent of the labor force had secondary education, as compared with only 33 percent in 1983 . There was a two percentage point decline in the share of those having only primary-level education in the labor force, from 47 percent to 45 percent.

\subsubsection{The educational system}

Mauritius has a relatively well-developed educational system. Universal primary education was attained by the middle of this century. This factor may have played a major role in the early onset and success of family planning in Mauritius. Education at all levels has been provided free since 1977. This has led to a gradual improvement in the enrollment ratio at the secondary level over the past decade, resulting in an enrollment of 80 percent in the 10-14 age group and 36 percent in the 15-19 age group in 1990. The facilities at the University of Mauritius for tertiary education are limited; hence more than half the number pursuing tertiary education go abroad to countries such as the UK, France, India, the People's Republic of China, and Pakistan. Topics of studies include medicine, law, and engineering.

The educational facilities at all levels are good. The teacher to pupil ratios at the primary and secondary levels are 1 to 33 and 1 to 21 , respectively, on average. Many of the school buildings are built specifically for education, at the primary level in particular. School books are provided free to all at the primary level and to deserving students at the secondary level. Regular reviews have been carried out to revise school curriculum in the light of changing socioeconomic requirements. Three major examinations assess the educational performance of students: the Certificate of Primary Education is held after six years of primary schooling and ranks students for secondary schools; the School Certificate is taken after five years of secondary schooling; and the Higher School Certificate is taken after seven years of secondary 
schooling. The last two exams are moderated externally by Cambridge University for most subjects, and are thus internationally accepted.

The weakness of the existing system is the nonuniformity of schools at the secondary level. There is a wide disparity between the 16,600 seats available in the "quality" schools and the remaining 62,600 seats. The competition to enter the former is extremely intense, and students and parents are under heavy pressure during most of the primary cycle.

The Master Plan for Education (Ministry of Education and Science, 1991), which was prepared in 1991 with much public support, attempts to resolve the weakness in the system by introducing nine years of basic education. The plan proposes that facilities of different academic and technical/vocational combinations be built gradually in order to provide appropriate education to all students who complete the primary cycle. The objective is to phase out the Certificate of Primary Education at the end of the primary cycle, thus enabling all students to move on to an educational program which is in line with their own potential and aptitude.

Recurrent expenditure on education currently stands at 13 percent of the total national budget, thus making education one of the largest users of government funds. Salaries and wages account for the largest share of this expenditure, and some trimming could be made through the introduction of various measures, including the grouping of subjects taught at the various schools. More than 70 different subjects are taught at the secondary level. In line with government policy to promote local languages, five languages (apart from English and French) are taught at the primary level. At most of the schools, physical improvements have been made regularly to educational infrastructure. The Master Plan envisages a major investment of $\$ 65$ million over the next decade. Facilities will be expanded for teaching science, computer skills, and technical subjects at the secondary level, for building and improving laboratories and teaching halls at the tertiary level, and for intensifying the use of correspondence courses at all levels.

\subsection{Rationale for the Export Processing Zone}

Sugar remained the main crop of the Mauritian economy till the 1950s, when the need to diversify the economic base was first felt. The pressure of rapid population growth on the stagnant sugar sector - the predominant economic activity - left little room for improving the living standards of the population. Unemployment had skyrocketed to about 20 percent of 
the labor force, and all signs indicated that the country was caught in a "poverty trap." Based on the then available technology, the land-use limits to increasing sugar production had already been reached, with a production of some 700,000 metric tons. The situation as regards labor was paradoxical. Even though unemployment was raging at 20 percent, it was difficult to get workers, in particular youth, to enter into any agricultural occupation, be it sugar or tea.

The policy to industrialize the economy was adopted as a means to lift the economy out of the doldrums. In the first round, with the setting up of the Development Certificate (DC) scheme in the 1960s, a whole range of import substitution industries was set up to meet local requirements. By 1970 the limit to produce certain goods had been reached; it was evident that in some cases, production of certain items was no longer profitable. In addition, many of the initial problems of unemployment and lack of growth persisted, despite the DC scheme. It became evident that the scheme had done little to resolve the unemployment problem. Most of the industries that had been set up were capital intensive, employing only a handful of workers each.

Nevertheless, the DC scheme had an important positive impact. It taught a nucleus of entrepreneurs the necessary managerial expertise for undertaking large-scale (in Mauritian terms) production and helped these entrepreneurs develop the skills for taking risks. Equipped with these skills, Mauritian entrepreneurs felt quite confident to enter into export-market production when they were given the incentives to do so. For government planners, the continuing problems faced by the country left no choice but to turn to another scheme - this time, export-market production - to resolve them. Hence, by the 1970 s, the country was ready to move into export-market production.

Thus Mauritius, like many resource-poor countries of the Far East adopted a strategy of export-market production in 1970. Unlike many of the others in the field at that time, Mauritius had no particular raw materials, had little knowledge of the export market, and knew even less about possible production technologies. In most of the initial Export Production Zone industries (henceforth referred to as EPZ industries), the Mauritian entrepreneur was, therefore, confined to providing the capital - either from his own resources or from loans from the Development Bank of Mauritius - and management; and the other inputs - namely, market information, technology, and so on - were provided by the foreign partner. 


\subsubsection{Local factors favoring EPZ development}

Despite the handicaps with which Mauritius entered into export-market production, Mauritius had three basic assets which proved to be critical for its initial success. First, it had a large pool of fairly well-educated, bilingual, intelligent, and easily trainable workers. As stated in the first National Development Plan, "Our people are our only asset." While most youths shunned agricultural employment, they willingly allowed themselves to be subjected to the harsh industrial discipline.

Employment in the newly opened industries was eagerly sought by both the male and female unemployed. In the initial years (till 1977), when the wage rates for females were lower than for males, there was a bias toward employing females who, in addition to being fairly docile, had almost the same educational qualifications as males.

Second, Mauritius had a stable political environment. As examined by Bheenick and Schapiro (1989), there were several features of the domestic environment which were favorable to the industrialization efforts in Mauritius. The constitution of Mauritius, which was based on the Westminster model, provided "the right of the individual to protection for the privacy of his home and other property and from deprivation of property without compensation." In order to further win the confidence of prospective investors, Mauritius joined two important international investment guarantee mechanisms. These were the International Convention for the Settlement of Investment Disputes (ICSID) and the Multilateral Investment Guarantee Agency (MIGA). Unlike some countries which have adopted a policy of discrimination to foster the development of some specific groups in society, Mauritius adopted a policy of equal rights for all segments of its society, irrespective of religion, race, or creed.

Finally, Mauritius had a well-developed social and economic infrastructure network. It had a central bank, a stock exchange, a development bank, and a leasing company. The internal and external communications network was relatively good, and facilities for schooling, health, and social security were available for all on a country-wide basis.

As pointed out by Bheenick and Hanoomanjee (1988), given that most facilities were comparatively well spread out between the rural and urban areas and all Mauritians enjoyed free health services and education, there were few signs of overt social disruption even when unemployment was high and living standards poor. 


\subsubsection{External factors favoring EPZ development}

The external factors have also been important to setting up the Mauritius EPZ; in some cases they may be even more important than the local factors. The most important external factors have been the access to the European market for Mauritian goods through the Lomé Convention. Mauritian goods are subject to the rules of origin condition of the European Common Market. The European Economic Community also had specific agencies, such as the Center for Industrial Investment (CID) and the European Investment Bank, which were responsible for bringing EC investors to the African, Caribbean, and Pacific (ACP) countries, including Mauritius. The European Investment Bank invested in several private sector initiatives in Mauritius.

Mauritian goods enjoyed preferential entry to the US market through the General System of Preferences (GSP). These two factors were critical for enticing Asian investors to Mauritius. In addition, the inflow of Hong Kong capital has been very important for the success of the EPZ and thus the recent industrialization in Mauritius. Hong Kong has accounted for more than 50 percent of all capital invested in Mauritius during the period from 1985 to 1989. Uncertainty over the merger with mainland China in 1997 would appear to have shaken business confidence and caused an outflow of capital from Hong Kong. Mauritius has a large Sino-Mauritian community and has been a fortunate recipient of some of this outflow. There are few signs of this source drying up. Since 1975, however, other countries such as France, the UK, Germany, and South Africa have also invested in Mauritius.

By 1970, when the EPZ legislation was formulated, the legislation for promoting import substitution industries was already in place. Starting from the Income Tax (Amendment) Ordinance of 1961, which provided a range of incentives to import substitution industries, the facilities for encouraging import substitution industries were extended, and customs drawback schemes were introduced to encourage domestic firms to export goods. In 1970, the government introduced the Export Processing Zone Act which incorporated a generous combination of incentives and facilities (Ministry of Industry and Industrial Technology, 1990). These included:

- Duty-free imports of machinery, spare parts, and raw material.

- Exemption from income tax on dividends during the first 10 years of operation from the start of production, and free repatriation of dividends.

- Free repatriation of capital (without appreciation) after approved status from the Bank of Mauritius has been obtained. 
- Easy access to electric power, loans, investment, and export finance at preferential rates.

- Export credit and export insurance facilities.

- Capital depreciation allowances and investment credits.

- Comparatively flexible labor legislation.

- Exemption from payment of half the normal registration fee on land and buildings purchased for new enterprises.

- Issue of residence and work permits to shareholders and expatriate technical and professional workers.

- Accessibility to factories for lease or rent.

- Guarantee against nationalization.

The corporate tax structure has been simplified since 1985. All new and old companies opting for the new option are charged a flat rate of only 15 percent for the duration of their operations, compared with the standard rate of 35 percent (Ministry of Industry and Industrial Technology, 1990). In addition to the EPZ scheme, there are two other schemes to promote exports. The Export Service Zone Scheme was introduced in 1981 to stimulate the export and re-export of manufactured goods and services by establishing specialized firms. It has also sought to encourage the development of professional services in marketing, financial, and export services. The Hotel Management Incentives Act was introduced to provide incentives to companies to set up specialized managerial and marketing services in approved hotel development, and has aimed at attracting tourists to Mauritius.

A major review of the EPZ strategy became necessary in the early $1980 \mathrm{~s}$, as part of the country's structural adjustment program. Steps were taken to harmonize the facilities for the EPZ and the DC schemes. DC companies that exported part of their products were entitled to the same tax concessions as EPZ companies for the amount exported. Double Taxation Conventions were signed with France, the UK, and India to ensure that industrialists would be entitled to deduct taxes paid on dividends earned in Mauritius.

Other institutional support arrangements included the privatization of the Development Bank of Mauritius in 1988. The objective was to "facilitate industrial, agricultural and economic development in Mauritius." In order to attract private capital to the industrial sector two organizations were launched: the Stock Exchange of Port Louis and the Unit Trust Scheme. Undoubtedly, the most important development in export promotion has been the Mauritius Export Development and Investment Authority (MEDIA) set 
up in 1985. Since 1987 MEDIA has focused its campaigns on non-textile sectors. While MEDIA has been important in providing administrative support to meet the needs of industrialists, its ability to spearhead and finetune industrial development is yet to be tested. Another organization whose importance is growing with industrialization is the Mauritius Standards Bureau. Being responsible for certification and quality improvement, its role in raising the status of the label "Made in Mauritius" to a mark of excellence is strategic.

\subsubsection{The growth of the EPZ}

Two distinct phases in the development of EPZ can be discerned: the first phase, 1970-1980; and the second phase, 1980-1990.

The first 10 years of EPZ industrialization were difficult. The total number of EPZ companies remained below 100 for the first decade of its development. In the early stages, the majority of investors came from Hong Kong, followed by France, with foreign joint ventures accounting for more than half the companies which were set up in this period. Textiles and clothing were the main sectors into which investment flowed. Studies undertaken during the period show that Mauritius was attractive as a base for subcontracting and export-market production in terms of the cost of production and the basic facilities available (Bheenick and Hanoomanjee, 1988), but its success was somewhat dissipated by time-consuming administrative procedures for obtaining EPZ certificates, as well as by other requirements which were - in theory - expected to attract investors to Mauritius.

Some 50 new industrial establishments were set up in Mauritius outside the EPZ during 1970 to 1980 . Approximately 35,800 new jobs were created during this period in the industrial sector, of which 56 percent $(20,300)$ were in $\mathrm{EPZ}$ industries. EPZ companies accounted for 17 percent of the value added in the industrial sector in 1976. By 1980, its share had escalated to 28 percent, while import substitution industries (Development Certificate companies) accounted for 55 percent of industrial sector value added. Table 8.5 presents the growth of the EPZ within the industrial sector.

Mauritius had not made much headway with industrialization by 1980 . After 20 years of the Development Certificate scheme, the manufacturing sector accounted for about 15 percent of total GDP; in the early 1960s the manufacturing sector made up 16 percent of total GDP. The efforts to industrialize had some impact on employment creation; about a third of the 


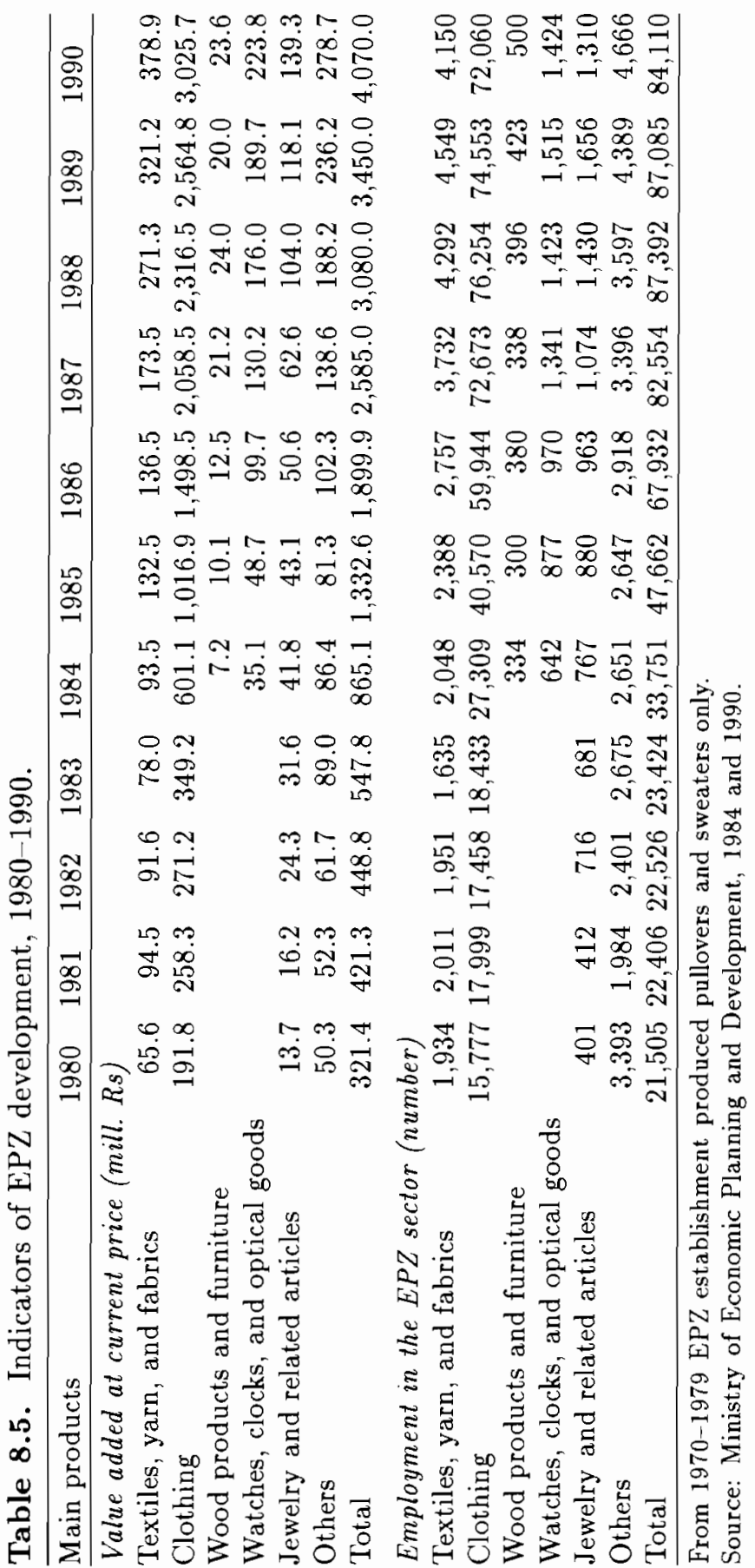


new jobs that were created between 1960 and 1980 were in the manufacturing sector. There was also little change on the export performance of the economy, with agriculture still accounting for more than 70 percent of total exports. In the early 1960s, nonagricultural exports were negligible.

Since the 1980s, there has been considerable development in the manufacturing sector. This sector accounted for some 15 percent of the GDP in the period from 1970 to 1980 . It began rising in 1984 (from 18.1 percent in 1984 to 23.2 percent in 1991). The highest rate attained was 24.6 percent in 1986. Much of the rise in the value added of the manufacturing sector since the mid-1980 has been due to the phenomenal growth of the EPZ sector. After accounting for less than 5 percent of the value added of the manufacturing sector up to 1982, its share escalated to a peak of 13.5 percent in 1988 and has since stabilized at around 12.8 percent.

In terms of employment, a similar trend is evident. The position of the agricultural sector as the main source of employment, accounting for 47 percent of total employment in large establishments in 1970, had fallen to 29 percent in 1980. The downward trend continued in the 1980s and reached 17 percent in 1991. The achievements of the manufacturing sector in creating new jobs have outweighed its success in terms of value added. The impact of the industrialization policies, in particular, for export market production, on creating new jobs was almost immediate. The manufacturing sector, which accounted for 6 percent of total employment (in large establishments) in 1973 , jumped to 12 percent by 1974; in 1988 it reached 39.4 percent. Since then it has fallen slightly; in 1991 it was 38.4 percent.

The encroachment of the manufacturing sector has been most significant in terms of export earnings. Given the monopoly position held by sugar in the Mauritius economy until 1970, more than 80 percent of total export earnings were made up of earnings from sugar. With the development of the EPZ sector, this figure fell to 60 percent in 1980 and to 28 percent in 1991. EPZ exports, in turn, moved from accounting for less than 10 percent of total export earnings in 1975 to over 24 percent in 1980 and to 62 percent in 1991.

\subsubsection{Sectoral development}

The Mauritius EPZ has been dominated by clothing firms. There has been some diversification away from this subsector: nonetheless, clothing continues to account for some 70 percent of total EPZ output. Next in importance is textiles with a contribution of 10 percent to EPZ value added. 
With the exception of the diamond-cutting industry, which benefited from the EPZ even before the EPZ Act officially passed in the Legislative Assembly, activities outside the main sectors started only after the 1980s. The new areas were jewelry, wood furniture, leather and footwear, and electronics. The contributions of these sectors in terms of value added, employment, and export earnings have been limited.

\subsubsection{EPZ markets}

The main market for EPZ products is the European Economic Community, of which France is the most important outlet, followed by the United States of America. In recent years there has been some decline in exports to the USA, but it has remained the second most important market. The market pattern reflects the ethnic characteristics of the EPZ firms. While many of the larger French partnerships export to France, the US market is monopolized by Hong Kong business concerns - operating alone or in partnerships with Mauritians. The markets for the non-textile exports are mainly the USA, Germany, and East Asia.

\subsubsection{EPZ imports}

Notwithstanding the EC rules of origin which restrict the sources of raw material to EC or ACP member countries, the EPZ imports come from a variety of sources. The most important of these sources are France, Germany, Hong Kong, and Japan. The main imports are textiles, yarn and fabrics, machinery and transport equipment, and wool and animal hair. An important feature of the EPZ goods is the high import content of their finished products, which is estimated at almost 75 percent of the value of output. Some vertical linkages have been introduced in the wearing apparel sector. Among the textile factories, there are two important weaving mills, which offer a range of cotton and blended cotton fabrics. Considerable scope exists for furthering the backward linkages.

\subsection{Transition to a Newly Industrializing Country Status}

The success of the EPZ has been due to the juxtaposition of several favorable factors. External resources and internal political stability were crucial. 
Since the beginning of the 1990s, some of the leading subsectors have been declining. There has been a down turn in the overall growth rate of the industrial sector. This sector, which had registered growth rates of 13 and 16 percent in 1985 and 1986 , has declined to less than 10 percent since 1989. The share of the industrial sector in the overall economy is fluctuating around 31 percent. There has been feeble growth in employment and new industries.

Much of the decline of the industrial sector stems from the marginal growth in the EPZ. Growth rates have declined from the heights of 30 percent in 1985 and 34 percent in 1986 to less than 5 percent for the period after 1989. Employment and investments have declined slightly since 1988. Exports, on the other hand, have fluctuated widely over the past five years. The growth rate between 1989 and 1990 was around 10 percent. The share of the EPZ in the industrial sector has continued to increase.

Within the EPZ, the wearing apparel subsector retains its dominant position, accounting for more than 70 percent of the total EPZ value added. In terms of employment, its position is even stronger and more than 80 percent of EPZ workers are employed in this subsector. This subsector also has one of the lowest ratio of value added to exports. This ratio has fluctuated from 35 percent for wearing apparel to 80 percent for textile yarn and 25 percent for watches, clocks, and optical goods. A major weakness of the Mauritius EPZ is the low value added per worker.

On the positive side, there has been some improvement in the net exports of the EPZ sector over the past five years. Net exports (total EPZ exports minus total EPZ imports) increased from around Rs 750 million in 1985 to around Rs 4.0 billion in 1990. This is indicative of the steady backward linkages that are slowly taking root in Mauritius. The opening up of two textile mills has contributed to this improvement. Similarly, there has been an improvement in the ratio of net exports to total exports. In percentage terms, it improved from 23 percent to 35 percent over the period from 1985 to 1990 . In addition, there has been some diversification in the EPZ base. Jewelry, software development, electronics, and leather products are some of the potential growth areas.

Continued success calls for a new set of rules, as the game of exportmarket production has changed for Mauritius. The achievement to date largely stems from the utilization of available labor. From a situation of 20 percent unemployment in the 1970 s, Mauritius reached a position of full employment by the late 1980s. The labor force has increased from 254,700 
in 1972 to 415,500 in 1990 . A total of 66,000 female workers entered the labor force during this period. Labor has acted as the engine of growth (World Bank, 1992a). Further increases in output must, perforce, come from improved productivity. As a result of its success in attaining full employment and as a consequence increasing labor costs, Mauritius can no longer compete internationally on the basis of low cost.

In terms of productivity improvement, Mauritius has three options. First, in the case of knitwear, for example, the adoption of improved technology can bring about an increase in productivity. The replacement "of hand-operated machines by numerically-controlled automatic machines will not only result in higher output per hour ... [but also] allow more complex patterns and higher flexibility since they can be directly connected with CAD-systems" (German Development Institute, 1992). Only a few of the largest companies have installed automatic machines, and some form of government assistance will be necessary to encourage medium-size and small firms to follow. Productivity could also be improved by better management techniques, reorganization on the plant floor, and training programs.

With regard to garments, where there is comparatively less scope for improvements in production technology, value added can be increased by moving into the higher value range of garments. Entry into the higher market segment, however, requires a more aggressive marketing strategy than is currently in practice. A survey of Mauritius garment firms undertaken recently indicates that "the share of total sales to the three most important customers varies between 50 and 80 percent for the majority of the enterprises visited" (German Development Institute, 1992). It appears that the tendency is for Mauritian entrepreneurs to cultivate a few customers with whom they can develop long-term contracts. Local entrepreneurs are reluctant to venture into arrangements with new customers. In order to stay in business, local garment manufacturers will need to move away from traditional customers, to develop the capacity to create original designs, and to respond swiftly to changes in fashions in the clients' markets.

Finally, in order to compete effectively with countries such as Turkey and Tunisia which are newly emerging garment producers, as well as with Eastern Europe which has a long tradition in garment manufacture, the government has to adopt a macroeconomic policy stance which continues to be conducive to export manufacturing that is essentially a "buyers' market." The international and local conditions are constantly changing; competition from other suppliers is intense; and the fashion industry is highly 
volatile. Nevertheless, Mauritius must be able to capture orders due to its high-quality product, on-time delivery, original design capacity, and regular contacts with the markets. In order to cope with these conditions a whole program of improvements needs to be undertaken. The port and the local transport system should be revamped and made more efficient. The banking and financial sector needs to be reorganized to enable small and medium-size firms to have access to credit for increasing productivity and other improvements, and finally the education and training system should be geared to providing the skills needed by industry. There is no place in "corporate Mauritius" for the inefficient firm or the entrepreneur who only wishes to hold on to existing markets. Any attempt to perpetuate inefficiency, for example, with the importation of cheap labor, will prove to be disastrous in the long run and will run counter to the strategy of moving upmarket. The same philosophy of excellence is required if Mauritius is to move into new areas such as electronics and computer data entry, in which it has made a feeble attempt. 



\title{
Chapter 9
}

\section{Sustainable Tourism}

\author{
M. Sen Ramsamy
}

You gather the idea that Mauritius was made first and then Heaven, and that Heaven was copied after Mauritius. Mark Twain

\section{$9.1 \quad$ Introduction}

Tourism originates in an art of living which reflects economic well-being and high social status. Over the years, tourism has developed a solid reputation as one of the world's major economic activities with a high potential for further growth. The challenges of the late 20th century for the industry are twofold: to ensure sustainable growth and to adopt a development strategy that will be economically viable, socially acceptable, and environmentally sound in the long term.

Admittedly, however, several cases of environmental damage have taken place in various parts of the world as a result of tourism and tourism-related development. Examples of these are the concrete developments along the Costa Brava; in Acapulco; along the Adriatic coast north of Dubrovnik; and in Cancun, Mexico. These cases are unfortunately the direct consequences of an unplanned development strategy and very often a mismanagement of resources. Tourism in the Republic of Mauritius is essentially dependent 
on natural resources. Conscious of the necessity for a judicious utilization of the limited resources available, the government of Mauritius has established a policy for selective tourism development. The underlying principle of this policy is to maximize foreign exchange earnings while preserving the country's natural charm and elegance.

The quote from Mark Twain at the beginning of this chapter clearly illustrates the quality of Mauritius as it was perceived by travelers in the 1800s. Today, with its population of 1.1 million inhabitants and its rapid evolution from an agricultural economy to an industrialized one, Mauritius is currently propelling its way to become a leading economic force in the Indian Ocean region. As a result of the recent accelerated pace of development, the natural panorama of the country has obviously undergone important changes.

\subsection{History}

Tourism in Mauritius began in 1952 with the creation, by the Mauritius Hotels, of the first hotel establishment (see Figure 9.1). It was called the Park Hotel and was situated at Curepipe on the central plateau of the island. The choice of the site, which is the wettest area of Mauritius, gives an indication that promoting tourism was not the prime factor for the development of the industry at that time. In fact, the Park Hotel served mainly as accommodations for the crews of the few airlines which started to include Mauritius in their flight schedules.

The first beach hotel was constructed by the Mauritius Hotels at Le Morne in the southwest of the country in 1954, and consisted of only six bedrooms. That structure did not, however, attract many foreign visitors except for a few tourists from nearby Réunion Island and Madagascar. With the opening, by the same group, of another beach hotel at Le Chaland near the airport in 1961, the in-flow of tourists and airline crews became more regular. The late 1960s witnessed an uninterrupted growth in hotel development, especially in the wake of the independence celebrations in 1968.

Tourism as an economic activity in Mauritius started around 1971, when a 90-room hotel was built - again by the Mauritius Hotels - at Trou aux Biches in the northwest of the island. Following the boom of the early 1970 s, investment in self-contained bungalow projects was accelerated by other business groups. Association with foreign companies started with the setting up of the Club Med and the St. Geran Hotel by the Southern Sun 


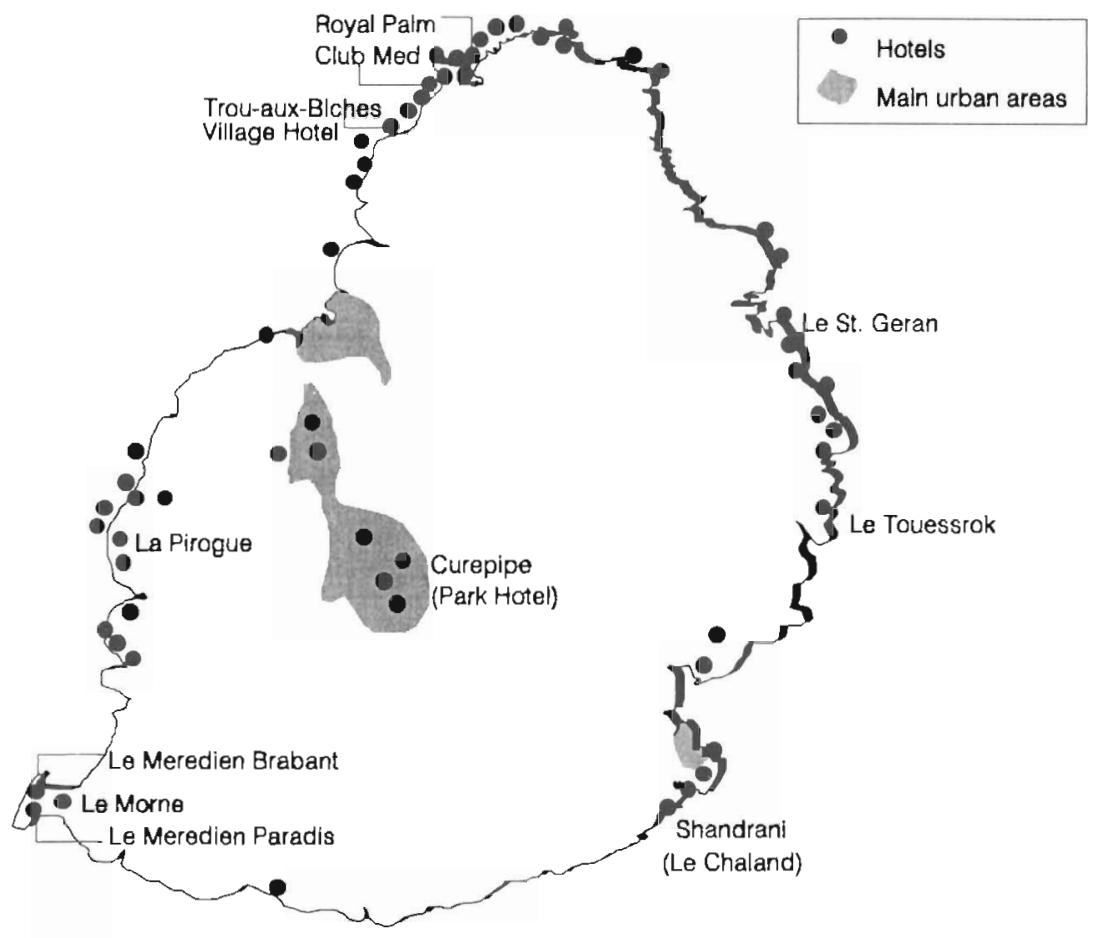

Figure 9.1. Location of main tourist zones and major hotels.

Hotels. The Mauritius Hotels (today Beachcomber Lid.), the Southern Sun (now Sun Resorts Ltd.), and the Club Med triggered an increase in tourism in Mauritius.

The man who, in a way, laid the foundation of tourism in Mauritius and whose pioneering works had markedly elevated the country as a tourist destination par excellence on the international front was Mr. Amédée Maingard de la Ville-es-Offrans (1918-1981). His dedication has recently been immortalized by the creation of a foundation that bears his name. Besides having an impact on hotel development and tour operations in Mauritius, Mr. Amédée Maingard was one of the founders of the national carrier, Air Mauritius, in 1967.

Today, Beachcomber Ltd. has five major resort hotel complexes on the island: Les Meridiens Brabant and Paradis at Le Morne; Shandrani (formerly Le Chaland); Trou-aux-Biches Village Hotel; Royal Palm Hotel; and the recently acquired Le Mauricia Hotel (ex-Pullman). The Royal Palm Hotel 
represents a master piece in the art of architectural creations. For its part, Sun Resorts Ltd. has created three famous deluxe resort hotels: St. Geran Hotel in the east, Le Touessrok Hotel in the southeast, and La Pirogue Hotel in the west. Today Mauritius has a total capacity of approximately 5,000 rooms in 80 hotel establishments scattered in the various tourist zones of the island.

To shake off the severe recession that gripped the island's economy during the late 1970 s and early 1980 s, the then newly formed coalition government decided to attract a larger volume of foreign investment in the various sectors of the economy. Beginning in 1982, tourism, like the manufacturing sector, was also called upon to play a more significant role in the economic takeoff of Mauritius. The consolidation of the existing markets and the cultivation of new tourist-generating sources were the priorities of the time. This boost in tourism was accompanied by considerable pressure for additional room capacity, which in turn stimulated further development in the hotel sector. The first phase of tourism development in Mauritius was therefore set in motion.

Since 1982, the government has adopted a strategy of offering a package of incentives for hotel development through the grant of the Hotel Development Certificate coupled with the provision of adequate state-financed infrastructure services. As a result, a large inflow of foreign capital contributed to Mauritius's struggle to pull itself out of its dangerous economic stagnation of the late 1970s. The economic "miracle" thus took shape, but at a cost. The mushrooming of large resort hotels along the coast from 1986 started, however, to show signs of decay on the physical environment especially along the coast.

The economic diversification programs adopted at that time had served the government in its endeavor to wipe out the unemployment problem which severely plagued the country. These programs, however, did not take into account the need for sound long-term planning. Proper inter-ministerial coordination at the technical level was also lacking. This resulted in additional strain on the island's natural resources. Since 1988 a restrictive policy has been applied on development in the hotel sector. New hotel projects are discouraged, and approved projects have been frozen until market evolution becomes more promising. The present excess room capacity in Mauritius has had a direct bearing on the average room occupancy rates registered in the hotel industry during the past three years. On the other hand, the 
Table 9.1. Comparative value-added figures, 1991.

\begin{tabular}{llc}
\hline & Billion rupees & \% GDP \\
\hline EPZ & 4.500 & 12.6 \\
Sugar & 3.300 & 9.2 \\
Financial and business services & 2.165 & 6.1 \\
Tourism & 1.180 & 3.3 \\
\hline
\end{tabular}

persistent proliferation of unlicensed bungalows along the coast has fueled the relatively downward trend in hotel occupancy.

In the second phase of the economic development plan, the role of tourism as the third force of the Mauritian economy needs to be clearly demonstrated through the formulation of correct policy measures and development strategy. The implementation of the future action plans of the Ministry of Tourism, in consultation with the various partners of the industry, is determined primarily by considerations of overall economic policy on the basis of long-term benefits to the national economy.

\subsection{Economic Significance of Tourism}

Tourism represents the third pillar of the economic structure: the Export Processing Zone (EPZ) and agriculture are the other two pillars. Statistics published by the CSO show that for 1991 the EPZ generated Rs 12.136 billion; sugar, Rs 5.317 billion; and tourism, Rs 3.875 billion. Value-added figures are given in Table 9.1. Foreign exchange earnings from tourism, as a percentage of total exports of goods and services, increased from 5.9 percent in 1975 to 9.4 percent in 1985 , and to about 14.9 percent in 1990 . The contribution of tourism to GDP in 1991 was estimated at 3.3 percent. This percentage is, however, an underestimation of actual contribution to GDP.

Tourism in Mauritius comprises four main activities: hotels and restaurants; inland tour services, including boat excursion trips; international air travel; and handicrafts and shopping facilities. The first two activities have a direct bearing on tourism, while the last two have only an indirect link depending on their level of involvement with tourists. Economists find the economic measurements of the indirect services and their respective contributions to the GDP a rather difficult task, as national accounting conventions do not draw an accounting boundary around the tourism sector as a whole. However, based on the tourist expenditure surveys carried out every 
Table 9.2. Employment ${ }^{a}$ in the tourist industry, 1987-1991.

\begin{tabular}{|c|c|c|c|c|c|c|}
\hline \multirow[b]{2}{*}{ Industrial group } & \multicolumn{2}{|l|}{1987} & \multicolumn{2}{|l|}{1989} & \multicolumn{2}{|l|}{1991} \\
\hline & March & Sept. & March & Sept. & March & Sept. \\
\hline Restaurants & 674 & 725 & 949 & 1,019 & 919 & 763 \\
\hline Hotels & 3,453 & 3,670 & 4,379 & 4,600 & 6,422 & 6,860 \\
\hline Travel \& tourism & 1,428 & 1,732 & 1,877 & 2,065 & 2,759 & 2,765 \\
\hline Total & 5,555 & 6,127 & 7,205 & 7,684 & 10,100 & 10,388 \\
\hline
\end{tabular}

${ }^{a}$ Large establishments only (i.e., employing 10 or more).

Source: CSO, 1991.

two years by the Mauritius Government Tourist Office, expert analysis concludes that it would seem reasonable to increase tourism's contribution to GDP by a factor of 1.5 to compensate for other expenditure, thus giving a total approximate contribution of 4.8 percent to GDP.

\subsection{Employment}

Tourism operations create three categories of employment: direct, indirect, and induced. Direct employment in tourism consists of jobs carried out in direct link with the tourism sector, such as hotel staff, tour operators, and guides. Indirect employment relates to those employed in other activities used as support services to tourism, while also catering to local needs. This category includes taxi drivers, bankers, and food producers. Induced employment concerns those persons engaged in activities remunerated by persons classified in the above two categories, and hence having no relationship with tourism directly. The last type of employment, however, goes beyond the scope of this chapter.

The official statistics on employment in tourism activities only take into account the classification of direct employment. Moreover, figures for tourism establishments with fewer than 10 employees are not computed. Table 9.2 provides an indication of the employment configuration in the tourism industry from 1987 to 1991.

The direct employment figures shown in Table 9.2 provide only an incomplete picture of employment in the tourism sector. Taking into consideration those tourist establishments employing fewer than 10 persons together with employment in nonregistered commercial activities, a fair estimate of direct employment in the tourism sector would be 13,760. Indirect employment is estimated at twice the number of direct jobs created, i.e., 
approximately 27,520 . Consequently, total direct and indirect employment in tourism would be equivalent to approximately 8.8 percent of a working population of 470,000 .

\subsection{Tourism Development Pattern}

\subsubsection{Policy and strategy}

The space limitation of Mauritius, along with the fragile sociocultural fabric of this pluri-ethnic society, warrants a rational approach to tourism development on the basis of long-term vision and an application of sound planning techniques. Consequently, the upmarket image of the destination is strongly supported by policy measures and development strategies tailored to ensure sustainable growth.

The marketing strategy of the Ministry of Tourism, implemented by the Mauritius Government Tourist Office, is to target the high-spending segment of the long-haul affluent markets to help maximize foreign exchange earnings. The distaste for mass tourism is emphasized through the prohibition of charter flights to service the island. The consolidation of the existing market sources constitutes a major task. Prudent penetration of new markets like Japan, Australia, South Africa, India, and Scandinavia is being undertaken to diversify the base of the island's tourist-generating sources. Market research and evaluation are therefore essential to be able to carry out fruitful operations on the highly competitive international market. The marketing office of the Ministry of Tourism has been promoting these potential markets for years to maintain a competitive edge with other holiday destinations offering similar attractions.

To offset the negative effects of urbanization in tourist zones and the resultant change in the coastal topography, the Ministry of Tourism has imposed (besides a freeze in the hotel sector due to excess room capacity) a series of regulatory measures with a view to preserving the scenic landscape of these zones. Such measures include:

- A ban on high-rise complexes - the maximum height of buildings should be restricted to one floor or to the height of a palm tree.

- Hotel projects now frozen should not exceed two hundred rooms.

- Strict compliance must be made with all sanitary regulations.

- Architectural designs must be appropriate for characteristics of the zone.

- Marine environment must be carefully preserved. 
- Plot coverage ratio must be maintained within 40 percent.

- Sufficient space must be provided for proper landscaping.

- Buildings must be set back from roads and/or the high water mark.

In addition, the quality of service offered to visitors - for which Mauritius is world famous - should be provided by a well-trained staff. An increase in rooms has currently resulted in a shortage of trained personnel in the hotel sector. Staff poaching has consequently become more or less common practice which requires immediate remedial measures. Besides government-funded training courses through the Industrial and Vocational Training Board, in-house training courses are highly encouraged for the hotel sector. The launching of a certificate course in travel and tourism also forms part of the government's strategy to improve the quality of service at all levels of tourism operations in Mauritius (airlines, tour operators, guides, and travel agents).

\subsubsection{Air access policy}

Tourism development in Mauritius is closely linked with international air travel. The air communication network of Mauritius is predominantly controlled by the national carrier Air Mauritius. Other scheduled international air services are also provided by Air France, British Airways, South African Airways, Singapore Airlines, among others. Most major cities of the world are connected through regular scheduled flights with stop-overs or nonstop services, especially to and from Europe. A diversification of the route network is necessary in the light of major developments taking place on the international front. Obtaining landing rights for Air Mauritius in Australia, after years of negotiations, has been a step in this direction.

On the other hand, the government's policy for selective tourism development dictates an extremely cautious approach to charter flight operations. In an attempt to ward off the risk of opening up the destination to mass tourism, charter flights are not allowed to service the country's air route. The operation of charter services to and from Réunion Island, a French territory close to Mauritius, by charter companies has prompted a large flow of visitors to Mauritius via that destination at cheaper rates. Island-hopping from Réunion Island therefore constitutes a matter of concern for the whole Indian Ocean area.

In spite of the constraints discussed above, government policy pertaining to air access remains essentially based on the consolidation of existing routes and on flexibility and reciprocity. 
Table 9.3. Tourist arrivals by country of residence, 1981-1991.

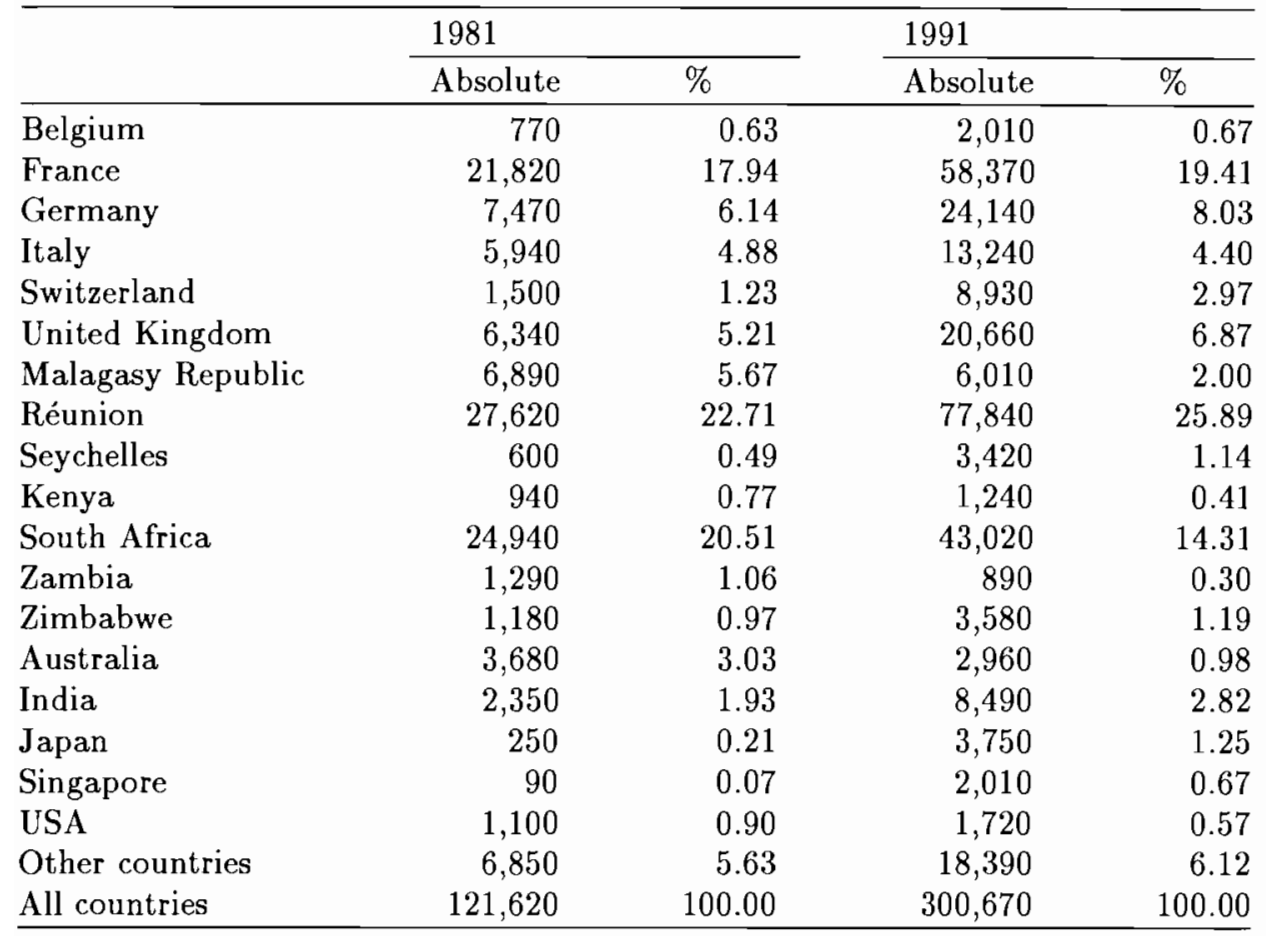

\subsubsection{Marketing}

In line with the stated policy to tap upscale clientele, the marketing strategy of the government is therefore geared toward the long-haul affluent markets. Besides its office in London, the Mauritius Government Tourist Office has established branches in various traditional markets such as France, Germany, Italy, Switzerland, the USA, Singapore, and, until recently, Japan. The participation of Mauritius in world tourism fairs and the launching of regular promotional campaigns, in collaboration with the private sector, have so far yielded quite positive results for the industry.

The fruit of the market cultivation is normally appreciated through the influx of well-off consumers. In terms of tourist arrival figures, France remains the leading tourist-supply source from long-haul destinations followed by Germany, the United Kingdom, Italy, and Switzerland (Table 9.3). On the medium-haul destination, the Republic of South Africa constitutes a fair percentage of total tourist arrival figures. The opening of South Africa to the 
external world represents a potential avenue for new market penetration by many countries. Mauritius is geographically well placed to take advantage of that evolution.

\subsubsection{Tourist zones}

Mauritius is approximately $1,860 \mathrm{~km}^{2}$ with 1.1 million inhabitants and comprises three main tourist zones. The physical development of these zones is subject to restrictive policy measures to discourage possible abuse of the social and environmental structures. The three zones are:

- The northern tourist zone, a vast expanse of coastal area from Balaclava to Grand Gaube.

- The eastern tourist zone, a coastal stretch from Roches Noires to Trou d'Eau Douce.

- The southwestern tourist zone, a coastal line stretching from Flic-en-Flac to Le Morne.

Increasing development pressure on the physical structure of the tourist zones warrants the establishment of a strategic planning system for more rational land use, bearing in mind sensitivity to the protection of the surrounding seaboard. A study of the northern tourist zone by the Physical Land Development Plan will help trace the appropriate line of action for proper land zoning and utilization. The northern tourist zone covers approximately $20 \mathrm{~km}$ of coastline and consists of 26 beach hotels with a total of 1,891 rooms. An estimate of 830 rooms are also available to visitors in this area in the form of guest houses, flats, and bungalows.

The eastern tourist zone has $39 \mathrm{~km}$ of coastline and approximately 1,290 rooms. The room configuration of this zone is expected to undergo changes in the coming years after the completion of new hotel projects which have been frozen for the time being.

The southwestern zone stretches over $37 \mathrm{~km}$ and comprises 16 beach hotels with 1,036 rooms. An addition of five hotel complexes, also placed in obeyance, will further extend room capacity when restrictions are relaxed.

\subsubsection{Rodrigues}

The island of Rodrigues, which is the tenth district of Mauritius, has recently witnessed an accelerated pace of tourism development with the opening of its 
first deluxe hotel at Pointe Coton. It is worth emphasizing here that tourism development in Rodrigues should not follow the Mauritius tourism development model. The island of Rodrigues must, by all means, complement the Mauritian tourism product by creating facilities that bring in positive values to the tourism circuit in general. Rodrigues should also be encouraged to preserve its rustic style and charm.

\subsubsection{Tourist attractions}

Mauritius is promoted and exclusively perceived as an upmarket tourist destination which attracts visitors with a high-spending pattern from the traditional tourist-generating markets, principally Europe. As an island destination, Mauritius is limited in terms of space and natural resources. The main attractions of the island consist, obviously, of the white sandy beaches, the glittering seascapes, and the warm tropical sun of the Southern Hemisphere. These attractions are further embellished with a wide spectrum of related services such as yachting, big game fishing, scuba diving, windsurfing, parasailing, and undersea walking.

Because of these attractions and facilities, the beach represents an important share in the development of tourism in Mauritius. Out of $321.5 \mathrm{~km}$ of coastline, 9 percent has been allocated for hotel development; 16 percent, for villas; and 11 percent, for public beaches. The rest of the coastline is either under vegetation or simply inaccessible. Beach availability therefore constitutes a rare resource to be exploited in a judicious and well-planned manner.

In an attempt to alleviate the pressure resulting from a concentration of visitors along the coast, diversification of tourism has been encouraged through the creation of tourism-related facilities and attractions that are located inland. These attractions should, however, highlight the rich sociocultural texture of the Mauritian society, its historical background, its culinary art, its rhythmic music (called the sega), and, above all, the legendary hospitality and warmth of this cosmopolitan nation.

Most of the existing inland attractions are environmentally oriented. The Pamplemousses Garden in the northern part of the island stands out as a rare botanical sanctuary. The Casela Bird Park, the Le Val Nature Park, and the Domaine du Chasseur are only a few examples of inland attractions created in line with the government's policy for a diversification of tourism. These parks provide a boost to eco-tourism. 
Another recently opened major tourist attraction is the Domaine Les Pailles near the capital city of Port Louis. Conforming with the new policy of development of tourism-related projects that are sensitive to the environment, the promoter of the Domaine has brought about a sort of revolution in the art of creation that deserves special mention. The product comprises two high-class restaurants built on a vast portion of land cradled in a valley, where safaris and tours on horse-driven carriages constitute the principal attractions. Besides being an ideal venue for leisure, the Domaine Les Pailles provides a rare opportunity for a thrilling journey into the past. The architectural structures of the past have been restored in minute detail.

For its part, the Mauritian hotels, most of which are situated on the seafront, ensure maximum comfort in luxurious settings. Altogether, the facilities provided further enhance the intimate charm and elegance of Mauritius. Statistics on the hotels in Mauritius are given in Tables 9.4 to 9.6.

\subsection{Proliferation of Unlicensed Bungalows}

The restrictive policy on hotel development, in favor of tourism-related projects, was designed to provide more space to tourism professionals. This policy has been disturbed slightly by the proliferation of unlicensed bungalows in the coastal zones, to the detriment of hotel establishments. The availability of rooms at cheaper rates in the informal accommodation sector is reflected in the relatively downward trend in room occupancy rates in recent years.

Besides the 5,000 rooms available in the hotel sector, the present capacity of the nonregistered bungalows is approximately 2,000 . In an attempt to curb the ascending trend of tourist bungalow development such accommodation units must be registered. This exercise will enable the government to keep records of the economic activities carried out in the informal sector, while reaping returns from taxes. However, in line with the policy to increase upmarket tourism, standards will need to be established and enforced for all licensed accommodations.

If the performance of the large hotels can be termed as satisfactory, the slow rate of growth registered by the new entrants in the hotel sector has prompted considerable discounting, which inevitably means a squeeze on profit margins. This situation could be reversed should these new hotel properties initiate new forms of overseas marketing and promotional activities to boost demand. Simultaneously, investment in training is a sine qua 

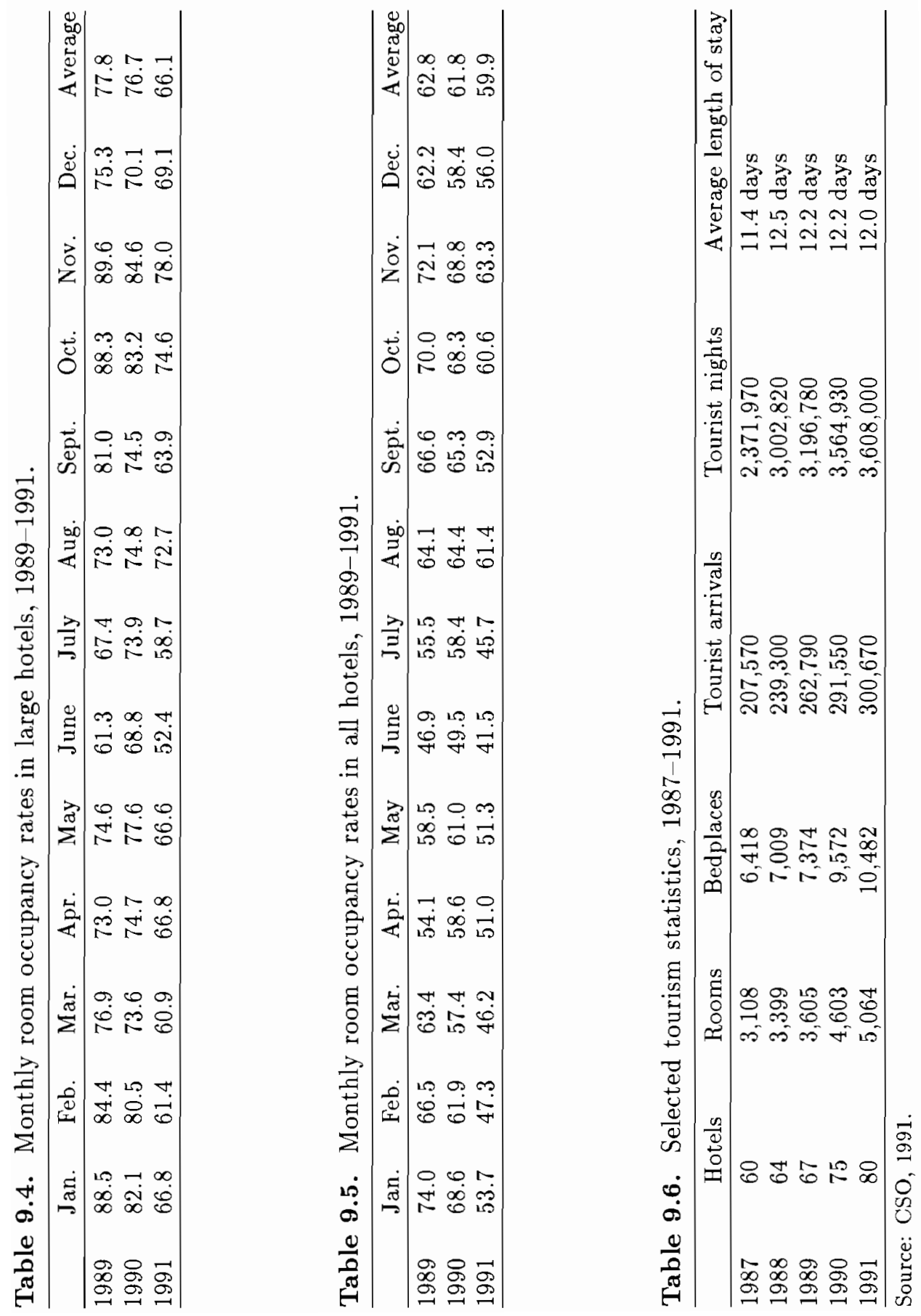
non for survival in the industry as the success of tourism depends largely on the quality of service offered.

\subsection{Social Impact of Tourism}

Mauritius, also known as the United Nations in miniature, contains all the ingredients for a good social impact assessment. A recent survey carried out by an expert consultancy firm based in the UK, Cleverdon Steer, has revealed that Mauritian attitudes toward tourists are quite favorable. However, opinions tend to differ on the planning model adopted for the development of the industry, especially with regard to hotel development near the beach.

The majority of the local population ( 69.5 percent) is favorable to the physical presence of foreigners in the country. This behavior is still more pronounced when Mauritians strongly support the idea of more interaction between visitors and themselves. There is a general belief that tourism contributes to a large extent to the national economy (70.1 percent); nevertheless, 32.3 percent perceive tourists as disease vectors. Concerns about the relative scarcity of some food items due to tourist consumption (23.9 percent) and crowded beaches (7.9 percent) have also been expressed. The provision of adequate amenities and facilities on public beaches for the general public by the local authorities may, however, modify the percentage for the beach concern evaluated above. To encourage state investment in the creation of leisure amenities, public opinion must become aware of the need to maintain hygienic conditions on the beach and for proper utilization of these facilities.

\subsection{Sewage Disposal in Tourist Zones}

The well-being of the economy in the recent years has resulted in a greater volume of investments by the local population in residential and commercial projects, and an intensification of activities in the tourist zones. Consequently, specific environmental impact control has been exercised in an attempt to mitigate any eventual negative side effects of such developments. Several control mechanisms have been engineered to keep environmental pollution at a minimum. For sewage disposal, the following conditions are imposed prior to granting a Development Permit by the local authorities, and after consultation with the relevant government bodies: 
- The installation of a septic tank followed by an absorption pit for private residential bungalows.

- The installation of a septic tank together with absorption pits and a kitchen grease trap for hotels with fewer than 75 rooms, restaurants, and similar establishments.

- The compulsory installation of a treatment plant for hotels having more than 75 rooms.

The sanitary regulations in force in Mauritius compel hotel operators to discharge the treated effluent into the hinterland to avoid beach contamination. In practice, however, for residential units and commercial complexes the system is found to contain a few deficiencies. Recent on-site inspections have revealed that the operations of sewage-treatment plants by the hotels do not give satisfactory results, as observed from the poor quality of the treated effluent. The lack of proper training facilities for maintenance personnel also contributes to the poor performance of these plants. Consequently, as often observed, the re-use of the treated effluent for irrigation purposes is often questioned.

\subsection{Lagoon Pollution}

Polluted lagoons can cause serious harm to tourism if remedial actions are not taken. A proper system of monitoring and control must be established to prevent severe damage. With the intensification of commercial activities inland, and the rapid urbanization effects of tourism along the coast, a general deterioration of the lagoons is bound to occur, especially near the developing areas.

The activities of motor boats and the lack of proper control of oil spilling in the lagoons have resulted in visible damage to the marine ecosystem. The contamination of seawater may also result from inland industrial effluent discharged in rivers that generally also carry relatively large volumes of toxic components. Fortunately though, such damage has not yet attained any alarming proportions. Utmost caution is, however, warranted.

To reduce the damage caused to the marine ecosystem to an acceptable level, the extraction of corals and shells from the waters is forbidden. This prohibition, however, should be accompanied by more rigid control on the sale of imported shells, if not their prohibition. 


\subsection{Conclusions}

The prerequisites for the orderly and successful development of tourism are proper planning and monitoring. Strategic planning enables objectives and guidelines to be established as a basis for policy formulation, while master planning translates these aims into a detailed action framework. Planning of any type is, however, not a goal in itself. The monitoring of development plans in coordination with the relevant bodies is an essential tool in the implementation and polishing of programs. Provision for adjustments in these programs is necessary to attain the objectives in the constantly evolving market forces.

Taking into consideration the nature of tourism as an activity which is sensitive to social pressures and psychological factors and changes in preferences and economic conditions, coupled with the changing profile of the tourists themselves, planners in tourism should make room for flexibility in their approach to be able to adjust development strategies according to market forces and trends.

The raw material used for tourism development comprises basically natural and/or manufactured attractions, a mild climate, social tranquility, and political stability. Fortunately, Mauritius is endowed with all the ingredients necessary for sustainable growth of its tourism industry. Any intensification of activities in other sectors of the economy could, however, result in a partial or even a complete exhaustion of some of these factors, particularly the more vulnerable ones such as natural resources. The success of tourism very often gives way to temptations for further exploitation of resources which can, in the long term, prove detrimental to the fundamental interests of tourism itself. Tourism is therefore condemned to abide strictly by the rules of nature conservation for its own survival.

The success story of tourism in Mauritius has been confirmed by the relatively satisfactory performance of the sector in adverse conditions marked by international conflicts such as the Gulf War. The task of intelligently managing this success now constitutes a challenge for both the government and the private sector. To meet this challenge certain requirements must be met: acceptance of the policy and development strategies adopted, a cautious and realistic approach to planning, and discipline in the execution of works. 


\section{Chapter 10}

\section{Energy}

Jaishree Beedasy and Revin Panray Beeharry

\subsection{Introduction}

At any level of economic development, energy is an input to the production and consumption systems. As a country's economy changes, the energy mix required to meet its total energy needs changes as well. To support economic development, to expand food production, and to halt environmental degradation, developing countries need to review their energy supply/demand patterns. It is of prime importance, therefore, to obtain an insight into the country's energy flow. For this purpose, analyses of the past and present production and consumption trends of commercial and noncommercial energy and the energy intensities of the various economic sectors of Mauritius are undertaken in this chapter. An assessment of potential energy supply alternatives is also presented.

\subsection{History}

In the early days, the Mauritian population met its energy needs from local resources; it depended on fuelwood and charcoal for cooking. Most of the fuelwood was obtained from the forests in the proximity of the settlements. The population density was low and fuelwood was in plentiful supply. Over the course of time, in addition to cutting the wood for fuel, scrub forests were being converted for agricultural and residential purposes. Consequently, 
fuelwood became steadily less available. The pressure on the forests, to some extent, was alleviated by the utilization of imported fuel and kerosene.

Transportation in Mauritius was limited to vehicles and carts drawn by horses and oxen. After a period of economic and population growth in the mid-19th century, two changes took place in the local transport system. Some sugar factories near the coast began to use small boats to transport sugar to the harbor. By 1862, the rapidly growing commerce and sugar industry led to the introduction of trains. Railways were important for moving freight and passenger traffic until around 1920. From the 1920s until just after World War II, the railways faced increasing competition from road transport (buses and lorries) and became unprofitable. In 1962, during a period of rapid increase in the price costs of coal and an increase in the scarcity of firewood, the decision to close the railway system was taken.

Industrial production, until quite recently, was limited to sugar-cane milling. Originally, cane was crushed using animal power, and extracted juice was evaporated in vats over open fires. The cane pulp was sun dried and used as fuel, but it had to be supplemented by firewood. The technology for sugar manufacturing developed significantly through the advent of steam for motive power generation and for process heating. By 1822, the vertical mills operated by oxen were replaced by mills generated by steam turbines. The evaporation station, however, was a big consumer of energy. The energy needs of factories were met only partly by burning the dried cane pulp-bagasse and had to be supplemented by firewood. There was a drastic change in the situation with the application of Rillieux's proposals of multiple utilization of steam in multi-effect evaporators. This development permitted the sugar industry to achieve energy self-sufficiency by burning its own bagasse.

As the country developed, the energy requirements increased and there was a change in demand for fuel types. Fossil fuels began to be imported to gradually substitute for the scarce and less efficient local fuel sources (except for the manufacture of raw sugar).

\subsection{Energy Sources}

Mauritius does not have any proven fossil fuel reserves. The country's local energy sources meet only a limited part of the energy demand. Mauritius depends on imported fossil fuel for more than 80 percent of its needs (excluding sugar milling). The total primary energy consumption in 1990 was around 


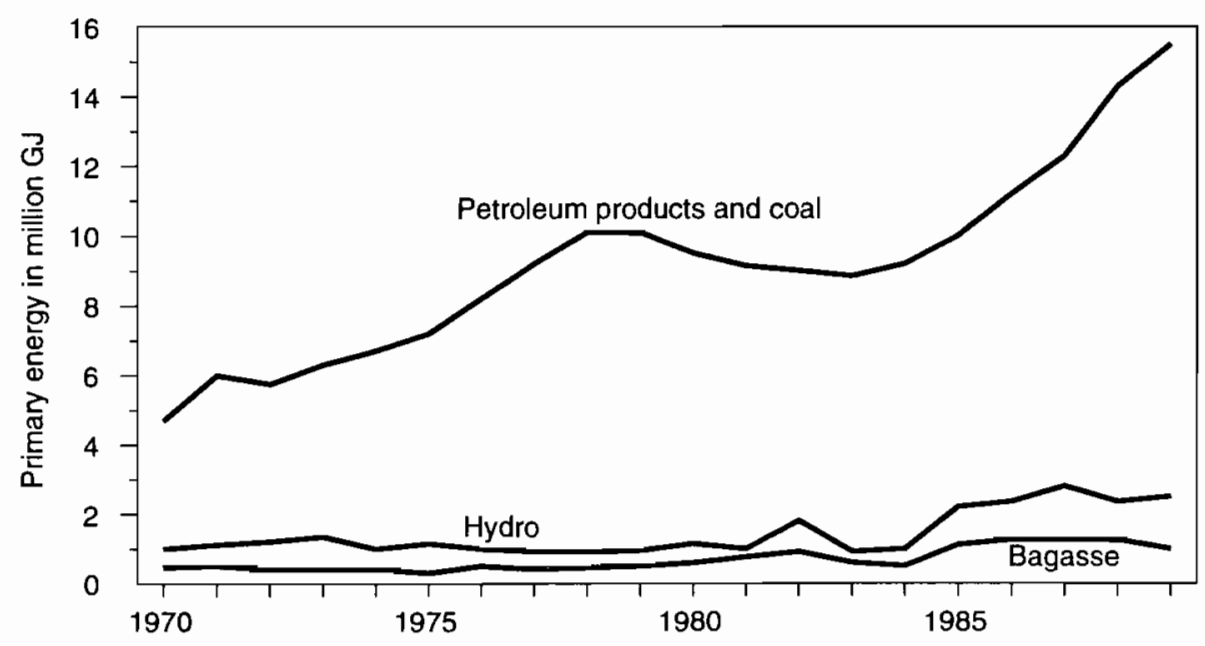

Figure 10.1. Primary energy consumption in Mauritius, 1970-1989, excluding energy for sugar manufacturing and fuelwood. Source: Baguant, 1989 .

600,000 metric tons of coal equivalent (TCE). This has more than tripled since 1970, when it was only 163,000 TCE. Imported energy sources are used for various activities. Diesel oil is used mainly by the heavy transportation sector, and for starting up some electric generators. The light transportation area uses gasoline. Kerosene and liquified petroleum gas (LPG) are used for cooking by the residential and commercial sectors. Some industries use imported coal to generate steam, and one sugar factory uses imported coal in its dual furnace during intercrop for electricity generation.

The energy sources available locally are woody biomass, bagasse, and water. Woody biomass caters mainly to the residential sector for cooking purposes; bagasse provides energy for running sugar factories and produces excess electricity which is sold to other sectors; hydropower is used for the production of electricity. Energy consumption by source type is shown in Figure 10.1.

Local primary energy sources include hydro and bagasse, which are used for electricity production for other sectors. There are no reasonably accurate statistics on noncommercial energy (wood and charcoal) for the past years. It is therefore difficult to quantify the growth in energy demand due to actual growth from that due to substitution of woody biomass for fossil fuel 
Table 10.1. Total energy consumption, in percent, in 1989.

\begin{tabular}{lccc}
\hline & $\begin{array}{l}\text { Excl. } \\
\text { noncommercial } \\
\text { energy }\end{array}$ & $\begin{array}{l}\text { Incl. } \\
\text { woody } \\
\text { biomass }^{a}\end{array}$ & $\begin{array}{l}\text { Incl. woody } \\
\text { biomass and } \\
\text { noncommercial } \\
\text { bagasse }\end{array}$ \\
\hline Imprgy sources & 84.5 & 77.5 & 43.2 \\
Bagasse (commercial) & 7.3 & 6.7 & 3.7 \\
Hydro & 8.2 & 7.7 & 4.2 \\
Woody biomass & & 7.1 & 3.9 \\
Bagasse (noncommercial) & & & 45.0 \\
Total & 100.0 & 100.0 & 100.0 \\
\hline
\end{tabular}

${ }^{a}$ Assuming 60 percent of residential consumption.

and/or electricity. Bagasse which is used as fuel in the sugar industry has also not been accounted for, as it is within the boundary of this industry. It is interesting to note that if woody biomass (assuming it is 60 percent of total residential energy consumption as estimated in a survey carried out by the University of Mauritius) is taken into consideration, total local energy is more than 20 percent (see Table 10.1) of the total energy consumed, as compared to 15 percent if woody biomass is excluded. It is 57 percent if bagasse used for sugar manufacture is taken into account.

\subsection{End Users}

At any level of economic development, energy is an input to the production and consumption systems. The mix of activities and the level of private income change as a country develops; these items are also changed by deliberate planning. The changes in the energy use can be decomposed into a set of causal relationship or effects. Minor shifts in the mix of activities may therefore result in significant changes in total demand and demand for specific fuels. To review the development over time of energy use by the Mauritian economy a disaggregated microeconomic approach is adopted. Two main uses of energy are distinguished: one for consumption purposes, i.e., directly consumed by households; the other for production purposes in the agricultural, industrial, and services sectors. Figure 10.2 shows the energy consumption by economic sectors. They all follow similar consumption trends. From 1970 to 1979 there is a rise. With the energy crisis and 


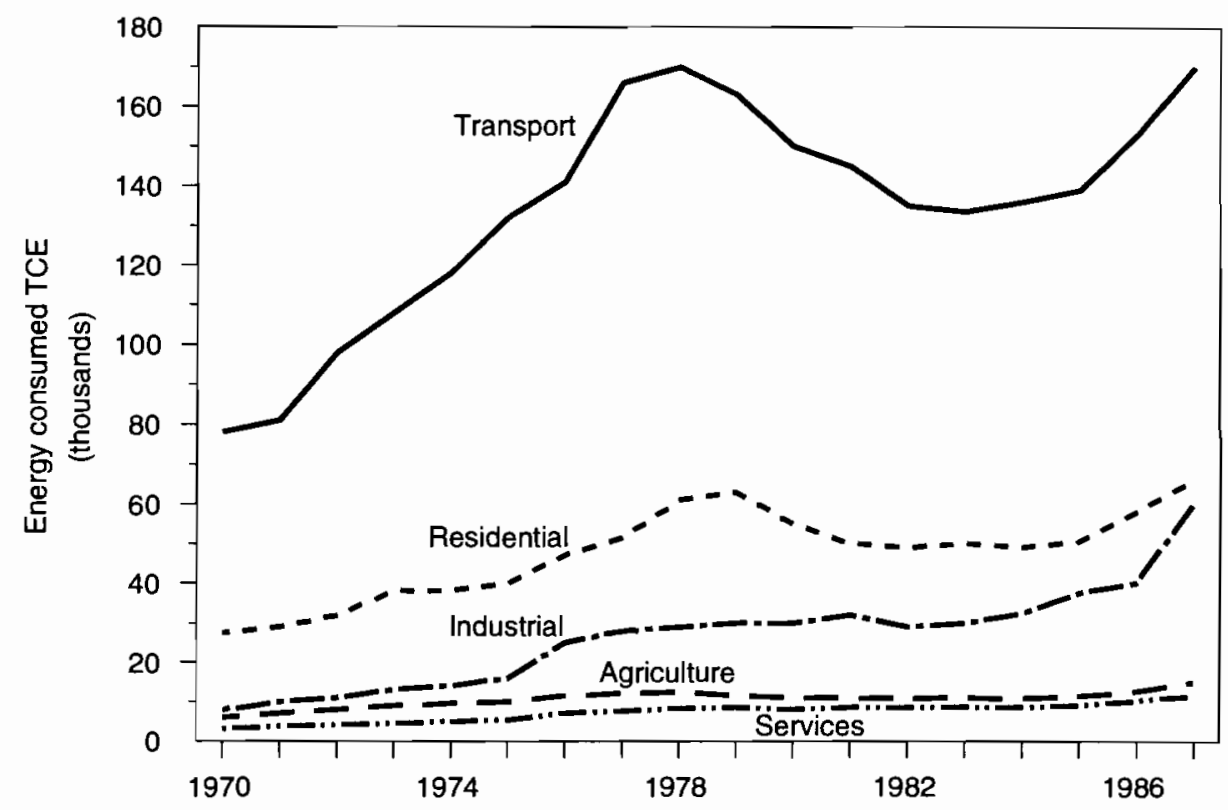

Figure 10.2. Energy consumption by economic sectors in Mauritius.

recession in the $1980 \mathrm{~s}$, a decline in energy use is observed. Since the mid1980s there has been a constant rise. An analysis by sector is carried out in Section 10.5.

Energy is essential to economic growth and development, but the linkages between energy and development are complex and still not completely understood. According to Proops (1984), a consensus seems to be emerging concerning the relationship between a country's energy use and its national product. Therefore, if the energy used/output is plotted over time, many developed countries exhibit a convex curve, while developing countries display a rising trend. When an economy reaches the postindustrial stage, an increasing proportion of activities falls in the services sector, which is less energy intensive. Therefore, there is a general belief that continued economic growth of a country will entail less energy per unit of additional output. The per capita consumption of commercial energy is $0.5 \mathrm{TCE}$ for the developing world, while it is around $6 \mathrm{TCE}$ for the developed world. Mauritius, which is still developing, has a per capita consumption of energy of 0.6 TCE. 


\subsection{Sectoral Energy Intensity}

Two factors affect total energy consumption: the relative growth of sectors, such as transport versus services; and the energy intensity within each sector.

\subsubsection{Transportation}

The transportation sector has a special place in the energy demand. It is by far the largest consumer of gasoline and diesel, the mix being in the ratio of 40 to 60 . It accounted for 49 percent of primary energy consumption in 1970 and 39 percent in 1989. This is the most energy-intensive sector of the Mauritian economy; its energy intensity (EI) is some $4 \mathrm{~kg}$ coal equivalent (CE) per dollar (Baguant and Manrahhan, 1990, Table 2-I). The energy intensity increased for a few years after 1970, and has been decreasing since the energy crisis. In Mauritius, personal travel and vehicle ownership has risen with GDP and household income. There is a growing demand for greater personal mobility and movement of goods. As transport is totally dependent on oil, and likely to remain so for some time to come, the sector's share in energy consumption is bound to continue growing in the future, together with the actual oil consumption growing at the rate of almost 15 percent annually. But the growth in transport energy can be met by more efficient vehicles and use of diesel fuel instead of gasoline. There has been a great decrease in EI from $6.4 \mathrm{kgCE}$ per dollar in 1970 to $3.9 \mathrm{kgCE}$ per dollar in 1989. Three factors may be responsible for this decrease:

1. The replacement of inefficient vehicles by new and more efficient ones.

2. The substitution of regular gasoline for premium which is more efficient.

3. The rapidly growing output of "transport and communications" and communications sectors which are not energy intensive.

\subsubsection{Industrial}

The industrial sector referred to here includes all the manufacturing industries of the Export Processing Zone: beverage industries, the textile industries, food processing, and construction. It excludes, however, the sugar factories that use the sugar by-product (bagasse) for their energy requirements. Industry is the second largest energy consumer of all sectors. It depends mainly on electricity ( 35 percent) and fuel oil (46 percent), and to a small extent on LPG (1 percent). Since 1987 it has also depended on coal (18 percent). The EI in industry has increased by a factor of 1.5 since 
1970 , i.e., from 74 to $125 \mathrm{kgCE}$ per $\$ 1,000$. With an expanding industrial sector, the EI has been increasing overall, even though the impact of the oil crises in the mid-1970s and early 1980s caused a decrease at the time. The stagnation and decrease of the EI in the mid-1980s were due to the increase in industrial output by mainly labor, not energy-consuming machines. In that period, unemployment in the country reached alarming proportions and threatened its social and economic well-being. This led the Mauritian government to promote the establishment of new industries to absorb the surplus labor. Since 1987, however, EI has been increasing because several new industries, such as those in the textile sector, have been equipped with coal-fired steam generation plants.

Given quasi-full employment and the scarcity of labor, industries in the future are likely to become more capital intensive. Mechanization, along with a growing EPZ sector, will lead to an increase in energy consumption. The extent of the increase will depend largely on the energy intensity of the new industries. Most of the industries now belong to the textile or manufacturing sectors. Echiburu (1977) made a study of the labor/energy tradeoff for UK industries for the period between 1948 and 1975. Her results for the marginal energy requirements to substitute one man-hour were $1 \mathrm{kWh}$ per man-hour for textile industries; $10 \mathrm{kWh}$ for iron and steel industries; $2 \mathrm{kWh}$ for food, drink, and tobacco industries; and $2 \mathrm{kWh}$ for all manufacturing industries. According to Bheenick and Hanoomanjee (1989), the industrial future of Mauritius lies in the direction of such high-growth, high-technology industries as information, communication, and electronics. The energy requirements of information processing are relatively low; the greatest need of such industries is skilled workers.

\subsubsection{Agricultural}

The agricultural sector is dominated by sugar-cane plantations. The current policy of the government is to promote agricultural diversification by intensifying the growing of sugar cane and releasing land for other food crop cultivation. Energy carriers in this sector are diesel, fuel oil, and electricity. There is a lack of data available for this sector on the quantities of different types of fuels; consequently estimates have been used. The sugar industry is very energy intensive, but - as mentioned above -- self-sufficient in its energy requirements. Bagasse is used for electricity production for the sugar factories and for operating irrigation works during the growing season. Any excess electricity produced by the sugar industry is sold to other sectors. During 
the off-season those sectors provide the electricity for maintenance purposes and for irrigation. Diesel is also used for pumping in water irrigation.

Although one might expect that agriculture is not a very energy-intensive sector, its EI has doubled from around 30 to $60 \mathrm{kgCE}$ per $\$ 1,000$ and now matches the industrial sector. In the early 1970 s it was still labor intensive and not mechanized, but mechanization has gradually increased in this sector. In addition, there are fluctuations in the EI whenever the price and production of sugar change. The trend in energy consumption has been increasing with the introduction of mechanical loaders for the sugar cane, and further use of machines for irrigation, transportation, and land preparation. More intensive mechanization will be required as a result of a scarcity of labor and the policy to intensify sugar production per hectare in order to release land for other crops. This will cause further increases in the EI in the years to come. However, at present, there is much room for efficiency improvements in the use of equipment and vehicles in this sector.

\subsubsection{Commercial and Services}

This sector is made up of private and public services: commercial stores, hotels, restaurants, government buildings, and offices. It is the least energyintensive sector, but there has been an increase in EI between 1970 and 1987 from 14 to $19 \mathrm{kgCE}$ per $\$ 1,000$. This is mainly due to the growth of tourism and improvements in the public infrastructure. The fuels used are electricity ( 90 percent) and LPG (10 percent), the latter being used for cooking in hotels and restaurants.

\subsubsection{Residential}

This sector is different from the above sectors in that it uses energy for consumption purposes and not for production purposes, and therefore cannot be expressed as TCE per dollar. It is the main user of noncommercial energy, fuelwood, and charcoal. Commercial energy consumption time series are readily available. The commercial fuel mix is electricity, kerosene, and LPG in the ratio $57: 41: 2$ in 1970 and $62: 20: 18$ in 1989. The substitution of kerosene is likely to continue with the lowering of tax on LPG in 1986-1987, improved electricity supply over the entire island, and improved standard of living. A significant percentage of household fuel is wood, which is purchased in local markets or gathered. 
Table 10.2. Average residential energy consumption by type of energy carrier units: $\mathrm{MJ} /$ month/household.

\begin{tabular}{lrrrrrr}
\hline Energy carrier & \multicolumn{1}{c}{ Urban } & \multicolumn{1}{c}{$\%$} & \multicolumn{1}{c}{ Rural } & \multicolumn{1}{c}{$\%$} & \multicolumn{1}{c}{ Island } & \multicolumn{1}{c}{$\%$} \\
\hline LPG & 403.79 & 26.04 & 225.31 & 7.66 & 293.42 & 12.17 \\
Kerosene & 314.83 & 20.30 & 400.84 & 13.62 & 368.02 & 15.26 \\
Wood & 421.82 & 27.20 & $2,113.95$ & 71.85 & $1,468.22$ & 60.89 \\
Charcoal & 94.04 & 6.06 & 38.58 & 1.31 & 59.74 & 2.48 \\
Electricity & 316.09 & 20.39 & 163.69 & 5.56 & 221.85 & 9.20 \\
All sources & $1,550.58$ & 100.00 & $2,942.36$ & 100.00 & $2,411.25$ & 100.00 \\
\hline
\end{tabular}

Source: Baguant and Beeharry, 1989.

Table 10.3. Number of households in Mauritius using wood and charcoal.

\begin{tabular}{lccc} 
& Total households & Wood & Charcoal \\
\hline Total & 195,475 & 93,285 & 19,486 \\
Urban & 95,430 & 27,823 & 14,380 \\
Rural & 100,045 & 65,462 & 5,106 \\
\hline
\end{tabular}

Source: Baguant and Beeharry, 1989.

An analysis on total energy consumption can only be carried out through a house-to-house survey. One such survey was carried out by the University of Mauritius in 1988. However, such surveys can only capture a small sample at one point in time. The survey showed that woody biomass made up some 60 percent of the total household energy consumption (see Table 10.2). Urban energy consumption per household is lower than rural consumption because the efficiency of using woody biomass is significantly lower when compared to the other fuels. Table 10.3 shows the number of households still depending on wood and charcoal as cooking fuel. According to the forestry department, the amount of fuelwood removed free of charge is five times the amount sold. In view of the fact that this energy supply is not officially approved, continued supply from these sources cannot be taken for granted. The shortage of woody biomass and the government's policy to preserve forests and protect the environment will foster the shift toward commercial fuels.

\subsection{Environmental Impact}

Until recently, there has been little emphasis on the environmental issues associated with present energy usage - except on the dangers of deforestation. 
There is, nevertheless, a great need to control pollution due to emissions from the combustion of fuels. The use of coal-fired boilers for generating process steam in certain industries is also viewed with concern. The pollutants released are sulfur dioxide, carbon dioxide, and carboniferous particles. Some industries use diesel or oil-fired boilers which emit sulfur dioxide and carbon dioxide. When combustion of any of these fuels is incomplete carbon monoxide is also produced.

The thermal-generating power stations also pollute the air with gases like carbon dioxide and sulfur dioxide. The sugar factories produce fly ash when bagasse is combusted. Depending on the wind speed and direction, the fly ash can be carried quite far from the factories and deposited in residential areas.

A slow deterioration in the quality of environment has been observed in the urban areas and along the main road networks. The recent increase in road traffic, together with the numerous old vehicles on the roads, is responsible for this. Spills of fuel and engine oil deteriorate roads; used oil is discarded into rivers, streams, or drains along the roads. Another source of pollution is the gaseous emission from the exhaust pipes of vehicles, including inorganic lead compounds, unburned fuel, carbon dioxide, carbon monoxide, and nitrogen oxides. Mauritius still uses only leaded petrol with a lead content between 0.57 and 0.67 grams per liter of petrol. The present density of vehicles per kilometer of road is 68 , and it is expected that it will increase to 115 by the year 2000 . If this occurs, the environment will be greatly affected by the presence of lead. The lead content of petrol must be decreased or there must be a decrease in the number of vehicles on the roads. This could be achieved by introducing a mass transit system along the highly congested routes linking the urban areas of the district of Plaines Wilhems to the capital, Port Louis. Another positive step would be the promotion of bicycles. Cycling could become a healthy and "clean" fad in the year 2000 .

It is crucial to inform and educate Mauritians about the dangers of pollution and the ways to curb the deterioration of the environment. This latter aim is not easy to achieve without adequate pollution control legislation. The Ministry of Environment and Quality of Life is responsible for the formulation and implementation of environmental protection and conservation policies and programs. 


\subsection{Local Resources}

The level of commercial energy consumption and production in Mauritius, if examined along the lines of Parikh (1980), is in a phase of development just above the subsistence threshold. It is still on the steeply rising slope of the energy/output curve. For further development and progress, an adequate supply of energy has to be maintained. In view of the pressure of the rapidly developing industrial sector - increasing transport and the mechanization of agriculture - this may pose quite a challenge. Simultaneously, with regard to possible worldwide agreements on the reduction of greenhouse gas emissions, as well as local pollution, alternatives should be considered. The options which could be adopted to overcome these constraints include the use of some alternative energy sources, as discussed below.

\subsubsection{Bio-Fuel}

\section{Bagasse}

Bagasse is a major source of energy in the local context. From the point of view of steam production, its most important property is its moisture content. The average heat content of bagasse at 50 percent moisture is 9.9 GJ per metric ton. The production of bagasse is $280 \mathrm{~kg}$ per metric ton of cane. Annually some 5.5 million metric tons of sugar cane are harvested, with an energy potential from bagasse of 15 million GJ per year.

Efficient sugar factories produce excess steam and/or bagasse, which is used for the production of electricity for sale to other sectors. Currently this export amounts to $10 \mathrm{kWh}$ per metric ton of cane. If the Central Electricity Board were to offer a reasonable price per unit, the sugar factories could be motivated to improve this figure to $20 \mathrm{kWh}$ per metric ton of cane. This can be achieved with some minor modifications to the existing infrastructure. If high pressure boilers and condensing turbines were to replace existing equipment, total electricity production could reach $60 \mathrm{kWh}$ per metric ton of cane. This electricity, however, would only be available during the harvest season. For a continuous supply another fuel could be combusted during the nongrowing season. Such a scheme is already in operation at one of the sugar factories (Flacq United States Limited), where a dual furnace enables the combustion of coal during the off-season. This system has had positive results. If this measure were to be adopted, the total production 
would provide some $990 \mathrm{GWh}$, i.e., an additional $660 \mathrm{GWh}$ from the coal. According to Baguant and Manrahhan (1991) this would cover half the total energy needs for electricity in the year 2010 .

\section{Molasses}

Molasses is a by-product of the sugar industry. Ethanol can be obtained from molasses by fermentation and distillation, and low-grade ethanol can be used as a cooking fuel substitute. This would reduce the quantity of woody biomass and kerosene utilized in the kitchen. It is technically feasible to replace 1 liter of kerosene with 1.25 liters of $85^{\circ}$ (low-grade) ethanol. The volume of ethanol required for complete replacement of kerosene can be produced from locally available molasses. But, again, to encourage this shift, appropriate policies need to be formulated.

\section{Biogas}

This is a cheap source of energy with a simple production process, and can be worked by people with little training. The process uses animal waste and kitchen waste to produce methane through fermentation. This can be used either directly for cooking or by further conversion into power for small machines.

\section{Anaerobic Wastewater Treatment}

Currently, a project is being carried out at the University of Mauritius for the treatment of wastewater from the sugar industry. The wastewater is fed to a tank; during anaerobic treatment of the effluent, methane is produced at one end, while at the other clean water is obtained. No further energy is required for heating during the process, as the wastewater is already hot. This project seems to be very promising in terms of wastewater disposal and energy production.

\subsubsection{Solar energy}

Mauritius receives between 8 and 10 hours of sunshine daily. The average insolation on a horizontal surface in Mauritius varies from about $6 \mathrm{kWh}$ per $\mathrm{m}^{2}$ per day in the summer to $3.25 \mathrm{kWh}$ per $\mathrm{m}^{2}$ per day in the winter.

In fact, Mauritian electricity needs could be met by solar cells covering a few square kilometers of the country! Solar energy can be used directly for 
crop drying and water heating. Power can also be derived from small-scale convertors of solar energy, e.g., for water pumping.

In Mauritius, solar water heaters have already been tried and proved to be technically feasible; some hotels and households are already using such heaters. A survey carried out by the University of Mauritius in 1989 found that 9 percent of the electricity consumed in the household was used solely for heating water for hygienic uses. It is also assumed that firewood for cooking heats a certain percentage of water. Therefore, if most of the energy for heating water were obtained from solar heaters, electricity requirements could be reduced by at least 10 percent. However, high costs deter the spread of solar heaters.

\subsubsection{Wind energy}

Mauritius has a continual wind speed varying from four to eight meters per second, representing a large energy potential. The harnessing of wind energy has not progressed as far as other forms of energy; further studies need to be carried out. Wind power can be applied to uses such as water pumping and generation of electricity.

\subsubsection{Hydropower}

Hydro electricity contributes up to 30 percent of the total electricity supply. Currently, the total hydropower installed capacity is $51 \mathrm{MW}$, and it is believed that up to a capacity of $75 \mathrm{MW}$ can be reached. In the future, a pump hydro scheme could be developed to provide power at peak periods. The use of a pump hydro system allows the conversion of excess base power into more valuable peak power. A pump hydro scheme can allow an extension of the hydro capacity once the maximum of $75 \mathrm{MW}$ is reached. An advantage of this scheme is that, being a closed circuit, once the water is in the system it will be independent of climatic conditions, as opposed to hydropower plants.

\subsection{Future Carbon Emissions}

The environmental impact of energy use in Mauritius depends on the mix of energy carriers as well as the future economic development path. Carbon emissions are of special concern in this context. Mauritius's contribution to global $\mathrm{CO}_{2}$ emissions is minimal, not only in absolute terms but also on a per capita basis ( $240 \mathrm{~kg}$ carbon per capita); it has approximately the 


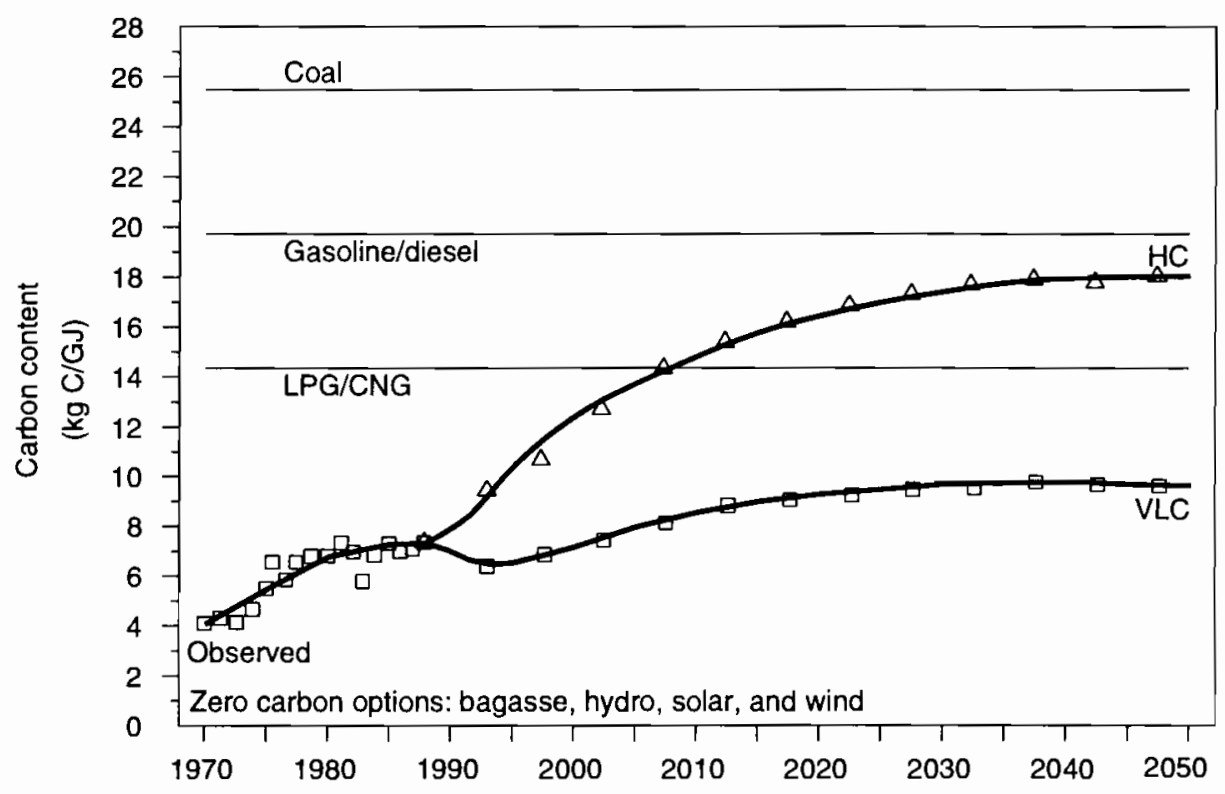

Figure 10.3. Net carbon content of energy supply according to a high carbon content (HC) scenario and a very low carbon content (VLC) scenario, combined with the economic boom scenario from Chapter 16 .

same level as India despite a much more advanced economic state. And Mauritius's emissions are much lower than those of Northern industrialized countries with an average per capita emissions of around $3,500 \mathrm{~kg}$. But if Mauritius is to sign binding international agreements on the reduction of carbon emissions, the issue becomes relevant.

The impact of such hypothetical agreements on Mauritius's emissions, and the energy system in general, has been studied recently by Beeharry (1992) based on the scenarios defined in Chapter 16. The principal options for decarbonization in Mauritius are surplus electricity from bagasse (biomass from sugar production), more hydro electricity, onshore and offshore wind energy, and photovoltaic energy.

Figure 10.3 shows the evolution of carbon content under a high carbon content (HC) variant and a very low carbon content (VLC) variant, in both cases assuming the economic and environmental parameters of an optimistic boom scenario (see Chapter 16). Energy use is ranked on the vertical axis from zero carbon options to compressed natural gas, gasoline, and finally 
coal. Compared to the current $240 \mathrm{~kg}$ of carbon per capita, this figure implies that part of the reduction is possible through fuel substitution, achieved by the transition from a high carbon energy supply mix to a very low carbon energy supply mix. The remaining reduction could only be achieved by more radical changes in the energy supply mix, such as electrifying transportation and providing required electricity from zero net carbon fuels.

In summary, the calculations show that despite further increases in energy use under the boom scenario, energy efficiency improvements combined with enhanced use of bagasse have the potential of reducing energy-related $\mathrm{CO}_{2}$ emission to levels well below the assumed target of $420 \mathrm{~kg}$ of carbon per capita that could be part of an international agreement of equal per capita emissions rights by 2050 .

\subsection{Conclusion}

The capital investment for the implementation of some of the schemes for reducing carbon contents and dependence on imported energy will necessitate considerable funding which would have to come from local and foreign sources. It could be argued that if Mauritius can afford so many vehicles, electrical appliances for households, and sophisticated machinery for its industries, it could well afford to import fuel. The important issue is not only whether it could afford to buy fuel, but also whether it could be less dependent on imported energy sources while exploiting available local resources to the fullest. There would be a net positive impact on the environment as the quantities of the more polluting fuels would decrease. The above-mentioned measures would undoubtedly reduce firewood consumption and help in forest preservation. For further development of the country, the demand for energy will increase. It is crucial, therefore, to plan ahead and adopt energy strategies that are compatible with the environment. 



\section{Part III}

\section{Understanding Through Modeling}





\section{Chapter 11}

\section{Philosophy of the PDE Approach}

Wolfgang Lutz

Formal models on computer are a tool to support the human brain. In the same way that a pencil can help the scientist remember his present thoughts, a computer model can help the scientist consider simultaneously more variables and interdependencies than he could manage even with a welltrained mind. Because population-development-environment interactions are highty complex, a nonformal, noncomputerized analysis such as that presented in the chapters in Part II can only describe relevant aspects and interactions one after the other. This approach may be appropriate for understanding the history and describing the course of events that have already taken place and that will not be altered by the model of the scientist, although its interpretation may well be altered.

When attempting to project possible future trends, on the other hand, the simultaneous consideration of all important interactions between the variables is absolutely essential. Any one-dimensional projection of a trend that disregards likely influences of other variables is bound to be wrong in the sense that reality will be different. Hence, at least for the future, we need to use computer modeling to combine and evaluate complex sets of assumptions about individual variables and specific linkages. Despite its superiority in many aspects to a purely mental model, a computer model will always be 
far short of an exact representation of reality. The best circumstance one can hope for is to capture the most relevant aspects of the system.

Any design of a model includes difficult choices of variables and assumed mechanisms. The results of the model will crucially depend on those choices. The challenge for our attempt to design the PDE model was to be as comprehensive and flexible as possible. We chose to meet this challenge by designing a model with two levels: a "hard-wired" level and a soft level. In the basic (hard-wired) structure of the model we stick to unambiguous relationships which can hardly be debated even by scientists with greatly conflicting views. In the "soft" part of the model, which is operationalized through the tools of scenario setting, all the less straightforward and controversial linkages may be defined. A comparison of the outcomes of alternative specifications in the soft part then can help to better understand the alternative behavior of the system and put into perspective differences in opinion expressed in the literature about interdependencies and feedbacks.

In short, the PDE model is a flexible and user friendly computer tool to comprehend the relationships between population change $(\mathrm{P})$, socioeconomic development (D), and environmental factors (E). It gives a broad accounting framework which quantitatively specifies the most important and immediate effects of some sectors of the system on others. It is flexible in the sense that the user is free to choose different values for a large number of parameters, and to define any combination of possible trends and policies - as well as feedback mechanisms - through the tools of time-dependent interactive scenario setting. The PDE model aims at enhancing scientific understanding and demonstrating the longer-term consequences of alternative policies or external developments. It has no immediate advocacy purpose.

When discussing the philosophy and basic structure of PDE models, it is important to distinguish between the general PDE approach, which could be applied to other countries or regions, and the specific form of PDE Mauritius. The latter was made to fit specific Mauritian conditions ranging from the climate to economic structure, data availability, and time constraints in the completion of the model. The Mauritius model should be seen as a first attempt and a prototype of a PDE application.

The first letter in PDE refers to population; the second, to development; and the third, to environment. This sequence is not arbitrary; it expresses the basic philosophy of the model. Population is taken as the point of departure as one of the basic driving forces that - together with many other factors - has an impact on development within environmental constraints. 


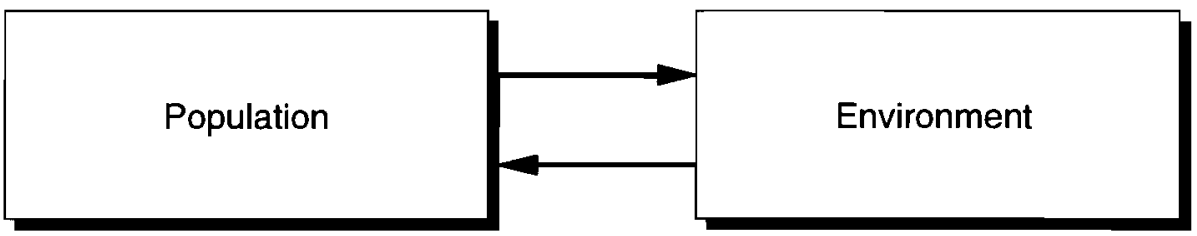

Figure 11.1. The "box approach" to studying population and environment.

Frequently, scholars addressing population-environment issues tend to view them in terms of two independent boxes (see Figure 11.1) with a causal arrow between the boxes. While the population box can be defined as a distinct entity (the number of people in a certain region), it is usually unclear what the environment box should contain. It might be one very specific aspect of environmental change, such as deforestation or air pollution. But generally the environment must not be represented by an independent box because environment and the laws of nature are everywhere and no line can be drawn around nature. Nothing is independent of the environment, including the human population which is part of nature and in all basic life-supporting functions dependent on the environment.

Rather than viewing population-environment linkages in terms of a linear causal chain, it should be visualized as a series of concentric circles where the sphere of development, i.e., the sum of social, economic, and cultural activities, is intermediate between the demographic aspects of the human population and the natural environment (see Figure 11.2).

Every life on earth, every economic activity, and every kind of development is embedded in the laws of nature. In this sense, the environment should not only be seen as a constraint, but also as the basic life-support system that makes all human activities possible. It is simply impossible to think of economic activity as being independent of the physical environment. The reason most economic models do not explicitly consider the environment is that such models have a limited scope and, for the models' specific purposes, environmental variables have been considered irrelevant.

No one person could deny that without air to breathe or without such resources as sufficient water, energy, and raw materials economic activity would be impossible. These basic life- and economy-supporting factors were assumed to be in abundance and were therefore omitted from the equations - a legitimate simplification, if these assumptions are true. However, environmental constraints have become more visible recently, and, accordingly, 


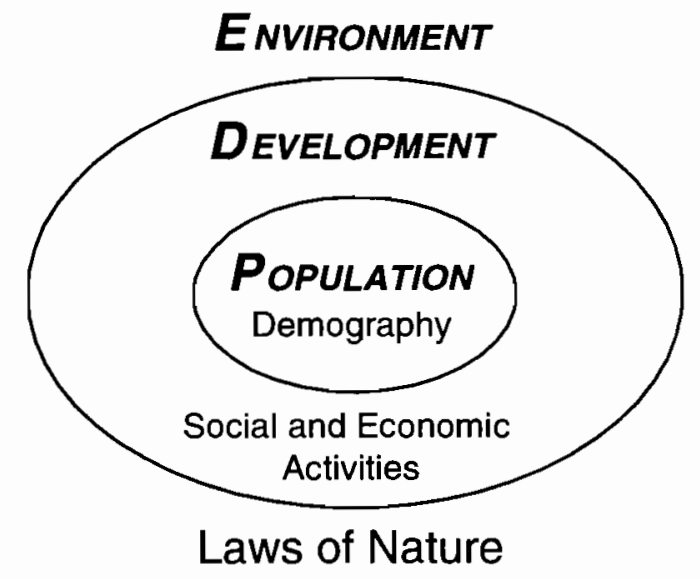

Figure 11.2. Population embedded in a socioeconomic sphere and in environment.

economic models must begin to include these factors in order to be considered relevant representations of reality. There is no doubt that economic activity and development are, at every point, subordinate to the laws of nature, and for this reason population and development are entirely embedded in the environment, as they are shown to be in Figure 11.2.

Within the sphere of development and economic activity, people are the agents. They are the ones who conduct the activities, develop routines, traditions, cultures, knowledge, and infrastructure. As well, there is no doubt that human life is dependent on certain forms of social and economic activities, and that further development of these activities makes life on earth possible for more people. This is why the population is constantly embedded in the sphere of development, which comprises social and economic activities. However, it is also clear that the demographic characteristics of the population are not the only determinants of these activities. It is mostly such qualitative aspects of the population as human skills and knowledge, along with accumulated infrastructure (capital) and the sum of environmental influences (traditional production factor "land"), that determine development. In the long run, the human resource factor (human capital in its quantitative and qualitative aspects) seems to be the most relevant for development. For this reason PDE assigns population a key role in the analysis of development within the ecosphere. Certainly, a large number of significant other factors 
influence development, which are specified as exogenous and endogenous variables in the economic module of $\mathrm{PDE}$.

The environment is everywhere; but how should it be meaningfully captured in a quantitative model? Most of the analyses which claim to consider the environment in the context of development select one or two very specific aspects of the environment, be it $\mathrm{CO}_{2}$ emissions or rates of deforestation. These specific analyses can be useful as illustrations for certain impacts, but they cannot claim to comprehensively capture development-environment interactions. Attention is currently being given to carbon emissions, because of the fear of climate warming, and to the level of CFCs and its impact on the ozone layer. Tomorrow, however, new environmental priorities may arise, such as immediate problems of water supply, toxic waste, radiation, or possible new threats to human health. Because such a disjointed and fractional approach to environmental questions could turn out to be rather short lived - hence missing some of the more important interactions - the PDE approach attempts to be as comprehensive as possible by, at least in theory, giving attention to all possible environmental aspects.

When thinking of how to find a meaningful differentiation of the environment as it relates to human life on earth, it can be instructive to go back to the very origins of Occidental thinking in ancient Miletas, around 600 B.C. There Anaximander, who had supposedly drawn the first map of the world, claimed that four elements - water, air, fire, and earth - made up the world and were in some kind of balance. These early attempts to understand nature and the environment of people may also be useful in structuring our thinking in how to identify relevant environmental aspects for the modeling of population-environment interactions. Water, air, and land can readily be taken as environmental subsystems that deserve special treatment and are described by separate modules in the environmental segment of PDE. Fire can be interpreted as energy that is also worth separate treatment. Another environmental system, which is not mentioned by Anaximander, is the sum of living species on earth. For our purposes it is useful to distinguish between the human species, the population, and other species with special attention to the change in biodiversity. This philosophy is the basis for the general PDE model as shown in Figure 11.3.

When attempting to translate these general ideas into an operational quantitative model for the computer, in a specific case-study application, a large number of specifications and definitions are required. In this we tried to follow three basic principles of modeling: 
1. The model should only include relevant aspects that could potentially make a difference in the case considered.

2. The model should be as simple and straightforward as possible, avoiding "magic" black boxes.

3. Only unambiguous and direct relationships should be hard-wired in the model. All other aspects should be treated as part of the soft model structure, as expressed by scenario settings.

While there is little that is new about the first two principles, the third may need some explanation. Our approach is based on one of the lessons we have learned from global modeling of the 1970s and early 1980s. The system should not become an artificial world in itself which, due to many predefined feedback loops, develops its own life and takes off in directions that can hardly be followed by common sense and have little to do with reality. We wanted to avoid hard-wired unchangeable feedback loops that are based only on ambiguous theory and scattered empirical evidence.

An example of this is whether fertility and mortality levels should be made direct functions of any other demographic, economic, or environmental parameters in the model. Because the vast literature on socioeconomic fertility determinants does not suggest any clear and simple functional relationship between fertility and a set of non-demographic parameters, we decided not to specify such a relationship in the hard-wired part of the model. Instead, the user can decide when and how in the course of running the model the fertility levels in the different population groups should be changed, based either on changing socioeconomic or environmental conditions or simply on assumptions about relevant cultural and behavioral changes. This possibility of user-defined feedback through scenario assumptions is called the soft model. With respect to fertility, there are also several hard-wired aspects which work through the changing educational composition of the population: if the user assumes different fertility levels for different educational groups, a change in the educational composition of the population - which is also influenced by economic and government policy parameters - has a direct impact on the average fertility level in the population. This is a simple consequence of changing weights. Similar distinctions between hard and soft parts of the model can be found for many different sectors.

Following these thoughts, Figure 11.3 gives the model proposed as a general guideline for the PDE approach. At the center one finds the population broken down - in the first instance - by age and sex. This gives the traditional age pyramid with men (on the left) and women (on the right), 


\section{basic Structure of the General PDE MODEL}

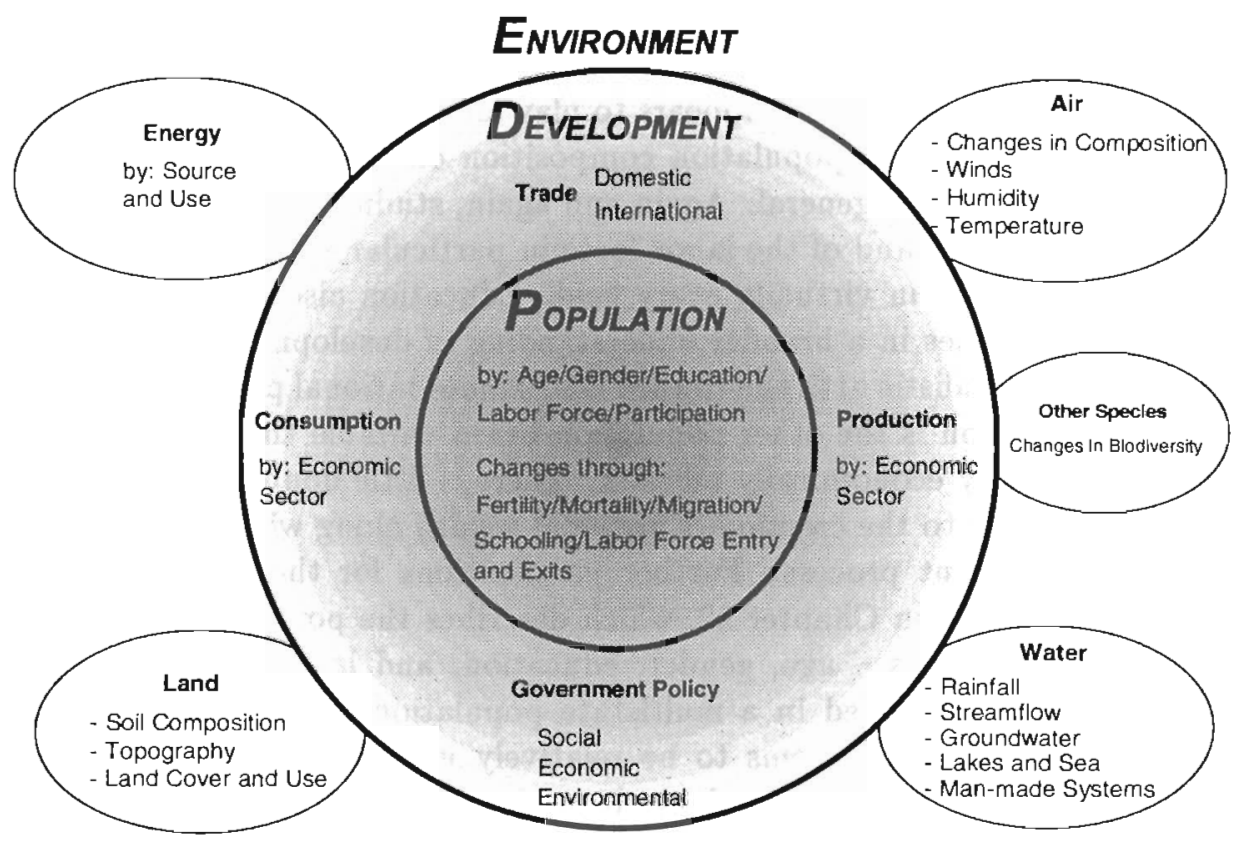

Figure 11.3. Basic structure of the general PDE model.

with the youngest age group at the bottom and the oldest at the top. Although some models deal primarily with total population size, we believe that age structure, in particular, is an essential feature of the population which has immediate effects on the economy and society. Furthermore, over time, disregarding the population age structure would make it impossible to capture the momentum of population growth which - in many less developed countries - is quantitatively an extremely significant phenomenon. The growth rate of the population can only be indirectly affected through fertility rates, with the population structure exerting momentum. As will be shown in the following chapters, Mauritius gives a good illustration of this point.

In addition to looking at population size by age and sex, the suggested PDE population module includes two other important variables which are population based (i.e., refer to groups of individuals in the population). 
These also address certain aspects of social development, namely, education and labor-force participation. With regard to education, there is an enormous amount of demographic literature indicating that education is one of the most important, if not the single most important, covariate of demographic behavior. Education appears to play an equally important role with regard to the effects of population composition on economic and socioeconomic development in general. Again and again, studies show that the skills of the population - and of the labor force in particular - are a major determinant of progress in virtually every field. Education also seems to be one of the key variables in a broader understanding of development as a change from a rather fatalistic attitude toward life to more rational planning. Laborforce participation is the other population-based variable that is considered to be particularly economically relevant. There is little doubt that the labor force contributes to the creation of national wealth along with advancement in the development process. Further justifications for the choice of these variables are given in Chapter 12, which describes the population module.

All these aspects - age, gender, education, and labor-force participation - are cross-classified in a multistate population model. This form of the population module seems to be relatively unambiguous, with respect to both substance and methodology. It is an attempt to summarize, in one compact unit, the essentials of population dynamics that can be handed over to the rest of the model for economic, environmental, and policy considerations. Parameters of change in the population module are fertility, mortality, and migration in each subgroup, as well as schooling and labor-force entry and exit.

In Figure 11.3 the population parameters are embedded at every point in the sphere of social and economic activities, including accumulated knowledge and infrastructure that may be summarized by the notion of development. This includes models of production and consumption by economic sectors as well as imports, exports, and domestic trade. Obviously savings, investments, and government expenditures also need to be considered. Finally government policies play a crucial role in all social, economic, and even environmental aspects.

Unlike most other modeling attempts at addressing these issues, the PDE model does not want to be primarily an economic model. Its emphasis is on the population-environment relationship. But because population factors hardly ever directly interact with environmental factors, the economic module is intended to serve as a linkage between the two. In designing the 
economic module, one is faced with a dilemma: on the one hand, the philosophy of the PDE approach asks for as simple a model as possible to serve the purpose of linking population to the environment, whereas, on the other hand, one is in competition with a large number of very sophisticated economic models that do not attempt to provide this linkage. For the Mauritius application, a form of the input-output table has been combined with certain features of general equilibrium models. The final product still reflects the evolution of thinking and development, and, although it is functional, it could well be improved for another application. In particular, it may be necessary to reconsider whether the advantages of an input-output table are worth its limitations. These aspects are discussed in Chapter 13.

But no matter which approach to economic modeling is chosen, certain features should be retained. These are reflected in the Mauritius model, as described below. With regard to the linkage of the economic module to the population module, all of the selected basic population characteristics - sex, age, education, and labor-force participation - must be reflected in the economic input parameters and must make a difference in the results. In the Mauritius application, age, gender, and labor-force participation determine the size of the active population, as opposed to the dependent population (children, elderly, homemakers). Higher labor-force participation reduces the size of the dependent population. The educational composition of the population also has important independent effects on the economy. Firstly, higher education is assumed to increase economic productivity and, as a consequence, the competitiveness on the world market, and lead to faster technological progress. Secondly, consumption patterns are assumed to depend on age and education. Because the population module can only provide such information about individuals that cannot be directly translated into household distributions, consumption is also defined for individuals by age instead of the usual household definition.

Another general criterion for the economic module is that it should consider the main components of the economy separately, in order to allow the analysis of changes in the economic structure. But a model of the world market for relevant export goods (such as sugar in Mauritius) is not being attempted. It would be a very complex task in itself. Instead external factors - such as export demand - are treated through scenario-defined input parameters. The economic module should also produce some basic indicators of material well-being, quantify government expenditures and investment in various important aspects of infrastructure, education, and social security, 
and provide unemployment figures. Finally, the economic module is expected to produce - as output variables - the input parameters for the various environmental modules. These parameters include water-demand figures, water pollution, solid waste, and changes in land use.

Figure 11.3 finds the environment broken down into four basic environmental sectors: air, water, land, and energy. The air module should be concerned with the chemical composition of the air, along with air temperatures and humidity, and the direction, speed, and seasonality of winds. The specific aspects and models selected to describe relevant aspects of atmospheric change depend, to a great degree, on the country or region chosen. In urban and industrial areas in particular, emphasis would be placed on air pollution which displays immediate implications on human health and on the health of the vegetation, especially forests. For more global considerations, attention would probably be directed to greenhouse gases along with those gases responsible for ozone depletion. In the specific case of Mauritius, the fundamental modeling principle - of only including variables that are assumed to have an effect on the outcome - resulted in the decision to omit the air module altogether. The almost permanent winds in the area immediately transport any kind of air pollution over the vast Indian Ocean. Some minor local air-pollution problems, located near sugar mills, did not justify an extensive consideration of air-quality questions. The questions of air temperature and humidity, relevant to the water balance of Mauritius, are extensively dealt with in the water module.

The water module is probably the most relevant of the environmental aspects, due to its direct link to human life-support systems. Problems with water supply can, in both the short and long term, lead directly to health problems such as those caused by lack of food production or by the consumption of contaminated water. Because most regions have different semiindependent water systems such as rivers, groundwater, lakes, and coastal waters, the water module should consist of several sub-modules that describe and model the dynamics of the systems relevant for life in the specific regions. For each subsystem, two important and different aspects of water need to be considered: the quantity and the quality. Both aspects are important, and problems with either one may cause problems for the system. However, quantity and quality are not independent. The quality of a given amount of polluted water can be improved by adding clean water. Hence, quantity can solve the quality problem. 
Hydrological modeling is a large scientific field in itself. After a review of the relevant literature, the following approach was chosen: the surface freshwater model is basically concerned with the balance of water requirements (demand) and water availability (supply) at a given user-defined minimum water-quality standard. Supply and demand for water are specified in terms of physical quantities. The water-quality standard chosen, together with the user's decision about investments in wastewater treatment, determines the dilution flow component of water demand. In this way, water quantity and quality have been linked into a common system. The freshwater supply is based on information about precipitation, evaporation, and historical flow data. The water supply is measured in terms of aggregated minimum flow which the user can choose to increase by investing in storage capacities.

In the specific case of Mauritius, the approach described above was applied, taking the island as one more or less homogeneous region. In other, more heterogeneous, cases one would certainly have to specify a more complex multiregional model and account for the possibility of water being transported by rivers from one region to another. The model also includes a separate module on water dynamics and sedimentation in the lagoons surrounding large parts of Mauritius. The Mauritius water module is described in detail in Chapter 15.

Theoretically, the land module includes all aspects of surface structure, vegetation, and soil composition. In cases where soil degradation and erosion are serious problems, appropriate models which describe these phenomena in physical terms need to be chosen. In the case of Mauritius, the land module is mostly concerned with questions of land use and regional distribution, which are closely tied to economic changes and the values of different categories of land. This module distinguishes between four major types of land use: urban use (including settlements and industries), sugar-cane fields, other agriculture, and beaches which, because of the tourist industry, have by far the highest value per land unit. There are also protected lands (crown lands) and hardly usable areas on Mauritius. The land-use module reconciles competition from different users, and puts constraints on the economic module and on environmental aspects. This part of the model is discussed extensively in Chapter 14.

The influence of all nonhuman living things (other species), as included in Figure 11.3, was not mentioned by Anaximander, but can certainly be very relevant for the human-environment interaction. This aspect includes considerations of biodiversity as well as the changing distribution of species 
ranging from bacteria to whales. It is relevant not only for basic life-support systems but also for the disease environment that affects human mortality and partly also fertility. In the case of Mauritius, however, these questions were not considered in the quantitative model because of the first principle discussed earlier, i.e., changes in other species are generally not considered to make a big difference in Mauritius over the next six decades. Because of their impact on the lagoons, coral reefs are given special attention; vegetation is also considered in the land-use module.

Energy, the fourth of the basic elements mentioned by Anaximander, could be treated either as a separate module or as part of the economic module. Because of its close relationship to the economy, it was decided to initially treat energy considerations as part of the economic module (Chapter 13). If more sophisticated and independent energy modeling were to be considered desirable, a separate energy module would liave the advantage that energy could be treated on physical instead of monetary terms as is done, for instance, by the ECCO models (King, 1991). The same is true for agriculture, which in PDE Mauritius is considered one of several economic sectors. In a predominantly agricultural country it might make sense, however, to create a separate agricultural module, possibly in conjunction with the land module.

The specific form of the PDE approach chosen for PDE Mauritius consists of four semi-independent modules: population, economy, water, and land use. The population and water modules can also be used as fully independent models in themselves if scenarios are defined for parameters designed to be imported from other modules. In the specific Mauritian PDE application, the land-use module is so closely tied to the economic module that it seems pointless to run the two independently.

The full model has close to 1,000 parameters. The following chapters give comprehensive descriptions of the four modules and their interactions in an intentionally informal manner to make it comprehensible to a broad audience. Full descriptions of all model equations are given in a series of separate IIASA Working Papers (Prinz, 1992; Toth, 1992; Wils, 1993). 


\section{Chapter 12}

\section{The Population Module}

Wolfgang Lutz and Christopher Prinz

\subsection{The Model}

\subsubsection{Determinants and characteristics of population change}

In this chapter we describe the specific structure of the multistate population model chosen for the population module of PDE Mauritius. Figure 12.1 gives some general aspects of the relationship between input and output parameters in a population model for a case that considers age, sex, and place of residence. It is important to distinguish between determinants and characteristics of population change. Only the characteristics of the population have an effect on the economy and the environment. The basic characteristics are total size, growth rate, density, age distribution (including mean age and demographic dependency ratios), sex ratio, and regional distribution of the population. These supposedly relevant characteristics of the population, however, cannot be influenced directly but can only be affected by changes in one or more of the three basic determinants of population change, namely, fertility, mortality, and migration.

The effects of changes in fertility, mortality, and migration on population claracteristics are not always immediate, but they follow the laws of population dynamics. Even a severe famine or certain epidemics do not directly diminish total population size but work through age- and sex-specific death 


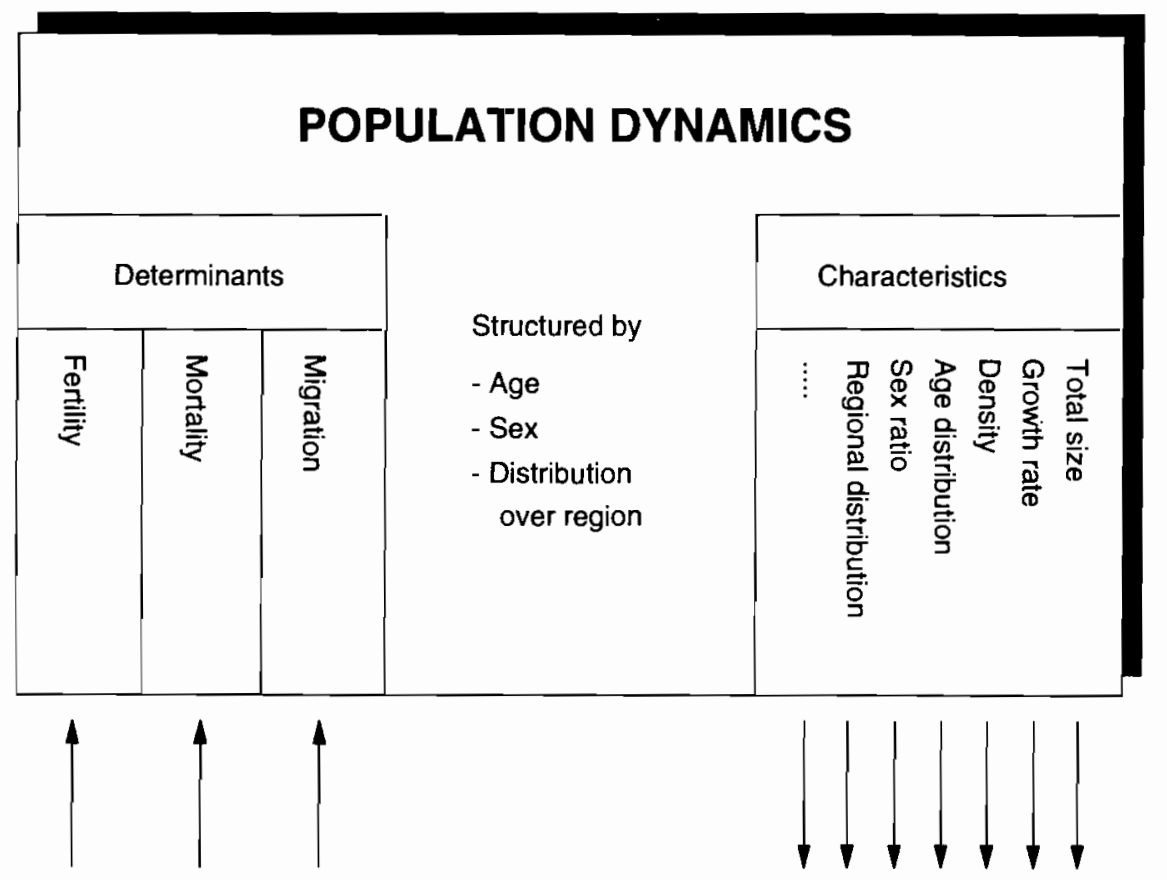

\section{Physical, economic, social, cultural, political context}

Figure 12.1. Determinants and basic characteristics of changing population patterns by age, sex, and place of residence.

rates that are applied to the given population structure. Different structures may lead to different numbers of people dying. This dependence on the age structure is still more obvious in the case of fertility when a rapid decline in age-specific fertility rates, for instance, is applied to a very young age structure of the population. It may take many years until it results in significantly declining growth rates. This is called the momentum of population growth which can be nicely illustrated in the case of Mauritius where fertility in the late 1980 s was already below replacement level but the growth rate of the population was still above 1 percent per year. The simple reason for this is that more and more young women that were born during the high-fertility 1960 s entered the prime childbearing ages. 
The determinants of fertility, mortality, and migration are very complex including biological, economic, social, and cultural aspects. For the reasons discussed in Chapter 11 we do not predefine the way in which fertility, mortality, or migration change as a result of changes in the economic or environmental modules of the PDE model, but the user has the freedom to choose the fertility, mortality, or migration response considered necessary by the means of scenario setting.

\subsubsection{Choice of demographic dimensions considered}

The population module of PDE Mauritius can be used either independently to study population dynamics by age, sex, education, and labor-force participation or as an integral part of the PDE model. It represents a summary of the most important aspects of population dynamics with respect to the four basic dimensions of population structure (age, sex, education, and laborforce participation) that are considered relevant for any interaction between the population and its environment.

Space limitation does not permit a summary of the huge demographic literature on these four dimensions of demographic structure and change. Instead the population module is presented here as a proposed basic demographic model including the essentials that a demographer would consider appropriate. Certainly there are many other important demographic dimensions, most notably marital status, marital duration, parity, and household composition, but we assume that few demographers would challenge the choice of the four most relevant dimensions.

Age and sex are at the very base of demographic analysis and of immediate relevance for population growth. For example, the momentum of population growth can only be understood and modeled when the age structure of the population is considered. Sex composition by age is essentia] for determining the fertility level and also very relevant for mortality rates because male and female mortality patterns tend to be quite different. Migration also tends to vary strongly with both age and sex. For these reasons age and sex would be the absolute minimum any self-respecting demographer could accept in a population module. However, the (non-demographic) literature of demo-economic and other modeling is full of examples of models that consider only total population size and the crude birth and death rates, i.e., the number of births and deaths per thousand persons in the population. 
Because these models do not consider the effect of the age structure on the birth rate (that is independent of the number of children per woman) their findings are sometimes greatly misleading.

Education is not a demographic variable in the strict sense but it is a population characteristic that is increasingly considered one of the most relevant aspects for not only fertility, mortality, and migration but also economic productivity and technological change. The empirical evidence of the relevance of education on these variables is overwhelming both at the micro-level and at the macro-level. Generally, better education leads to lower fertility, lower mortality, higher migration, and higher productivity. The measurement of education, however, is less straightforward than the measurement of age and sex.

There are two main criteria for the distinction between educational groups: by reading and writing skills (literacy) or by years of formal education completed. The usefulness of the two approaches depends on the status of the specific population in the process of social development. In an industrialized society where almost everybody can read and write the distinction by formal education is much more useful, whereas in a country with large proportions still illiterate reading and writing skills are the most important criteria. In the case of Mauritius, where already in the 1960s large proportions of the population were literate, it was decided to distinguish between primary, secondary, and tertiary education.

Labor-force participation is probably the least self-suggestive of the four dimensions considered. It is a dichotomous variable that indicates whether a person is part of the labor force or not. Generally this is defined as a population-based measure that is independent of the question of actual employment. Hence the labor force includes all people that are actually working (including those on sick or maternity leave) and the unemployed. Somewhat loosely one can say that the labor force consists of all people that want to work. Obviously the numerical measurement of this also depends on national definitions, which may differ from country to country. For example, a housewife who is theoretically willing to work but does not take any concrete steps toward finding a job because she considers it hopeless and does not register as unemployed because she is not entitled to benefits may be considered part of the labor force in some cases and outside the labor force in others. Despite these problems of definition, major changes in labor-force participation rates indicate major social changes that have significant impacts on the economy at various levels. 
One prominent demographic variable that is omitted in this population module is marital status. Because marriage is still closely related to fertility in most countries of the world, changes in marriage patterns have immediate consequences on birth rates. This is also true for Mauritius where the rapid fertility decline in the late 1960s and early 1970 s was to a significant extent due to increases in the age at marriage (see Chapter 4). Regardless of this importance of marriage it is of interest here only as an intermediate variable influencing fertility. For this reason marital status as an independent variable has not been specified; nevertheless all scenario assumptions on fertility include the marital-status dimension.

Considerable attention has also been given to determining whether household size and structure should be explicitly treated in the model. A strong argument in favor of this is that private consumption patterns are usually defined in terms of household consumption, not by individual consumption. There is, however, no feasible way to convert information based on individuals (such as given in the form chosen for the population module) directly into information on households. Even if these two different aspects could be matched for the starting year, there is no way to guarantee consistent changes in both when patterns are projected into the future. For this reason the population module sticks to the individual as the unit of analysis; in the economic part, consumption patterns are also defined on an individual basis.

\subsubsection{A multistate population model}

The traditional cohort component method of population projection is designed to forecast populations only by age and sex. If we want to include the two additional dimensions - education and labor-force participation we must refer to the tools of multistate population projection. This method was originally developed to consider and forecast populations simultaneously in several regions that interact with each other, i.e., in addition to having a child or dying, people can also migrate to another state at any age and at any time (see Rogers and Willekens, 1986; Keyfitz, 1985; among others). This methodology, however, is not limited to the analysis of geographical regions. It can also be applied to different population groups (marital-status groups or educational groups) living in the same region or groups defined by any other criterion.

For the purpose of breaking down the population by education and laborforce participation, seven states have been defined as shown in Figure 12.2. 


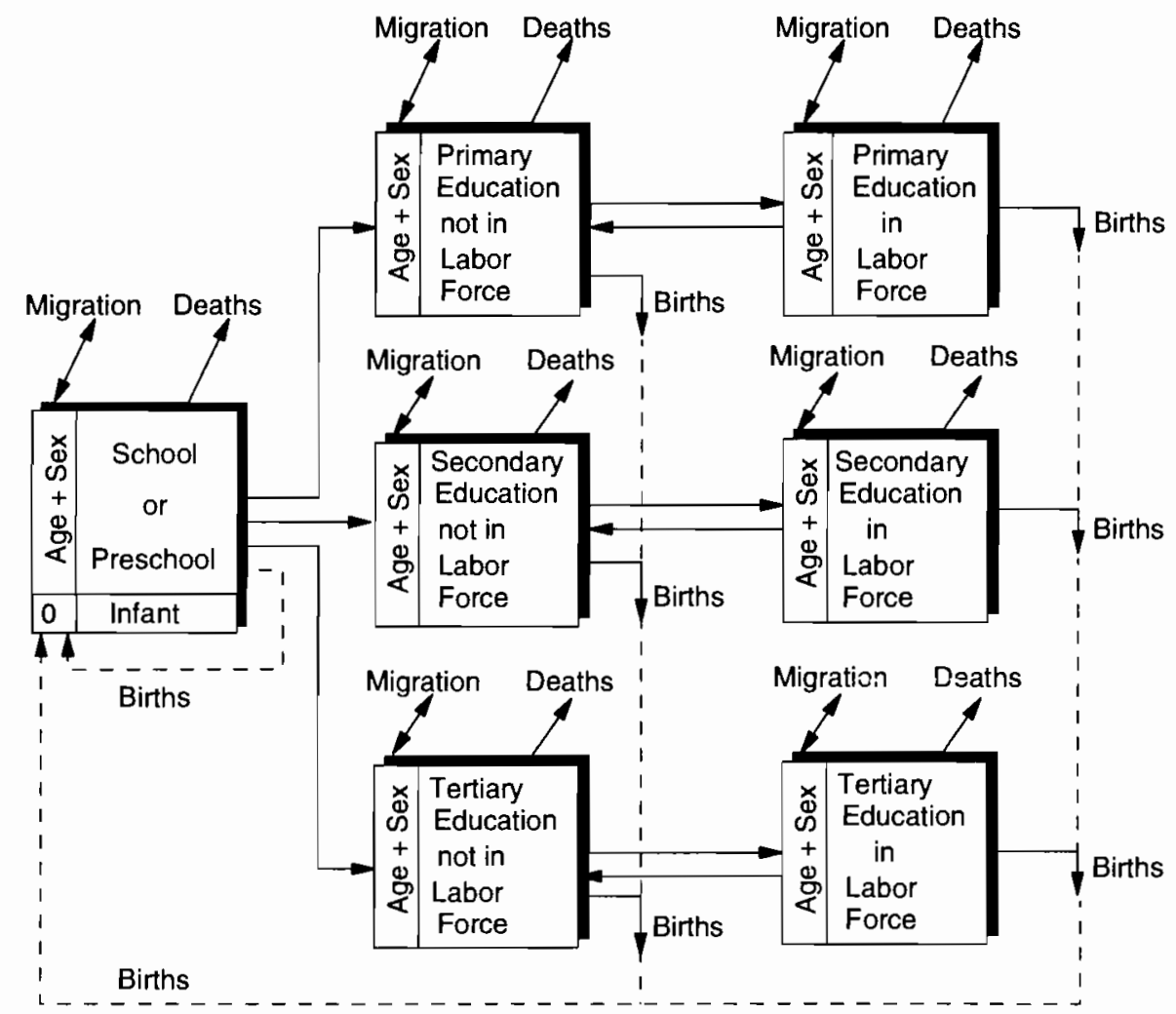

Figure 12.2. Basic structure of the population module with seven states for women. For men it is identical except for births.

The first state on the left includes all children and the total population in school or university. All newborns start in this category. When leaving school they go to the population group with some primary education or some secondary education or some tertiary education; each of these categories is further divided into the group that does not participate in the labor force or the group that does participate in the labor force. The age- and sex-specific rates at which men and women move from one group into the next are based on empirical data for the starting year and subject to scenario specifications for all years thereafter. Multiple transitions within one time period - which is five years in the case of PDE Mauritius - are possible. For instance, someone may leave school, enter the group with secondary education not in the labor force, move on to secondary in the labor force, and go back to not 
in the labor force within a five-year period. Within each group women have children according to the schedule of age-specific fertility rates, which can be defined separately for each group and which may change over time according to scenario specifications. Newborns do not enter the group of their mother but start at age zero in the group of children and students.

In addition to the possible transition to another group - where the model is semi-hierarchical because not all transitions go in both directions - people can leave the states by either emigration from Mauritius or death. People may also enter the states by immigration. Age- and sex-specific death rates can also be defined separately for each group. Because of the lack of empirical information on differentials in these rates, however, the default in the program is identical mortality rates in all states. Migration is specified in terms of absolute numbers and assumed to differ substantially with educational groups, with the most educated showing the highest mobility.

To what extent the resulting population characteristics (the output parameters of the population module) influence the economic and environmental modules is discussed in the description of the respective modules in later chapters. In short, most of the effects of population size and structure on the environment work via the economy: higher education directly increases labor-force participation; consumption is dependent on educational level and age; the supply of labor is given by educational groups; and government expenditures are directly dependent on the age structure (pension, health, and educational expenditures). There are also direct effects of population size on the land-use module with respect to land demand for housing and on the water module with respect to gross water intake by private households.

\subsection{The Data}

\subsubsection{Population structure in the starting years}

This section focuses on the information that was assembled and estimated to give the starting population structure according to the above-defined population states (see Chapter 4 for the population history of Mauritius). The population module uses two kinds of scenarios: one makes projections from 1990 to 2050 and one looks at possible alternative histories from 1962 onward. These starting years have been chosen because they were census years.

The main source of information used for the model was the Mauritian 1990 Population Census. In this census, 37 questions were asked, including questions about age, sex, marital status, citizenship, address, address five 
years ago, age at marriage, number of children, religion, school attendance, educational qualification, occupation, activity status, employment status, and place of work. From the census results we derived (partly estimated) the population distribution across the seven states in our model. The 1962 population distribution was estimated from several sources, such as the $D i$ gest of Educational Statistics (several issues), publications from previous population censuses, and additional material from the Ministry of Economic Planning and Development.

Between 1962 and 1990, the Mauritian population increased from less than 700,000 people to more than 1 million. During that period, the proportion of children declined from 54.5 percent to 38.5 percent. This decline corresponded to an increase in the proportion of people in working age (from 40 percent in 1962 to 53 percent in 1990) as well as an increase in the proportion of people aged 60 years and over (from 5.4 percent to 8.4 percent).

In 1962, the proportions of women aged 15-24 and 25-44 in the labor force were only 8 percent and 21 percent, respectively. By 1990, 37 percent and 44 percent of these female population groups were part of the labor force. Together with the aging of the population and the higher educational attainment of women, this increase was responsible for a very significant increase in the overall percentage of women in the labor force: from 15 percent in 1962 to 35 percent in 1990 (see Table 12.1). Due to the high number of young adults the respective figure for men increased also slightly from 80 percent in 1962 to 82 percent in 1990 , but the proportion of working men aged 45 years and over clearly declined.

The educational qualifications of the labor force also changed drastically. In 1962 , the proportion of women with only primary education was 85 percent in the age group 25-44 and 93 percent in the age group 45-64 (see Table 12.1). By 1990, the proportions declined to 56 percent and 78 percent, respectively. Similarly, the proportion of men with at least secondary education increased from 24 percent and 9 percent for age groups $25-44$ and 45-64, respectively, in 1962 to 51 percent and 26 percent by 1990. These changes are explained by strong shifts in school enrollment ratios during the period. Enrollment among females aged 10-14 years increased from 50 to 80 percent, and among females aged 15-19 years from 10 percent to 35 percent. Among males, the increase in school enrollment started some years earlier and thus was less marked during the observed period. Interestingly, by 1990 school enrollment ratios no longer differed by sex. 
Table 12.1. Labor-force participation and educational distribution of the labor force by sex and age, in 1962 and 1990, in percent.

\begin{tabular}{|c|c|c|c|c|c|c|c|c|}
\hline \multirow{3}{*}{$\begin{array}{l}\text { Age } \\
\text { group }\end{array}$} & & & \multicolumn{6}{|c|}{ Of those in the labor force } \\
\hline & \multicolumn{2}{|c|}{$\begin{array}{l}\text { Labor-force } \\
\text { participation }\end{array}$} & \multicolumn{2}{|c|}{$\begin{array}{l}\text { Primary } \\
\text { education }\end{array}$} & \multicolumn{2}{|c|}{$\begin{array}{l}\text { Secondary } \\
\text { education }\end{array}$} & \multicolumn{2}{|c|}{$\begin{array}{l}\text { Tertiary } \\
\text { education }\end{array}$} \\
\hline & $\mathbf{F}$ & $\mathrm{M}$ & $\bar{F}$ & $\mathrm{M}$ & $\mathrm{F}$ & $\bar{M}$ & $\overline{\mathrm{F}}$ & M \\
\hline \multicolumn{9}{|l|}{1962} \\
\hline $15-24$ & 8 & 64 & 71 & 66 & 29 & 34 & 0 & 0 \\
\hline $25-44$ & 21 & 97 & 85 & 76 & 15 & 22 & 0 & 2 \\
\hline $45-64$ & 23 & 86 & 93 & 91 & 7 & 7 & 0 & 2 \\
\hline $65+$ & 6 & 24 & 100 & 81 & 0 & 17 & 0 & 2 \\
\hline Total & 15 & 80 & 85 & 77 & 15 & 22 & 0 & 1 \\
\hline \multicolumn{9}{|l|}{1990} \\
\hline $15-24$ & 37 & 77 & 51 & 44 & 49 & 56 & 0 & 0 \\
\hline $25-44$ & 44 & 97 & 56 & 49 & 42 & 48 & 2 & 3 \\
\hline $45-64$ & 27 & 77 & 78 & 74 & 21 & 23 & 1 & 3 \\
\hline $65+$ & 4 & 16 & 90 & 87 & 9 & 10 & 1 & 3 \\
\hline Total & 35 & 82 & 58 & 52 & 40 & 45 & 2 & 3 \\
\hline
\end{tabular}

\subsubsection{Dependency ratios based on labor-force participation, productivity, and age of dependents: A first analysis}

Especially with regard to economic development, it is essential to look at dependency ratios, which give the number of dependents per active. High dependency ratios tend to impede economic development, whereas low dependency ratios are favorable. Since the model provides the population distribution over labor-force status and educational status, it is possible to calculate a more appropriate dependency ratio than the commonly used total dependency ratio (TDR) which only considers the age structure of the population. This more comprehensive total dependency ratio considering labor-force participation (TDR-LF) can be calculated, by distinguishing between the labor force and the population not in the labor force (students, homemakers, disabled people, retirees, and so on).

To make the TDR-LF even more closely related to economic productivity, information on educational status of the labor force can be incorporated. Productivity increases with educational attainment, so different weights for the three educational statuses seem plausible. As information on productivity by education is not available, information on average salary by educational status is used instead. The average salary in Mauritius - expressed 
Table 12.2. Alternative dependency ratios (dependents per 100 actives), in 1962 and 1990.

\begin{tabular}{llcl}
\hline Dependency ratio & 1962 & 1990 & Change \\
\hline TDR & 103 & 60 & $-42 \%$ \\
TDR-LF & 259 & 146 & $-44 \%$ \\
TDR-LF-P & 232 & 118 & $-49 \%$ \\
TDR-LF-AD & 360 & 217 & $-40 \%$ \\
TDR-LF-P-AD (=SDDR) & 321 & 175 & $-45 \%$ \\
\hline
\end{tabular}

TDR: Total dependency ratio.

LF: Considering labor-force participation.

P: Considering productivity as approximated by education.

$\mathrm{AD}$ : Considering age of dependents.

as a ratio - currently is about 1:2:4 for primary-, secondary- and tertiaryeducated people. Assuming a strong but not perfect correlation between productivity and salary, the following weights were considered reasonable for the calculation of a total dependency ratio considering labor force and productivity (TDR-LF-P): 1 for the primary-educated labor force, 1.5 for the secondary-educated labor force, and 2 for the tertiary-educated labor force.

Not all dependents impose an equal burden on the economy. For the most part, the burden varies with age. Per capita health expenditure in Mauritius is relatively low below age 60 , but increases steeply thereafter. Per capita education expenditure is very high (especially for students) and concerns only the population below age 25 . As a result, the adult population not in the labor force (mainly homemakers) is less of a financial burden. The following weights were used for the calculation of a total dependency ratio considering labor force and age of dependents (TDR-LF-AD): 2 for the school population, 1 for the adult non-labor-force population, and again 2 for the retired population.

All of these elements can be combined in one dependency ratio. It is calculated by using labor-force participation and different weights for different groups of actives and dependents, and it is called total dependency ratio considering labor force, productivity, and age of dependents (TDR-LF-P-AD), or alternatively socio-demographic dependency ratio (SDDR).

Table 12.2 gives the dependency ratios for 1962 and 1990 together with the percent change during that period. In 1962, the total dependency ratio (TDR) was $103 ; 100$ people aged $15-59$ years supported 103 children and elderly people. However, considering labor force (TDR-LF) it turns out that in reality 100 actives had to care for 259 dependents. Adding information 
on productivity and age of dependents (TDR-LF-P-AD) results in an even higher figure, 321 dependent equivalents per 100 active equivalents in 1962 . The reduction in dependency caused by the consideration of productivity by education (TDR-LF-P) is clearly more than made up for by the increase in dependency caused by the inclusion of age of dependents (TDR-LF-AD).

While the absolute level of dependency differs strongly by the extent of refinement of the simple total dependency ratio, the rates of change turn out to be surprisingly similar. Within 30 years, the dependency ratios were nearly cut in half. The TDR declined by 42 percent - mainly due to the remarkable decline in fertility - down to a level of 60 in 1990. The most refined ratio, TDR-LF-P-AD, declined by 45 percent down to a level of 175 dependent equivalents per 100 active equivalents. The similarity of changes in different dependency ratios during the last three decades is a result of the decline in fertility which dominated changes in labor force. In the future this may be different, making changes in those dependency ratios as much dependent on the level of refinement as on the levels of the different ratios.

The trend of the dependency ratios is correlated with the economic development in Mauritius. At least, the sharp decline in the ratios coincided with the economic boom over the past decades. It will be interesting to study alternative developments of the various dependency rates together with economic trends in the future under alternative population and economic scenarios to learn more about the role of population dependency in economic development. 



\title{
Chapter 13
}

\section{The Economic Module}

\author{
Anne Babette Wils*
}

\subsection{Introduction}

The economic module developed for Mauritius is an input-output model for a small, open economy. The economy is seen as a mediator between the population and the environment. The effect of a given or growing number of people on the environment certainly differs depending on the activities of the people. By using resources of an environment in a prudent, or careless, manner a population can live well, or poorly, for a long period.

It matters to the environment whether the people are engaged in growing sugar, dyeing woolens, or international banking. Sugar production requires large amounts of land and water, and dumps organic waste into the rivers; dyeing woolens requires little land but a great deal of water, and dumps chemical waste into the rivers; international banking by itself, on the other hand, requires almost no interaction with the environment (although the consequences of international banking action on a country's economy may affect its environment). Our concern with the different effects of various economic sectors led us to choose the input-output model structure.

The input-output model calculates the output of the economy by sectors. There can be, e.g., 100 or 200 sectors. This model has 15 sectors, which makes it a relatively aggregated input-output model. The model calculates

\footnotetext{
*I acknowledge my indebtedness to Markus Amann, Warren Sanderson, Einar Holm, Wolf-
} gaug Lutz, and Esther Hanoomanjee for their substantial contributions. 
total production by sector based on the final demand by sector. Final demand is consumption by end users of a product.

Each sector has population and environment coefficients. To produce a million rupees worth of sugar requires different labor input than a million rupees turnover at an international bank. For each sector, unit requirements of labor by education are necessary input. Similarly, for each sector the unit requirements for land and water and the unit emissions of waste are also needed. Depending on the structure of the economy by sector, the interaction with the population and the environment is completely different.

The labor coefficients differ by the education of the labor force. A better educated labor force is assumed to be more productive than a less educated labor force, all else being equal.

In the complete model, in order to make consistent economic scenarios, adjustments are often required in the population or environment or policy variables. For example, it is possible - and was often the case - that in scenario building the results show, e.g., more land, or more laborers witl tertiary education, demanded than available. The calibration of the scenarios is a fascinating learning process described in Chapter 16.

\subsection{General Model Structure}

The model is one in which exports and education are the main driving forces. The size of the population is also important. Population influences government expenditure and the composition of private consumption demand.

Because of the way consumption and investment multipliers are specified, the structure of the model is such that it can be applied only to economies which are very open - where import and export value is a large portion of the GDP - and which have relatively small domestic markets.

The main model assumptions are:

1. Export demand is exogenous, provided by the scenario maker. Government demand is a function of population and an exogenously provided per capita expenditure. Private consumption and investment demand are endogenous. Gross output is calculated from export demand, government demand, private consumption, and investment demand. GDP and imports are calculated from gross output.

2. The labor coefficients - number of people needed to produce one unit of output in each sector - are driven by the education of the labor force: the more educated the population, the fewer people needed to produce 
one unit of output. The labor coefficients are further influenced by an exogenous variable: technological change.

3. Private consumption is a function of per capita income and spending distribution. We allow spending on three main goods: housing, food and "other." The model distinguishes three main income classes: low, with primary education; medium, with secondary education; and high, with tertiary education.

4. The environmental coefficients - land and water necessary per unit of output and pollution emissions per unit of output - are exogenous to the economic model and determined in the land and water models.

5. In each period, private consumption demand equals GDP minus taxes minus savings.

6. Investment demand is devoted to increasing or maintaining the desired stock of capital. The desired capital stock depends on the level of (desired) gross output. A part of the desired capital stock exists in the form of vintage capital. Considerations such as interest and profit are not included. Investments equal savings plus net borrowing from abroad.

7. The savings rate is an endogenous variable which is adjusted to satisfy assumptions 5 and 6 simultaneously. Maximum and minimum possible savings rates are provided by the scenario maker. Investments which cannot be paid for when the maximum savings rate is reached are paid for by borrowing abroad. Interest is paid on loans, and loans are amortized by raising the savings rate in the following period to pay off as much of the debt as possible with that rate, and this continues until the debt is repaid.

8. The model is a series of single-period models with changes occurring between periods. The model calculates exactly what production is needed to fulfill final demand, and therefore, by definition, all goods produced are sold in the same year.

9. Prices are fixed.

\subsubsection{The Mauritian input-output table}

The main tool of input-output analysis is a matrix called the input-output table. Table 13.1 provides the 1987 Mauritius table as it was prepared by the Central Bureau of Statistics and adapted for the project. As a proxy for the 1990 table, Table 13.1 lists 1987 data. However, actual 1990 levels of export demand by sector, published by the Central Bureau of Statistics, were used in the model. 
Table 13.1. Input-output table of Mauritius, 1987, including employees and wages.

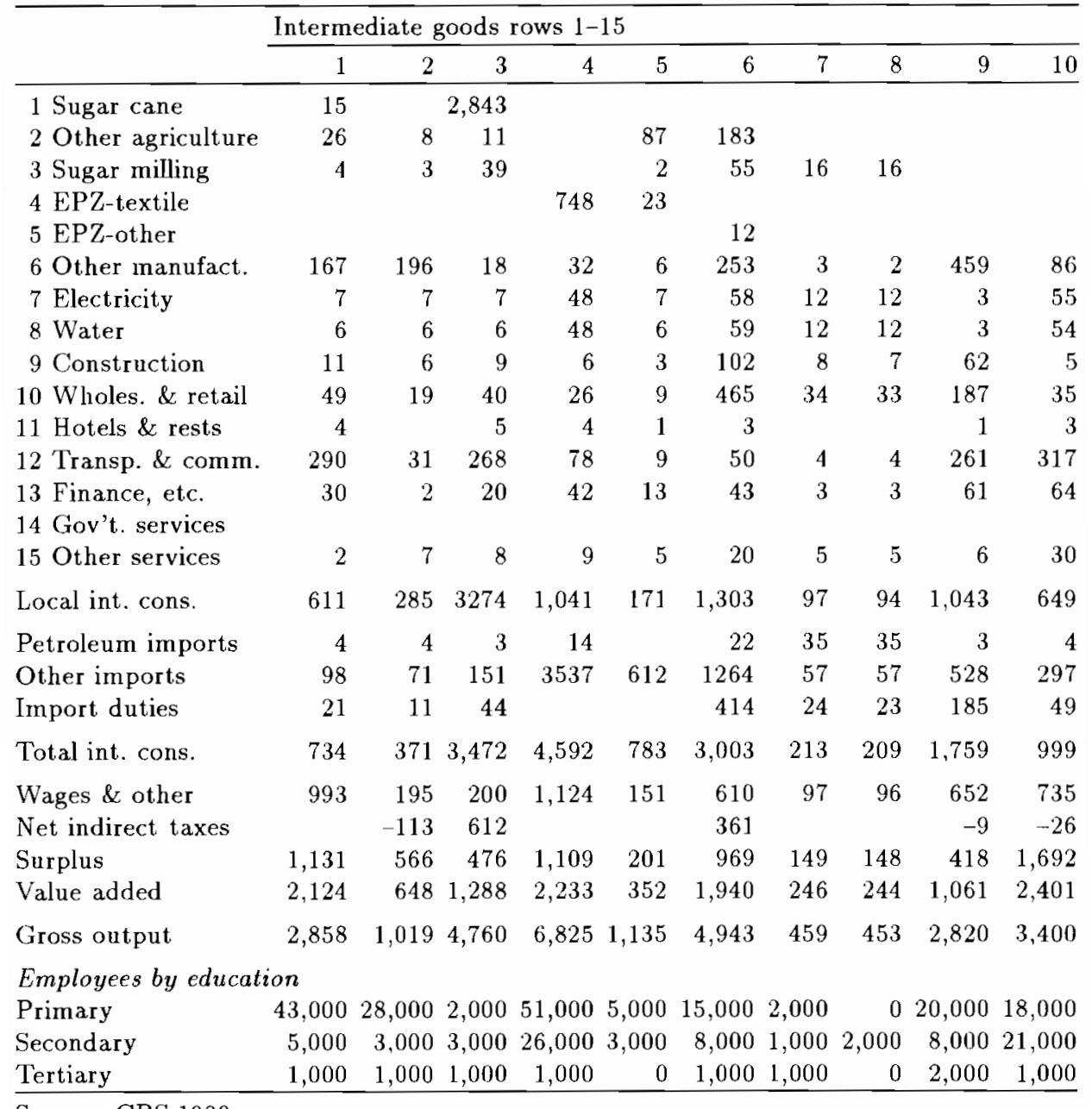

Source: CBS, 1989 .

The input-output table summarizes the complex web of transactions between firms and customers, and firms and other firms in the economy. The table distinguishes between two kinds of demand. If the buyer is a final user, who consumes the good, we are talking about final demand. Final demand is shown in the right-hand side of the table in the columns labeled "consumers," "government," "investment," and "exports." If the buyer is 
Table 13.1. Continued.

\begin{tabular}{|c|c|c|c|c|c|c|c|c|c|c|c|}
\hline & & & & & Interm. & Final d & lemand & & & & Total \\
\hline 11 & 12 & 13 & 14 & 15 & demand & Cons. & Gov't. & Inv. & Stock & Export & Demand \\
\hline & & & & & 2,858 & & & & & & 2,858 \\
\hline 70 & & & 4 & 4 & 393 & 577 & & & & 49 & 1,019 \\
\hline 10 & & & & & 145 & 73 & & & 133 & 4,409 & 4,760 \\
\hline & & & & & 771 & 110 & & & 400 & 5,544 & 6,825 \\
\hline & & & & & 12 & & & & & 1,123 & 1,135 \\
\hline 90 & 122 & 29 & 40 & 60 & 1,563 & 3,050 & & 60 & & 270 & 4,943 \\
\hline 31 & 17 & 10 & 15 & 23 & 313 & 147 & & & & & 459 \\
\hline 31 & 17 & 10 & 14 & 22 & 305 & 147 & & & & & 453 \\
\hline 8 & 1 & 100 & 1 & 6 & 335 & 856 & 195 & 1,526 & -92 & & 2,820 \\
\hline 65 & 278 & 53 & 75 & 25 & 1,393 & 1,561 & & 340 & & 106 & 3,400 \\
\hline 1 & 6 & 1 & 4 & 6 & 39 & 150 & & & & 1,091 & 1,280 \\
\hline 36 & 118 & 44 & 33 & 48 & 1,591 & 875 & & & & 1,585 & $4,05]$ \\
\hline 30 & 72 & 418 & 4 & 1 & 806 & 407 & & & & 734 & 1,947 \\
\hline & & & & & & 14 & 2,527 & & & & 2,541 \\
\hline 15 & 51 & 5 & 10 & 5 & 183 & 1,051 & & & & 78 & 1,312 \\
\hline 387 & 682 & 670 & 200 & 200 & 10,707 & 9,018 & 2,722 & 1,926 & 441 & 14,989 & 39,803 \\
\hline 12 & 300 & 1 & 10 & 6 & 453 & 103 & & & & & 556 \\
\hline 191 & 651 & 307 & 261 & 66 & 8148 & 3,598 & & 1,759 & 430 & 650 & 14,585 \\
\hline 35 & 327 & 50 & 35 & 52 & 1,270 & 1,150 & & 331 & & & 2,751 \\
\hline 625 & 1,960 & 1,028 & 506 & 324 & 20,578 & 13,869 & 2,722 & 4,016 & 871 & 15,639 & 57,695 \\
\hline 225 & 935 & 437 & 2,035 & 410 & 8,895 & & & & & & \\
\hline 120 & 16 & 37 & & 132 & 1,130 & & & & & & \\
\hline 310 & 1140 & 445 & & 446 & 9,200 & & & & & & \\
\hline 655 & 2,091 & 919 & 2,035 & 988 & 1,9225 & Total $\mathrm{v}$ & alue ad & ded $=$ & GDP & & \\
\hline 1,280 & 4,051 & 1,947 & 2,541 & 1,312 & 39,803 & Total $\mathrm{g}$ & ross ou & tput & & & \\
\hline 5,000 & 10,000 & 0 & 27,000 & 15,000 & 241,000 & & & & & & \\
\hline 7,000 & 18,000 & 8,000 & 23,000 & 13,000 & 149,000 & & & & & & \\
\hline 0 & 2,000 & 9 & 5,000 & 2,000 & 18,009 & & & & & & \\
\hline
\end{tabular}

another firm, who uses the good as input, this is domestic "intermediate demand." Intermediate demand is shown in the $15 \times 15$ matrix of the sectors in the upper left portion of the table. The rows of 15 sectors indicate to whom the output of each sector was sold. The columns of 15 sectors indicate the input to each sector's product. Below the intermediate demand matrix are three rows for imports. 
Economic product is shown in the next three rows. It is the value added. Value added is divided among wages, indirect taxes (negative taxes are subsidies), and surplus. These are indicated separately in three rows. The sum of these three, value added, is shown in the row directly below.

The next row of the input-output table shows gross output value. This is the sum of the value of the domestic intermediate goods, imports, and value added. The total gross output of each sector is exactly equal to the total final and intermediate demand from that sector - compare the last row with the last column. Goods that are not sold are accounted as increases in stocks. The total value added shown in the right-most cell of the row for value added is equal to GDP. GDP is equal to total final demand from consumers plus government consumption plus investments plus exports minus total imports.

The input-output table is a concise summary of the activities of a given economy in a given year. For use in modeling, we use this table to make the unit matrix by setting gross output in each sector to 100 , and dividing the intermediate goods and the value added appropriately. This adjusted table, called the coefficients matrix, indicates the state of technology in a country.

\subsubsection{Technical coefficients matrix and technological change}

With a given coefficients matrix and varied vectors of final demand, different output scenarios can be calculated. In such scenarios there is no technological change. This inflexibility has often been used as an argument against input-output models. However, we do allow for technological change.

Labor productivity changes through an explicit scenario variable, which is exogenous, and through endogenous change in labor productivity via education (see Section 13.5). The education profile of the labor force is a result of the population module (see Chapter 12 and Prinz, 1992).

Capital productivity is changed through an exogenous capital ratio variable. There is no endogenous connection between labor and capital productivity, as would be provided in a Cobb-Douglas type of output calculation. Section 13.6 on capital productivity discusses how labor and capital productivity changes should be combined.

Emission treatment, costs of treatment, and levels of emission are explicitly dealt with in the water module (see Chapter 15 and Toth, 1992). Energy efficiency has been studied by Beeharry (1992) using the Mauritius model. Changes in the land productivity are included in the land-use module (see Chapter 14). 


\subsection{Calculation of Gross Output, Value Added, and Final Demand}

The gross output in each of the 15 sectors, the vector $G$, can be written in terms of final demand and the Leontief matrix derived from the technical coefficients matrix, $A$ :

$$
G=L\left(E+C+I_{f}\right)
$$

and

$$
L=(I-A)^{-1}
$$

where $E, C$, and $I_{f}$ are the vectors for exogenous final demand (exports and government services), private consumption, and investment, respectively. All three vectors refer to domestic final demand. $A$ is the technical coefficients matrix; and $I$, the identity matrix.

Through the introduction of a matrix multiplier derived in Wils (1993), gross output can be written wholly in terms of $E$ only and the vintage capital stock vector, $V$. The vectors for $C$ and $I_{f}$ are then derived from gross output.

\subsubsection{Exogenous export and government demand}

Export demand is an exogenous variable in the model. Scenario makers specify what they believe will be, or might be, the export demand for Mauritius. This does not mean that Mauritius has no influence over the kind of goods it will export. As a matter of fact, the government policy of the past few decades undoubtedly helped the observed export expansion. In this case, the user can play with different export policies and the success or failure thereof. The exports are paid for in the same year as delivery. The exports provided by the scenario maker are the vector $E_{x}$.

Government final demand is a function of the population size and scenarios specified for the per capita expenditure on school education, university education, public health, and general services. School education expenditure applies only to the number of children in school; university education applies to the calculated number of enrolled people aged 20 and over; public-health expenditure applies to the whole population but follows the age pattern observed in the late 1980s for hospital treatment; and general expenditure applies to the whole population equally. This results in a vector $E_{g}$. The sum of $E_{x}$ and $E_{g}$ is the exogenous demand vector, $E$. 
One could argue that public expenditure is budgeted in another way: the government specifies how much it would like to spend and then, depending on the size of the population, per capita expenditure goes up and down. However, we feel that the public budget is very much pushed and pulled by the size of the population and by the changes in the age structure. Health expenditures soar as the elderly population increases because each elderly person has a "right" to a certain level of treatment, and, if there is not enough equipment or personnel, more is sought. Schools are opened and closed depending on the size of the classes and the number of pupils.

Unlike exports, government expenditure is paid for domestically, and the income for government is derived from taxes and import duties. The model does not automatically require a balanced budget. The scenario maker must increase or decrease taxes or expenditure and rerun the model in order to balance the budget. Through this, the scenario maker acquires a sense of the dynamics of the government budget.

\subsubsection{Gross output with endogenous investments}

To make investments endogenous, let us assume that investment spending is devoted to increasing or maintaining the stock of capital, $K$, at the desired level. Let us further assume that desired capital stock depends on the level of (desired) gross output. Considerations such as interest rates and profit are not included. The relationship between the vector of capital stock and the gross output, $G$, can then be written as the diagonal capital ratio matrix, $K R$ :

$$
K=K R \cdot G \text {. }
$$

The relationship between investment and gross output is shown in Figure 13.1. For each level of gross output, there is a requirement for capital according to this capital ratio. This $K$-line starts at the origin. There is also vintage capital stock available to the economy, represented by the $V$-line. At zero gross output, all capital stock is still available. Up until a certain level of gross output, production is low, and vintage capital in all sectors suffices, and is used up at a rate equal to the capital ratio. There are no investments.

At gross output level A, one sector "runs out" of vintage capital, and, for increases in gross output, investments in this sector are needed. The investment $I$-line departs from level $A$ with a low curve (only one sector 


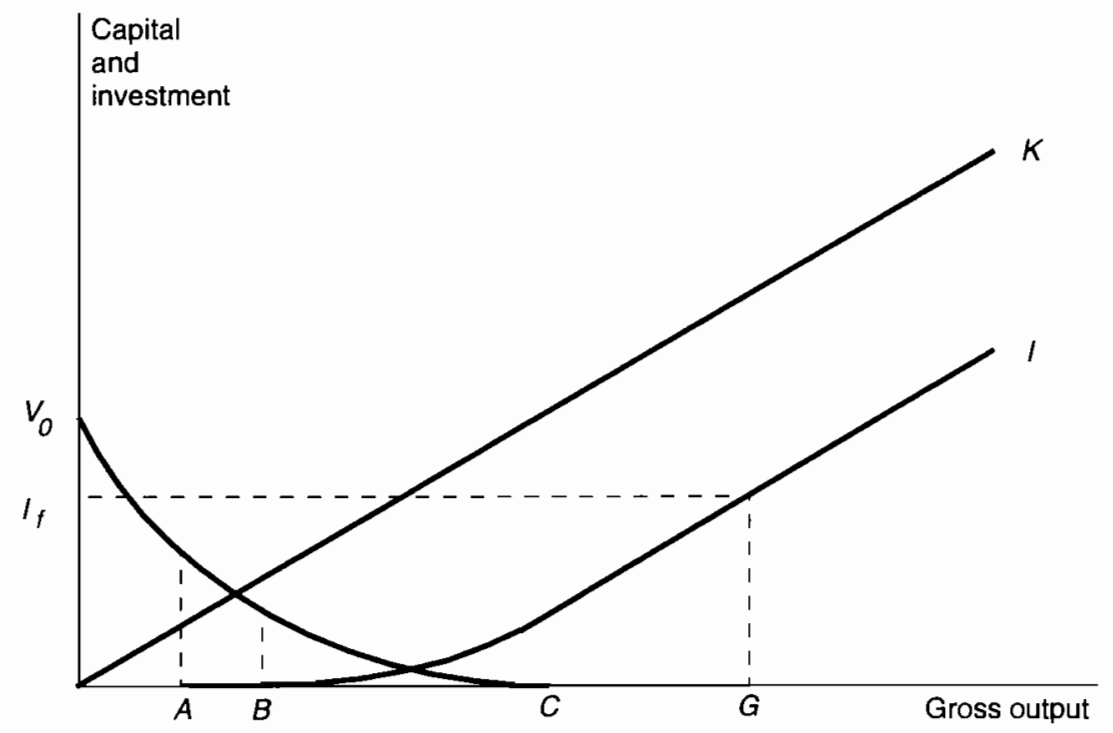

Figure 13.1. Investments as a function of gross output: $K=K R \cdot G ; I_{f}$ $=$ actual investments; $V=$ vintage stock left at each level of output.

needs investments). The curve of the $V$-line becomes a little flatter, as now, less capital is used per unit of final demand. At slightly higher production for higher gross output level B, a second sector "runs out" of vintage capital, and also requires investments. The $I$-line curve becomes a little steeper. This process continues until level $\mathrm{C}$, where all sectors require new investments if the gross output expands further. Beyond this point, the $I$-line is parallel to the $K$-line.

The actual amount invested will depend on the equilibrium level of gross output. Written very simply:

$$
I_{f}=\max (0, K R \cdot G-V) .
$$

In other words, if $K R \cdot G-V$ is negative, $I_{f}$ is set to zero, otherwise $I_{f}=K R \cdot G-V$. Inserting equation 13.4 into 13.1 and solving for $G$ we obtain a new equation for gross output as a function of exogenous demand, private consumption, and vintage capital:

$$
G=(I-L \cdot K R)^{-1} L(E+C-V) .
$$




\subsubsection{Gross output with endogenous private consumption and investments}

It now remains to write $C$ in equation (13.5) in terms of $E$. Let us assume that private consumption is equal to income minus tax, $T$, minus savings, $S$. Private consumption is equal to $Y_{c}$, consumed income. Income is equal to the value-added portion of gross output. For the moment, we assume there is no external income from interest, transfers from abroad, or government transfers. Then, consumed income $Y_{c}$ can be written:

$$
Y_{c}=V R \cdot T S \cdot G,
$$

where $V R$ is the diagonal matrix whose $i$ th element is the ratio of value added in sector $i$ to gross output in that sector and $T S$ is the diagonal matrix where each element $t s_{i}$ is equal to $\left(1-t_{i}-s\right)$ where $t_{i}$ is the tax rate in sector $i$ and $s$ is the national savings rate.

The $Y_{c}$ vector provides the source of income used for private consumption, but not the final demand vector for private consumption (e.g., a person whose source of income is in the construction sector spends the income in many other sectors). To obtain the final demand vector for private consumption, $Y_{c}$ is pre-multiplied with the redistribution matrix $R_{c}$. The $R_{c}$ matrix provides the unit per capita consumption distribution. The $i, j$ th element of each column shows the proportion of income earned in sector $j$ consumed privately in sector $i$. The columns of the $R_{c}$ matrix sum to less than unity because a portion of private consumption demand goes to imports. Currently, about one-third of private demand is for imported goods. The $R_{c}$ matrix in future scenario years depends on income distribution (see Section 13.4). Private consumption of domestic goods can now be written as:

$$
C=R_{C} \cdot T S \cdot V R \cdot G \text {. }
$$

The $R_{c}, T S$, and $V R$ matrices are known and exogenous, and can be reduced to one known output-to-consumption matrix, OTC. Then

$$
C=O T C \cdot G \text {. }
$$

Inserting this into the equation for gross output gives a new gross output equation:

$$
G=(I-L \cdot K R)^{-1} L(E+O T C \cdot G-V) .
$$

Separating out the expression with $G$ on the right-hand side of the equation and solving for $G$ gives: 


$$
G=\left[I-(I-L \cdot K R)^{-1} L \cdot O T C\right]^{-1}(I-L \cdot K R)^{-1} L(E-V) .
$$

This is gross output written solely in terms of exogenous demand and known vectors and matrices.

The inverse expressions indicate, for each unit of exogenous demand $E$, given the vintage capital stock $V$, how much more output is produced via multipliers for private consumption and investments. The restrictions on this expression are discussed in Wils (1993). The restrictions are such that the model can be applied to small, open economies.

\subsubsection{Balanced savings and investments}

It is also a model assumption that the savings rate is endogenous and such that it satisfies model assumptions 5 and 6 . To do this, the module takes the savings rate from the previous period as small $s$. It calculates GDP and private consumption, investments, and savings. It checks if savings are equal to investments. If not, then $s$ is raised or lowered and the economy recalculated, until equality is reached. In the case that there are still insufficient funds at the maximum savings rate, there is borrowing from abroad. In the case that there is too much savings at the minimum savings rate relative to desired investment, the unused amount is carried over to the next period (see Figure 13.2).

\subsection{Private Consumption Demand and Income Distribution by Education}

It is evident that it is important to know the $R_{c}$ matrix, the redistribution matrix for private consumption, as an exogenous variable. At the same time, it is empirically known that the distribution of private consumption over a collection of goods is dependent on the level of income and the distribution of income, both endogenous. The distribution of private consumer demand is one of the points where the size and the education distribution of the population affects the total output of the economy.

Private consumer demand is, of course, mainly determined by the level of income. It is known that as people become more wealthy, and more educated, they not only spend more income, but also spend it on different goods. Poor people spend a far greater proportion of their income on basic items such as food, whereas the more wealthy spend a large proportion of 


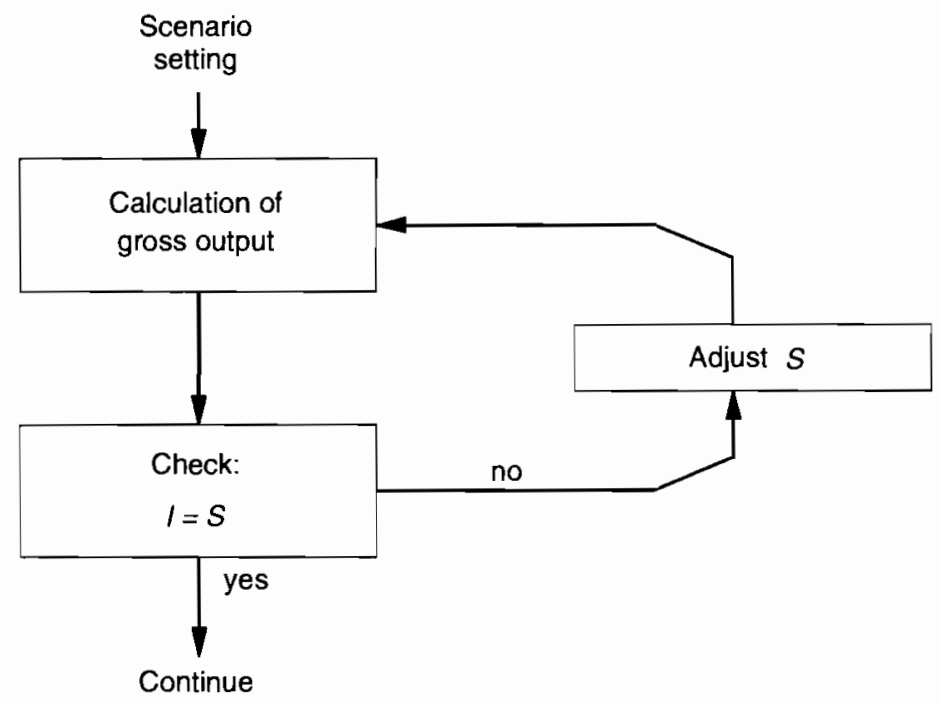

Figure 13.2. Finding $G$ where savings and investments are equal, by iteration.

their income on leisure goods. The distribution of income spending has a great effect on the environment. For example, as per capita income goes down, the relative consumption of food goes up and with it the demand for domestic agricultural produce, which needs water, fertilizers, and land.

To implement such changes in consumption patterns depending on wealth, we propose to distinguish between three types of consumption (food, housing, and "other") and three income classes (low, middle, and high), given by the three education groups (primary, secondary, and tertiary). It is observed that, in general, as per capita income increases, the proportion of income spent on food decreases, and the proportion spent on other things increases. By contrast, there is evidence that, at least on Mauritius, the proportion of income spent on housing is much less variable.

\subsubsection{Income in three groups}

The total consumed income vector $Y_{c}$ is distributed over the workers of the three education groups (primary, secondary, and tertiary) according to the number of workers in each education group in each sector, and the relative income of each education group. 
It is assumed that in all sectors workers with tertiary education earn the most, and workers with primary education the least. In all sectors $j$, workers with tertiary education earn four times as much as those with primary education, and workers with secondary education earn twice as much. This estimate was confirmed in interviews with Mauritian experts.

\subsubsection{Consumption in three broad groups}

We aggregated the data in the Mauritian Household Survey into the three main consumption categories. The observed proportion of income spent on housing, $h$, in the household survey is only 0.1 when imputed rent is excluded. This is extremely low, but home ownership is very high on Mauritius - 98 percent of households in the 1990 census - and expenditure includes almost only relatively simple construction costs and very little rent.

The observed monthly per capita proportion of income spent on food, $f$, in the household survey for different per capita income is shown in Figure 13.3. A logarithmic regression through the observed points estimates the relationship between percentage of income spent on food and monthly per capita income. The proportion of income spent on food is a function of per capita income, $y$ :

$$
f=f(y) .
$$

This $f$ is estimated using the exogenous portion of gross output (it could not be solved analytically with the whole equation for $G$ ).

The proportion of income spent on "other," $o$, is the residual:

$$
o=1-h-f(y) \text {. }
$$

The three income groups and the three consumption groups, plus the distribution of consumption over 15 sectors within the three main consumption groups, are used to find the $R_{c}$ matrix.

There are two ways in which population affects the $R_{c}$ matrix. First, a larger population reduces per capita income (all else being equal) which affects $f(y)$. On the other hand, a redistribution of $f(y)$ in favor of food could result in a kind of consumption that increases output - for example, if there are large income multipliers associated with agricultural production or food processing. In the scenarios, a larger absolute population did result in a higher total GNP, at lower per capita levels, given the same exogenous demand and vintage capital. Second, the education distribution of the workers affects the relative size of the three income groups. 


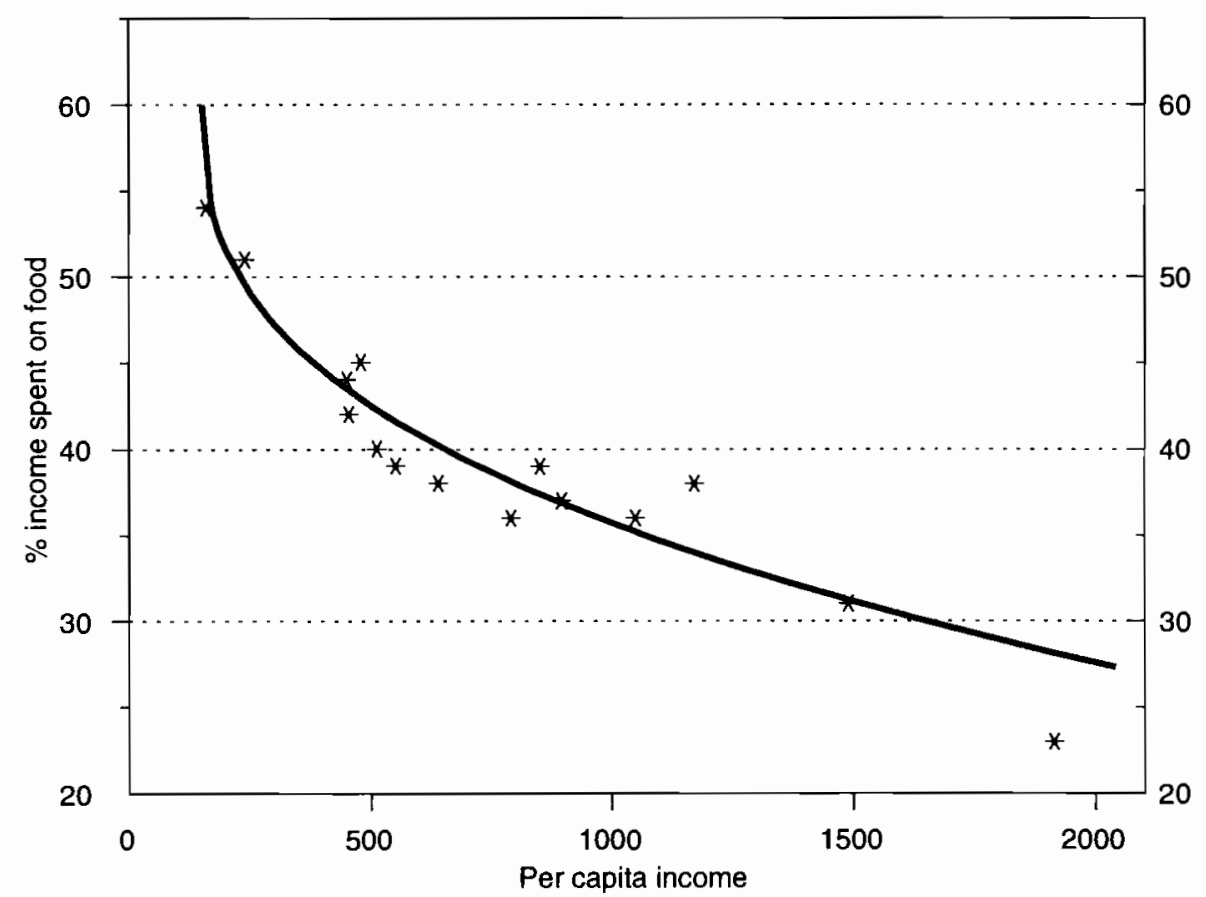

We assume that the maximum income spent on food is 0.9 and the minimum is 0.25 , at high levels of income. The percentage of annual per capita income spent on food, $f\left(Y C A P^{e}\right)$ is given by

$$
\begin{array}{lll}
f\left(Y C A P^{e}\right)=0.9, & & Y C A P^{e}<72 \mathrm{Rs} / \text { year } \\
f\left(Y C A P^{e}\right)=\left[-.1 \ln \left(Y C A P^{e} / 12\right)+1.08\right], & 72<Y C A P^{e}<48,286 \mathrm{Rs} / \text { year }, \\
f\left(Y C A P^{e}\right)=0.25, & & Y C A P^{e}>48,286 \mathrm{Rs} / \text { year },
\end{array}
$$

for each of the three education groups, $e$.

Figure 13.3. Observed expenditure on food in households of different monthly per capita income consumed and a line fitted through the observation points. Source for points: CBS, 1989.

\subsection{Education and Labor Productivity}

Increasing labor productivity is one of the keys to a higher GDP, and one of the keys to increasing labor productivity is increasing the education attainment of the labor force. This maxim is reflected in the model via the unit labor demand coefficients. It is assumed that workers with higher 
education are more productive, even at the same job. Further, it is assumed that changes in the education distribution of the employed mirror the changes in the distribution of education in the whole labor force.

A better-educated labor force means more educated workers employed and more productivity. When the labor force is more productive, the unit labor coefficients decrease (fewer people necessary to produce one unit of output). For more details, see Wils (1993).

Labor productivity can also change exogenously from technological innovation. The scenario maker gives a proposed increase in productivity which is supposed to come from some technical innovation. This is exogenous.

Higher productivity would result in the paradox of increased unemployment if the economy stagnates. However, in cases of relatively full employment, and a growing economy, increased productivity is the only way to increase per capita wealth.

\subsection{Changes in Capital Intensity}

The capital ratio vector $K R$, discussed in Section 13.3, can be interpreted as being an indicator of the efficiency of the capital used for production. It indicates how much capital (in present money value) is needed per unit production of output in a given year. A change in the capital ratio is one of the indicators of technological change. Conceptually, technological change can be divided into two categories: increasing capital intensity and increasing capital efficiency.

More capital-intensive production means that one uses more capital to produce a given value of output. This development must always be accompanied by higher labor productivity and lower labor costs, or a decrease in other costs, in order to be economically rational. An economy with a traditional artisan type of production has a very low capital ratio, say needles and scissors for output of dresses. But in these economies per capita output or labor productivity is also low. The introduction of new machines increases the capital ratio, and therewith capital costs, but it also increases labor productivity and this is one of the main sources of increased economic wealth. The decision to invest in a machine is only rational if one can save costs elsewhere, so that ultimate profit increases. With a sewing machine, each worker can make five dresses a day compared with only one in the days of hand-sewing. A more advanced machine increases output even more. 


\subsection{Exogenous Balances}

In the economic module, there are pairs of variables that must have similar values or where only one of the two can be larger than the other, such as labor supply and demand. Some of these pairs are automatically adjusted in the model: for example, consumer demand and disposable consumer income and investment spending and investment funds. Other pairs are not hardwired together, and so the user must check them while making scenarios. These are:

- Taxes and government consumption must be roughly equal. In some scenarios, there may initially be an enormous government consumption deficit or surplus. The user needs to go back to the scenario setting and make a policy decision: Will there be tax cuts? Or tax increases? Should there be decreased consumption, and, if so, in what area?

- Labor demand should not exceed labor supply, although the converse is allowed and means unemployment. If there is a labor shortage, the model does not intervene, but results show this is an impossible situation. The user has to increase labor productivity, increase migration, or decrease demand. It is possible that shortages in skilled labor of a certain type constrain the economy, but this is beyond the immediate scope of the model. However, the model can be used to estimate the types of labor that will be needed. The model produces scenario estimates of the demand for labor in each sector. If the user has an idea of the types of skills needed in that sector, then the model can be used to estimate the requirements for specific labor skills.

- Investment spending and savings must be equal. The model allows fluctuations in the proportion of savings, depending on the calculated need for new capital and so this pair is largely equaled. When the scenario maker changes the $K R$ vector, it is wise to check that this continues to hold. In scenarios where there are no changes in $K R$, the investments are balanced internally by the model.

When the user makes a scenario, it usually takes a few steps of calibration before the first two pairs above fit, and a few more steps before the environment variables also fit. It is only when all pairs fit that there is a realistic or possible scenario. In the course of this effort, the user will acquire an understanding of the interactions in the system. This is probably as important as the results of the final scenarios themselves. 


\title{
Chapter 14
}

\section{Land Use and Regional Distribution}

\author{
Einar Holm
}

\subsection{Introduction}

The island of Mauritius has a total area of $1,860 \mathrm{~km}^{2}$, and a coastline length of $322 \mathrm{~km}$; it is of volcanic origin, with low coastlands and a high plateau. The narrow coastal strip is a valuable land resource for the country. Coral reefs encompass a large portion of the island, resulting in sheltered lagoons. These, in turn, contribute to the attractiveness of the beaches for recreation and tourism, the latter of which has expanded rapidly during the past decade. Because of the sheltered nature of the lagoons, along with their increased use for recreation and tourism, an important environmental concern arises regarding the use of methods which avoid the accumulation of contaminated water.

Before the first known settlements in the 17 th century, the island was largely covered by natural forest - including substantial numbers of ebony trees. The transformation of the landscape began with the deforestation of this valuable resource, and was accelerated with the introduction of sugar cane almost a century later. It eventually became the largest spatially dominant economic land use of the island.

The gradual conversion of forests and grasslands into sugar-cane production culminated in the 20th century. In 1965, 53 percent of all land on 
the island was used for the cultivation of sugar cane; only 4 percent of the land was used for growing other agricultural products. Hence, for a substantial period of time, Mauritius has imported at least two-thirds of its food including foodcrops, livestock, and poultry.

Before describing the land-use module of the PDE model, we look at more general questions which concern the relationship between land-use change and the development of the economy, the population, and the environment in Mauritius. We also explore several possibilities and constraints which are designed to help achieve sustainable development on the island.

Following this is a description of the land-use module of the Mauritius model. This section includes discussions on the module's assumptions, limitations, and construction principles; its relationship to the Mauritian economy; the population and water modules; the scope of potential questions to raise; and the different output alternatives.

\subsection{Mauritian Land Use from an International Perspective}

From a land-use perspective, Mauritius is dominated by agriculture. According to FAO statistics, slightly more than 60 percent of its total land area was used for agriculture in 1988 - including arable land, permanent crops, and permanent pasture. In comparison, the international average for agricultural land use was approximately 37 percent. Single country examples are the USA at 46 percent, China at 45 percent, the former Soviet Union at 27 percent, and Canada at 9 percent. A mere 15 percent of the world's total land area belongs to countries which have a higher proportion of their land area devoted to agriculture than Mauritius.

Human settlement is another kind of land use on Mauritius. Mauritian population density is very high on a global comparison; close to 600 inhabitants per $\mathrm{km}^{2}$. This corresponds to an average population distance (the distance between an inhabitant and his or her nearest neighbor, assuming that all individuals live evenly distributed over the total land area of the country) of 44 meters. In China, the distance "between people" is greater, 97 meters ( 122 inhabitants per $\mathrm{km}^{2}$ ); in USA, 206 meters ( 27 inhabitants per $\mathrm{km}^{2}$ ); in the former USSR, 299 meters (13 inhabitants per $\mathrm{km}^{2}$ ); in Canada, 634 meters ( 3 inhabitants per $\mathrm{km}^{2}$ ). The difference between the Mauritian and the Canadian population distance -44 meters and 634 meters, respectively - is indeed substantial, but not as great as the difference between 600 
inhabitants per $\mathrm{km}^{2}$ and 3 inhabitants per $\mathrm{km}^{2}$ would imply. This might well be seen as a technical point, but subjective interpretations of different measures probe the mind. One old and prevailing stream of thought which deals with the prospects of developing countries is the Malthusian idea of relating development to carrying capacity or density, especially with regard to agricultural land. The expected disadvantage of high density is exponentially related to measures of density. A hypothesis for this chapter is that such a view is almost totally irrelevant for Mauritius - as well as for other countries - as it develops out of the constraints of a pure, static subsistence economy. The domain-oriented spatial production and reproduction constraints of a harvesting society are gradually replaced by the "linear" constraints of an emerging network society, where industrial and service production is based on spatial interaction between more or less specialized individuals.

However measured, Mauritius's relative position on the global population-density scale is extreme. Only six countries are more densely populated than Mauritius. Including Mauritius, these countries occupy just 0.1 percent of total world land area, yet contain 2.3 percent of the global population. One-half of the global population lives in countries with one-tenth of the total land area of the world.

Mauritius has a very low rating in a global comparison of available agricultural land area per inhabitant (ca. 0.1 hectares per inhabitant). Most countries have at least 10 times this agricultural land ratio ( 1 hectare per inhabitant), although a considerably smaller proportion of their total land area is devoted to agriculture. This is, of course, a reflection of the extremely high population density on the island.

If the mere possession of large areas of land suitable for agriculture per inhabitant - were an important prerequisite for agricultural production and for economic development in general, then Mauritius and other densely populated regions would occupy a very disadvantageous position.

Table 14.1 shows GNP from agriculture per capita and per hectare of land; the amount of agricultural land; and population density on Mauritius and other selected regions and countries relative to the world average. The global average of each factor is set to 100 .

Several conclusions can be drawn for Mauritius and the other countries and regions. Mauritian agricultural production per capita is 41 percent higher than the global average. This is the combined result of a land productivity that is 11 times higher than the global average, a 55 percent higher share of total land area used for agriculture than the average, and a level 
Table 14.1. Decomposition of agriculture land productivity in selected countries and regions in 1987. Index: world $=100$.

\begin{tabular}{lcccc}
\hline & $\begin{array}{l}\text { AgrGNP/Pop } \\
(\$ 87 / \text { inh.) }\end{array}$ & $\begin{array}{l}\text { AgrGNP/Agrland } \\
(\$ 87 / \mathrm{ha})\end{array}$ & $\begin{array}{l}\text { Agrland/Totland } \\
(\mathrm{ha} / \mathrm{ha})\end{array}$ & $\begin{array}{l}\text { Totland/Pop } \\
\text { (ha/inh.) }\end{array}$ \\
\hline Mauritius & 141 & 1,100 & 155 & 8 \\
Ethiopia & 32 & 20 & 135 & 116 \\
China & 55 & 121 & 113 & 40 \\
Canada & 301 & 82 & 22 & 1,710 \\
World & 100 & 100 & 100 & 100 \\
Standard dev. & & & & 459 \\
$\quad$ (143 countries) & 102 & 627 & 56 & \\
\hline
\end{tabular}

of land area per capita that is just 8 percent of the global country average. Mauritius has a very high agricultural productivity which almost compensates for its lack of land area.

As shown in Table 14.1, the greatest global variations are in land productivity (AgrGNP/Agrland) and in total land area per capita (Totland/Pop). Variations in the portion of land used for agriculture are smaller.

\subsection{Modeling Land-Use Change}

The land-use and the economic modules of the Mauritius model are closely related. Essentially, land is regarded as a production factor in almost the same sense as capital and labor. The primary assumption is that a certain amount of production, in a certain sector, at a particular point in time, requires a certain amount of land. Like capital and labor, land is regarded as one of the inputs - besides intermediate goods - required to produce output.

The basic economic model is an input-output model with linear production functions without returns to scale, which permits no substitution for the postulated proportions of factor inputs. Therefore, land demand ( $L D)$ from a certain production sector $(s)$, within a certain time period $(t)$, is simply given by the product of total production $(G)$ and the inverse land productivity $\left(l_{s t}\right)$ (equal to rupee value of output per $\mathrm{km}^{2}$ ) in the sector:

$$
L D_{s t}=\left(1 / l_{s t}\right) G_{s t} .
$$

The vector of land productivity coefficients is a subset of the technology matrix for that specific point in time. Between time periods in the model it is possible to change land productivity in each economic sector as desired. 
It should be noted that the division of behavioral assumptions in two different time scales is implicit in this model. Everything that is triggered by changes in final demand is assumed to work out and approach a new equilibrium at the beginning of each five-year time period. Contrary to this, (most) changes in final demand itself, the structure of the economy, productivity estimates, labor supply, among other variables, are explicitly changed between five-year periods.

Assumptions regarding land use are also divided in the same way. The land productivity coefficients for different kinds of land use might be changed between periods. The actual land-use pattern - the division of the island space into different usages - is determined at the beginning of each fiveyear time period. It is constrained by the amount of land available and the amount of water available for irrigation. In case of a land or water conflict the solution is found through the iteration. If there is a land shortage, the model endogenously changes final demand - which is primarily supplied exogenously - until a production mix is achieved which fits the land constraints. The model uses priority rules (see Section 14.3.6) to decide which sectors of final demand to reduce. Figure 14.1 gives an overview of the model's timing of main activities, including user interaction.

\subsubsection{Land-use transformations}

Some special properties of land resources distinguish it from labor and capital. The total amount of land can rarely be increased, neither can land itself be moved. It is seldom possible to invent and construct a new piece of land as can be done with capital equipment. It is only the usage of a piece of land that can be changed gradually: every new use of land replaces the former use of the same land. In addition, the transition from one type of land use to another is often heavily constrained and not symmetrical. It is, in most cases, easy to convert agricultural land into urban land, whereas the opposite demands capital demolition - to say the least. The quality of land and its suitability for different uses is heavily affected by its present and former uses. It is possible to degrade soils by irrigation and fertilizers to such an extent that the land is no longer suitable for even the same agriculture use as before, or a transition into another use may trigger a sudden release of nitrogen into the groundwater.

On Mauritius, the main change in land use since 1965 has been the transformation of sugar-cane land into urban space. Figure 14.2 illustrates this point. Up to 1986 , the area used for growing sugar cane had decreased 


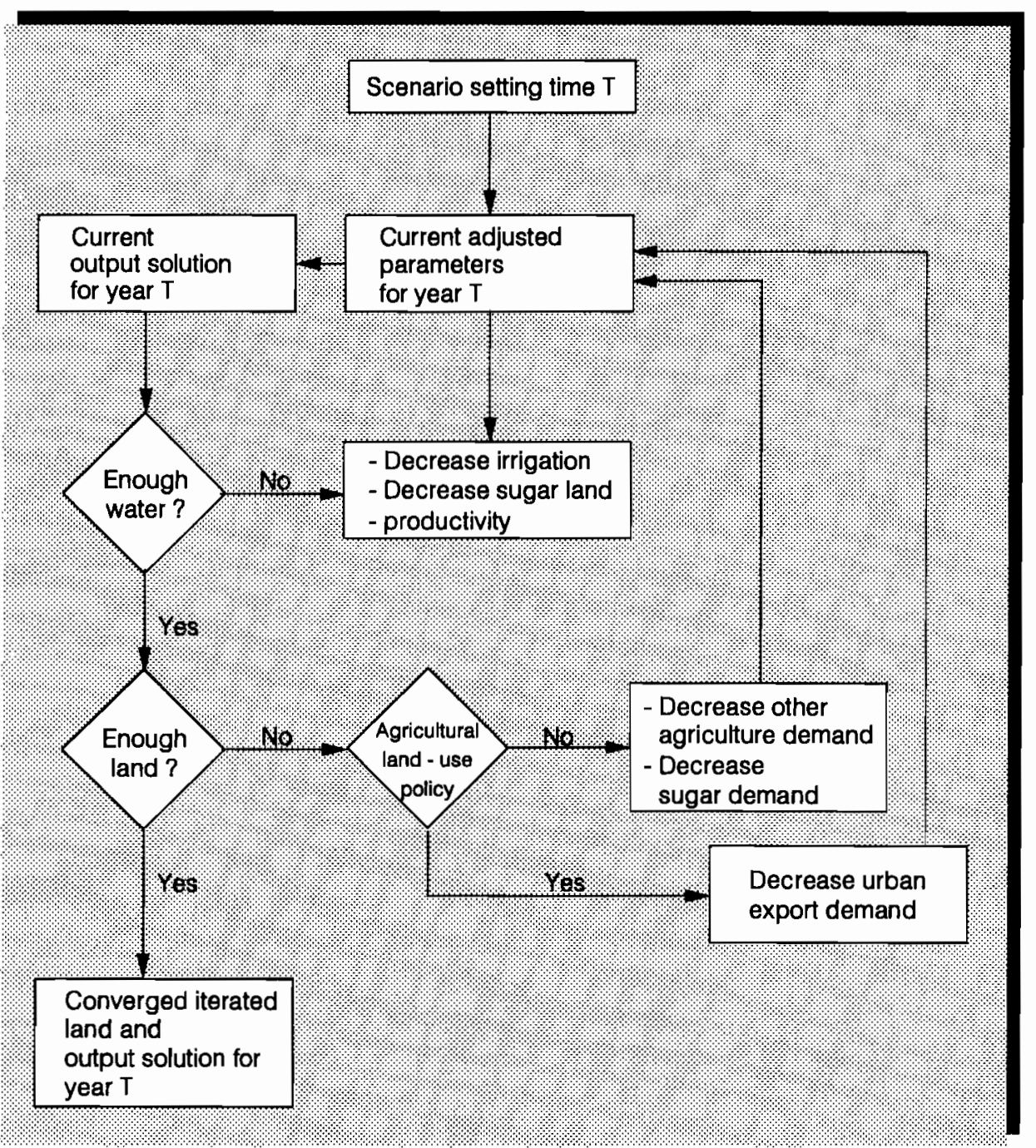

Figure 14.1. Overview of activity timing in the model.

by 15 percent: 8 percent of the total land area of the island. Over the same period, urban space increased by 215 percent, thereby increasing its share in the total island space to 7 percent. Other land-use changes have 


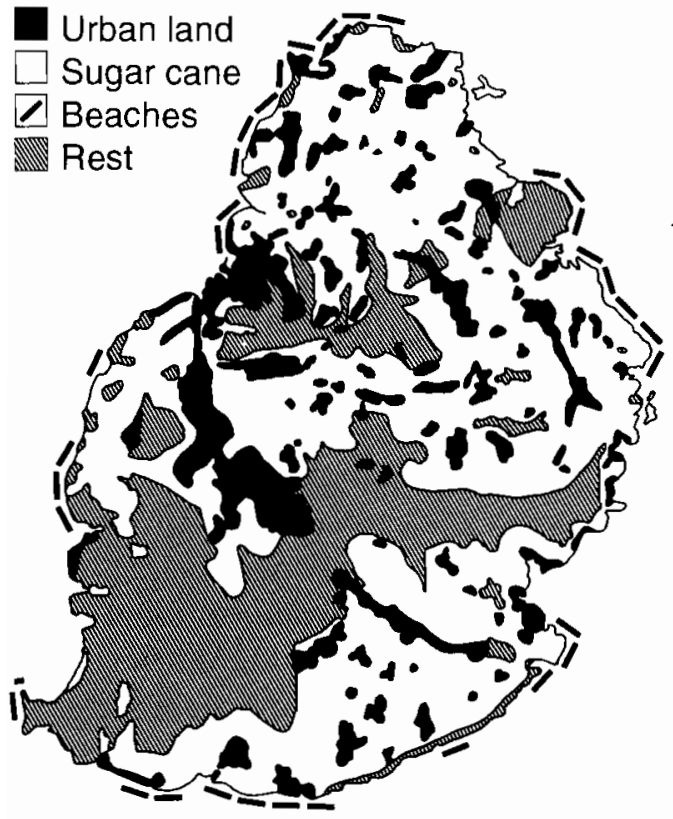

\section{Land use in Mauritius 1965 vs. 1986}

In hectare (thousands)

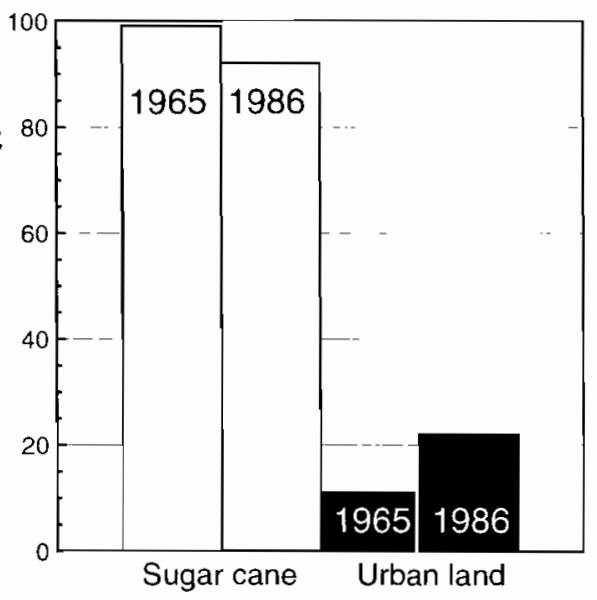

Figure 14.2. Land use in Mauritius.

also been economically significant. Tea production lost one-third of its former cultivation area, whereas land for production of foodcrops increased by approximately 50 percent to 1.6 percent of the total land.

The tourist industry, in addition, has demanded small but very scarce land resources, particularly during its period of rapid growth in the late $1980 \mathrm{~s}$. It is estimated that some 50 hotels on the beach now occupy almost $125 \mathrm{~km}$ of the coastline, which has a total area of $12.5 \mathrm{~km}^{2}$. Admittedly, this a small proportion of the total island space, but not a great deal more of the same kind is available. This land use directly competes with land use for recreational purposes, for example, public beaches.

For the purposes of the model, a crude classification of land use - as well as simple shortcuts regarding possible transitions - has been utilized. The model distinguishes between sugar-cane land, other agricultural land, urban land, and beaches. Sugar-cane and agricultural lands can be traded and transformed into urban land. Urban land cannot be reconverted to sugar-cane or other agricultural lands. Beach land cannot be transformed. 
The main simplification in the land-use module is that the transitions are primarily classified by category and area only - not by location. For example, the model calculates how much land is transferred from sugar-cane use into residential use during each period, but not the specific locations of the different sections of land transferred. There is no detailed spatial constraint on the transition. Suppose there is an extreme (and not actual) situation where all urban areas are surrounded by other agricultural land; the model would ignore this and still convert sugar-cane land directly into urban land. However, the aggregated results - changes in land use by category for the island as a whole - are not severely affected by this lack of spatial constraint. There is enough direct spatial contact between, for example, sugar-cane land and urban land for all calculated transitions to become possible. Urban land increases in accordance with user-specified policy options regarding the spatial distribution of future urban growth (concentrated around present main urban centers or decentralized growth of small urban centers). What is lacking is the certainty that the availability of suitable local land to transfer in specific surroundings would not act as a constraint on total land transition into urban use.

\subsubsection{Agricultural land}

Agricultural land use is divided into two categories in the model: sugar-cane land and other agriculture. These two categories can be transferred into each other in the model and can also overlap via intercropping. Intercropped land is that part of agriculture land simultaneously utilized for both sugar-cane cultivation and other agriculture. The user specifies the change over time in the percentage of other agriculture land that is also used for sugar cane. It is possible to take agricultural land out of use without transferring it to urban use.

Land demand for sugar growing and for other crops is determined by equation (14.1) - just as in determining commercial land use. Sugar and other agricultural land productivity change over time are set by the user, but this user setting might become partly endogenously overridden during execution. If there is a shortage of water for irrigation, agricultural land productivity decreases.

If total water demand on the island is larger than total supply - in a certain time period at a user-specified quality level - then as much as possible of the shortage is directly carried over to reduced use of irrigation in sugarcane agriculture, since it is the dominant consumer of water on the istand. 
Correspondingly, productivity is decreased. The user supplies a value (between 0 and 1 ) of an elasticity measure $\left(e_{t}\right)$, which summarizes the impact on production of irrigation cover, along with the importance of irrigation on production. The impact on production is channeled through the changed productivity of land. If $e=1$, then water shortages will reduce production proportionally; if it is 0.1 , then 10 percent less water than demanded will reduce production by 1 percent. The impact of user setting and water shortage is implemented as follows:

$$
l_{s, t}=l_{\text {user }, s, t}+e_{t} l_{\text {user }, s, t}\left(W S_{s, t}-W D_{s, t}\right) / W D_{s, t} .
$$

In equation (14.2), $s$ is the sugar-cane production sector; $l_{u s e r, s, t}$ is the part of land productivity set by the user; $W S_{s, t}$ is the available water supply remaining for sugar agriculture after satisfying all other water demands; $W D_{s, t}$ is water demanded by sugar-cane agriculture before correction (if there is an initial shortage, then $W D_{s, t}$ is equal to $W S_{s, t}$ after correction).

\subsubsection{Urban land}

Urban land use is treated as an absorbing state in the model: it is possible to convert agriculture land into urban use, but once that is done it remains urban land. The only source for urban land in the model is agricultural land, which - empirically speaking - is also the dominating origin. Urban land is primarily divided into commercial and residential land. The level of demand for commercial land is directly connected to the corresponding output of the economy's production sectors given in equation (14.1), whereas the demand for residential land is mainly a function of household consumption and land price:

$$
L D_{s t}=\left(h_{1} P_{t}+h_{2} C_{t} / h_{3}\right) \cdot 10^{-6} .
$$

Here $s$ is the residential sector only; $h_{1}$ is the minimum residential space per person (default $10 \mathrm{~m}^{2}$ ); $P$ is total population; $h_{2}$ is the share of private consumption spent on housing (default 9 percent); $C$ is private consumption; and $h_{3}$ is price (value) of residential land per $\mathrm{m}^{2}$. The parameters are set by the user for the entire scenario period over time. Hence, the elasticity of housing demand - with respect to income per capita - is assumed to be 1 .

\subsubsection{Beaches}

Beaches are regarded as the key resource for tourism. Following from this, all economic activity in the hotel and restaurant sectors is directly related 
to the length of beaches, even though many are not directly located on the beach. The beach land is divided in two categories in the model. The first category consists mainly of the present number of beaches used primarily by tourists. This is estimated to be some $125 \mathrm{~km}$ in length, based on descriptive material prepared by the National Physical Development Plan (NPDP, 1990) and the map of Mauritius (Figure 14.2). It is also assumed that this part of the coastal strip is the best, most attractive, and the one most easily used for tourism. Essentially, this land use is never changed by the model. What could be changed is, for example, the numbers and concentration of the tourists. In addition to these primary beaches, a list of potential secondary beaches - covering some $46 \mathrm{~km}$ - has been drawn up, based on the same sources. This land use includes hotels under construction, along with other parts of the coast that could be transformed into beaches for tourist hotels with some investments, regardless of present use. The assumption is implemented by giving secondary beaches a capital output ratio twice as high as beaches in the first category. (For a discussion of capital output ratio, see Chapter 13.)

\subsubsection{Other land}

"Other land" consists of mountains, forests, savannahs, grasslands, and meadows which currently are only marginally used in the economy of Mauritius (see Figures 14.2 and 14.3). It is possible for the user to redefine total available land for urban and agriculture by transferring some land to and from the "other land" category.

\subsubsection{Land-use competition}

In order to obtain a crude indicator of the degree to which a certain kind of land use contributes to the support and welfare of a population, one can use economic indicators such as production and consumption.

A comparison of value added and space requirements reveals that rural land use produces less than Rs 3 million per $\mathrm{km}^{2}$, whereas the economic activities on the coastal strip have been estimated at Rs 35 million per $\mathrm{km}^{2}$, and the different urban activities create values of some Rs 64 million per $\mathrm{km}^{2}$. These figures hint at the strength behind the economic forces geared toward substituting rural land for use by industry, urbanization, and export activities during a development process. 


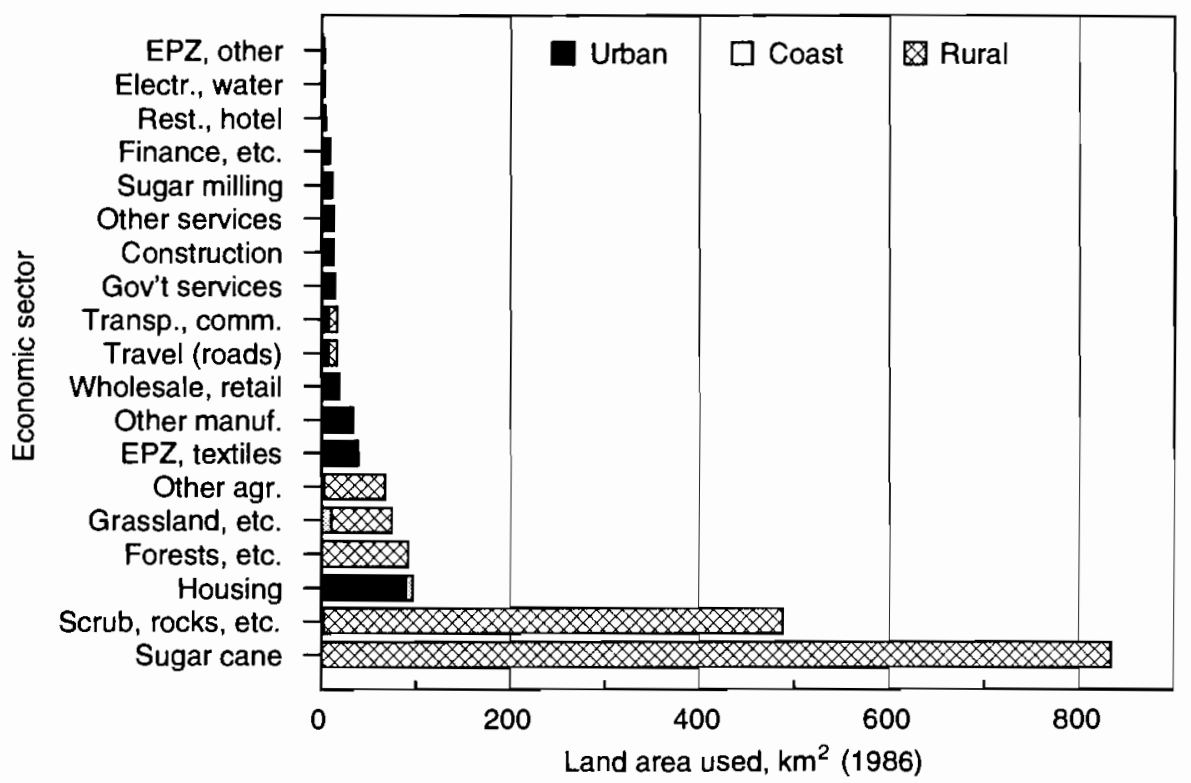

Figure 14.3. Land area used by economic sector and by land-use type.

For each period, the model produces new and different demands on each kind of land use from households and from the different production sectors. If exports and/or income per capita grows, then urban land demand increases unless, of course, the increase in urban land productivity increases faster.

In some scenarios more land may be demanded than is available. Therefore, implementing a mechanism for resolving land-use conflicts is unavoidable. This can be achieved through the market, by public planning, or through a combination of both. The market solution means that the activity with the highest profit per unit of land would be able to pay the highest price, get the land, and win the game. The public-planning solution means that the government allocates land for different purposes according to an adopted rationale. Most countries apply a combination of the approaches. Even in a predominately market economy there is often a market failure with certain kinds of land uses - such as investments in urban and interurban infrastructures. This is because there is no market which gives profit signals before the infrastructure is built. Rather, the market is created by public investment. 
The solution chosen for the model is also a combination of the two approaches. The market principle is used as the baseline mechanism, but the outcome can also be heavily constrained by public intervention. Two special policy options are explicitly formulated: "sugar policy" and "agricultural policy."

The market principle of allocating land cannot be directly implemented in the model as this requires markets with supply, demand, and resulting prices. However there are no markets or prices in the model, only demand at fixed prices and - in the case of land - a given supply. One can consider profit per unit of land as a substitute, but this is also based on (almost) fixed relations to total production rather than on market prices. In the model, profit per unit of land is almost proportional to production per unit of land, so the latter is certainly available as a substitute.

Figure 14.4 gives a detailed picture of the production of values per unit of land by the different sectors. Other agriculture produces more value per unit of land than sugar-cane growing. The consumption value of residential housing is higher than agricultural use of the same land, but considerably lower per unit of land in comparison to all other remaining sectors. In Mauritius, the production of value added per unit of land of tourist beach hotels is superior to all other land-use categories - including urban use.

The ratio of the extremes - tourist hotels and sugar cane - is 70 to 1. On average, urban activities produce at least 20 times more per unit of land than rural activities. Approximately 80 percent of the value produced or consumed is based on activities that occupy a mere 10 percent of the land area. Only sugar-cane production rates highly in both land used and absolute value added.

As can be seen, production or value added per unit of land varies tremendously between the main land uses: agriculture, tourism, and urban activities. Therefore, one further simplification of the decision rule for the model has been applied. Instead of monitoring the changes in production per unit of land over time, it is assumed that there is no variation over time of the ranking. This suggests a simple decision rule:

In the case of conflict, urban land demand wins over agricultural land demand unless a specific policy to preserve agricultural land is stipulated by the user.

If there is no policy stipulated, and if the land available for sugar and other agriculture is less than demanded when the urban land demand is satisfied, then both of the agricultural sectors decrease proportionally. The 


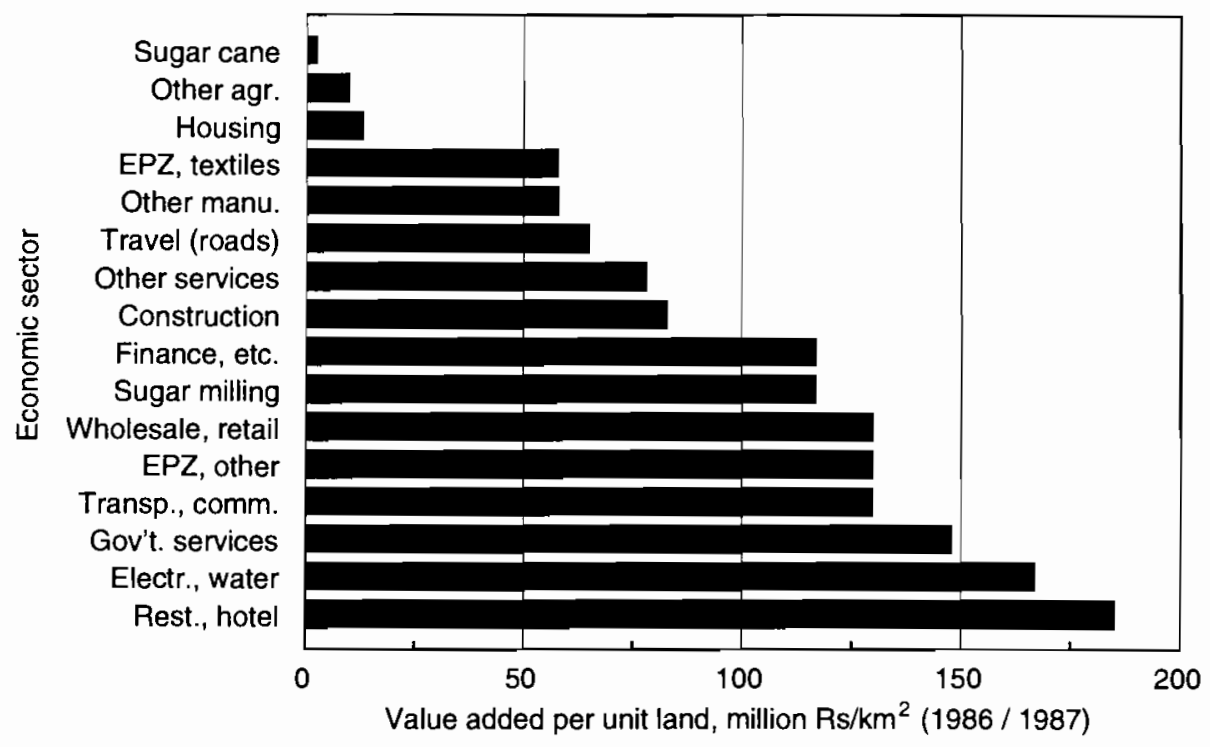

Figure 14.4. Value added per unit of land by economic sector.

decrease in demand for sugar land is initiated by decreasing export demand for sugar proportional to the land shortage. Decreases in other agricultural land demands are initiated by proportional decreases in export demands, and in domestic household demand for food. This decrease is exactly compensated by an increase in import demand from households. Urban land is not allowed to decrease, regardless of the development of land demand. Consequently, agricultural land cannot increase; but it may remain constant.

\subsubsection{Rural land policy}

Often, people find the solution to a land-use conflict that would be given by the market objectionable. Most countries and regions, for example, experience debates about the conversion of neighboring agricultural land into urban use. It is often the case that a country's largest and oldest towns are located in the middle of the best agricultural land available simply because of their function as service nodes for the population in their uplands. Historically, also, the majority of the population was farmers, necessarily concentrated in numbers in the best agricultural areas. Sometimes the location is also affected by a town's function as a trade or transit center in the 
transport, coastal, or river network. Opposition to further urbanization is strengthened by the argument that this land is not just average agricultural land, but often the very best agricultural land. This is promoted by a traditional overestimation of the importance of agriculture in all but the least developed economies, through the popular belief that self-sufficiency in food production is desirable, and by the fact that those surroundings often also contain large parts of the country's historical heritage: they are often the site of the most well-known cultural landscapes of the country.

Other arguments are also posed against urban proliferation. A dense and concentrated urban environment might be made more transport efficient with a program aimed at increasing the use of public transport and encouraging walking - which has the added advantage of reducing $\mathrm{CO}_{2}$ emissions. There is also the danger of a nitrogen time bomb being released into groundwater as a result of the change in land use, because continuous use of fertilizers has built up remainders in the soils, which in turn have been kept at a point of equilibrium by demands from currently grown agricultural crops such as sugar cane.

To facilitate an exploration of the economic and environmental consequences of putting constraints on urban growth, for whatever reason, two policy options have been prepared for the model. These have been labeled "sugar policy" and "agricultural policy." If the user specifies sugar policy, then sugar agriculture gets preferential treatment, and hence the land it demands even if the same land is demanded by urban activities. With an agricultural policy, then other agricultural land is maintained at its demanded level wherever possible. The main consequence of these policies is that urban growth is constrained, and hence the growth of various urban economic activities becomes restricted.

If there are both sugar and non-sugar agricultural policies, then the final demand in urban sectors is decreased proportional to the shortage of land. If there is only a sugar policy, then demand in urban activities and other agriculture is decreased first. If that is not sufficient, then sugar land demand is also decreased (via decreased sugar demand). On the other hand, if only an other agricultural policy exists, then other agriculture absorbs the land it requires from sugar land, and sugar demand is decreased so that its land demand fits its remaining stock of land.

The rural land policies might put a constraint on urban growth. If so, then final demand for exports from the urban sectors, as well as household 
demand for food and other goods, is reduced proportionally. The decreased domestic household demand is exactly compensated with increased imports.

\subsubsection{Settlement distribution}

The model calculates the increase in population, and in the total size of urban areas for the island as a whole, based on specific scenario assumptions regarding the development of population, economy, land use, and environment. In addition, the model calculates the spatial distribution of the total population for each year based on user-supplied assumptions about settlement behavior and policy. The results are presented on maps. The following alternatives are considered in the model:

1. Distribution proportional to initial number of inhabitants. This uncomplicated principle assumes population to grow at equal rates in all urban areas. Although simple, it is difficult to find empirical and theoretical support for this type of urban growth.

2. Distribution proportional to change in population 1985-1990. This alternative is based on the observed change in spatial population distribution on the island. The important observation is that it also produces a very different distribution compared to the result from alternative 1 . The difference is most obvious for Port Louis. Its population was almost unchanged during the period given, and the small increase that did occur was only the result of population momentum, since there was a net out-migration to several other areas near the capital city. However, at the same time there was a general ongoing local decentralization from the core of the densest towns to their surroundings: a process of decentralized concentration.

\subsection{Summary}

Because of its high degree of integration with the population and economic parts of PDE Mauritius, the land-use module cannot be run independently. The land-use module divides land into five main categories: sugar, other agriculture, urban, beach, and "other" noncommercial land. Land demand is determined by the economic output and the land productivities of each sector. In case of a land conflict, when more land is demanded than available, the model reduces the economic output according to specified priority rules. 



\section{Chapter 15}

\section{Modeling the Water Systems}

Ferenc L. Toth*

\subsection{Introduction}

This chapter is concerned with the water systems in Mauritius. Section 15.2 identifies water management and land use as the most important long-term environmental issues in Mauritius. Section 15.3 provides a brief overview of various components of water systems within Mauritius. The conceptual framework and principles of operation of the surface freshwater model, which includes water supply, water demand, and water balance, are described in Section 15.4. This section is followed by the presentation of the lagoon model in Section 15.5. Finally, Section 15.6 presents the user interfaces of the water models, through a discussion of the principles for scenario construction and the user-specified water-policy variables.

\footnotetext{
*This chapter is a substantially revised version of Toth (1992). The author is indebted to László Somlyódy and Toolseeram Ramjeawon for their comments on earlier versions. Special thanks are due to László Somlyódy and Günther Fischer for their help in developing and formulating the lagoon model. Any remaining errors are the sole responsibility of the author.
} 


\subsection{Water Management and Land Use}

Mauritius has, so far, been able to avoid the disruptive environmental implications of hard-core poverty and fast economic development. Although there are signs of environmental degradation, up to now they have not been very severe. Environmental problems in the past were largely episodic, localized events. Fly ash emissions from burning bagasse at sugar factories, dust releases at stone-crushing plants, and exhaust emissions from vehicles in congested urban areas are the most typical forms of air pollution (MEQOL, 1991). Due to massive fertilization of sugar-cane plantations, high values of nitrates ( 30 to $50 \mathrm{mg}$ per liter) have been measured at some groundwater extraction points, but they were short lived (CWA, 1991). There are also localized water-quality degradation problems in estuaries near urbanized or industrial areas, and in closed segments of the lagoons in the vicinity of high-density tourist locations. By and large, however, various components of the environment in Mauritius are still in relatively good condition.

Mauritian society has successfully completed demographic transition. Fertility rate dropped to near-replacement level within a few years in the late 1960s and early 1970s (Lutz and Wils, 1991; Xenos, 1991). The Mauritian economy is beyond the takeoff phase of economic development; real annual GDP growth rates scored between 5 percent and 9 percent in the mid-1980s; industry grew between 8 percent and 16 percent annually; and industrial investments doubled (Rs 747 million to Rs 1,480 million) between 1984 and 1988 (CSO, 1988a). Unlike in most LDCs, especially in the African region, future pressure on the environment in Mauritius will not originate with a fast-growing population, but rather with the increasing wealth of the slowly growing population which is expected to stabilize at 120 percent to 140 percent of the present population size (Prinz, 1992).

Now beyond demographic transition and economic takeoff, Mauritius has reached a critical phase of development. In less than a decade, the government has successfully solved the problems of the early 1980s: inflation, unemployment, balance of payment problems in the domestic economy and associated foreign exchange shortages, debt problems in the international economic relations. Now there is a possibility of looking further into the future to assess the full range of available development options (see, for example, MIIT, 1990). Current economic policies will shape the next cycle of investments and may lead to changes - desired or undesired - in the economy, society, and environment of the country. 
Today, there is increasing concern about longer-term prospects for economic development, and for the environmental quality to support it. An option that has gained some popularity in many developing countries is to speed up economic development at the expense of the environment and restore the environment later when it is easily affordable. This is simply not viable for Mauritius for several reasons. First, due to the small area and high population density, relatively small levels of degradation would be felt even in the short term, in the form of health effects for the population and natural resource constraints for the economy. Second, island ecosystems tend to be more fragile than their continental counterparts, making it possible that minor degradations may be irreversible. Third, the tangible finiteness of the resource base (soils, groundwater) on an island makes any loss much more painful than at other locations where reserve areas are available.

These concerns support the proposition that the sooner Mauritius finds its way toward sustainable development, the better. This was recognized in the late 1980 s by the government of Mauritius and several international agencies. As a result of their joint effort, a national environmental action plan was developed. This meant that Mauritius became the first country in Africa to implement an environmental strategy in accordance with the recommendations of the Brundtland report: economic growth and environmental protection are to be considered mutually reinforcing (Rathnam and Opsal, 1989):

The foundation of our national policy is: to protect and improve the environment as well as to foster harmony between the quality of life and sustainable development for the economic, social and cultural benefits of the present and future generations. [GOM, 1991, p. 1]

The geographical location of Mauritius reduces the usually long list of environmental concerns to problems related to water and land use. Although incidents of local visibility degradation and dust pollution are occasionally reported, their long-term impacts are negligible. Air pollutants are swept out by the almost constant medium-speed winds (between 7 and 16 knots) and distributed over the ocean. (In the least windy month of April, there are fewer than three days of calm altogether.) Deforestation was by and large completed by the 1930s leaving a meager 1 percent covered by native vegetation.

This situation leaves us with two major environmental and resource management issues. The first issue is one of allocating land to its most suitable 
use among the many competing land-use options (conservation, tourism, settlement, agriculture, industry), combined with a sustainable management of land use. These issues are addressed by Holm (1992). The second issue is a major concern for environmental management: water. This chapter deals with the surface freshwater system and the lagoons of Mauritius.

The highly acclaimed Brundtland report (1987) has been severely criticized for its failure to adequately address the issue of the role of water in sustainable development (Falkenmark, 1988). Humanity's interaction with the global water cycle has substantially intensified over the past few decades. Even more significant are the disruptions to, or degradation of, water resources on the regional and local scales in many parts of the world. The advantage that Mauritius has is that, being an island, inhabitants have complete control over their own water resource base.

Sustainable development in terms of water managements implies a longterm availability of water in required quantity and appropriate quality. The aims implicit in any meaningful sustainability study means that we are primarily concerned with gross, highly aggregated figures and indicators which detect and analyze imbalances at this aggregated level. As a consequence, attention to regional and seasonal imbalances are omitted in our waterquantity analyses, along with episodic high levels of pollutant discharges and the associated environmental damages.

The modeling approach for the water part of the Mauritius model system was selected to fit the purposes of a long-term, sustainability study. Additional selection criteria included the special characteristics of the hydrologic system of the island, and the availability of data on both quantity and quality aspects of natural water systems and water use from Mauritian sources.

\subsection{Overview}

Mauritius's hydrological network follows the typical pattern of small volcanic islands. Rivers originate in the center and flow toward the coast through a dense and heterogeneous river network. Were the island a perfect circle, the average river length would be $24.3 \mathrm{~km}$. Of the 93 rivers registered by the Central Water Authority, the shortest one is 130 meters long (des Galets), while the longest river is $38.4 \mathrm{~km}$ (Grand River South East). The average river length is $9.38 \mathrm{~km}$. 
In most regions, the rivers intersect with the rich and versatile groundwater systems of the island. A geological heritage of volcanic origin is present in the form of aquifers. These are permeable basaltic lava rocks that lie between two relatively impermeable strata. The aquifers receive their recharge in an area where they are exposed at the surface (mainly in the central plateau region). The infiltrating water percolates downward through openings in the rocks (spaces between the grains of sedimentary rocks, lava tubes, openings between lava flow layers) until it reaches an impermeable stratum at the bottom. At this point, water accumulates in the rock. Wherever the land surface intersects the water table, the water flows out as springs.

An example of the diverse relationships between surface-water and groundwater systems is found in the central-east region of Mauritius. River Françoise provides a significant amount of water to the underlying aquifer, while further downstream the same aquifer feeds Deep River, especially during the dry season. In the north, several perennial rivers (River du Tombeau, River des Calebasses, among others) are known to be connected to the aquifers of the region. In the south, flow values of River Tabac were observed to be connected to fluctuations of the water table in the region, indicating that there is a water transfer from the river to the aquifer (CWA, 1991).

This geophysical network is operated by the annual climate cycle. The moderate tropical climate dominating in Mauritius is characterized by two seasons. Rainy and warm summers (November to April) often bring tropical cyclones - which are sometimes devastating, but also provide large amounts of rainfall. In cyclone-free years, precipitation is normally not sufficient for surface reservoirs to completely refill and underground aquifers to fully recharge. Cool and dry winters (May to October) sometimes bring droughts, especially between September and November. The amount and spatial distribution of long-term average rainfall for four characteristic months are presented in Chapter 10. Average monthly rainfall data for the whole island are summarized in Table 15.1, and demonstrate that the annual distribution of precipitation in Mauritius is uneven though not extreme.

The relatively high annual levels of rainfall do not guarantee that a sufficient amount of water is always available. A major source of water loss in Mauritius is evaporation and evapotranspiration, both direct functions of the heat input which is in turn determined by the net global radiation. Data on sunshine hours (annual mean) and mean monthly temperatures (for February and August) are shown in Figure 15.1. The spatial distribution of the resulting mean annual evaporation rates is presented in Figure 15.2. 


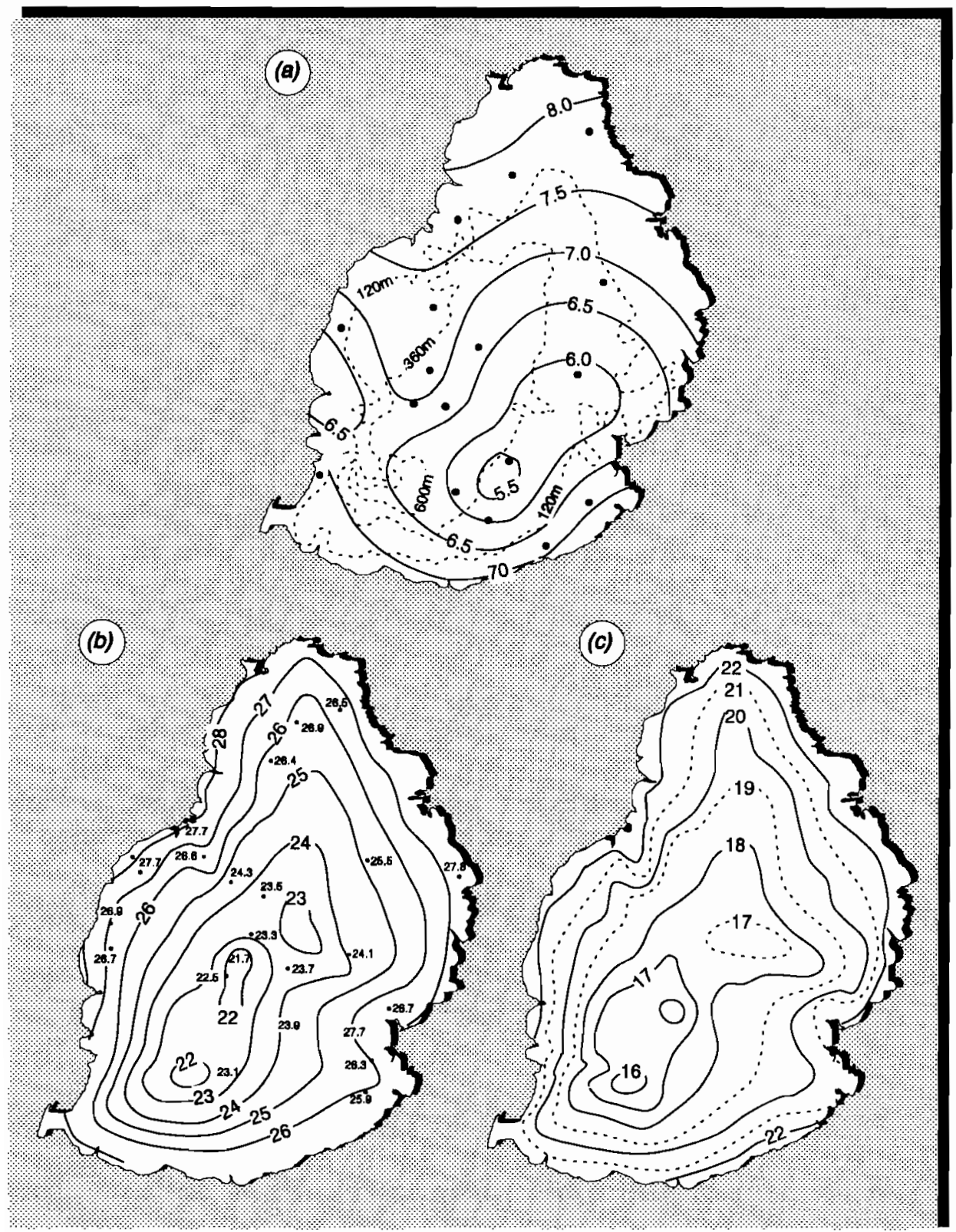

Figure 15.1. Radiation and temperatures $\left({ }^{\circ} \mathrm{C}\right):(a)$ mean annual duration of sunshine in hours per day; $(b)$ mean monthly temperatures in February; (c) mean monthly temperatures in August. Source: Padya, 1989. 


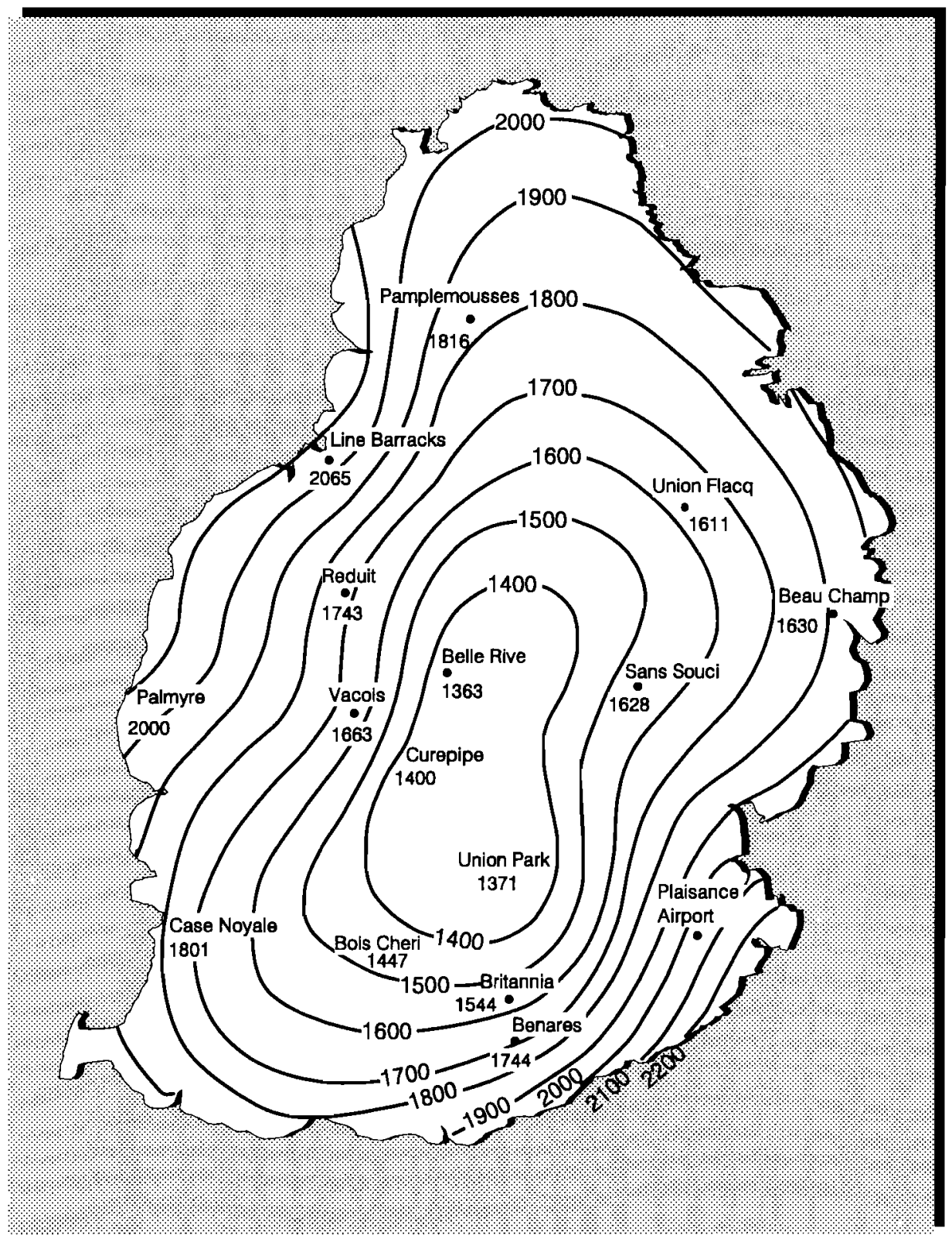

Figure 15.2. Mean annual evaporation (mm). Source: Padya, 1989. 
Table 15.1. Average monthly rainfall in Mauritius.

\begin{tabular}{lccccccr}
\hline Month & Jan. & Feb. & Mar. & Apr. & May & June & July \\
\hline mm & 295 & 280 & 309 & 216 & 161 & 140 & 133 \\
\% of annual & 13.9 & 12.2 & 14.5 & 10.2 & 7.6 & 6.6 & 6.3 \\
\hline Month & Aug. & Sept. & Oct. & Nov. & Dec. & Year & \\
\hline mm & 124 & 83 & 74 & 101 & 206 & 2,122 & \\
\% of annual & 5.7 & 3.9 & 3.5 & 4.7 & 9.7 & 100 & \\
\hline
\end{tabular}

Source: Padya, 1989.

Since the early days, people in Mauritius have increasingly interfered with the island's surface-water and groundwater systems. First, inhabitants of the island were fortress-minded and coast-bound. Their top priority was a well-protected and easily defendable port - as they depended on external linkages for their food supplies - and the availability of freshwater. Over the centuries, with the growth of population and the spread of economic activity, the natural conditions of the island were modified. Land was cleared for new sugar-cane plantations, thus modifying the rainfall-runoff conditions and evapotranspiration ratios. Water diversions were created to transfer water to areas where it was not available but was badly needed. Boreholes were drilled and pumping stations installed to utilize groundwater resources.

The present freshwater network includes 93 rivers in 47 river basins with more than one hundred diversions on rivers, five man-made lakes, two natural lakes, and nine storage reservoirs on the surface. The underground system includes four main aquifers exploited through 239 boreholes and small wells at the rate of 80,000 to $100,000 \mathrm{~m}^{3}$ per day. Major flows in the water system are presented in Figure 15.3.

This system has to support a water-intensive economy. An estimated one-fifth of the agricultural area is irrigated - approximately 15,000 hectares which is largely covered by sugar-cane plantations. The most important industrial sector is also a heavy water user: in $1987,2.83$ million $\mathrm{m}^{3}$ water was consumed by the textile industry, the bulk being used for dyeing textiles in the dye-houses. The water demand of the most successful sector of the 1980 s - the tourism industry - has also increased drastically. In itself, the high population density of the island suggests a high density of water use by the domestic sector. The demand for the supply of clean freshwater is projected to increase over the coming decades in each sector (CWA, 1989). 


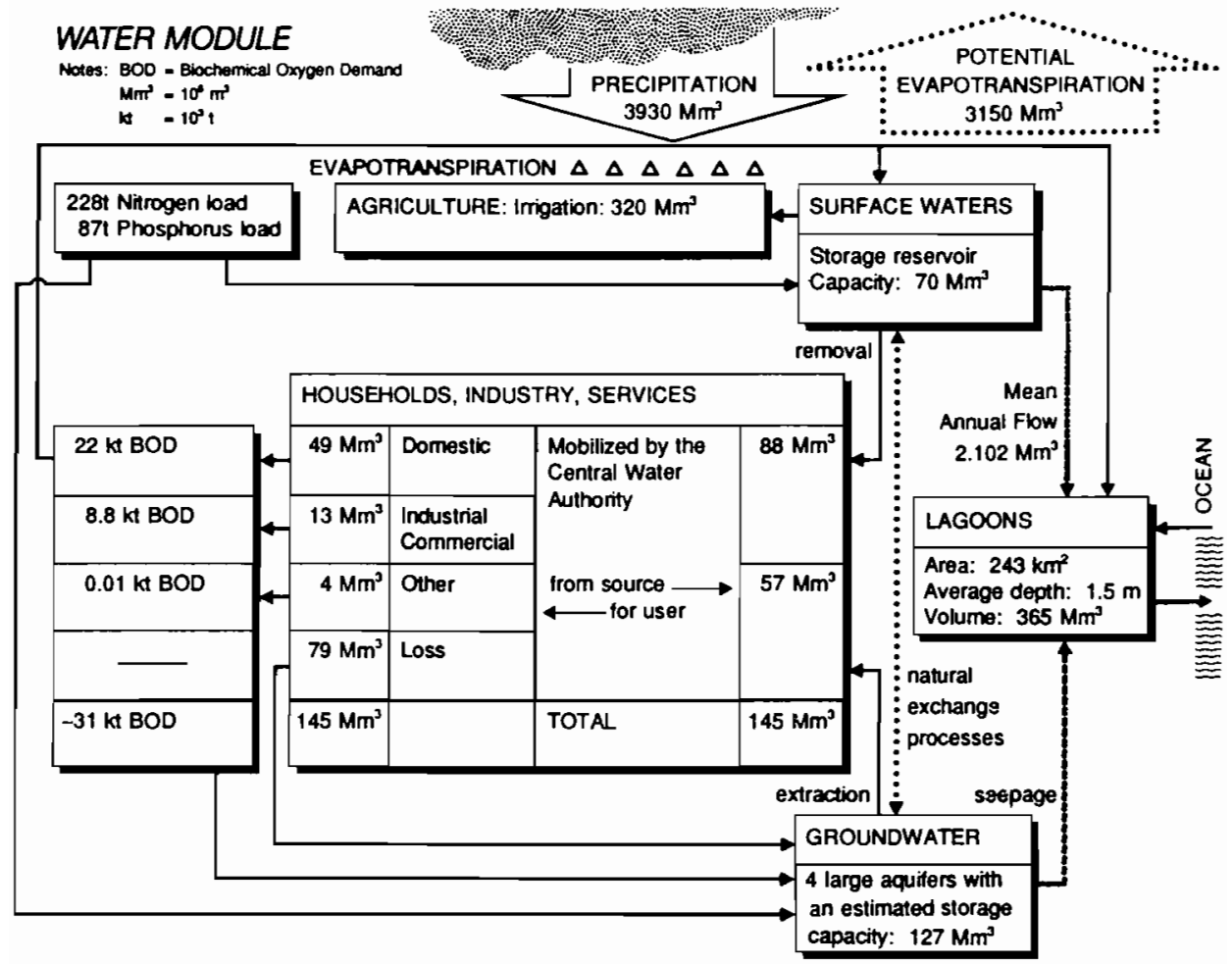

Figure 15.3. Major water stocks and flows.

In the past, the utilization of water resources successfully contributed to economic growth. However, increasing evidence indicates that this contribution has not been without a price. The high nitrogen levels ( 45 to $50 \mathrm{mg}$ per liter), which are occasionally measured in boreholes, especially in the northern and eastern regions during the sugar-cane planting period, are due to high levels of fertilizer use in the cane fields. Although there has been no apparent sign of an increasing tendency of nitrogen levels, these values may indicate that the buffering capacity of the soils is becoming depleted. Very little is known about the fate of industrial pollutants discharged with the wastewater. Dye-house effluents contain such pollutants as ammonia, chloride, nitrate, phosphate, and sulfate. Many dyes contain chromium and other heavy metals. Industrial effluents are discharged largely untreated. As the most typical waste disposal method is soak pits, most of these pollutants seep into the ground. There are no signs of any impact on the groundwater 
system yet, but if this practice continues the Mauritians may well be building an underground chemical time bomb for themselves.

Because rivers in the island are short and relatively fast-flowing, there is little chance for pollutants to undergo biochemical degradation. However, this also implies that the possibility for deposition of pollutants in river beds and sediments is also very limited. The ultimate result is that most pollutants are transported by rivers to the lagoons, which are formed by a barrier reef around most of the island's coastline. They are shallow, partly open, and partly closed bodies of water that are regularly renewed by a relatively large volume of tidal exchange. Despite this, signs of local degradation of both water and sediment quality have been detected in several segments of the lagoon. It is, therefore, important to trace the fate of pollutants in the lagoons by examining the potential accumulation processes and the long-term changes in concentrations of pollutants in the water and in the sediment.

Freshwater comprises a substantial part of the very limited natural resource base of Mauritius. Being a vital resource, there is a definite need to study the water constraints when we look at long-term development options and want to ensure the sustainability of development. Studies and models must include both quantity and quality aspects. This involves modeling both the resource and the waste-management implications of alternative development paths. The lack of appropriate data, together with the uncertainties associated with such long time horizons as the present project is examining, inhibits the building of very detailed models. On the other hand, there is no real need for them. The level of aggregation in the water model corresponds to that of the economic model. Despite this, the approach chosen makes it possible to analyze long-term trends and constraints and to find a sustainable development strategy for a long-term balance between water supply and water requirements.

\subsection{The Surface Freshwater Model}

The surface freshwater part of the water module is an integrated economicecological model covering both the quantity and quality aspects of water management. The primary objective of the model is to calculate the balance of water requirements (demand) and water availability (supply) for any given scenario of demographic and economic development according to the water policy specified by the user. 
Some of the basic ideas used in this model originate in a study prepared by the Resources for the Future (see Wollman and Bonem, 1971) in the 1960s. The RFF model in turn draws on the work done by the Senate Select Committee on National Water Resources (Wollman, 1960). The water supply section of the Committee report was considerably improved by a study conducted by Löf and Hardison (1966).

The present model considers Mauritius a single region. There are several arguments for and against this treatment. One could argue that the nonhomogeneous hydrological network, along with the uneven distribution of population and economic activities, would call for a regionally disaggregated approach. This would not be practical for several reasons. Firstly, the population and economic modules track demographic and development processes at the level of national aggregates. An attempt to decompose these processes for smaller regions would increase the complexity of the model to such an extent that would simply not be justifiable considering the area of the island. (The total area of Mauritius is far below the typical unit size in regional development and environment models.)

The second reason for the aggregated approach also follows from the small geographical size. It is relatively inexpensive to divert water from regions (watersheds) of abundance to those of shortage or to allocate waterintensive activities in regions where the resource is available. Similar arguments are valid on the water pollution side. One strategy would be to locate new polluting activities in regions where present discharge levels are low, thereby spreading pollution around an average level (the model does just this). Alternatively, one could concentrate these economic sectors in specific areas, which would make the provision of treatment facilities economically more efficient and reduce pollutant discharge altogether (this option is also available in the model).

Supply of and demand for water are specified by the physical quantities in the water model. An overview of the water model is presented in Figure 15.4. For each time step, the size of the population and the level and structure of economic activities are considered in order to calculate the demand for water. Demand is also affected by two water-policy variables, which in turn determine the dilution flow component of water demand (see below): firstly, the user's target for water quality, which is specified by the required water-quality standards for rivers; secondly, the user's decision about investments in wastewater treatment. 


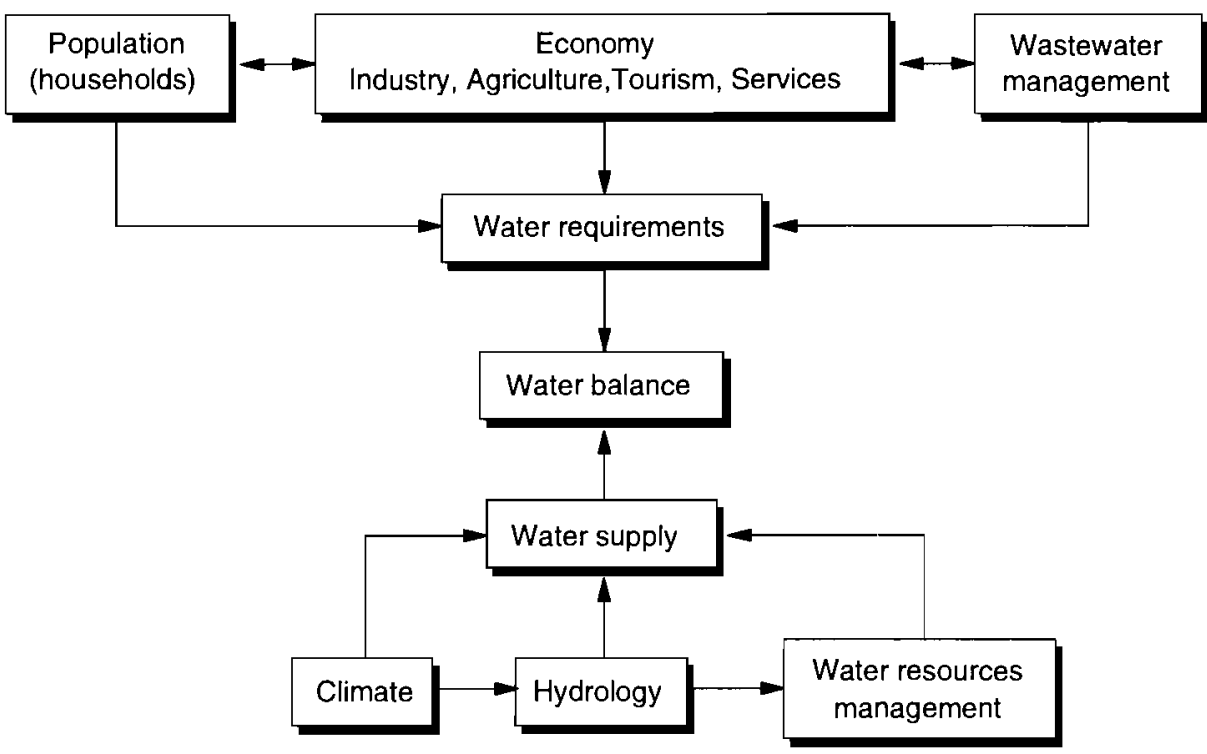

Figure 15.4. Overview of the surface freshwater model.

Water supply is calculated on the basis of historical flow data. The policy instrument available to the user to increase the supply of water is to invest in storage facilities - that is, to construct new reservoirs.

Finally, the water balance is calculated in each time step through a comparison of supply and demand. As irrigation is the single biggest component of water demand, and the bulk of the irrigation water goes to sugar cane, it follows that the water available for sugar-cane irrigation is the only feedback from the water balance to the other two models. The amount of irrigation water is automatically reduced to the level of water availability. This would, of course, affect sugar-cane productivity. Nevertheless, the model gives a warning to the user that a water deficit is detected in the current scenario run. It is then left to the user to experiment with the water-policy variables to establish whether water supply and demand can be balanced for the given scenario by implementing water policies that do not restrict irrigation. If this is not possible, the intended development path is clearly not sustainable due to natural resource constraints. 


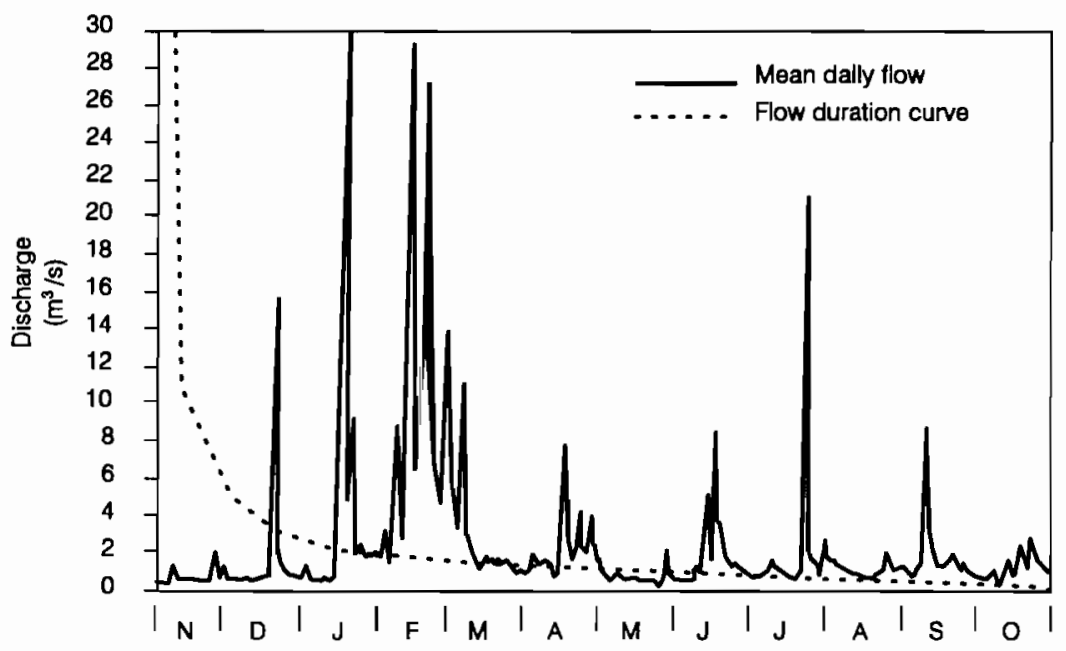

Figure 15.5. Typical flow duration curve for a high capacity river. Source: CWA, 1988.

\subsubsection{Water supply}

In this model, the supply of water is measured by aggregated minimum flow. This definition has three implications.

Firstly, water supply is measured by streamflow - the amount of water passing a gauging station or measuring device at any given time. Water supply is the frequency distribution of these measurements over time. The frequency distribution under natural (unregulated) conditions depends on the physical geography of the watershed. The amount of precipitation and its variation over time determine the "natural supply" of water; geology and topography influence the ratios for infiltration and runoff; and biogeography (vegetation cover) is the primary factor in evaporation losses (evapotranspiration). As presented in Section 15.3, the seasonal distribution of precipitation is uneven, though not extreme, in Mauritius. Correspondingly, flood flows are very ligh and low flows are relatively low, but most rivers are perennial. A typical flow duration curve is presented in Figure 15.5.

The streamflow approach to water supply implies that the model does not allow either water imports from outside Mauritius or the desalination of seawater. These options are unaffordable under present conditions, and are likely to remain economically inefficient over the long term (e.g., the 
use of desalinized seawater for irrigation). The model also assumes that aquifers discharge into a surface-watercourse, hence automatically including their contribution in the measures of surface flow. The diverse linkages between surface flows and the groundwater system were presented in Section 15.3. These linkages demonstrate the important role of groundwater in measurements of surface flows. There are no slowly recharging "stocktype" underground aquifers in Mauritius (like the Ogallala aquifer in North America or the huge aquifer under the desert in Libya), therefore groundwater abstraction and recharge processes can be considered additions and subtractions from the same resource of surface flows. A minor source of error can arise from the fact that past and present utilization of groundwater resources has not yet reached the maximum sustainable level. The historically observed minimum flow value should be revised upward, to the extent that additional groundwater mobilization can increase the minimum dependable flow (the bottleneck in the low-flow period), but this error is estimated to be below 3 percent. As long as groundwater abstraction and recharge are kept in balance, the model provides a reasonably accurate representation of the water resources.

Secondly, water supply is the minimum amount of water that is available at a specified level of reliability over time. It is also called the minimum dependable flow. In this model, the flow that is equaled or exceeded 95 percent of the time under present regulatory (storage) conditions is considered to be the present minimum flow. The minimum-flow approach fits the overall objective of our model system: to find water-management strategies that satisfy the water demand of the population and the economy over the long term, without extended periods of water deficiency when water-related activities would need to be reduced or temporarily suspended. Minimum dependable flow at 90 percent of reliability implies a 10 percent chance of deficiency. This corresponds to a deficiency period of more than one month every year when irrigation and water-intensive industrial activities, the two most important foreign exchange earners, would need to be reduced. The economic implications of regularly returning periods of extended water shortage would probably be severe. This supports the proposition that environmentally unsustainable development is also not affordable economically.

Thirdly, flow data from all watersheds are combined to provide the total amount of water available. Aggregated flow data indicate the sum of flow measurements from those gauging stations located closest to the discharge 
point in each watershed. Due to the special circumstances in Mauritius (irrigation is by far the biggest water user), and, because the relatively short 20-to-30-year flow records do not take into account the amount of water lost upstream via irrigation, the minimum flow data have had to be modified to keep the model consistent. This was achieved by increasing the level of minimum flow by the amount of water lost (evaporated and evapotranspirated) due to irrigation upstream in the period when minimum flow values were measured.

Virgin or unregulated flow conditions can be modified by adding storage capacities to the hydrologic system. The purpose of additional storage capacity is to smooth the flood frequency curve by retaining water from flood flows and using it to increase the level of minimum dependable flow in periods of low flow. The theoretical maximum flow that could be achieved by maximum regulation is the mean annual flow. This is the level of water supply when the surplus flow gained from additional storage is equal to the evaporation losses resulting from the newly added storage facility.

Flood control storage requires special treatment in this formulation of a flow-storage relationship. Due to specific operating considerations, storage capacities created explicitly for flood control purposes are only partially useful for minimum flow regulation. As the river basin approaches maximum regulation, the need for separate flood control storage capacity decreases. The model takes care of this assumption by including only that fraction of existing flood control storage corresponding to the ratio of present (actual) flow to maximum attainable flow. It turns out that none of the reservoirs in Mauritius is explicitly operated as a flood control storage facility. Regardless of this, the procedure to handle flood control storage has been implemented in order to keep the model general and easy to implement for other countries.

The data base of the model includes inventories of past and possible future storage facilities. Data in the past reservoir inventory (PRI) include the most important parameters of all reservoirs completed before the base year of the model, such as purpose (irrigation, flood control, hydroelectric, recreation, or mixed), capacity, and depth. Similarly, data in the new reservoir inventory (NRI) cover all possible sites where future reservoir constructions are either planned or being considered by the Central Water Authority. Again, the parameters include purpose (as above), location, capacity, depth, surface area, evaporation rate, total cost, and cost per unit of storage capacity (Rs per $\mathrm{m}^{3}$ ). 
The user's water policy, related to water supply, is entered in the model via the NRI table. The most relevant data in the table are displayed under the appropriate submenu in the scenario-setting phase. The user can decide which reservoirs should be constructed and when by entering the year in which construction should be started. The total costs are automatically accounted for, in the economic model, under the government expenditures category. Completion is assumed to take five years with the newly built storage beconing available at the beginning of the next period.

The supply section of the model begins by calculating the initial flood control storage - that is, the total amount of storage capacities that were built primarily for flood control purposes prior to the initial year of the model. This capacity would gradually be included in the available total gross storage at the rate at which total capacity is approaching full regulation.

For each time step (every five-year period), the model calculates the present minimum flow - that is, the level of water supply. The procedure is started by determining the present total gross storage by adding the newly completed storage capacities (depending on the user-specified investment decisions) to the already existing storage capacity. Due to the special treatment of the initial flood control storage capacity, some adjustment is necessary. The present total available storage is computed by adding a fraction of the initial flood control storage (according to the ratio of the present net flow in the previous time stop to the mean annual flow) to the present total gross storage.

The flow-storage function describes the relationship between the total storage capacity available for flow regulation and the level of minimum sustained flow. The next step in the model makes use of the flow-storage function to determine the present gross flow from the present total available storage. The resulting value, however, needs to be adjusted for the evaporation losses from the newly completed reservoirs.

Evaporation losses from existing storage (from those completed before the base year) are already captured by the historical flow data. The evaporation loss rate is derived by subtracting the basic evapotranspiration rate of the vegetation cover before the reservoir was constructed from the reservoir evaporation rate. Total evaporation loss is then the product of evaporation loss rates and the area of reservoirs.

Finally, present net flow is calculated by reducing the amount of gross flow according to the total evaporation losses. This, then, gives the level of water supply on which the population and the economy in Mauritius 
can count on with 95 percent reliability. Results from the demand section of the model determine whether it is sufficient for the given socioeconomic development scenario.

Depending on the user's decision, this procedure can be used in the model to test water availability with a reliability of 98 percent. In this case, a modified flow-storage function is used to determine the actual flow values. In addition, the model makes it possible for the user to study the impacts of unusually long drought periods. For these experiments, the level of present net flow is reduced according to a user-specified shortage ratio.

\subsubsection{Water demand}

The demand for water in this model is also expressed in physical quantities. Water demand represents the total amount of water required for various uses. Hydrologists and water managers distinguish three categories of water use: withdrawal uses, when water is physically removed from the natural watercourse (households, industry, agriculture, services); on-site uses, for which the amount of water available in the watercourse is critical (navigation, water required to keep the ecological balance of swamps and wetlands or to control soil erosion); and flow uses, when the rate of water availability is the key factor (hydroelectric power generation, waste dilution, estuary maintenance). Some uses do not affect water quality, while others severely downgrade the quality of water when the water returns to the natural watercourse. Some uses return practically the same amount of water as was diverted, while other uses such as irrigation result in high rates of water loss.

Due to the size, geographical characteristics, and hydrological conditions of Mauritius, and partly due to data limitations, two components of water demand are considered in this model: losses from withdrawal uses and the dilution flow required to keep water quality in streams and rivers above the standard values. Through these components, water quantity and quality considerations are linked in the model. Total water demand is expressed in streamflow (e.g., $\mathrm{m}^{3}$ per second) and is comparable to water supply.

\section{Withdrawal Losses}

There are two components of losses associated with water withdrawals for use in households and the economic sectors. The first component is net water consumption, which is the amount of water not returned to the natural watercourse because it was evaporated, transpirated by plants, incorporated 
into products, or used another way. The second follows from a special feature of wastewater management in Mauritius: a considerable fraction of residential and industrial sewage is directly discharged into the lagoons. (There are plans to extend sewage outfalls beyond the reef and discharge sewage into the ocean.) This water is lost as a freshwater resource, thus the direct discharge part of water loss includes the total amount of wastewater which is discharged into receiving media other than rivers and ground.

Net water consumption is derived from the population module for households and from the input-output model for the economy. Specific gross intake figures $\left(\mathrm{m}^{3}\right.$ per person-year and $\mathrm{m}^{3}$ per million rupees of output) were calculated from the 1987 input-output table, irrigation data, and water statistics of the Central Water Authority. Total gross water intake, in each time step, is computed by the model using actual population size and actual levels of economic activity in each sector. For each present (and possible future) sector of the economy, rates of loss are also estimated, indicating what fraction of the water intake is used up (evaporated, incorporated into products, etc.) by the given sector. Net water consumption is then calculated from gross intake values and rates of loss.

Direct discharge, the second component of withdrawal losses, accounts for the amount of water which is not returned to the freshwater course, but rather discharged into salty waters - in the case of Mauritius, the lagoons. Direct discharge is calculated in this model by reducing the amount of return flow (gross intake minus net consumption) according to the ratios of wastewater discharge into lagoons and, when appropriate, the ocean.

\section{Dilution Flow}

Required dilution flow is calculated according to the user-specified waterquality standards from the amount of pollutants discharged into streams and rivers after various levels of wastewater treatment. Three types of pollutants are considered in this model: organic wastes expressed in terms of biochemical oxygen demand (BOD), nitrogen (N), and phosphorous (P). Required dilution flow is calculated for each pollutant, and the largest of the three values is taken as the ruling dilution flow.

Specific gross BOD discharge rates (kg BOD per person-year and $\mathrm{kg}$ BOD per million rupees of output) were derived from the 1987 input-output table and various studies conducted by the Central Water Authority. These specific values are combined in the water model with actual population figures from the demographic model, along with the structure and levels of 
economic activities in the input-output model, in order to provide gross BOD production values for each of the 16 sectors ( 15 economic sectors and the domestic sector).

Although the current level of wastewater treatment in Mauritius is very low, the model provides the necessary tools to analyze the environmental impacts of alternative development strategies on both waste production and waste management, as well as to keep track of costs and necessary investments to prevent environmental degradation. Four levels of treatment are considered in the model: no treatment (raw discharge), primary treatment, secondary treatment, and tertiary treatment. Fractions of wastewater, from all sectors subject to one of the three real treatment levels, depend on the amount of sewage generated and the available treatment capacities.

For each period in a given scenario run, the user can allocate money to construct new treatment capacities for each treatment level. Specific treatment costs include annualized construction and operating costs per $\mathrm{m}^{3}$ of wastewater treated. Newly added treatment capacities are derived from a combination of the investment decisions specified by the user and the specific treatment costs stored in the model's data base. Thus, new treatment facilities can become available with a one-period delay. Given the updated inventory of treatment capacities, the model calculates what fraction of wastewater from the different sectors is going through each of the four levels of treatment.

Based on the treated amount and the efficiency of treatment, we get the total amount of pollutant discharge. Only part of the total wastewater discharge goes into rivers. Therefore, only the fraction discharged into streams and rivers is considered when we calculate the required dilution flow. For BOD, a simple biodegradation model is used to calculate the level of flow necessary to meet the water-quality standard specified. The biodegradation model calculates the waste assimilation capacity of the freshwater system. It is based on the amount of water available for the re-oxygenation process, and the specific reaction coefficients characterizing decomposition and re-aeration processes under Mauritian conditions.

The procedures to calculate the required dilution flows for nitrogen $(\mathrm{N})$ and phosphorous (P) are quite similar. Amounts of discharge are linked to amounts of BOD discharges through sector-specific ratios. Sectors 1 and 2 (sugar-cane production and other agriculture) are notable exceptions; no BOD is produced in the sugar-cane sector, but the amount of $N$ and $P$ leaching into the groundwater and rivers are significant due to high ratios of 
fertilizer use. There is some BOD discharge from the other agriculture sector because it includes animal husbandry, but it is impossible to keep track of its share from the total output value in the input-output model. Wastewater discharge from the animal husbandry sector goes to the ground anyway, so it does not affect the quality of inland surface waters and the quality of water in the lagoon. Therefore, only the $\mathrm{N}$ and $\mathrm{P}$ loads to rivers from other agriculture is taken into account. Parts of the $\mathrm{N}$ and $\mathrm{P}$ discharges will be consumed in biodegradation processes. Actual amounts depend on BOD availability and on the ratio at which $\mathrm{N}, \mathrm{P}$, and $\mathrm{BOD}$ enter these processes. Any remaining amounts of $\mathrm{N}$ and $\mathrm{P}$ need to be diluted according to the userspecified water-quality standards. These procedures provide three values of minimum flows which are necessary to dilute the amounts of BOD, N, and $P$ reaching the surface freshwater system in Mauritius. The ruling dilution flow will be the highest of these three required flows.

\subsubsection{Water balance}

The sum of the required dilution flow and withdrawal losses is taken as total water demand. It is expressed by flow ( $\mathrm{m}^{3}$ per second) in order to make it comparable to the level of water availability, which is also calculated in terms of streamflow. The resulting water balance is reported to the user, together with other results of the model.

The only implication of a negative water balance on the demographic processes or economic development is the reduced availability of water for irrigation. Unless there is a real danger of absolute water shortage when the physical quantity of water is insufficient or the water is so polluted that it cannot be used even for the least demanding industrial purposes - which is not the case in Mauritius - this approach is realistic. Poor water quality does not necessarily inhibit economic growth. Witness the Chao Phraya River which has been practically dead for years, yet Thailand's economic growth - headquartered in Bangkok - still continues at double digit rates.

In particular, there is no feedback to the population module in the form of increasing mortality or morbidity rates. Despite increasing evidence that various forms of environmental pollution affect the health status of the population, these relationships are difficult to quantify. Therefore, any attempt to include this linkage in a simple aggregated model like the one built for Mauritius would have resulted in obscure relationships. The model does not include economic feedbacks either. There is no penalty for increasing costs 
of providing potable water due to higher treatment requirements from river abstraction points when water quality in rivers declines. These are clear deficiencies of the model, but they cannot be avoided if we want to keep the model defendable. The information provided by the surface freshwater model is nonetheless useful and important for the user. In Section 15.6, its uses for formulating water policies are discussed.

\subsection{The Lagoon Model}

The coral reef surrounding the island of Mauritius encloses a shallow body of water. The reef extends over 70 percent to 80 percent of the coastline at a distance of from one hundred meters to several hundred meters. There are both positive and negative consequences of this formation. On the positive side, the barrier reef breaks the high energy waves of the ocean far off the coast, thus significantly reducing coastline erosion and beach erosion. On the negative side, however, the reef traps part of the pollutants from inland. This leads to considerable degradation of water and sediment quality, especially in the closed parts of the lagoon.

The coral reef itself is in danger. Coral and coral sand are extracted at rates far above natural replenishment (Manrakhan, 1991). Shells and fish are selectively removed by both spearfishing and aquarium collecting (GOM/World Bank, 1988), thus disturbing food cliains and the ecological balance. Raw sewage being pumped into the lagoons is also killing the living coral. Still existing illegal fishing methods using explosives and the use of chemicals (poison) by aquarium fish catchers (World Bank, 1989) are the main coral killers. An estimated one-third of the corals is already dead.

The economic value of the lagoons is significant. The Ministry of Economic Planning and Development (MEPD, 1988) estimated the economic value of various activities related to the lagoons at Rs 2.8 billion per year. Direct employment in these activities involves more than 10,500 people. Some 98 percent of the economic value and 73 percent of employment is associated with the tourism industry.

It follows that the reef and the lagoons play an important role in maintaining the environmental quality and economic prosperity of the island. Therefore, the future of the lagoons must be addressed by any sustainability study concerned with the management of the island's limited natural resources. 


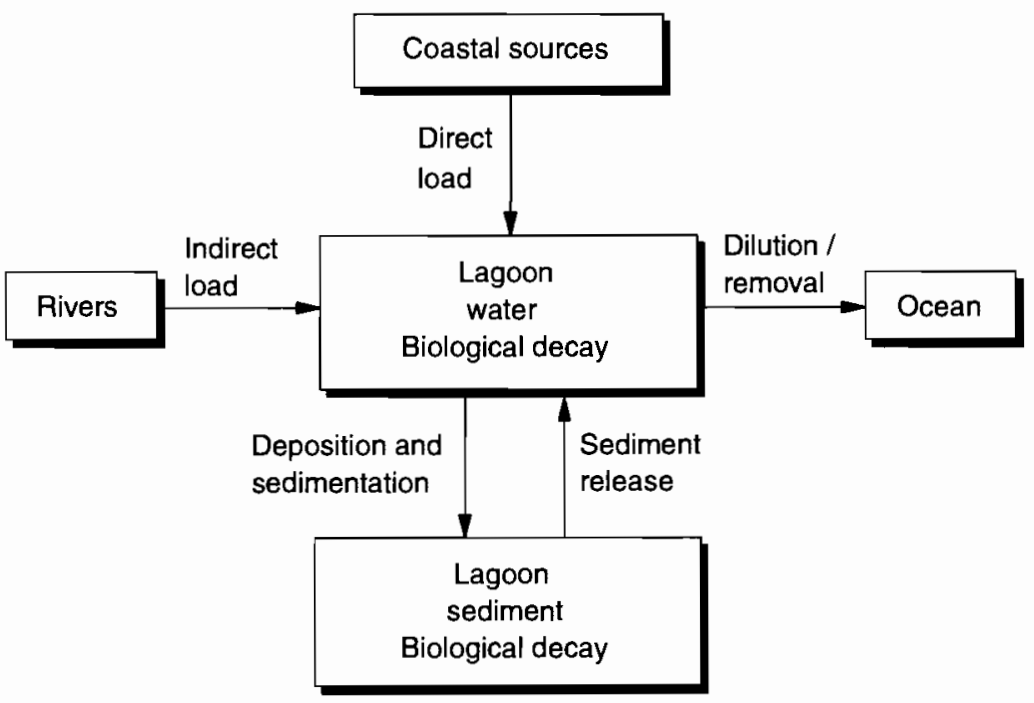

Figure 15.6. Pollutant flows in the lagoon model.

The lagoon model of the water module is a simple two-box model which keeps track of the pollutants reaching the lagoons. An overview of the model is presented in Figure 15.6. The first of the two large boxes represents water quality - that is, the concentration of pollutants in the lagoon water while the second box represents the quality of the sediment. The two boxes are linked by a series of exchange processes, and their dynamic behavior is modeled by a pair of inhomogeneous differential equations.

The surface freshwater model, presented in Section 15.4, keeps track of three pollutants (BOD, nitrogen, phosphorous) as they are generated, treated, and discharged. There are two sources of pollution load to the lagoons. The first source is direct discharge, and includes the amount of pollutants discharged directly from the sources located near the coast or via one of the four sewage outlets to the lagoon. The second source of lagoon pollution is the rivers system. The amount of pollutants discharged to rivers is reduced according to a simple biodegradation model, the remainder being added as pollutant load to the lagoon.

In the model, six processes affect the concentration of pollutants in the lagoon. The quality of water is decreased by the incoming flow of pollutants (direct discharge and via rivers). Pollutant concentration is decreased by a 
biological decay process. The amount of water delivered to the lagoon by rivers causes the same amount of outflow from the lagoon, thus removing the corresponding amount of pollutants from the lagoon. Tidal water brings significant amounts of water to the lagoon in a regular cycle. This water dilutes pollutants in the lagoon water and removes part of them with the low tide. The rate of dilution depends on turbidity and the rate of exchange - that is, the ratio of the volume of water coming in with the tidal waters to the volume of water in the lagoon at low tide. The current version of the model assumes complete mixing, taking the whole lagoon volume as effective volume.

The process of sedimentation also reduces the concentration of pollutants in the water by depositing and accumulating pollutants in the bottom sediment. Depending on the relative concentration of pollutants in the water and in the sediment, this process can also go in the opposite direction. In this case, the sediment is releasing pollutants back to the water. The rate of sedimentation is a function of turbidity and pollutant concentration.

The accumulation of pollutants in the sediment is primarily driven by the concentration of pollutants in the water. Deteriorating water quality (higher pollutant concentration) leads to more intensive sedimentation and results in increasing accumulation of pollutants in the sediment. Depending on the oxygen balance of the sediment and the availability of oxygen in the system, part of the deposited pollutants will undergo biological decay in the sediment. In turn, high pollutant concentration in the sediment will increase the internal load of pollutants as a result of a higher level of sediment release. The process also works in the opposite direction: if external pollutant load is reduced and water quality thus improved, internal load will decrease as well with a certain time lag.

While in the case of the surface freshwater system the aggregated approach is appropriate for purposes of the present model system, it is much less defendable for the lagoon model. Extended parts of the coastline, especially in the south, are completely open and the coral fringe is missing altogether. Pollutants discharged or delivered to the ocean in this region are immediately diluted and washed away by the ocean. At the opposite extreme, closed segments of the lagoons in the vicinity of outflows of polluted rivers and dense industrial and tourist areas show signs of severe degradation. These parts of the lagoons receive much more pollution per unit of water volume, while processes of pollutant removal (outflow, biological decay) are limited. Averaging out these regional differences is a serious source 
of error in the current version of the model. Despite intensive efforts, however, it was impossible to get access to the appropriate data that would have made regionalization of the lagoon model possible. Yet, the possibility is there. The same model could be used for one or more selected segments of the lagoon by replacing current aggregated values by appropriate parameters (volume, area, pollution load, rates of deposition, decay, etc.) characterizing the lagoon segment at hand.

Also due to lack of data, the only pollutant considered in the current version of the lagoon model is BOD. With the appropriate data on nitrogen and phosphorous available, the model could easily be supplemented with a simple eutrophication model. Yet again, this extension would only make sense for a regionally disaggregated version of the lagoon model.

Results of the lagoon model are reported to the user together with results of the surface freshwater model. The two most important output variables are the pollutant concentration figures for the water and for the sediment.

There is no feedback from the lagoon water quality to any other part of the system. This means that deterioration of the lagoon can reach arbitrarily high levels without any implication on the population or the economy. This is, of course, unrealistic. It is obvious from the economic data presented at the beginning of this section that a major loser due to polluted lagoons would be the tourism industry. Yet, it would take heroic assumptions to quantify the decrease in tourism demand as a function of pollutant concentration in the lagoon. Considering the Mauritian aspiration to discourage cheap, package-tour tourists and attract the "upmarket clientele" of the "high-spending segment of the long-haul affluent markets" (MEQOL, 1991 , p. 224), a decline of the tourism sector would be rather steep as a result of declining water quality in the lagoon.

If the user is not satisfied with the long-term trend of water quality in the lagoon as it was reported from a given scenario run, the most useful option available is to increase sewage treatment. By investing in additional wastewater treatment facilities, pollutant content of the direct discharge and the amount of pollutants delivered by rivers can be reduced. The fate of pollutants, once they get to the lagoon, is largely governed by natural processes, so there is not much a manager could do. In situ, rehabilitation techniques like sediment dredging or sludge removal are not pernitted by the current version of the model, although they could be considered for a disaggregated version. 


\subsection{Scenarios and Water Policies}

In the water module it is not possible to predefine exact scenarios at the beginning of a 60 -year time horizon. Water requirements and water quality will depend on the user's economic and social policies, along with what lappens in the population and economic models as a result. Models in the water module measure the environmental implications of the given population and economic development scenario in terms of water balance in the inland surface-water system and in terms of water quality in the lagoons. The only resource constraint defined in the form of a direct feedback relationship is between the surface-water model and the economic model. When water shortage is detected by the model, the amount of water available for irrigation will automatically be reduced to restore the water balance. Reduced irrigation leads to lower yields and lower sugar-cane production. This implies that the user should apply a trial-and-error approach by resetting the water-policy variables for the same demographic and economic scenarios, should it be found that the results are not satisfactory in terms of water availability and/or water quality.

\subsubsection{Water-policy variables}

There are three groups of variables in the water module that reflect the user's preferences or intentions in terms of water management. These are: required water quality standards (RWQS), investments in treatment, and investments in storage. Since the model combines quality and quantity aspects, water balance requirements for any given scenario of population and economic development can be met by a large set of combinations of the three policy variables. The principal difference between the quality standards and the other two variables is that the former reflects the user's preference for environmental quality, whereas the treatment and storage variables are the basic instruments to achieve the given environmental quality.

Thus, the scenarios can be classified by the following target environmental qualities:

- Moderate. RWQS is $4 \mathrm{mg}$ per liter for dissolved oxygen (DO), $10 \mathrm{mg}$ per liter for $\mathrm{N}$, and $0.1 \mathrm{mg}$ per liter for $\mathrm{P}$; these are the current environmental standards in Mauritius and also the default values that appear in the scenario-setting menu. 
- High. RWQS for DO could be pushed as high as $6 \mathrm{mg}$ per liter, while they can be reduced to $5 \mathrm{mg}$ per liter for $\mathrm{N}$ and to $0.05 \mathrm{mg}$ per liter for $\mathrm{P}$.

- Low. RWQS for DO can be reduced to $1 \mathrm{mg}$ per liter, while permitted $\mathrm{N}$ and $\mathrm{P}$ concentrations can be allowed to increase up to $30 \mathrm{mg}$ per liter and $0.3 \mathrm{mg}$ per liter, respectively.

Due to the nonlinearities characterizing the system both on the input side (pollutant discharge vs. treatment) and on the impact side (eutrophication, biochemical degradation, and other processes), small changes in the RWQS parameters tend to generate major shifts both in the water balance (calculated and reported by the system) and in the induced environmental impacts (not represented in the system).

Water-management strategies are specified by allocating investments in wastewater treatment and water-storage facilities. Again, there are major differences associated with each option. Investments in treatment reduce the overall load on the water system by abating pollutants before the wastewater is returned to the natural watercourse. They also reduce the required dilution flow necessary to maintain the specified RWQS. In contrast, investments in storage will increase the minimum sustained flow, thus the amount of flow available to dilute pollution discharge in order to meet the specified RWQS will be higher. In the short rivers of Mauritius, however, biochemical degradation is limited. Therefore, the use of increased dilution flow as a strategy to maintain water quality in the rivers implies a pushing out of the problems to the lagoons, which will thus receive much higher pollutant loads than they would under a treatment-oriented strategy. Additional flaws of the storage-oriented strategy include the land area lost due to inundation to construct dams and reservoirs, along with other environmental impacts of dam construction and operation. Nonetheless, both the treatment and storage options are available in the model.

The attempt to define sensible scenarios for investments in either treatment or storage should be based on knowledge of the economic development scenario. Some directions in economic development imply heavy increases in the "production" of water pollutants included in our model, others may imply discharge of pollutants not included, and still others may not affect the water system at all. An expansion of leather tanning as an EPZ sector would fall in the first category, some branches of the electronics industry with their heavy metal problems are examples of the second, and some 
service industries such as information technology or financial services (offshore banking) have no water-related effects. Yet, an attempt to define extreme water strategies might involve the following:

\section{A) Treatment}

- No investment in water treatment.

- "Low investment" scenario, e.g., 1 percent of the current government investments allocated for wastewater treatment.

- "High investment" scenario, e.g., 10 percent of the current government investments allocated for wastewater treatment.

\section{B) Storage}

- No investment in water storage.

- "Low investment" scenario, e.g., one-quarter of the potential dams constructed between 1990 and 2050 in ascending order of the cost per unit of storage.

- "High investment" scenario, e.g., all potential dams constructed between 1990 and 2050 in ascending order of the cost per unit of storage.

It will take some experimentation with the model for any user to determine the cost-effectiveness of the default scenarios and water policies. The author's recommendation for a default scenario is the following: unless the specified economic policy is expected to generate drastic increases in the discharge of $\mathrm{BOD}, \mathrm{N}$, and $\mathrm{P}$ from industrial and agricultural sources, the best use of resources implies a combination of moderate investments in treatment (somewhere between the "low" and "high" treatment scenarios) and no investment in storage. This scenario might also help to keep water quality in the lagoon at an acceptable level.

A combination of the recommended default scenarios for RWQS and for water management should keep a positive water balance in the river flows. This may still imply unacceptable deterioration of water quality in the lagoons. It was not possible to build a large number of meaningful and defendable feedback relationships into the model. Therefore, for the default run and for any subsequent scenario runs, the user should always check and evaluate environmental implications of population and economic scenarios, both in the inland surface water quality and in the lagoon water quality. 


\subsubsection{Other water-management parameters}

There are four environmental media receiving wastewater discharge in the current version of the model: groundwater, rivers, lagoon, and the ocean beyond the reef. Direct discharges to the rivers and the lagoon and pollutant transport by the rivers to the lagoon are properly handled by the model. The missing link in the present version of the model is the pollutant transport from groundwater to rivers and the pollutant absorption capacity of the groundwater system.

Lacking any data on groundwater movement and quality, it is impossible to construct a meaningful model of these processes. It is evident, however, that the absorption capacity of the groundwater system is limited. Therefore, direct discharge of untreated sewage from domestic and industrial sources to absorption pits must eventually be phased out. The user can model this transition by modifying the disposal matrix that indicates what fraction of the wastewater from different sectors is discharged to which receiving media. Even if this redirected discharge is treated, it will pose an additional load to the surface flow or the lagoon model.

When and how fast this transition takes place depends on when and how fast the signs of contaminating groundwater will make it necessary. Three basic scenarios can be proposed as default:

- Transition soon and fast: phasing out groundwater discharge starts in 1995 and is completed by 2015 .

- Transition soon and gradual: phasing out starts in 1995 and is completed by 2040 .

- Transition later and gradual: phasing out starts in 2020 and groundwater discharge is reduced to 30 percent of its original value by 2050 .

The geographical location of Mauritius would clearly permit the discharge of untreated sewage in the ocean beyond the reef. If the pipes go sufficiently beyond the reef, wastes are diluted by the ocean and are not expected to pose any significant repercussions on either the corals or the lagoon. Yet, this solution does not appear to be environmentally friendly. Moreover, the costs of building and operating these kinds of disposal facilities might well be close to what it would take to build and operate treatment plants. Currently none of the sewage outlets go beyond the reef. We have no data about the construction and operation costs of such facilities. Should this option be seriously considered in the future, the model can be easily modified to accommodate it. 


\section{Chapter 16}

\section{Scenarios for Mauritius, 1990-2050}

Christopher Prinz and Anne Babette Wils

\subsection{Introduction}

The scenarios described in this chapter and Chapter 17 serve to answer some of the main questions raised by the project: What is the effect of population growth and education on development? Can economic development occur without population control? What is the effect of population on environment? In this chapter the answers to these questions relate to the very specific situation of Mauritius and its population, economy, and environment, but are generalized whenever possible.

To answer those questions our PDE Mauritius model is used to calculate alternative future paths in the population, development, and environment components, and the interactions between these components. The time horizon chosen in this application of PDE Mauritius is 60 years, starting in 1990. This time horizon is sufficiently long to see the long-term effects of our assumptions. Longer time horizons with this model become too speculative.

Often in modeling the main question is: What is most likely to happen? Under such circumstances one needs to have one baseline scenario, possibly with a few variations. This is typically the case of a prediction model.

Models like PDE Mauritius are to be used for policy making, to see what possible futures exist and what the alternative policy reactions are. Such a 
model can be used to explore which policies would be most robust even in the face of different futures. The model is also used to answer questions on interactions. To understand a system, it is important to explore alternatives. What happens when I change one particular variable? What is the main environmental constraint, given different economic developments? How does the size and the education of the population matter to development? To find the answers, different alternatives need to be compared. In contrast to econometric models, PDE Mauritius is not used to predict the future, but rather to understand the complex population-development-environment system.

The scenario approach is used both to demonstrate the strength of the model and to find reasonable and robust policies. In this type of approach the if-then nature of the calculation is emphasized more than a likely prediction. A scenario approach is expected to make all assumptions very explicit and to offer a sensitivity analysis over the assumptions chosen. Scenarios are developed on the basis of a possible "story" which has content, rather than "high" and "low" deviations from the "likely" path.

To understand the interactions, two subscenarios were chosen for each of the three PDE components - population, development, and environment. We feel these subscenarios reflect possible extreme developments in each component. Each partial scenario is already a complex composite. In each component the two partial scenarios represent what might be considered a modern, successful path versus a traditional, passive path.

Section 16.2 discusses the basic scenario definitions in detail. It also provides an explanation of the resulting scenario combinations. Section 16.3 presents unbalanced, raw scenario results. Here, population is discussed in more detail since - in the discussion of population and environment - it is important to understand the dynamics of population growth and population inertia, and possible effects of education campaigns and female labor-force participation. In Section 16.4, the unbalanced, raw combinations are modified into a form that makes them consistent multi-sectoral scenarios. A number of specific issues, such as food self-sufficiency, sectoral distribution of the economy, and water treatment, are addressed.

\subsection{Scenario Setting}

\subsubsection{Scenario assumptions}

Table 16.1 gives a detailed description of the definition of the scenario assumptions for population, the economy, and the environment. 
Table 16.1. Assumptions for two scenarios in each of the three sectors.

\begin{tabular}{|c|c|c|}
\hline \multicolumn{3}{|l|}{ Population sector } \\
\hline & Traditional & Modern \\
\hline Fertility & $\begin{array}{l}3.0 \text { children per woman by } \\
2000 \text {. }\end{array}$ & $\begin{array}{l}1.5 \text { children per woman } \\
\text { by } 2010 .\end{array}$ \\
\hline Mortality & $\begin{array}{l}\text { Constant; male/female life } \\
\text { expectancy } 65 / 73 \text { years. }\end{array}$ & $\begin{array}{l}\text { Male/female life expect- } \\
\text { ancy } 80 / 85 \text { years by } 2030 \text {. }\end{array}$ \\
\hline Net migration & Zero. & Zero. \\
\hline Education & Transition rates constant. & W. European rates by 2010 \\
\hline $\begin{array}{l}\text { Female economic } \\
\text { activity }\end{array}$ & $\begin{array}{l}\text { Return to } 1983 \text { activity } \\
\text { rates. }\end{array}$ & W. European rates by 2010 \\
\hline \multicolumn{3}{|l|}{ Economic sector } \\
\hline & Crisis & Boom \\
\hline \multicolumn{3}{|l|}{ Exports } \\
\hline Sugar & $\begin{array}{l}50 \% \text { reduction in } 2000 \\
\text { then constant. }\end{array}$ & No change. \\
\hline EPZ textiles & $\begin{array}{l}\text { Decrease by } 35 \% 2000-2010 \text {, } \\
\text { and further } 15 \% \text { by } 2050 .\end{array}$ & $\begin{array}{l}\text { Increase to twice the } \\
1990 \text { level in } 2005, \\
\text { then constant. }\end{array}$ \\
\hline EPZ manufactures & No change. & $\begin{array}{l}\text { Linear increase to } 25 \text { times } \\
\text { the } 1990 \text { level in } 2050 .\end{array}$ \\
\hline Tourism & No change. & $\begin{array}{l}\text { Increase to twice the } \\
1990 \text { level in } 2005 \\
\text { then constant. }\end{array}$ \\
\hline $\begin{array}{l}\text { Sales, transportation, } \\
\text { business services }\end{array}$ & No change. & $\begin{array}{l}\text { Linear increase to } 25 \text { times } \\
\text { the } 1990 \text { level in } 2050 \text {. }\end{array}$ \\
\hline \multicolumn{3}{|l|}{ Environment sector } \\
\hline & Laissez-faire & Garden \\
\hline $\begin{array}{l}\text { Land productivity } \\
\text { Sugar cane }\end{array}$ & $\begin{array}{l}0.5 \% \text { increase annually } \\
\text { until } 2050 \text {. }\end{array}$ & No change. \\
\hline $\begin{array}{l}\text { Water storage } \\
\text { investments }\end{array}$ & No investments. & $\begin{array}{l}\text { Increase to twice the } 1990 \\
\text { storage capacity by } 2050 \text {. }\end{array}$ \\
\hline
\end{tabular}

The traditional population scenario assumes constant mortality and school enrollment, an increase in fertility, and a decline in female economic activity, reflecting social stagnation or a return to a more traditional society. The modern population scenario, on the other hand, assumes large increases in life expectancy, school enrollment, and female economic activity, and a further decline in fertility, reflecting rapid social development to a level similar to a modern European or Far East Asian society. 
The economic crisis scenario assumes a discontinuation of the Lomé Convention in 2000, which results in a drastic decrease in sugar and textile exports. The other potential export sectors are too weak to compensate for these losses, and stay constant. Or, alternatively, the world market in general does not demand as much as before due to a global economic crisis. Total exports decline by some 25 percent in the first 10 years of crisis and then remain stagnant. In contrast, in the economic boom scenario, the Lomé Convention remains in force. The present rapid increase in exports continues. The current sources of wealth - sugar, textile, and tourism - remain constant or grow slightly, but are overtaken by other much more dynamic, futureoriented non-textile EPZ industries and service export sectors. Total export growth is about 5 percent annually until 2020 and 1.5 percent annually until 2050.

In the laissez-faire environmental policy scenario no environmental management policies are implemented, and no care is taken of water: reservoir capacities remain at 1990 levels. Higher fertilizer use and better seeds lead to a 0.5 percent annual increase in sugar yields per hectare. The main feature of the garden policy scenario is the investment in water resources to ensure water quantity and quality on the island. Storage capacity is increased considerably, which adds some 70 percent to the present net water flow. Fertilizer use is not increased further causing a stagnation in sugar-cane land yields.

It must be said that within the ranges of today's world these scenarios are a narrow band. Under Mauritius's present condition, it is hard to imagine changes that would lead to certain world extremes in demographic and economic indicators. The combination of these scenarios gives eight $(2 \times 2 \times 2)$ raw base scenarios:

1. traditional/crisis/laissez-faire

2. traditional/boom/laissez-faire

3. traditional/crisis/garden

4. traditional/boom/garden

5. modern/crisis/laissez-faire

6. modern/boom/laissez-faire

7. modern/crisis/garden

8. modern/boom/garden

Some of these combinations are more likely and thus skctch a more realistic future for Mauritius than others. For example, we can well imagine the traditional/crisis/laissez-faire scenario because it fits the image of 
many existing developing countries which are poor, have high fertility, have no environmental protection measures, etc. The modern/crisis/laissez-faire scenario is more uncommon, as it denotes a demographically advanced society that is still caught in poverty. The Indian state Kerala and Sri Lanka may be considered examples of such areas. Much more difficult to imagine is the traditional/crisis/garden combination: here we have a traditional, poor society, which, for some reason, rather than investing in its population and economy, is saving its natural resources. This is what is sometimes prescribed to developing countries by the industrialized world, for example, when it comes to the discussion of emission "rights" of $\mathrm{CO}_{2}$ into the atmosphere or the "right" to pollute the oceans or the "right" to cut down rainforests. Equally unusual is the modern/crisis/garden scenario: this is the idealistic society which is responsible to its members in a social sense and cares for the environment - over and above what is simply necessary for conservation - but which is poor.

We can very well imagine the modern/boom scenarios, reflecting a society that completed the demographic transition, with a modern, growing economy, like Mauritius, the Small Tigers, or Thailand. There are also a number of examples for a traditional/boom combination, such as the big oil producers and exporters on the Arabian peninsula which still show very traditional demographic behavior. Any boom scenario combination is realistic with either garden care or a laissez-faire approach to environmental conservation.

\subsubsection{Scenario making with PDE Mauritius}

As is described in Chapter 11, the hard-wired model is mostly hierarchical. The population input produces population results. These results, plus the input for the economy, provide the economic results. And again, the population results, plus the economic results, plus the input for water and land provide environmental results. These are uni-directional effects which are hard-wired in the model. What is crucial, however, in PDE modeling, is the feedback. That means, we are concerned not only with the influence of the population on the economy, but also with influences of the economy on the population; not only with the influence of the economy on the environment, but also with influences of the environment on the economy.

The nature and the strength of many of these feedbacks are subject to much debate among scientists (see Chapter 11); therefore, we have not hardwired many of them in the model. These feedbacks need to be defined by the 
scenario maker. There are two types of feedbacks. One is the balances: that is, supplies of any goods and/or resources must always be greater than demands. The other feedbacks are influences, such as the effect of the standard of living on fertility or labor productivity.

The feedbacks discussed in this chapter are of both types. We discuss the balances first and why some balances are not solved internally by the model. The variables that are not balanced internally are: labor, government spending and taxes, and - to a certain extent - water and land. Other balances are resolved internally, in the form of hard-wired feedbacks. Most importantly these are household income and expenditure and investments and savings plus debts. We have chosen not to balance labor, government, and all water and land internally because in case of a conflict, multiple solutions are possible.

The PDE model does not stop calculating when it runs into imbalances in these selected variables. It continues to run, "as if" there were sufficient labor, sufficient money, and sufficient water and land. However, in the presentation of the results of the scenario the imbalance is shown. After running a scenario, the user has to check the results - in particular, the results of the variables that need to be balanced. If there is an imbalance, the scenario maker needs to decide how to deal with it.

The resolution of labor, budget, water, and land conflicts is not unequivocal. For example, the scenario which specifies an economic boom and a traditional (uneducated, unproductive) population results in a labor shortage. Now, something has to be changed. The economic demand has to decrease or the technology must be improved to demand less labor or the population. assumptions must be changed. We, as the modelers, have not hard-wired the decision of which element has to change and how much, because we feel that various solutions are possible in reality: if there is tension on the labor market, the economy will react by growing less than it otherwise could or labor productivity will increase or the labor force will adapt or any combination of the three alternatives.

Conflict can also occur in water demand and supply. Say a given economic scenario increases the demand for water beyond the supply. What should happen? Would economic growth be stunted? Or would the government build water-treatment and water-recycling plants? Or would water conservation methods be imposed? We do not know what is best without trying out the different options. The advantage of PDE Mauritius is that all 
sorts of options are indeed available (see Chapter 13 concerning the economy and Chapter 15 concerning water for more details).

A very important element of this kind of model is that the user can test various types of reactions, and see which one would lead to a more desirable future. Also, with this model, if the user runs into a conflict somewhere in a future scenario year, he or she can go back to the starting year, with knowledge of the conflict, and change the path of the future, to see if another plan works better.

The other type of feedback is that of influences such as the idea that higher income lowers fertility or that a higher level of pollution increases mortality. This type of feedback was discussed in Chapter 3 . The significance of such feedbacks is the strength or the elasticity of the feedback loop. We learned in Chapter 3 that depending on the speed of the advance of pollution abatement technology, a model could compute a wonderful or a catastrophic future. The problem is that we do not know the speed of technological advance; we do not know the strength of the relationship between, say, migration and unemployment. We deliberately did not include this type of feedback internally in the model, because the debate on these feedbacks continues. With our model the effects of various assumptions, such as income does not influence fertility or higher income reduces fertility, can be tested.

\subsection{Raw, Unbalanced Scenarios}

\subsubsection{Population results}

A main concern of the project is the interplay between population and the environment. The environment, without influence from human activity, is relatively stable over a long period of time - that is, the same annual cycles, the same soil type, the same coral reefs, etc. The environment of Mauritius, by itself, would remain in more or less the same state as it was described in Section 16.2. Not so the human population. Population is an element that experiences faster change than the environment, with regard to both its size and its composition. It is also subject to lagged changes; a fertility decline in 1990 only significantly affects population size and growth in one generation's time. It is therefore useful to look at the dynamics of population change in more detail - how changes in fertility, mortality, education, and such would affect the future of the population - before turning to the interaction with the environment and the economy. 
Table 16.2. Selected population developments under two scenarios, 2020 and 2050 .

\begin{tabular}{|c|c|c|c|c|c|}
\hline \multirow[b]{2}{*}{ Output variable } & \multirow{2}{*}{$\begin{array}{l}\text { Observed } \\
1990\end{array}$} & \multicolumn{2}{|c|}{ Traditional population } & \multicolumn{2}{|c|}{ Modern population } \\
\hline & & 2020 & 2050 & 2020 & 2050 \\
\hline Population size (in $1,000 \mathrm{~s}$ ) & 1,022 & 1,463 & 1,895 & 1,252 & 1,151 \\
\hline Population aged $60+$ & $8 \%$ & $13 \%$ & $14 \%$ & $18 \%$ & $35 \%$ \\
\hline Population aged $0-19$ & $38 \%$ & $35 \%$ & $36 \%$ & $24 \%$ & $17 \%$ \\
\hline $\mathrm{SDDR}^{a}$ & 193 & 173 & 179 & 126 & 148 \\
\hline \multicolumn{6}{|l|}{ Labor force (in 1,000 s) } \\
\hline Female & 126 & 195 & 245 & 234 & 223 \\
\hline Male & 290 & 404 & 510 & 376 & 289 \\
\hline \multicolumn{6}{|l|}{$\begin{array}{l}\text { Labor force with } \\
\text { primary education }\end{array}$} \\
\hline Female & $58 \%$ & $20 \%$ & $15 \%$ & $20 \%$ & $13 \%$ \\
\hline Male & $53 \%$ & $32 \%$ & $29 \%$ & $30 \%$ & $19 \%$ \\
\hline \multicolumn{6}{|l|}{$\begin{array}{l}\text { Labor force with } \\
\text { secondary education }\end{array}$} \\
\hline Female & $40 \%$ & $73 \%$ & $77 \%$ & $65 \%$ & $62 \%$ \\
\hline Male & $45 \%$ & $64 \%$ & $67 \%$ & $60 \%$ & $63 \%$ \\
\hline \multicolumn{6}{|l|}{$\begin{array}{l}\text { Labor force with } \\
\text { tertiary education }\end{array}$} \\
\hline Female & $2 \%$ & $7 \%$ & $8 \%$ & $15 \%$ & $25 \%$ \\
\hline Male & $2 \%$ & $4 \%$ & $4 \%$ & $10 \%$ & $18 \%$ \\
\hline
\end{tabular}

${ }^{a}$ Socio-demographic dependency ratio as defined in Chapter 12.

Some population scenario results are presented in Table 16.2. Despite the low level of fertility assumed in the modern alternative, the Mauritian population would increase by some 25 percent until 2020 . This is entirely due to the young age structure, and is a prime example of the momentum of population growth. In the long run, however, negative population growth is observed due to sub-replacement fertility. Under the traditional scenario the Mauritian population almost doubles and reaches 1.9 million by the year 2050. For a more extensive discussion of scenarios results with varying fertility, mortality, and migration levels see Prinz (1991).

It has been found that typically countries which have just completed the demographic transition, such as Mauritius, will experience considerable population aging during the immediately following decades. While the proportion of the population aged 60 years and over does not quite double under traditional scenario assumptions, it quadruples in the long run under modern assumptions. Aging is the result of low mortality as well as low fertility. 
Strong population aging seems probable, since a long-term return to a fertility level as high as that assumed under the traditional scenario (overall TFR equal to about three children per woman) has so far never been experienced by any country that has completed the demographic transition. Depending on the fertility assumptions, the proportion of children declines significantly; even under traditional assumptions the proportion is always below the 38 percent observed in 1990 , but under modern assumptions this proportion is cut in half.

The development of the socio-demographic dependency ratio (SDDR), a dependency ratio considering economic activity, productivity (or education) of the labor force, and age of dependents (see Chapter 12 for more details), develops surprisingly similar in the long run with the two different scenario assumptions. First, it never again reaches a level as high as the 193 dependents per 100 actives observed in 1990 . The SDDR strongly declines during the next three decades under modern population assumptions, by 35 percent, as a consequence of very low fertility. Under traditional assumptions it would still decline by some 15 percent by the turn of the century. By 2020 , the SDDR starts to increase again under the modern scenario as a consequence of rapid aging, i.e., the immense increase in the number of elderly. Due to the fertility recovery, under the traditional scenario after around 2010 the socio-demographic dependency ratio varies from 170 to 180 . If lower SDDRs have a positive influence on the economy as indicated in some of the literature, then further economic development is favored cluring the coming decades simply by changes in the socio-demographic composition of the population.

In the medium term the size of the labor force develops in a similar manner under both scenarios. While under the traditional scenario the more than 40 percent increase in the labor force by 2020 is caused by high fertility, under the modern scenario it is to a large extent due to increased female labor-force participation. In the long run, however, the effect of high fertility will be much stronger. Table 16.2 also gives some information on genderspecific characteristics of the Mauritian labor force. The share of the female labor force in the total labor force increases from 30 percent in 1990 to between 32 percent by the year 2020 under traditional assumptions and 44 percent by 2050 under modern scenario settings.

The educational distribution of the labor force and of the population as a whole is in a state of transition. While even in 1990 a majority of the labor force had only primary education, this proportion declines rapidly to 
about one-fifth among the female and about one-third among the male population by 2020 in both scenarios (see Table 16.2). The lower proportion of primary-educated among working women results from higher labor-force participation rates among secondary- and tertiary-educated women, as compared to primary-educated women. Interestingly, especially among women, there is little difference between traditional and modern assumptions as regards the proportion of primary-educated workers in the labor force. This is due to the combined effect of increasing labor-force participation rates and increased educational attainment. In the total population, the percentage with only primary education is around one-third and is slightly higher among women than among men by 2050 (only one-fourth in the case of modern population development).

Most striking is the projected increase in the number and proportion of tertiary-educated people. Taking both sexes together, the tertiary-educated proportion increases to around one-fifth of the labor force by 2050 under modern population development. Among the total population the figures are 8 percent and 14 percent for the female and male population, respectively. This huge increase would give tremendous room for changes in the structure of the Mauritian economy. Under traditional assumptions the increase in the tertiary-educated proportion is small.

\subsubsection{Multi-sectoral results}

The combination of the $2 \times 2 \times 2$ scenarios produces eight raw scenarios. In these scenarios, technology is assumed to remain unchanged, hence, labor and land productivity is kept constant at their 1990 levels. Selected results for the eight scenarios are shown in Table 16.3. The table gives supplies, demands, and resulting balances of four important variables that will eventually have to be balanced: budget, labor, water, and land.

The first four columns of Table 16.3 show the supply results of the four variables. Taxes are a result of production levels which in Mauritius largely depend on assumed export levels. In the boom scenario, taxes increase to six times the 1990 value in the long run, while in the crisis scenario they decline slightly. The labor supply is purely the result of the population module, in particular of school enrollment ratios and labor-force participation rates. In the traditional scenario there are 755,000 people in the labor force in 2050 , and in the modern scenario, with the smaller population, 512,000. Up until 2020 , no significant difference between the two scenarios exists since lower fertility rates in the modern scenario are compensated by higher education 


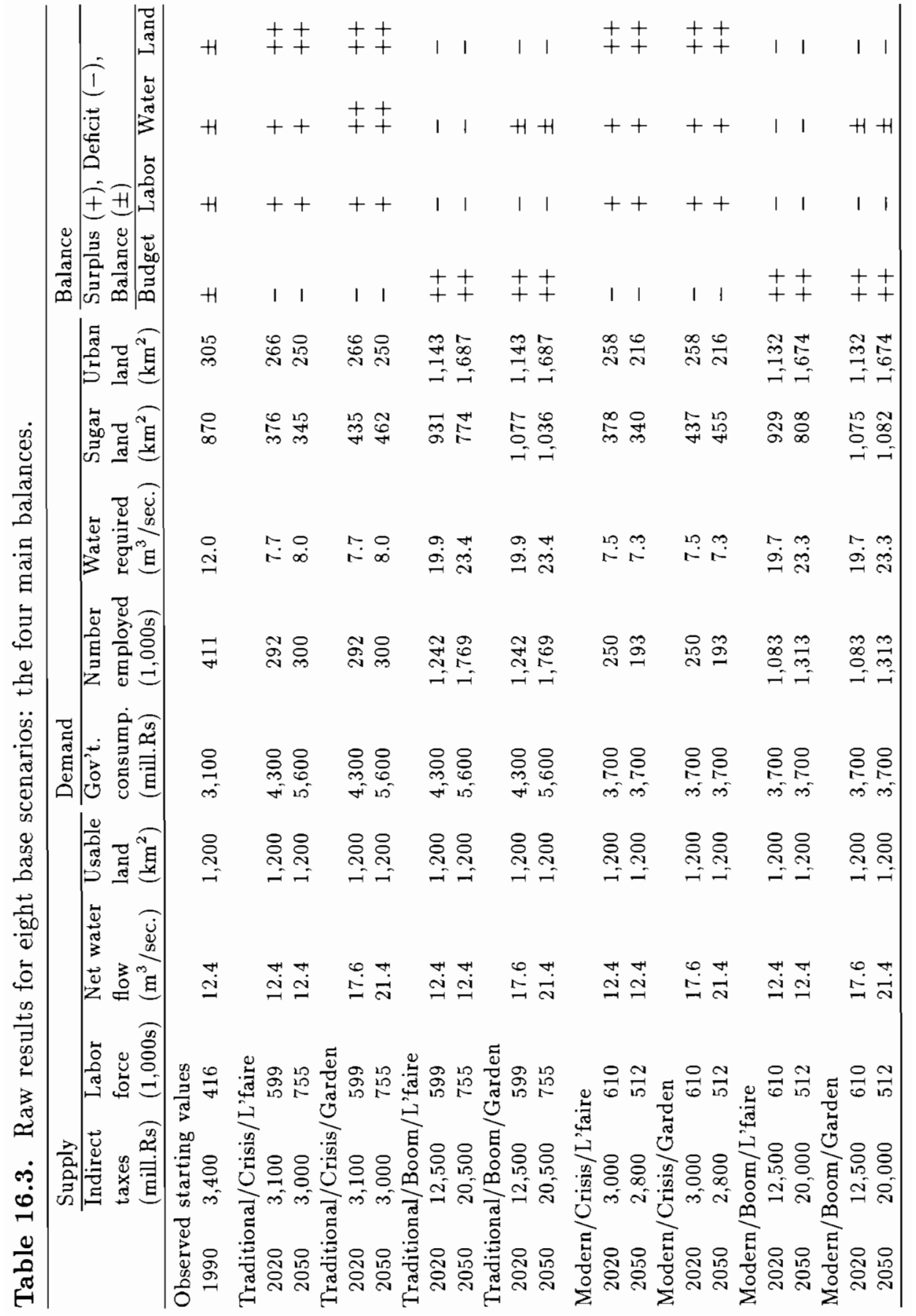


and labor-force participation levels. The water supply is purely a result of the two environmental scenarios concerning water investments. In the garden scenario, water supply increases from $12.4 \mathrm{~m}^{3}$ of water per second to 21.4 $\mathrm{m}^{3}$ per second by 2050 because of increased reservoir capacity (see Chapter 15 for the workings of the water module). In the laissez-faire scenario, the water supply remains stationary at the 1990 level.

The usable land supply remains stationary in all scenarios - that is, around $1,200 \mathrm{~km}^{2}$. There is no scenario input that the land available increases by reclaiming land or decreases through inundation. The possibility of land losses due to a sea-level rise is not discussed in this chapter, because climate-change impacts in Mauritius are largely unknown, but could be tested by the model.

The supplies have to be equal to or greater than the corresponding demand levels. The next five columns in Table 16.3 show budget demand, labor demand, water demand, and sugar and urban land demand. These demand levels are complex results. Government expenditure results from the combination of population results and per capita government consumption. Since this variable does not include the environmental expenditures and because group- and age-specific government consumption (mainly education, health, and pension expenditures) was kept constant in all scenarios, different results are obtained only for the two population scenarios. Under traditional assumptions government expenditure increases linearly in accordance with the population size increase. In the modern scenario, after an immediate increase, government expenditure remains almost constant. The lower costs of a smaller population size is compensated by higher government costs of aging and the longer average schooling of the population.

The labor demand results mainly from three factors: the export level; the population size and structure; and the education of the labor force (see Chapter 13 for details). Hence, both demographic and economic assumptions matter. Due to the shrinking economy in the crisis scenarios the employment figure declines. Under boom scenario assumptions, on the contrary, employment increases rapidly as a consequence of the booming economy (the assumption of constant labor productivity by education group must be re-emphasized). Within the crisis or boom scenarios, each of which is combined with a modern and a traditional population, the differences in employment are almost totally due to the very different educational structure of the labor force. As a consequence of the built-in productivity increase from higher education levels, with a booming economy and almost the same 
level of production, 1.7 million employees are needed under the conditions in the traditional scenario, while only 1.3 million employees are needed if they are better educated (modern scenario).

Water requirements result mainly from production levels and treatment levels and have only a slight dependence on population size and structure. In the raw scenarios, treatment levels are equal (zero) for all the scenarios. Hence, water demand is almost solely the result of economic assumptions, with a declining demand under crisis assumptions and a doubling of 1990 requirements by the year 2050 under boom assumptions. Under the latter scenario water requirements do not increase parallel to production levels because the big current water consumers (the sugar and the textile industries) decline in relative size compared to the growing other EPZ, other manufacturing, and service sectors.

Land requirements mainly result from production levels and to a smaller extent from demand for private housing. The better-educated, wealthier, people in the modern scenario demand more land per capita; however, this effect is compensated by the larger population size under the traditional scenario. For sugar-land demand, the assumption of continued sugar-cane land productivity increases under the laissez-faire scenario gives significantly lower land requirements when compared to the garden scenario. The negative effect of this assumption, badly polluted water as a consequence of increased fertilizer use, does not show up in the water results in Table 16.3. This is because pollution is measured by taking the "largest polluter" of biological oxygen demand (BOD), nitrates, or phosphates. In these scenarios, BOD is always the largest polluter (see Chapter 15 for the workings of the dilution flow in the water module).

In case of an economic crisis, no land conflicts would arise; under an economic boom, however, raw land requirements at (unrealistic) constant productivity would increase far beyond the actual size of the island.

Several conclusions can be drawn from the raw scenario exercise (see the last four columns in Table 16.3). In the crisis scenarios no physical constraints - neither water nor land - are to be expected. On the other hand, large underemployment is likely and a significant budget deficit, in particular with traditional population developments, unavoidable. In the boom scenarios, on the contrary, substantial water and land conflicts occur and have to be resolved. Water constraints are to a large extent eased by an environmental garden policy. Land conflicts have to be settled by lower production or higher land productivity. It is difficult to provide a sufficiently 
large and educated labor force, in particular with a traditional population. The high income from taxes, on the other hand, would allow for an enormous increase in per capita government expenditures. Alternatively, taxes could be reduced substantially.

Several of the raw scenario combinations are impossible, and all of them need further adjustments in order to become consistent. These adjustments are discussed in Section 16.4. The adjustments lead to completely new scenarios which differ from the eight raw scenarios. The reader may ask then why not make balanced scenarios straight away? The raw scenarios serve as starting points for a discussion of possible future developments and illustrate structural inconsistencies which become evident in the multi-sectoral approach.

\subsection{Balanced Multi-sectoral Scenarios}

As was explained in Section 16.2, four criteria for a balanced scenario have to be checked by the user: the labor balance must be positive and desirably close to zero; taxes and government consumption must be balanced; the water balance must at least be positive; and land demand cannot exceed available land. Small water and land constraints are automatically solved by the model but may alternatively be influenced by the user through changes in the water module or in land productivity.

The process of balancing the scenarios reveals many alternatives. How do we choose between them? In the case of a water shortage, for example, do we decrease the economic activity on the island or let the government enlarge the water storage capacities or rather invest in water-treatment plants?

This section describes a stepwise movement from a traditional, crisis society with a laissez-faire attitude to the environment, via successive movements, to a modern, prosperous, boom economy with concern to keep the environment of the island clean, like a garden. The path uses different combinations. The section also includes details on alternatives such as agricultural, industrial, or service development; food self-sufficiency; a sugar policy which gives priority to sugar over all other economic expansion; and early or late treatment of wastewater. The objective in each step, or scenario, is to find the maximum economic welfare in 2050 within a balanced scenario and within the given scenario framework. 


\subsubsection{The crisis scenarios: Population and environment in poverty}

The first of the raw, base scenarios is the traditional/crisis/laissez-faire combination. By 2050 the population is 1.9 million and growing at a rate of 1 percent annually. Labor is extremely imbalanced - there are 755,000 persons in the labor force and only 300,000 employed. There is a positive land and water balance calculated for 2050 , and government consumption exceeds tax income (see Table 16.3).

\section{Underemployment}

The huge unemployment in this scenario is socially unacceptable and also not likely to materialize. The lack of possibilities would certainly discourage people from being in the labor force. Although labor-force participation of women is already low in this traditional population - for example, 34 percent for women aged 35-39 in 2000 as compared to 46 percent in 1990- we return to the starting year 1990 and assume a 2 percent annual decrease in female labor-force entrance rates from 1990-2050. We further assume that the male labor-force participation rate also decreases from 1990 via early retirement of men. This is expressed in a 2 percent annual increase in labor-force exit rates (see Chapter 12 for details). Keeping the scenario input otherwise exactly the same, these two changes result in a labor-force size of 683,000 in 2050 , and a labor balance with 56 percent unemployed. Other results in the scenario stay the same.

The line marked traditional in Figure 16.1 shows the development of the labor force with the original scenario assumptions, and the line marked traditional/crisis shows the reduced labor-force size. The reduction is small. This is because the bulk of the labor force, young and middle-aged men, has not been affected. This group, despite discouragement, would probably remain looking for work in order to survive. They would probably be willing to work for lower wages and accept fewer working hours: the typical underemployment situation of many poor countries. This development can be simulated by decreasing labor productivity - a person working 50 percent would register with half of the labor productivity of a person working full-time and be considered 50 percent underemployed. To balance the labor force with this mechanism, labor productivity has to be decreased to less than one-half of the 1990 level by 2050 . 


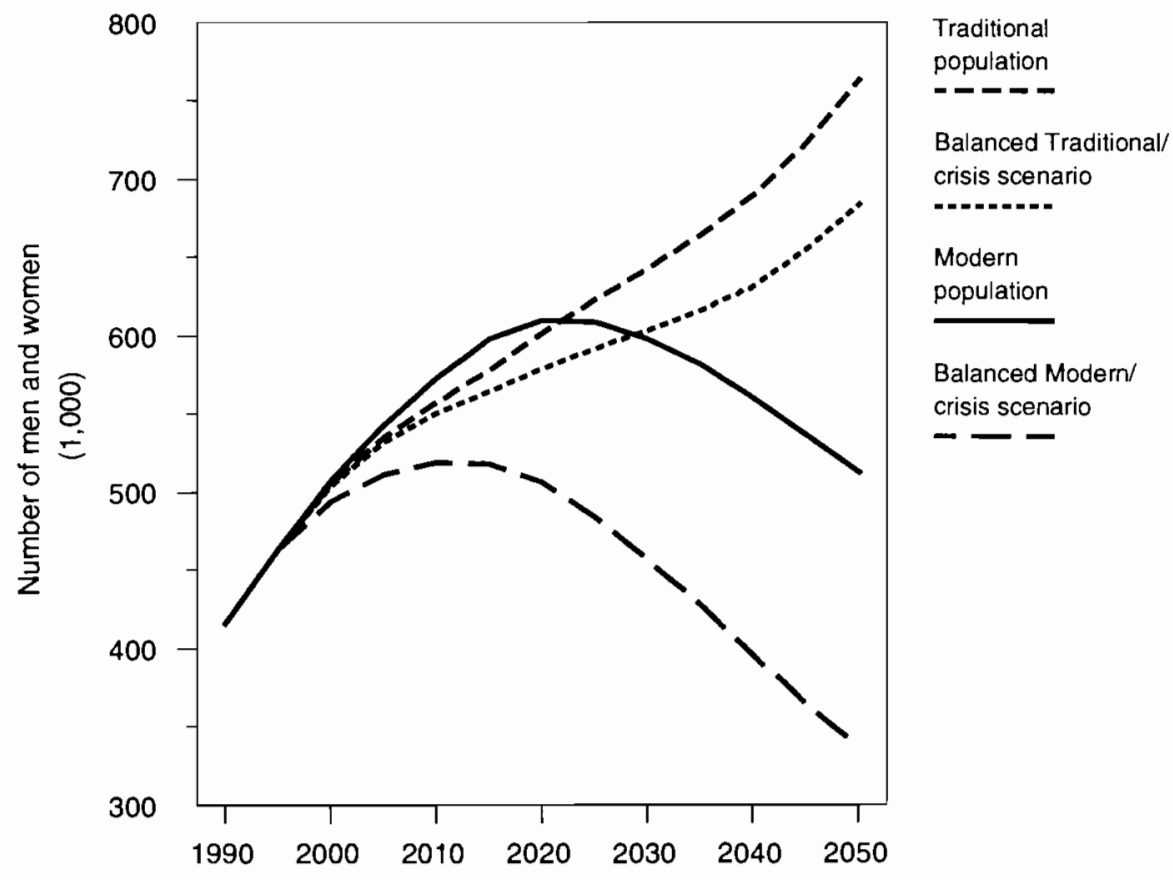

Figure 16.1. The development of the labor-force size in the raw traditional and modern scenarios, and in the balanced crisis scenarios.

These steps show that in a situation of potentially severe unemployment, where the labor force greatly exceeds the number of jobs offered, the reduced labor-force participation of discouraged groups, such as women and older men, only marginally reduces the size of the labor force. The bulk of a labor-force reduction would have to come from young and middle-aged men.

The balanced results of this scenario are shown in Table 16.4 (see column labeled traditional/crisis/laissez-faire). The table gives selected input and output variables in the starting year, 1990, and in two scenario years: 2020, which is the middle of the scenario period, and 2050, the last scenario year.

The GDP in this first balanced scenario starts at Rs 22,200 per capita in 1990 (1987 Rs), that is $\$ 2,310$ (1990 dollars); decreases to Rs 14,200 per capita in 2020, and ends at Rs 11,900 per capita in 2050 . This is only some 30 percent above the value of the 1962 GDP per capita which was Rs 8,900 (again 1987 prices). Total GDP remains almost constant over the whole period after the year 2005; however, it has to be distributed over a 


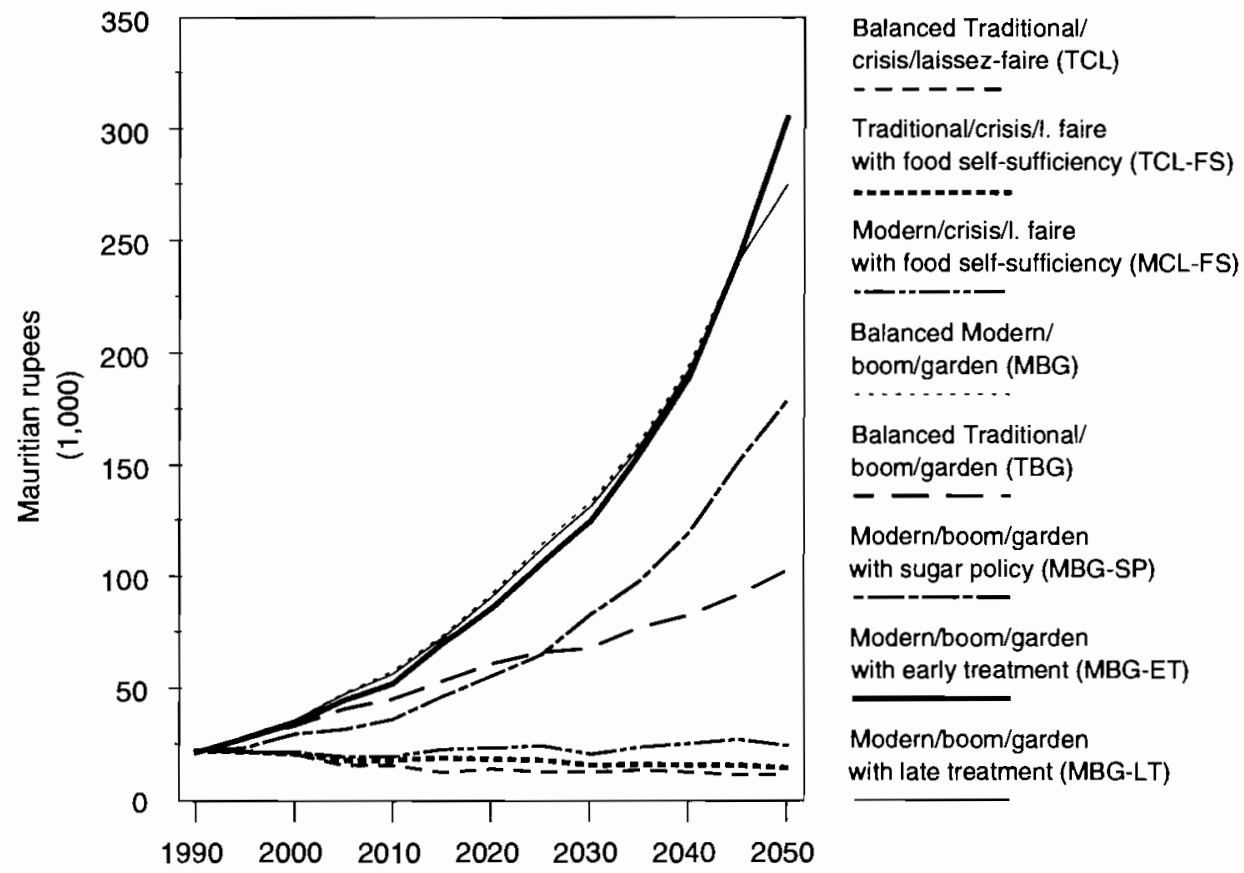

Figure 16.2. Projected income per capita in eight balanced scenarios.

constantly increasing population. The development of GDP per capita is shown in the traditional/crisis/laissez-faire line of Figure 16.2.

A land surplus is calculated for 2050 in this scenario because there is a decrease in land used for sugar. There is also a water surplus, because there is much less irrigation due to the decrease in sugar production. The water surplus is shown in Figure 16.3. The solid net water flow line indicates the constant availability of water at the 1990 annual flow level. The traditional/crisis/laissez-faire line plunges from almost full use of the water supply from 1990 to 2000 to a much lower level in 2005. As we assume no resumption of economic activity, the water demand remains at this low level, and increases only very slowly as the population increases and consumes more water. As a consequence of the shrinking economy, in particular the textile industry, water pollution, measured in the concentration of BOD in the lagoon, is also lower in the future than in 1990. In order to balance the budget, per capita government expenditure has to be reduced 1 percent 
Table 16.4. Balanced results for eight selected consistent scenarios.

\begin{tabular}{|c|c|c|c|c|c|}
\hline Variable & Year & $\begin{array}{l}\text { Traditional/ } \\
\text { crisis/ } \\
\text { laissez-faire }\end{array}$ & $\begin{array}{l}\text { Traditional/crisis/ } \\
\text { laissez-faire } \\
\text { with food } \\
\text { self-sufficiency }\end{array}$ & $\begin{array}{l}\text { Modern/crisis/ } \\
\text { laissez-faire } \\
\text { with food } \\
\text { self-sufficiency }\end{array}$ & $\begin{array}{l}\text { Modern/ } \\
\text { boom/ } \\
\text { garden }\end{array}$ \\
\hline \multirow{3}{*}{$\begin{array}{l}\text { Population size } \\
(1,000 \mathrm{~s})\end{array}$} & 1990 & 1,022 & & & \\
\hline & 2020 & 1,463 & 1,463 & 1,172 & 1,252 \\
\hline & 2050 & 1,895 & 1,895 & 972 & 1,151 \\
\hline \multirow{3}{*}{$\begin{array}{l}\text { Labor force } \\
\qquad(1,000 \mathrm{~s})\end{array}$} & 1990 & 416 & & & \\
\hline & 2020 & 579 & 579 & 506 & 610 \\
\hline & 2050 & 683 & 683 & 335 & 512 \\
\hline \multirow{3}{*}{$\begin{array}{l}\text { Total income } \\
\text { (mill. Rs) }\end{array}$} & 1990 & 22,700 & & & \\
\hline & 2020 & 20,700 & 27,200 & 27,600 & 114,300 \\
\hline & 2050 & 22,500 & 27,700 & 23,900 & 351,500 \\
\hline \multirow{3}{*}{$\begin{array}{l}\text { Income per capita } \\
\text { (Rs) }\end{array}$} & 1990 & 22,200 & & & \\
\hline & 2020 & 14,200 & 18,600 & 23,500 & 91,300 \\
\hline & 2050 & 11,900 & 14,600 & 24,600 & 305,300 \\
\hline \multirow{3}{*}{$\begin{array}{l}\text { Total exports } \\
\text { (mill.Rs) }\end{array}$} & 1990 & 19,400 & & & \\
\hline & 2020 & 14,500 & 14,500 & 14,500 & 111,000 \\
\hline & 2050 & 14,000 & 14,000 & 14,000 & 310,000 \\
\hline \multirow{3}{*}{$\begin{array}{l}\text { Government per } \\
\text { cap. expenditure } \\
(1990=100)\end{array}$} & 1990 & 100 & & & \\
\hline & 2020 & 74 & 89 & 109 & 381 \\
\hline & 2050 & 54 & 78 & 120 & 1,455 \\
\hline \multirow{3}{*}{$\begin{array}{l}\text { Labor } \\
\text { productivity } \\
(1990=100)\end{array}$} & 1990 & 100 & & & \\
\hline & 2020 & 50 & 65 & 69 & 231 \\
\hline & 2050 & 45 & 54 & 69 & 632 \\
\hline \multirow{3}{*}{$\begin{array}{l}\text { Land use for } \\
\text { sugar cane } \\
\left(\mathrm{km}^{2}\right)\end{array}$} & 1990 & 870 & & & \\
\hline & 2020 & 402 & 437 & 435 & 444 \\
\hline & 2050 & 359 & 395 & 369 & 311 \\
\hline \multirow{3}{*}{$\begin{array}{l}\text { Land use for } \\
\text { other agriculture } \\
\left(\mathrm{km}^{2}\right)\end{array}$} & 1990 & 73 & & & \\
\hline & 2020 & 85 & 184 & 193 & 167 \\
\hline & 2050 & 97 & 175 & 145 & 177 \\
\hline \multirow{3}{*}{$\begin{array}{l}\text { Land use for } \\
\text { urban activities } \\
\left(\mathrm{km}^{2}\right)\end{array}$} & 1990 & 305 & & & \\
\hline & 2020 & 275 & 365 & 368 & 623 \\
\hline & 2050 & 283 & 361 & 297 & 768 \\
\hline \multirow{3}{*}{$\begin{array}{l}\text { Land productivity } \\
\qquad(1990=100)\end{array}$} & 1990 & 100 & & & \\
\hline & 2020 & 100 & 100 & 100 & 232 \\
\hline & 2050 & 100 & 100 & 100 & 535 \\
\hline \multirow{3}{*}{$\begin{array}{l}\text { Total water } \\
\text { demand } \\
\left(\mathrm{m}^{3} / \text { second }\right)\end{array}$} & 1990 & 12.0 & & & \\
\hline & 2020 & 8.0 & 12.4 & 12.3 & 13.0 \\
\hline & 2050 & 8.7 & 12.4 & 10.8 & 17.2 \\
\hline \multirow{3}{*}{$\begin{array}{l}\text { Dilution flow } \\
\text { required } \\
\left(\mathrm{m}^{3} / \mathrm{second}\right)\end{array}$} & 1990 & 2.4 & & & \\
\hline & 2020 & 1.5 & 1.6 & 1.6 & 2.3 \\
\hline & 2050 & 1.6 & 1.7 & 1.5 & 2.9 \\
\hline \multirow{3}{*}{$\begin{array}{l}\text { Level of } \\
\text { BOD in the } \\
\text { lagoon }\left(\mathrm{kg} / \mathrm{m}^{3}\right)\end{array}$} & 1990 & 0.27 & & & \\
\hline & 2020 & 0.20 & 0.23 & 0.23 & 0.56 \\
\hline & 2050 & 0.21 & 0.23 & 0.21 & 0.93 \\
\hline \multirow{3}{*}{$\begin{array}{l}\text { Water treatment } \\
\text { investments } \\
\text { (mill.Rs) }\end{array}$} & 1990 & 0 & & & \\
\hline & 2020 & 0 & 0 & 0 & 0 \\
\hline & 2050 & 0 & 0 & 0 & 0 \\
\hline
\end{tabular}


Table 16.4. Continued.

\begin{tabular}{|c|c|c|c|c|c|}
\hline Variable & Year & $\begin{array}{l}\text { Tradit./ } \\
\text { boom/ } \\
\text { garden }\end{array}$ & $\begin{array}{l}\text { Modern/boom/ } \\
\text { garden with } \\
\text { sugar policy }\end{array}$ & $\begin{array}{l}\text { Modern/boom/ } \\
\text { garden with early } \\
\text { water treatment }\end{array}$ & $\begin{array}{l}\text { Modern/boom/ } \\
\text { garden with late } \\
\text { water treatment }\end{array}$ \\
\hline \multirow{3}{*}{$\begin{array}{l}\text { Population size } \\
(1,000 \mathrm{~s})\end{array}$} & 1990 & 1,022 & & & \\
\hline & 2020 & 1,463 & 1,252 & 1,252 & $\mathbf{1}, 252$ \\
\hline & 2050 & 1,895 & 1,151 & 1,151 & 1,151 \\
\hline \multirow{3}{*}{$\begin{array}{l}\text { Labor force } \\
\qquad(1,000 \mathrm{~s})\end{array}$} & 1990 & 416 & & & \\
\hline & 2020 & 601 & 610 & 610 & 610 \\
\hline & 2050 & 763 & 512 & 512 & 512 \\
\hline \multirow{3}{*}{$\begin{array}{l}\text { Total income } \\
\text { (mill.Rs) }\end{array}$} & 1990 & 22,700 & & & \\
\hline & 2020 & 90,000 & 70,000 & 107,800 & 114,300 \\
\hline & 2050 & 196,300 & 206,400 & 351,400 & 317,000 \\
\hline \multirow{3}{*}{$\begin{array}{l}\text { Income per capita } \\
\text { (Rs) }\end{array}$} & 1990 & 22,200 & & & \\
\hline & 2020 & 61,400 & 55,900 & 86,100 & 91,300 \\
\hline & 2050 & 102,900 & 179,200 & 305,200 & 275,300 \\
\hline \multirow{3}{*}{$\begin{array}{l}\text { Total exports } \\
\text { (mill.Rs) }\end{array}$} & 1990 & 19,400 & & & \\
\hline & 2020 & 77,100 & 62,500 & 111,000 & 111,000 \\
\hline & 2050 & 157,100 & 179,600 & 310,000 & 310,000 \\
\hline \multirow{3}{*}{$\begin{array}{l}\text { Government per } \\
\text { cap. expenditure } \\
(1990=100)\end{array}$} & 1990 & 100 & & & \\
\hline & 2020 & 314 & 256 & 195 & 381 \\
\hline & 2050 & 556 & 805 & 1,477 & 1,455 \\
\hline \multirow{3}{*}{$\begin{array}{l}\text { Labor } \\
\text { productivity } \\
(1990=100)\end{array}$} & 1990 & 100 & & & \\
\hline & 2020 & 178 & 120 & 231 & 231 \\
\hline & 2050 & 315 & 360 & 632 & 632 \\
\hline \multirow{3}{*}{$\begin{array}{l}\text { Land use for } \\
\text { sugar cane } \\
\left(\mathrm{km}^{2}\right)\end{array}$} & 1990 & 870 & & & \\
\hline & 2020 & 437 & 770 & 477 & 444 \\
\hline & 2050 & 354 & 775 & 316 & 311 \\
\hline \multirow{3}{*}{$\begin{array}{l}\text { Land use for } \\
\text { other agriculture } \\
\left(\mathrm{km}^{2}\right)\end{array}$} & 1990 & 73 & & & \\
\hline & 2020 & 98 & 78 & 163 & 167 \\
\hline & 2050 & 90 & 101 & 173 & 177 \\
\hline \multirow{3}{*}{$\begin{array}{l}\text { Land use for } \\
\text { urban activities } \\
\left(\mathrm{km}^{2}\right)\end{array}$} & 1990 & 305 & & & \\
\hline & 2020 & 627 & 324 & 583 & 623 \\
\hline & 2050 & 712 & 360 & 780 & 768 \\
\hline \multirow{3}{*}{$\begin{array}{l}\text { Land productivity } \\
(1990=100)\end{array}$} & 1990 & 100 & & & \\
\hline & 2020 & 178 & 232 & 232 & 232 \\
\hline & 2050 & 315 & 535 & 535 & 535 \\
\hline \multirow{3}{*}{$\begin{array}{l}\text { Total water } \\
\text { demand } \\
\left(\mathrm{m}^{3} / \text { second }\right)\end{array}$} & 1990 & 12.0 & & & \\
\hline & 2020 & 10.7 & 14.1 & 11.5 & 13.0 \\
\hline & 2050 & 12.8 & 19.4 & 15.1 & 15.2 \\
\hline \multirow{3}{*}{$\begin{array}{l}\text { Dilution flow } \\
\text { required } \\
\left(\mathrm{m}^{3} / \text { second }\right)\end{array}$} & 1990 & 2.4 & & & \\
\hline & 2020 & 2.0 & 2.7 & 0.6 & 2.3 \\
\hline & 2050 & 2.4 & 3.6 & 0.7 & 0.7 \\
\hline \multirow{3}{*}{$\begin{array}{l}\text { Level of } \\
\text { BOD in the } \\
\text { lagoon }\left(\mathrm{kg} / \mathrm{m}^{3}\right)\end{array}$} & 1990 & 0.27 & & & \\
\hline & 2020 & 0.44 & 0.43 & 0.15 & 0.56 \\
\hline & 2050 & 0.60 & 0.71 & 0.24 & 0.23 \\
\hline \multirow{3}{*}{$\begin{array}{l}\text { Water treatment } \\
\text { investments } \\
\text { (mill.Rs) }\end{array}$} & 1990 & 0 & & & \\
\hline & 2020 & 0 & 0 & 4,750 & 0 \\
\hline & 2050 & 0 & 0 & 4,750 & 57,000 \\
\hline
\end{tabular}




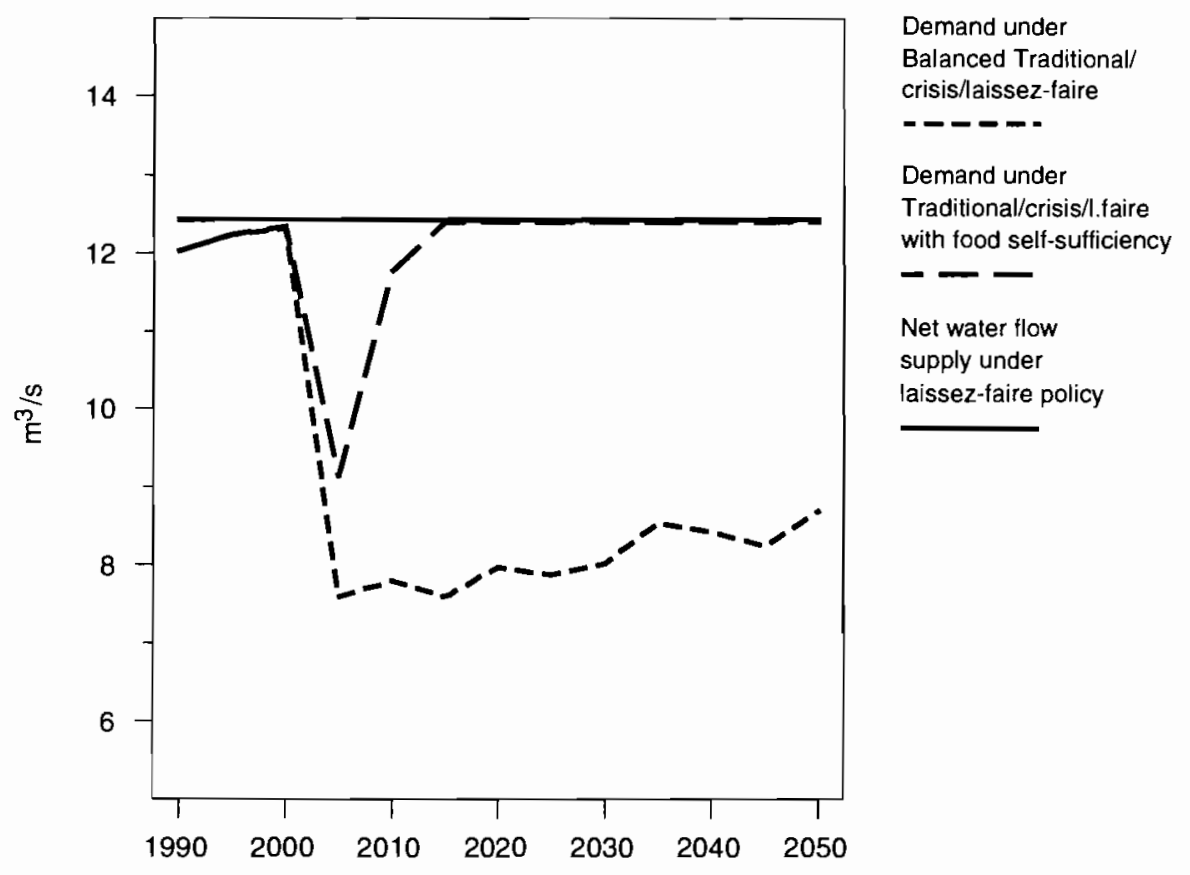

Figure 16.3. Water supply and demand under traditional/crisis scenarios.

annually to only 54 percent of today's level by the year 2050 . These results are shown in Table 16.4.

In a formal sense, this scenario is balanced. However, we can imagine that in a situation of poverty and underemployment, on the one hand, and surplus land and water resources, on the other hand, a different development could occur. Namely, that in reaction to the economic crisis, food imports would be reduced and domestic food production increased correspondingly, thus making better use of the surplus labor, land, and water resources.

\section{Food Self-Sufficiency}

The idea behind import substitution is that it has two positive interrelated effects: it reduces the amount of money which is "lost" abroad because it reduces imports, and it strengthens the internal economy because there is an increase in domestic production.

In its early history, Mauritius was self-sufficient in food for many years, but it currently has a long tradition of importing food. Today, Mauritius 
produces about one-third of the food its population consumes, and in the original crisis scenarios would continue to do so. Food self-sufficiency does not necessarily have high priority in an open export-oriented economy, but it may be a good strategy of sustainable development and resilience to international crises.

During World War II when transportation of food to the island was severely curtailed, Mauritius tried to attain temporary food self-sufficiency (see Chapter 7). Selected food crops, such as maize, cassava, potatoes, and sweet potatoes, were grown. Today, these staples are grown marginally. Fruits and vegetables are grown on the island, and deer, pigs, and chickens are bred. Mauritius is largely self-sufficient in these foods today. Major food imports include rice, wheat, maize, beef, and milk. In the food self-sufficient scenario, there would be a major dietary change.

To explore the effects of import substitution in the traditional/crisis/ laissez-faire scenario, we assume almost complete food self-sufficiency by the year 2010. Domestic food demand is increased by 50 percent every five years from 2000 to 2010 to around 80 percent of total food consumption, and imports are reduced by 50 percent in the period 2000-2005 (to the remaining 20 percent of food consumption). This new production obviously demands an increase in the proportion of land to be used for agriculture. In the crisis scenario, this land is available, because of available sugar land. In 2020, the land use for other agriculture is $184 \mathrm{~km}^{2}$ compared to $73 \mathrm{~km}^{2}$ in 1990 . The total land use in that year is $986 \mathrm{~km}^{2}$, which leaves room for more expansion.

However, as the additional food has to be grown and hence irrigated on the island, the limits of water availability are reached already by 2020.[1] After that year, no further increases in food production are possible. The water balance also includes the higher evapotranspiration from more food crops. Of course, more efficient irrigation methods could be used and the sea could be harvested. But all this must be seen in the context of the scenario: Mauritius is poor in this future, and limited in its technical and creative resources.

Figure 16.3 shows the development of the water demand in this food self-sufficiency scenario. The water demand dips from 2000 to 2005 as the crisis sets in, but the reaction to produce domestic food has not been fully completed. By 2010, the water demand increases again, because of increased irrigation for local food crops. We see that after 2010 the curve flattens. In 2020 , it hits the supply curve again. At this point, the model reduces irrigation and the productivity of agriculture, depending on the extent of 
the water shortage. The fact that the water demand curve hits the supply curve means that the water shortage is solved internally for the rest of the scenario years.

A garden policy with investments in water storage capacity would allow the food production to increase further, parallel to population growth. On the other hand, due to the high investment costs, the gains from additional local production would about equal the losses from higher government expenditures.

What is the effect of food self-sufficiency on total GDP? In the year of the crisis (2000), it decreases from Rs 24,000 to Rs 22,000 million. This is the combined result of lower GDP from lower exports and higher GDP from local food production. After that, exports stabilize and GDP increases because of reduced imports and increased local production. The scenario value for GDP in 2020, when the water limits for food production are reached, is Rs 27,000 million (see traditional/crisis/laissez-faire scenario with food self-sufficiency in Table 16.4). The increase between 2000 and 2020 is almost completely due to food self-sufficiency (some increase in GDP is due to a larger population base). However, because in this scenario the water limits are reached by the year 2020, no further increase in GDP is possible along this path. As population increases, the per capita income decreases correspondingly. In 2020 , per capita income is still Rs 18,600 ; in 2050 it is only Rs 14,600 . This is 23 percent higher than without food self-sufficiency, but is still only at the 1982 level of per capita income, and the trend in 2050 in this scenario is decreasing income, as shown in the TCL-FS line of Figure 16.2.

The underemployment, or low labor productivity situation, in this scenario is a little better than the TCL scenario without food self-sufficiency, because we assume that there are more people active in agriculture. The reduction in labor productivity which would occur with a balanced labor force is only some 10 percentage points less than without food self-sufficiency, with the same assumptions about lower female labor-force entrance and early male retirement. The results of this scenario are shown in Table 16.4.

\section{Small Modern Population}

Taking the economic crisis and the food self-sufficiency option described above as fixed parts of the balanced crisis scenario, what other developments or changes in the scenario path are possible? With a smaller modern population the relatively fixed GDP would not have to be divided over a growing population. With this scenario, population size is only 1.15 million 
in 2050. Exports are at the same, low level: Rs 14,000 million in 2050, i.e., only two-thirds of what they were in 1990 . We expect GDP to be lower in this scenario than in the crisis scenario with traditional population, because there is less income produced by the domestic market and activities as a consequence of the lower number of people.

The labor force is again completely imbalanced. The labor entrance and exit rates and the productivity changes found in the scenario above have been replaced by the inputs for the modern scenario. There is paradoxically high unemployment with the small population in the raw scenario. The labor demand is 193,000 persons and the supply is 512,000 . Figure 16.1 shows the development of the labor force in the modern scenario. There is a peak in labor-force size in 2020. After that, the reduced fertility assumed in this scenario starts to affect the size of the labor force.

The labor demand is some 35 percent lower than the 300,000 workers needed with the traditional labor force. This is partly because of lower economic activity with a smaller population. It is also because of higher productivity due to higher education of the labor force and consequently lower labor demand even with the same economic development.[2]

Before the crisis in the scenario year 2000 , labor already becomes slightly imbalanced. Then, in the five crisis years, the labor demand decreases from 400,000 to 300,000 , while the labor force increases from 500,000 to 550,000 . Hence, unemployment jumps up from 20 percent to 45 percent. In the raw scenario, no reaction from the side of the labor force is envisioned. However, the labor balance as calculated in this raw scenario would not have come true. The unemployment would have prompted a reaction. The worker discouragement phenomenon would have induced men and women to leave the labor force early or refrain from entering. A reduction in labor-force entrance rates for women ( 2 percent annually) and an increase in labor-force exits for men (also 2 percent annually) results in the same, lower labor-force participation rates as in the traditional/crisis scenario. This reduces the labor-force size in 2050 from 512,000 to 412,000 .

Further, the well-educated Mauritians would seek to emigrate, as they did in the 1960s and 1970s. Since we are assuming a world crisis in this scenario, the emigration could not be very great. In the period from 1962 to 1985 , before the island's economic takeoff, average annual emigration was about 3,000 . We use this estimate as a reasonable maximum. We, therefore, include emigration of 3,000 annually from 1995 to 2050 . This reduces the labor force further to about 335,000 in 2050 . The development of the labor 
force with these changed scenario assumptions is shown in the modern/crisis line in Figure 16.1. In this scenario, there is a substantial difference in laborforce size with the changed scenario assumptions. Since this labor-force size is still too high, labor productivity would have to be decreased to a level some 30 percent below the current level.

The key in this scenario was emigration, and not only lower productivity as in the former traditional/crisis scenario. Emigration is assumed to be possible because of the high education of the work force. We do observe that there is emigration of highly educated personnel from Asia, for example, nurses from the Philippines. Because the population base of Mauritius is so small and the ties to receiving countries, particularly France and Great Britain, so strong, we can assume emigration levels which alleviate unemployment. In this respect, the Mauritius scenario is not applicable to most other places of the world. As a consequence of emigration, not only the labor force but also the total population decreases, to less than 1 million by 2050. It should be noted that this scenario does not advocate the implied brain-drain. Rather, it points out that in a world of migration competition, only the well educated have a chance. We also cannot speak of harmful brain-drain in a situation where many well-educated people remain behind as in this scenario - many of them being only consumers and not producers. Moreover, emigrants are often a valued source of transfer.

In this scenario, with the low economic activity and the small population, the water and the land balances are always positive, even with the assumed food self-sufficiency. The GDP, which is calculated in the balanced scenario, is Rs 24,000 million in 2050 or Rs 24,600 per capita, roughly equal to the 1990 level, as shown in the MCL-FS line in Figure 16.2. Results are also given in Table 16.4 for the modern/crisis/laissez-faire scenario with food self-sufficiency. Another main advantage of the smaller population in this scenario is that government consumption is very low. To match total tax income, in this scenario it is even possible to increase per capita government consumption 0.33 percent annually to some 20 percent above the current level by 2050 . Thus, the quality of education and health care would increase.

Total exports in this scenario are still only Rs 14,000 million; however, in terms of income, the reduction of food imports and the increase of local production is able to fully compensate a one-third reduction in exports. In present-day Mauritius this is not possible because both land and water are used for sugar-cane cultivation. In the crisis scenario, it is possible because the sugar-cane production is reduced by half. This balanced 
modern/crisis/laissez-faire scenario with food self-sufficiency cannot be further improved by building water reservoirs, because there is sufficient water on the island for this level of population and economic activity.

\subsubsection{The boom scenarios: Population and environment in prosperity}

Scenarios which are probably more relevant to Mauritius are those which foresee a continuation of the economic growth that the island has experienced recently. In the five years from 1985 to 1990 , GDP at factor cost and constant prices grew at a rate of around 8.9 percent annually. The growth in 1991 was lower, 4.1 percent, but still a healthy level (calculated from World Bank, 1993). The respective export growth rates were 15 percent and 2.4 percent. The growth since 1985 has been due to the sudden mushrooming of the textile industry (see Chapter 7). Recently, growth has slowed down; the reason for this slowdown - whether market saturation, higher wages in Mauritius, or full-employment levels - is a topic for another analysis. The intention is to diversify the export economy. In the boom scenarios, this is successful.

In the raw boom scenarios, GDP would increase roughly sixfold, to about two-thirds of the 1993 OECD per capita levels. We consider this increase to be rather low for the optimistic scenario. Some experimentation with plausible labor- and land-productivity increases and with the optimistic goal of seeing what would be necessary to raise Mauritian per capita GDP levels to the current level of Switzerland resulted in slightly different boom inputs. The balanced boom scenarios envision a 7.6 percent average annual increase in the service exports (compared to 25 percent in the raw scenarios), an increase that is possible given the present low level of service exports and that would be necessary if Mauritius wants to be successful in, e.g., offshore banking. The rest of the scenario assumptions are unchanged. These scenarios are reminiscent of the usual scenario for development which is decreasing population growth, increasing education, and increasing economic growth going from an agricultural to an industrial to a postindustrial society. The difference with the usual scenario is that we must embed our results in the limited supply of population and natural resources.

Traditionally there is no explicit care for the environment: nature is regarded as the unending supplier of resources. This philosophy is reflected in the raw modern/boom/laisse $z$-faire scenario. However, from the raw scenarios we see an enormous water shortage. The shortage could be removed 
almost entirely simply by investing in water storage capacities - the garden assumption. Therefore, in the following, boom scenario assumptions are combined only with garden assumptions, in which reservoir capacity increases such that water supply increases from $12.4 \mathrm{~m}^{3}$ per second in 1990 to $21.4 \mathrm{~m}^{3}$ per second by 2050 .

\section{Increasing Productivity}

From Table 16.3 we see that the raw modern/boom/garden scenario results in an enormous land conflict, and also an immense labor shortage. Due to the installation of reservoirs the water shortage is small. On the other hand, taxes by far exceed government expenditures. With the new assumptions on export growth, the labor and land shortages are even greater; but labor and land must be balanced.

Under the assumption of a booming national and international economy, unchanged fixed technologies as were assumed in the raw boom scenarios are unlikely. In the model, changes in technology are first of all expressed through changes in labor productivity. Second, if a given number of people are producing more, then we can assume that they are producing greater value without using much more space. Land productivity also increases. In our experimentation, we concluded with a 3 percent annual increase in labor productivity (independent of the economic sector), which we feel could reflect a plausible optimistic technological advance, and a 3 percent annual increase in urban land productivity. By 2050, labor productivity and land productivity are five times higher than their values in 1990 because of this change.

Through this productivity increase, labor demand from the economy grows slowly, and keeps pace with the size of the labor force provided with modern population assumptions (610,000 in 2020, and 512,000 in 2050) until around 2035 even with the large assumed increases in production. However, by 2050 a labor shortage of some 100,000 appears again. During this late stage Mauritius enters the situation that could be facing the Northern countries in a few years: the population and the labor force are declining in size, while the economy is expected to continue to grow.

If we want to keep the export settings, that is, keep the economic growth, what must be done to come to grips with the shrinking labor force? There are a number of options: labor immigration; early improved education of the population (resulting in higher productivity); or additional assumed changes in technology, i.e., in labor productivity. For the first option, we would need some 6,500 well-educated immigrants (workers) annually between 2035 and 
2050. If migration is not restricted to temporary labor migration, the total yearly number of immigrants would be close to 15,000 . In total then, in 15 years, 200,000 foreigners would enter a society of a million inhabitants, as has been observed in the past (for example, the influx of labor to small oil-producing states). Still, this is a number that might be difficult to obtain and particularly to integrate.

Alternatively, the productivity of the labor force could be increased by improvements in education. The labor could be balanced by 2050 if the majority of Mauritians continued schooling beyond the secondary level beginning in the year 2000. The influence of this great increase in tertiary education would only be felt slowly in the labor force because it takes at least 50 years for a new schooling policy to penetrate completely into the labor force. By 2050, the higher education would both reduce labor demand - through higher productivity of tertiary-educated labor - and increase labor supply - through higher labor-force participation rates of tertiary-educated men and women. Since tertiary-educated women have less children on average, this change would also slightly reduce the total population size and exacerbate the labor shortage. However, a population with two-thirds of the labor force being educated at the tertiary level has not been observed in any country today and may not be likely in the future either.

A third option to solve the labor shortage in the period 2035-2050 is to increase labor productivity further to fit the need. We have chosen this option for the balanced modern/boom/garden scenario: labor productivity is increased 4 percent annually between 2035 and 2045 , and 5 percent annually during the last five-year period, just enough to balance labor supply and demand. These are assumptions necessary to attain the 1993 Swiss level of GDP with high education, low fertility rates, and ultimate population decline.

What happens to the land when we assume 3 percent annual productivity increases in the urban sectors? In general, in case of small land conflicts, the solution offered by the model is to take land away from the least productive commercial sector (sugar) and to use it for more productive urban expansion. However, land conflicts arising from urban activities themselves cannot be solved by the model. In this scenario, with the large increase in service exports, land demand from urban activities alone would exceed land supply by more than 100 percent at present land productivity levels. This is why a 3 percent annual increase in land productivity is necessary, multiplying urban land productivity by five in the long run. Sugar-cane land 
productivity increases only 0.5 percent annually; other agriculture land productivity increases 1.6 percent per year. With these productivity changes the remaining land conflict is within the boundaries that can be handled by the model itself: sugar production is reduced to give way for all other sectors. Land used for sugar cane declines from $870 \mathrm{~km}^{2}$ in 1990 to $311 \mathrm{~km}^{2}$ in 2050 , while land used for urban activities increases from $305 \mathrm{~km}^{2}$ to 768 $\mathrm{km}^{2}$ in this scenario (see Table 16.4).

Figure 16.4 shows the development of land used for sugar in the balanced boom scenarios. There is a smooth, monotonic decrease as urban activities increasingly crowd out sugar activities. The figure also shows the development of land used for sugar in the crisis scenario, in which sugar land drops to half of its previous level in the assumed crisis period from 2000 to 2005. Ultimately, both the boom and the crisis scenarios result in the same, low level of sugar land, but for very different reasons. These results are discussed in the next section on sugar policy.

As with land, the model can solve small water conflicts by removing water for irrigation purposes - which reduces the productivity of sugar cane slightly - and using it for other sectors. The water shortage is small in this scenario. The irrigation reduction is (more than) sufficient to reduce water demand below the net water flow supplied throughout the scenario. If water demand from non-irrigation exceeded water supply, this conflict would have to be solved by the user.

In contrast to the poverty scenarios discussed above, in the raw boom scenarios the budget balance is highly positive. As before, we chose to let tax rates remain unchanged and increase per capita government consumption, which mainly comprise education, health, and pension expenditures. In order to compensate the huge tax increase, per capita government consumption can be increased 5 percent annually over the whole period, or 4 -fold by 2020 and more than 14 -fold by 2050 (Table 16.4)! The immense increases in the quality of education and health care are parallel to the labor productivity increases, although this is not a hard-wired result of the model itself.

What is the income effect of all these changes that have eventually led to a balanced modern/boom/garden scenario? Total GDP grows at a remarkable speed - some 4.6 percent annually over a 60 -year period, parallel to the export growth. Per capita income increases to more than Rs 300,000 per year, a level that more or less corresponds to today's income level in Switzerland. Due to substantially lower loousing costs - simpler construction and no heating - and because the present GDP is an understatement 


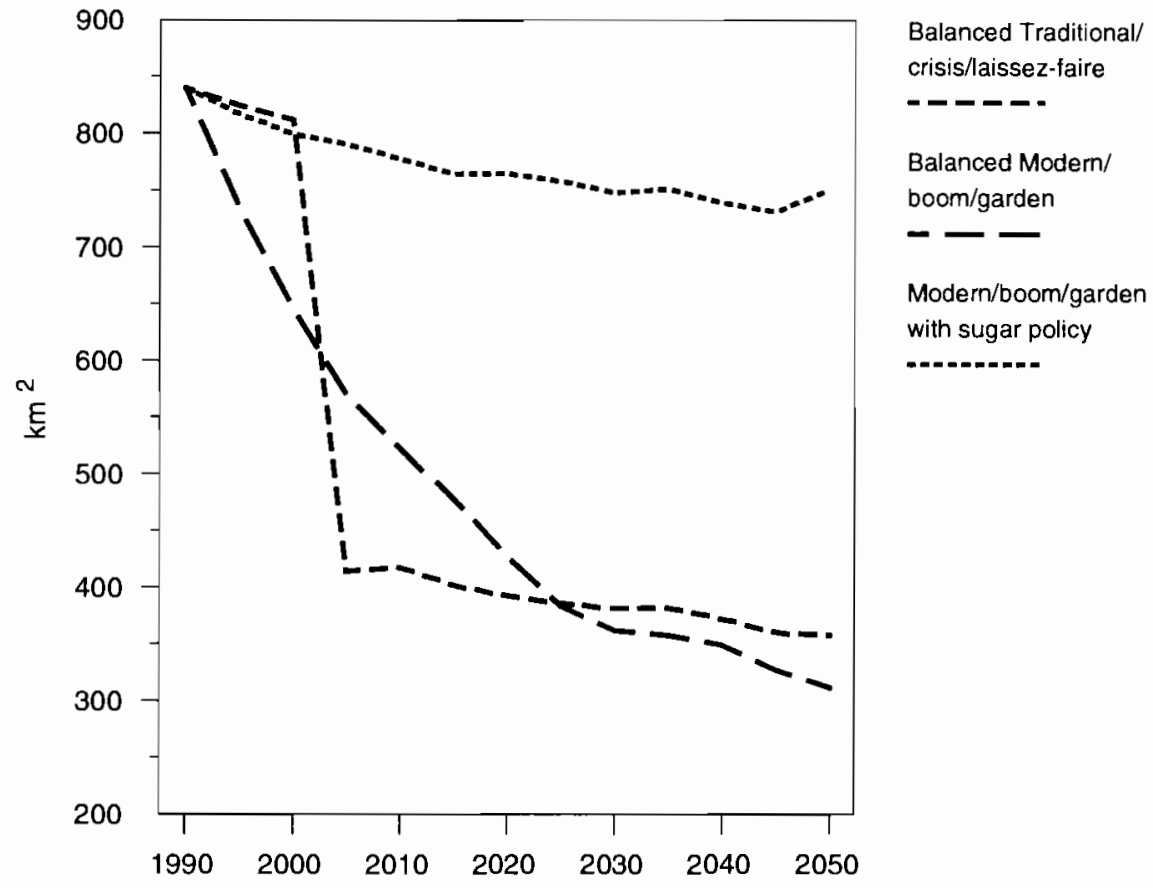

Figure 16.4. Changes in the development of sugar land in the balanced/ traditional/crisis/laissez-faire, balanced/modern/garden, and modern/boom with sugar policy scenarios.

of actual purchasing power in Mauritius, the 14-fold increase in per capita GDP would actually result in a material welfare clearly exceeding current Swiss levels. The development of income per capita is shown in the $M B G$ line in Figure 16.2.

But this scenario also has some negative effects. Due to the enormous production increase, the environment would have to suffer: water pollution increases rapidly. The concentration of organic waste in the lagoon, measured in terms of $\mathrm{kg}$ of BOD per $\mathrm{m}^{3}$ of water, doubles by 2020 and increases fourfold by 2050 (see Table 16.4).[3] As some negative effects are already visible in some parts of the lagoon with today's levels of organic waste concentration, a destruction of the lagoons with these pollution levels seems likely. Water treatment to keep the lagoon clean seems a must, in particular since a booming economy can afford this investment. Issues of water treatment are discussed in detail in later sections. 


\section{Sugar Policy}

In the balanced modern/boom/garden scenario land conflicts are solved in such a way that sugar cane has to give way for more productive urban activities. This feature, however, is contrary to current government policy. For many, often idealistic, reasons, Mauritius is reluctant to give up its sugar cane, and the current policy is to keep the present sugar output. Would it be possible to have both wealth and sugar?

Choosing the option "sugar policy" in the land-use module of the PDE model takes current government views into account. Under these conditions, any demand for sugar is satisfied first, and the remaining land is distributed to the remaining economic activities. A direct impact of this is that industrial and service production is constrained at a lower level than is demanded domestically and from abroad, triggering a contraction of the whole economy.

The development of the modern/boom/garden scenario, with a 14-fold increase in per capita GDP, is discussed above. With a sugar policy the development is quite different. Due to some land productivity increases for sugar, in the future somewhat less land is required to produce the present amount of sugar. This is shown in the sugar policy line of Figure 16.4 on sugar land. Losing in the case of a land conflict, urban activities are reduced drastically and, as a consequence, total exports are reduced by some 40 percent (compare Table 16.4). Hence, by 2050 total GDP increases 9-fold instead of 15 -fold. This is shown in the MBG-SP (sugar policy) line in Figure 16.2.

As a consequence of the lower level of exports, there are a number of additional differences between the balanced modern/boom/garden scenario and the balanced sugar policy scenario. Per capita government expenditure increases are lower, and labor productivity increases due to technological advance need not be as high. Water demand, on the other hand, would be higher. Sugar production is the most intense water user in Mauritius. Much water is "lost" through evapotranspiration of the sugar cane, and then much water is necessary to dilute the biological waste from sugar-cane processing. Compared to the previous modern/boom scenario, with regard to water pollution an unusual result arises: river water pollution (wastewater dilution) is higher ( 24 percent by 2050 ), while lagoon water pollution (organic waste concentration) is lower ( -25 percent by 2050$)$. This is documented in Figure 16.5 and Figure 16.6, which give lagoon and river water pollution under various scenarios. 


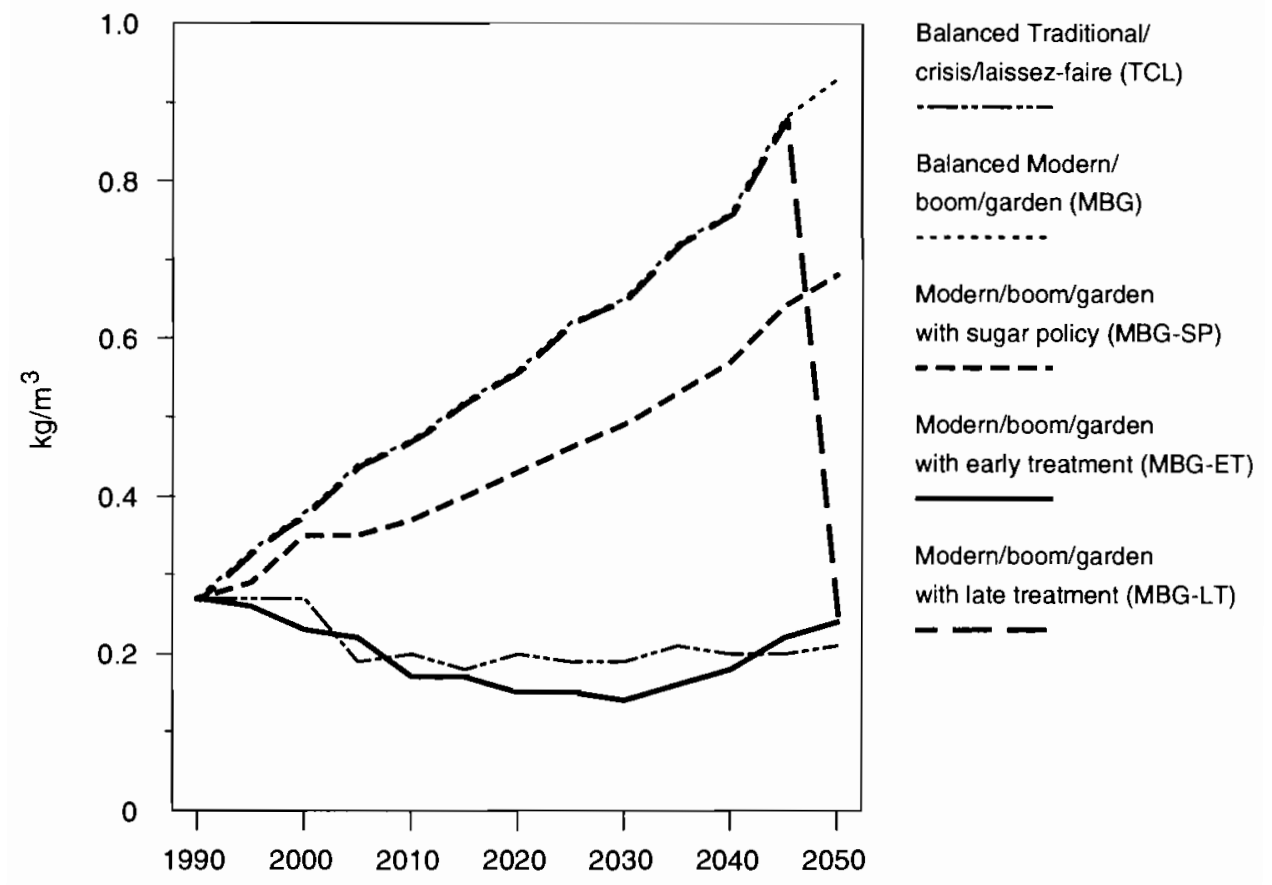

Figure 16.5. Lagoon water pollution measured in terms of biological oxygen demand in the lagoon, five selected scenarios.

The reason river water pollution increases in this scenario compared to the two above is that most of the sugar production waste is dumped directly into the rivers of the island. So, since there is more sugar production, there is more waste dumped into the rivers. Urban activity waste, on the other hand, is dumped to a much larger extent in the lagoons. As there is much less urban activity possible in this sugar policy scenario, so there is much less waste dumped into the lagoons.

\section{Large Traditional Population}

Is a similar economic boom possible also with a growing, traditional population? In this scenario we assume a return to higher fertility rates, constant mortality rates, and lower education and labor-force participation rates. By 2050 , population size is 65 percent larger with a traditional as compared to a modern population. The labor force is 49 percent larger (see Section 16.3.1), 


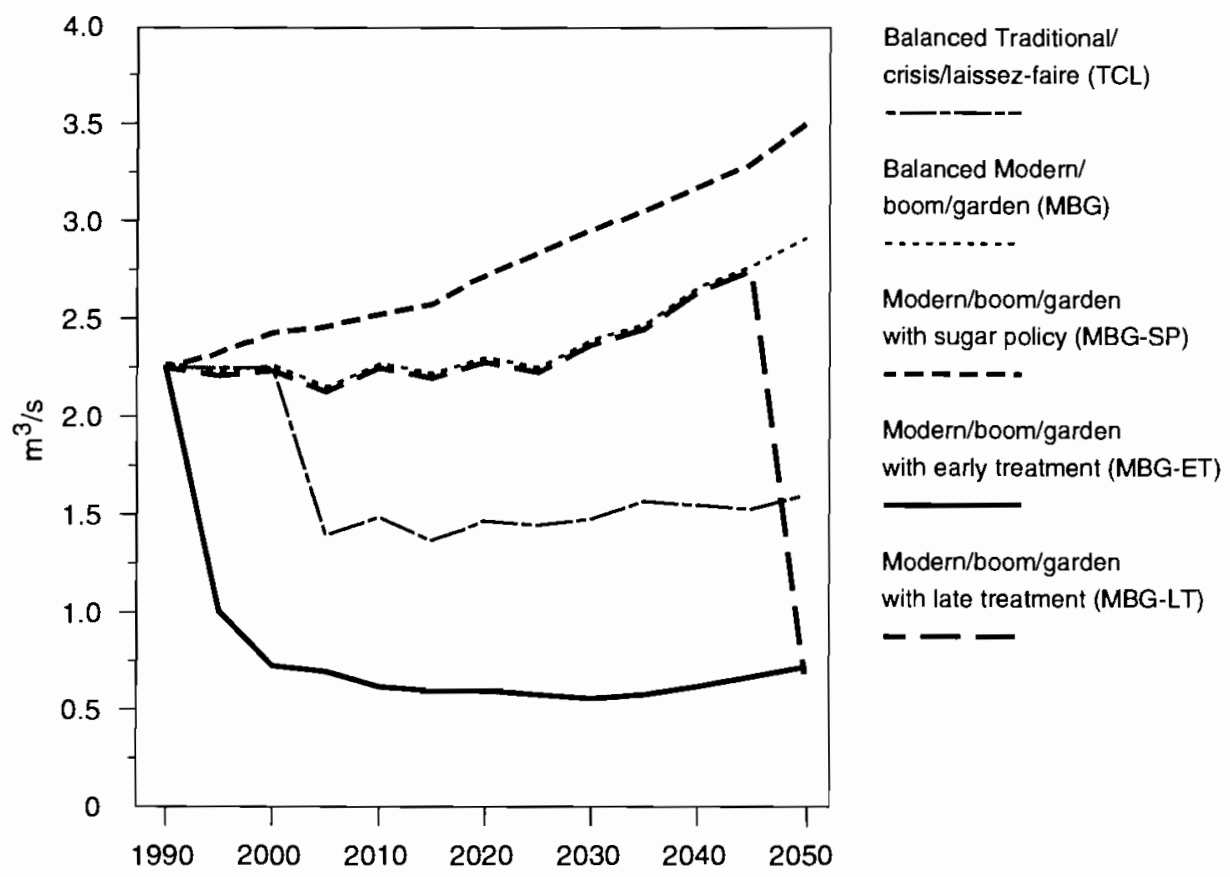

Figure 16.6. River water pollution measured in terms of the required wastewater dilution flow, five selected scenarios.

but at the same time it is less productive, i.e., more workers are needed to produce the same amount. If we take the same export assumptions as in the previous modern/boom/garden scenario, the labor productivity increase necessary in this scenario would be almost the same, or 3 percent annually.

There remains the question of how realistic this assumption is. Is it realistic to assume the same productivity increase from technological advance regardless of whether the population is well educated and therefore able to adapt to new technology or less educated and presumably less flexible? Most certainly not. To reflect the lower propensity for rapid technological advance, labor and also urban land productivity are assumed to increase "only" 2 percent annually. Productivity increases only 3-fold (instead of more than 5 -fold) over the entire 60 -year period.

The consequences of this change are striking. Notwithstanding the larger population, Mauritius would be hit by an immense labor shortage with the 
high export demand discussed in the section above on increasing productivity. In order to match the labor supply, total exports would have to be cut in half. EPZ other exports increase only 2 -fold (instead of 25 -fold), and - except for the finance sector which remains unchanged - service exports increase only 25 -fold. As a consequence, by 2050 total GDP increases to Rs 196,000 million under this traditional/boom/garden scenario, compared to Rs 351,000 million with modern population development. Not only must the income be divided over a larger - and still increasing - population, but also total GDP generated is lower. Per capita income increases 2.5 percent annually, on average, with a traditional population, but 4.4 percent annually with a modern population. By 2020, GDP per capita is 50 percent larger with a smaller, better educated population, by 2050 it is 200 percent larger. The development of the slower income per capita growth in this scenario is shown in the TBG line of Figure 16.2.

Also because of the larger population and the reduction in exports, in this scenario per capita government expenditures increase only fivefold in the long run. The quality of education and health care would certainly be lower than with a modern population development.

Water demand, river pollution, and lagoon pollution are much lower than under modern/boom/garden settings. These environmental results seem somewhat surprising under the traditional/boom/garden assumptions. The lower concentration of organic waste in the lagoon is a direct consequence of lower production. The lower water demand (both for irrigation and for waste dilution), however, is mainly a consequence of reduced urban land productivity, which creates severe land conflicts and hence causes a reduction in production of sugar and other agriculture. The larger population size has only a marginal impact on the environment.

\section{Early Water Treatment}

A negative effect of the balanced modern/boom/garden scenario is the rapid increase in organic waste concentration in the extremely sensitive lagoon. This is shown in the $M B G$ line in Figure 16.5. The biological oxygen demand increases from $0.27 \mathrm{~kg}$ per m $\mathrm{m}^{3}$ in 1990 to 0.56 in 2020 and to 0.93 in 2050 . The high BOD levels mean there is a nutrient enrichment in the lagoon eutrophication. Eutrophication results in the proliferation of certain species, usually algae, but also sea urchins in Mauritius, at the cost of other species, and results in an impoverishment of aquatic life. It is believed that this may 
kill the corals. In 1982, a UNEP study showed that roughly two-thirds of the corals were still alive but that "urgent immediate measures must be taken in order to prevent further deterioration" (Ramjeawon, 1991).

If the corals die and the lagoons are polluted, this certainly would mean the end of the tourism industry in Mauritius and would deprive Mauritians of a great source of quality of life. Would it be threatening in other respects? It is not known how fast dead corals would degrade and stop their function of protecting the island from the high seas. Nor is it known how much artificial protection (for example, concrete) would cost.

Even if we do not know at what BOD levels life in the lagoon would or could eventually die, we know that already with current organic waste concentrations some smaller parts of the lagoon have started to die. It therefore seems wise to set an upper limit of organic waste concentration; we have set it at the 1990 level: $0.27 \mathrm{~kg}$ required BOD per $\mathrm{m}^{3}$. Is it possible, with a rapidly growing economy, to keep lagoon pollution below this level? And, if it is, what are the costs and to what extent is income growth affected?

In the modern/boom/garden scenario with early water treatment everything stays the same as in the balanced scenario without water treatment, except that no increase in the organic waste concentration in the lagoon is allowed. In order to do so, a considerable amount of wastewater has to be treated so that it can be reused in the production processes. In the water module, water treatment is possible at three different treatment levels which differ by unit cost and effectiveness. For example, to remove 30 percent of the BOD from textiles costs Rs 172 per $\mathrm{m}^{3}$ of wastewater; to remove 90 percent costs Rs 604; and to remove 95 percent costs Rs 741 all at 1987 prices with present technology. Treatment at the secondary level turns out to be the best combination of costs and effectiveness in almost all sectors. The sectors that produce large amounts of BOD in Mauritius are sugar milling, the three manufacturing sectors, and tourism. The other sectors produce virtually none (see Toth, 1992). At the most extreme, sugar milling produces $1,155 \mathrm{~kg}$ of biological oxygen demand per Rs 1 million of output, compared to between 2 and $14 \mathrm{~kg}$ per Rs 1 million of output in the service sectors (the differences lie in the productivity of the workers in these service sectors). Only the five most polluting sectors have been chosen for treatment. The results are shown in the early treatment line in Figure 16.5. The BOD level in the lagoons remains low. As a matter of fact, the level is as low as in the crisis scenarios which have very much lower economic activity. 
Over the whole period $1990-2050$, Rs 285 billion would have to be invested in wastewater treatment in this scenario to keep organic waste concentration in the lagoons at the 1990 level. This is 12 times the 1990 total GDP (1987 prices). One-third of the total goes into other EPZ industries, one-third into other manufacturing, and one-ninth into each of the three other sectors (sugar milling, textiles, tourism). To distribute the burden on the economy equally, in the early water treatment scenario Rs 4.75 billion are invested each year. This gives a relatively heavy burden on the economy during the first years (for example, 20 percent of total GDP in 1990), but an insignificant burden in the long run (only 1 percent of total GDP in 2050). The model assumes that the machines for water treatment are not produced in Mauritius, but are imported. Therefore, investments in water treatment are actually lost from the Mauritian economy.

The reader may ask why not invest a constant percentage of GDP in water treatment, to spread the treatment burden evenly in a relative sense. This is not possible because there is a greater concentration of more polluting activities in 1990 (particularly textile and sugar) compared to the production envisioned for the future in this scenario. In order to keep the same leve] of cleanliness in the lagoons in the next few years, while still being active in more polluting activities, Mauritius would actually have to invest a large portion of its GDP in treatment plants.

The consequences of early water treatment are convincing. Firstly, with such a policy it is possible to keep the organic waste concentration below the 1990 level throughout the projection period. The BOD level is below 0.20 during most of the period and increases to 0.24 by 2050 (see Figure 16.5). Secondly, river water pollution is reduced to only one-third of its current 1990 level. This is a combined effect of wastewater treatment and of increases in urban production at the expense of sugar production, which is the main source of river water pollution in Mauritius (see Figure 16.6). And thirdly, in the long run this policy does not have any negative effect on wealth; total GDP increases to the same high level as under the no treatment scenario. As we can be sure that life in the lagoon will stay alive, perhaps only in this early water treatment scenario could the projected income growth actually be achieved.

The main difficulty of this policy is that, in the short sun, it would lower the income growth. Per capita government expenditures could not be increased before the turn of the century, since all of the additional tax income would have to be spent for the installation of water-treatment plants. 
Throughout the period, however, per capita income would only lag 5 percent behind the no treatment scenario. In Figure 16.2, the early treatment line for per capita income is slightly below the $M B G$ line and the late treatment line until 2040. On the other hand, it is necessary to start treating water immediately in order to avoid a rapid destruction of the lagoon; and the current economic boom indeed makes the huge investments possible. Moreover, early treatment avoids the necessity of sudden, huge investments later on and one-time higher costs, as we explore in the late water treatment scenario.

\section{Late Water Treatment}

What would or could happen if the Mauritian government does not enact an early water treatment policy, but instead starts to install treatment plants only after the destruction of the lagoon becomes evident?

The environmental consequences cannot be tested in the model. If the government adopts such an ad hoc policy, various possibilities exist: the lagoon may be dead before the late wastewater treatment is begun; part of the lagoon may be dead while other parts are alive or at least revivable; in the most optimistic case, the process of lagoon destruction might be reversible. For the last possibility, we can at least calculate the economic costs of such a late water treatment policy. Although it does not necessarily reflect the most likely option.

For the modern/boom/garden scenario with late water treatment we assume that no water-treatment plants are installed until the year 2045. Everything has developed as under the balanced modern/boom/garden scenario, and BOD in the lagoon has increased to $0.88 \mathrm{~kg}$ per $\mathrm{m}^{3}$ by 2045 . Suddenly, the lagoon collapses or for some other reason the government decides to take immediate water-treatment actions. The same amount of Rs 285 billion is invested during the period $2045-2050$, or Rs 57 billion annually (that is, for example, 20 percent of total GDP in 2050). The level of pollution is immediately decreased, as is shown by the late treatment line in Figure 16.5 and also in Figure 16.6.[4] To pay for this investment, taxes have to be increased by 120 percent. This tax increase lowers the total and per capita. GDP in 2050 compared to the early water treatment scenario by not less than 10 percent. The cost of this scenario is seen in Figure 16.2 where the late treatment line dips below the $M B G$ and the early treatment line in the last period. 


\subsection{Conclusions}

In this chapter a series of alternative future scenarios for Mauritius are presented. There are two main groups of scenarios: population and environment in poverty and in prosperity. In the description of the crisis scenarios, the effects of a large, traditional versus a small, modern population are discussed. Import substitution via food self-sufficiency is investigated. Under the assumption of an economic boom, we explore differential sectoral developments and their effects on wealth and the environment. The problems of a larger, less educated and a smaller, more educated labor force are compared. Conscientious early and ad hoc late pollution abatement are considered alternatives. In this section we provide a comprehensive summary for each of the eight scenarios.

\subsubsection{Population and environment in poverty}

- Underemployment: In an assumed export crisis in Mauritius, a great surplus of labor, land, and water occurs. Income per capita decreases. A reduction of the labor-force participation rate of women and older men does not alleviate unemployment greatly because the majority of the labor force, young and middle-aged men, is not affected. A reasonable reduction in the labor-force participation rates is not a mechanism which can "solve" substantial unemployment. The economy that does not react to a reduction in exports by increasing domestic production underutilizes the resources that have been freed up by the export reduction.

- Food self-sufficiency: In the case of excess labor, land, and water resources and a small export market, simple production of locally needed goods - in this scenario, food - does help increase income. Because of the low level of technology assumed, land productivity cannot be increased; and because of low income, water supply cannot be improved. This results in a ceiling beyond which the simple economy cannot grow.

- Small modern population: With lower fertility rates the population stabilizes so that the island is able to provide food for the whole population within the water and land constraints given. Higher education rates (which indirectly contribute to lower fertility) are the basis for assuming certain emigration in a world of migration competition. This also alleviates some of the island's problems. Together, these developments result in a significantly higher income per capita. 


\subsubsection{Population and environment in prosperity}

- Increasing productivity: For the economy of Mauritius to reach current Western and Japanese standards of income, exports and, hence, GDP have to increase an average of 4.5 percent annually over the next 60 years. Such growth is only possible with significant changes in technology. Labor would be a major limiting factor. This rapid increase in wealth would also coincide with rapid environmental destruction, if there were no concern for the environment in the form of wastewater treatment - even if the rapid growth would essentially concern a relatively "clean" service economy.

- Sugar policy: Strict agricultural policies, in this scenario to protect sugar, would constrain a rapidly growing and developing economy. Giving priority to sugar was reasonable at an earlier stage of development, but it will not be beneficial in the future, if it is possible to expand in other directions. To avoid the drawbacks of rapid urban expansion the transition from agriculture should be well planned and managed.

- Large traditional population: A large, growing population with insufficient education obstructs a booming economy in various ways. With a less educated labor force, technological advance would be slower and economic growth would be more restricted by labor than with a more educated population. In addition, any increase in wealth has to be distributed over the larger, and still increasing, population. Environmental problems could be less dramatic because of lower production, but they could also be more dramatic because of increased production in more polluting economic sectors. In both cases, the lower income would make environmental care relatively more expensive.

- Early water treatment: To keep the sensitive lagoon, the coral reef, and the variety of species alive, immediate measures have to be taken. By installing wastewater-treatment facilities today, organic waste concentrations in the lagoon can be kept below the current level even with a rapidly growing economy. In the short run, an early treatment policy would be a relatively heavy burden for the economy. In the long run, however, these investments would be paid back - and possible environmental disasters can be avoided.

- Late water treatment: Water pollution could be kept consistently low with early treatment. With late treatment, pollution levels could increase greatly before being reduced to some low, acceptable level. If 
some types of lagoon life die in the interim, this loss would be irreparable, even if subsequent cleaning efforts returned the water to a quality that could sustain life.

In conclusion, this extensive exercise of defining a few selected scenarios among the myriad of possibilities and discussing their results prove once more the extent to which results depend on assumptions in any modeling effort of this kind. The advantage of this specific exercise, however, is that it is deeply embedded into the actual Mauritian situation. Empirical data fill most parts of the model, and the degree of variations introduced through model assumptions is initially very limited, but increases over time.

Since the future is inherently uncertain and the alternative scenarios considered are at least theoretically possible alternative paths of development, we still think that such modeling exercises can make a useful contribution to a better understanding of the options for sustainable development in a place like Mauritius.

\section{Notes}

[1] In the scenario it is assumed that a large part of the additional food production comes from "private agriculture," grown in the households' gardens. Therefore, as a consequence of higher demand for irrigation, two water variables were changed for the household sector: specific gross intake $(+65$ percent every five years between 2000 and 2010) and the rate of water loss $(+50$ percent every five years over the same period).

[2] The higher productivity can be calculated as follows (see Wils, 1993). In the modern scenario, in 2050,25 percent of the labor force has tertiary education, with a productive weight four; 60 percent, secondary education with a productive weight two; and 15 percent, primary education only with a productive weight one. The productivity index of this distribution is $(25 \times 4)+(60 \times 2)+$ $15=235$. In the traditional scenario, 6 percent of the labor force has tertiary education, 70 percent secondary, and 24 percent primary. The productivity index of this distribution is $(6 \times 4)+(70 \times 2)+24=188$. The modern labor-force productivity is 25 percent higher than the traditional.

[3] The biological oxygen demand (BOD) is the inverse of the organic waste concentration; i.e., it is the oxygen demand needed to keep the current organic waste concentration unchanged.

[4] This immediate reduction of the organic waste concentration presupposes that no additional harm is done to the environment through accumulation of organic waste. 



\section{Chapter 17}

\section{Alternative Histories Since 1962}

Christopher Prinz

\subsection{Introduction}

In Chapter 16 alternative future pathways for Mauritius to 2050 are developed and discussed. The analysis shows how PDE Mauritius can be applied, how scenarios can be created, and which results the model can provide. These scenarios of the future can help Mauritian decision makers to evaluate some possible policy actions concerning the population, the economy, and the environment.

PDE Mauritius cannot only be used for the period from 1990 to 2050 . It can be used for any period, provided data for the starting year are available. In the following application the period from 1962 to 1987 has been selected.[1] There are several good reasons for running PDE Mauritius for this particular period.

First, it is an ideal way of testing the model's equations, data reliability, and the parameter estimation. If the model is reasonably capable of estimating the demographic and economic structure of Mauritius in the late 1980s and early 1990s based on input parameters for the year 1962, it should also be able to do so for the future based on input parameters for the year 1990 . 
Since no economic data were available before the early 1960s, the census year 1962 has been chosen as the starting year. This year is the most suitable starting year because both the sudden demographic transition and the rapid economic development took place afterward.

Given the reasonable reconstruction of the period 1962-1987 we can start to specify alternative historical scenarios to improve our understanding of population-development-environment interactions even more. By varying the assumptions we may be able to determine some reasons for the rapid economic growth, and we may be able to find answers to several interesting questions. Was the fertility decline a major driving force for development? Or was the driving force the rapidly increasing educational level of the population? Was the socio-demographic development important at all? Or were external trade and foreign investment the main source of growth? Would economic growth have been possible without the Lomé Convention, which, among other things, regulates the amount and price of sugar exports? Was setting up the EPZ industries, especially the textile industry, crucial? Was it worth destroying parts of the coast and polluting the lagoon to provide hotels for the tourism industry?

Section 17.2 is concerned with testing the PDE Mauritius model by reconstructing the past, i.e., the period from 1962 to 1987.[2] Some of the demographic, economic, and environmental variables and parameters are discussed in more detail, including some information on data sources and data estimation.

Section 17.3 deals with the population module of PDE Mauritius which can also be run separately. Several historical population scenarios are designed, and the demographic results are discussed in detail. The projections are carried out for the period from 1962 to 2022 in order to accentuate the long-term impact of demographic changes, such as increasing fertility. Speculations are made concerning the possibilities for economic growth on the basis of socio-demographic development paths.

In Section 17.4 the demographic assumptions of Section 17.3 are supplemented by economic assumptions to enable the application of the full PDE Mauritius model for the period from 1962 to 2002. Nine alternative scenarios are specified to answer the questions raised above. Also, answers to the speculations in Section 17.3 are given. Comprehensive conclusions are drawn for each scenario. 


\subsection{Reconstructing the Past}

Testing a model by applying it to a historical period for which empirical input and output data are available is a common procedure to assess the quality of a model. Model results and thus the reliability of the model's equations and of the parameter estimation procedures involved can easily be checked on the basis of observed real data. The main restriction for such a "controlled experiment" is the availability of input parameters for a sufficiently long period. Not surprisingly, for a country like Mauritius, which is just about to leave the stage of a poor developing country, many if not most of the model parameters are simply not known. However, since some of the main parameters, such as fertility, mortality, education, laborforce participation, export demand, import demand, wages, and government expenditures, were available or could reasonably be estimated for at least some years in the past, an application of the PDE Mauritius model starting in 1962 turned out to be possible. In the following sections some of the real and estimated parameters are discussed in detail for each of the modules.

\subsubsection{Population}

In contrast to other sections of the model, reconstructing the historical population development is to a large extent based on observed data. The structure of the starting population for the year 1962, including information on sex, age, and labor-force status, was taken from 1962 census publications. Estimates of the educational distribution, which is a result of previous (unknown) school-leaving rates, were based on available figures. The related error is less of a problem because by 1962 the majority of the adult population still had only primary education.

Information on fertility and mortality, the two main components determining population growth, was readily available from the publications of the Central Statistical Office (CSO) in Mauritius (Digest of Demographic Statistics, census publications). Mortality was assumed to be independent of education and labor-force status. Since 1962, mortality rates declined continuously to a level that was typical for Europe some 20 to 30 years ago. Female life expectancy at birth increased by 11 years (from 62 years in 1962 to 73 years in 1990), while male life expectancy increased by 6 years (from 59 to 65 years). At the same time, Mauritius experienced an extremely 
rapid fertility decline, and is now beyond the demographic transition. The total fertility rate, which gives the average number of children born to each woman, declined from around six children in the early 1960s to fewer than two children in 1985-1986. It has increased slightly since, reaching the level of 2.3 children in 1990. There is a strong negative correlation between fertility and education, i.e., fertility is lower among well-educated women. Agespecific fertility rates by level of education are only available for 1983 (from the fertility analysis report of the housing and population census). It was assumed that educational differentials in fertility did not change over the period considered (1962-1987).

Despite the existing data on fertility and mortality, it is difficult to reconstruct the exact age structure of the Mauritian population as data on the sex and age structure of migrants to and from Mauritius are missing. The annual number of net emigrants, which fluctuated around 3,000 between 1962 and 1988 , is the only figure available. Model migration patterns were used to distribute those 3,000 annual emigrants across sex and age, while crude assumptions were made concerning their education and labor-force status distribution. The basic assumption was that well-educated people have a higher propensity to leave the country, be it for personal or professional reasons.

Information on age-specific enrollment ratios, which are required for the reconstruction of the educational distribution of the population, was taken from different CSO publications (Digest of Educational Statistics, Education Analysis Report). In the critical age span school enrollment ratios increased significantly, in particular among women: from 45 percent to 78 percent and from 8 percent to 33 percent for age groups $10-15$ and 15-20, respectively, compared with changes from 60 percent to 78 percent and from 24 percent to 36 percent among men. Today, there is virtually no gender difference in schooling in Mauritius.

Labor-force participation rates among primary- and secondary-educated women increased rapidly, for example, from 14 percent to 40 percent and from 33 percent to 57 percent at ages 30-39. Among tertiary-educated women and among all men, economic activity has always been between 90 and 100 percent and has not changed significantly in the last three decades.

In summary, due to both limited data availability and the translation of existing data into model parameters, the educational structures and, in particular, the labor-force structure of the population were less precisely reconstructed than its size and age structure. 


\subsubsection{Economy}

Reconstructing the economic history of Mauritius is more difficult in the sense that several parameters had to be estimated on the basis of very limited information. It is at the same time less difficult in the sense that it has to match fewer criteria, i.e., it has a higher degree of freedom. First, the heart of the economic module, the input-output ( $\mathrm{I}-\mathrm{O})$ table, had to be constructed for the starting year 1962. Second, for each parameter a reasonable time path had to be estimated. The $1962 \mathrm{I}-\mathrm{O}$ table was built and adjusted combining our knowledge on Mauritius with information from the Annual Digest of Statistics (CSO), publications from the Bank of Mauritius, and the Economic and Social Data Sheets published by the World Bank (World Tables 1976, 1980, 1988-1989). Changes over the period 1962-1987 were reproduced as closely as possible in order to match the observed data. Since each parameter had to be specified sector by sector, the whole exercise involved the estimation of a time path of some 600 parameters, the most important ones are discussed below.

In 1962, export demand was dominated by sugar milling. Sugar exports were equal to Rs 2,660 million (1987 prices) or 87 percent of all exports. By 1987 sugar-milling exports increased to Rs 4,400 million, but their share among total export demand declined to less than 30 percent. The EPZ textile sector was the leading sector in 1987 (Rs 5,500 million or 37 percent); other important sectors included transport and communication (11 percent), EPZ other ( 7 percent), tourism ( 7 percent), and finance ( 5 percent).

For wages, an increase of 5 percent for each five-year period, in all sectors and for each educational level, was found to be reasonable. Sectoral and educational differentials were kept at the 1987 level throughout the period. For example, wages in the finance sector are five times higher than in the other agriculture sector; wages of employees with tertiary education are two times the wages of those with secondary education; and wages of workers with secondary education are again two times the wages of those with primary education.

Government expenditure is calculated according to one of the following: student status (education expenditure), age and sex (health expenditure), or per capita (other government expenditure, except water). These patterns were kept constant throughout the period 1962-1987, but per unit government expenditure was adjusted to approximately match observed government revenues. Between 1962 and 1987 per unit government expenditure 
increased by 80 percent, the largest increase having occurred between 1972 and 1977.

For some parameters - for example, unit domestic household demand (by type of demand and by sector), the capital/output ratios (by sector), taxes per unit of output (by sector), per unit import demand (by sector), or value added per unit of output (by sector) - 1987 data were used throughout the whole period. Other parameters - such as labor-productivity increase from technological change (by sector), employment per unit of output (by sector and education), or unit domestic intermediate demand, the centerpiece of the input-output matrix - have been specified in detail but are not discussed here.

\subsubsection{Land use}

For the land-use module, which is closely connected to the economic module, only a few parameters have to be specified to reconstruct the history. Some parameters, like total usable land available, are constant by nature. Another very important land-use variable, such as fertilizer use, can be set constant at the current level throughout the period because approximately the same amount of fertilizers was already in use in the 1960s. Intercropping, i.e., planting tomatoes or other crops within sugar-cane fields, was very limited in the early 1960s. We specified the percentage of other agriculture obtained from intercropping sugar-cane fields to have increased linearly from 0 percent in 1962 to the 40 percent observed in 1987.

Land-use productivity, a critical parameter in case of land conflicts, has increased steeply: 20 percent in each subsequent five-year period.

\subsubsection{Water}

In the historical analysis, the water module is a very special case. All of the numerous parameters can be kept constant at current levels. Some parameters were kept constant for natural and physical reasons; these parameters include precipitation, river length, river velocity, minimum available flow, dissolved oxygen saturation level, or ratios of biological oxygen demand (BOD) to nitrates and BOD to phosphates in wastewater. Other parameters, like water-quality standards, are qualitative. Water supply, which is determined not only by precipitation and evaporation but also by the availability of reservoirs is also constant, as all (except one small) reservoirs were completed between 1914 and 1962. Some features of the water module, like 
wastewater disposal and treatment, are not of importance for the historical exercise.

Water demand by sector per unit of output has to be kept constant at the current level as no information exists for the past. In addition, it seems reasonable to assume that gross water intake and the rate of water loss per unit (by sector) have not changed significantly.

Given the satisfactory reconstruction of the period from 1962 to 1987, one can start forming "what-if" questions. For this historical period, environment is only a small issue, as neither water nor land constraints - the two major issues for the future - were observed.

\subsection{Population Histories}

The uniqueness of the population module lies in its combination of pure demographic factors - fertility, mortality, and migration - and some sociodemographic factors - student status, completed educational status, and labor-force status. The advantage of this sort of classification is made clear in Section 17.3 .3 on socio-demographic dependency ratios. To accentuate the long-term impacts of demographic changes the following analysis is based on projections for the period from 1962 to 2022 .

\subsubsection{Scenario specification}

Before we can turn to the discussion of "what-if" questions, we have to specify some alternative population histories in detail. Five scenarios have been selected for the analysis:

1. Reconstructed development scenario:[3] assuming observed development between 1962 and 1987, i.e., assumptions for this period correspond to the assumptions in Section 17.2.1, and keeping all parameters constant after 1987.

2. Constant parameters scenario: keeping all parameters constant at their 1962 level throughout the whole period 1962-2022 and evaluating what would have happened until today and further into the future if nothing would have changed since 1962 .

3. Fertility stagnation scenario: assuming constant 1962 fertility throughout the whole projection period, everything else being equal to the reconstructed development scenario, thus isolating the socio-demographic effect of the rapid fertility decline. 
4. Delayed development scenario: keeping all parameters constant at their 1962 level up until 1977 and shifting the socio-demographic development observed between 1962 and 1987 to the period from 1977 to 2002, thus evaluating the effect of delaying the socio-demographic transition by 15 years.

5. Social stagnation scenario: combining observed demographic development of fertility, mortality, and migration with social stagnation (i.e., education and economic activity constant as of 1962 throughout the whole projection period) and evaluating the impact of constant school enrollment ratios and labor-force participation rates.

Scenarios 1 to 3 are also discussed in Section 17.4 which employs the full PDE Mauritius model, while scenarios 4 and 5 are only used in the analysis of the population histories. Scenarios 2 to 5 are all designed under the assumption that observed socio-demographic development was so rapid that any imaginary alternative can only assume slower or no growth (like the constant parameters scenario), partial growth (like the fertility and the social stagnation scenario), or delayed growth (like the delayed development scenario).

\subsubsection{Selected results}

The main results of the population histories exercise are given in Table 17.1, and projections of the total population size are given in Figure 17.1. Figure 17.1 is a logarithmic scale to accentuate changes in the historical period 1962-1987 and to put less emphasis on the future. The figure shows that the Mauritian population grew from almost 700,000 inhabitants in 1962 to about 1 million in 1987 and would grow to 1.3 million by 2022 under the reconstructed development scenario. If the demographic transition could not have been completed (constant parameters scenario), the population size would have increased exponentially (see the straight line in the logarithmic-scaled figure) and thus would have doubled by 1987 . It would have reached almost 3.8 million by 2022 . The lower population size in the fertility stagnation scenario is due to the educational structure of the female population, that is, a high proportion of well-educated women leads to a lower overall fertility rate. Delaying the socio-demographic transition by only 15 years (delayed development scenario) would have brought the population size to almost 2 million by the year 2022; that is, in Mauritius, delaying the transition by 15 years would have led to a 50 percent increase in the number of inhabitants in the long run. 
Table 17.1. Hypothetical population developments, 1962-2022.

\begin{tabular}{|c|c|c|c|c|c|c|}
\hline & $\begin{array}{l}\text { Total } \\
\text { population } \\
(1,000 \mathrm{~s})\end{array}$ & $\begin{array}{l}\text { School } \\
\text { population } \\
(1,000 \text { s })\end{array}$ & $\begin{array}{l}\text { Labor } \\
\text { force } \\
(1,000 \mathrm{~s})\end{array}$ & $\begin{array}{l}\text { Labor } \\
\text { force } \\
(\%)\end{array}$ & $\begin{array}{l}\text { Well- } \\
\text { educated } \\
(\%)\end{array}$ & $\begin{array}{l}\text { Elderly } \\
\text { population } \\
(\%)\end{array}$ \\
\hline 1962 & 687 & 280 & 191 & 28 & 22 & 4 \\
\hline \multicolumn{7}{|c|}{ Reconstructed development scenario } \\
\hline 1977 & 902 & 298 & 286 & 32 & 39 & 6 \\
\hline 1992 & 1,081 & 316 & 404 & 37 & 53 & 7 \\
\hline 2007 & 1,222 & 308 & 509 & 42 & 63 & 8 \\
\hline 2022 & 1,291 & 290 & 546 & 42 & 69 & 14 \\
\hline \multicolumn{7}{|c|}{ Constant parameters scenario } \\
\hline 1977 & 1,012 & 386 & 281 & 28 & 38 & 5 \\
\hline 1992 & 1,555 & 603 & 425 & 27 & 46 & 4 \\
\hline 2007 & 2,423 & 937 & 683 & 28 & 48 & 3 \\
\hline 2022 & 3,789 & 1,450 & 1,067 & 28 & 49 & 4 \\
\hline \multicolumn{7}{|c|}{ Fertality stagnation scenario } \\
\hline 1977 & 1,013 & 408 & 286 & 28 & 39 & 5 \\
\hline 1992 & 1,553 & 678 & 456 & 29 & 54 & 5 \\
\hline 2007 & 2,338 & 963 & 787 & 34 & 65 & 4 \\
\hline 2022 & 3,463 & 1,380 & 1,232 & 36 & 69 & 5 \\
\hline \multicolumn{7}{|c|}{ Delayed development scenario } \\
\hline 1977 & 1,012 & 386 & 281 & 28 & 38 & 5 \\
\hline 1992 & 1,388 & 471 & 434 & 31 & 47 & 5 \\
\hline 2007 & 1,691 & 487 & 651 & 38 & 55 & 6 \\
\hline 2022 & 1,943 & 489 & 804 & 41 & 63 & 9 \\
\hline \multicolumn{7}{|c|}{ Social stagnation scenario } \\
\hline 1977 & 907 & 278 & 282 & 31 & 38 & 6 \\
\hline 1992 & 1,109 & 279 & 386 & 35 & 46 & 7 \\
\hline 2007 & 1,290 & 292 & 470 & 36 & 48 & 8 \\
\hline 2022 & 1,422 & 297 & 498 & 35 & 48 & 13 \\
\hline
\end{tabular}

The school population size behaves similarly, with scenario differences being even more pronounced.

With respect to the size of the labor force very interesting results are obtained. Until around 1992, the size of the total labor force would have been very similar under both the constant parameters and the reconstructed development scenario (see Table 17.1). There are two reasons for this: first, in the medium term the labor force is only to a small extent affected by fertility changes during the period 1962-1987; second, until 1992 the increase in labor-force participation rates of women since 1962 could have actually offset the decline in fertility during the 1960s and 1970s. The difference 


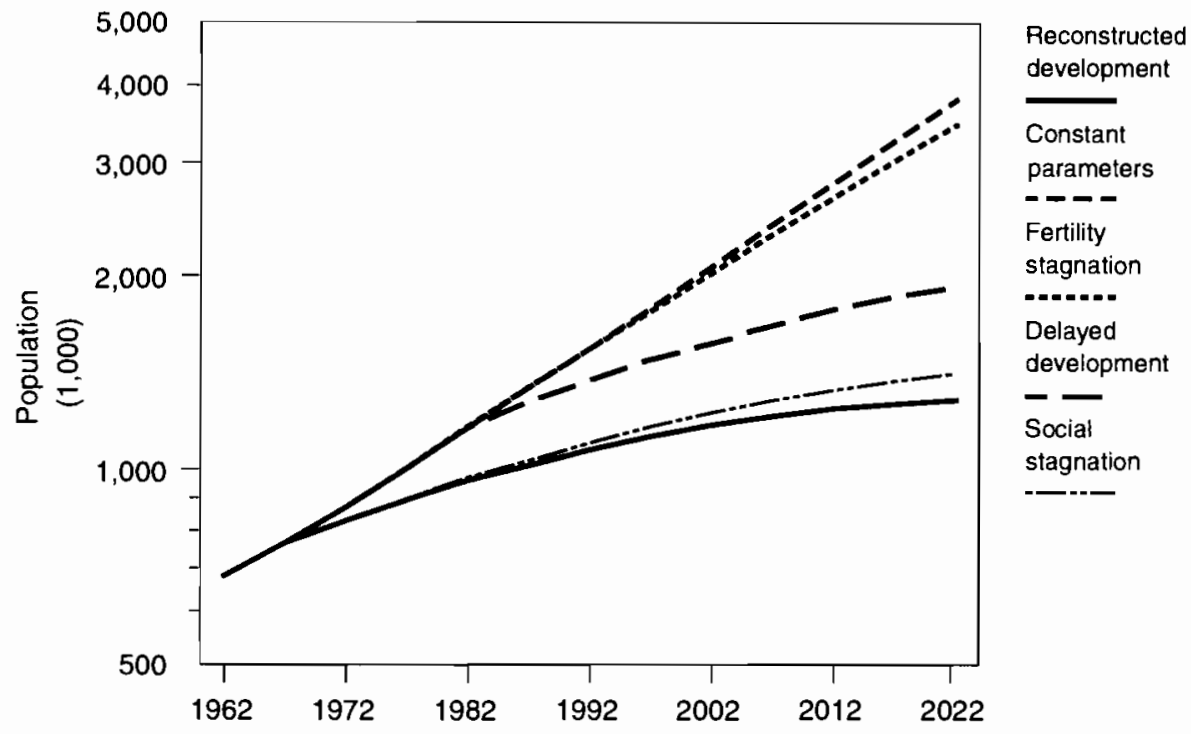

Figure 17.1. Projected population size, 1962-2022, logarithmic scale.

between the two scenarios is that in 1992 in the reconstructed development scenario 37 percent of the population belongs to the labor force, while under the constant parameters scenario the respective figure is only 27 percent. By the year 2022, reconstructed development results in a labor force equal to 51 percent of the size of the labor force under constant development, while the total population size is only 34 percent of the respective size under constant parameters. Without the increase in labor-force participation rates and in school enrollment ratios, i.e., under social stagnation assumptions the labor force would have been lower by 5 percent by 1992 and by 9 percent by 2022 , under otherwise identical fertility and mortality assumptions (compare scenarios 1 and 5). The remarkable impact of increased economic activity of women is also demonstrated by the fact that by the year 2002 delayed development gives the same size of the labor force when compared with constant parameters, with only 70 percent of the respective total population size.

Since a strong increase in school enrollment ratios took place before 1962 , the educational distribution changes even under constant development assumptions. The proportion of the labor force with at least some secondary 
education would have increased from 22 percent in 1962 to 43 percent in 1987 (see Table 17.1, column labeled "well-educated"). With reconstructed sociodemographic development, the respective increase would be or was much stronger: to more than 50 percent of the labor force by 1992, and even up to 70 percent in the long run. With delayed development assumptions the respective proportion would be some 10 percentage points lower during most of the period but would converge in the long run.

A phenomenon that can be observed in any country that has completed its demographic transition, and thus also in Mauritius, is the remarkable aging of the population. Even without additional mortality improvements after 1987 , the proportion of the population aged 60 years and over would increase from currently 7 percent to 14 percent by 2022 (Table 17.1, reconstructed development scenario). With constant 1962 development - without completion of the demographic transition - no aging would have taken place. A 15-year delay in the transition would have directly translated into a 15-year delay in the aging process.

\subsubsection{Socio-demographic dependency ratios}

As in Chapters 12 and 16, the development of the socio-demographic dependency ratio (SDDR) should be emphasized. This ratio measures the burden of the labor force considering its educational distribution and status and age of the dependents. As can be seen from Figure 17.2, the SDDR declined from 376 in 1962 to 225 in 1987 and it would continue to decline to 162 by the year 2012 under constant 1987 assumptions (compare reconstructed development scenario).

With constant 1962 development, the socio-demographic dependency ratio would have ranged between 330 and 350 throughout the projection period. Assuming a certain correlation between the development of the economy and the SDDR, significant economic development would probably not have taken place. Delaying the demographic transition and the sociodemographic development by 15 years would have delayed the decline of the SDDR and thus possibly the economic boom by some 15 years.

Looking at the results for the social stagnation scenario, which combines the observed demographic transition with social stagnation, i.e., no change in schooling and economic activity, one can conclude that during the period 1962-1977 the socio-demographic dependency ratio was dominated 


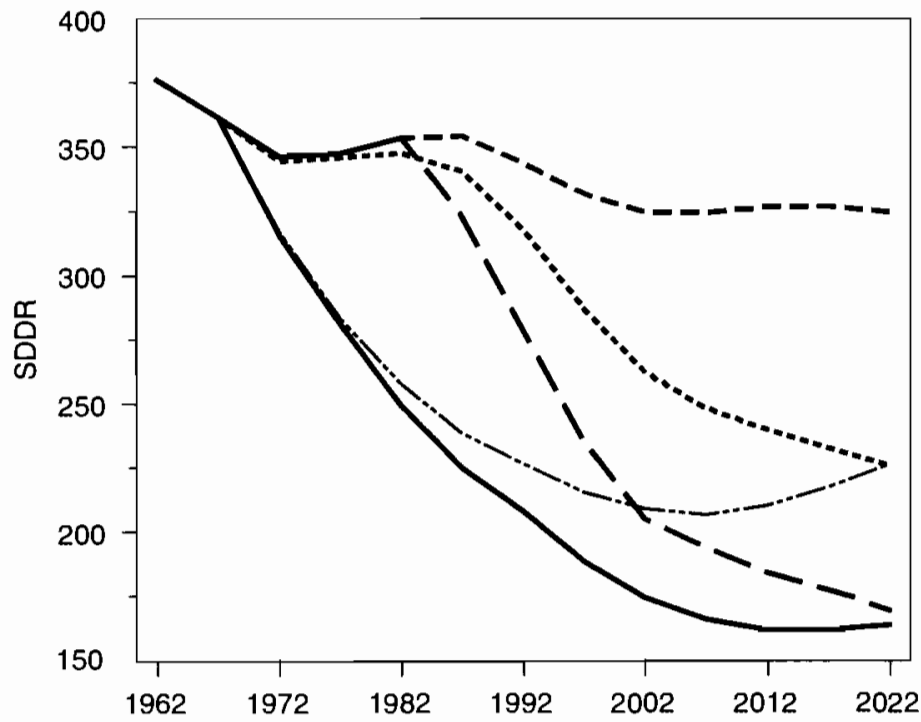

Reconstructed development

Constant parameters

Fertility stagnation

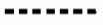

Delayed development

Social stagnation

Figure 17.2. Projected socio-demographic dependency ratio (dependent equivalents per 100 active equivalents), 1962-2022.

by changes in the age structure of the population, while after 1982 socioeconomic changes started to prevail. Comparing reconstructed development with social stagnation, the socio-demographic dependency ratio would have been 9 percent higher by 1992 and even 38 percent higher by 2022 without changes in labor-force participation rates and school enrollment ratios. As can be seen in Figure 17.2, in the long run the social stagnation scenario gives an SDDR that is as high as the fertility stagnation scenario, even though it was 30 percent lower in 1992.

Whether alternative developments of the socio-demographic dependency ratio hinder or favor economic development can be tested by the full population-development-environment model. A general conclusion will be difficult since the relation depends on the economic strategy adopted. The full model will also be able to trigger the effects of alternative population developments on the environment, again mainly via economic development. The ability to identify the impact of population changes, such as extreme aging or excessive growth, on both economic development and environmental degradation is one of the features of the model. 


\subsection{Population-Development-Environment Histories}

When running the full PDE model one is confronted with a complex scenario design. Hundreds of parameters can be manipulated and specified but to make the comparison of different scenarios understandable one has to concentrate on a few major parameters. If we change only one or two values we can more easily project what will happen to the population, to the economy, and to the environment. The analysis that makes use of the full PDE model is only carried out for the period 1962-2002, since it is not reasonable to keep economic parameters constant over a longer period of time. Nevertheless, by projecting until 2002 instead of 1987 one can get an idea of what could have happened in the future under alternative historical pathways.

\subsubsection{Scenario specification}

As in Section 17.3, a first step in the analysis is the detailed description of the scenarios to be investigated. After careful consideration, nine scenarios were specified:

1. Reconstructed development scenario: assuming observed development in all areas between 1962 and 1987, i.e., assumptions for this period correspond to the assumptions in Sections 17.2.1 to 17.2.4, and keeping all parameters constant after 1987 .

2. Constant parameters scenario: keeping all parameters in all areas constant at 1962 levels throughout the period 1962-2002, thus evaluating what would have happened if nothing had changed since 1962 or, alternatively, what would have happened without any economic and sociodemographic development.

3. Fertility stagnation scenario: assuming the constant 1962 fertility level throughout the whole projection period; all other parameters are equal to the reconstructed development scenario, thus isolating the economic and environmental effects of the rapid fertility decline.

4. Socio-demographic stagnation scenario: combining reconstructed development in all economic and environmental parameters with sociodemographic stagnation (i.e., fertility, mortality, migration, education, and economic activity constant as of 1962 throughout the whole projection period), thus evaluating the impact of high fertility and mortality rates and low school enrollment ratios and labor-force participation rates 
on the economy and the environment. Government education and health expenditures were reduced to reflect higher mortality and lower educational levels.

5. Economic stagnation scenario: combining reconstructed development in all population-related parameters with economic stagnation (i.e., stage of the economy constant as of 1962 throughout the whole projection period), thus evaluating the impact of economic underdevelopment together with rapid socio-demographic development.

6. Sugar drop scenario: assuming that the sugar protocol of the Lomé Convention was not signed in 1970 and thus sugar exports were reduced to one-third of their actual level throughout the period 1972-2002; all other parameters are equal to the reconstructed development scenario, thus isolating the contribution of sugar exports to the actual economic development and environmental degradation.

7. Tourism stagnation scenario: assuming that the tourism industry was not developed after 1962; all other parameters are equal to the reconstructed development scenario, thus isolating the contribution of tourism to the actual economic development and environmental degradation.

8. No EPZ exports scenario: assuming that the EPZ textile and EPZ electronics and other sectors were not introduced; all other parameters are equal to the reconstructed development scenario, thus isolating the contribution of the successful EPZ industries to the actual economic development and environmental degradation.

9. EPZ export boom scenario: assuming that EPZ textile and EPZ electronics and other exports would have been twice the observed amount of exports; all other parameters are equal to the reconstructed development scenario, thus isolating the effect of even faster growth in the successful EPZ industries. To make this assumption possible the laborforce participation rate of secondary-educated women had to be raised to that of tertiary-educated women.

Scenarios 2 to 5 were designed to answer some general questions within the population-development-environment debate. For example, what was the contribution of population development to the development of Mauritius, on the one hand, and to environmental degradation, on the other hand, as opposed to developments in the economy? What was the contribution of the fertility decline as compared with socio-demographic development? 
Scenarios 6 to 9 were developed to answer some specific economic questions concerning development strategies, in particular specifying the impacts of sugar-cane growing and milling, the tourism industry, and the EPZ industries.

Scenarios 2 to 8 are lower economic growth alternatives since reconstructed development was quite rapid; only scenario 9 investigates whether and under what circumstances even more rapid growth would have been possible.

In the following we discuss some of the main output variables; comprehensive conclusions are drawn for each alternative scenario.

\subsubsection{Selected results}

Five major areas are discussed below: income and economic growtll; employment; foreign-trade balance and budget balance; production and land use of sugar; and water requirement and water pollution. The results are summarized in Table 17.2, which gives observed 1962 and projected 1987 values for various output variables. Population-related results are discussed in detail in Section 17.3, and therefore are not repeated below.

\section{Income}

Figure 17.3 gives GNP per capita for scenarios 1 to 5 . The reconstructed development scenario shows a steep increase from Rs 9,000 in 1962 to Rs 18,000 in 1987. In the case of constant 1962 development, GNP per capita would have continuously declined parallel to population growth to only Rs 5,900 by 1987. If the observed population patterns of a strong decline in fertility and an increase in schooling and economic activity of women had developed under these conditions, gains in terms of income would have only been marginal: GNP per capita would have continued to decline more or less continuously (compare the economic stagnation scenario). On the other hand, if only the economy but not the population had developed further (sociodemographic stagnation scenario) rapid economic growth would have taken place. By 1987, GNP per capita would have reached Rs 14,400, a level some 20 percent below the level under reconstructed development. However, due to the momentum of population growth, a rapid decline in GNP per capita would take place in the future with no further economic development after 1987. GNP per capita would return to the 1962 level by 2012 . 


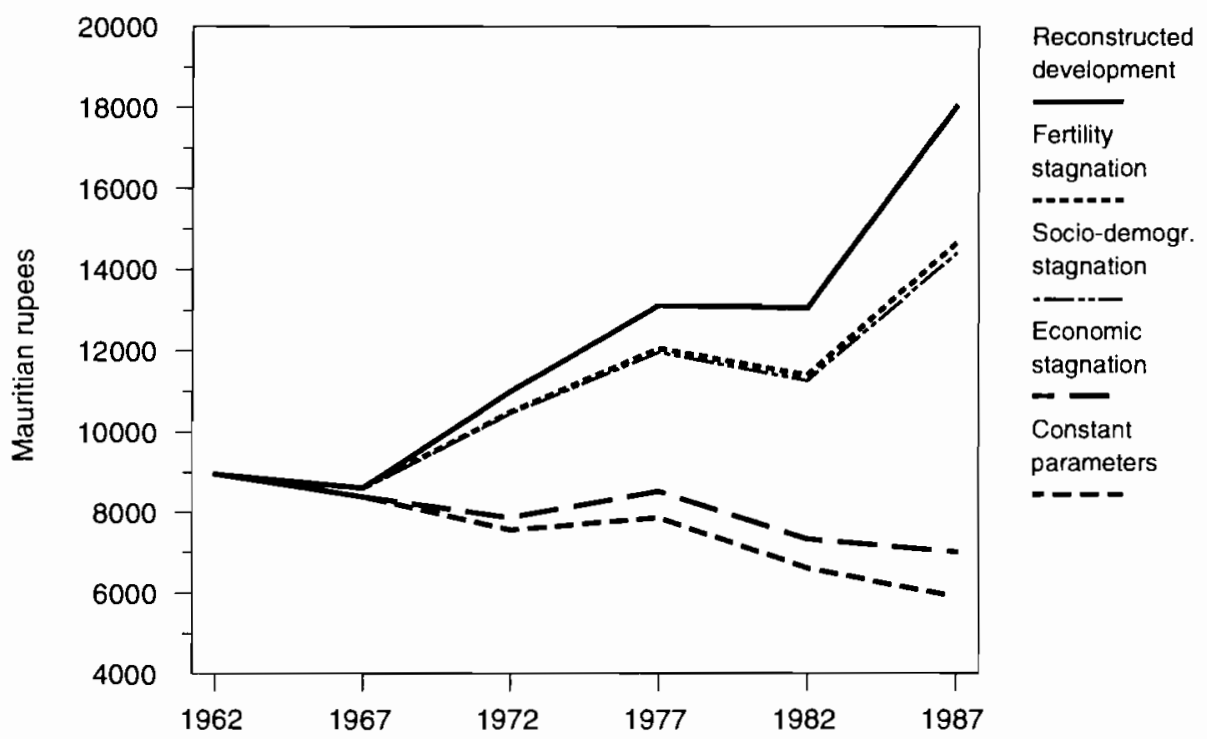

Figure 17.3. Projected income per capita, 1962-1987, in rupees: scenarios 1 through 5 .

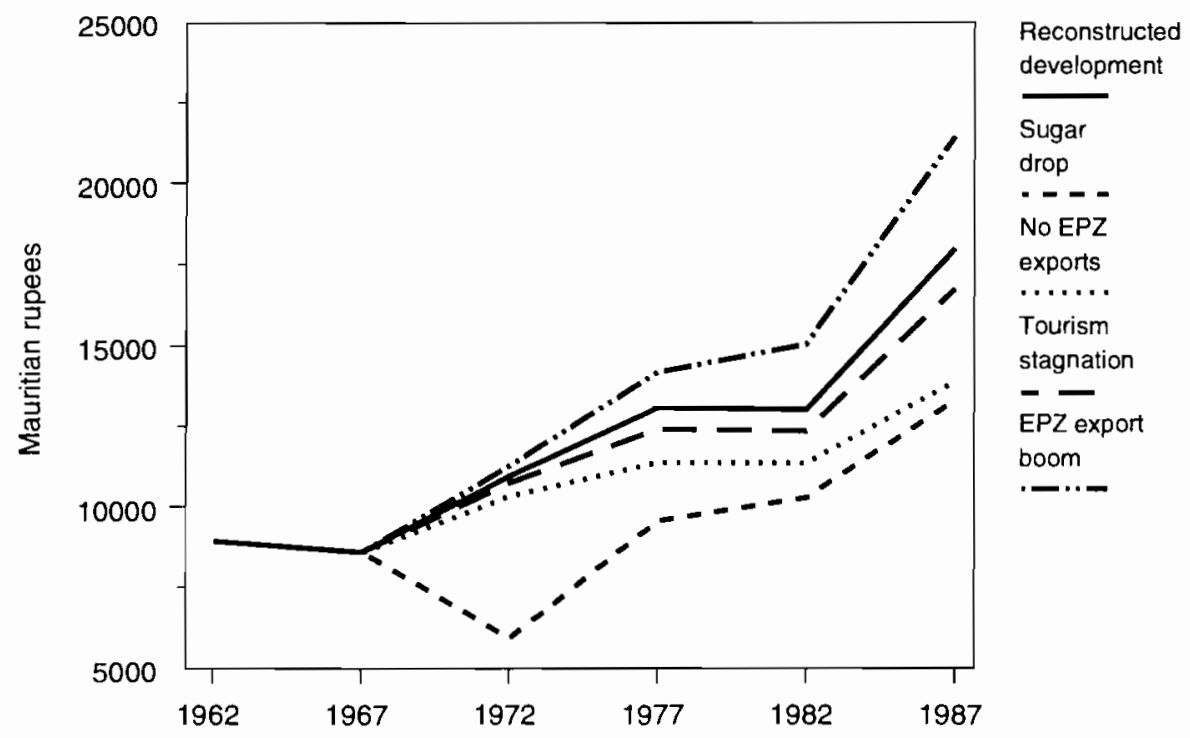

Figure 17.4. Projected income per capita, 1962-1987, in rupees: scenarios 1 and 6 through 9 . 
Taking into account the fertility stagnation scenario we conclude that almost all of the drop in per capita income resulting from the sociodemographic stagnation scenario is due to high fertility. The main conclusions that can be drawn from Figure 17.3 are that changes in the economy are far more important for development than population changes, in particular in the short and medium term, and that education is less important for development than fertility as far as income is concerned.

Figure 17.4 gives GNP per capita for scenario 1 and scenarios 6 to 9 . In any of the purely economic scenarios income growth would have been rapid and would have gone beyond or close to the level we would have reached under the socio-demographic stagnation scenario. Population changes turn out to be as important for development as any single economic measure.

Interestingly, both under the assumption of a drop in sugar exports to only one-third of the observed level and under the assumption that no EPZ industry would have developed, GNP per capita would have reached around Rs 13,600 by 1987 , a level some 25 percent below reconstructed development, however, with significantly different development paths. Altogether, sugar and EPZ exports were equally important for Mauritius's rapid development. The relatively marginal contribution of tourism to economic growth is also shown in Figure 17.4.

Comparing the observed development with the EPZ export boom scenario shows that in theory even faster development of the economy would have been possible. However, in practice this development path would not have been feasible. It would have lacked the required labor force and could have been realized only if labor-force participation rates of secondaryeducated women had been equal to those of tertiary-educated women, i.e., around 90 percent. Alternatively, much larger labor-productivity increases would have been necessary.

Table 17.2 also gives total income produced in Mauritius. Due to the larger internal demand from a larger population, total income is larger under the two constant 1962 fertility stagnation scenarios when compared with the reconstructed development scenario.

Under the reconstructed path scenario, average annual growth in income per capita was 2.8 percent over the period considered. It would have been more than 1.5 percent under all other scenarios, except for those that assumed economic stagnation. Under the latter assumption, the Mauritius population would clearly have become poorer. 


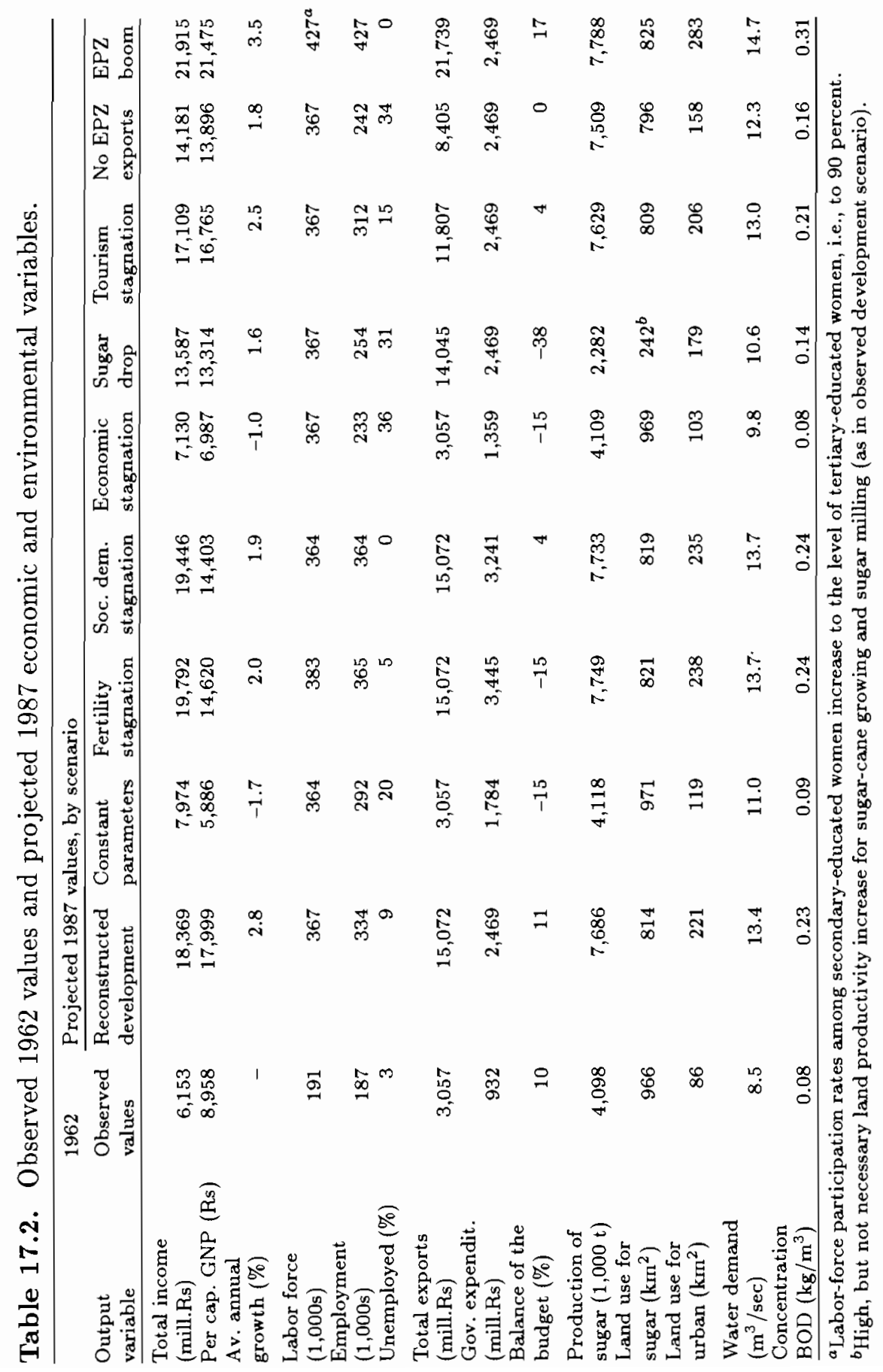




\section{Employment}

Table 17.2 gives employment and unemployment figures for each of the nine scenarios. According to the reconstructed development scenario, unemployment was high in the 1970 s and early 1980 s and at 9 percent in 1987 . With no further economic development, unemployment would increase steeply thereafter and reach some 30 percent by 2002 . Notwithstanding the larger size of the population and thus also of the labor force, during the period 1962 1987 population changes alone (fertility stagnation and socio-demographic stagnation scenarios) would have hardly affected the unemployment rate. Until 1987 unemployment would have been lower since the large number of well-educated people in the labor force, resulting from higher fertility rates, would even have accentuated the productivity of urban activities and could have easily been employed in the economy. The continuously increasing population would have had to struggle with over-proportionally increasing unemployment only in the long run.

Constant 1962 development would have led to continuously rising unemployment, up to one-fifth of the labor force by 1987 . Employment would have been only at 85 percent of the observed level by 1987 and would reach the same level by 2002 , however, with significantly higher unemployment due to the large size of the labor force. Much lower employment and much higher unemployment rates would have been realized under the economic stagnation scenario. Together with economic stagnation the low size of the labor force stemming from population development hinders the development of the industrial sectors and thus increases unemployment.

Both the sugar drop and the no EPZ exports scenarios result in high unemployment rates over the whole period. In accordance with the scenario assumption, the sugar drop scenario leads to a sudden increase in unemployment by 1972 , while it remains around 30 percent until 1992 . Without the successful introduction of the EPZ industries, unemployment would have risen more or less continuously to some 34 percent by 1987 , nearly as high as under the economic stagnation scenario.

The tourism industry makes a more significant contribution to total employment than to total income. By 1987, the unemployment rate would have been 15 percent if the tourism industry had not been developed further after 1962. The EPZ export boom scenario would have resulted in full employment over the whole period, and it would even have been difficult to recruit enough labor force for the large employment produced. 
Interestingly, the correlation between GNP per capita and unemployment is very high. Scenarios that result in lower economic growth simultaneously result in higher unemployment and vice versa.

\section{Foreign-Trade and Budget Balances}

Exports, which are given in Table 17.2, are entirely input-determined; imports also depend on the size and structure of the population. Under the reconstructed development paths, the foreign-trade balance was positive over the whole period. Exports exceed imports by some 20 percent. The economic scenarios 6 through 9 do not significantly deviate from this pattern. Economic stagnation would have led to an increase in imports without an increase in exports making the trade balance deteriorate to -20 percent by 1987. Due to the increasing size of the population, socio-demographic stagnation on top of economic stagnation, i.e., constant development, would have accentuated the increase in imports and worsened the foreign-trade balance (-33 percent by 1987).

Socio-demographic stagnation alone, however, would not have affected the trade balance. At least until 1987, the higher demand from the larger population would have been compensated by its lower education and thus lower per capita demand of the population. In the case of fertility stagnation the trade balance would have worsened somewhat as the large number of highly educated people would have demanded more expensive goods and thus would have increased imports, without any compensating effects.

Government expenditure is a function of the size, age structure, and educational structure of the population, on the one hand, and of the per capita expenditure, on the other. Under the reconstructed development scenario total government expenditure, which comprises education, health, and other expenditures, would have increased from around Rs 930 million in 1962 to around Rs 2,500 million by 1987 (see Table 17.2). Under the fertility stagnation scenario, with its large size and well-educated population, this increase would have been much larger (Rs 3,500 million by 1987) and would be especially large in the long run. At the other extreme we find the economic stagnation scenario. Government expenditure would have increased to only Rs 1,360 million by 1992 under this scenario due to the small size of the population and the low 1962 per capita expenditure.

Taxes are somewhat artificial in Mauritius since the large producers, the EPZ industries, are exempted from paying taxes. As a consequence, the budget balance, which is slightly positive during the whole period under 
the reconstructed development scenario, would have remained positive also under the EPZ scenarios. Assumptions of the sugar drop scenario would have reduced taxes and thus would have worsened the budget balance to about -30 percent between 1972 and 2002. The population stagnation scenarios all lead to very significant budget deficits, especially in the long run, for example, -15 percent by 1987 under the constant development alternative.

\section{Sugar Production}

Table 17.2 gives total production of sugar measured in 1,000 tons. Due to the increase in land and labor productivity, the amount of sugar produced almost doubled from 4.1 million tons in 1962 to more than 7.6 million by 1987 . However, as a consequence of increasing land productivity, the amount of land needed to produce this sugar declined from 81 percent to 68 percent of total arable land. At the same time, urban activities (i.e., industries, services, and households) rapidly increased; land requirements for these activities increased as sugar-land requirements decreased. Under constant development, both the amount of sugar produced and the land required to produce it would have remained close to its 1962 levels; urban activities would have slightly increased as a consequence of population growth.

Under the sugar drop scenario, sugar production would have gone down to only 2 million tons in 1972 and would have remained at that level. If land productivitiy had increased further, the amount of land needed to produce that sugar would have declined accordingly, thus freeing land for urban activities.

\section{Water Requirement and Pollution}

The amount of water required, measured in $\mathrm{m}^{3}$ per second, by some of the development paths is shown in Figure 17.5. According to the reconstructed development scenario, water requirement would liave increased from $8.5 \mathrm{~m}^{3}$ per second in 1962 to $13.7 \mathrm{~m}^{3}$ per second in 1987. Pollution of rivers, measured as the dilution flow required to clean up the water, would have increased proportionally. Pollution of the lagoon, however, measured as the concentration of organic waste in lagoon water and sediments (BOD concen(ration), would have almost tripled (see Table 17.2).

Without changes in the economy (economic stagnation scenario) the increase in both water requirement and water pollution would have corresponded to the population growth. Adding socio-demographic stagnation 


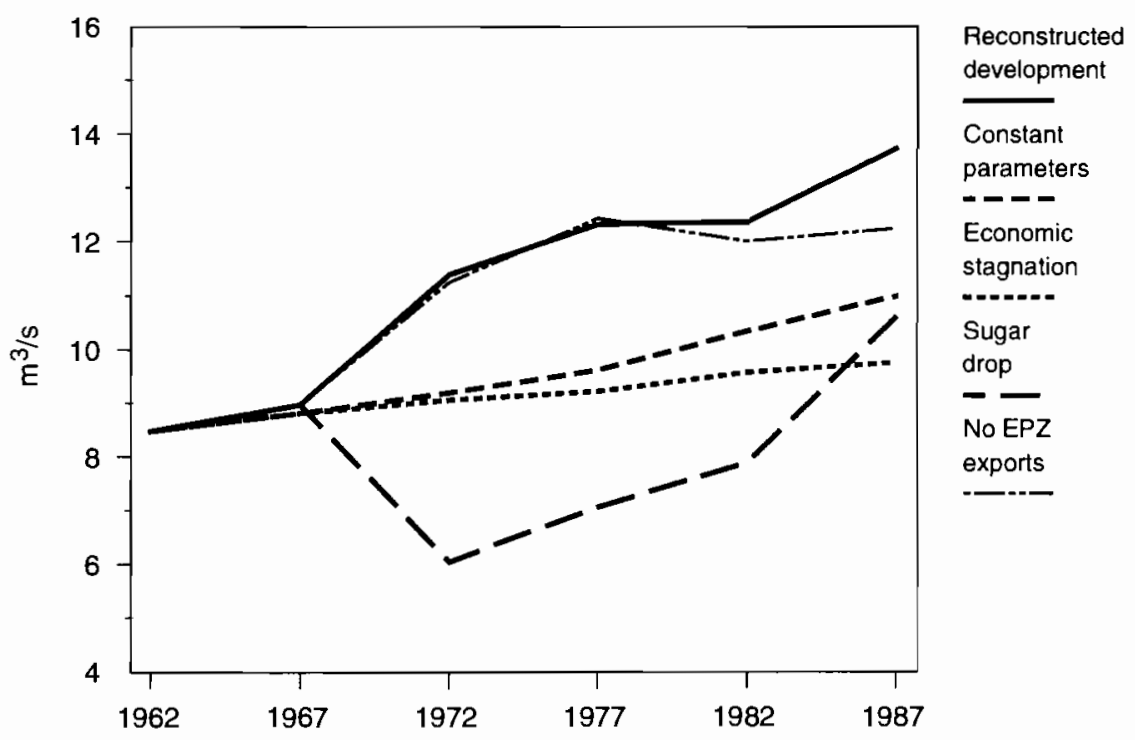

Figure 17.5. Projected total water demand, 1962-1987, in $\mathrm{m}^{3}$ per second: five scenarios.

(constant development) would have resulted in an increase in water requirement to 11 million $\mathrm{m}^{3}$ per second by 1987 , being a consequence of the rapid population growth under that particular scenario. River water pollution would have also changed drastically.

Figure 17.5 also shows the contribution of the sugar sector and of the EPZ industries to total water demand. Given the current level of economic activity, the big water user in Mauritius is clearly the sugar industry, mainly due to irrigation. Reducing sugar production to one-third of its actual level would have almost cut total water requirements by 1987 to the same level as under the economic stagnation scenario. Both the sugar drop and the no EPZ exports scenarios would have had a very positive impact on river and lagoon water pollution; under these scenarios the amount of water pollution is almost the same.

\subsubsection{Comprehensive conclusions}

In this final section the principal conclusions of the alternative historical development paths are summarized for each scenario. 
1. Reconstructed development scenario: the full PDE Mauritius model was reasonably able to reconstruct the history of Mauritian development during the period from 1962 to 1987. The economy grew with amazing speed, doubling GNP per capita to Rs 18,000. The educational level of the population increased remarkably, as did economic activity of women. Unemployment was brought down to a reasonable level; the foreigntrade balance was significantly positive; and the budget was generally balanced. Production of sugar doubled, albeit using much less land to grow sugar; however, water demand and in particular water pollution increased in accordance with economic growth.

2. Constant parameters scenario: if neither the population nor the economy had developed further after 1962, population size would have increased at a remarkable rate to more than 1.5 million by now, while the economy would have stagnated. As a consequence, GNP per capita would have fallen continuously to only a few thousand rupees in the long run. Mauritius would, by today, be a poor developing country. Unemployment would be tremendous (around 20 percent by 1987); the foreign-trade and the budget deficit would soon have reached unsustainable levels. Only the environment would have benefited - due to economic stagnation as both water requirement and water pollution would have increased to a smaller extent.

3. Fertility stagnation scenario: if Mauritian women had continued to bear more than five children on average, development would clearly have been much more difficult. Until the 1990s remarkable economic growth would have occurred albeit at a significantly lower level, but in the long run continued population growth would have increasingly made development difficult if not impossible. For some periods, unemployment rates would have been lower than under reconstructed development, while the foreign-trade, and in particular the budget balance, would have developed in an alarming manner. Due to the large number of people, water demand and pollution would have been some 10 percent higher by 1987 under this scenario than under the reconstructed development scenario. By 1987, high fertility would not have entirely hindered development, but in the long run a reduction in fertility would have been very advantageous.

4. Socio-demographic stagnation scenario: adding socio-demographic stagnation to constant fertility would first and foremost have led to a completely different educational structure of the Mauritian population. As a 
consequence, and also due to accentuated population growth, the development of the economy would have been even more difficult (as compared with the fertility stagnation scenario) and GNP per capita would have developed at a slower speed. Also as a consequence of different education developments, both the foreign-trade balance (less-educated people demand less expensive goods and reduce imports) and the budget balance (fewer people in school reduce education expenditures) would have developed slightly more favorable. In the long run, however, no advancement in education would have put strong restrictions on possible development in Mauritius. Limitations already imposed by continued high fertility would have been accentuated by a steady low educational level.

5. Economic stagnation scenario: economic stagnation combined with reconstructed population developments would have resulted in an economic disaster almost as bad as under the constant parameters scenario. Unemployment would even have been worse; by 1987 more than a third of the population willing to work would have been unemployed. Due to the lower population size, GNP per capita, the foreign-trade balance, and the budget deficit would have developed more favorably than under constant development, but still in an unsustainable manner. One should note that in this scenario benefits from the higher educational level of the population were not economically realized.

6. Sugar drop scenario: assuming that the sugar protocol of the Lomé Convention had not been signed in 1970 clearly shows the importance of the contribution of the sugar industry to development in Mauritius during the last three decades. GNP per capita would have been reduced by more than 25 percent (1987), while unemployment would have been high (some 20 percent to 30 percent) throughout the period. Both the foreign-trade balance (sugar exports hardly need any imports) and, in particular, the budget deficit (the sugar industry is one of the main taxpayers) would have developed very unfavorably. Interestingly, the large drop in land required for sugar-cane growing could not have been used by any other agricultural, industrial, or service sector; 50 percent of total usable land would not have been used under this scenario. Since sugar is a major water user in Mauritius - at least until today - total water demand would have increased by only 25 percent since 1962 and water pollution increases would have been lower. 
7. Tourism stagnation scenario: in terms of output variables from the PDE model, tourism had only a small share in overall development of Mauritius. GNP per capita would have been somewhat lower; unemployment, some 5 percentage points higher. The budget deficit and, particularly, the foreign-trade balance would have developed less favorably. The indirect value of tourism, for example, familiarizing visitors with the island in the Indian Ocean and therefore making them interested in investing in Mauritius, is not measured by the model but should not be disregarded.

8. No EPZ exports scenario: not having introduced EPZ industries would have lowered Mauritian development to a level comparable to the sugar drop scenario. Unemployment would have increased rapidly to levels that would have been observed under economic stagnation, indicating that EPZ industries are the main employers in Mauritius today. In contrast to the sugar drop scenario, the budget deficit (the EPZ industries are tax exempt), the foreign-trade balance, and to a lesser degree water demand would have developed very much like they have under reconstructed development. Water pollution, however, would have decreased because the textile factories are significant polluters.

9. EPZ export boom scenario: doubling EPZ exports would have reinforced economic growth in Mauritius, through zero unemployment and a higher amount of imports and exports. But, the high labor demand could have only been satisfied if economic activity of secondary-educated women had been increased to the level of tertiary-educated women or if labor productivity had increased more rapidly. It seems justifiable to say that on the basis of the already very rapid observed socio-demographic development during the period 1962 to 1987 not much higher economic development would have been possible in Mauritius.

\section{Notes}

[1] The calculations have been carried out until 2002 - and for the population part even until 2022 - but without considering further changes in model parameter after 1987, i.e., keeping all parameters constant as of 1987.

[2] Since data for the year 1992 are not available yet, a reliable historical reconstruction starting in 1962 and using a model that is based on five-year calculations should cover the period 1962-1987; moreover, the most recent complete inputoutput table available in Mauritius goes back to the year 1987.

[3] Here, and also in the following, "observed development" refers to the reconstructed historical path and not to the observed data. 



\section{Part IV}

Our Present Understanding: What Have We Learned? 



\title{
Chapter 18
}

\section{Lessons from Mauritius in the Global Context}

\author{
Wolfgang Lutz
}

\subsection{Introduction}

This concluding chapter of the book is an attempt to synthesize the information provided in Part II ("Understanding Through History") and Part III ("Understanding Through Modeling") and to relate it to the present global population-environment debate. For doing so, five substantive questions have been singled out that, on the one hand, capture some of the main arguments stressed in the debate and, on the other, belong to areas where our empirical work on Mauritius can make real contributions. These two criteria exclude questions of a purely conceptual nature and questions to which the answers are already known.

Part of the problem in the population-environment debate is that in many cases, the models chosen predetermine the answer. If certain variables are not included in the model (be it a conceptual model or a computer model), the results can never attribute these variables any significance. Similarly, the structure of the model and the way in which variables are linked inay exclude some relevant mechanisms. As discussed in Chapter 1, for instance, the Ehrlich identity in its simple multiplicative form, assuming independence between population size, affluence, and technology, does not 
cover the case in which population growth has a positive effect on technology (the Boserup/Simon argument) or the case in which population growth diminishes affluence (the Malthusian argument) or when increasing affluence lowers population growth (the usual development argument).

It is not possible to design a model that is entirely free from personal views or the views dominant in scientific disciplines as well as society. Certain basic approaches to analysis always predetermine our questions, our data categories, and the structure of our models. The only approach we can take in this is to take advantage of the multitude of scientific views expressed within disciplines and across disciplines and to try to develop models that do not already predetermine apparently controversial issues.

A major challenge for the PDE model for Mauritius was to define such an interdisciplinary and intersubjective model that can be accepted in its basic structure by the bulk of participants in the population-developmentenvironment discussion and is quantitatively operational, i.e., consists of more than general words. The approach chosen was to have two parts of the model: the hard-wired model, which only includes unambiguous relationships on which scientific consensus can be expected; and the soft model, which can quantify all kinds of feedbacks and interactions that the user wants to define. With this approach differences in assumptions and results can be nailed down and evaluated in a specific and clear form.

The emphasis of this book is on the process of better understanding the complex mechanisms that link population, development, and environmental variables. This understanding has been approached both through the analytical description of man-environment interactions in the history of Mauritius as well as through quantitative modeling. When discussing the following five questions to which the Mauritius study can make a contribution, reference is made to both approaches.

\subsection{How Did Population Density Affect the Environment and Human Life Over the Centuries?}

The popular argument is that with limited agricultural space and limited natural resources, increasing population density results in increasing stress on food supplies and damage to the environment. The food aspect of this argument goes essentially back to Malthus, whereas the explicit environmental concerns are of a much more recent date. Here the most frequently stated 
argument is that higher density forces people to utilize marginal lands resulting in deforestation, species extinction, soil erosion, desertification, and ultimately war or starvation. Support for this density-stress argument comes from animal ecology, where the basic concept of a limited carrying capacity is self-evident.

This density argument, however, has been challenged by scholars mostly from the field of economics. Boserup (1981) and Simon (1982) even say that under certain conditions increasing density is conducive to technological advance because societies are pressed for innovations. A somewhat different argument is based on the concept of economies of scale, which points to the benefits of higher density because of a larger market, better infrastructure, and greater division of labor.

The history of a small, densely populated, and very remote island seems to be an ideal setting for checking the empirical validity of these arguments.

\subsubsection{Population density and deforestation}

When the first Dutch merchant ships came to Mauritius in 1638 the uninhabited island was almost completely covered with lush tropical forests in which a large variety of unique species lived. By the end of the 17th century 200 Dutch and about 100 slaves had managed to strip the island of most of its valuable ebony trees, changing the composition of the forests forever.

As can be seen in Figure 18.1 significant deforestation started during the French rule in the late 18 th century. The French, aiming at permanent settlement of the island, were interested in food self-sufficiency and also started to expand sugar-cane production. Hence there were three different reasons for deforestation: land required for food production, land required for sugar-cane production, and wood required for construction and cooking including the refining of sugar. Population density increased very slowly during this period.

The most significant deforestation in Mauritian history happened during the 1840s. Within a decade almost two-thirds of the remaining forest disappeared. This event coincided with the abolition of slavery in 1833 and the immigration of large numbers of indentured laborers from India, but the peak of Indian immigration was a decade after this massive deforestation. Because of this timing, deforestation can hardly be explained by the subsistence needs of the immigrants. However, the first arriving Indians were probably instrumental as laborers in clearing the woods. At this time the first modern sugar factory was built requiring more firewood. 


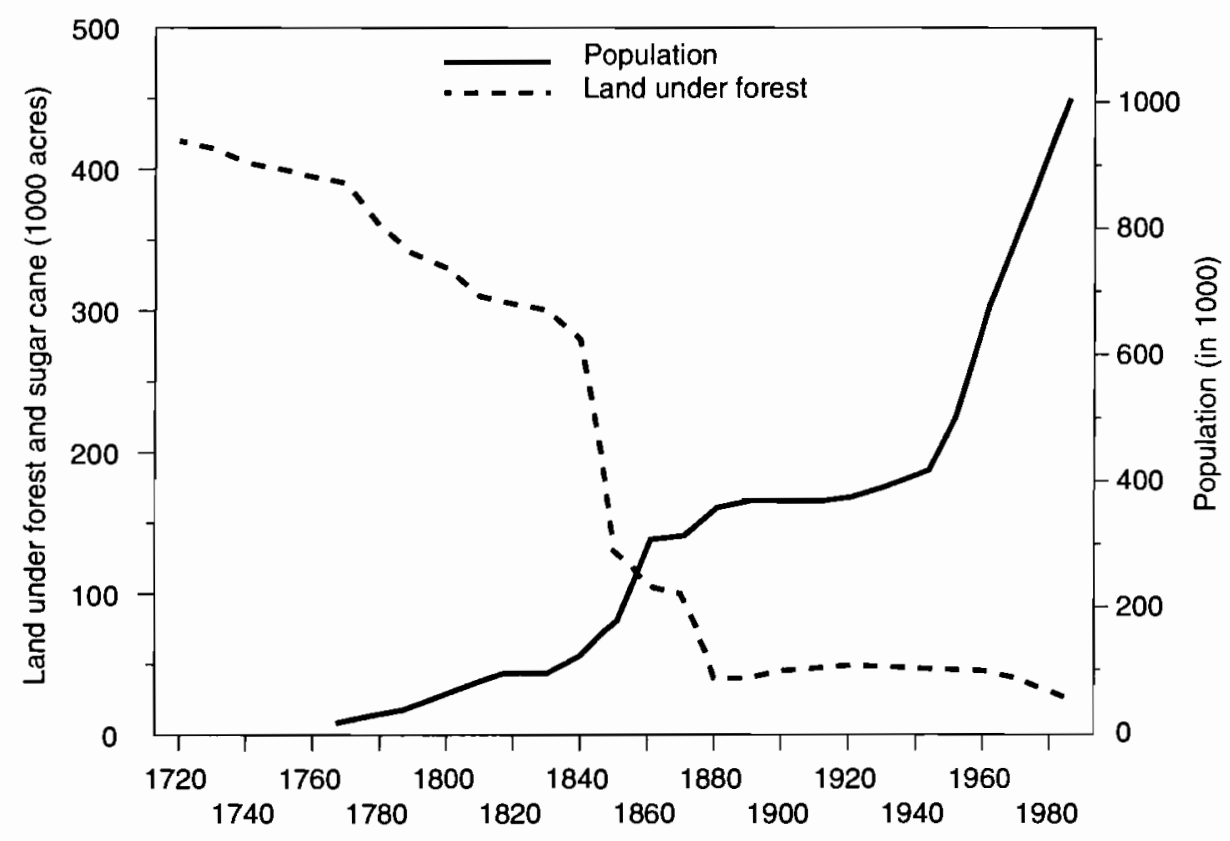

Figure 18.1. Population growth and land under forest in Mauritius, 17201985 .

By the late 19th century almost all of the accessible land had been deforested. About 3 percent of the original forest survived in some mountainous regions. Government efforts at reforestation and protection of some crown lands slightly increased the wood coverage, but the forested area did not change much thereafter. The population explosion since the 1960 s has not significantly affected the land area covered by forests. However, recent surveys on energy use indicate that the remaining woods have been partly damaged by uncontrolled use of firewood.

\subsubsection{Population growth and loss of species}

No systematic survey of species has ever been conducted in Mauritius. But early descriptions of the island indicate that the original flora and fauna were plentiful, and that several types of birds and reptiles that existed on Mauritius could be found nowhere else in the world. The most famous of these animals is without doubt the flightless dodo bird, which became an international symbol of species extinction long before the present debate 
on biodiversity. The dodo disappeared during the 17th century most likely through the consumption of the eggs rather than through direct hunting (there have been reports about the bad taste of the meat).

Aside from the extinction of many unique species that was largely the consequence of the destruction of their habitat - the original forest - many other species retreated from Mauritius (most notably the giant turtle), while other plants and animals were brought to the island deliberately (e.g., sugar cane, vegetables, spices, and domestic animals) or unintentionally (such as rats). Currently Mauritius officially lists one mammal species and three bird species as being threatened by extinction. In international comparisons considering land area this gives a very high value per $10,000 \mathrm{~km}^{2}$ (Green, 1992), which is a consequence of its remote island status. Concerning the microfauna in the soils there are indications that the original balance still exists in some remote mountain areas but is being threatened by the intrusion of other species.

Since most of the lost species in Mauritius presumably disappeared during the early history of human settlement on the island when population density was still very low, it is difficult to draw direct causal connections between the two variables based on Mauritian evidence.

\subsubsection{Population density and food supply}

The Dutch settlers in the 17 th century were interested in short-term exploitation rather than sustainable agriculture, so food supply was a permanent problem. The French, who considered Mauritius strategically important and wanted to sustain their presence for a long period, emphasized the expansion of food production to make the island self-sufficient and robust against crises. The British thereafter opted for cash crops at the expense of food production. Food was partly imported from other British colonies. This, together with the fact that the population had doubled through Indian immigration, made the food supply more vulnerable to external events.

One such event was World War II. But the worst could be avoided in Mauritius because, expecting major problems with food imports, the government ordered sugar plantations to use about one-quarter of their land exclusively for food cultivation. Although food production targets were never reached, this quick response showed the flexibility and robustness of the Mauritian system. This strategy, however, cannot necessarily be generalized to other countries. The well-developed infrastructure and the small size of 
the island made this success possible. After the war, however, this food program was ended, despite frequent food supply problems.

To combat the vulnerability to food crises and also to feed the rapidly growing population, Mauritius made another effort at food self-sufficiency in the 1970s as part of a general import substitution policy. Some improvements were achieved with potatoes and other food crops, but, because of cheap and often subsidized food imports, the economics of these diversification programs were not favorable. It was simply more profitable to produce sugar and buy cheap food on the world market. If the infrastructure is sufficient for a high volume of international trade, as is the case in Mauritius, and the country is rich enough to pay for the food, population size and density of a specific place do not seem to negatively influence food supply. Whether there is enough food on the world market is another question.

As part of our future scenario calculations using the PDE Mauritius model, we also studied whether a certain minimal degree of food selfsufficiency would be advisable under sustainable development criteria. In short, the results show that under an assumed future economic crisis, it is advantageous to have a rather high proportion of food self-sufficiency, which also helps reduce unemployment. Under prosperous economic conditions, however, increased food production would mean lower income. Hence the key to robust policies is to assure maximum flexibility that allows a quick increase in food production (similar to World War II), should the state of international trade require it.

\subsubsection{Population density and disease environment}

Originally Mauritius must have been a very healthy place for humans. The first inhabitants were said to have been a group of seriously ill sailors abandoned by their ship. Some time later when the ship returned, all the sailors were in good health.

In the following centuries many diseases came to the island via immigrants or merchant ships. Death rates in the 19th century show frequent peaks due to cholera, smallpox, and other epidemics. Prior to 1862 malaria, a major killer in subsequent years, was not endemic to Mauritius. However, once malaria reached Mauritius it induced the resettlement of many Mauritians from the coast to the cooler highlands. In 1919 the Spanish flu killed more than 6 percent of the population. The spread of these diseases resulted from high density, poor sanitation, and a lack of treatment possibilities. 
After 1945 the death rate dropped to less than half its previous level within a few years as a consequence of malaria eradication, antibiotics, and preventive medicine. Today the mortality conditions in Mauritius are similar to those in Europe with no visible negative influence of population density.

\subsubsection{Conclusion}

The evidence shows that in the early days, very low population density was an obstacle to sustainable agriculture and development on the island. Most of the deforestation and species loss were not related to population density but to shortsighted economic exploitation. Some of the human suffering, however, especially that due to diseases before modern medicine, seems to be related to population density beyond a certain threshold. Pollution due to the recent industrialization, again, seems to have resulted more from a lack of environmental legislation than from population density. The increasing proportion of land used for urban purposes is certainly related to increasing density but does not automatically imply environmental destruction.

Saying that the density-stress argument could not be verified for Mauritius as a direct cause of environmental destruction, however, does not exclude the possibility of more indirect effects operating through attitudes. In order to find jobs for the rapidly increasing number of young people (a consequence of population growth), society as well as government may give more weight to attracting international companies without many conditions, than to setting strict pollution standards. This issue, which is only indirectly related to density and more to international competition in production costs, is a problem not specific to Mauritius but affecting most countries of the world.

\subsection{What Triggered the World's Most Rapid Fertility Decline?}

As described in Chapter 4, the total fertility rate in Mauritius declined from 6.2 in 1963 to only 3.2 in 1972 . This decline happened essentially simultaneously within all ethnic groups. It is assumed to be the most rapid fertility decline in the world at least at the national level. In this section, an attempt is made to identify the most important factors that contributed to this drastic and completely voluntary change in Mauritian reproductive patterns. 


\subsubsection{Social and economic development before the fertility decline}

A most remarkable feature of the Mauritian fertility decline is that it happened in the absence of any economic growth. Per capita income was very low and stagnant during the 1950s and 1960s (see Figure 18.4 below). This contradicts the popular view that economic development is the main reason for a decline in desired family size and consequently fertility. Figure 18.2, however, shows that the relationship between economic growth and fertility decline varies in developing countries. In some countries such as Mauritius, Bangladesh, and to some extent Thailand, the fertility decline preceded economic growth. The historical fertility transitions of some Northern European countries (e.g., Finland) also followed this pattern. In a number of countries fertility declined simultaneously with increasing income, and in a third group (mostly Arab countries) income grew without much fertility decline. This comparison shows that on an empirical basis, it is hard to argue that income growth is an essential determinant of declining fertility. Similar diversity of the fertility-income relationship is also shown at individual levels (such as in the World Fertility Survey, Cleland and Scott, 1987).

In Mauritius, income had not grown in the years prior to the onset of the fertility decline, but social development and especially education were well advanced by this time. Already in 1960 nearly universal primary education had been achieved in Mauritius and aspirations for secondary education for girls almost equaled that for boys. This high educational status of the younger generation and especially of younger women is probably the single most important factor in explaining the Mauritian fertility decline. This assumed effect of female education on fertility can be seen as operating through three different mechanisms: first, it increases the age at marriage, and indeed it could be shown that about half of the steep fertility decline in Mauritius is attributable to changing marriage patterns; second, education is likely to change the value system by putting more emphasis on the life opportunities of children and women than on large families; third, there is evidence that education increases the acceptance of family-planning methods by women and increases the relative status of a woman within the family to carry out her own (usually lower) desired family size.

In sharp contrast to the non-relationship between fertility and income in Figure 18.2, Figure 18.3 shows that the strong association between basic female education and the onset of fertility transition that has been observed in Mauritius is very common in the rest of the world as well. As the sample of 

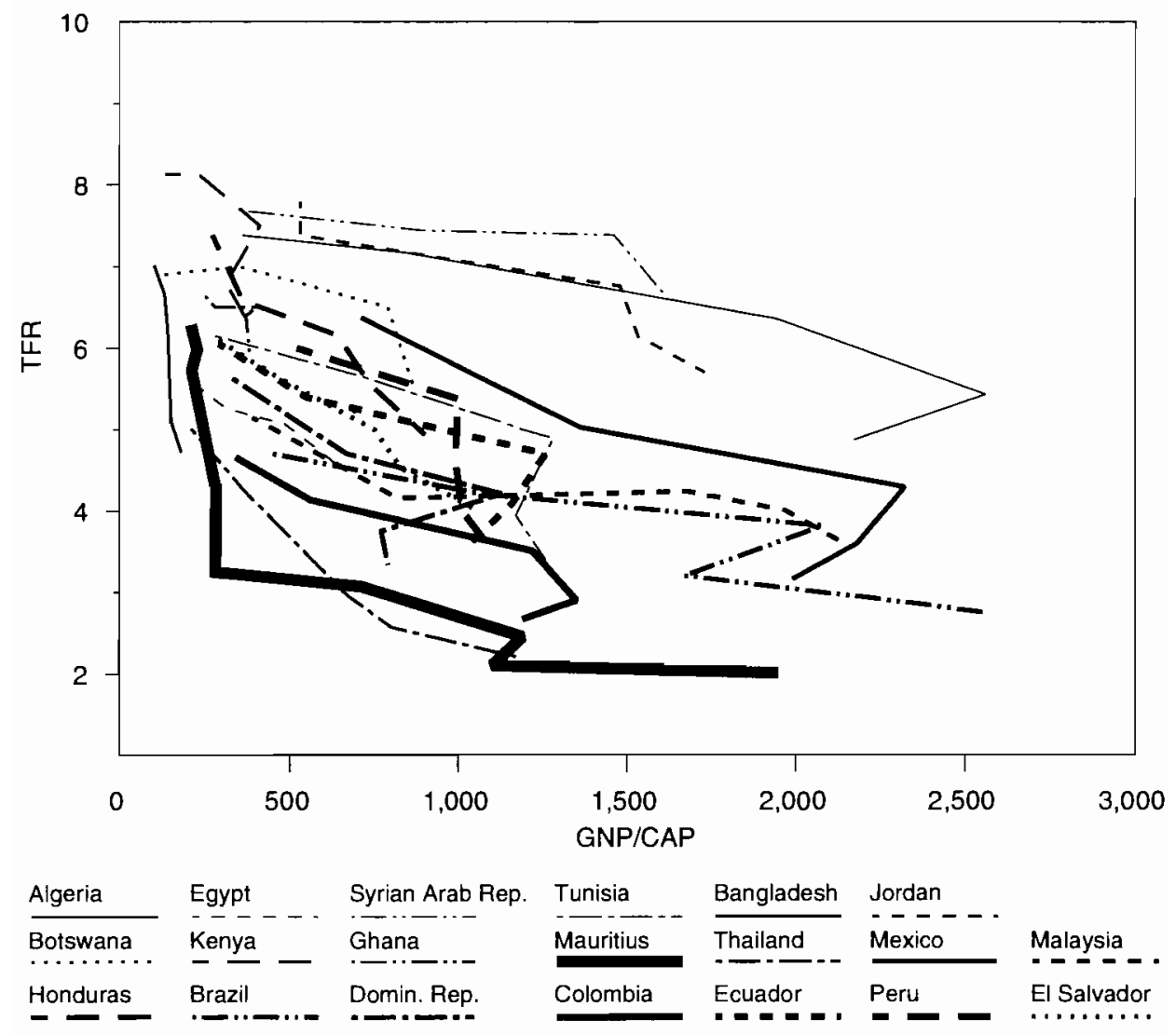

Figure 18.2. Relationship between per capita income and fertility in a sample of developing countries (1970-1990) and in Mauritius (1950-1990).

20 other developing nations shows, there seems to be some kind of threshold at the time when about half of the society's women can read and write. Since educational efforts are usually rather recent, this means that in practice most younger women are literate, while illiteracy is still high among the elderly. Only in some Arab countries is this threshold not clearly visible.

The literature on the relationship between fertility and education as well as between fertility and income is extremely large. No attempt has been made to review it here. However, it should be pointed out that trends in Mauritius strongly support the already overwhelming evidence (especially at the micro level) that basic education, especially of women, is an extremely 


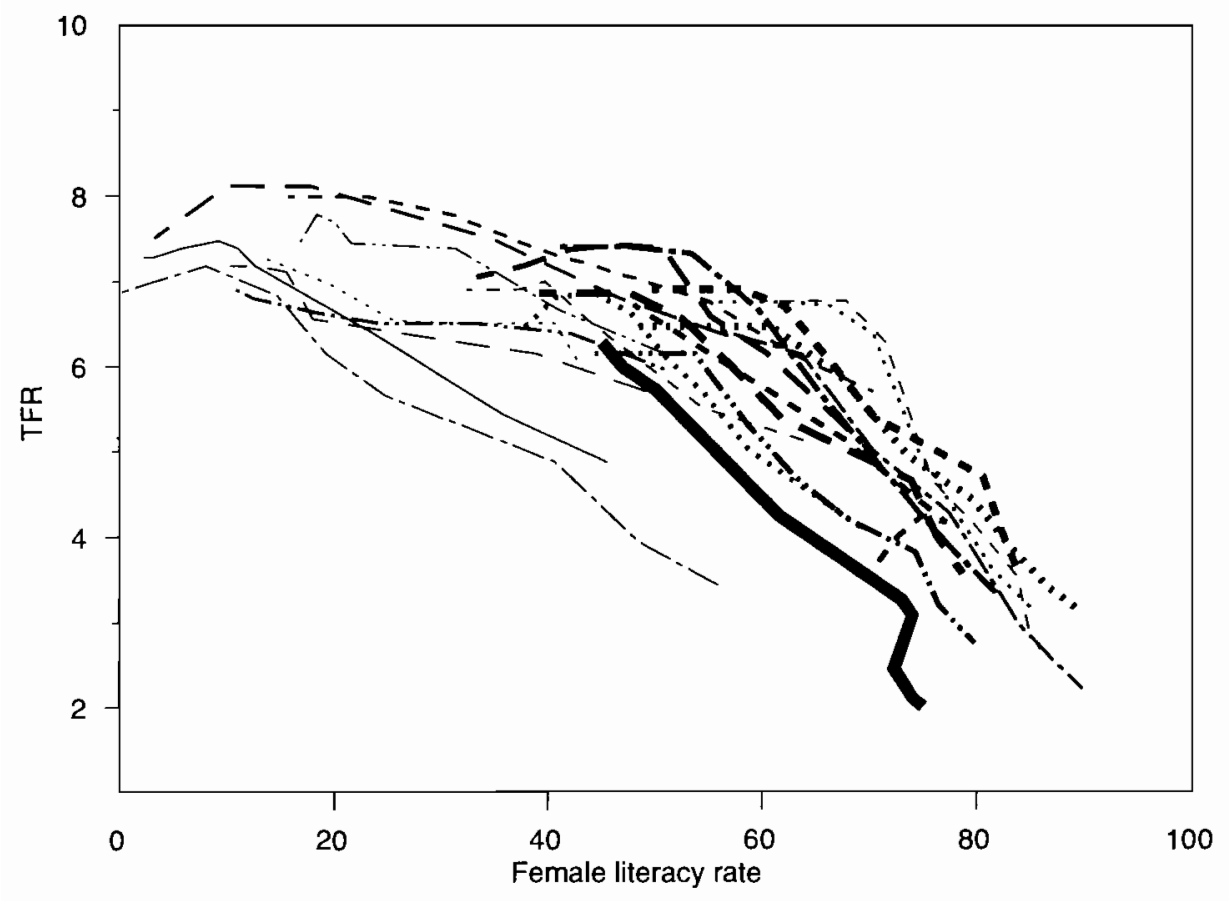

\begin{tabular}{|c|c|c|c|c|c|c|}
\hline Algeria & Botswana & Iran & Iraq & Syrian Arab & Tunisia & Jordan \\
\hline Kenya & Ghana & Mauritius & Thailand & Mexico & Malaysia & vador \\
\hline Honduras & Brazil & Domin. Rep. & Colombia & Ecuador & $\begin{array}{l}\text { Venezuela } \\
\text {.......1. }\end{array}$ & Peru \\
\hline
\end{tabular}

Figure 18.3. Relationship between female literacy rates and total fertility rates in a sample of developing countries with a total fertility rate above 6.0 in $1950(1950-1990)$.

important factor in explaining the onset of fertility decline, whereas increasing income had no visible direct role in Mauritius.

\subsubsection{The role of ethnic and religious factors}

In the early 1960s the scientific reports by Titmuss (Titmuss and Abel-Smith, 1968) and Meade (1968) on the future of Mauritius had identified rapid population growth as the main obstacle to development. These scientific studies had an important influence on policy makers and the general public in Mauritius in their understanding that - to use Malthusian language - the 
island would have to suffer from a positive check (i.e., increased mortality), or at least severe poverty, if no preventive check (i.e., declining fertility) was found.

The influential religious communities, although traditionally pronatalist (Roman Catholic, Hindu, Muslim), found it difficult to oppose this argument, especially on a small island where spatial limitations were clearly visible. With regard to the Catholic church, which was most influential in Mauritius, it was largely one individual, the French Jesuit Lestapis, who convinced Catholic authorities and politicians that the church doctrine was not against family planning in general but only against certain methods. As a consequence, Catholics did not block the introduction of government-supported family-planning programs, and established their own family-planning organization which propagated natural methods and also received government support.

In his report Titmuss (published as Titmuss and Abel-Smith, 1968) had expected that the great ethnic diversity of Mauritius would present a major problem to the acceptance and success of his recommendations. But this was not the case in Mauritius. Fertility declines within the Hindu, Muslim, and Chinese communities were even more rapid than in the total population that included the "General Population" (a residual category including Europeans, Africans, etc.) in which fertility had already been below average in 1962. In Mauritius other factors were obviously strong enough to easily overcome the potential impediment of ethnic diversity. There has always been peaceful coexistence between the religions in Mauritius, and religious leaders have shown flexibility on the family-planning issue.

\subsubsection{The role of family planning}

The declines in age-specific fertility and marriage rates as well as the use of various family-planning methods since 1962 have been well monitored in Mauritius (Xenos, 1991). It has been calculated that about half of the births averted between 1962 and 1972 were attributable to marriage postponement, the other half to a drop in marital fertility. This coincidence of rapid transition in marriage patterns and in marital fertility may explain the extraordinary speed of the Mauritian fertility decline. In 1952, 57 percent of the young Indian women aged 15-19 were married in Mauritius. By 1962, this percentage had declined to 37 percent, and further declined by more than half to 15 percent in 1972 . In the age group 20-24, the percentage fell 
from 85 percent in 1962 to 58 percent in 1972 . This trend toward increasing age at marriage was universal among all ethnic groups.

The decline in marital fertility was strongest in the higher age groups, a typical pattern for fertility transition. In the age group 30-34 the birth rate declined from 0.256 in 1963 to only 0.128 in 1972. For all age groups above 35 the rates more than halved over these few years. The index of family limitation $(m)$ increased threefold over this period. This is directly related to the strong family-planning efforts in both propagating smaller families and providing efficient contraceptive methods, together with improved health care and counseling.

Although the decision to launch strong family-planning efforts was based on a broad national consensus and saw active government support, the external financial contributions of IPPF and UNFPA were also instrumental for the successful implementation on a larger scale. The number of new participants in the two Mauritian family-planning programs grew very rapidly during the late 1960s and peaked between 1970 and 1972. Surveys show that contraceptive use had reached 46 percent in 1975 (30 percent "supplied" methods and 16 percent "natural" methods) and 74 percent in 1985 (44 percent "supplied" and 30 percent "natural"). In the early 1970s the density of family-planning clinics was one of the highest in the world.

\subsubsection{Conclusion}

Based on extensive surveys of historical and modern fertility transitions, Coale (1974) specified three preconditions for the introduction of deliberate family limitation, i.e., fertility control dependent upon the number of children already born. All three of these conditions find strong support from the study of the Mauritian fertility transition.

1. "Fertility must be within the calculus of conscious choice." This refers to a psychological and cultural transition that seems to be intimately tied to education, especially female education. Also the fact that Mauritius had a minority group of French origin with already lower fertility in 1962 may have facilitated a kind of cultural diffusion process on this issue similar to that in Europe at the beginning of this century.

2. "Reduced fertility must be advantageous." It was at both the macro and micro levels that Mauritians understood that lower fertility was advantageous to them. At the macro level the scientific reports by Titmuss and Meade seem to have been of crucial importance. At the level of 
families it seems to have been the rather high cost of education together with the high desirability of education as a prerequisite for a career that made some difference. Also the early introduction of social policies to support the disabled and elderly made parents less dependent on their adult children.

3. "Effective techniques of fertility reduction must be available." The wide distribution of modern contraceptive methods, especially the pill, through family-planning organizations certainly facilitated the rapid decline in fertility. Both international aid and good local family-planning organizations offering a wide variety of methods were also instrumental.

\subsection{Did Declining Fertility Stimulate Economic Development?}

In the previous section we concluded that economic growth was not among the factors bringing down the fertility rate in Mauritius. Now we consider the opposite direction of causation: Did fertility decline and the slowing population growth rate exert a positive influence on the start of the economic boom of the 1980s? Does the traditional Coale and Hoover (1958) argument on capital shortage due to many children hold for Mauritius? Or were other mechanisms dominant during the past three decades?

At the international level the aggregate empirical evidence on this issue seems to be very mixed depending to a large degree on the choice of variables. In a 1986 report the US National Academy of Sciences presented a summary of recent research on the economic consequences of population growth in developing countries. Most of that report focuses on the question of whether slowing population growth is advantageous under certain economic and resource availability criteria. The conclusions distinguish between short-term and long-term consequences. For the short term the report generally sees beneficial consequences of slower population growth. But for the long run, it stresses the possibility of positive effects of population growth due to incentives for improved organization and technology.

Such general statements on the long-term behavior of highly complex and hard-to-understand societal and economic systems, however, are largely based on abstract concepts with little possibility for empirical support. Consequently the report concludes:

In short, the effects of rapid population growth are likely to be conditioned by the quality of markets, the nature of government policies, and features 
of the natural environment. Since the effects are so dependent on these conditions, a reliable assessment of many of the net effects of population growth can best be carried out on the national level. [NAS, 1986, p. 89]

In this section we look at the evidence for Mauritius.

\subsubsection{Fertility, population growth, and income}

Figure 18.4 plots the evolution of three basic variables in Mauritius: per capita income, population size, and fertility. The timing of changes in these variables gives important indications of their relationship. The first observation on the demographic side is that despite dramatic fertility decline, total population size is rather inert and increases steadily. This trend is due to the momentum of population growth and the fact that mortality also improved.

Because of the almost linear trend in population size between 1950 and 1990 , it is difficult to make any argument directly related to GNP which, on a per capita basis, fluctuated between Rs 9,000 and Rs 12,750 between 1950 and 1970 and then shows two big jumps in the 1970s and the late 1980s. If increasing population size should have induced economic growth, one must make the unlikely assumption that some magic population density thresholds were reached in 1970 and 1985. Based on these data, it is equally difficult to argue that total population size was an obstacle to economic growth.

It is much more instructive, however, to study the relationship of income to fertility instead of total population size, which is quite a different question because of different assumed mechanisms of causation. (Looking at the rates of population growth would be a mixture of these two aspects.) It is remarkable to see that the first big increase in income followed immediately after the first big fertility decline. The second jump in income followed another moderate fertility decline that brought fertility down to replacement level.

Several chapters in this book have extensively discussed the nondemographic factors associated with the phases of economic development. In the late 1980s the introduction of the Export Producing Zone (EPZ) policies seems to be the overwhelming determinant. In the 1970 s the external reasons for the rapid income growth are less clear. It coincides with Mauritian independence, its first industrialization efforts, favorable international conditions, and stable sugar prices. But the preceding fertility decline may have well been instrumental for this economic takeoff.

We can think of two arguments in addition to the Coale-Hoover savings argument that support a causal effect from declining fertility to increasing income. The first relates to the increase of young women in the labor force 


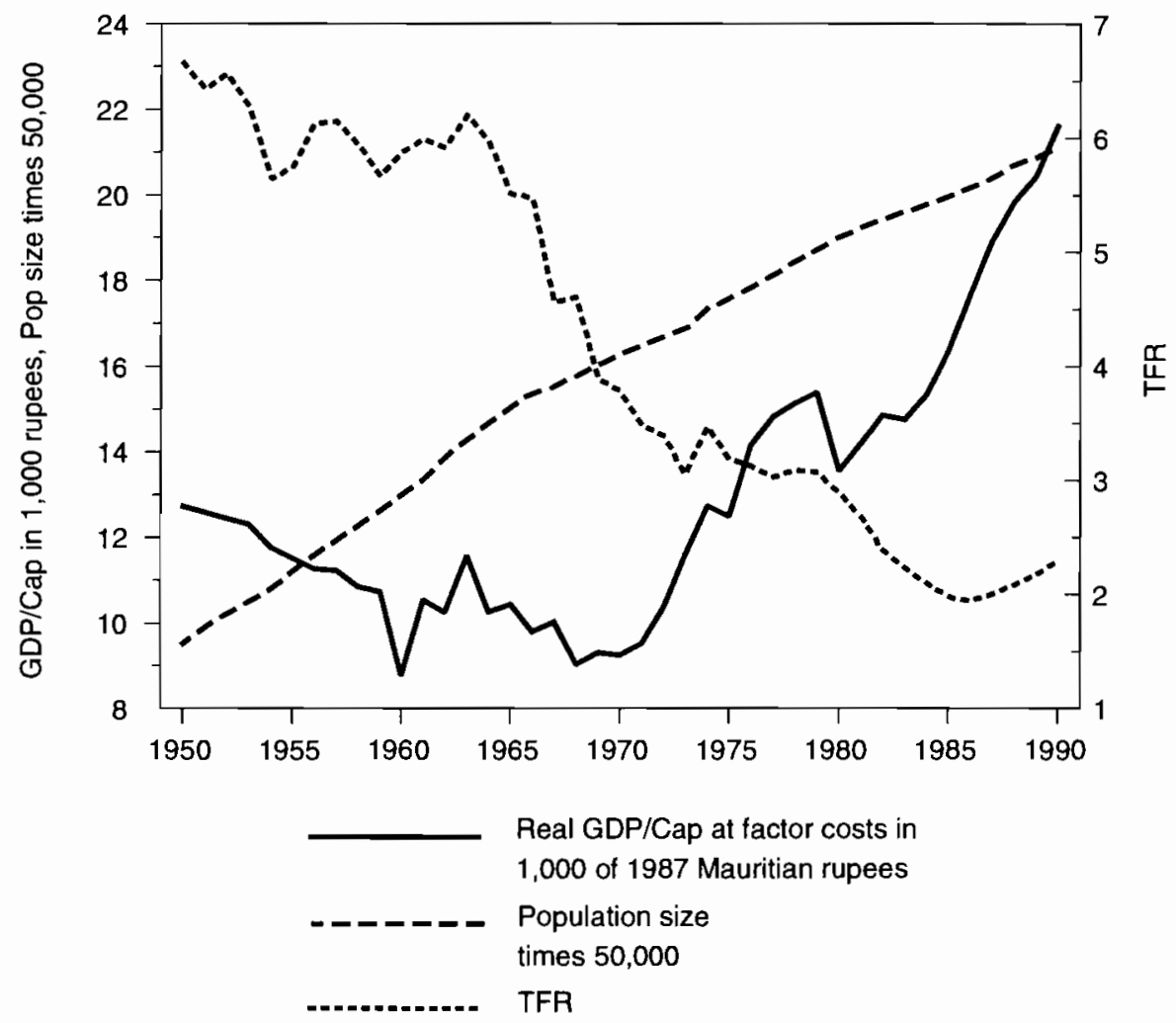

Figure 18.4. Total fertility rate, per capita income, and population size in Mauritius, 1950-1990.

working in new factories instead of being at home with children. And indeed, female labor-force participation rates in Mauritius increased from 20 percent in 1972 to 28 percent in 1983. For young women (aged 20-24) this increase was even stronger, reaching 40 percent in 1983. Mostly in textile factories but also in the service sector, the rapidly increasing young female labor force contributed substantially to economic growth. Following the traditional pattern of high fertility and young age at marriage, this could not have happened. Certainly, to be effective, such a development requires the availability of new jobs for women, which was the case in Mauritius.

The second argument is much broader. It relates to the view that the fertility transition is essentially based on a transition in attitudes, on a change from aiming at quantity of children to the quality of life for children (skills, 
higher status). This refers to the first of Coale's basic conditions for a sustained marital fertility decline as discussed above. Some even call it a transition from fatalism to individual rationality. Now the argument is, once individual planning has been introduced into one's private life, it is this psychological transition that consequently results in longer-term investments into the future, including training (of oneself and of children) and economic activities. Such longer-term investments at the individual as well as at the familial and societal levels are also the basis for any economic development. In this sense the fertility decline may be seen as being closely related to a takeoff in economic development.

There are several other countries where the sequence of fertility decline and economic growth is similar to Mauritius (most notably China), but, as shown above, the two developments may also be simultaneous or in specific cases (such as some Arab oil-exporting states) in reversed order.

\subsubsection{What would have happened without fertility decline?}

The PDE Mauritius model developed for this study not only makes projections into the distant future but can also be used to construct alternative histories (see Chapter 17). In this case 1962 (a census year) is chosen as the initial state. Thereafter the observed development for 25 years (up to 1987) is reconstructed as one scenario. But several hypothetical alternative scenarios also have been calculated, four of which will be briefly discussed here for a quantitative assessment of the role of population variables in income growth.

Table 18.1 shows that the development observed between 1962 and 1987 brought a 101 percent increase in per capita GNP. If no development had taken place - i.e., all demographic, social, and economic parameters had remained at their 1962 level - GNP per capita would have declined to twothirds of the already very low level by 1987 . If, however, fertility had declined and education had improved with constant economic parameters, per capita income would have declined by only 22 percent. Hence a fertility decline would have made a bad situation somewhat (a third) better.

In the case of assumed progress in the economic parameters along the circumstances actually observed between 1962 and 1987 but without a fertility decline, per capita income would have increased by "only" 63 percent instead of 101 percent, i.e, one-third less. If one also assumed no social development, which mostly refers to observed education patterns, GNP per capita would have increased by "only" 61 percent, i.e., somewhat more than half of the observed increase. 
Table 18.1. Observed and hypothetical effects of declining fertility under different social (mostly education) and economic scenarios on per capita income in constant Mauritian rupees.

\begin{tabular}{|c|c|c|c|}
\hline & 1962 & 1987 & $\%$ change \\
\hline Observed development & 8,958 & 17,999 & +101 \\
\hline All 1962 parameters constant & & 5,886 & -34 \\
\hline No economic development but fertility decline & & 6,987 & -22 \\
\hline Economic development but no fertility decline & & 14,620 & +63 \\
\hline
\end{tabular}

Because there are many other relevant economic variables, such as unemployment, government deficit, and trade balance, that develop differently under the various scenarios, the figures on GNP in 1987 demonstrate only part of the economic consequences of alternative demographic and educational developments. But the directions and the orders of magnitude are clear: between 1962 and 1987 the exogenous economic parameters had a larger relative influence on income than direct effects of fertility decline, which also made a visible difference. When extending these hypothetical histories to 2002 the negative relative effect of higher fertility and lower education is even stronger.

\subsubsection{Conclusion}

In short, there are several reasons for assuming that the fertility decline in Mauritius had a role in triggering the subsequent economic boom. Despite the fact that economic and political variables are the most visible determinants of economic growth, the model also shows that without a fertility decline, Mauritius would be clearly worse off today. At a deeper level psychological changes associated with the fertility transition may be essential for economic development.

\subsection{What Are the Conditions for Sustainable Economic Growth in Mauritius?}

This question is extensively and comprehensively studied in Chapter 16, which compares a large number of scenarios for the period from 1990 to 2050 using the full PDE Mauritius model. For each segment of the model (population, economy, environment) two opposing sets of parameters have been defined (traditional-modern, crisis-boom, laissez-faire-garden) which 
are then combined in aggregate scenarios and adjusted to meet the basic required balances (water, labor, budget) and some user-defined feedback mechanisms. Specific policy options (such as priority to sugar or food selfsufficiency) have also been tested in this context. A concise summary of the results of these alternative model runs is given in Section 16.4. This section highlights some of the key results under a somewhat broader perspective.

\subsubsection{Water as the basic physical constraint even on a tropical island}

The international discussion on resource availability has recently given more attention to the management of renewable resources since the concern about nonrenewable resources has somewhat diminished. Water is a very special kind of renewable resource because its local availability is essentially determined by the climate and topography, and can only be transported over longer distances under specific conditions. On Mauritius total freshwater availability must essentially be considered as a "fixed resource" with significant seasonal and annual variations.

Whether Mauritius has scarce or plentiful freshwater resources depends on whether we consider water per person or water per land area. Figure 18.5 shows a cross-classification of a number of countries according to these two variables. Mauritius is found in the lower-right side of the graph, indicating that, because of its tropical climate and mountains, Mauritius has more water per $\mathrm{km}^{2}$ than most other countries in the world, whereas it has very low per capita water resources. The discrepancy results from the very high population density of Mauritius.

The set of future scenarios consistently shows that water availability at a given high standard of quality is the essential environmental constraint to unlimited economic growth in Mauritius. Whether this constraint will actually inhibit economic growth depends on the investment made into water storage and treatment. Under environmental laissez-faire policies, together with an export-driven economic boom, the limits will be met relatively soon. But the model also shows that timely investment into water-management infrastructure will make possible very rapid additional economic growth. This is especially the case when growth is not based on irrigation-intensive sugar cane but rather on industry and services. Among the many relevant aspects of water management, wastewater treatment comes out as the most significant.

Another aspect which is considered in the water module of the PDE model is the water quality of the lagoon which surrounds large parts of 


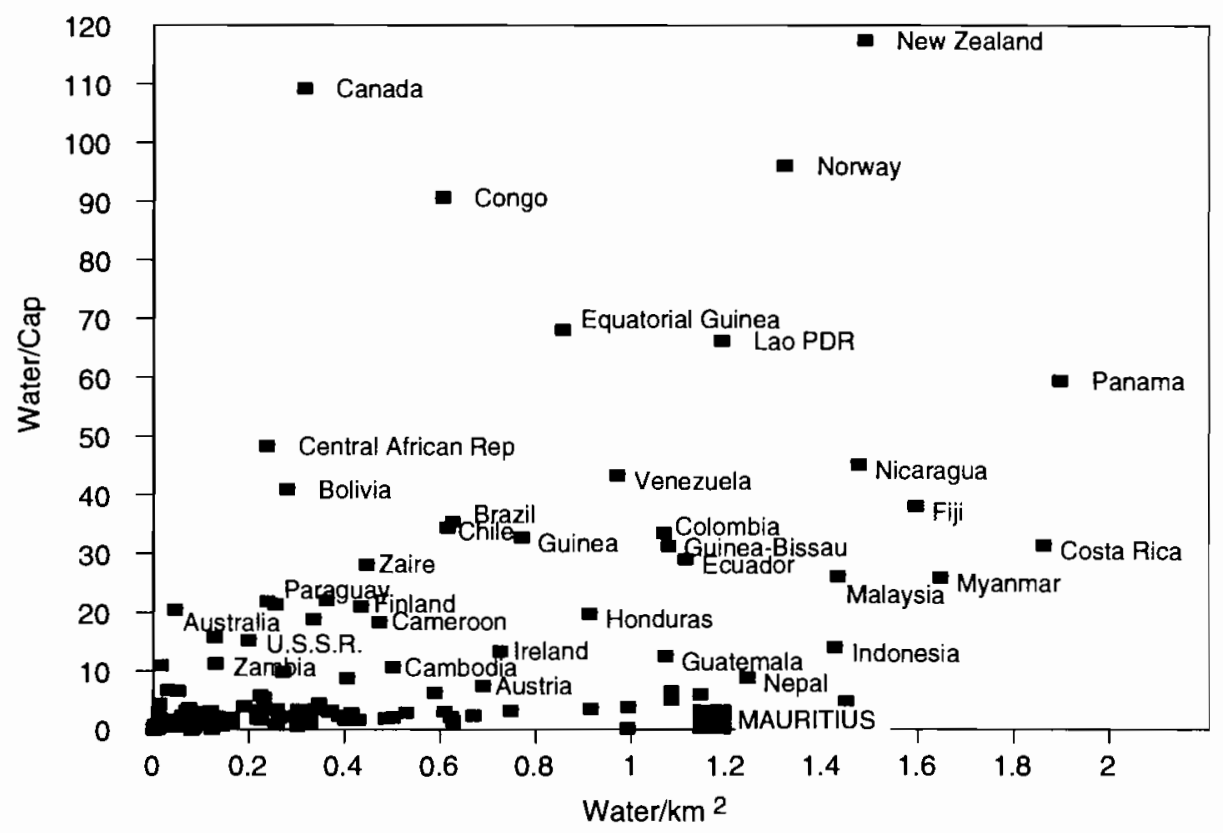

Figure 18.5. Annual domestic freshwater resources per person and per $\mathrm{km}^{2}$ in several countries of the world.

Mauritius and is an important natural asset, not least for tourism. It also affects the survival of the partly damaged coral reef. It is shown that enforced legislation on water treatment and waste disposal can make a big difference.

\subsubsection{Future agriculture and industrial production}

Sugar cane has traditionally been the backbone of the Mauritian economy. Sugar fields and sugar factories still dominate the Mauritian landscape. Industrial exports (especially textiles) have surpassed sugar exports only in recent years. Over the past decades sugar prices and quantities guaranteed to Mauritius by the European Community were a very important element of stability during the onset of the recent economic boom in Mauritius. But prospects for the future are unclear if not shaky. Sugar exports to the USA have significantly declined due to changes in diet, and it is not clear how the European market, where domestic sugar beet is a serious competitor, will develop. The recent labor scarcity in Mauritius and the general increase in salaries have also affected the labor-intensive sugar plantations negatively. 
Several scenarios have been calculated that assume drastic changes in international sugar demand and domestic factors such as a sugar policy for reasons of tradition rather than profitability. The general result is that it does not make sense to intensify sugar growing (which already has very high fertilizer and irrigation inputs) for economic and environmental reasons. Sugar refining, however, can be made more efficient especially by using the large energy potential of bagasse. To prohibit the conversion of sugar land for industrial or urban use is neither economical nor practical, but the present land conversion tax that depends on the fertility of the soil is an interesting solution.

Future industrial growth is assumed to be mostly driven by export demand. If Mauritius remains in the export market dominated by textiles, it could significantly increase its per capita income to several times the present GNP/capita. Through a structural change in the economy, toward higher value-added products and especially services, however, its economic growth could potentially be even more rapid (following the example of the Asian Tigers) and achieve income levels by 2050 that are higher than today's European levels. Because of a move toward less polluting and less water-intensive industries, this would also be possible from an ecological perspective. Aside from favorable international conditions one domestic prerequisite for such a rapid and sustainable development is a highly skilled labor force.

\subsubsection{Role of tourism}

Despite the rapid growth of international tourism in Mauritius over the past years, in 1990 foreign exchange earnings from tourism comprised only 15 percent of the total exports and an estimated 3.3 percent of the GDP. But there are also important indirect benefits from tourism. Mauritius has made a clear choice for high-quality expensive hotels and has put a limit on the number of hotel rooms. Because of the limited availability of attractive beaches there is an inherent conflict between private and public access that requires careful management.

In an international perspective Mauritius is still in the early stage of the tourist resort cycle (see Debbage, 1991) in which very rapid expansion may be followed by stagnation and even decline because of loss of attractiveness. To avoid destructive development, such as that on the Bahamas, Mauritius must regulate and limit the expansion of tourism. The present policy of high-cost and quantitative limitations (no charter flights are allowed to land in Mauritius) seems to be a move in the right direction. But to remain 
internationally competitive in the future, attention must also be given to the water quality in the lagoon, the status of the reefs, the preservation of original landscapes, and cultural events.

In a way high-level selective tourism in international competition turns out to be conducive to environmental protection. It provides a very quick economic feedback mechanism that cannot be ignored even in short-term politics. Small signs of environmental destruction and pollution may cause tourists to go to cleaner islands.

\subsubsection{Population and labor force}

The role of population variables in actual and hypothetical past developments has been discussed extensively above. Because Mauritius has now passed the fertility transition, it is highly unlikely that it will return to the high premodern levels. The population is currently growing by 1 percent per year which is entirely due to the momentum of population growth, i.e., the young age structure of the population and some mortality improvements. Alternative future fertility assumptions have been considered separately for all three educational groups of women, and result in fertility levels somewhat above replacement level ("traditional") or below replacement level ("modern"). Fertility is also influenced by the changing educational compositions of the population. In the "traditional" case the total population size of Mauritius would increase from today's 1.1 million to 1.9 million by 2050 ; in the "modern" case it would only increase to 1.25 million in 2020 and then decline to 1.15 million by 2050 .

These alternative population sizes and structures also have a sizeable impact on the future trends in the economic variables of the model. When comparing the two scenarios, which have the "boom" assumptions in the economic sector and the "garden" assumptions in the environmental sector, the "modern" assumptions in the population-education sector result in a 64 percent higher per capita income in 2050 than the one using the "traditional" assumptions. Hence stagnation in the social development that brings lower fertility and higher productivity through better education would have serious negative effects even under otherwise very favorable economic conditions.

The size and quality of the labor force are of special concern. For the past two decades the World Bank has identified the Mauritian labor force, including an increasing number of educated women, as "the engine of economic growth." If Mauritius is to be successful in expanding into new markets requiring higher technology, the quality of the labor force once again will 
be the key to success. For this reason the economic development plans of the government put high emphasis on further technical training of the labor force. As long as the local expertise is flexible enough to adjust to new technologies, investment into human capital will be one of the most effective and most robust strategies for sustainable economic development in Mauritius.

\subsubsection{Dependence on the global economy and the global environment}

Although Mauritius is rather isolated geographically, it is interwoven into the global economy. The overwhelming dependence on export earnings and imports of food and most other consumer goods has a long tradition. A change in this situation does not seem to be possible without a significant loss in welfare. Especially with a further diversification of export and import markets that makes Mauritius less vulnerable to possible crises in specific world regions, the benefits of such an international orientation far outweigh the risks. But significant flexibility in the change of markets and necessary imports is an important component of resilient development strategies.

Mauritius is hardly affected by any transport of pollutants from other countries, but it would certainly be affected by changes in the global climate. The Mauritian contribution to global warming is negligible not only because of its small population but because it has one of the lowest $\mathrm{CO}_{2}$ emissions per GNP in the world. Present general circulation models are not yet detailed enough to study the impact of a doubling of $\mathrm{CO}_{2}$ on rainfall and temperature, given the Mauritian topography. For the region, the various models tend to show a temperature increase of between 2 and 3 degrees Celsius and also some increase in precipitation in the already wet months. Effects of a possible increase in the sea level depends on, among others things, whether the coral reefs are healthy enough to grow with the same speed. Probably the most relevant question for Mauritius is the future of cyclones, since Mauritius is situated in the usual path of cyclones through the Indian Ocean. An increase in the intensity of cyclones would be destructive; a change in their paths might be advantageous; and an increase in the frequency of cyclones with lower intensity may also be good because of the possibility of more rain.

\subsubsection{Conclusion: Toward a prosperous garden island}

The scenario that combines all the "good" assumptions in the three segments of the PDE Mauritius ("modern" for the population sector, "boom" 
for the economy, and "garden" for the environment) can be called the "Prosperous Garden Island Scenario." This scenario points the direction toward sustainable development. It is called "garden island" because Mauritius has little original nature left and has a largely man-made environment. For this reason the metaphor of a man-made, well-kept garden is seen as appropriate for Mauritius. It also reflects the high population density and need not be in conflict with economic growth and prosperity. In fact some wealth is necessary to sustain the garden. It also requires wise environmental legislation, good infrastructure, as well as the skills and willingness of the population to take good care of the garden. In most of these aspects Mauritius seems to be on the right track.

\subsection{What Are the Policy Priorities?}

After extensive elaboration of the many specific questions that include numerous qualifications and differentiations because of the intrinsic complexity of the system, it is justified at this point to ask for the most significant policy priorities that follow from the study. Two important policy issues become apparent when studying the history and the future of Mauritius under a truly comprehensive perspective.

\subsubsection{Foresight and accountability}

Throughout Mauritian history, things went well when government policy considered a longer time horizon; irreparable damage was caused when immediate advantages were the only objective. For example, the scientific studies on Mauritius in the 1960 s, showing that a change was necessary, had a long time horizon, and were fortunately heard by responsible politicians and understood at the individual and societal levels. Such flexibility and foresight was the basis for the Mauritian success story. Similar foresight is being shown now in the first steps being taken by Mauritian authorities toward sustainable development that cares about the environmental heritage.

A comparison of Mauritius to other countries in the African region since the 1960s shows that one of the main nonmaterial differences is that during the whole period, Mauritius had a truly democratic system. Despite the extreme ethnic heterogeneity, this system managed to settle conflicts peacefully and develop a sophisticated balance of power. Although this dimension is beyond our quantitative model, it comes out as most important under a holistic perspective in the historical analysis. 
Many things could have gone wrong in Mauritian politics that could have inhibited development or even ruined the island. Desperate economic conditions and extremely high unemployment - in 1983 still half of the male youth cohort born around 1960 was unemployed - could have easily started ethnic tension and conflict over still severe social inequalities.

There are several reasons for the peaceful coexistence of very diverse ethnic groups that differ not only by language, religion, and skin color but to a large extent also by social class in Mauritius. One reason is that no group can claim to be the original population of the island; everyone descended from immigrants. Another reason is that under the British rule, 1810-1967, the very influential and rich Franco-Mauritian estate owners were allowed to keep their land and language but not political power; they learned to find other mechanisms to serve their interests. Finally, after independence the first prime minister, Sir Ramgoolam, established an important Mauritian tradition of ruling by consensus, by inviting the Conservative Party to share power although his Independence Party had a sufficient majority in Parliament (see Chapter 4).

Despite many political squabbles, in most issues of real importance, foresight was paired with personal accountability. Decision makers who are accountable to the majority of the population, including families and the children who represent the future generation, and who do not primarily serve their own interests or those of a subgroup seem to be a basic prerequisite for sustainable development.

The political accountability in Mauritius is extended to the individual level where it is understood that one is accountable for one's own choices, including the number of children, educational level, and the environment. This may be regarded as a prerequisite for demographic transition as well as for modern economic development in balance with the natural environment. This empowerment of the people seems to be the underlying reason for the Mauritian success story. The people can read, they are informed about most critical issues, and they have shown that they can take an active role in determining their country's fate.

\subsubsection{Investment in human skills and the status of women}

The second important policy lesson is the crucial importance of the human resource in sustainable development. The story of Mauritius tells us that the first policy priority in international efforts for sustainable development should focus on the development of people or what economists call human 
capital. This is the "ultimate resource" under a longer time horizon, but in terms of skills (and attitudes) rather than sheer quantity. It is not the starving and unskilled desperate who bring about progress, but those that have the skills and the possibility of thinking creatively and caring about others at all different levels. The Mauritian experience suggests that education is the key, especially basic education of broad segments of the population rather than of elites in an otherwise illiterate society.

More specifically, it is the basic education of women and their status in society that seems to have a very important role in the transition to lower fertility. It may also be conducive to sustainable development through increased female activity and greater weight of women in decision making together with their supposed tendency to care more about their children's future and harmony with nature than about unnecessary consumption and technology. On this last presumption, however, little empirical analysis has been done. But the gender dimension at familial and societal levels certainly needs more attention in the context of sustainable development.

The provision of family-planning services, one specific and heatedly debated policy issue, is one factor that is conducive to the fertility transition and is desirable not only for macro-level considerations but also for facilitating individual choice and personal life-course planning. Family planning, however, should not be singled out of the context of female status and health care, and pushed as an independent "engineering" solution. This does not work and can be counterproductive. Instead it should be viewed as one aspect of empowering women, men, and families to more actively plan their lives and to make a difference in their society. It is part of the investment in the human resource.

With respect to the priorities in international development policies, this suggests a radical change of emphasis. Less attention should be given to large-scale technological projects that often prove to be inappropriately designed for the specific local conditions and may even turn out to be harmful to the environment and the social fabric. In contrast, investment into the human resource - education, health, and family planning - can hardly be wrong, but is likely to result in immeasurable and far-reaching benefits to individuals, communities, and nations. It is a very robust policy that may only show modest immediate results, but a great payoff in the long run. 



\section{Chapter 19}

\section{Epilogue: How Useful is the Mauritius Study for Other Parts of the World?}

Wolfgang Lutz

The question of transferability of the Mauritius model and of some of the basic findings to other countries under different social, economic, and environmental conditions is legitimate and has often been asked. It needs to be answered at three different levels.

\subsection{Application to Small Tropical Island States}

The model as it stands, as well as much of the substantive analysis in the fields of water management, land use, agriculture, tourism, energy, etc., could rather easily be applied to a number of small tropical island states in the Caribbean or Pacific that show surprising partial parallels to Mauritius, not only in terms of climate and the dominating role of sugar cane but in some cases in terms of population and political histories. Here again, one could distinguish between a more formal application of PDE Mauritius and a simple transfer of the Mauritius findings. In the first case one could essentially use the same software and adjust the data base to the island chosen. By this, one could derive new empirical findings of direct relevance to the selected island. Currently, one such study is being conducted for 
the Cape Verde Islands. The other, certainly much smaller, effort would be to simply take the findings from Mauritius and see how much of the basic messages could be reasonably transferred to the other island's situation. For general policy guidelines this may even be sufficient.

\subsection{Development of New PDE Models for Very Different Regions}

The PDE model presents a general approach that can be applied to any region in the world. For PDE Mauritius a number of specific choices had to be made for operationalizing the model and adhering to the principle that only sectors should be considered that can potentially make a difference. For this reason, PDE Mauritius does not have a separate air pollution module. Currently, applying the PDE framework to countries radically different from Mauritius is being considered. One candidate is Bolivia, where ecological and ethnic diversity is so great that the model definitely needs to distinguish between different regions and different ethnic groups within regions. Also the economic module requires significant modification for a country with a very important informal sector.

For a better understanding of the interactions between population, development, and environment under a global perspective it would certainly be desirable to have a number of case studies using the same general approach but being carried out under very diverse social, economic, and environmental conditions.

\subsection{Contribution to Scientific Discussion and Awareness Creation}

The scientific aspirations of the study presented in this book clearly go beyond the island of Mauritius. It has been our hope that the study will help structure the still highly confused debate on population-environment issues which cuts across various disciplines by looking at specific empirical evidence in terms of both a qualitative historical analysis and a clearly structured quantitative computer model. The design of the model should be acceptable to most social scientists as well as natural scientists. Opposing views on the population-environment issue can be made very explicit through alternative assumptions on the basis of this common quantitative model. This could 
help prepare the groundwork for a common understanding across disciplines and between traditional opponents by more clearly identifying the differences and putting them into perspective.

Another use of the PDE Mauritius model and future models for other regions lies in the training of students, scholars, and policy makers worldwide to help them view the issues of population change, socioeconomic development, and environmental change in an interconnected and comprehensive way. Viewing these processes under a longer time horizon, be it the study of historical trends or running the model into the future, will contribute to the understanding of the notion of sustainable development in specific contexts. 



\section{References}

Action Familiale, 1988, Action Familiale 1963-1988, Port Louis, Mauritius.

Addison, J., and Hazareesingh, K., 1984, A New History of Mauritius, Macmillan, London, UK.

Arcia, G., Merino, L., Mata, A., and O'Hanlon, B., 1991, Modelo Interactivo de Poblacion y Medio Ambiente en Costa Rica - Análisis y Proyecciones para el Valle Central, Asociación Demográfica Costarricense, San José, Costa Rica.

Baguant, J., 1989, Energy data book: Energy supply and consumption, 19701989, in Energy Use and Policy Planning in Mauritius, Vol. 1, University of Mauritius.

Baguant, J., and Beeharry, P.R., 1989, Household energy consumption survey, in Energy Use and Policy Planning in Mauritius, Vol. II, University of Mauritius. Baguant, J., and Manrahhan, J., 1990, Energy Use and Policy Planning in Mauritius, Energy Data Bank: Energy Supply and Consumption 1970-1989, University of Mauritius.

Baguant, J., and Manrahhan, J., 1991, Use of petroleum products: Opportunities and constraints - Power sector, in African Energy Policy Research Network, University of Mauritius.

Barney, G.O., 1980, Global 2000: The Report to the President, Entering the 21st Century, US Government Printing Office, Washington, DC, USA.

Barney, G.O., Kreutzer, W.B., and Garrett, M.J., eds., 1991, Managing A Nation: The Microcomputer Software Catalog, 2nd Edition, Westview Press, Boulder, CO, USA.

Barnwell, J.P., and Toussaint, A., 1949, A Short History of Mauritius, Longmans, London, UK.

Beeharry, R.P., 1992, Decarbonization of Energy Supply in Small Developing Countries: A Study of Long-Term Policy Options for Mauritius, Draft Paper, IIASA, Laxenburg, Austria.

Bell, D., 1990, Contradictions of modernity, Society March/April:43-50.

Bheenick, R., and Hanoomanjee, E., 1989, Mauritius: Towards an Industrial Training Strategy, Ministry of Economic Planning and Development, Port Louis, Mauritius.

Bheenick, R., and Schapiro, M.O., 1989, Mauritius: A case study of the export processing zone, in R. Bheenick et al., eds., Successful Development in Africa: 
Case Studies of Projects, Programmes and Policies, World Bank, Washington, DC, USA.

Bingham, A., 1985, Singapore traps urban runoff, Worldwater May:33-35.

Bissoondoyal, S., 1963, A Concise History of Mauritius, Bharatiya Vidya Bhavan, Bombay, India.

Boserup, E., 1981, Population and Technological Change, University of Chicago Press, Chicago, IL, USA.

Boserup, E., 1990, Economic and Demographic Relationships in Development, Essays selected and introduced by T.P. Schultz, Johns Hopkins University Press, Baltimore and London.

Boullé, B., 1989, The Sugar Protocol and Mauritius, Mauritius Sugar Syndicate, Port Louis, Mauritius.

Braudel, F., 1979, Civilization matérielle, économie et capitalisme, XVe-VXIIIe siècle. Tome 1; Les structures du quotidien: le possible et l'impossible, Armand Colin, Paris, France.

Brookfield, H.C., 1957, Mauritius: Demographic upsurge and prospect, Population Studies 11(2):102-122.

Brookfield, H.C., 1981, Man, environment and development in the outer islands of Fiji, Ambio 10(2-3):59-67.

Brundtland, G.H., Chairman, World Commission on Environment and Development, 1987, Our Common Future, Oxford University Press, Oxford, UK.

Brundtland, G.H., 1989, How to secure our common future, Scientific American $261: 190$.

Bury, J.B., 1982, The Idea of Progress: An Inquiry into Its Origin and Growth, Greenwood, Westport, CT, USA (reprint of 1932 edition).

CBS (Central Bureau of Statistics), 1989, Mauritian Household Survey, 1989, Port Louis, Mauritius.

Chan, P.K., and Chan, N.W., 1981, Water resources development in Hong Kong, in Proceedings of a Seminar on Water Management in Small Island States, Cyprus Joint Technical Council and Commonwealth Engineering Council.

Cleland, J., and Scott, C., eds., 1987, The World Fertility Survey: An Assessment, Oxford University Press, New York, NY, USA.

Coale, A., 1974, The demographic transition, in UN, The Population Debate, Dimensions and Perspectives: Papers of the World Population Conference, Bucharest, New York, NY, USA.

Coale, A.J., and Hoover, E.M., 1958, Population Growth and Economic Development in Low-Income Countries, Princeton University Press, Princeton, NJ, USA.

Cole, H.S.D., Freeman, C., Jahoda, M., and Pavitt, K.L.R., eds., 1973, Models of Doom: A Critique of The Limits to Growth, Universe Books, New York, NY, USA.

Colony of Mauritius, 1879, Administrative Repori, 1879, Port Louis, Mauritius.

Commoner, B.H., 1971, The Closing Circle: Nature, Man, and Technology, Alfred A. Knopf, New York, NY, USA. 
Coombes, A.N., 1963, Aperçu de l'évolution de l'agriculture à l'ile Maurice, Port Louis, Mauritius.

CSO (Central Statistical Office), 1947, 1957, 1967, Yearbook of Statistics, Ministry of Economic Planning and Development, Port Louis, Mauritius.

CSO (Central Statistical Office), 1956, Natality and Fertility in Mauritius, Port Louis, Mauritius.

CSO (Central Statistical Office), 1976-1988, Annual Digest of Agricultural Statistics, Ministry of Economic Planning and Development, Port Louis, Mauritius. CSO (Central Statistical Office), 1985-1990, National Accounts of Mauritius, Ministry of Economic Planning and Development, Port Louis, Mauritius.

CSO (Central Statistical Office), 1987, Digest of Statistics, Port Louis, Mauritius.

CSO (Central Statistical Office), 1988a, Digest of Industrial Statistics 1988, Rose Hill, Mauritius.

CSO (Central Statistical Office), 1988b, Housing and Population Census of Mauritius, 1983, Volume VI: Health, Morbidity and Mortality, Port Louis, Mauritius.

CSO (Central Statistical Office), 1989, 1990, Digest of Agricultural Statistics, Ministry of Economic Planning and Development, Port Louis, Mauritius.

CSO (Central Statistical Office), 1990a, Annual Yearbook of Statistics, Port Louis, Mauritius.

CSO (Central Statistical Office of Mauritius), 1990b, Housing and Population Census of Mauritius, Port Louis, Mauritius.

CSO (Central Statistical Office), 1991, Handbook of Statistical Data on Tourism, December 1991, Port Louis, Mauritius.

CWA (Central Water Authority), 1988, Hydrology Year Book 1984-1985 - 1986, GOM Ministry of Energy, Water Resources, and Postal Services, Port Louis, Mauritius.

CWA (Central Water Authority), 1991, Master Plan Study on Water Resources of Mauritius: Conclusions and Recommendations, GOM Ministry of Energy, Water Resources, and Postal Services, Port Louis, Mauritius.

Daly, H.E., 1986, Review of population growth and economic development: Policy questions, Population and Development Review 12(3):582-585.

Darwin, C., 1934, Charles Darwin's Diary of the Voyage of the H.M.S. "Beagle," Cambridge University Press, Cambridge, UK, excerpt reprinted in Population Bulletin 18(5)[1962]:114-115.

Dean, W., 1983, Deforestation in southeastern Brazil, in R.P. Tucker and J.F. Richards, eds., Global Deforestation and the Nineteenth-Century World Economy, Duke University Press, Durham, NC, USA.

Debbage, K.G., 1991, Tourist destination cycles and sustainable development: A comparative analysis of the Bahamas and Mauritius, in W. Lutz and F.L. Toth, eds., Population, Economy, and Environment in Mauritius, CP-91-01, IIASA, Laxenburg, Austria.

De Sornay, P., 1950, Isle de France - Ile Maurice, Port Louis, Mauritius. 
Deville, J., and $\mathrm{Ng}$ Kee Kwong, K.F., 1984, Nitrogen leaching from soils cropped with sugar cane under the humid tropical climate of Mauritius, Indian Ocean, Journal of Environmental Quality 13:471-474.

Dornbush, R., and Fischer, S., 1981, Macro-Economics, 2nd Edition, McGraw-Hill, New York, NY, USA.

Echiburu, R., 1977, Energy Analysis of Energy and Labor Substitution in Manufacturing, Energy Studies Unit, Strathclyde University, Glasgow, Scotland.

Edmonds, J.A., and Reilly, J., 1983, A long-term global energy-economic model of carbon dioxide release from fossil fuel use, Energy Economics 5(2):74-88.

Edmonds, J.A., and Reilly, J., 1985, Global Energy: Assessing the Future, Oxford University Press, New York, NY, USA.

Edmonds, J.A., Pitcher, H.M., Barns, D., Baron, R., and Wise, M.A., 1991, Modeling future greenhouse gas emissions: The second generation model description, Paper prepared for the United Nations University Conference on Global Changes and Modeling, Tokyo, October, Pacific Northwest Laboratory, Washington, DC, USA (to be published by UN University Press).

Ehrlich, P., 1968, The Population Bomb, Ballantine, New York, NY, USA.

Ehrlich, P.R., and Ehrlich, A.H., 1970, Population, Resources, Environment, Freeman, San Francisco, CA, USA.

Ehrlich, P.R., and Ehrlich, A.H., 1990, The Population Explosion, Simon and Schuster, New York, NY, USA.

Ertuna, 1988, Treatment and use of sewage effluent for irrigation in Western Asia, in FAO Regional Seminar on the Treatment and Use of Sewage Effluent for Irrigation, Butterworths, London, UK.

Falkenmark, M., 1988, Sustainable development as seen from a water perspective, in Stockholm Group for Studies on Natural Resource Management (SGN), Perspectives of Sustainable Development: Some Critical Issues Related to the Brundtland Report, SGN, Stockholm, Sweden.

Food Production Board, 1950, Memorandum on Long Term Policy, Government of Mauritius, Port Louis, Mauritius.

German Development Institute (GDI), 1992, Perspectives of the Clothing and Textile Industry in Mauritius in the Face of Changing External and Internal Conditions - Challenges for Enterprises and Institutions.

Gilbert, A.J., and Braat, L.C., eds., 1991, Modelling for Population and Sustainable Development, Routledge, London, UK.

Gleadow, F., 1904, Report on the Forests of Mauritius with a Preliminary Working Plan, Government of Mauritius, Port Louis, Mauritius.

GOM (Government of Mauritius), 1991, White Paper on National Environmental Policy, Port Louis, Mauritius.

GOM (Government of Mauritius)/World Bank, 1988, Mauritius: Environmental Investment Program for Sustainable Development, Port Louis, Mauritius.

Green, C.P., 1992, The Environment and Population Growth: Decade for Action, Series M, No. 10, May, UNFPA, New York, NY, USA. 
Hardin, G., 1993, Living Within Limits: Ecology, Economics, and Population Taboos, Oxford University Press, New York, NY, USA.

Holm, E., 1992, Land-use Change on Mauritius, Manuscript, IIASA, Laxenburg, Austria.

Hopkins, A.G., 1973, An Economic History of West Africa, Longmans, London, UK.

Jevons, S., 1909, The Coal Question: An Enquiry Concerning the Progress of the Nations and the Probable Exhaustion of Our Coal Mines, Macmillan, London, UK.

Keyfitz, N., 1985, Applied Mathematical Demography, 2nd Edition, Springer-Verlag, New York, NY, USA.

Keyfitz, N., 1991, Population growth can prevent the development that would slow population growth, in J.T. Mathews, ed., Preserving the Global Environment: The Challenge of Shared Leadership, Norton, New York, NY, USA.

Keyfitz, N., and Flieger, W., 1990, World Population Growth and Aging, University of Chicago Press, Chicago, IL, USA.

King, J., 1991, The ECCO approach to planning sustainable development, in A.J. Gilbert and L.C. Braat, eds., Modelling for Population and Sustainable Development, Routledge, London, UK.

King, H., and Dowd, J.E., 1991, The health status of the Mauritian population and prospects for change, in W. Lutz and F.L. Toth, eds., Population, Economy, and Environment in Mauritius, CP-91-01, IIASA, Laxenburg, Austria.

Kostolany, A., 1987, Kostolany's Wunderland von Geld und Börse, Busse and Seewald, Herford, Germany.

Lewis, W.A., 1955, The Theory of Economic Growth, Allen and Unwin, London, $\mathrm{UK}$.

Löf, G.O.G., and Hardison, C.H., 1966, Storage requirements for water in the United States, Water Resources Research 2(3):323-354.

Lutz, W., forthcoming, What do we need more urgently: Better data, better models, or better questions, in J. Clarke and B. Zaba, eds., Environment and Population Change, Ordina Editions, Liège, Belgium.

Lutz, W., and Toth, F.L., eds., 1991, Population, Economy, and Environment in Mauritius, CP-91-01, IIASA, Laxenburg, Austria.

Lutz, W., and Wils, A.B., 1991, The demographic discontinuities of Mauritius, in W. Lutz and F.L. Toth, eds., Population, Economy, and Environment in Mauritius, CP-91-01, IIASA, Laxenburg, Austria.

Lutz, W., Wils, A.B., and Prinz, C., 1990, Rapid fertility decline through family planning preceding economic growth: The case of Mauritius, Paper presented at the CICRED/UNFPA Meeting on "Effects of Family Planning on Fertility," New York, 7-9 November.

Ly-Tio-Fane, 1958, Mauritius and the Spice Trade: The Odyssey of Point Poivre, Esclapon Ltd., Port Louis, Mauritius.

Malthus, T.R., [1798] 1967, Population: The First Essay, with a foreword by K.E. Boulding, University of Michigan Press, Ann Arbor, MI, USA. 
Mannick, A.R., 1979, Mauritius: Development of a Plural Society, Spokesman, Nottingham, UK.

Mannick, A.R., 1989, Mauritius: The Politics of Change, Dodo Books, Mayfield, UK.

Manrahhan, J., 1991, "Mauritius 2000" and the IIASA research framework: A view from the Reduit Campus, in W. Lutz and F.L. Toth, eds., Population, Economy, and Environment in Mauritius, CP-91-01, IIASA, Laxenburg, Austria.

Mauritius Chamber of Agriculture, 1953-1991, Annual Reports of the President, Port Louis, Mauritius.

Mauritius Chamber of Agriculture, The Mauritius Chamber of Agriculture 18531953, Port Louis, Mauritius.

Mauritius Chamber of Agriculture, 1991, The Sugar Industry - Situation and Outlook: Elements for a Strategic Re-appraisal, Port Louis, Mauritius.

Meade, J.E., 1967, Population explosion, the standard of living, and social conflict, The Economic Journal 77(June):233-255.

Meade, J.E., Foggon, G., Houghton, H., Lees, N., Marchall, R.S., Roddan, G.M., and Selwyn, P., 1968, The Economic and Social Structure of Mauritius, Frank Cass, London, UK.

Meadows, D.H, Meadows, D.L., Randers, J., and Behrens III, W.W., 1972, The Limits to Growth, Universe Books, New York, NY, USA.

Meadows, D.L., Behrens III, W.W., Meadows, D.H., Naill, R.F., Randers, J., and Zahn, E.K.O., 1974, Dynamics of Growth in a Finite World, Wright-Allen Press, Cambridge, MA, USA.

Meadows, D.H., Richardson, J., and Bruckmann, G., 1982, Groping in the Dark: The First Decade of Global Modelling, John Wiley \& Son, Chichester, UK.

Meadows, D.H., Meadows, D.L., and Randers. J., 1992a, Beyond the Limits: Confronting Global Collapse, Envisioning a Sustainable Future, Chelsea Green Publishing, Post Mills, V'T, USA.

Meadows, D.H., Meadows, D.L., and Randers, J., 1992b, Beyond the Limits: Global Collapse or a Sustainable Future, Earthscan Publications Limited, London, UK.

Meier, R.L., 1959, Modern Science and the Human Fertility Problem, Wiley, New York, NY, USA.

MEPD, 1988, National Development Plan 1988-1990, Ministry of Economic Planning and Development, Port Louis, Mauritius.

MEQOL, 1991, State of the Environment in Mauritius, GOM Ministry of Environment and Quality of Life, Port Louis, Mauritius.

MIIT, 1990, Mauritius at Crossroads: The Industrial Challenges Ahead, Ministry of Industry and Industrial Technology, Port Louis, Mauritius.

Ministry of Economic Planning and Development, 1984, Digest of Industrial Statistics, Port Louis, Mauritius.

Ministry of Economic Planning and Development, 1986, Report of the Fact-Finding Committee on Crownlands, Government of Mauritius, Port Louis, Mauritius. 
Ministry of Economic Planning and Development, 1990, Digest of Industrial Statistics, Port Louis, Mauritius.

Ministry of Education and Science, 1991, Master Plan for Education, Port Louis, Mauritius.

Ministry of Environment and Quality of Life, 1991, State of the Environment of Mauritius, Government of Mauritius, Port Louis, Mauritius.

Ministry of Health, 1987, Family Planning and Demographic Yearbook, Port Louis, Mauritius.

Ministry of Housing, Lands, and the Environment, 1990, Land Resources: Preliminary Analysis, Port Louis, Mauritius.

Ministry of Industry and Industrial Technology, 1990, Mauritius at Crossroads: The Industrial Challenges Ahead, Port Louis, Mauritius.

Mitchell, B.R., 1982, Historical Statistics, Macmillan, London, UK.

Myrdal, G., 1968, Asian Drama: An Inquiry into the Poverty of Nations, Twentieth Century Fund, New York, NY, USA.

NAS (US National Academy of Sciences), 1986, Population Growth and Economic Development: Policy Questions, National Academy Press, Washington, DC, USA.

$\mathrm{Ng}$ Kee Kwong, K.F., Figon, L.C., and Deville, J., 1990, Nitrogen Fertilization of Sugar Cane in Mauritius - The Ecologists' Way, Mauritius Sugar Industry Research Institute, Reduit, Mauritius, unpublished manuscript.

NPDP (National Physical Development Plan), 1990, Coastal Zone Appraisal Survey, Paper No. 6.1, May, Planning Division, Ministry of Housing, Lands, and Environment, Port Louis, Mauritius.

Padya, B.M., 1989, Weather and Climate in Mauritius, Mahatma Gandhi Institute, Moka, Mauritius.

Parahoo, K.A., 1986, Early colonial health developments in Mauritius, International Journal of Health Services 16(3):409-423.

Parikh, J.K., 1980, Energy Systems and Development, Oxford University Press, Delhi, India.

Paturau, M., 1988, Histoire Economique de l'ile Mauritius, Port Louis, Mauritius.

Picardi, A.C., 1974, A systems analysis of pastoralism in the West African Sahel, Annex 5 to A Framework for Evaluating Long-Term Strategies for the Development of the Sahel-Sudan Region, Center for Policy Alternatives Report CPA 74-9, MIT, Cambridge, MA, USA.

Prinz, Ch., 1991, Scenarios for future demographic trends in Mauritius, in W. Lutz and F.L. Toth, eds., Population, Economy, and Environment in Mauritius, CP-91-01, IASA, Laxenburg, Austria.

Prinz, Ch., 1992, Modeling the Population of Mauritius, WP-92-43, IIASA, Laxenburg, Austria.

Proops, J.L.R., 1984, Energy intensities, input output-analysis and economic development, in M. Ciaschini, ed., Input-Output Analysis: Current Developments, Chapman and Hall, London, UK. 
Ramjeawon, T., 1991, Water systems and water management on the island of Mauritius, in W. Lutz and F.L. Toth, eds., Population, Economy, and Environment in Mauritius, CP-91-01, IIASA, Laxenburg, Austria.

Rathnam, M.S.V., and Opsal, K., 1989, Preparation of an Environmental Action Plan for Mauritius, UNEP Industry and Environment, July-December 1989, Nairobi, Kenya.

Repetto, R., 1992, Accounting for environmental assets, Scientific American 266(6):64-70.

Richards, J.F., 1986, World environmental history and economic development, in W.C. Clark and R.E. Munn, eds., Sustainable Development of the Biosphere, Cambridge University Press, Cambridge, UK.

Richards, J.F., 1990, Land transformation, in B.L. Turner II, W.C. Clark, R.W. Kates, J.F. Richards, J.T. Mathews, and W.B. Meyer, eds., The Earth as Transformed by Human Action: Global and Regional Changes in the Biosphere over the Past 300 Years, Cambridge University Press, Cambridge, UK.

Rogbeer, G., 1984, Mauritius water resources, in Proceedings of a Regional Workshop on Water Resources of Small Islands, Suva, Fiji, Technical Publication Series No. 182, Part 3, Commonwealth Science Council.

Rogers, A., and Willekens, F., eds., 1986, Migration and Settlement: A Multiregional Comparative Study, D. Reidel, Dordrecht, Netherlands.

Rosenbluth, G., 1976, Economists and the growth controversy, Canadian Public Policy 11(2):225-239.

Roth, D.M., 1983, Philippine forest and forestry: 1565-1920, in R.P. Tucker and J.F. Richards, eds., Global Deforestation and the Nineteenth-Century World Economy, Duke University Press, Durham, NC, USA.

Rouillard, G., 1990, Historique de la Cenné à sucre à L'ile Maurice 1639-1989, Mauritius' Chamber of Agriculture, Port Louis, Mauritius.

Rowe, J.S., 1990, Summing it up, in C. Mungall and D.J. McLaren, eds., Planet Under Stress, Oxford University Press, Toronto, Canada.

Sanderson, W.C., 1980, Economic-Demographic Simulation Models: A Review of Their Usefulness for Policy Analysis, RR-80-14, IIASA, Laxenburg, Austria.

Simon, J.L., 1981, The Ultimate Resource, Princeton University Press, Princeton, NJ, USA.

Simon, J.L., 1982, A scheme to promote world economic development with migration, in J.L. Simon and P.H. Lindert, eds., Research in Population Economics, Volume 4, JAI Press, Greenwich, CT, USA.

Singer, H.F., 1992, Warming theories need warning label, The Bulletin of the Atomic Scientists 48(5):34-39.

Slesser, M., 1991, Planning for sustainable development, in A.J. Gilbert and L.C. Braat, eds., Modelling for Population and Sustainable Development, Routledge, London, UK.

Slesser, M., and King, J., 1988, Resource accounting: An application to development planning, World Development 16(2):293-303. 
Smil, V., and Knowland, W.E., 1980, Energy in the Developing World, Oxford University Press, Oxford, UK.

Thomson, T., 1881, Report on the Forests of Mauritius: Their Present Condition and Future Management, Colonial Government of Mauritius, Port Louis, Mauritius.

Titmuss, R., and Abel-Smith, B., 1968, Social Policies and Population Growth in Mauritius, Frank Cass, London, UK.

Toth, F.L., 1992, Models of the Water Systems in Mauritius, WP-92-71, IIASA, Laxenburg, Austria.

UNEP (United Nations Environment Programme), 1982, Environmental Problems of the East-African Region, UNEP Regional Seas Report and Studies No. 12, Nairobi, Kenya.

UNEP (United Nations Environment Programme), 1991, Freshwater Pollution, UNEP/ GEMS Environment Library No. 6, Nairobi, Kenya.

Wallerstein, I., 1974, The Modern World System, Academic Press, New York, NY, USA.

Wallerstein, I., 1976, Three stages of African involvement in the world economy, in P. Gutkind and I. Wallerstein, eds., The Political Economy of Contemporary Africa, Sage, London, UK.

Wallerstein, I., 1980, The Modern World System II, Academic Press, New York, NY, USA.

Walter, A., 1910, The Sugar Industry of Mauritius: A Study in Correlation, A.L. Humphreys, London, UK.

WHO (World Health Organization), 1993, World Health Statistics Quarterly, Geneva, Switzerland.

Williams, F., 1964, British Historians and the West Indies, P.N.M. Publishing, Port of Spain, Trinidad.

Williams, M., 1990, Forest, in B.L. Turner II, W.C. Clark, R.W. Kates, J.F. Richards, J.T. Mathews, and W.B. Meyer, eds., The Earth as Transformed by Human Action: Global and Regional Changes in the Biosphere over the Past 300 Years, Cambridge University Press, Cambridge, UK.

Wils, A.B., 1993, Input-Output Model for a Small, Open Economy Applied to Mauritius, WP-93-56, IIASA, Laxenburg, Austria.

Wilson, E.O., ed., 1988, Biodiversity, National Academy of Sciences/Smithsonian Institution, Washington, DC, USA.

Wittfogel, K.A., 1957, Oriental Despotism, Yale University Press, New Haven, CT, USA.

Wollman, N., 1960, Water Supply and Demand, Committee Print No. 32, Senate Select Committee on National Water Resources, 86th Congress, 2nd Session, Washington, DC, USA.

Wollman, N., and Bonem, G.W., 1971, The Outlook for Water: Quality, Quantity, and National Growth, Johns Hopkins University Press, Baltimore, MD, USA.

World Bank, 1984, World Development Report, World Bank, Washington, DC, USA. 
World Bank, 1986, Mauritius: The Sugar Sector, Problems and Prospects, Washington, DC, USA.

World Bank, 1989, Economic Development with Environmental Management: Strategies for Mauritius, Mimeo, World Bank, Washington, DC, USA.

World Bank, 1992a, Mauritius: Expanding Horizons, Washington, DC, USA.

World Bank, 1992b, World Development Report 1992: Development and the Environment, Oxford University Press, New York, NY, USA.

World Bank, 1993, World Tables 1993, Johns Hopkins University Press, Baltimore, MD, USA.

Worldwater/WHO, 1987, The International Drinking Water Supply and Sanitation Decade Directory, Edition 3, Thomas Telford Ltd., London, UK.

Xenos, C., 1977, Fertility Change in Mauritius and the Impact of the Family Planning Programme, Ministry of Health, Port Louis, Mauritius.

Xenos, C., 1991, Family planning and fertility change in Mauritius, in W. Lutz and F.L. Toth, eds., Population, Economy, and Environment in Mauritius, CP-9101, IIASA, Laxenburg, Austria. 

ISBN 3-540-58301-7

ISBN 0-387-58301-7 